COMPREHENSIVE GRAMMAR RESOURCES Henk van Riemsdijk \& István Kenesei, series editors

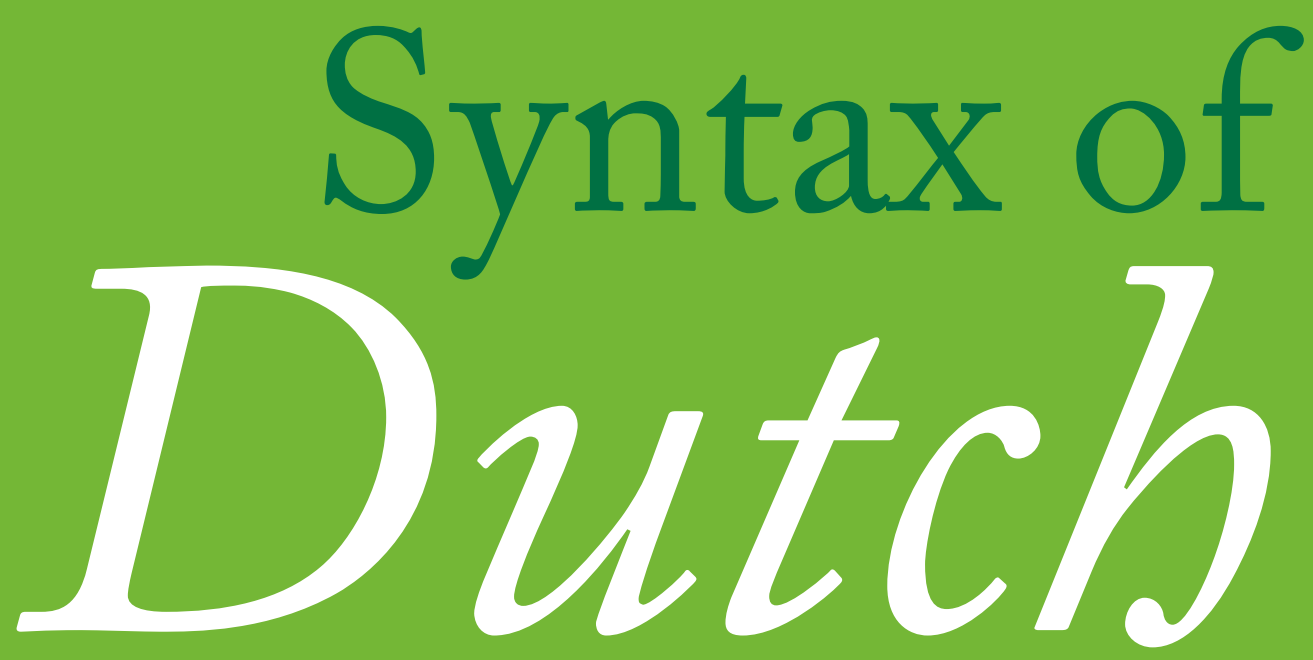

\title{
Coordination and Ellipsis
}

Hans Broekhuis

Norbert Corver 


\section{Syntax of Dutch \\ Coordination and Ellipsis}




\title{
Comprehensive Grammar Resources
}

\author{
Editors: \\ Henk van Riemsdijk \\ István Kenesei \\ Hans Broekhuis
}




\title{
Syntax of Dutch Coordination and Ellipsis
}

\section{Hans Broekhuis Norbert Corver}

\author{
With the cooperation of: \\ Hans Bennis \\ Frits Beukema \\ Crit Cremers \\ Henk van Riemsdijk
}

\section{Amsterdam University Press}


The publication of this book is made possible by grants and financial support from: Netherlands Organisation for Scientific Research (NWO)

Center for Language Studies

University of Tilburg

Truus und Gerrit van Riemsdijk-Stiftung

Meertens Institute (KNAW)

Utrecht University

This book is published in print and online through the online OAPEN library (www.oapen.org).

OAPEN (Open Access Publishing in European Networks) is a collaborative initiative to develop and implement a sustainable Open Access publication model for academic books in the Humanities and Social Sciences. The OAPEN Library aims to improve the visibility and usability of high quality academic research by aggregating peer reviewed Open Access publications from across Europe.

Cover design: Studio Jan de Boer, Amsterdam

Layout: Hans Broekhuis

$\begin{array}{ll}\text { ISBN } & 9789463720502 \\ \text { e-ISBN } & 9789048542895 \\ \text { DOI } & 10.5117 / 9789463720502 \\ \text { NUR } & 624\end{array}$

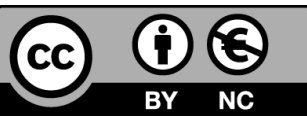

Creative Commons License CC BY NC

(http://creativecommons.org/licenses/by-nc/3.0)

(c) Hans Broekhuis \& Norbert Corver/Amsterdam University Press, Amsterdam 2019

Some rights reserved. Without limiting the rights under copyright reserved above, any part of this book may be reproduced, stored in or introduced into a retrieval system, or transmitted, in any form or by any means (electronic, mechanical, photocopying, recording or otherwise). 


\section{Coordination and ellipsis}

Abbreviations and symbols

Preface and acknowledgments v v v v v

1. General introduction $\quad v$

2. Main objective $\quad$ v

3. Intended readership $\quad \mathrm{V}$

4. Object of description vi

5. Organization of the material $\quad x i$

6. History of the project and future prospects xii

7. Acknowledgments xiii

Introduction 1

Chapter 1

Coordination $\quad 3$

Introduction $\quad 6$

1.1. General properties 6

1.2. Monosyndetic, polysyndetic and asyndetic coordination 46

1.3. Coordinands 59

1.4. Coordinators 113

Chapter 2

Ellipsis in coordinate structures $\quad 247$

Introduction $\quad 248$

2.1. Conjunction Reduction 249

2.2. Gapping 271

2.3. Combining conjunction reduction and gapping 310

2.4. Conclusion 314

Chapter 3

Borderline cases of coordination?

Introduction $\quad 316$

3.1. Four supposed borderline cases $\quad 316$

3.2. A note on the semantic side of gapping 332

3.3. Conclusion and a potential problem 334

Bibliographical notes $\quad 337$

Glossary $\quad 339$

$\begin{array}{ll}\text { Subject index } & 355\end{array}$

$\begin{array}{ll}\text { List of references } & \mathbf{3 6 7}\end{array}$ 
This content downloaded from 131.211.104.173 on Wed, 19 Feb 2020 10:39:01 UTC All use subject to https://about.jstor.org/terms 


\section{Abbreviations and symbols}

This appendix contains a list of abbreviations and symbols that are used in this volume. Sometimes, conventions are adopted that differ from the ones given in this list, but if this is the case this is always explicitly mentioned in the text.

\section{References to the other volumes of the Syntax of Dutch.}

References to the chapters and sections in the other volumes in the series Syntax of Dutch are preceded by a letter: V + section \# refers to the three volumes on Verbs and verb phrases; $\mathrm{N}+$ section \# refers to the two volumes on Nouns and noun phrases; A + section \# refers to the volume on Adjectives and adjective Phrases, and $\mathrm{P}+$ section \# refers to the volume on Adpositions and adpositional phrases. P3.2, for example, refers to Section 3.2 in Hans Broekhuis (2013). Syntax of Dutch: Adpositions and adpositional phrases. Amsterdam: AUP.

\section{Symbols and abbreviation used in the main text}

${ }^{\circ} \mathrm{xxx} \quad$ refers to the $\mathrm{xxx}$ in the glossary

$\begin{array}{ll}\text { Abbreviations used in both the main text and the examples } \\ \text { AP } & \text { Adjectival Phrase } \\ \text { CP } & \text { Complementizer Phrase } \\ \text { DP } & \text { Determiner phrase } \\ \text { NP } & \text { Noun Phrase } \\ \text { Noun phrase } & \text { Used when the NP-DP distinction is not relevant } \\ \text { PP } & \text { Prepositional Phrase } \\ \text { TP } & \text { Tense Phrase } \\ \text { VP } & \text { Verb Phrase }\end{array}$

Symbols, Abbreviations and conventions used in the examples

$t \quad$ Trace (the original position of a moved element)

$\mathrm{XXX} \quad$ Small caps indicate that XXX is assigned contrastive accent

Abbreviations used as subscripts in the examples

$\begin{array}{llll}1 \mathrm{p} / 2 \mathrm{p} / 3 \mathrm{p} & 1^{\text {st }}, 2^{\text {nd }}, 3^{\text {rd }} \text { person } & \mathrm{pl} & \text { Plural } \\ \text { acc } & \text { Accusative } & \text { dat } & \text { Dative } \\ \text { pred } & \text { Predicate } & \text { nom } & \text { Nominative } \\ \text { sg } & \text { Singular } & & \end{array}$

\section{Abbreviations used in the glosses of the examples}

AFF

Affirmative marker

COMP

prt.

PRT

REFL
Complementizer: dat 'that' in finite declarative clauses, of 'whether/if' in finite interrogative clauses, and om in infinitival clauses

Particle that combines with a particle verb

Particle of different kinds

The short form of the reflexive pronoun, e.g., zich; the long form zichzelf is usually translated as himself/herself/itself 


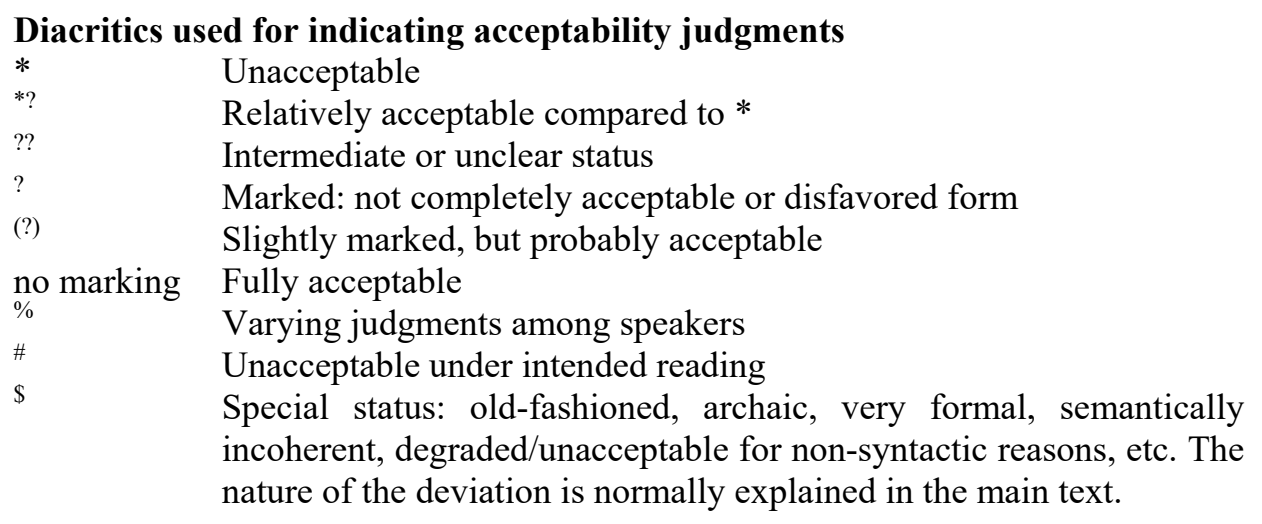

\section{Other conventions}

\begin{tabular}{|c|c|}
\hline $\mathrm{xx} / \mathrm{yy}$ & Acceptable both with $\mathrm{xx}$ and with yy \\
\hline *xx/yy & Unacceptable with $\mathrm{xx}$, but acceptable with yy \\
\hline $\mathrm{xx} / * \mathrm{yy}$ & Acceptable with $\mathrm{xx}$, but unacceptable with yy \\
\hline$(\mathrm{xx})$ & Acceptable both with and without $\mathrm{xx}$ \\
\hline$*(\mathrm{xx})$ & Acceptable with, but unacceptable without $\mathrm{xx}$ \\
\hline$(* x x)$ & Acceptable without, but unacceptable with $\mathrm{xx}$ \\
\hline . $<x x>$ & Alternative placement of $\mathrm{xx}$ in an example \\
\hline$. .<* \mathrm{xx}>.$. & Impossible placement of $\mathrm{xx}$ in an example \\
\hline$X X \ldots Y Y$ & Italics indicate binding \\
\hline $\mathrm{XX}_{\mathrm{i}} \ldots \mathrm{YY}_{\mathrm{i}}$ & Coindexing indicates coreference \\
\hline $\mathrm{XX}_{\mathrm{i}} \ldots \mathrm{YY}_{\mathrm{i}}$ & Counter-indexing indicates disjoint reference \\
\hline $\mathrm{XX}$ & Unacceptable with index $i$, acceptable with index $j$ \\
\hline & Unacceptable with index $j$, acceptable with index $i$ \\
\hline & Constituent brackets of a constituent XP \\
\hline
\end{tabular}

\section{Logical symbols}

\begin{tabular}{|c|c|}
\hline $\begin{array}{l}\wedge: \text { Conjunction or distributive AND } \\
\vee: \text { Inclusive disjunction } \\
\rightarrow: \text { Material implication } \\
>: \text { Larger than } \\
\neg: \text { Negation }\end{array}$ & $\begin{array}{l}\oplus \text { : cumulative AND } \\
\underline{\mathrm{v}} \text { : Exclusive disjunction } \\
\leftrightarrow: \text { Material equivalence } \\
<: \text { Less than }\end{array}$ \\
\hline $\begin{array}{l}\exists x: \text { Existential operator } \\
\text { p, q, ..: proposition letters } \\
\text { IF: Entails } \\
\equiv: \text { Is logically equivalent to }\end{array}$ & $\begin{array}{l}\forall \mathrm{x}: \text { Universal operator } \\
\varphi, \psi, \chi: \text { formula letters } \\
\mid \neq: \text { Does not entail }\end{array}$ \\
\hline
\end{tabular}




\section{Preface and acknowledgments}

\section{General introduction}

Dutch is an official language in the Netherlands, Belgium-Flanders, Surinam, Aruba and the Netherlands Antilles. With about 22 million native speakers it is one of the world's greater languages. It is taught and studied at more than 175 universities around the world (source: taalunieversum.org). Furthermore, Dutch is one of the most well-studied living languages; research on it has had a major, and still continuing, impact on the development of formal linguistic theory, and it plays an important role in various other types of linguistic research. However, much information is hidden in scientific publications that are mainly of interest for and accessible to certain groups of formal linguists or that are more or less outdated in the light of more recent findings and theoretical developments, and more material is buried in publications with only a limited distribution or which are simply inaccessible to large groups of readers because they are written in Dutch. The series Syntax of Dutch (SoD) therefore aims at providing a comprehensive scientifically based description of the syntax of Dutch that is accessible to a wider international audience. For similar phonological and morphological descriptions the reader is referred to taalportaal.org (which also contains the complete $S o D$ and similar descriptions of Frisian and Afrikaans).

\section{Main objective}

The main objective of $S o D$ is to present a synthesis of currently available syntactic knowledge of Dutch. It gives a comprehensive overview of the relevant research on Dutch that not only presents the findings of earlier approaches to the language, but also includes the results of the formal linguistic research carried out over the last four or five decades, which often cannot be found in earlier reference books. It should be emphasized, however, that $S o D$ is primarily concerned with language description and not with linguistic theory; the reader will generally look in vain for critical assessments of theoretical proposals made to account for specific phenomena. Although $S o D$ addresses many of the central issues of current linguistic theory, it does not provide an introduction to current linguistic theory itself. Readers interested in such an introduction are referred to one of the many existing introductory textbooks, or to handbooks like The Blackwell Companion to Syntax, edited by Martin Everaert \& Henk van Riemsdijk, or The Cambridge Handbook of Generative Syntax, edited by Marcel den Dikken. A recommendable syntactic description of Dutch in a more theoretical setting is The Syntax of Dutch by JanWouter Zwart in the Cambridge Syntax Guides series.

\section{Intended readership}

$S o D$ is not intended for a specific group of linguists, but aims at a more general readership: it intends to be a work of reference accessible to a large audience with some training in linguistics and/or neighboring disciplines and it aims at providing support to all researchers interested in matters relating to the syntax of Dutch. The 
descriptions that $S o D$ provides are generally also accessible to advanced students of language and linguistics. We have tried to avoid jargon from specific theoretical frameworks and to use as much as possible the lingua franca that linguists use in a broader context. Whenever we introduce a notion that is not part of the lingua franca, we provide a brief clarification in the glossary; first occurrences of such notions in a certain context are normally marked by means of the marker ${ }^{\circ}$.

\section{Object of description}

The object of description is aptly described by the title of the series, Syntax of Dutch. This title suggests a number of ways in which the empirical domain is restricted, which we want to spell out here in more detail by briefly discussing the two notions syntax and Dutch.

\section{Syntax}

Syntax is the field of linguistics that studies how words are combined into larger phrases and, ultimately, sentences. This means that we do not systematically discuss the internal structure of words (this is the domain of morphology) or the way in which sentences are put to use in discourse: we only digress on such matters if this is instrumental in describing the syntactic properties of the language. For example, Chapter N1 contains an extensive discussion of deverbal nominalization, but this is only because this morphological process is relevant for the discussion of complementation of nouns in Chapter N2. And Section N8.1.3 will show that the word order difference between the two examples in (1) is related to the preceding discourse: if pronounced with neutral (non-contrastive) accent, the object Marie may only precede clausal adverbs like waarschijnlijk 'probably' if it refers to some person who has already been mentioned in (or is implied by) the preceding discourse.

(1) a. Jan heeft waarschijnlijk Marie gezien.

$[$ Marie $=$ discourse new $]$

Jan has probably Marie seen

'Jan has probably seen Marie.'

b. Jan heeft Marie waarschijnlijk gezien. [Marie $=$ discourse old] Jan has Marie probably seen

'Jan has probably seen Marie.'

Our goal of describing the internal structure of phrases and sentences means that we focus on competence (the internalized grammar of native speakers), and not on performance (the actual use of language). This implies that we will make extensive use of constructed examples that are geared to the syntactic problem at hand, and that we will not systematically incorporate the findings of currently flourishing corpus/usage-based approaches to language. Corpus data and other sources of actual language use will only be used insofar as this may shed light on matters concerning the internal structure of phrases; see Broekhuis (2016) for a more extensive motivation of this choice. One case for which this type of research may be syntactically relevant is the word order variation in the (italicized) ${ }^{\circ}$ verb clusters in examples like those in (2), which has been extensively studied since Pauwels (1950) 
and which has been shown to be sensitive to a large number of interacting variables, see De Sutter (2005/2007) for extensive discussion.

(2) a. dat Jan dat boek gelezen heeft.

that Jan that book read has

'that Jan has read that book.'

b. dat Jan dat boek heeft gelezen.

that Jan that book has read

'that Jan has read that book.'

This being said, it is important to point out that $S o D$ will pay ample attention to certain aspects of meaning, and reference will also be made to phonological aspects such as stress and intonation wherever they are relevant (e.g., in the context of word order phenomena like in (1)). The reason for this is that current formal grammar assumes that the output of the syntactic module of the grammar consists of objects (sentences in the case of syntax) that relate form and meaning. Furthermore, formal syntax has been quite successful in establishing and describing a large number of restrictions on this relationship. A prime example of this is the so-called ${ }^{\circ}$ binding theory, which accounts (among other things) for the fact that referential pronouns like hem 'him' and anaphoric pronouns like zichzelf 'himself' differ in the domain within which they can/must find an antecedent. For instance, the examples in (3), in which the intended antecedent of the pronouns is given in italics, show that whereas referential object pronouns like hem cannot have an antecedent within their minimal clause, anaphoric pronouns like zichzelf 'himself' must have an antecedent within this domain, see Section N5.2.1.5, sub III, for more detailed discussion.
a. Jan denkt dat Peter hem/*zichzelf bewondert. Jan thinks that Peter him/himself admires 'Jan thinks that Peter is admiring him [= Jan].'
b. Jan denkt dat Peter zichzelf/*hem bewondert. Jan thinks that Peter himself/him admires 'Jan thinks that Peter is admiring himself [= Peter].'

\section{Dutch}

SoD aims at giving a syntactic description of what we will loosely refer to as Standard Dutch, although we are aware that there are many problems with this notion. First, the notion of Standard Dutch is often used to refer to written language and more formal registers, which are perceived as more prestigious than the colloquial uses of the language. Second, the notion of Standard Dutch suggests that there is an invariant language system that is shared by a large group of speakers. Third, the notion carries the suggestion that some, often unnamed, authority is able to determine what should or should not be part of the language, or what should or should not be considered proper language use. See Milroy (2001) for extensive discussion of this notion of standard language.

$S o D$ does not provide a description of this prestigious, invariant, externally determined language system. The reason for this is that knowledge of this system does not involve the competence of the individual language user but "is the product of a series of educational and social factors which have overtly impinged on the 
linguistic experiences of individuals, prescribing the correctness/incorrectness of certain constructions" (Adger \& Trousdale 2007). Instead, the notion of standard language in $S o D$ should be understood more neutrally as an idealization that refers to certain properties of linguistic competence that we assume to be shared by the individual speakers of the language. This notion of standard language deviates from the notion of standard language discussed earlier in that it may include properties that would be rejected by language teachers, and exclude certain properties that are explicitly taught as being part of the standard language. To state the latter in more technical terms: our notion of standard language refers to the core grammar (those aspects of the language system that arise spontaneously in the language learning child by exposure to utterances in the standard language) and excludes the periphery (those properties of the standard language that are explicitly taught at some later age). This does not mean that we will completely ignore the more peripheral issues, but it should be kept in mind that these have a special status and may exhibit properties that are alien to the core system.

A distinguishing property of standard languages is that they may be used among speakers of different dialects, and that they sometimes have to be acquired by speakers of such dialects as a second language at a later age, that is, in a similar fashion as a foreign language (although this may be rare in the context of Dutch). This property of standard languages entails that it is not contradictory to distinguish various varieties of, e.g., Standard Dutch. This view is also assumed by Haeseryn et al. (1997: Section 0.6.2), who make the four-way distinction in (4) when it comes to geographically determined variation.

- Types of Dutch according to Haeseryn et al. (1997)

a. Standard language

b. Regional variety of Standard Dutch

c. Regional variety of Dutch

d. Dialect

The types in ( $4 b \& c)$ are characterized by specific properties that are found in certain larger, but geographically restricted regions only. The difference between the two varieties is defined by Haeseryn at al. (1997) by appealing to the perception of the properties in question by other speakers of the standard language: if the majority of these speakers do not consider the property in question characteristic for a certain geographical region, the property is part of a regional variety of Standard Dutch; if the property in question is unknown to certain speakers of the standard language or considered to be characteristic for a specific geographical region, it is part of a regional variety of Dutch. We will not adopt the distinction between the types in (4b) and (4c) since we are not aware of any large-scale perception studies that could help us to distinguish the two varieties in question. We therefore simply join the two categories into a single one, which leads to the typology in (5).

- Types of Dutch distinguished in $S o D$
a. Standard Dutch
b. Regional variety of Dutch
c. Dialect of Dutch 
We believe it to be useful to think of the notions in (5) in terms of grammatical properties that are part of the competence of groups of speakers. Standard Dutch can then be seen as a set of properties that is part of the competence of all speakers of the language. Examples of such properties in the nominal domain are that nonpronominal noun phrases are not morphologically case-marked and that the word order within noun phrases is such that nouns normally follow attributively used adjectives but precede PP-modifiers and that articles precede attributive adjectives (if present); cf. (6a). Relevant properties within the clausal domain are that finite verbs occupy the co-called second position in main clauses whereas non-finite verbs tend to cluster in the right-hand side of the clause (see (6b)), and that finite verbs join the clause-final non-finite verbs in embedded clauses (see (6c)).
a. de oude man in de stoel the old man in the chair
b. Jan heeft de man een lied horen zingen.
[word order within noun phrases] Jan has the man a song hear sing 'Jan has heard the man sing a song.'
c. dat Jan de man een lied heeft horen zingen. that Jan the man a song has hear sing 'that Jan has heard the man sing a song.'
[verb second/clustering]
[verb clustering]

Regional varieties of Dutch arise as the result of sets of additional properties that are part of the competence of larger subgroups of speakers - such properties will define certain special characteristics of the variety in question but will normally not give rise to linguistic outputs that are inaccessible to speakers of other varieties; see the discussion of (7) below for a typical example. Dialects can be seen as a set of properties that characterizes a group of speakers in a restricted geographical areasuch properties may be alien to speakers of the standard language and may give rise to linguistic outputs that are not immediately accessible to other speakers of Dutch; see the examples in (9) below for a potential case. This way of thinking about the typology in (5) enables us to use the language types in a more gradient way, which may do more justice to the situation that we actually find. Furthermore, it makes it possible to define varieties of Dutch along various (e.g., geographical and possibly social) dimensions.

The examples in (7) provide an example of a property that belongs to regional varieties of Dutch: speakers of northern varieties of Dutch require that the direct object boeken 'books' precede all verbs in clause-final position, whereas many speakers of the southern varieties of Dutch (especially those spoken in the Flemish part of Belgium) will also allow the object to permeate the verb sequence, as long as it precedes the main verb.

(7) a. dat Jan $<$ boeken $>$ wil $<*$ boeken $>$ kopen.

[Northern Dutch] that Jan books wants buy 'that Jan wants to buy books.'

b. dat Jan $<$ boeken $>$ wil $<$ boeken $>$ kopen. that Jan books wants buy 'that Jan wants to buy books.' 
Dialects of Dutch may deviate in various respects from Standard Dutch. There are, for example, various dialects that exhibit morphological agreement between the subject and the complementizer, which is illustrated in (8) by examples taken from Van Haeringen (1939); see Haegeman (1992), Hoekstra \& Smit (1997), Zwart (1997), Barbiers et al. (2005), Van Koppen (2005/2017) and the references given there for more examples and extensive discussion. Complementizer agreement is a typical dialect property as it does not occur in (the regional varieties of) Standard Dutch.
a. $\mathrm{As}_{\mathrm{sg}}$ Wim komp $\mathrm{sg}$, mot jə zorgə dat je tuis ben. when Wim comes must you make.sure that you at.home are 'When Wim comes, you must make sure to be home.'
b. Azzəpl Kees en Wim komməpl, mot jə zorgə dat je tuis ben. when Kees and Wim come must you make.sure that you home are 'When Kees and Wim come, you must make sure to be home.'

The examples in (9) illustrate another property that belongs to a certain set of dialects. Speakers of most varieties of Dutch would agree that the use of possessive datives is only possible in a limited set of constructions: whereas possessive datives are possible in constructions such as (9a), in which the possessee is embedded in a ${ }^{\circ}$ complementive PP, they are excluded in constructions such as $(9 \mathrm{~b})$, in which the possessee is a direct object. Constructions such as (9b) are perceived (if understood at all) as belonging to certain eastern and southern dialects, which is indicated here by means of a percentage sign.

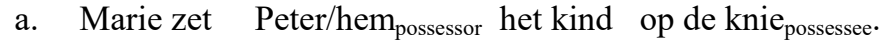
Marie puts Peter/him the child onto the knee
'Marie puts the child on Peter's/his knee.
b. ${ }^{\%}$ Marie wast Peter/hem possessor $_{\text {de handen }}$ possessee.
Marie washes Peter/him the hands
'Marie is washing Peter's/his hands.'

Note that the typology in (5) should allow for certain dialectal properties to become part of certain regional varieties of Dutch, as indeed seems to be the case for possessive datives of the type in (9b); cf. Cornips (1994). This shows again that it is not possible to draw sharp dividing lines between regional varieties and dialects and emphasizes that we are dealing with dynamic systems; see the discussion of (5) above. For our limited purpose, however, the proposed distinctions seem to suffice.

It should be stressed that the description of the types of Dutch in (5) in terms of properties of the competence of groups of speakers implies that Standard Dutch is actually not a language in the traditional sense; it is just a subset of properties that all non-dialectal varieties of Dutch have in common. Selecting one of these varieties as Standard Dutch in the more traditional sense described in the first paragraph of this subsection is not a linguistic enterprise and will therefore not concern us here. For practical reasons, however, we will focus on the regional variety of Dutch spoken in the northwestern part of the Netherlands. One reason for doing this is that the main authors of $S o D$ are native speakers of this variety and can therefore simply appeal to their own intuitions in order to establish whether this variety does or does 
not exhibit a certain property. A second reason is that this variety seems close to the varieties that have been discussed in the linguistic literature on "Standard Dutch". This does not mean that we will not discuss other varieties of Dutch, but we will do this only if we have reason to believe that they behave differently. Unfortunately, however, not much is known about the syntactic differences between the various regional varieties of Dutch and since it is not part of our goal to solve this problem, we want to encourage the reader to restrict the judgments given in $S o D$ to speakers of the northwestern variety (unless indicated otherwise). Although in the vast majority of cases the other varieties of Dutch will exhibit identical or similar behavior given that the behavior in question reflects properties that are part of the standard language (in the technical sense given above), the reader should keep in mind that this cannot be taken for granted as it may also reflect properties typical for the regional variety spoken by the authors of this work.

\section{Organization of the material}

$S o D$ is divided in four main parts that focus on the four LEXICAL CATEGORIES: verbs, nouns, adjectives and adpositions. Lexical categories have denotations and normally take arguments: nouns denote sets of entities, verbs denote states-ofaffairs (activities, processes, etc.) that these entities may be involved in, adjectives denote properties of entities, and adpositions denote (temporal and locational) relations between entities.

The lexical categories, of course, do not exhaust the set of word classes; there are also FUNCTIONAL CATEGORIES like complementizers, articles, numerals, and quantifiers. Such elements normally play a role in phrases headed by the lexical categories: articles, numerals and quantifiers are normally part of noun phrases and complementizers are part of clauses (that is, verbal phrases). For this reason, these functional elements will be discussed in relation to the lexical categories.

The four main parts of $S o D$, which were published in 2012-2016 have the subtitle $X s$ and $X$ phrases, where $X$ stands for one of the lexical categories. This subtitle expresses that each part discusses one lexical category and the ways in which it combines with other elements (like arguments and functional categories) to form constituents. Furthermore, the four main parts of $S o D$ all have more or less the same overall organization in the sense that they contain (one or more) chapters on the following topics.

\section{Characterization and classification}

II. Internal syntax

A. The lexical domain I: Argument structure

B. The lexical domain II: Modification

C. The functional domain

III. External syntax

For a more detailed description of these topics we refer to the prefaces of the four main parts because the present $S o D$ volume is special in that it discusses two issues that are normally included in descriptive grammars but that do not fit in the overall organization of this work: coordination and ellipsis in coordinate structures. For the organization of this volume we refer to the introduction on page 1 . 


\section{History of the project and future prospects}

With the publication of this volume, the SoD-project will come to an end. The idea for the project was initiated in 1992 by Henk van Riemsdijk. In 1993 a pilot study was conducted at Tilburg University and a steering committee was installed after a meeting with interested parties from Dutch and Flemish institutions. However, it was only in 1998 that a substantial grant from the Netherlands Organization of Scientific Research (NWO) was finally obtained. Since then various parties have made it possible to continue the project. The project has resulted in the following parts, which all appeared in the series Comprehensive Grammar Resources published by Amsterdam University Press.

\section{Noun and noun phrases (2012)}

\section{Hans Broekhuis, Evelien Keizer and Marcel den Dikken}

This work, which was published in two volumes, discusses the internal make-up as well as the distribution of noun phrases. Topics covered include complementation and modification of noun phrases, properties of determiners (article, demonstratives), numeral and quantifiers, and also the use of noun phrases as arguments, predicates and adverbial modifiers.

II. Adjectives and adjective phrases (2013)

Hans Broekhuis

This work discusses the internal make-up as well as the distribution of adjective phrases. Topics covered include complementation and modification, comparative and superlative formation, and the attributive, predicative and adverbial uses of adjective phrases. Special attention is paid to the so-called partitive genitive construction and the adverbial use of past/passive participles and infinitives.

\section{Adpositions and adpositional phrases (2013)}

\section{Hans Broekhuis}

This work, which was published in late 2013, discusses the internal make-up and the distribution of adpositional phrases. Topics covered include complementation and modification of adpositional phrases, as well as their predicative, attributive and adverbial uses. A separate chapter is devoted to the formation and the syntactic behavior of pronominal PPs like erop 'on it', which also includes a more general discussion of the syntax of R-words such as er 'there'.

\section{Verbs and Verb phrases (2015-6)}

Hans Broekhuis, Norbert Corver and Riet Vos

This work, which was published in three volumes, discusses the internal make-up and distribution of verb phrases and clauses. After a general introduction covering various issues including tense marking, volume 1 provides an extensive discussion of argument structure and verb frame alternations. Volume 2 is devoted to various types of verbal/clausal complements in complex clauses. Volume 3 discusses adverbial modification and the organization (word order) of the clause.

\section{Coordination and ellipsis}

\section{Hans Broekhuis, Norbert Corver}

In addition to the four main parts mentioned in I-IV, the present volume provides an extensive discussion of coordination and ellipsis in coordinate structures. 
The fact that the final volume appears now does not mean that work on the SoDproject will be terminated. Since the work listed in I to III was written in the period 1998-2002 but only published between 2012-2016, it is clear that it can no longer be considered fully up-to-date. We therefore plan the preparation of a revised version of $S o D$. This will also enable us to remove various omissions and inconsistencies that arose due to the fact that the various main parts were not written simultaneously but consecutively in a span of two decades.

The output of the $S o D$ project has also been integrated into a broader project initiated by Hans Bennis and Geert Booij, which resulted in the online grammar Language Portal Dutch/Frisian (taalportaal.org), which includes similar projects on the phonology and the morphology of Dutch. As the name suggests, the Language Portal Dutch/Frisian also includes a grammatical description of Frisian. In fact, the Language Portal project is expanding and now also includes a partial grammatical description of Afrikaans (which will be completed in the near future).

The series editors of Comprehensive Grammar Resources series are in the process of initiating a number of grammar projects comparable to $S o D$ : languages include Basque, Japanese, Mandarin, Polish, Russian, Spanish and Swedish. Two volumes on noun phrases of the Syntax of Hungarian were published in 2018, and another volume on adpositional phrases in Hungarian is on its way.

\section{Acknowledgments}

Over the years many Dutch linguists have commented on parts of the work presented here and since we do not want to tire the reader by providing long lists of names, we simply thank the whole Dutch linguistic community; this will also safeguard us from the embarrassment of forgetting certain names. The persons mentioned on the title pages of the various volumes have all played an important role. Anneke Neijt and Hans Bennis should be mentioned especially, however, because Anneke played a crucial role in getting the SoD-project started while Hans played a crucial in getting it finished. Carole Boster and Frits Beukema also need special mention, as they ensured that $S o D$ is written in legible and grammatical English, and never blamed the editor of the SoD-series for stubbornly repeating most of his mistakes.

We gratefully acknowledge the financial and moral support of various institutions and thank them for the opportunity they have given us for bringing $S o D$ into being, and to a close. The pilot study for the project, which was undertaken from November 1993 to September 1994, was made possible by a subsidy from the Center for Language Studies and the University of Tilburg. It resulted in a project proposal that was eventually accepted by The Netherlands Organisation for Scientific Research (NWO) in 1998, which enabled us to produce the main body of work mentioned in Section 6, sub I to III, during the period from May 1998 to May 2001. This work could be prepared for publication in the period from April 2008 to October 2010 thanks to a subsidy from the Truus und Gerrit van Riemsdijk-Stiftung. Since November 2010 Hans Broekhuis has continued his work on $S o D$ as a staff member of the Meertens Institute (KNAW) in Amsterdam. SoD became part of the project Language Portal Dutch/Frisian, which was again financed by The Netherlands Organisation for Scientific Research (NWO) and which also made it 
possible for Norbert Corver en Crit Cremers to join the SoD-team from 2011-2016; this has resulted in the works mentioned in Section 6, sub IV. In 2017 Hans Broekhuis and Norbert Corver have joined forces in writing the present volume.

September 2018

Hans Broekhuis

Co-author and editor of Syntax of Dutch

Henk van Riemsdijk

Series editor of Comprehensive Grammar Resources 


\section{Introduction}

This part of Syntax of Dutch deals with coordination as well as ellipsis phenomena found in coordinate structures. Coordination will be the main topic of Chapter 1 . Although coordinate structures resulting from coordination prototypically involve a single COORDINATOR such as en 'and' or of 'or', it cannot be said that such coordinators select for certain internal or external ${ }^{\circ}$ arguments. This means that these coordinate structures differ from other syntactic structures in that they are not (extended) ${ }^{\circ}$ projections of an argument-taking lexical ${ }^{\circ}$ head. Instead, coordinators typically join two or more similar phrases (which will be referred to as COORDINANDS) into a larger phrase of the same kind. Some illustrations are given in (1) with the coordinator en 'and': example (1a) involves the coordination of two main clauses and ( $1 \mathrm{~b} \& \mathrm{c})$ the coordination of two nominal phrases. Section 1.1 starts by discussing a number of more general properties of coordinate structures and their constituting parts. The discussion in Sections 1.2 to 1.4 provides a detailed discussion of the various types of coordinate structures and their constituting parts, that is, the coordinators and the coordinands.

(1) a. [ $[\mathrm{CP}[\mathrm{CP}$ Jan leest het boek $]$ en $[\mathrm{CP}$ Peter leest het artikel]].
Jan reads the book and Peter reads the article
'Jan is reading the book and Peter is reading the article.'
b. Jan leest $[\mathrm{NP}[\mathrm{NP}$ het boek] en [NP het artikel]].
Jan reads the book and the article
'Jan is reading the book and the article.'
c. [NP [NP Jan $]$ en [NP Peter $]]$ lezen het boek.
'Jan and Peter read the book

Chapter 2 discusses the fact that coordinate structures are prone to reduction. The examples in (2) show that identical elements in the coordinands tend to be left unpronounced, which is indicated by means of strikethrough. We will focus on two main types of ellipsis. Example (2a) is a case of BACKWARD CONJUNCTION REDUCTION: right-peripheral material in the left coordinand is normally left unpronounced to the extent that it is identical to that of the right coordinand. Example (2b) is a case of GAPPING: the right coordinand of the coordination is reduced by non-pronunciation of (at least) the finite verb.

(2) a. [[Jan leest het boek en

Jan reads the book about coordination and

[Peter leest het artikel over coördinatie]].

Peter reads the article about coordination

'Jan is reading the book and Peter is reading the article on coordination.'

b. [[Jan leest het boek] en [Peter het artikel]].

Jan reads the book and Peter reads the article

'Jan is reading the book and Peter the article.' 
Although coordinate structures are relatively easy to recognize, Chapter 3 will discuss a number of cases, which have been claimed to exhibit some but not all of the properties of coordination. The forms that will be discussed are als 'as' and dan 'than' in comparative constructions, behalve 'except/besides', in plaats van 'instead of', and laat staan 'let alone'. We will argue that here we are not dealing with borderline cases of coordination but with run-of-the-mill subordination; the claim that these forms exhibit borderline behavior and should therefore be analyzed as coordinator-like elements is to be attributed mainly to the misconception that gapping is possible in coordinate structures only. 


\section{Chapter 1 \\ Coordination}

Introduction $\quad 6$

1.1. General properties 6

I. Syntactic function 6

II. Monosyndetic, polysyndetic and asyndetic coordinate structures $\quad 7$

III. Two closed classes: simple and correlative coordinators $\quad 8$

IV. Meaning contribution of coordinators 9

A. Some basic notions from propositional calculus 10

B. Coordination of clauses: conjunction and disjunction 11

C. Coordination of predicative and adverbial phrases: intersection and union $\quad 15$

1. Set theory: intersection, union, and complement 16

2. Proper nouns and singular definite expressions 18

3. Plural definite descriptions 19

4. Universally quantified noun phrases $\quad 22$

5. Existentially quantified noun phrases 24

6. Negative existentially quantified noun phrases 25

7. Conclusion 27

D. Coordination of noun phrases: distributive and cumulative readings 28

E. Unexpected readings of predicate conjunction with en 'and' 33

$\begin{array}{ll}\text { F. Concluding remarks } & 39\end{array}$

V. Prosodic restrictions on coordinands $\quad 40$

VI. Pragmatic restrictions on coordinands $\quad 40$

VII. Distinguishing coordinators from other elements 41

A. Coordinators versus subordinators $\quad 42$

B. Coordinators versus conjunctive adverbials $\quad 43$

C. On the semantic difference between coordinators and subordinators 46

1.2. Monosyndetic, polysyndetic and asyndetic coordination 46

I. Monosyndetic and asyndetic coordination 47

A. Asyndetic coordinate structures do not occur clause-internally 48

$\begin{array}{ll}\text { B. Potential counterexamples } & 50\end{array}$

1. Numerals 51

2. Stacked attributively used adjectives 51

3. Other cases: complex onomatopoeias and reduplication 52

C. Asyndetically linked clauses $\quad 54$

II. Monosyndetic and polysyndetic coordinate structures 56

III. A note on correlative coordinators $\quad 57$

1.3. Coordinands 59

$\begin{array}{lr}\text { I. Co-occurrence restrictions } & 60\end{array}$

A. The coordinands have the same syntactic function $\quad 60$

B. The coordinands have the same syntactic distribution 63

C. Predicative coordinands: the individual/stage-level distinction $\quad 70$

D. Other restrictions $\quad 71$ 
II. Coordinate structure constraint and across-the-board movement 72

A. Coordinate structure constraint $\quad 72$

B. An apparent counterexample: "split" coordinate structures 73

$\begin{array}{ll}\text { 1. Leftward movement of first coordinand } & 74\end{array}$

2. Extraposition of the [en/of/maar XP] string $\quad 74$

3. Ellipsis accounts $\quad 76$

$\begin{array}{ll}\text { C. More potential counterexamples: asymmetrical coordination } & 79\end{array}$

D. Across-the-board movement $\quad 81$

1. Across-the-board movement is indeed movement 83

2. All movement types can be applied across-the-board $\quad 85$

3. Replacement test $\quad 86$

4. The coordinands are of the same of type $\quad 87$

$\begin{array}{ll}\text { III. Embedding/recursivity } & 91\end{array}$

A. Associativity and commutativity of conjunction and disjunction 92

B. Hierarchically ordered coordinate structures $\quad 95$

C. Hierarchical coordinate structures: word order and meaning 96

D. Hierarchical coordinate structures and prosody $\quad 97$

E. Ambiguities in triadic coordinate structures with en 'and' 98

F. Ambiguities in larger polyadic coordinate structures with en 'and' 101

G. A potential problem: polyadic coordinate structures with noch 'nor' $\quad 104$

IV. Are coordinate structures binary branching? 109

$\begin{array}{lll}\text { 1.4. Coordinators } & 113\end{array}$

1.4.1. Simple coordinators 115

I. The simplex coordinator en 'and' 116

A. Restrictions on the coordinands 116

1. Categorial/semantic restrictions on the coordinands 116

2. Syntactic functions of conjunctive coordinate structures 121

3. Coordinands of different types $\quad 122$

4. Conclusion 125

B. Agreement with nominal coordinands with "mixed" feature specifications 125

1. Person 126

$\begin{array}{ll}\text { 2. Number } & 127\end{array}$

3. Gender 134

C. Special interpretations: asymmetrical conjunction $\quad 138$

$\begin{array}{ll}1 . \text { Temporal (consecutive) ordering } & 139\end{array}$

$\begin{array}{lr}2 . \text { Reason/cause and concession } & 140\end{array}$

3. Condition 141

4. Deixis 145

5. Fixed collocations and ordering conventions $\quad 146$

$\begin{array}{ll}\text { D. Special uses } & 147 \\ & 1 . \text { Paftionig conjunction }\end{array}$

$\begin{array}{ll}\text { 1. Partitioning conjunction } & 147\end{array}$

2. Emphatic conjunction $\quad 148$

3. Comment (specification, qualification, correction, etc.) 150

$\begin{array}{ll}\text { 4. Intensifying conjunction } & 152\end{array}$

$\begin{array}{ll}\text { 5. Additive conjunction } & 152\end{array}$

6. Coordinate structures with missing conjuncts $\quad 153$

II. The simplex coordinator of 'or' $\quad 155$

$\begin{array}{ll}\text { A. Restrictions on the coordinands } & 155\end{array}$

1. Categorial/semantic restrictions on the coordinands $\quad 155$

2. Syntactic functions of disjunctive coordinate structures $\quad 158$

$\begin{array}{ll}3 . \text { Coordinands of different types } & 160\end{array}$

$\begin{array}{ll}\text { 4. Conclusion } & 160\end{array}$

B. Agreement with nominal coordinands with "mixed" feature specifications $\quad 161$ 
C. Special interpretations $\quad 165$

1. Inclusive and exclusive disjunction $\quad 166$

2. Asymmetrical disjunction I: $\mathrm{p} \vee \mathrm{q} \quad 169$

3. Asymmetrical disjunction II: $\neg \mathrm{p} \vee \mathrm{q} \quad 172$

4. Another case of asymmetrical disjunction with logical impact? 173

$\begin{array}{ll}\text { 5. Fixed collocations and ordering conventions } & 174\end{array}$

6. Conclusion 175

D. Balanced ordination (balansschikking) 175

1. A bird's eye view on the logically oriented literature 176

2. Balanced ordination (balansschikking) is not a syntactic relation $\quad 179$

3. Conclusion 186

$\begin{array}{ll}\text { E. Other special uses } & 186\end{array}$

1. Paraphrasing and approximative of 'or' $\quad 186$

2. Of niet 'or not' 188

$\begin{array}{lr}\text { III. The simplex coordinator noch 'nor' } & 189\end{array}$

A. Restrictions on the coordinands 190

B. Agreement with nominal coordinands with "mixed" feature specifications 192

$\begin{array}{ll}\text { C. Meaning/interpretation } & 194\end{array}$

IV. The simplex coordinator maar 'but' 194

$\begin{array}{ll}\text { A. Restrictions on the coordinands } & 194\end{array}$

B. Subject-verb agreement $\quad 199$

$\begin{array}{ll}\text { C. Meaning/interpretation } & 202\end{array}$

$\begin{array}{ll}\text { D. Special uses } & 205\end{array}$

V. The simplex coordinators want 'because' and dus 'so' 207

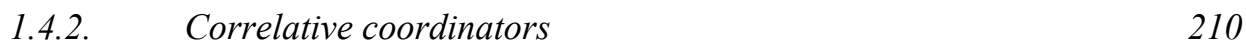

$\begin{array}{ll}\text { I. General discussion } & 212\end{array}$

A. Correlative coordinators versus correlative adverbials $\quad 212$

B. Correlative coordinators versus correlative adverbial phrases $\quad 214$

$\begin{array}{ll}\text { C. Conclusion } & 217\end{array}$

$\begin{array}{ll}\text { II. The four most frequent forms } & 217\end{array}$

$\begin{array}{ll}\text { A. En ... en ... 'and ... and' } & 217\end{array}$

B. Zowel ... als.. 'both ... and ...' 222

C. Of ... of ... 'either ... or ..' 225

$\begin{array}{ll}\text { D. Noch ... noch ... 'neither ... nor ...' } & 227\end{array}$

III. The syntactic representation of correlative coordinators $\quad 228$

$\begin{array}{ll}\text { A. Complex-head analysis } & 229\end{array}$

1. Arguments favoring the complex-head hypothesis 229

2. Arguments against the complex-head hypothesis 231

B. Double-head analyses $\quad 233$

1. The AgrCoP-version of the double head analysis 233

2. The CorP-version of the double head analysis 235

C. The initial part of a correlative coordinate structure is a focus particle 236

$\begin{array}{ll}\text { 1. The initial part of a correlative occupies a designated focus position I } & 237\end{array}$

2. The initial part of a correlative occupies a designated focus position II $\quad 240$

3. Split correlative coordinate structures are biclausal 242

4. Conclusion 244 


\section{Introduction}

This chapter provides an extensive discussion of coordination. Section 1.1 starts by considering a number of more general properties of coordinate structures and their constituting parts, after which we continue by investigating some typical syntactic properties of coordinate structures. Section 1.2 first considers in more detail the differences between monosyndetic, polysyndetic and asyndetic coordinate structures. Section 1.3 investigates certain (presumed) properties of their coordinands, including co-occurrence restrictions on coordinands, their island behavior, recursivity of coordination, and the ability of coordinate structures to split, as in Ik heb Peter gisteren gezien en Marie 'I saw Peter yesterday, and Marie'. Section 1.4 concludes by providing more detailed information about the syntactic behavior, interpretation and use of some individual coordinators.

\subsection{General properties}

This section discusses a number of general properties of coordinators and the structures they occur in. We start with three very brief subsections: Subsection I illustrates the syntactic function of coordinators, namely that they combine two or more coordinands into a coordinate structure of the same kind; Subsection II shows that coordinate structures come in three main types, viz., monosyndetic, polysyndetic and asyndetic coordinate structures; and Subsection III shows that we can distinguish between simplex and correlative (or complex/discontinuous) coordinators. Subsection IV constitutes the main part of this section and provides a fairly detailed discussion of the semantic contribution of coordinators. They differ from lexical ${ }^{\circ}$ heads such as verbs or nouns in that they do not have a denotation, which leads to the conclusion that coordinators are functional ${ }^{\circ}$ heads; see, e.g., Grootveld (1992/1994) and Johannessen (1998:ch.3) for more arguments in favor of this claim as well as some problems for it. Subsections V and VI briefly mention some phonological and pragmatic restrictions on the coordinands in a coordinate structure. Subsection VII concludes by discussing some procedures for distinguishing coordinators from other elements like subordinators such as omdat 'because' and conjunctive adverbials such as daarom 'for that reason'.

\section{Syntactic function}

Coordinators are used to combine two or more coordinands into a coordinate structure of the same kind (see Section 1.3 for a detailed discussion). This entails that the coordinators are not part of the coordinands themselves, but external to them. That this is indeed the case is clear from the coordinate structure in (1a) with two sentences (main clauses) as coordinands; the coordinator maar 'but' precedes the sentence-initial position of the second coordinand and must therefore be sentence-externally; see V9 for a review of the internal structure of clauses. The unacceptability of example (1b) shows that the coordinator maar cannot occupy the sentence-initial position itself, which conclusively shows that it cannot function as a ${ }^{\circ}$ clausal constituent (that is, ${ }^{\circ}$ argument, adverbial or ${ }^{\circ}$ complementive). For completeness' sake, example (1c) shows that the unacceptability of (1b) is not due 
to the fact that the coordination slot is empty, which we indicated by $\varnothing$, as filling $\varnothing$ with the coordinator en does not improve the result.
(1) a. [[CP Jan is ziek $]$ maar [CP Marie is op vakantie $]]$. Jan is ill but Marie is on vacation
b. *[[ ${ }_{\mathrm{CP}}$ Jan is ziek $] \varnothing[\mathrm{CP}$ maar is Marie op vakantie $\left.]\right]$. Jan is ill but is Marie on vacation
c. *[[CP Jan is ziek] en [CP maar is Marie op vakantie $]]$. Jan is ill but is Marie on vacation

\section{Monosyndetic, polysyndetic and asyndetic coordinate structures}

The examples in (1) show that coordinators are not clausal constituents. It is also clear that they are not lexical heads either, in the technical sense that they project; that is, they differ from verbs, noun, adjectives and adpositions in that they do not take ${ }^{\circ}$ arguments and cannot be modified. The fact that coordinators are not lexical heads may also account for the fact that they are neither obligatory nor unique within a coordinate structure: although coordinate structures normally contain just one single coordinator preceding the final coordinand, the coordinator can sometimes be repeated before all coordinands (except the first) or be left out entirely. The names normally used for the three types of coordination are given to the right of the examples (from Greek syndetos 'bound together'). We will discuss the three types of coordinate structures in (2) more extensively in Section 1.2.
a. [Jan, Marie en Peter] komen morgen.
[monosyndetic]
Jan Marie and Peter come tomorrow
'Jan, Marie and Peter will come tomorrow.'
b. [Jan en Marie en Peter] komen morgen.
Jan and Marie and Peter come tomorrow
'Jan and Marie and Peter will come tomorrow.'
c. [Jan, Marie, Peter], ze komen morgen allemaal.
Jan Marie Peter they come tomorrow all
'Jan, Marie, Peter. they will all come tomorrow.'
[polysyndetic]
[asyndetic]

It should be noted that not all coordinate structures with more than one coordinator are polysyndetic, due to the fact that coordination is recursive in the sense that coordinate structures can be embedded as a coordinand in a larger coordinate structure. The conventional way of addressing an audience of mixed age and gender given in (3a) can be used to illustrate this; the vocative consists of two asyndetically coordinated coordinate structures, namely dames en heren and jongens en meisjes, which are each monosyndetic; the vocative phrase as a whole thus contains two occurrences of the coordinator en 'and' without being a polysyndetic coordinate structure itself. The same thing is illustrated by (3b), which involves asyndetic coordination of three monosyndetic coordinate structures, each referring to a couple: the resulting structure therefore contains three occurrences of en without being polysyndetic. The recursive property of coordination will be more extensively discussed in Section 1.3, sub III. 
(3) a. [[Dames en heren], [jongens en meisjes]], welkom! ladies and gentlemen boys and girls welcome 'Ladies and gentlemen, boys and girls, welcome!'

b. [[Jan en Marie], [Peter en Els], [Ad en Ton]], ze komen allemaal. Jan and Marie Peter and Els Ad and Ton they come all 'Jan and Marie, Peter and Els, Ad and Ton, they will all come.'

\section{Two closed classes: simple and correlative coordinators}

Coordinators resemble functional heads such as articles in that they form a closed class. We will provisionally follow the tradition in assuming that there are two lexical types, simple coordinators such as en 'and' and correlative coordinators such as zowel ... als ... 'both ... and ...'. Example (4) provides an exhaustive set of coordinators found in present-day Dutch: the forms marked by the number sign \# are more or less restricted to formal language and writing, which shows that the set of coordinators used in colloquial speech is extremely small. We will ignore the more formal forms in what follows unless they exhibit a behavior crucial for the discussion at hand.

(4) a. Simple coordinators: " alsmede 'as well as', " alsook 'as well as', "benevens 'besides', "dan wel 'or', "doch 'but', dus 'so', en 'and', maar 'but', noch 'neither', of 'or', ofwel 'or', want 'because'.

b. Correlative coordinators: en ... en ... 'as well as', ${ }^{\sharp}$ hetzij ... hetzij/of 'either ... or ...', noch ... noch ... 'neither ... nor ...', of ... of ... 'either ... or ...', ofwel ... ofwel ... 'or ... or ...', zowel ... als ... 'both ... and ...'.

Correlative coordinators do not readily fit in the typology of coordinate structures given in Subsection II because (5a) shows that both conjuncts are preceded by a subpart of the correlative. In fact, if more than two coordinands are present the second part of the correlative is normally repeated, as illustrated by (5b). Note in passing that we gloss the second part of als as and in order to stay close to both ... and ..., although it might be more appropriate to gloss it as as; this will be done throughout this volume.
a. [Zowel Jan als Peter] is ziek.
both Jan as Peter is ill
'Both Jan and Peter are ill.'
b. [Zowel Jan, ${ }^{\%}$ (als) Marie, als Peter $]$ is ziek.
both Jan as Marie as Peter is ill
'Both Jan and Marie as well as Peter are ill.'

The percentage sign in $(5 \mathrm{~b})$ is used because it has been claimed that the als-part before the second coordinand is occasionally left out in actual speech; cf. taaladvies.net/taal/advies/vraag/1223. Although this does result in a relatively mild deviance, the fact that leaving out the noch-part before the second coordinand in (6b) gives rise to a severely degraded result suggests that we may be dealing with a performance error. We will leave this issue for future research. 
(6) a. Noch Jan noch Peter is ziek. neither Jan nor Peter is ill

b. Noch Jan, *(noch) Marie noch Peter is ziek. neither Jan nor Marie nor Peter is ill

The list of correlative coordinators in (4b) shows that zowel ... als 'both ... and ...' is slightly exceptional in having morphologically distinct subparts; in most other cases the first and second part have the same form. This makes it somewhat difficult to distinguish correlative from polysyndetic coordinate structures; the distinction mainly rests on the generally adopted claim that while the first coordinand is obligatorily preceded by the first subpart of a correlative, it cannot be preceded by a coordinator in polysyndetic constructions.

(7) a. Noch Jan, noch Marie noch Peter is ziek.

[correlative] neither Jan nor Marie nor Peter is ill

b. Jan, noch Marie noch Peter is ziek. Jan nor Marie nor Peter is ill

[polysyndetic]

The claim that the forms in (4b) are "discontinuous" coordinators is not uncontroversial, and depends on the internal structure that we assign to coordinate structures such as in (5); we return to this issue in Section 1.4.2.

\section{Meaning contribution of coordinators}

Subsection I has shown that coordinators do not function syntactically as ${ }^{\circ}$ clausal constituents but as linkers of specific linguistic units (including main clauses); this entails that coordinators do not contribute to the meaning of the coordinands but have some other meaning still to be defined. The discussion below will be partly phrased in terms of propositional calculus; Subsection A will start by introducing some of the basic notions. Subsections B to D will then continue by discussing coordinate structures of the types in (8).

(8) a. [[Jan is in Utrecht] en [Marie is in New York $]]$.

[clauses] Jan is in Utrecht and Marie is in New York

b. Jan is [[ziek] en [moe]]. Jan is ill and tired

c. [Els en Marie] hebben de rots opgetild. Els and Marie have the rock prt.-lifted 'Els and Marie have lifted the rock.'

[predicative phrases] [noun phrases]

The starting point of our discussion is the hypothesis generally adopted by logical grammarians from the $19^{\text {th }}$ century that coordinators link sentences and not parts of sentences, which will be referred to as BECKER'S CONJECTURE. This conjecture entails two things: (i) apparent coordination of non-clausal phrases, as in (8b\&c), results from clausal coordination followed by conjunction reduction; (ii) the meaning of coordinate structures can be exhaustively described by means of propositional logic. Subsection B starts by discussing the meaning of coordinate structures with clausal coordinands such as (8a) in a propositional calculus. Subsection $\mathrm{C}$ continues by considering apparent non-clausal coordinate structures with a predicative (or an adverbial) function such as (8b), and will show that 
propositional calculus is not fit to provide a proper description of the meaning of such cases. From this we will conclude that Becker's conjecture cannot be maintained, which will receive further support by the discussion of coordinate structures with nominal coordinands in Subsection D. Subsection E briefly addresses a number of unexpected readings of predicate conjunctions with en 'and' while Subsection $\mathrm{F}$ provides a number of concluding remarks pertaining to the meaning of coordinators.

\section{A. Some basic notions from propositional calculus}

The propositional calculus approach to coordination can be traced back to Becker (1832) and work by other logical grammarians from the $19^{\text {th }}$ century, and was also adopted by early generative grammarians including Chomsky (1957); we refer the reader to Bakker (1968: Section I.5), Dik (1968) and Van Oirsouw (1987:ch.1) for extensive critical reviews of these two periods. Becker conjectures that coordinators link sentences and not parts of sentences: "Konjunktionen verbinden Sätze, und nicht eigentlich einzelne Glieder des Satzes" (p.141-2). In current terminology, this amounts to saying that coordinators should be translated as logical connectives in a propositional calculus, which are used for forming complex formulas out of more simple ones: this is illustrated in (9) for cases in which the input of the logical operation consists of one or two atomic formulas indicated by the proposition letters $\mathrm{p}$ and $\mathrm{q}$.
a. Negation: $\neg \mathrm{p}$
b. Conjunction (logical AND): $\mathrm{p} \wedge \mathrm{q}$
c. Inclusive disjunction (logical OR): $\mathrm{p} \vee \mathrm{q}$
d. Material implication: $\mathrm{p} \rightarrow \mathrm{q}$

Propositional calculus is recursive in the sense that the complex formulas in (9) can be used as the input for further logical operations: the operands of the logical operation can therefore be represented more adequately by means of the letters $\varphi$ and $\psi$, which stand for well-formed (atomic or complex) formulas. Observe that negation differs from the other logical connectives in that it has a single operand; it can therefore also be considered as an operator with a formula in its scope.
(10) a. Negation: $\neg \varphi$
b. Conjunction: $\varphi \wedge \psi$
c. Inclusive disjunction: $\varphi \vee \psi$
d. Material implication: $\varphi \rightarrow \psi$

The meaning contribution of the four logical connectives in (9) can be defined by means of the truth tables in Table 1, which specify the truth conditions on the complex formulas in (10); the digits 0 and 1 stand for "false" and "true", respectively. The truth of a complex formula depends on the input of the logical operation by which it was formed; $\neg \varphi$ is only true if $\varphi$ is false; $\varphi \wedge \psi$ is only true if both $\varphi$ and $\psi$ are true; $\varphi \vee \psi$ is true unless $\varphi$ and $\psi$ are both false; and $\varphi \rightarrow \psi$ is true unless $\varphi$ is true while $\psi$ is false. 
Table 1: Truth tables for negation, conjunction, disjunction, and material implication

\begin{tabular}{||c|c|c|c|c|c||}
\hline \multicolumn{2}{|c||}{ INPUT } & \multicolumn{4}{|c||}{ OUTPUT } \\
\hline$\varphi$ & $\psi$ & $\begin{array}{c}\neg \varphi \\
\text { negation }\end{array}$ & $\begin{array}{c}\varphi \wedge \psi \\
\text { conjunction }\end{array}$ & $\begin{array}{c}\varphi \vee \psi \\
\text { inclusive } \\
\text { disjunction }\end{array}$ & $\begin{array}{c}\varphi \rightarrow \psi \\
\text { material } \\
\text { implication }\end{array}$ \\
\hline \hline 1 & 1 & 0 & 1 & 1 & 1 \\
\hline 1 & 0 & 0 & 0 & 1 & 0 \\
\hline 0 & 1 & 1 & 0 & 1 & 1 \\
\hline 0 & 0 & 1 & 0 & 0 & 1 \\
\hline
\end{tabular}

This subsection has discussed the four basic logical connectives from propositional logic. Subsection B will show that these do not suffice to describe coordination of clauses in a one-to-one fashion, but that there are more extensive sets of logical connectives that do cover all cases.

\section{B. Coordination of clauses: conjunction and disjunction}

The assumption that coordinators function semantically as logical connectives normally leads to a classification such as given in (11).

(11) a. Conjunctive coordinators (logical AND): dus 'so', en 'and', en ... en ... 'as well as', maar 'but', want 'because', zowel ... als ... 'both ... and ...'

b. Disjunctive coordinators:

(i) Inclusive (logical OR): of 'or'

(ii) Exclusive (logical XOR): of(wel) ... of(wel) ... 'either ... or ...'

c. Logical NOR: noch 'nor', noch ... noch ... 'neither ... nor ...'

Conjunction and disjunction can readily be expressed by means of a coordinator, although the latter seems to come in two subtypes with slightly different truth conditions: the propositional calculus meanings of these types of disjunctive coordinators are given in Table 2 . We will use the connective $\underline{v}$ for exclusive disjunction, although it can also be expressed quite adequately in the more primitive terms of conjunction and disjunction: $(\varphi \vee \psi) \wedge \neg(\varphi \wedge \psi)$.

Table 2: Truth tables for conjunction, disjunction and logical NOR

\begin{tabular}{|c|c|c|c|c|c|}
\hline \multicolumn{2}{|c|}{ INPUT } & \multicolumn{4}{|c|}{ OUTPUT } \\
\hline$\varphi$ & $\psi$ & $\begin{array}{c}\varphi \wedge \psi \\
\text { conjunction }\end{array}$ & $\begin{array}{c}\varphi \vee \psi \\
\text { inclusive } \\
\text { disjunction }\end{array}$ & $\begin{array}{c}\varphi \underline{\vee} \Psi \\
\text { exclusive } \\
\text { disjunction }\end{array}$ & $\begin{array}{c}\neg(\varphi \vee \psi) \\
\text { logical NOR }\end{array}$ \\
\hline 1 & 1 & 1 & 1 & 0 & 0 \\
\hline 1 & 0 & 0 & 1 & 1 & 0 \\
\hline 0 & 1 & 0 & 1 & 1 & 0 \\
\hline 0 & 0 & 0 & 0 & 0 & 1 \\
\hline
\end{tabular}

There are various logical connectives that do not have a corresponding coordinator in Dutch (or any other natural language); these include material implication, material equivalence, as well as logical NAND. The truth conditions for these 
connectives are given in Table 3; observe that logical XNOR is logically equivalent to material equivalence, so that we can ignore this option in what follows.

Table 3: Truth tables for material implication/equivalence and logical NAND/NOR

\begin{tabular}{|c|c||c|c|c|c||}
\hline \hline \multicolumn{2}{|c||}{ INPUT } & \multicolumn{4}{c||}{ OUTPUT } \\
\hline$\varphi$ & $\psi$ & $\begin{array}{c}\varphi \rightarrow \psi \\
\text { material } \\
\text { implication }\end{array}$ & $\begin{array}{c}\varphi \leftrightarrow \psi \\
\text { material } \\
\text { equivalence }\end{array}$ & $\begin{array}{c}\neg(\varphi \wedge \psi) \\
\text { logical NAND }\end{array}$ & $\begin{array}{c}\neg(\varphi \underline{\vee} \psi) \\
\text { logical XNOR }\end{array}$ \\
\hline \hline 1 & 1 & 1 & 1 & 0 & 1 \\
\hline 1 & 0 & 0 & 0 & 1 & 0 \\
\hline 0 & 1 & 1 & 0 & 1 & 0 \\
\hline 0 & 0 & 1 & 1 & 1 & 1 \\
\hline
\end{tabular}

We expressed the meanings of logical NAND and NOR in the tables above by means of negation with the more familiar connectives $\wedge$ and $\vee$ in its scope, but they are sometimes also expressed directly by means of symbols such as $\bar{\lambda}$ and $\bar{v}$. This is a random decision immaterial to the main point of our present discussion that logical NOR can be expressed in Dutch by means of the coordinator noch 'nor' while logical NAND cannot be expressed by means of a coordinator (although it can of course be expressed by means of more elaborate descriptions; cf. Het is niet zo dat $\varphi \wedge \psi$ 'It is not the case that $\left.\varphi \wedge \psi^{\prime}\right)$.

An important argument for assuming that coordinators should be translated as logical connectives in a propositional calculus is related to the commutative laws in (12), which show that the logical connectives in Table 2 allow the operands to swap places without affecting the truth conditions of the formula as a whole. The commutative rules in (12) express this by means of the symbol $\equiv$ (is logically equivalent to): (12d) follows from (12b) but we nevertheless give it here for convenience.
- Commutative law:
a. Conjunction: $(\varphi \wedge \psi) \equiv(\psi \wedge \varphi)$
b. Inclusive disjunction: $(\varphi \vee \psi) \equiv(\psi \vee \varphi)$
c. Exclusive disjunction: $(\varphi \underline{\vee} \psi) \equiv(\psi \underline{\vee} \varphi)$
d. Logical NOR: $\neg(\varphi \vee \psi) \equiv \neg(\psi \vee \varphi)$

The truth conditions for conjunction in Table 2 state that $p \wedge q$ is only true if both $\mathrm{p}$ and $\mathrm{q}$ are true. This is a proper description of example (13a) with the coordinator en 'and', which is true only if Jan is in Utrecht and Marie is in New York. The same holds for example (13b) with the coordinator want 'because'.

(13) a. [[Jan is in Utrecht] en [Marie is in New York]].

Jan is in Utrecht and Marie is in New York

b. [[Jan is in Utrecht] want [Marie is in New York]].

Jan is in Utrecht because Marie is in New York

If the coordinators en 'and' and want 'because' are to be translated as logical conjunctions, we would predict that the coordinated clauses in (13a\&b) can swap places, as in (14), without affecting the truth conditions of the coordinate structure 
as a whole. The coordinate structures in (13a) and (14a) are indeed logically equivalent in the sense that they both entail the truth of both coordinands.

(14) a. [[Marie is in New York] en [Jan is in Utrecht]].

Marie is in New York and Jan is in Utrecht

b. [[Marie is in New York] want [Jan is in Utrecht]].

Marie is in New York because Jan is in Utrecht

Although the same holds for the coordinate structures in (13b) and (14b), it does not seem likely that these examples will be construed as fully equivalent expressions in discourse, which is reflected by the fact that different conditions are imposed on their use. The reason for this is that want does not only have a conjunctive meaning but in addition expresses that the truth of the second conjunct in some sense explains the truth of the first conjunct: the truth of (13b) is thus not merely based on the truth of $\mathrm{p}$ and $\mathrm{q}$, but rather on the truth of $\mathrm{q}$ and the material implication $\mathrm{q} \rightarrow \mathrm{p}$, cf. Lagerwerf (1998:20), Van der Heijden (1999:202-3) and Verhagen (2005:192ff.).

Table 4: Truth table for want 'because' in (13b)

\begin{tabular}{||c|c|c||c||}
\hline \multicolumn{3}{|c|}{ INPUT } & OUTPUT \\
\hline $\mathrm{p}(\mathrm{J}$ is in $\mathrm{U})$ & $\mathrm{q}(\mathrm{M}$ is in NY) & $\mathrm{q} \rightarrow \mathrm{p}$ & $\mathrm{q} \wedge(\mathrm{q} \rightarrow \mathrm{p})$ \\
\hline \hline 1 & 1 & 1 & 1 \\
\hline 1 & 0 & 1 & 0 \\
\hline 0 & 1 & 0 & 0 \\
\hline 0 & 0 & 1 & 0 \\
\hline
\end{tabular}

By inverting the two coordinands, as in (14b), we get the output indicated in Table 5 , which is based on the truth of $\mathrm{p}$ and the material implication $\mathrm{p} \rightarrow \mathrm{q}$. The two truth tables show that (13b) and (14b) have the same truth conditions, but that they are computed in a largely different manner, which is reflected by the actual interpretation and the concomitant use conditions on these coordinate structures.

Table 5: Truth table for want 'because' in (14b)

\begin{tabular}{||c|c|c||c||}
\hline \multicolumn{3}{|c|}{ INPUT } & OUTPUT \\
\hline $\mathrm{p}(\mathrm{J}$ is in $\mathrm{U})$ & $\mathrm{q}(\mathrm{M}$ is in NY) & $\mathrm{p} \rightarrow \mathrm{q}$ & $\mathrm{p} \wedge(\mathrm{p} \rightarrow \mathrm{q})$ \\
\hline \hline 1 & 1 & 1 & 1 \\
\hline 1 & 0 & 0 & 0 \\
\hline 0 & 1 & 1 & 0 \\
\hline 0 & 0 & 1 & 0 \\
\hline
\end{tabular}

We can provide a similar account for the fact that the two examples in (15) with the coordinator dus 'so' do not obey the same use conditions in discourse. The difference is again due to the fact that conjunctivity does not exhaustively describe the meaning of $d u s$, and that we have to postulate in addition that the truth of the first conjunct explains the truth of the second conjunct, cf. Verhagen (2005:199ff.). The truth of (15a) is thus not just based on the truth of $p$ and $q$, but rather on the truth of $\mathrm{p}$ and the material implication $\mathrm{p} \rightarrow \mathrm{q}$. 
(15) a. [[Jan is in Utrecht] dus [Marie is in New York]]. Jan is in Utrecht so Marie is in New York

b. [[Marie is in New York] dus [Jan is in Utrecht]]. Marie is in New York so Jan is in Utrecht

This means that (15a) is synonymous with (14b) in the relevant respects and that its interpretation can thus be described by means of Table 5. Example (15b), on the other hand, is synonymous with (13b) and its interpretation is therefore properly described by Table 4. The purpose of discussing the use conditions on want 'because' and $d u s$ 'so' is to show that their lexical meanings cannot solely be exhaustively described in terms of truth values of the coordinands; they do have conjunctive semantics but impose the additional restrictions on the operands of the conjunction indicated by (16). We use the symbol $\cong$ to indicate the logical translation of the coordinate structure, while the Greek capitals are used as convenient symbols for syntactic objects that translate as propositional formulas indicated by the corresponding Greek letters in lower case.

$$
\begin{aligned}
& \text { a. } \Phi \text { want } \Psi \cong \psi \wedge(\psi \rightarrow \varphi) \\
& \text { b. } \Phi \text { dus } \Psi \cong \varphi \wedge(\varphi \rightarrow \psi)
\end{aligned}
$$

The disjunctive coordinators of 'or' and of ... of ... 'either ... or ...' do not seem to pose the same problems as the conjunctive coordinators: they behave in full accordance with the commutative law in (12b) by allowing inversion of the coordinands without any truth-functional effects: these coordinators can readily be translated as, respectively, inclusive and exclusive conjunction.
a. [[Jan is in Utrecht] of [Marie is in New York]]. Jan is in Utrecht or Marie is in New York
$[\mathrm{p} \vee \mathrm{q}]$
$a^{\prime}$. [[Marie is in New York] of [Jan is in Utrecht]]
b. [Of [Jan is in Utrecht] of [Marie is in New York]]. either Jan is in Utrecht or Marie is in New York
$\mathrm{b}^{\prime}$. [Of [Marie is in New York] of [Jan is in Utrecht]].

It should be noted, however, that it is sometimes difficult or even impossible to interpret of 'or' as inclusive disjunction; examples such as (17a) are interpreted as involving exclusive coordination in many contexts. That of should nevertheless be translated as inclusive conjunction is clear from the answers to question (18a) given in the (b)-examples: the available answers nicely reflect the truth table for disjunction in Table 1. We postpone to Section 1.4.1, sub II, further discussion of the question as to why of is often interpreted as exclusive disjunction in examples such as (17a).

(18) a. Is Jan of Marie aanwezig?

is Jan or Marie present

b. Ja, Jan/Marie is er.

yes Jan/Marie is here

$b^{\prime}$. Ja, ze zijn er allebei.

yes they are here both

'Yes, they are both here.' 
$b^{\prime \prime}$. Nee, ze zijn er allebei niet. no they are here both not

'No they are both absent.'

The primed examples in (19) show that noch 'nor' and noch ... noch ... 'neither ... nor ...' cannot be used to coordinate full main clauses. However, the fact that $\left(19 \mathrm{a}^{\prime}\right)$ entails that the two propositions Jan/Marie is in Utrecht are both false suggests that these coordinators can nevertheless be translated as logical NOR. The same follows of course from the fact that $\left(19 b^{\prime}\right)$ entails that the propositions Jan/Marie is in New York are both false.
a. *[[Jan is in Utrecht] noch [Marie is in New York]]. Jan is in Utrecht nor Marie is in New York
$a^{\prime}$. [Jan noch Marie] is in New York. Jan nor Marie is in New York
b. *[Noch [Jan is in Utrecht] noch [Marie is in New York]]. neither Jan is in Utrecht nor Marie is in New York
$\mathrm{b}^{\prime}$. [Noch Jan noch Marie] is in New York. neither Jan nor Marie is in New York

Let us now return to Becker's conjecture that coordinators link sentences and not parts of sentences, which entails (i) that apparent coordination of non-clausal phrases results from clausal coordination followed by conjunction reduction and (ii) that the meaning of coordinate structures can be exhaustively described by means of propositional logic. Although this subsection has shown that data supporting the second entailment exist, it should be emphasized that the lexical meaning of some coordinators cannot be exhaustively described in terms of the truth values of their coordinands. This was illustrated for the coordinators want 'because' and dus 'so', which are lexically specified as indicated in (16) above; they do not only have a conjunctive meaning but also express a lexically specified material implication in the sense that the truth of one of the coordinands explains the truth of the other coordinand. It should also be pointed out that there is also a problem with the first entailment of Becker's conjecture, according to which the primed examples in (19) should be derived from a coordinate structure with two clauses by conjunction reduction, because the unacceptability of the primeless examples suggests that noch 'nor' and noch ... noch ... 'neither ... nor ...' cannot be used in such structures. For this reason, Subsection $\mathrm{C}$ will discuss this entailment in more detail.

\section{Coordination of predicative and adverbial phrases: intersection and union}

This subsection investigates in more detail the entailment of Becker's conjecture that apparent coordination of non-clausal phrases such as in the examples in (20) should result from clausal coordination followed by conjunction reduction: "Wenn jedoch einander beigeordnete Sätze dasselbe Subjekt oder Prädikat [...] mit einander gemein haben; so wird das beiden Sätzen gemeinsame Glied des Satzes ein Mal ausgelassen" (Becker 1832:142). 
(20) a. Jan heeft Marie bezocht en een boek gekocht.

Jan has Marie visited and a book bought

'Jan has visited Marie and bought a book.'

b. Jan is ziek en moe.

Jan is ill and tired

'Jan is ill and tired.'

c. Jan rent graag in het bos en op het strand.

Jan runs gladly in the wood and on the beach

'Jan likes to run in woods and on beaches.'

According to Becker's conjecture, the examples in (20) must be assigned the representations in (21) with two coordinated clauses, in which the parts with strikethrough are left unpronounced.

(21) a. [[Jan heeft Marie bezocht] en [Jan heeft een boek gekocht]].

Jan has Marie visited and Jan has a book bought

b. [[Jan is ziek] en [ $\tan$ is moe]].

Jan is ill and Jan is tired

c. [[Jan rent graag in hetbos] en [ op het strand]].

Jan runs gladly in the wood and Jan runs gladly on the beach

This subsection will show that there are strong reasons to reject the representations in (21) in favor of the simpler representations in (22) without conjunction reduction, derived by coordination of the predicative/adverbial phrases.

(22) a. Jan heeft [[vp Marie bezocht] en [vp een boek gekocht]].

[VPs]

Jan has Marie visited and a book bought

b. Jan is [[AP ziek] en [AP moe]].

Jan is ill and tired

c. Jan rent graag [[pp in het bos] en [pp op het strand]].

Jan runs gladly in the wood and on the beach

\section{Set theory: intersection, union, and complement}

The coordinate structures in the representations given in (22) perform a similar predicative or adverbial function as their coordinands would have performed if they had been used in a non-coordinated structure. This correctly accounts for the intuition that examples such as $(22 \mathrm{a} \& \mathrm{~b})$ express that the individual referred to by Jan is a member of the set of individuals denoted by the coordinated VPs/APs, while (22c) expresses that the event referred to by Jan running is part of the set of events denoted by the coordinated locational PPs. The meanings of the coordinate structures in (22) cannot be expressed by propositional calculus because the nonclausal coordinands are not assigned a truth value, but they can be expressed by means of the VENN DIAGRAMS in Figure 1, in which the circles A, B and C represent the sets denoted by the coordinated phrases. 


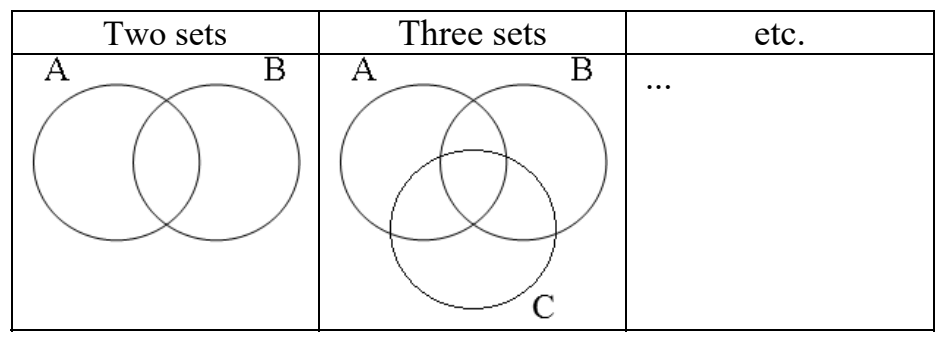

Figure 1: Illustrations of Venn diagrams

The meaning contribution of coordinators is that they select a specific subpart of these Venn diagrams. We will illustrate this below by means of the copular constructions in (23).

(23) a. Jan is ziek en moe.

Jan is ill and tired

[conjunction; AND]

b. Jan is ziek of moe.

[inclusive disjunction: OR]

Jan is ill or tired

c. Jan is of ziek of moe.

Jan is either ill or tired

[exclusive disjunction: XOR]

d. Jan is noch ziek noch moe.

[logical NOR]

Jan is neither ill nor tired

By using the copular constructions in (23), the speaker contends that the individual referred to by Jan is located in the grey areas of the Venn diagrams in Figure 2; note that also in the later diagrams in this chapter, grey will be used to mark the area selected by the coordinator/connective. The coordinator en (logical AND) expresses that Jan is part of the intersection of the sets denoted by the coordinands, while the coordinator of 'or' (logical OR) expresses that Jan is part of the union of these sets. The coordinator of ... of ... (logical XOR) expresses that Jan is either part of the complement of $\mathrm{A}$ or part of the complement of $\mathrm{B}$, with the net result that it cannot be located in the intersection of A and B. The coordinator noch 'nor' (logical NOR) expresses that Jan is excluded from both $\mathrm{A}$ and $\mathrm{B}$ as a result of which Jan must be located in the complement of the union of $\mathrm{A}$ and $\mathrm{B}$.

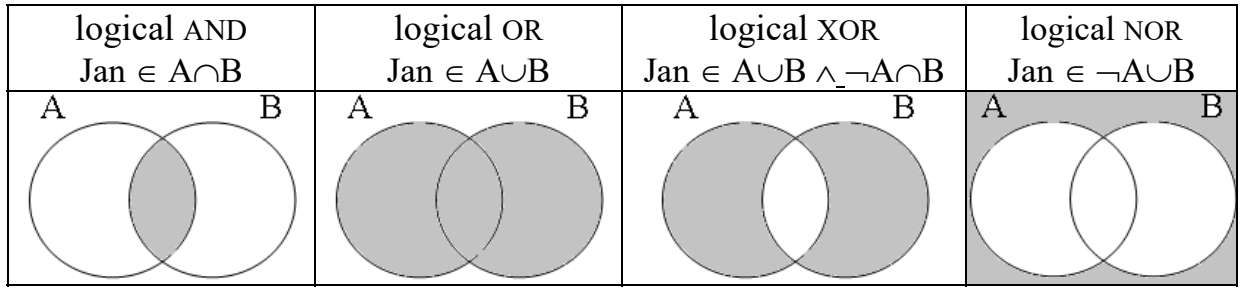

Figure 2: Set-theoretic interpretation of coordinators

The following subsections will argue on semantic grounds that the syntactic representations in (22) are the correct ones. The main reason for claiming this is that Becker's conjecture wrongly predicts that the primeless examples in (24) are logically equivalent with the primed ones. This is not categorically true but depends 
on the type of NP that is used; see, e.g., Zwart (1981) and Winter (2001a:10). For the sake of convenience, we will refer to the coordinate structures in the primeless and primed examples as, respectively, the long and the short form.
a. NP heeft/hebben gezongen en NP heeft/hebben gedanst.
NP has/have sung and NP has/have danced
$a^{\prime}$. NP heeft/hebben gezongen en gedanst.
NP has/have sung and danced
b. NP heeft/hebben gezongen of NP heeft/hebben gedanst.
NP has/have sung or NP has/have danced
$b^{\prime}$. NP heeft/hebben gezongen of gedanst.
NP has/have sung or danced
[long form]
[short form]
[long form]
[short form]

\section{Proper nouns and singular definite expressions}

The logical equivalences of the long and short forms hold true if the subject is a proper noun like Jan or a singular definite description such as de jongen 'the boy'. Example (25) illustrates this for Jan only, but the result would be the same if the noun phrase de jongen 'the boy' was substituted for this proper noun.
a. Jan heeft gezongen en Jan heeft gedanst.
Jan has sung and Jan has danced
$\mathrm{a}^{\prime}$. Jan heeft gezongen en gedanst.
Jan has sung and danced
b. Jan heeft gezongen of Jan heeft gedanst. Jan has sung or Jan has danced
$b^{\prime}$. Jan heeft gezongen of gedanst.
Jan has sung or danced

The truth values for the long forms in Table (26) are simply repeated from the truth tables for conjunction and inclusive disjunction discussed in subsection B. We added the truth values for the short forms to facilitate comparison, despite the fact that we will see that they cannot be computed from the presumed input (as the atomic propositions given as "input" should rather be seen as entailments of the short forms). The truth values for the short forms are based on the ones reported in the semantic literature (such as Zwart 1981 and Winter 2001a:10), as in the present case, or will be motivated explicitly in the accompanying main text, as in many of the cases discussed in the next subsections. Since the truth values of the short and the long forms are identical in the case at hand, we may conclude that these forms are indeed logically equivalent.

(26) Truth table for cases with a proper noun as subject

\begin{tabular}{||c|c||c|c||c|c||}
\hline \multicolumn{2}{|c||}{ Presumed input } & \multicolumn{2}{c||}{ logical AND } & \multicolumn{2}{c||}{ Logical OR } \\
\hline Jan has sung & Jan has danced & $(25 \mathrm{a})$ & $\left(25 \mathrm{a}^{\prime}\right)$ & $(25 \mathrm{~b})$ & $\left(25 \mathrm{~b}^{\prime}\right)$ \\
\hline \hline 1 & 1 & 1 & 1 & 1 & 1 \\
\hline 1 & 0 & 0 & 0 & 1 & 1 \\
\hline 0 & 1 & 0 & 0 & 1 & 1 \\
\hline 0 & 0 & 0 & 0 & 0 & 0 \\
\hline
\end{tabular}


Truth table (26) can also be represented by means of the Venn diagrams introduced in Subsection 1; this is illustrated in Figure 3 for logical AND. In order to facilitate comparison between the long and the short forms in (25), the cells above the Venn diagrams provide the truth values of both cases in the given situation; dots are used to indicate the location of the entities denoted by the predicates A and B. Figure 3 shows that the coordinator en 'and' requires the referent of Jan to be included in the intersection of the sets denoted by the coordinands $(A \cap B)$, which is given in grey, that is, as in the leftmost diagram. This hold both for the long and the short form in the (a)-examples in (25).

\begin{tabular}{|c|c|c|c|}
\hline $\begin{array}{c}\mathrm{p} \wedge \mathrm{q}=1 \\
\operatorname{Jan} \in \mathrm{A} \cap \mathrm{B}=1\end{array}$ & $\begin{array}{c}\mathrm{p} \wedge \mathrm{q}=0 \\
\mathrm{Jan} \in \mathrm{A} \cap \mathrm{B}=0\end{array}$ & $\begin{array}{c}\mathrm{p} \wedge \mathrm{q}=0 \\
\text { Jan } \in \mathrm{A} \cap \mathrm{B}=0\end{array}$ & $\begin{array}{c}\mathrm{p} \wedge \mathrm{q}=0 \\
\text { Jan } \in \mathrm{A} \cap \mathrm{B}=0\end{array}$ \\
\hline $\mathrm{A}$ & & & $\mathrm{A}$
\end{tabular}

Figure 3: Conjunction of clauses and predicates (Subject: Jan)

The Venn diagrams in Figure 4 illustrate the four possibilities for inclusive oR: the short and long forms with the coordinator of 'or' in $\left(25 \mathrm{~b} \& \mathrm{~b}^{\prime}\right)$ are both true if Jan is included in $\mathrm{A}$, in $\mathrm{B}$ or in the intersection $\mathrm{A} \cap \mathrm{B}$, that is, in the union $\mathrm{A} \cup \mathrm{B}$ given in grey.

\begin{tabular}{|c|c|c|c|}
\hline$p \vee q=1$ & $p \vee q=1$ & $p \vee q=1$ & $p \vee q=0$ \\
$\operatorname{Jan} \in A \cup B=1$ & Jan $\in A \cup B=1$ & Jan $\in A \cup B=1$ & Jan $\in A \cup B=0$ \\
\hline$A$ & & &
\end{tabular}

Figure 4: Inclusive disjunction of clauses and predicates (Subject: Jan)

\section{Plural definite descriptions}

The previous subsection has established that the long and short forms in (24) are logically equivalent if the subject is a proper noun or a singular definite description. However, this does not hold true for cases in which the subject is a plural definite description such as de jongens 'the boys' in (27).

(27) a. De jongens hebben gezongen en de jongens hebben gedanst. the boys have sung and the boys have danced

$a^{\prime}$. De jongens hebben gezongen en gedanst. the boys have sung and danced

b. De jongens hebben gezongen of de jongens hebben gedanst. the boys have sung or the boys have danced

$b^{\prime}$. De jongens hebben gezongen of gedanst. the boys have sung or danced 
The truth tables for the examples in (27) are as given in (28): the values for the long forms in the primeless examples are again repeated from the truth tables for conjunction and inclusive disjunction given in subsection $\mathrm{B}$, while those for the short forms will be motivated in the discussion below by means of Venn diagrams.

(28) Truth table for cases with plural definite noun phrases

\begin{tabular}{|c|c||c|c||c|c|}
\hline \multicolumn{3}{|c||}{ Presumed input } & \multicolumn{2}{c|}{ logical AND } & \multicolumn{2}{c|}{ Logical OR } \\
\hline the boys have sung & the boys have danced & $(27 \mathrm{a})$ & $\left(27 \mathrm{a}^{\prime}\right)$ & $(27 \mathrm{~b})$ & $\left(27 \mathrm{~b}^{\prime}\right)$ \\
\hline \hline 1 & 1 & 1 & 1 & 1 & 1 \\
\hline 1 & 0 & 0 & 0 & 1 & 1 \\
\hline 0 & 1 & 0 & 0 & 1 & 1 \\
\hline 0 & 0 & 0 & 0 & 0 & $0 / 1$ \\
\hline
\end{tabular}

Assume that the contextually given set of boys consists of 5 members and consider the Venn diagrams in Figure 5 for the (a)-examples in (27). These forms with the coordinator en 'and' require the full set of boys (indicated here by $\mathrm{Sb}$ ) to be included in the intersection of the sets denoted by the coordinands, as sketched in the first diagram. The (a)-examples in (27) are false in all other situations: the second and third diagrams sketch situations in which only one of the coordinands of (27a) is true, namely cases in which one of the two sets denoted by the predicates HAVE SUNG and HAVE DANCED includes the full set of boys Sb and one is empty, while the fourth diagram sketches the situation in which both sets are empty.

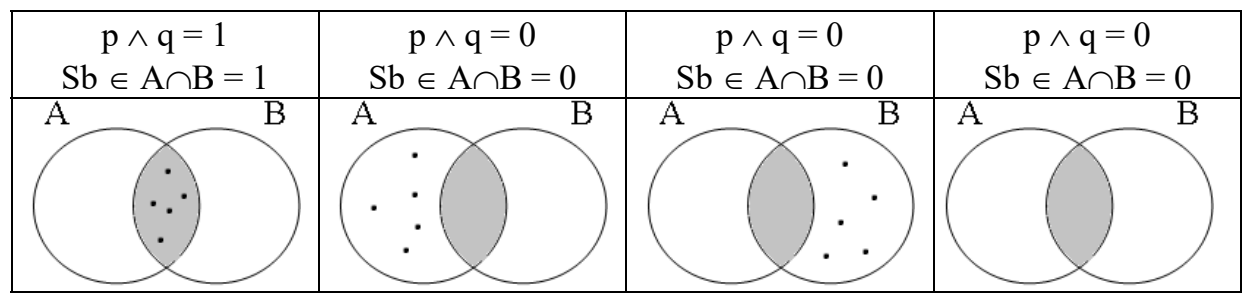

Figure 5: Conjunction of clauses and predicates (Subject: de jongens 'the boys')

The simple propositions in Table (28) are not only false if the sets denoted by their predicates are empty but also if these sets do not include the full contextually given set of boys $\mathrm{Sb}$, as depicted in the last three Venn diagrams in Figure 6. If the long and the short forms in the (a)-examples in (27) indeed require the full set of boys to be included in the intersection $\mathrm{A} \cap \mathrm{B}$, we again predict that speakers will have identical judgments pertaining to the truth values for the situations depicted in the Venn diagrams in Figure 5 and Figure 6.

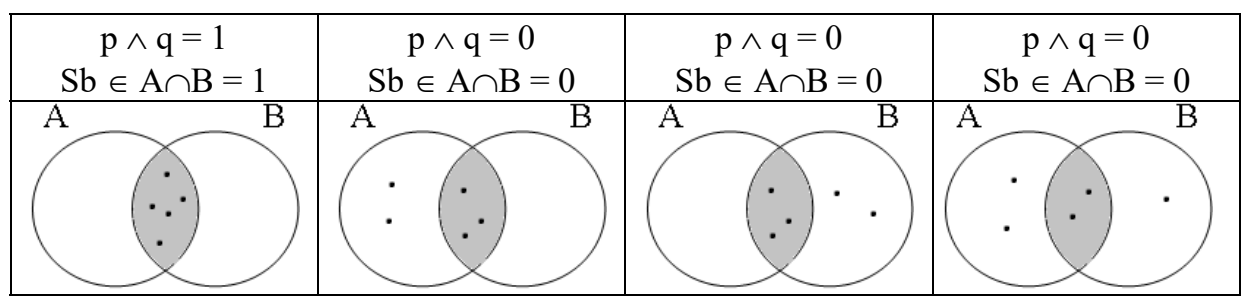

Figure 6: Conjunction of clauses and predicates (Subject: de jongens 'the boys') 
This prediction is indeed true for the long form in (27a) and also for the short form with the correlative conjunctive coordinator en ... en ... 'both ... and ...' in (29a). However, this is not so clear for the short form with the simple conjunctive coordinator en 'and' in $\left(27 \mathrm{a}^{\prime}\right)$, repeated as $(29 \mathrm{~b})$, because at least some speakers accept the latter form as a proper description for all situations in Figure 6; (29b) can be used, for instance, if the boys in a certain group were engaged in the activities of dancing and singing (while the girls were otherwise engaged) even if the speaker knows that some of the boys performed just one of these activities.

(29) a. De jongens hebben en gezongen en gedanst. [consistent with Figure 6] the boys have and sung and danced

'The boys have both sung and danced.'

b. De jongens hebben gezongen en gedanst. [not consistent with Figure 6] the boys have sung and danced

'The boys have sung and danced.'

We will not dwell on this complication here but return to it in Subsection E, and continue with the discussion of the (b)-examples in (27) with the disjunctive coordinator of 'or'. The Venn diagrams in Figure 7 illustrate the same conceivable situations as in Figure 6 for inclusive OR. The interesting case is the fourth one: since neither A nor B properly includes the set $\mathrm{Sb}$, the propositions $\mathrm{p}$ and $\mathrm{q}$ are both false; in accordance with this, the long form in (27b) is also false. However, example $\left(27 b^{\prime}\right)$ is correctly predicted to be true because the full set of boys is included in the union $A \cup B$; this short form can indeed be used for describing the situation sketched by the Venn diagram.

\begin{tabular}{|c|c|c|c|}
\hline $\begin{array}{c}p \vee q=1 \\
S b \in A \cup B=1\end{array}$ & $\begin{array}{c}p \vee q=1 \\
S b \in A \cup B=1\end{array}$ & $\begin{array}{c}p \vee q=1 \\
S b \in A \cup B=1\end{array}$ & $\begin{array}{c}p \vee q=0 \\
S b \in A \cup B=1\end{array}$ \\
\hline $\mathrm{A} B$ & $\mathrm{~A} \quad \mathrm{~B}$ & $\mathrm{~A} \quad \mathrm{~B}$ & \\
\hline
\end{tabular}

Figure 7: Inclusive disjunction of clauses and predicates (Subject: de jongens)

This shows that the long and the short forms in the (b)-examples of (27) are not logically equivalent, and hence that they cannot be derived by coordination of clauses and subsequent conjunction reduction. It is also important to observe that the two (b)-examples would both be false if one or more boys had neither sung nor danced, as depicted in Figure 8 with $\mathrm{C}$ being some predicate other than HAVE SUNG or HAVE DANCED. 


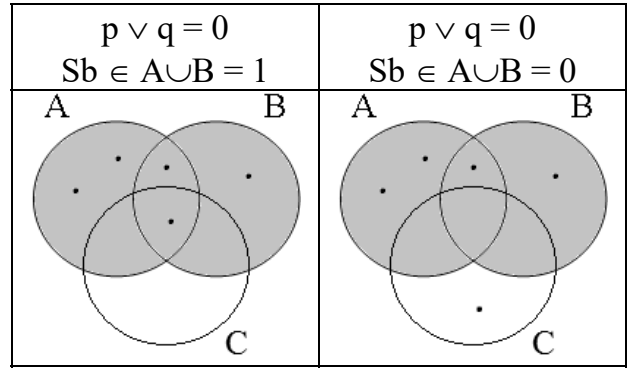

Figure 8

This difference in truth value for the short form in $\left(27 b^{\prime}\right)$ in the situations depicted in two Venn diagrams in Figure 8 shows that it is not categorically true that the short form is true if the simple propositions in Table (28) are false; we expressed this by the use of the notation $0 / 1$ in the grey cells of this truth table. Observe that the fact that we cannot assign a unique value to this cell shows that propositional logic is not a suitable tool for calculating the meaning of the short form; we must appeal to predicate calculus for doing this.

\section{Universally quantified noun phrases}

If we put aside for the moment the problem discussed on the basis of examples in (29), universally quantified expressions like alle jongens 'all boys' or iedereen 'everyone' give us essentially the same results as plural definite descriptions. The long and short forms in (30) are equivalent if the coordinator is conjunctive en but not if it is disjunctive of; this will be illustrated for alle jongens only.
a. Alle jongens hebben gezongen en alle jongens hebben gedanst. all boys have sung and all boys have danced
$\mathrm{a}^{\prime}$. Alle jongens hebben gezongen en gedanst. all boys have sung and danced
b. Alle jongens hebben gezongen of alle jongens hebben gedanst. all boys have sung or all boys have danced
$b^{\prime}$. Alle jongens hebben gezongen of gedanst. all boys have sung or danced

The truth tables for the examples in (30) are given in (31): the values for the long forms in the primeless examples are again repeated from the truth tables for conjunction and inclusive disjunction given in subsection $\mathrm{B}$, while those for the short forms will be motivated in the discussion below.

(31) Truth table for cases with a universally quantified subject

\begin{tabular}{||c|c||c|c||c|c||}
\hline \multicolumn{3}{|c||}{ Presumed input } & \multicolumn{2}{c||}{ logical AND } & \multicolumn{2}{c||}{ Logical OR } \\
\hline all boys have sung & all boys have danced & $(30 \mathrm{a})$ & $\left(30 \mathrm{a}^{\prime}\right)$ & $(30 \mathrm{~b})$ & $\left(30 \mathrm{~b}^{\prime}\right)$ \\
\hline \hline 1 & 1 & 1 & 1 & 1 & 1 \\
\hline 1 & 0 & 0 & 0 & 1 & 1 \\
\hline 0 & 1 & 0 & 0 & 1 & 1 \\
\hline 0 & 0 & 0 & 0 & 0 & $0 / 1$ \\
\hline
\end{tabular}


The corresponding Venn diagrams for the examples with the conjunctive coordinator en 'and' are given in Figure 9. This case seems rather trivial: Example $\left(30 \mathrm{a}^{\prime}\right)$ cannot refer to the second and third situation because the full set of boys Sb is not included by one of the sets denoted by the predicates HAVE SUNG and HAVE DANCED, and it cannot refer to the fourth situation because both sets fail to include $\mathrm{Sb}$. Note in passing that we have used the formula $\forall \mathrm{x}: \mathrm{x} \in \mathrm{A} \cup \mathrm{B}$ as a convenient abbreviation for the formula $\forall \mathrm{x}[\operatorname{boy}(\mathrm{x}) \rightarrow \mathrm{x} \in \mathrm{A} \cup \mathrm{B}]$, in which the restrictor is explicitly mentioned.

\begin{tabular}{|c|c|c|c|}
\hline $\begin{array}{c}\mathrm{p} \wedge \mathrm{q}=1 \\
\forall \mathrm{x}: \mathrm{x} \in \mathrm{A} \cap \mathrm{B}=1\end{array}$ & $\begin{array}{c}\mathrm{p} \wedge \mathrm{q}=0 \\
\forall \mathrm{x}: \mathrm{x} \in \mathrm{A} \cap \mathrm{B}=0\end{array}$ & $\begin{array}{c}\mathrm{p} \wedge \mathrm{q}=0 \\
\forall \mathrm{x}: \mathrm{x} \in \mathrm{A} \cap \mathrm{B}=0\end{array}$ & $\begin{array}{c}\mathrm{p} \wedge \mathrm{q}=0 \\
\forall \mathrm{x}: \mathrm{x} \in \mathrm{A} \cap \mathrm{B}=0\end{array}$ \\
\hline & $\mathrm{A} \quad \mathrm{B}$ & $\mathrm{A} \quad \mathrm{B}$ & -5 \\
\hline
\end{tabular}

Figure 9: Conjunction of clauses and predicates (Subject: alle jongens)

The corresponding Venn diagrams for the examples with the disjunctive coordinator of 'or' in Figure 10 are more interesting. The crucial fact is that the short form alle jongens hebben gezongen of gedanst in $\left(30 \mathrm{~b}^{\prime}\right)$ is like de jongens hebben gezongen of gedanst in $\left(27 \mathrm{~b}^{\prime}\right)$ with the definite plural de jongens 'the boys' in that it can be used to describe situations sketched in the fourth diagram in which some but not all boys have sung and some but not all boys have danced, provided that all boys have performed at least one of these activities; this reading is not available for the long form in (30b).

\begin{tabular}{|c|c|c|c|}
\hline $\begin{array}{c}\mathrm{p} \vee \mathrm{q}=1 \\
\forall \mathrm{x}: \mathrm{x} \in \mathrm{A} \cup \mathrm{B}=1\end{array}$ & $\begin{array}{c}p \vee q=1 \\
\forall x: x \in A \cup B=1\end{array}$ & $\begin{array}{c}p \vee q=1 \\
\forall x: x \in A \cup B=1\end{array}$ & $\begin{array}{c}p \vee q=0 \\
\forall x: x \in A \cup B=1\end{array}$ \\
\hline $\mathrm{A} \quad \mathrm{B}$ & & A & $\mathrm{A}$ \\
\hline
\end{tabular}

Figure 10: Inclusive disjunction of clauses and predicates (Subject: alle jongens)

This shows that the long and the short forms in the (b)-examples in (30) are not logically equivalent, and hence that they cannot be derived by coordination of clauses and subsequent conjunction reduction. It is important to observe that also in this case the two (b)-examples would both be false if the union $A \cup B$ does not include the full contextually given set of boys. The difference in truth value for the short form in $\left(30 b^{\prime}\right)$ in the situations depicted in the two Venn diagrams in Figure 11 shows that it is not categorically true that the short form is true if the simple propositions in Table (31) are false; we expressed this by the use of the notation $0 / 1$ in the grey cells of this truth table. 


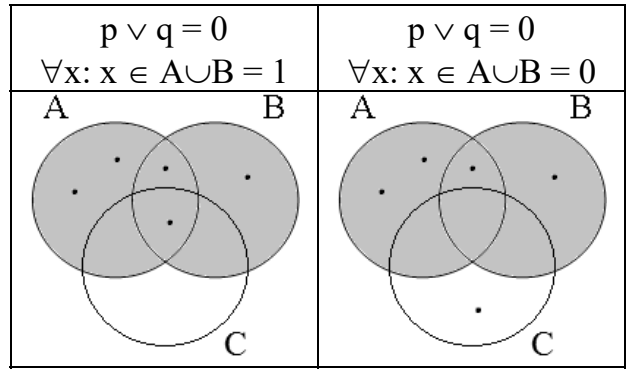

Figure 11

The discussion above shows again that long and short forms are not necessarily logically equivalent, and hence that they cannot be derived by coordination of clauses and subsequent conjunction reduction.

\section{Existentially quantified noun phrases}

Long and short forms are not logically equivalent either if the subject is an existentially quantified expression like sommige jongens 'some boys' or iemand 'someone'. We will illustrate this for the examples in (32).

(32) a. Sommige jongens hebben gezongen en sommige jongens hebben gedanst. some boys have sung and some boys have danced

$\mathrm{a}^{\prime}$. Sommige jongens hebben gezongen en gedanst. some boys have sung and danced

b. Sommige jongens hebben gezongen of sommige jongens hebben gedanst. some boys have sung or some boys have danced

$\mathrm{b}^{\prime}$. Sommige jongens hebben gezongen of gedanst. some boys have sung or danced

The corresponding truth tables are given in (33).

(33) Truth tables for cases with an existentially quantified subject

\begin{tabular}{||c|c||c|c||c|c||}
\hline \multicolumn{2}{|c||}{ Presumed input } & \multicolumn{2}{c||}{ logical AND } & \multicolumn{2}{c||}{ Logical OR } \\
\hline some boys have sung & some boys have danced & $(32 \mathrm{a})$ & $\left(32 \mathrm{a}^{\prime}\right)$ & $(32 \mathrm{~b})$ & $\left(32 \mathrm{~b}^{\prime}\right)$ \\
\hline \hline 1 & 1 & 1 & $0 / 1$ & 1 & 1 \\
\hline 1 & 0 & 0 & 0 & 1 & 1 \\
\hline 0 & 1 & 0 & 0 & 1 & 1 \\
\hline 0 & 0 & 0 & 0 & 0 & 0 \\
\hline
\end{tabular}

The interesting cases are those in the (a)-examples with the coordinator en 'and'. The first Venn diagram in Figure 12 illustrates a situation in which both coordinands of the long form in (32a) are true: (32a) is also true, as expected, but this does not hold for the short form in $\left(32 a^{\prime}\right)$, which is clearly false. This shows that the two (a)-examples are not logically equivalent. The formula $\exists x: x \in A \cup B$ is used as a convenient abbreviation for the formula $\exists x[\operatorname{boy}(x) \wedge x \in A \cup B]$, in which the restrictor is explicitly mentioned. 


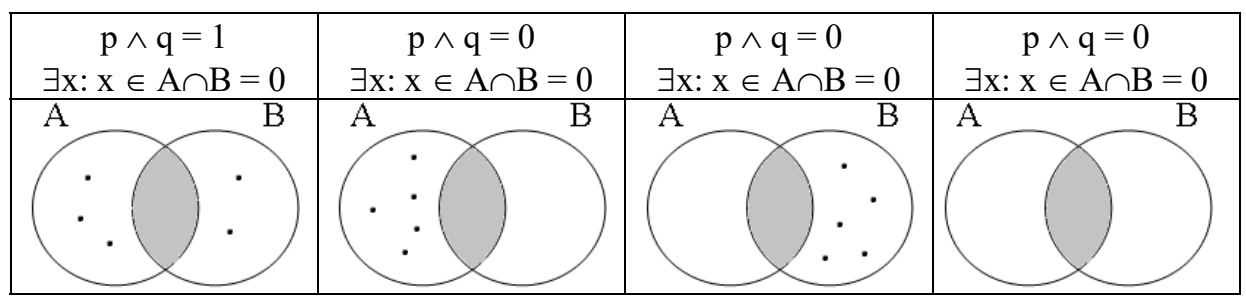

Figure 12: Conjunctive coordination of clauses and predicates (S: sommige jongens)

For completeness' sake, observe that although the material equivalence $(32 \mathrm{a}) \rightarrow$ $\left(32 a^{\prime}\right)$ is false, the material implication $\left(32 a^{\prime}\right) \rightarrow(32 a)$ is true: $\left(32 a^{\prime}\right)$ is true if the intersection $\mathrm{A} \cap \mathrm{B}$ is non-empty, as illustrated in Figure 13, and this entails that (32a) is true as well. This fact illustrated by the Venn diagrams in Figure 13 motivates the use of $0 / 1$ in the shaded cell of Table (33); see also Johannessen (1998:188) and Van Oirsouw (1987:32).

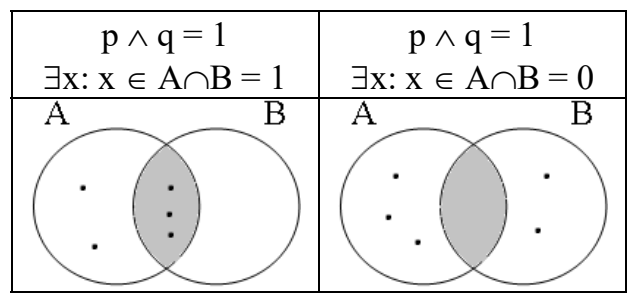

\section{Figure 13}

Figure 14 is added for completeness' sake to illustrate the equivalence of the long and the short form of the (b)-examples in (32); there are no situations imaginable in which the short and long form have different truth conditions.

\begin{tabular}{|c|c|c|c|}
\hline $\begin{array}{c}p \vee q=1 \\
\exists x: x \in A \cup B=1\end{array}$ & $\begin{array}{c}p \vee q=1 \\
\exists x: x \in A \cup B=1\end{array}$ & $\begin{array}{c}p \vee q=1 \\
\exists x: x \in A \cup B=1\end{array}$ & $\begin{array}{c}p \vee q=0 \\
\exists x: x \in A \cup B=0\end{array}$ \\
\hline$A \quad B$ & & & $\mathrm{~A}$ \\
\hline
\end{tabular}

Figure 14: Inclusive disjunction of clauses and predicates (S: sommige jongens)

The discussion above has shown again that the long and short forms are not necessarily logically equivalent because $\left(32 \mathrm{a}^{\prime}\right)$ can be false in situations in which (32a) is true, and, consequently, that the short form cannot have been derived from the long form by conjunction reduction.

\section{Negative existentially quantified noun phrases}

Although there are undoubtedly more cases that could be used to show that long and short forms are not equivalent, we will conclude with just one more case, in which the subject NP is the negative existentially quantified expression geen jongen 'no boy'. Note that the long forms are not common in actual speech but that speakers nevertheless have clear intuitions about their interpretation. 
(34) a. Geen jongen heeft gezongen en geen jongen heeft gedanst. no boy has sung and no boy has danced

$a^{\prime}$. Geen jongen heeft gezongen en gedanst. no boy has sung and danced

b. Geen jongen heeft gezongen of geen jongen heeft gedanst. no boy has sung or no boy has danced

$b^{\prime}$. Geen jongen heeft gezongen of gedanst. no boy has sung or danced

The truth tables for the examples in (34) are given in (35); these show that the long and the short forms have different truth conditions both with en 'and' and or 'or'.

(35) Truth tables for cases with a negative existentially quantified subject

\begin{tabular}{|c|c||c|c||c|c|}
\hline \multicolumn{2}{|c||}{ Presumed input } & \multicolumn{2}{c|}{ logical AND } & \multicolumn{2}{c|}{ Logical OR } \\
\hline no boy has sung & no boy has danced & $(34 \mathrm{a})$ & $\left(34 \mathrm{a}^{\prime}\right)$ & $(34 \mathrm{~b})$ & $\left(34 \mathrm{~b}^{\prime}\right)$ \\
\hline 1 & 1 & 1 & 1 & 1 & 1 \\
\hline 1 & 0 & 0 & 1 & 1 & 0 \\
\hline 0 & 1 & 0 & 1 & 1 & 0 \\
\hline 0 & 0 & 0 & $0 / 1$ & 0 & $0 / 1$ \\
\hline
\end{tabular}

Figure 15 provides the Venn diagrams for the (a)-examples in (34) with the coordinator en 'and': while the long form is true only if both A and B are empty, the short form is true as long as the intersection $A \cap B$ is empty.

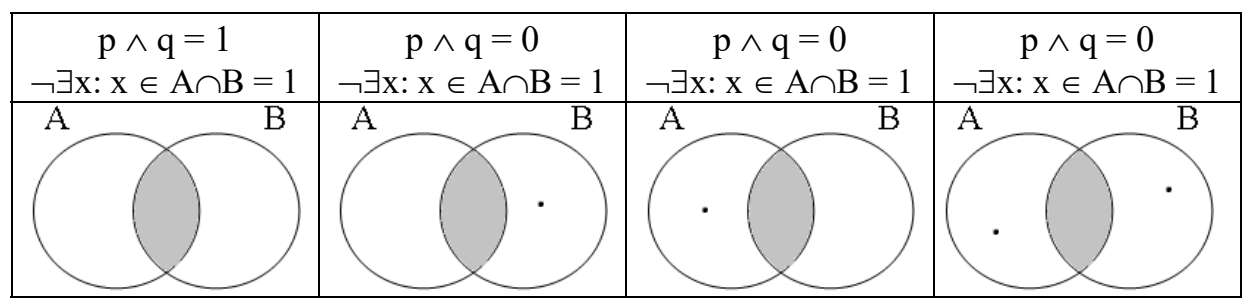

Figure 15: Conjunctive coordination of clauses and predicates (S: geen jongen)

For completeness' sake, Figure 16 illustrates that the truth of the short form cannot be computed by propositional calculus from the truth of the presumed input: in both situations sketched by the Venn diagrams the simple propositions are both false, while the truth value of the short form varies.

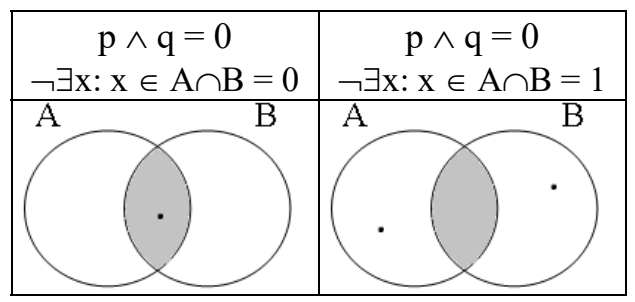

Figure 16 
Figure 17 provides the Venn diagrams for the (b)-examples in (34) with the coordinator of 'or': while the long form is true as long as either A or B is empty, the short form is only true if both A and B are empty.

\begin{tabular}{|c|c|c|c|}
\hline $\mathrm{p} \vee \mathrm{q}=1$ & $p \vee q=1$ & $p \vee q=1$ & $p \vee q=0$ \\
\hline$\neg \exists \mathrm{x}: \mathrm{x} \in \mathrm{A} \cup \mathrm{B}=1$ & $\neg \exists \mathrm{x}: \mathrm{x} \in \mathrm{A} \cup \mathrm{B}=0$ & $\neg \exists \mathrm{x}: \mathrm{x} \in \mathrm{A} \cup \mathrm{B}=0$ & $\neg \exists \mathrm{x}: \mathrm{x} \in \mathrm{A} \cup \mathrm{B}=0$ \\
\hline & & & \\
\hline
\end{tabular}

Figure 17: Disjunctive coordination of clauses and predicates (S: geen jongen)

For completeness' sake, Figure 18 demonstrates again that propositional logic is not a suitable tool for calculating the meaning of the short form: in the two situations sketched in the Venn diagrams the simple propositions $\mathrm{p}$ and $\mathrm{q}$ are both false, while the truth value of the short form varies.

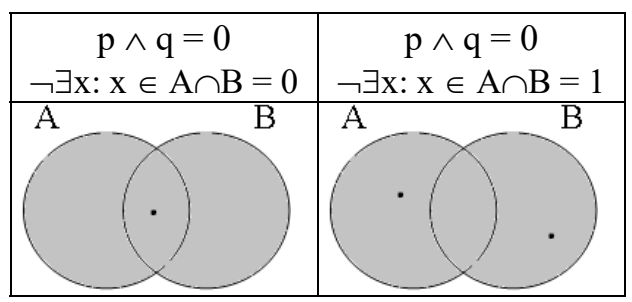

Figure 18

\section{Conclusion}

This subsection has discussed the prediction made by Becker's conjecture that the long and short forms in (24), repeated here as (36), are logically equivalent, that is, equivalent in terms of truth value.

(36) a. NP heeft/hebben gezongen en NP heeft/hebben gedanst.

NP has/have sung and NP has/have danced

$a^{\prime}$. NP heeft/hebben gezongen en gedanst.

NP has/have sung and danced

b. NP heeft/hebben gezongen of NP heeft/hebben gedanst.

NP has/have sung or NP has/have danced

$\mathrm{b}^{\prime}$. NP heeft/hebben gezongen of gedanst.

NP has/have sung or danced

Table 6 shows that this prediction is incorrect, as the long and the short forms are logically equivalent with singular definite NPs/proper names only. The reason for using the asterisk in this table is to indicate that more needs to be said about plural definites because of the contrast noted in the examples in (29); this will be done in Subsection E. 


\begin{tabular}{||l||c|c||}
\hline \multicolumn{1}{||l||}{} & CONJUNCTION & DISJUNCTION \\
\hline \hline SINGULAR DEFINITE NPS/PROPER NAMES & yes & yes \\
\hline PLURAL DEFINITE NPS & yes* & no \\
\hline UNIVERSALLY QUANTIFIED NPS & yes & no \\
\hline EXISTENTIALLY QUANTIFIED NPS & no & yes \\
\hline NEGATIVE EXISTENTIALLY QUANTIFIED NPS & no & no \\
\hline
\end{tabular}

Table 6: Logical equivalence of the long and short forms in (36)

The fact that the short forms often cannot be assigned a unique value in the truth tables given above shows that propositional logic is not a suitable tool for expressing their meaning. We must appeal to predicate calculus to do this: coordination of predicates gives rise to a complex predicate denoting the intersection of the input predicates in the case of a conjunctive coordinator such as en 'and' and to the union of these predicates in the case of a disjunctive coordinator such as of 'or'; the complex predicate is subsequently predicated of the subject. This conclusion is arrived at on the basis of cases with coordinators expressing conjunction and inclusive disjunction but carries over to cases with coordinators expressing logical XOR and NOR (cf. Figure 2).

\section{Coordination of noun phrases: distributive and cumulative readings}

Another type of problem for Becker's conjecture that apparent coordination of nonclausal phrases results from clausal coordination followed by conjunction reduction can be illustrated with the help of the examples in (37), in which (37b) should be derived by coordination of the two main clauses in the (a)-examples.
a. Els heeft de rots opgetild. Els has the rock prt.-lifted
$a^{\prime}$. Marie heeft de rots opgetild. Marie has the rock prt.-lifted
b. Els en Marie hebben de rots opgetild. Els and Marie have the rock prt.-lifted 'Els and Marie have lifted the rock.'
[meaning: p]
[meaning: q]
[meaning: $\psi]$

If Becker's conjecture were correct, apparent coordination of noun phrases by en should categorically lead to conjunction of the propositions expressed by the (a)examples, that is, $\psi=\mathrm{p} \wedge \mathrm{q}$. This is reasonable because it seems valid to conclude from the truth of the two (a)-examples that (37b) is true as well, in accordance with the valid argument schema in (38a), which expresses that the truth of the formulas to the left of the sign $\Vdash$ entails the truth of the formula to the right of the sign. However, the validity of the argument schemas in (38b\&c) also leads to the expectation that the truth of (37b) entails the truth of the (a)-examples, but this seems questionable.
a. $\quad \mathrm{p}, \mathrm{q} \vDash \mathrm{p} \wedge \mathrm{q}$
b. $\quad p \wedge q \Vdash p$
c. $\quad \mathrm{p} \wedge \mathrm{q} \Vdash \mathrm{q}$ 
The reason for doubt is that example (37b) is ambiguous between two readings, which are often referred to as the distributive and the cumulative (or collective/corporate) reading; see Dik (1968/1997) and, for a more recent review, Winter (2001a:ch.2/6). The examples in (39) show that the two readings can easily be distinguished by means of the modifiers allebei 'both' and samen 'together'.

(39) a. Els en Marie hebben allebei de rots opgetild. [distributive reading: $\psi \mathrm{d}$ ] Els and Marie have both the rock prt.-lifted

'Els and Marie have both lifted the rock.'

b. Els en Marie hebben samen de rots opgetild. [cumulative reading: $\psi \mathrm{c}$ ] Els and Marie have together the rock prt.-lifted

'Els and Marie have lifted the rock together.'

The distributive reading $\psi_{\mathrm{d}}$ is conjunctive in the sense that we may conclude from the truth of the two (a)-examples in (37) that (39a) is true as well and, vice versa, from the truth of (39a) that the two (a)-examples in (37) are both true. The cumulative reading $\psi_{\mathrm{c}}$, on the other hand, is not conjunctive in this sense; we can neither conclude from the truth of the two (a)-examples in (37) that (39b) is true, nor from the truth of (39b) that the two (a)-examples in (37) are true. This leads to the provisional conclusions in (40), which take the edge off Becker's conjecture: the cumulative reading of $(37 \mathrm{~b})$ cannot be derived by assuming coordination of sentences followed by conjunction reduction.

$$
\begin{array}{ll}
\text { a. } & \psi_{\mathrm{d}}=\mathrm{p} \wedge \mathrm{q} \\
\text { b. } & \psi_{\mathrm{c}} \neq \mathrm{p} \wedge \mathrm{q}
\end{array}
$$

In the primeless examples in (41) the cumulative reading is the only available one, as is clear from the fact illustrated in the primed examples that the nominal coordinate structures cannot be replaced by their coordinands. The unacceptability of the primed examples makes it quite unlikely that the primeless examples are derived from them by coordination and conjunction reduction.

(41) a. [Els en Marie] komen bijeen.

Els and Marie come together

'Els and Marie meet.'

$\mathrm{a}^{\prime}$. "Els/Marie komt bijeen.

Els/Marie comes together

b. Ik vind [Els en Marie] een goed team.

I consider Els and Marie a good team

$\mathrm{b}^{\prime}$. *Ik vind Els/Marie een goed team.

I consider Els/Marie a good team

One possible way of accounting for (40) is assuming that the coordinator en 'and' has two distinct meanings: the distributive meaning arises if en coordinates clauses, while the cumulative meaning arises if en coordinates noun phrases. We might represent the latter meaning as in (42), in which the connective $\oplus$ expresses that $\mathrm{x}$ and $\mathrm{y}$ do not function as discrete entities ("singular individuals") but as a "plurality" or "a plural individual" in the sense that they are thought of as a set of individual entities. 


$$
\mathrm{NP} \text { en } \mathrm{NP} \cong \mathrm{x} \oplus \mathrm{y}
$$

We refer the reader to Winter (2001a:ch.2) for a discussion of various formal semantic approaches to the cumulative reading, but for our more limited descriptive purposes the informal distinction between the connectives $\wedge$ and $\oplus$ suffices. It is unclear, however, whether distinguishing between a distributive and a cumulative meaning for the coordinator en is really needed in order to account for (40). One reason for doubting this is that plural definite descriptions such as de meisjes 'the girls' may give rise to a similar ambiguity as nominal coordinate structures with en. If the noun phrase de meisjes 'the girls' refers to Els and Marie, example (43a) is ambiguous in the same way as Els en Marie hebben de rots opgetild 'Els and Marie have lifted the rock' in (37b): both examples can be disambiguated by means of the modifiers allebei 'both' and samen 'together', as will become clear by comparing the (b)-examples in (43) with the examples in (39). This strongly suggests that the distinction between distributive and cumulative readings cannot be reduced to an ambiguity of en 'and'.

(43) a. De meisjes hebben de rots opgetild.

the girls have the rock prt.-lifted

'The girls have lifted the rock.'

b. De meisjes hebben allebei de rots opgetild. [distributive reading: $\psi \mathrm{d}$ ] the girls have both the rock prt.-lifted

'The girls have both lifted the rock.'

$\mathrm{b}^{\prime}$. De meisjes hebben de rots samen opgetild. [cumulative reading: $\psi \mathrm{c}$ ] the girls have the rock together prt.-lifted

'The girls have lifted the rock together.'

Cumulative readings are (cross-linguistically) restricted to conjunctive coordinate structures. We will illustrate this by means of the examples in (44).

(44) a. [[De katten] en [de honden]] vechten met elkaar. [ambiguous: $\psi \mathrm{d}$ or $\psi \mathrm{c}]$ the cats and the dogs fight with each.other

'The cats and dogs fight with each other.'

b. [[De katten] of [de honden]] vechten met elkaar. [ the cats or the dogs fight with each.other

'The cats or the dogs fight with each other.'

c. [[De katten] noch [de honden]] vechten met elkaar.

the cats nor the dogs fight with each.other

'Neither the cats nor the dogs fight with each other.'

Assume that the contextually determined set of cats consists of $c_{1}$ and $c_{2}$ and that the contextually determined set of dogs consists of $d_{1}$ and $d_{2}$ and consider the situations depicted in Figure 19. The distributive readings of the examples in (44) can be described by means of the situations in I and II: example (44a) claims that both are true, (44b) claims that at least one is true, while (44c) claims that neither is true. The only example with an alternate, that is, cumulative reading is (44a): it can also refer to situation III, in which all entities denoted by the definite descriptions de katten and de honden fight with each other. Although this is not immediately relevant for 
our present discussion, we want to note that (44a) can also refer to situation IV if the definite descriptions refer to collectives themselves (as indicated by the subscript $\mathrm{C}$ on the nouns).

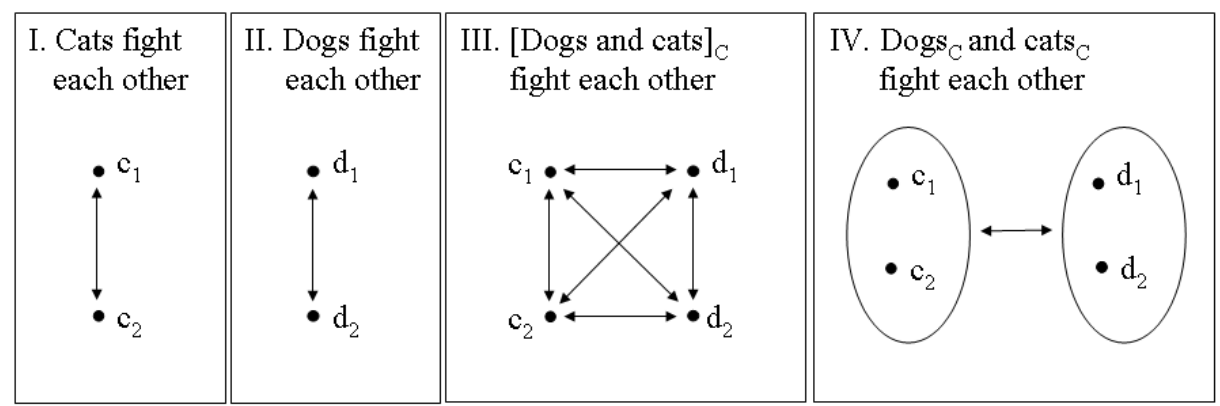

\section{Figure 19: Distributive versus cumulative readings}

The main conclusion of the discussion above is that Becker's conjecture that coordinators link sentences and not parts of sentences cannot be maintained on semantic grounds because propositional calculus cannot account for the cumulative reading of nominal coordinate structures with the conjunctive coordinator en. There are also morphosyntactic reasons to be skeptical about Becker's conjecture. One reason is related to subject-verb agreement. The representation in (45a) shows that coordination and conjunction reduction do not suffice to derive (37b) from the examples in $\left(37 \mathrm{a} \& \mathrm{a}^{\prime}\right)$ : because the former has plural agreement while the latter have singular agreement, we need an additional ad hoc mechanism which changes the singular finite verb into the plural one if conjunction reduction applies. This mechanism is not needed for the alternative representation in (45b) if we assume that nominal coordinate structures with en trigger plural agreement on the finite verb.

(45) a. *[[Els en [Marie heeft de rots opgetild]]. Els has the rock prt.-lifted and Marie has the rock prt.-lifted

b. [Els en Marie $]_{\mathrm{pl}}$ hebben $_{\mathrm{pl}}$ de rots opgetild. Els and Marie have the rock prt.-lifted

The examples in (46) show that more ad hoc mechanisms are needed to uphold Becker's conjecture: an example such as Els en Marie houden van elkaar 'Els and Marie love each other' does not only need adaptation of the finite verb form, but also an additional stipulation to allow violation of the condition on reciprocal elkaar 'each other' that it should have a plural antecedent within its own clause; the structure in (46b), on the other hand, satisfies this condition in a trivial way.

(46) a. *[[Els en [Marie houdt van elkaar]].

Els loves of each.other and Marie loves of each.other

b. [Els en Marie $]_{\mathrm{pl}}$ houden van elkaar.

Els and Marie love of each.other

'Els and Marie love each other.' 
The need for accepting these ad hoc stipulations strongly suggests that even if adopting Becker's conjecture were tenable from a semantic point of view, it would still have to be considered undesirable because it would lead to considerable complications in the syntactic description of coordination.

The examples so far involve ${ }^{\circ}$ clausal constituents (arguments, adverbials or complementives), but the collective and distributive readings can also occur with smaller constituents: cf. Haeseryn et al. (1997:1460). Example (47) is ambiguous between a collective and a distributive reading: according to the first reading Jan and Peter submitted various co-authored proposals, which were all rejected; according to the second reading Jan and Peter each submitted at least one proposal, and their proposals were all rejected.

$$
\begin{aligned}
& \text { De voorstellen van Jan en Peter zijn verworpen. } \\
& \text { the proposals by Jan and Peter are rejected } \\
& \text { 'The proposals from/by Jan and Peter have.been rejected.' }
\end{aligned}
$$

Haeseryn et al. (1997:1460) claim that nominal conjunctions may even be collective if they are used as the first member of a compound. Consider the examples in (48), in which strikethrough is used to indicate conjunction reduction. Haeseryn et al. claim that (48a) only has a distributive reading: we are dealing with one or more Christmas cards and one or more New Year cards. Example (48b), on the other hand, has a distributive reading: we are dealing with cards that can be used for sending end of year greetings. Although the semantic intuitions on the examples in (48) are correct, we leave it to others to decide whether the distributive-collective distinction is indeed the most apt one for accounting for them.
a. kerste en nieuwjaarskaarten
Christmas card and New Year cards
'Christmas cards and New Year cards'
b. [kerst en nieuwjaar] -s- kaarten
Christmas and New Year INFIX cards
'Christmas and New Year cards'

To conclude this subsection, we want to note that cumulative readings seem to be restricted to the simple conjunctive coordinator en: the examples in $(49 \mathrm{a} \& \mathrm{~b})$ show that the correlative coordinators en ... en ... 'and ... and ...' and zowel ... als ... 'both $\ldots$ and ...' are distributive. This is clear from the fact that the coordinate structures they head trigger singular agreement and cannot be used as subject of the predicate bijeen komen 'to come together'; cf. the (a)-examples in (41). Example (49c) further shows the same for the disjunctive coordinator of 'or'. De Vries \& Herringa (2008: section 3) suggest that the obligatoriness of the distributive reading of these coordinate structures is reflected by the fact that they normally trigger singular agreement on the finite verb if their coordinands are both singular.

(49) a. En Els en Marie heeft/*hebben gedanst. and Els and Marie has/have danced

$a^{\prime}$. *En Els en Marie komt bijeen. and Els and Marie comes together 
b. Zowel Els als Marie heeft/*hebben gedanst.

both Els and Marie has/have danced

$\mathrm{b}^{\prime}$. *Zowel Els als Marie komt bijeen.

both Els and Marie comes together

c. Els of Marie heeft $/ *$ hebben gedanst.

Els or Marie has/have danced

$\mathrm{c}^{\prime}$. *Els of Marie komt bijeen.

Els or Marie comes together

One of the reasons for claiming a relation between (obligatory) distributivity and singular agreement is that conjunctive coordination of noun phrases with the distributive quantifiers iedere 'every' and elk(e) 'each' also trigger singular agreement on the verb: this is illustrated in the examples in (50). De Vries \& Herringa (2008) suggest that this hypothesis may account for more "exceptional" cases of singular agreement; see the discussion in Section 1.4.1, sub IB.

(50) a. $\left[[\text { Elk boek }]_{\mathrm{sg}}\right.$ en $\left.[\text { elke CD }]_{\mathrm{sg}}\right]$ moet $_{\mathrm{sg}} / *$ moeten $_{\mathrm{pl}}$ genummerd worden. each book and each CD must/must numbered be

'Each book and each CD must be numbered.'

b. [[Iedere student] en [iedere docent]] krijgt $_{\mathrm{sg}} / *$ krijgen $_{\mathrm{pl}}$ korting. every student and every teacher gets/get discount

'Every student and every teacher gets a discount.'

The fact that the examples in (51) trigger plural agreement regardless of their interpretation (as distributive/cumulative) shows that this hypothesis can only be maintained if it is restricted to distributive readings due to the inherent properties of the coordinands or the coordinator, that is, it excludes distributive readings due to some property of an element external to the coordinate structure (e.g., the presence of the adverbial allebei 'both'); see De Vries \& Herringa (2008) for more discussion.

(51) a. Els en Marie hebben (allebei/samen) de rots opgetild.

Els and Marie have both/together the rock prt.-lifted

'Els and Marie have $<$ both $>$ lifted the rock < together $>$.'

b. De twee meisjes hebben (allebei/samen) de rots opgetild.

the two girls have both/together the rock prt.-lifted

'The two girls have $<$ both $>$ lifted the rock $<$ together $>$.'

\section{E. Unexpected readings of predicate conjunction with en 'and'}

This subsection discusses a number of problematic cases of predicate conjunction with en 'and'. Consider first the familiar type of example in (52), and assume that the definite description de jongens 'the boys' refers to the same set of individuals as the coordinate structure Jan and Peter in the relevant domain of discourse.

(52) a. Jan en Peter hebben gedanst en gezongen.

Jan and Peter have danced and sung

'Jan and Peter have danced and sung.'

b. De jongens hebben gedanst en gezongen.

the boys have danced and sung

'The boys have danced and sung.' 
Subsection C3 has shown that examples such as these are true only if the entities referred to by the subject are all part of the intersection of the sets denoted by the predicative coordinands $(A \cap B)$. Figure 20 illustrates this for six possible situations: the informal formulas above the Venn diagrams, in which Sb stands for the relevant set of boys referred to by the subject, indicate in which situations speakers would consider the examples in (52) true/false.

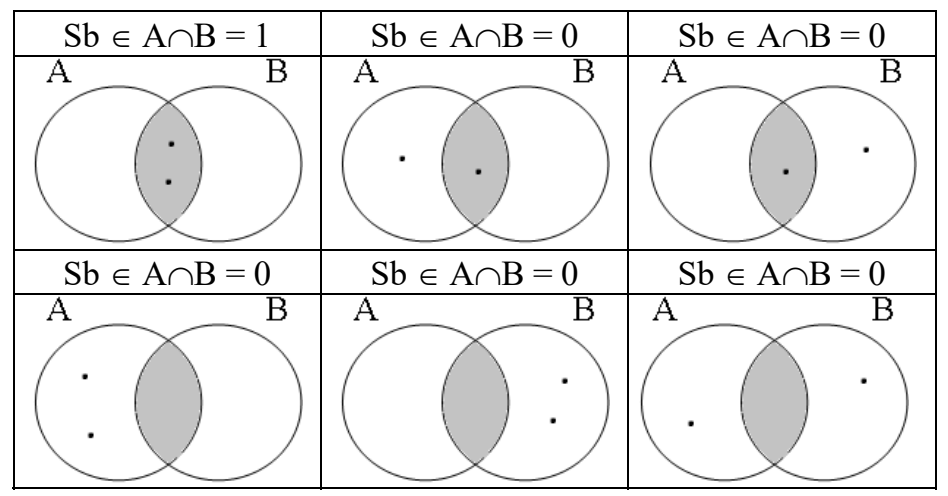

Figure 20: Conjunction of predicates with a subject referring to 2 entities

A complicating factor is that Winter $(2001 \mathrm{a} / 2001 \mathrm{~b})$ has argued that in some cases sentences with coordinated predicates behave in an unexpected way. Consider the examples in (53).

(53) a. De eenden zwemmen en vliegen.

the ducks swim and fly

'The ducks are swimming and flying.'

b. De eenden zwemmen en kwaken.

the ducks swim and quack

'The ducks are swimming and quacking.'

c. De eenden vliegen en kwaken.

the ducks fly and quack

'The ducks are flying and quacking.'

d. De eenden zwemmen, vliegen en kwaken.

the ducks swim fly and quack

'The ducks are swimming, flying and quacking.'

The discussion of (52) leads to the expectation that predicate conjunction by en 'and' requires the entities referred to by the subject de eenden to be located in the intersection of the sets denoted by the coordinated predicates. Examples such as given in (53) should therefore be true if all entities referred to by the subject (indicated by $\mathrm{S}$ ) are located in the grey areas in the Venn diagrams in Figure 21, where $\mathrm{A}, \mathrm{B}$ and $\mathrm{C}$ stand for the predicates used. 


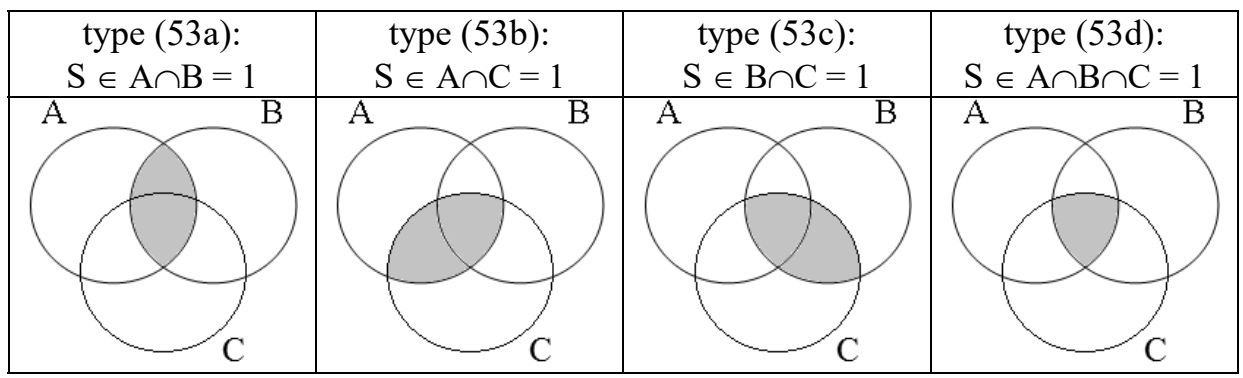

Figure 21: Predictions for examples such as (53)

Winter claims that this is not in accordance with the actual interpretations of the examples in (53). He illustrates this by means of the situation represented by the Venn diagram in Figure 22, with each dot representing a duck. Given that the contextually determined set of ducks is not included by one of the intersections marked in Figure 21, we expect all examples to be unfit to describe this situation. However, this does not seem to be borne out because example (53a) is accepted by many (if not all) speakers as a description of this situation; see Dik (1968:217-8) for similar examples/judgments.

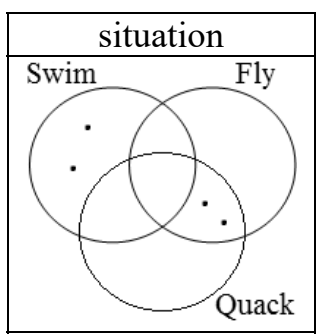

Figure 22

This surprising fact is not the only one posed by the set of examples in (53) in relation to the situation in Figure 22. Since ducks that fly also quack, and vice versa, the predicates FLY and QUACK denote the same subset of ducks and we might therefore expect that the two examples in $(53 \mathrm{a} \& \mathrm{~b})$ are logically equivalent. Winter claims that this expectation is not borne out either: contrary to example (53a), example (53b) is semantically well-behaved in that it cannot be used for referring to the situation sketched in Figure 22. Graphically, we can illustrate the difference in interpretation between (53a) and (53b) as in Figure 23, where the grey part indicates the areas that should include the contextually-defined set of ducks.

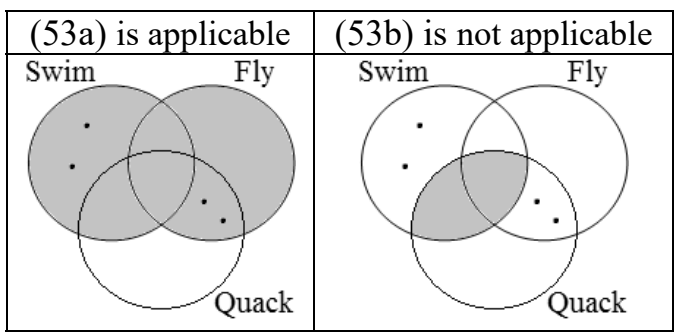

Figure 23 
One option of describing the unexpected reading of (53a) in the first Venn diagram in Figure 23 is by assuming that the conjunctive coordination en 'and' may give rise to two different readings, similar to that found in the case of coordination of two noun phrases discussed in Subsection D. The first reading would be the regular reading, with the coordinate structure denoting the intersection of the sets denoted by the coordinands. The second reading would be a more special one, with the coordinate structure referring to a collection of properties. This description of the more special reading correctly predicts that the set of ducks must be included in the union of the sets denoted by FLY and QUACK in order for (53a) to be considered true; (53a) cannot be used to describe the situation sketched in Figure 24.

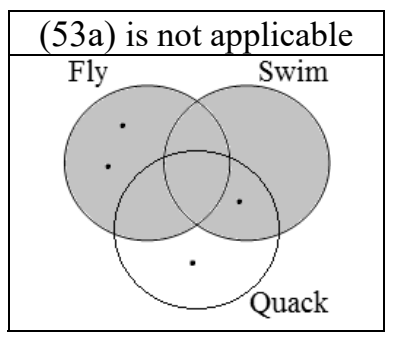

Figure 24

Winter claims, however, that this approach is problematic because it would not account for the fact that the more special reading is not available for (53b). Winter attributes this difference between (53a) and (53b) to the fact that the actions described by the predicates SWIM and FLY are mutually exclusive while those described by SWIM and QUACK are not. The examples in (54) illustrate this fact by showing that the corresponding long forms differ in usability: the number sign in (54a) indicates that this example cannot be used for describing a situation at one specific point in time simply because ducks are not able to fly and swim simultaneously; (54b), on the other hand, can be used for this because swimming and quacking can be done simultaneously.

(54) a. "De eenden zwemmen en de eenden vliegen.

the ducks swim and the ducks fly

'The ducks are swimming and the ducks are flying.'

b. De eenden zwemmen en de eenden kwaken. the ducks swim and the ducks quack

'The ducks are swimming and the ducks are quacking.'

The appeal to mutual exclusivity predicts similar contrasts between the more complex example in (53d), repeated here as (55a), and (55b) because WALK differs from QUACK in that it is mutually exclusive with SWIM and FLY. The number sign in (55a) again indicates that this example cannot be used for describing a situation at one specific point in time. 
(55) a. "De eenden zwemmen, vliegen en kwaken.

the ducks swim fly and quack

'The ducks are swimming, flying and quacking.'

b. De eenden zwemmen, vliegen en lopen in de wei.

the ducks swim fly and walk in the meadow

'The ducks are swimming, flying and walking in the meadow.'

The two examples indeed seem to differ in the expected way, as is demonstrated by the situations sketched in Figure 25. Note in passing that all sets must contain at least one individual duck for (55b) to be felicitously used. This is due to pragmatics: if the speaker knows that none of the ducks flies, the ${ }^{\circ}$ cooperative principle will select the utterance De eenden zwemmen en lopen in de wei as the more informative and accurate expression.

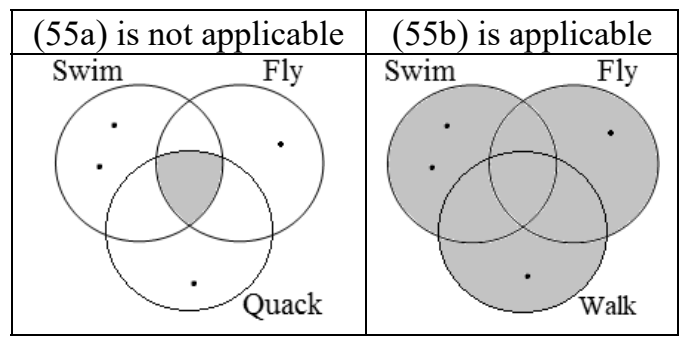

Figure 25

Although an appeal to mutual exclusivity is promising, we want to conclude with a potential problem for it related to examples of the type in $(52 \mathrm{~b})$, repeated here as (56). We have seen that (56) is semantically well-behaved if the contextually determined set of individuals referred to by the plural definite description is small, e.g., $\{$ Jan, Peter\}; the complete set should be located in the union of the sets denoted by the predicative coordinands in order for (56) to be true (cf. Figure 20).

De jongens hebben gedanst en gezongen.

the boys have danced and sung

'The boys have danced and sung.'

This is of course in line with the earlier discussion given that HAVE DANCED and HAVE SUNG are not mutually exclusive (which in fact seems to hold for all perfective verbal predicates). Subsection C3 has shown, however, that the situation is less clear if the cardinality of the set of boys is somewhat greater, as (56) seems to be usable for describing all situations depicted in Figure 26.

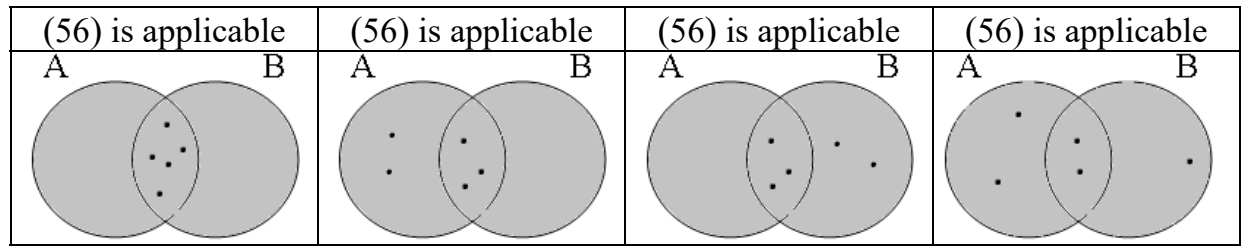

Figure 26 
The fact that the use conditions on (56) become more lenient if the cardinality of the referent of the subject increases suggests that Winter's conjecture is not fully correct and that some other factors may be involved (as well): for example, it may be the case that the predicates must be part of the same semantic field (such as "recreation") in order for relaxation of the use conditions to be possible. Because this brings takes us into hitherto unexplored territory, we leave this issue for future research.

We conclude this subsection by noting that the conclusion that conjoined predicates occasionally denote not the intersection but the union of the sets denoted by the coordinands may be relevant for solving the longstanding and recalcitrant problem of interwoven dependencies triggered by the modifier respectievelijk 'respectively' illustrated in (57); see Zhang (2010: section 6.4) for a historical review of the syntactic approaches to this problem as well as a proposal of her own. The entailment pattern shows that the first coordinands of the two coordinate structures must be paired with each other and that the same holds for the second coordinands.

(57) a. [Jan en Marie] komen uit, respectievelijk, [Duitsland en Zwitserland]. Jan and Marie come from respectively Germany and Swiss 'Jan and Marie come from Germany and from Switzerland, respectively.'

b. $\quad \vDash$ Jan komt uit Duitsland $\vDash \vDash$ Marie komt uit Zwitserland

c. I\# Jan komt uit Zwitserland I\# Marie komt uit Duitsland

[valid entailments]

[invalid entailments]

This entailment pattern comes as a surprise if predicative conjunctions denote the intersection of their coordinands, and for this reason it has been argued since the early 1970's that (57a) is derived from the clausal coordinate structure [[Jan komt uit Duitsland] and [Marie komt uit Zwitserland]]. Figure 27 shows that the pattern is easier to understand if predicative conjunctions can also denote the union of their coordinands (indicated by grey) under certain conditions, because the situation sketched in this figure would then be true.

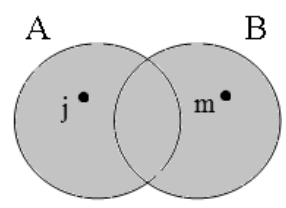

\section{Figure 27: interpretation (57a)}

It is important to note that the "union" reading in Figure 27 is also possible in examples such as Ze komen uit Duitsland en Zwitserland 'They come from Germany and from Switzerland' with the referential plural pronoun $z e$ 'they'; this part of the problem is therefore clearly something that cannot be dealt with in syntax. The only thing that remains to be done is accounting for the fact that the presence of the modifier respectievelijk forces this reading. Whether this should be done in syntax is again highly questionable because the presence of this modifier is not needed when the intended reading is clarified by other means. For instance, the 
intended reading of example (58) is clear from our knowledge of the world, and the use of respectievelijk is therefore superfluous.
De honden en de hanen blaften en kraaiden de hele nacht. the dogs and the roosters barked and crowed the whole night
'The dogs and roosters barked and crowed all night.'

Van Oirsouw (1987: section 1.2.4) claims that respectievelijk hardly ever occurs in spontaneous speech, which is confirmed by Uit den Boogaart (1975) and De Jong (1979), and that it is mainly used with bipartite coordinate structures, as its meaning in more complex examples is normally hard to work out without pen and paper. This in fact suggests that respectievelijk is not an element of core grammar, and we will therefore refrain from discussing it in any further detail. The most important conclusion to be drawn from the discussion of the examples in (57) and (58) is that the independently established fact that conjoined predicates may sometimes denote the union of the sets denoted by the coordinands may help to solve the problem of interwoven dependencies; the proper solution may in fact not be syntactic at all but rather of a semantic and/or pragmatic nature.

\section{F. Concluding remarks}

The previous subsections have shown that the meaning of coordinators cannot be exhaustively described by means of propositional logic. We therefore have to replace Becker's conjecture that coordination links clauses only by the generalization that coordinators link syntactic objects of the same semantic type; they create a new syntactic object of the same semantic type as the coordinands. Subsection B addressed cases in which coordination of syntactic objects of the semantic type $t$ (clauses expressing formulas with a certain truth value) results in a more complex object of type $t$; because the coordinands and the coordinate structure as a whole can all be assigned truth values, the meaning contribution of coordinators can readily be expressed by means of truth tables. Subsection C discussed cases in which coordination of syntactic objects of the semantic type $<\mathrm{e}, \mathrm{t}>$ (predicates denoting a set of entities with a specific property) results in a more complex syntactic object of type $<\mathrm{e}, \mathrm{t}\rangle$ : because the coordinands and the coordinate structure all denote sets, the meaning contribution of the coordinator can insightfully be expressed with the help of Venn diagrams. This suggests the semantic generalization in (59).

$$
\begin{aligned}
& \text { Generalization: coordination of two syntactic objects of semantic type } \tau \\
& \text { results in a more complex syntactic object of type } \tau
\end{aligned}
$$

It can be demonstrated that generalization (59) is also valid for cases in which nominal arguments or other syntactic objects are coordinated; we will not dwell on this here but refer the reader to Winter (2001a:ch.2) for extensive discussion. The validity of generalization (59) suggests that the differences in the way we have chosen to represent the meaning contributions of coordinators in the subsections above (by truth tables and Venn diagrams) does not reflect differences in the meaning contribution of coordinators but differences in the meaning of the coordinands and the resulting coordinate structures. Consequently, there is no $a$ 
priori reason for assuming that coordinators are polysemous in the sense that they express different meanings in different syntactic contexts. The proper formulation of the meaning contribution of coordinators is currently a much debated topic, but since discussing this issue here would lead us too far into formal semantics, we refer the reader to Zamparelli (2011: section 4) for a brief introduction to this topic as well as relevant references. For our present purpose, it suffices to keep generalization (59) in mind, as it will account for part of the syntactic restrictions on coordination discussed in Section 1.3.

\section{Prosodic restrictions on coordinands}

All coordinands in a coordinate structure must have accent, as is clear from the fact that weak (unaccented) pronouns are never part of a coordinate structure. The examples in (60) illustrate this for a coordinate structure functioning as subject (hence with subject pronouns) and (61) for a coordinate structures functioning as direct object (hence with object pronouns). Changing the person, number or gender features of the pronouns will not affect the acceptability judgments.

(60) - Subject pronouns in a coordinate structure

a. $\left[\mathrm{Wij}\right.$ strong en/of/noch $\left.\mathrm{zij}_{\text {strong }}\right]$ kunnen je helpen. we and/or/nor they can you help

'We and/or/nor they can help you.'

b. * $\left[\mathrm{We}_{\text {weak }}\right.$ en/of/noch zij $\left.\mathrm{j}_{\text {strong }}\right]$ kunnen je helpen.

c. $*\left[\mathrm{Wij}_{\text {strong }}\right.$ en/of/noch ze $\left.\mathrm{e}_{\text {weak }}\right]$ kunnen je helpen.

d. $*\left[\mathrm{We}_{\text {weak }}\right.$ en/of/noch ze $\left.\mathrm{weak}_{\text {wea }}\right]$ kunnen je helpen.

(61) Object pronouns in a coordinate structure

a. Jan kan [hem strong $_{\text {en/of/noch mij }}$ strong $\left._{\text {a }}\right]$ helpen. Jan can him and/or/nor me help 'Jan can help him and/or/nor me.'

b. *Jan kan ['m $\mathrm{m}_{\text {weak }}$ en/of/noch mij strong $]$ helpen.

c. *Jan kan $\left[\right.$ hem $_{\text {strong }}$ en/of/noch me weak $]$ helpen.

d. *Jan kan ['m $\mathrm{weak}_{\text {en }}$ /of/noch $\left.\mathrm{me}_{\text {weak }}\right]$ helpen.

\section{Pragmatic restrictions on coordinands}

There are a number of pragmatic restrictions on coordination: the coordinands cannot be totally random or completely identical, that is, the addressee must be able to relate the two coordinands in a coherent way and each coordinand must add some piece of information. Example (62a), for instance, is easier to accept than (62b) because the addressee may construe the coordinands in the former example as contrastive, while there is no obvious relation between the coordinands in the latter example. Example (62b) is fully grammatical, of course, because in the right context it would be felicitous to express that Jan being asleep is unfortunate as he could have helped the speaker out otherwise by driving him to the station.

\footnotetext{
a. [[Jan slaapt] en [Marie werkt]].

Jan sleeps and Marie works

'Jan is sleeping and Marie is working.'
} 
b. [[Jan slaapt] en [mijn band is lek]].

Jan sleeps and my tire is punctured

'Jan is sleeping and my tire has a puncture.'

Linking identical coordinands with the same propositional content, as in (63a), would normally be rejected as uninformative. The syntactic structure as such is not unacceptable, as is clear from the fact that examples such as (63b) are fully acceptable with an intensifying meaning. Note that the indices are used to express coreference.

(63) a. ${ }^{\$}\left[\left[\operatorname{Jan}_{\mathrm{i}}\right.\right.$ leest Max Havelaar $]$ en $\quad\left[\mathrm{hij} \mathrm{j}_{\mathrm{i}}\right.$ leest Max Havelaar $\left.]\right]$.

Jan reads Max Havelaar and he reads Max Havelaar

'Jan is reading Max Havelaar and he is reading Max Havelaar.'

b. [[Jan liep] en [hij $j_{\mathrm{i}}$ liep] en [hij $\mathrm{j}_{\mathrm{i}}$ liep]], totdat hij bij een oase kwam. Jan walked and he walked and he walked until he to an oasis came 'Jan walked endlessly until he came to an oasis.'

Pragmatics is also relevant for the interpretation of so-called asymmetrical coordinate structures; such cases will be discussed in Section 1.4.1, sub IC and IIC.

\section{Distinguishing coordinators from other elements}

Due to the fact that coordinators form a closed class, it is normally not difficult to recognize coordinate structures; this clearly holds for examples such as given in (64) with the conjunctive coordinator en 'and' and of 'or'. Furthermore, identifying coordinate structures is facilitated by their semantics, more specifically the fact that coordinate structures are of the same semantic type as their coordinands; (64a) involves two coordinands of type $t$ (clauses with a truth value) as well as a coordinate structure of type $t$, while (64b) involves two coordinands of type $<\mathrm{e}, \mathrm{t}>$ (predicates) and a coordinate structure of type $\langle\mathrm{e}, \mathrm{t}\rangle$. We refer the reader to the discussion of generalization (59) in Subsection IVF.

(64) a. [[Marie is in New York] en [Jan is in Utrecht]].

Marie is in New York and Jan is in Utrecht

b. Jan heeft [gewandeld of gefietst].

Jan has walked or cycled

It is sometimes difficult, however, to distinguish on semantic grounds conjunctive coordinators such as want 'because' in (65a) from subordinators found in adverbial clauses such as omdat 'because/as' in (65b) or so-called conjunctive adverbials of the type daarom 'because/for that reason' in juxtaposed clauses such as $(65 \mathrm{c})$.

(65) a. Marie is in New York want Jan is in Utrecht.

[coordinator]

Marie is in New York because Jan is in Utrecht

b. Marie is in New York omdat Jan in Utrecht is.

[subordinator] Marie is in New York because Jan in Utrecht is

c. Jan is in Utrecht; daarom is Marie in New York. Jan is in Utrecht for.that.reason is Marie in New York

[adverbial] 
The reason for this is that the examples in (65) would receive the same translation in propositional calculus as a conjunction of the propositions "Marie is in New York" and "Jan is in Utrecht". Moreover, they express a similar relation between the two propositions: the fact that Jan is in Utrecht is given as a rationale for the fact that Marie is in New York. This subsection will show, however, that it is easy to distinguish the three cases in (65) on syntactic grounds. The difference between the examples in $(65 \mathrm{a} \& \mathrm{~b})$ and those between the examples in $(65 \mathrm{a} \& \mathrm{c})$ will be discussed in separate subsections.

\section{A. Coordinators versus subordinators}

The main difference between the syntactic function of coordinators and subordinators is that while the former link syntactic phrases of the same type including main clauses, the latter introduce an embedded clause. The fact that (66a) involves coordination of two main clauses while (66b) involves a case of subordination is reflected in the placement of the finite verb: while it occupies the second position in the second coordinand in (66a), it occupies the clause-final position in the embedded clause in (66b).
- Placement of the finite verb
a. [[Marie is in New York] want [Jan is in Utrecht]].
Marie is in New York because Jan is in Utrecht
b. Marie is in New York [omdat Jan in Utrecht is].
Marie is in New York because Jan in Utrecht is
[subordinator]
[coordinator]

The structures given in (66) indicate that the embedded clause in (66b) functions as a ${ }^{\circ}$ clausal constituent of the main clause, while the clausal coordinands in (66a) are syntactically independent of each other in terms of clause structure. The examples in (67) show that this is reflected by the fact that while the embedded clause can be moved leftward into the initial position of the main clause, it is impossible to move the second coordinand into the initial position of the first coordinand. For completeness' sake, $\left(67 \mathrm{a}^{\prime}\right)$ shows that leftward movement of the second coordinand is also impossible if the coordinator want 'because' is pied-piped.
- Topicalization
a. *[Jan is in Utrecht $]_{\mathrm{i}}$ is Marie in New York want $t$.
Jan is in Utrecht is Marie in New York because
$\mathrm{a}^{\prime}$. *[Want Jan is in Utrecht $]_{\mathrm{i}}$ is Marie in New York $t_{\mathrm{i}}$. because Jan is in Utrecht is Marie in New York
b. [Omdat Jan in Utrecht is $]_{\mathrm{i}}$ is Marie in New York $t_{\mathrm{i}}$. because Jan in Utrecht is is Marie in New York

The two clauses coordinands entertain different relationships in the two constructions with want and omdat, as shown by the fact illustrated in (68) that they exhibit differences in ${ }^{\circ}$ binding possibilities; while the quantified subject of the first coordinand cannot trigger a bound variable reading on the pronominal subject of the second coordinand in the coordinate structure with want, the quantified subject of the main clause can trigger such a reading on the subject of the embedded clause. The reason is that the bound variable reading is possible only if the pronoun is 
${ }^{\circ} \mathrm{c}$-commanded by its quantified antecedent; this condition is only met in the case of embedding. Note that the bound variable reading is indicated by co-indexing.

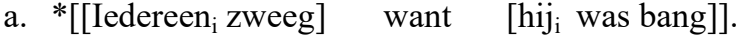 everyone kept.silent because he was afraid

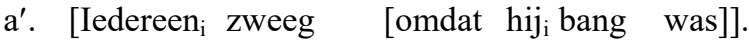 everyone kept.silent because he afraid was
'Everyone kept silent because he was afraid.'
b. *[[Niemand ${ }_{\mathrm{i}}$ zei iets $]$ want [hiji was bang]]. nobody said something because he was afraid
$b^{\prime}$. [Niemand ${ }_{i}$ zei iets] [omdat hiji bang was]]. nobody said something because he afraid was 'Nobody said anything because he was afraid.'

The difference between conjunctive coordinators and subordinators can sometimes also be made visible by subordinators in embedded contexts. This does not hold for the pair in (66) due to the fact that want 'because' cannot be used for coordinating embedded clauses, but it can be illustrated by means of the pair in $(69 \mathrm{a} \& b)$. First, note that the placement of the finite verb in the second clause already makes clear that maar 'but' is a coordinator linking two main clauses, while hoewel is a subordinator. In addition, the primed examples show that in embedded contexts the coordinands of the coordinate structure in $\left(69 a^{\prime}\right)$ must both be introduced by the subordinator dat 'that', while this subordinator cannot be used in the second clause in $\left(69 b^{\prime}\right)$ due to the fact that embedded clauses can be introduced by a single subordinator only.

- Use of the complementizer dat 'that' in embedded contexts

a. [[Marie is in New York] maar [Jan is in Utrecht]].

[coordinator] Marie is in New York but Jan is in Utrecht

$a^{\prime}$. Ik denk [[dat Marie in New York is] maar [dat Jan in Utrecht is]]. I think that Marie in New York is but that Jan in Utrecht is 'I think that Marie is in New York but that Jan is in Utrecht.'

b. Marie is in New York [hoewel Jan in Utrecht is]. [subordinator] Marie is in New York although Jan in Utrecht is

$\mathrm{b}^{\prime}$. Ik denk [dat Marie in New York is [hoewel (*dat) Jan in Utrecht is]]. I think that Marie in New York is although that Jan in Utrecht is 'I think that Marie is in New York although Jan is in Utrecht.'

Note in passing that I have ignored the fact that some speakers do allow the complementizer dat immediately after hoewel in examples such as (69b'), probably as a result of contamination invoked by the complex complementizer ondanks dat 'despite that', which has more or less the same meaning.

\section{B. Coordinators versus conjunctive adverbials}

While coordinators are external to the coordinands, conjunctive adverbials function as ${ }^{\circ}$ clausal constituents in the second clause in a coordinate structure. The coordinator want 'because' and the conjunctive adverbial daarom 'because/for that reason' express a similar relation between the two clauses but they do this by 
different means: in the case of want this is simply a matter of its lexical meaning, while in the case of daarom it is due to its demonstrative meaning "for that reason". The first two tests developed in the previous subsection are of no avail for distinguishing the conjunctive coordinator and the conjunctive adverbial in examples such as given in (70): the clauses are all main clauses and thus have their finite verb in second position; topicalization of the second clause is excluded in both cases because the clauses are syntactically independent of each other.
a. [[Marie is in New York] want [Jan is in Utrecht]].
Marie is in New York because Jan is in Utrecht
b. [Jan is in Utrecht]; [daarom is Marie in New York].
Jan is in Utrecht for.that.reason is Marie in New York
[coordinator]
[adverbial]

The tests we want to propose here are based on the main difference between conjunctive coordinators such as want and conjunctive adverbials such as daarom: while the latter is a clausal constituent, the former is not. As a result daarom can be replaced by the full adverbial PP of reason om die reden 'for that reason/that's why' while a similar substitution is not available for the coordinator want.
- Substitution by the adverbial PP om die reden 'for that reason'
a. *[[Marie is in New York] om die reden [Jan is in Utrecht]].
[coordinator]
Marie is in New York for that reason Jan is in Utrecht
b. [Jan is in Utrecht]; [om die reden is Marie in NY] Jan is in Utrecht for that reason is Marie in NY
'Jan is in Utrecht; that's why Marie is in NY.'
[adverbial]

Another test is that conjunctive adverbials can also appear in the ${ }^{\circ}$ middle field of the second clause, as is illustrated by (72b); observe, however, that this requires some other constituent to be placed in the initial position of the second clause, because of the ${ }^{\circ}$ verb-second requirement in Dutch. Example (72a) shows that conjunctive coordinators cannot appear in the middle field of the second clause; they are external to the second coordinand and therefore appear in front of it.
- Placement of the coordinator/conjunctive adverbial in the middle field
a. *Marie is in NY Jan is want in Utrecht.
Marie is in NY Jan is because in Utrecht
b. Jan is in Utrecht; Marie is daarom in NY.
[coordinator]
[adverbial]

A third test is the addition of the conjunctive coordinator en 'and'. Example (73a) shows that this is impossible in the case of coordination, simply because the syntactic slot for the coordinator is already filed by want. It is possible in case of conjunctive adverbials; it changes the juxtaposed structure into a coordinate one.
- Addition of en 'and'
a. [[Marie is in NY] (*en) want [Jan is in Utrecht]].
[coordinator] Marie is in NY and because Jan is in Utrecht
b. [Jan is in Utrecht]; (en) [daarom is Marie in NY]. Jan is in Utrecht and for.that.reason is Marie in NY
[adverbial] 
The test demonstrated in (73) is particularly useful for determining the status of the multifunctional element $d u s$ 'so', which can be used either as a coordinator, as in (74a), or as an adverbial phrase, as in the juxtaposed structure in (74b); the primed examples show that only the latter case allows addition of the coordinator en 'and'. The primed examples show that substitution can also be used as a test; the conjunctive adverbial dus can be replaced by an adverbial PP while the coordinator $d u s$ cannot. Considering the effect of placing the coordinator/conjunctive adverbial in the middle field will be of no use, as this will give rise to identical surface strings.
a. [[CP Jan heeft honger] (*en) dus [CP hij pakt een koekje]]. Jan has hunger and so he takes a cookie
'Jan is hungry so he takes a cookie.'
$\mathrm{a}^{\prime} . *[$ [CP Jan heeft honger] om die reden [CP hij pakt een koekje]]. Jan has hunger for that reason he takes a cookie
b. [[ср Jan heeft honger] (en) [cP dus pakt hij een koekje]]. Jan has hunger and so takes he a cookie
'Jan is hungry so he takes a cookie.'
$\mathrm{b}^{\prime}$. [[CP Jan heeft honger]; [ср om die reden pakt hij een koekje]]. Jan has hunger for that reason takes he a cookie
'Jan is hungry; for that reason he takes a cookie.'

For completeness' sake, we conclude this subsection by showing that the third test discussed in Subsection A, viz., the use of the complementizer dat 'that' in embedded contexts, does not fare any better in providing help for distinguishing between conjunctive coordinators and conjunctive adverbs than the first two tests discussed in the present subsection. The (a)-examples in (75) with the conjunction maar 'but', repeated from (69), show again that both clausal coordinands must be introduced by the subordinator dat 'that' in embedded contexts. However, the same holds for the two clauses in the (b)-examples with the conjunctive adverbial daarom 'for that reason'. The reason for not having mentioned this earlier in this subsection is that $\left(75 b^{\prime}\right)$ obligatorily exhibits the properties illustrated by (72) and (73): in embedded contexts the conjunctive adverbial must be in the middle field of the clause due to the impossibility of topicalization in embedded contexts. Note in passing that the second clause must be preceded by the coordinator en; this is due to the fact to be discussed in Section 1.2, that coordinate structures functioning as clausal constituents cannot be asyndetic.

- Use of the complementizer dat 'that' in embedded contexts

a. [[Marie is in NY] maar [Jan is in Utrecht]].

Marie is in NY but Jan is in Utrecht

$a^{\prime}$. Ik denk [[dat Marie in NY is] maar [dat Jan in Utrecht is]].

I think that Marie in NY is but that Jan in Utrecht is

'I think that Marie is in NY but that Jan is in Utrecht.'

b. [Jan is in Utrecht]; [daarom is Marie in NY].

Jan is in Utrecht for.that.reason is Marie in NY

[coordinator]

$\mathrm{b}^{\prime}$. Ik denk [[dat Jan in Utrecht is] en [dat Marie daarom in NY is]].

[adverbial] I think that Jan in Utrecht is and that Marie for.that.reason in NY is 'I think that Jan is in Utrecht and that for that reason Marie is in NY.' 


\section{On the semantic difference between coordinators and subordinators}

The examples in $(65 \mathrm{a} \& b)$, repeated here as (76), show that coordinators and subordinators are equally capable of specifying semantic relations between propositions; the two examples both express that the truth of the proposition "Jan is in Utrecht" can be seen as a rationale for assuming the truth of the proposition "Marie is in New York".

(76) a. Marie is in New York want Jan is in Utrecht. Marie is in New York because Jan is in Utrecht

b. Marie is in New York omdat Jan in Utrecht is. Marie is in New York because Jan in Utrecht is

[coordinator]

[subordinator]

It seems, however, that the contention in (76a) is more compelling in the sense that it is based on the premise "if Jan is in Utrecht, Marie is in New York". This premise is absent in (76b): the reason for Marie to be in New York may be of a more accidental nature: the speaker may know that either Marie or Jan should be present at a workshop in New York in order to present their joint paper. This would be in line with the claim in Subsection B that the material implication $\mathrm{q} \rightarrow \mathrm{p}$ functioning as a premise in (76a) is entailed by the lexical meaning of want; cf. (16). If so, this would suggest that coordinators are more amenable to stringent logical reasoning than adverbial clauses introduced by subordinators such as omdat 'because', which are principally used to provide additional, circumstantial information about the proposition expressed by their matrix clause. Since conjunctive adverbials such as daarom 'for that reason' are adverbial phrases themselves, assuming that, like adverbial clauses introduced by omdat 'because', they are likewise used for simply expressing circumstantial information is a very defensible point of view. It has been noted in the (cognitive-linguistic) literature that coordinators such as want are often of a more subjective nature than subordinators such as omdat; cf., e.g., Verhagen (2000). This seems consistent with the semantic analysis adopted here, as the premise implied by want need not be part of the ${ }^{\circ}$ common ground of the discourse and may in fact be based on a subjective opinion held by the speaker, while the subordinate omdat-clause prototypically points to a state of affairs in the common ground; cf. Verhagen (2005: Section 4.3).

\subsection{Monosyndetic, polysyndetic and asyndetic coordination}

Coordinators are not lexical ${ }^{\circ}$ heads in the technical sense that they project, that is, they do not take arguments and cannot be modified. That coordinators are not lexical heads is also reflected by the fact that they are neither unique nor obligatory within coordinate structures: although such structures prototypically contain just a single coordinator preceding the final coordinand, the coordinator can sometimes also be repeated before all coordinands (except the first) or be left out entirely. The resulting phrases are referred to as monosyndetic, polysyndetic and asyndetic coordinate structures, respectively. 
(77) a. [Jan, Marie en Peter] komen morgen.

[monosyndetic]

Jan Marie and Peter come tomorrow

'Jan, Marie and Peter will come tomorrow.'

b. [Jan en Marie en Peter] komen morgen.

[polysyndetic]

Jan and Marie and Peter come tomorrow

'Jan and Marie and Peter will come tomorrow.'

c. [Jan, Marie, Peter] ze komen morgen allemaal.

Jan Marie Peter they come tomorrow all

'Jan, Marie and Peter, they will all come tomorrow.'

[asyndetic]

The three types of coordinate structure in (77) do not alternate freely: we will show that the distribution of poly- and asyndetic coordinate structures is more restricted than that of monosyndetic structures. The discussions in subsections I and II will therefore take monosyndetic coordination as their point of departure and compare it with asyndetic and polysyndetic coordination, respectively. Subsection III concludes with a brief discussion of monosyndetic coordination with a correlative coordinator because such cases are not always easy to distinguish from polysyndetic coordination with a simple coordinator. Note that so-called correlative coordinate structures with a coordinator preceding each coordinand as in [En Jan en Marie en Peter komt morgen] 'And Jan and Marie and Peter will come tomorrow' will only be mentioned in passing in this section; they will be more systematically discussed in Section 1.4.2.

\section{Monosyndetic and asyndetic coordination}

This subsection discusses some differences between monosyndetic and asyndetic coordinate structures. Monosyndetic coordination is illustrated again in (78) for coordinate structures with, respectively, three and four coordinands and the coordinator en 'and'; the number of coordinands is in principle infinite (although there are also coordinators such as maar 'but', which allow at most two coordinands). The coordinator is located before the final coordinand, and the other coordinands (except the first one) are preceded by a brief pause, which is indicated by a comma in writing: because the coordinands must be accented (cf. Section 1.1, sub $\mathrm{V}$ ), this results in an intonation pattern similar to that found in cases of counting (one, two, three, ...); cf. Bakker (1968:61).

(78) a. [Jan, Marie en Peter] komen morgen allemaal.

Jan Marie and Peter come tomorrow all

'Jan, Marie and Peter will all come tomorrow.'

b. [Jan, Marie, Peter en Els] komen morgen allemaal.

Jan Marie Peter and Els come tomorrow all

'Jan, Marie, Peter and Els will all come tomorrow.'

Asyndetic coordination is illustrated in (79) for the same coordinands found in (78). There is no (phonetically realized) coordinator and the coordinands are all separated by a brief pause, which again gives rise to an intonation pattern similar to that found in cases of counting. 
(79) a. [Jan, Marie, Peter], die komen morgen allemaal . Jan Marie Peter DEM come tomorrow all 'Jan, Marie, Peter they will all come tomorrow.'

b. [Jan, Marie, Peter, Els], die komen morgen allemaal.

Jan Marie Peter Els DEM come tomorrow all

'Jan, Marie, Peter, Els they will all come tomorrow.'

The main difference between monosyndetic and asyndetic coordinate structures concerns their distribution: Subsection A will show that while the distribution of monosyndetic coordinate structures is not restricted in any obvious way, asyndetic coordinate structures normally do not occur clause-internally, that is, they are more or less restricted to main-clause external positions. Subsection B discusses a number of (potential) counterexamples to this claim. Asyndetic coordinate structures are prototypically interpreted as conjunctions: Subsection $\mathrm{C}$ will show, however, that there are more possibilities in asyndetically coordinated clauses.

\section{A. Asyndetic coordinate structures do not occur clause-internally}

The most conspicuous difference between mono- and asyndetic coordinate structures concerns their syntactic distribution: while the monosyndetic structures in (78) function as the subject of the clause, the asyndetic structures in (79) are contrastive, ${ }^{\circ}$ left-dislocated phrases. That this is not accidental is clear from the fact that the primeless examples in (80) are unacceptable; this suggests that asyndetic coordinate structures cannot be used as clausal constituents in colloquial speech. It is not the case, however, that asyndetic and monosyndetic constructions are in complementary distribution, as is clear from the fact illustrated by the primed examples in (80) that the asyndetic structures in (79) can easily be replaced by their monosyndetic counterparts. This clearly shows that monosyndetic coordinate structures have a wider distribution than their asyndetic counterparts.

$$
\begin{aligned}
& \text { a. *[Jan, Marie, Peter] komen morgen allemaal. } \\
& \text { Jan Marie Peter come tomorrow all } \\
& \text { a'. [Jan, Marie en Peter], die komen morgen allemaal . } \\
& \text { Jan Marie and Peter DEM come tomorrow all } \\
& \text { b. *[Jan, Marie, Peter, Els] komen morgen allemaal. } \\
& \text { Jan Marie Peter Els come tomorrow all } \\
& \text { b'. [Jan, Marie, Peter en Els], die komen morgen allemaal. } \\
& \text { Jan Marie Peter and Els DEM come tomorrow all }
\end{aligned}
$$

For completeness' sake, it should be noted that the primeless examples in (80) become acceptable if the coordinate structures as a whole are followed by an intonation break; this is not relevant here because these examples should then be analyzed as topic-drop constructions with left dislocation, that is, as constructions with a phonetically empty but syntactically present subject; we will not digress on this issue here and refer the reader to Section V11.2.2 for a discussion of topic drop. The examples in (81) show that asyndetic coordinate structures cannot occur as parts of clausal constituents either. We conclude from this that monosyndetic and asyndetic coordinate structures differ in that only the former can be embedded in larger syntactic structures (clauses and other phrases). 
(81) a. De lezing werd [door [Jan, Marie *(en) Peter]] gepresenteerd. the talk was by Jan Marie and Peter presented 'The talk was presented by Jan, Marie and Peter.'

b. [De lezingen [van [Jan, Marie *(en) Peter]]] waren allemaal interessant. the talks by Jan Marie and Peter were all interesting 'The talks by Jan, Marie and Peter were all interesting.'

The discussion above strongly suggests that asyndetic coordinate structures must be main-clause external in the sense of Chapter V14. This correctly predicts that asyndetic coordinate structures can be used in left-dislocated as well as in rightdislocated position. That this prediction is correct for left-dislocation was shown by the contrastive left-dislocation constructions in (79), and is further illustrated by the hanging topic constructions in the (a)-examples in (82) with a resumptive subject pronoun in non-initial position of the main clause. The (b)-examples show that asyndetic coordinate structures are also correctly predicted to be able to occur in right-dislocated position: we give these examples in non-main clause order to show that the coordinate structures follow the finite verb in clause-final position, that is, in a position that cannot be occupied by nominal arguments of the clause. Example (82c) is added to show that asyndetic coordinate structures can also be used as appositions (in parenthetical position); cf. N3.1.3.
a. [Jan, Marie, Peter], allemaal komen ze morgen. Jan Marie Peter all come they tomorrow 'Jan, Marie and Peter, they will all come tomorrow.'
a'. [Jan, Marie, Peter, Els], allemaal komen ze morgen Jan Marie Peter Els all come they tomorrow
b. dat ze morgen allemaal komen: [Jan, Marie, Peter]. that they tomorrow all come Jan Marie Peter 'that they will all come tomorrow: Jan, Marie and Peter.'
$\mathrm{b}^{\prime}$. dat ze morgen allemaal komen: [Jan, Marie, Peter, Els]. that they tomorrow all come Jan Marie Peter Els my classmates Jan Marie Peter come all 'My classmates — Jan, Marie, Peter- will all come.'
c. Mijn klasgenoten - Jan, Marie, Peter - komen allemaal.

Note that there are seemingly asyndetic coordinate structures that can occur in the right periphery of the clause such as Heeft iemand nog vragen, opmerkingen? 'Does anyone have any questions or remarks?' We will not digress here on this potential problem for our claim that asyndetic coordinate structures must be in a main-clause external position but return to it in subsection $\mathrm{C}$.

The fact illustrated by the examples in (80) above that sentence-external asyndetic coordinate structures like (79) can be replaced by monosyndetic ones (typically with en 'and') while clause-internal monosyndetic coordinate structures like (78) cannot be replaced by asyndetic ones has shown that monosyndetic coordinate structures have a wider syntactic distribution. It is worthwhile mentioning that the two types trigger slightly different readings when they can occur in the same position: the asyndetic coordinate structures are more open-ended in the sense that they function as incomplete enumerations, which is also clear from 
the fact that they are often pronounced with a somewhat wavering intonation. This effect can be illustrated quite clearly by means of the examples in (83), in which the phrase noem maar op! 'you name it!' emphasizes the open-endedness of the enumeration: the examples show that this phrase can follow asyndetic coordinate structures but not polysyndetic ones.
a. Iedereen was er: Jan, Marie, Peter, ...; noem maar op! everyone was there Jan Marie Peter call PRT prt. 'Everyone was present: Jan, Marie, Peter, ... You name it!'
b. ${ }^{\$}$ Iedereen was er: Jan, Marie en Peter, ...; noem maar op! everyone was there Jan Marie and Peter call PRT prt.

This enumerating use is also common with asyndetically coordinated clauses, as is shown by (84), in which the last three clauses constitute a (possibly incomplete) list of reasons for assuming that Jan was ill.

$$
\begin{aligned}
& \text { Jan was ziek: hij zweette, hij rilde, hij was misselijk. } \\
& \text { Jan was ill he sweated he shivered he was sick } \\
& \text { 'Jan was ill: he sweated, he shivered and he felt nauseous.' }
\end{aligned}
$$

We conclude this subsection by noting that the generalization that asyndetic coordinate structures normally do not occur as clausal constituents makes it easy to distinguish such structures from noun phrases with a nominal appositional phrase of the type discussed in N3.1.3, such as onze burgemeester 'our mayor' in (85a). The two noun phrases constituting the subject in this example also differ from coordinands in asyndetic (as well as other) coordinate structures in that they do not refer independently: the second noun phrase instead specifies more precisely the entity referred to by the proper name. A foolproof test to distinguish the two cases is the insertion of the coordinator en 'and' in front of the second noun phrase: while this is possible in asyndetic coordinate structures without any significant effect on the interpretation of the clause, it eradicates the appositional structure and replaces it by a coordinate one. This is reflected both by syntactic behavior and by meaning: the appositive structure Marie, onze burgemeester in (85a) refers to a single individual and triggers singular subject-verb agreement, while the coordinate structure Marie en onze burgemeester in (85b) refers to two different individuals and triggers plural agreement.
a. Marie, onze burgemeester, is/*zijn erg bekwaam. Marie our mayor, is/are very competent
'Marie, our mayor, is very competent.'
b. Marie en onze burgemeester $\mathrm{zijn} / *$ is erg bekwaam. [coordinate structure] Marie and our mayor are/is very competent
'Marie and our mayor are very competent.'

\section{B. Potential counterexamples}

Subsection A has argued that asyndetic coordinate structures have a more restricted distribution than their monosyndetic counterparts. They only occur main-clause externally, that is, they cannot be used as (parts of) clausal constituents. The claim that asyndetic coordinate structures are main-clause external is not unproblematic. 
First, such structures can readily be found as clausal constituents in more elevated and literary style (for, e.g., metrical or stylistic reasons), which is of course not sufficient to conclude that this option is also part of ${ }^{\circ}$ core syntax. Second, there are also a number of potential counterexamples that can readily be encountered in colloquial speech. The following subsections will discuss a number of cases of the second type.

\section{Numerals}

Dik (1997:190) mentions cases of the type in (86a\&b), in which two numerals seem to be asyndetically coordinated. Cases such as these are easy to find in colloquial speech; they differ from the corresponding structure with the coordinator of 'or' in that a true disjunctive reading is excluded. Examples like these have an approximative reading ("about four or five"), which is especially clear in examples with higher numbers such as $\left(86 a^{\prime} \& b^{\prime}\right)$, where the numbers mentioned provide a lower and an upper bound ("about thirty to forty"). We can probably set these cases aside because the semantics makes clear that they do not involve run-of-the-mill coordination. This conclusion can be further supported by the fact that the numerals can also be linked by the element à, which is normally not analyzed as a coordinator (but as a preposition): cf. Er wonen daar vier à vijf mensen.

(86) a. Er wonen daar [vier, vijf mensen].

there live there four five people

'Four or five people are living there.'

$a^{\prime}$. Er waren [dertig, veertig mensen] aanwezig.

there were thirty forty people present

b. Dit nummer duurt [vier, vijf minuten].

this track lasts four five minutes

'This track lasts for four or five minutes.'

$b^{\prime}$. De sonate duurt [dertig, veertig minuten]. the sonata lasts thirty forty minutes

\section{Stacked attributively used adjectives}

Haeseryn et al. (1997:1523) mention the case of stacked attributively used adjectives such as given in the primeless examples in (87). They argue that these adjectives are asyndetically coordinated because they receive a similar (conjunctive) interpretation as those in the predicatively used monosyndetic coordinate structures in the primed examples.

(87) a. Peter is een zachtaardig, lief kind.

Peter is a gentle sweet child

$a^{\prime}$. Peter is [zachtaardig en lief].

Peter is gentle and sweet

b. Marie is een lange, dunne vrouw.

Marie is a long skinny woman

$\mathrm{b}^{\prime}$. Marie is [lang en dun].

Marie is tall and skinny 
The claim that we are dealing with asyndetic coordination in the primeless examples is based entirely on semantic grounds, but it is not clear whether it is also justifiable on syntactic grounds. For instance, if we were dealing with asyndetic coordination, we would expect that Noun-ellipsis of the type discussed in Section A5.4 cannot affect a subpart of the presumed attributively used coordinate structure in [een [[korte en dikke] stok]]. Although example (88a), in which the empty nominal projection $[e]$ replaces the noun stok, is well-behaved with respect to this expectation, this clearly does not hold for example (88b) in which $[e]$ replaces the string dunne stok. We therefore conclude that the noun phrase can have the structure [een [korte [dikke stok]]].

(88) a. Jan wil een lange, dunne stok maar ik heb alleen een korte, dikke $[e]$. Jan wants a long thin stick but I have only a short thick 'Jan is looking for a long, thin stick but I only have a short, thick one.'

b. Jan wil een lange, dunne stok maar ik heb alleen een korte $[e]$. Jan wants a long thin stick but I have only a short 'Jan is looking for a long thin stick but I only have a short one.'

Examples such as (88b) are of course not conclusive for claiming that stacked attributive adjective must be hierarchically ordered, in view of the fact that we cannot a priori preclude that the object een lange, dunne stok is structurally ambiguous. Nevertheless, they at least cast some doubt on the appropriateness of a coordination analysis for (87b); we might as well be dealing with an attributive construction of the type in (89a), which Haeseryn et al. do not analyze as a case of asyndetic coordination because they claim that it is more properly paraphrased as in (89b).

(89) a. de lage witte huizen

the low white houses

b. de witte huizen die laag zijn

the white houses that low are

'the white houses that are low'

We conclude that we should provisionally reject the asyndetic-coordination analysis of the primeless examples in (87) for want of conclusive syntactic evidence. Another reason for doing this is that the semantic argument in favor of this analysis is also inconclusive, as is clear from the fact that Section 1.1, sub VII, has shown that semantic conjunction can easily be syntactically expressed by other means than coordination.

\section{Other cases: complex onomatopoeias and reduplication}

Corver $(2015 \mathrm{a} / 2015 \mathrm{~b})$ mentions yet another potential counterexample to the claim that asyndetic coordinate structures cannot occur a clausal constituents. Example (90a) shows that onomatopoeias can be used clause-internally. Interjections are often analyzed as clause-external elements given that they occur in a position preceding the sentence-initial position, as illustrated in (90b). However, it does not seem impossible to place an onomatopoeia in sentence-initial position either; example (90c) is marked compared to (90b) but seems grammatical. 
(90) a. De auto reed boem tegen de muur aan.

the car drove BOEM against the wall AAN

'The car drove — bang! - into the wall.'

b. Boem, [de auto reed tegen de muur aan].

BOEM the car drove against the wall AAN

c. (?) [Boem reed de auto tegen de muur aan].

BOEM drove the car against the wall AAN

Corver shows that complex onomatopoeias should be analyzed as syntactic units. The examples in (91), for instance, show that they can be used as an answer to a $w h$ question, that they can be used as the complement of "quotative" van (cf. V5.1.2.4, sub III), and that they can be coordinated themselves. He also argues that these syntactic units cannot be seen as lexical units (complex words) because the constituting parts do not occur in a fixed order; he therefore concludes that they should be analyzed as coordinate structures.

(91) a. Q: Hoe klonk het geluid van de botsing? A: [Pats, boem, knal]. how sounded the noise of the collision PATS BOEM KNAL

'What did the collision sound like?'

b. Jan reed [zo van [pats, boem, knal]] tegen de muur.

Jan drove so of PATS BOEM KNAL against the wall

c. Het servies viel [[pats, boem, knal] en [bam, boem, beng]] op de vloer. the crockery fell PATS BOEM KNAL and BAM BOEM BENG on the floor

If Corver's conclusion is correct, the fact illustrated in (92) that complex onomatopoeias such as pats boem knal exhibit similar behavior as the simplex ones in (90) would count as a counterexample to the claim that asyndetic coordinate structures do not function as clausal constituents.

(92) a. De auto reed [pats, boem, knal] tegen de muur aan.

the car drove PATS BOEM KNAL against the wall AAN

b. [Pats, boem, knal], [de auto reed tegen de muur aan]. PATS BOEM KNAL, the car drove against the wall AAN

c. (?) [[Pats, boem, knal $]$ reed de auto tegen de muur aan]. PATS BOEM KNAL drove the car against the wall AAN

Corver provides several reasons for assuming that the impression given by (90c) and $(92 \mathrm{c})$ that the onomatopoeias can function as clausal constituents is misleading. The examples in (93), for instance, show that onomatopoeias differ from manner adverbials in that they cannot be the antecedent of the pro-form zo 'so'.

(93) a. *Jan reed boem tegen een mur aan en Els reed zo tegen een boom aan. Jan drove BOEM against a wall AAN and Els drove so against a tree AAN

b. *Jan zakte krak door het ijs en Els zakte zo door de houten vloer. Jan fell KRAK through the ice and Els fell so through the wooden floor

If we may conclude from this that onomatopoeias do not contribute to the logical meaning of the clause, we should perhaps also conclude that they do not function as clausal constituents. Corver therefore suggests that (90c) and (92c) have an elided 
pronominal form daar in sentence-initial position as the result of some kind of topic-drop and that the onomatopoeias are external to the main clause.

(94) a. Boem, [? (daar) reed de auto tegen de muur aan]. BOEM there drove the car against the wall AAN

b. [Pats, boem, knal $]\left[{ }^{[?)}(\right.$ daar $)$ reed de auto tegen de muur aan]. PATS BOEM KNAL there drove the car against the wall AAN

Another potential problem for the claim that asyndetic coordinate structures cannot occur clause-internally are cases of reduplication given in (95), which are used for expressing adjectival amplification. The italicized phrases clearly have the syntactic functions specified within square brackets.

(95) a. De vergadering was saai, saai, saai. the meeting was boring boring boring

b. Je bent een domme, domme, domme jongen! [attributive] you are a stupid stupid stupid boy

c. Jan liep vlug, vlug, vlug de trap op.

[adverbial] Jan walked fast fast fast the stairs up 'Jan walked up the stairs very quickly.'

If the cases in (95) could be shown to involve asyndetic coordination, we would be dealing with uncontroversial counterexamples to our claim. An asyndetic analysis might be in order for (95a), given that it can also be realized as a monosyndetic coordinate structure of the complementive in (96a) provided that the modifier nog eens is present; however, a similar argument cannot be given for the attributive and adverbial cases.

(96) a. De vergadering was [saai, saai, en nog eens saai]. the meeting was boring boring and again once boring

b. *Je bent een [domme, domme en nog eens domme] jongen! you are a stupid stupid and again once stupid boy

c. *Jan liep [vlug, vlug en nog eens vlug] de trap op.

Jan walked fast fast and once again fast the stairs up

It seems too early to conclude from the examples discussed in this subsection that the otherwise robust generalization that asyndetic coordinate structures cannot occur as (subparts of) clausal constituents is invalid. We therefore provisionally assume that asyndetic coordinate structures only occur in main-clause external positions.

\section{Asyndetically linked clauses}

Asyndetic coordinate structures can normally be replaced by monosyndetic ones without any significant effect on the semantic interpretation. In the prototypical case asyndetic coordinate structures are purely conjunctive, as is clear from the fact that they can virtually always be replaced by syndetic ones with the coordinator en 'and'. However, if the asyndetically linked coordinands are sentential, they may also be contrastive, and in such cases the coordinator maar can also be used. Some examples adapted from Haeseryn et al. (1997:1522) are given in (97). 

a. Soms is ze bangig, (en/maar) soms is ze roekeloos. sometimes is she anxious and/but sometimes is she reckless 'Sometimes she is anxious, (and/but) sometimes she is reckless.'
b. Enerzijds is ze bangig, (en/maar) anderzijds is ze roekeloos. on.the.one.hand is she anxious and/but on.the.other.hand is she reckless 'On the one hand she is anxious (and/but) on the other hand she is reckless.'
c. Hij is bangig, (en/maar) zij is roekeloos. he is anxious and/but she is reckless 'He is anxious, (and/but) she is reckless.'

In the interrogative constructions in (98), which are also inspired by Haeseryn et al. (1997:1522), the relation between the asyndetically linked phrases is disjunctive in nature, as is clear from the fact that the coordinator of 'or' can be added. Note that the addition of of in examples such as given in (98) has a similar effect on the interpretation as noted earlier for the addition of en: the asyndetic coordinate structures are open-ended in the sense that they leave more options open, while the coordinate structures with of present the addressee with true binary choices. Observe that the intonation patterns of the two forms also differ: in the asyndetic cases, the two interrogative coordinands are pronounced with their own question contours, while in the syndetic cases we are dealing with a single question contour: compare Ga je mee? Blijf je thuis? and Ga je mee of blijf je thuis? with the question mark indicating the rise in tone typical of questions at the end of the utterance.
a. Zeg het maar: ga je mee? blijf je thuis?
tell it PRT go you prt. stay you home
$a^{\prime}$. Zeg het maar: ga je mee of blijf je thuis?
tell it PRT go you prt. or stay you home
'Well, tell me: are you coming with me or are you staying at home?'
b. Wanneer kom je hier: vandaag? morgen?
when come you here today tomorrow
$\mathrm{b}^{\prime}$. Wanneer kom je hier: vandaag of morgen? when come you here today or tomorrow
'When will you be here: today (or) tomorrow?'

Example (98b) probably involves disjunction of reduced questions: [[K je vandaag] of/Ø [morgen]]? Ellipsis may also provide a solution for the problem mentioned in Subsection A that examples such as (99a) are fully acceptable. We cannot analyze the two noun phrases as being the coordinands of an asyndetic coordinate structure, as in (99b), because this is incompatible with our earlier conclusion that asyndetic coordinate structures cannot be used as clausal constituents (here: direct object). However, we can account for the acceptability of (99a) by assuming that we are dealing with a sentential coordinate structure, with a reduced clause as the second coordinand. This analysis seems supported by the fact that (99a) can comfortably be pronounced with a single question contour if of 'or' is present but not if it is absent: compare Heeft iemand nog vragen of opmerkingen? versus Heeft iemand nog vragen? Opmerkingen? with the question marks indicating the typical rise in tone at the end of the utterance. 
(99) a. Heeft iemand nog vragen (of) opmerkingen?

has someone still questions or remarks

'Are there any questions or remarks?'

b. Heeft iemand nog [vragen of $/{ }^{*} \varnothing$ opmerkingen]?

$\mathrm{b}^{\prime}$. [[Heeft iemand nog vragen] Ø [hoerkingen]]?

\section{Monosyndetic and polysyndetic coordinate structures}

Polysyndetic coordination is illustrated in $(100 \mathrm{~b} \& \mathrm{c})$ for coordinate structures with respectively three and four coordinands and the coordinator en 'and'; the number of coordinands is in principle infinite. Each of the coordinands (except the first) is preceded by a coordinator; omission of any of these coordinators will rule out a polysyndetic analysis of these coordinate structures. The polysyndetic coordinate structures in $(100 \mathrm{~b} \& \mathrm{c})$ differ from their monosyndetic counterparts in (78) in that the coordinators are emphatically accented (which is indicated by small caps); for this reason, it seems justified to consider example (100a) with the intonation indicated as a case of polysyndetic coordination despite the fact that no more than one coordinator is present.

(100) a. [Jan EN Marie] komen morgen.

Jan and Marie come tomorrow

b. [Jan EN Marie EN Peter] komen morgen allemaal.

Jan and Marie and Peter come tomorrow all

'Jan and Marie and Peter will all come tomorrow.'

c. [Jan EN Marie EN Peter EN Els] komen morgen allemaal. Jan and Marie and Peter and Els come tomorrow all

'Jan and Marie and Peter and Els will all come tomorrow.'

Polysyndetic conjunctive coordination differs from monosyndetic conjunctive coordination in that its semantic use seems more restricted: while (101a) allows either a distributive or a cumulative interpretation in the sense that the individuals referred to by the subject may each have lifted the rock individually or they may have lifted the rock together, example (101b) seems to prefer a distributive interpretation, although Dik (1968:ch.11) and De Vries (2005) claim that a cumulative reading is also possible. The semantic contrast between the two examples seem to be confirmed by the fact that the addition of the modifier samen 'together', which triggers a cumulative reading, gives rise to a marked result in the in case of a polysyndetic coordinate structure; cf. Section 1.1, sub IVD.

(101) a. [Jan, Marie en Els] hebben de rots opgetild. [distributive/cumulative] Jan Marie and Els have the rock prt.-lifted

'Jan, Marie and Els have lifted the rock.'

$\mathrm{a}^{\prime}$. [Jan, Marie en Els] hebben samen de rots opgetild. [cumulative] Jan Marie and Els have together the rock prt.-lifted

'Jan, Marie and Els have lifted the rock together.' 
b. [Jan EN Marie EN Els] hebben de rots opgetild. [distributive preferred] Jan and Marie and Els have the rock prt.-lifted

'Jan AND Marie AND Els have lifted the rock.'

$\mathrm{b}^{\prime}$. ?? [Jan EN Marie EN Els] hebben samen de rots opgetild. [cumulative] Jan and Marie and Els have together the rock prt.-lifted

Compare: 'Jan AND Marie AND Els have lifted the rock together.'

The examples in (102) show that polysyndetic coordination is also possible with the disjunctive coordinator of 'or'. The polysyndetic coordinate structures in (102b\&c) again differ from their monosyndetic counterparts in that the coordinators are accented; for this reason, (102a) can also be considered a case of polysyndetic coordination despite the fact that there is only one coordinator present.

(102) a. [Jan OF Marie] komt morgen.

Jan or Marie comes tomorrow

b. [Jan OF Marie OF Peter] komt morgen. Jan or Marie or Peter comes tomorrow

c. [Jan OF Marie OF Peter OF Els] komt morgen. Jan or Marie or Peter or Els comes tomorrow

The generic examples in (103) suggest that disjunctive polysyndetic coordination is also semantically more restricted than its monosyndetic counterpart. The former is more strictly exclusive than the latter: example (103a) can be used to express that biographies, detective stories and thrillers constitute Jan's reading materials, while (103b) expresses Jan reading material is restricted to just one of these genres (although the speaker does not know which one) or, perhaps, that Jan goes through consecutive stages in which he reads one of these genres only.

(103) a. Jan leest biografieën, detectives of thrillers.

[inclusive disjunction] Jan reads biographies detectives or thrillers

'Jan reads bibliographies, detective stories or thrillers.'

b. Jan leest biografieën OF detectives OF thrillers. [exclusive disjunction] Jan reads biographies or detectives or thrillers

'Jan reads biographies, detective stories or thrillers.'

\section{A note on correlative coordinators}

Subsection II has shown that all non-initial coordinands in polysyndetic coordinate structures like $\left(104 a \& a^{\prime}\right)$ are preceded by a coordinator. The fact that the first coordinand is not preceded by a coordinator distinguishes polysyndetic coordinate structures from coordinate structures like $\left(104 b \& b^{\prime}\right)$ with a correlative coordinator, given that the first part of the correlative obligatorily precedes the initial coordinand. The two structures in (104) are difficult to distinguish on other grounds: they both require accent on the coordinators (as indicated by small caps) and they both receive a distributive interpretation in the sense that the individuals mentioned are involved in different eventualities "being on a holiday". 
(104) a. [Jan EN Marie] zijn op vakantie.

[polysyndetic]

Jan and Marie are on holiday

$a^{\prime}$. [Jan EN Marie EN Peter] zijn op vakantie.

Jan and Marie and Peter are on holiday

b. [EN Jan EN Marie] zijn op vakantie.

[correlative coordinator] and Jan and Marie are on holiday

$\mathrm{b}^{\prime}$. [EN Jan EN Marie EN Peter] zijn op vakantie. and Jan and Marie and Peter are on holiday

That the two types only differ in the presence of an "initial" coordinator may raise the question as to whether it is justified to distinguish the two structures. The answer should be in the affirmative since we also have correlative coordinators like zowel ... als ... 'both ... and ...' and (formal) hetzij ... of ... 'either ... or ...', in which the two parts are not homophonous.

(105) a. [Zowel Jan als Marie] is op vakantie.

both Jan and Marie is on holiday

'Both Jan and Marie are on holiday.'

b. De bijeenkomst zal [hetzij morgen of donderdag] plaatsvinden. the meeting will either tomorrow or Thursday] place-take 'The meeting will take place either tomorrow or on Thursday.'

It should be noted, however, that coordinate structures with correlatives are always "polysyndetic" when there are more than two coordinands; the examples in (106) show that replacing the coordinator (part) in front of the second or the third coordinand by an intonation break gives rise to a highly marked result (although it is claimed to be acceptable for at least some speakers according to taaladvies.net/taal/advies/vraag/1223); the same holds for structures in which both coordinators are replaced by an intonation break (not illustrated here).

(106) a. [En Jan *(en) Marie en Peter] zijn op vakantie.

and Jan and Marie and Peter are on holiday

$a^{\prime}$. [En Jan en Marie *(en) Peter] zijn op vakantie.

and Jan and Marie and Peter are on holiday

b. [Zowel Jan*(als) Marie als Peter] is op vakantie.

both Jan and Marie and Peter is on holiday

'And Jan and Marie and Peter are on holiday.'

$\mathrm{b}^{\prime}$. [Zowel Jan als Marie *(als) Peter] is op vakantie. both Jan and Marie and Peter is on holiday

Observe that (106b) also shows that it is the second part of the correlative coordinator that is repeated before the non-initial coordinand(s); substituting zowel for the first occurrence of als in (106b) leads to unacceptability regardless of the form of the element preceding the first coordinand, as is clear from the unacceptability of the examples in (107). 
(107) a. *[Zowel Jan zowel Marie als Peter] is op vakantie. both Jan both Marie and Peter is on holiday

b. *[Als Jan zowel Marie als Peter] is op vakantie. and Jan both Marie and Peter is on holiday

This suggests that the initial part of the correlative has a special status. This will be confirmed by the more extensive discussion of correlative coordinators in Section 1.4.2, where it will be shown that the initial part is not a coordinator-like element but a focus ${ }^{\circ}$ particle.

\subsection{Coordinands}

This section discusses a number of co-occurrence restrictions on the coordinands of a coordinate structure. Chomsky (1957), Schachter (1977), and many others have noticed that coordinands must be of the "same kind" as the coordinate structure as a whole. Subsection I will make this more precise by showing that the coordinands are subject to the co-occurrence restrictions in (108).

Co-occurrence restrictions on coordinands: Coordination is possible only if the coordinands can have the same syntactic function and occur in the same syntactic position as the coordinate structure as a whole.

Subsection II continues by showing that coordinate structures are normally islands for movement. Ross (1967) formulated this by means of the generalization in (109).

(109) Coordinate structure constraint: Extraction from a coordinate structure is impossible: neither the coordinands themselves nor any phrase contained in them can be extracted from the coordinate structure by movement; adapted from Ross (1967 (4.84)).

There is a well-known exception to this general rule, known as ${ }^{\circ}$ across-the-board movement; we will argue that the co-occurrence restrictions in (108) are capable of accounting for the cases covered by (109) as well as the supposed exceptional cases of across-the-board movement. This makes the coordinate structure constraint superfluous for providing an adequate description; the real question is therefore how to properly explain the co-occurrence restrictions in (108).

Subsection III continues by discussing the internal make-up of coordinate structures, and will argue that coordinators are two-place linkers, just like logical conjunction and disjunction in formal semantics. It implies that polyadic coordinate structures (i.e., structures with more than two coordinands) are recursive in the sense that coordinate structures can be embedded in (that is, be used as coordinands of) larger coordinate structures; this implies that polyadic coordinate structures are hierarchically structured. Subsection IV even goes one step further by showing that there are reasons for assuming that the same holds for dyadic coordinate structures because the two coordinands may exhibit different syntactic behavior: the first coordinand, for example, can enter into a relation with an element external to the coordinate structure, while the latter cannot. 


\section{Co-occurrence restrictions}

Chomsky (1957: 35-7) noted that coordination is a very useful test for establishing constituency, as it is possible only if the coordinands are constituents of the same kind. For instance, the post-nominal modifiers of boek 'book' in (110a\&b) can easily be coordinated, as is illustrated by (110c). The examples in (111) show the same thing with restrictive relative clauses.

(110) a. Marie las [boeken [over Hitler]].

[PP-modifier]

Marie read books about Hitler

b. Marie las [boeken [over Nazi-Duitsland]].

Marie read books about Nazi.Germany

[PP-modifier]

c. Marie las [boeken [[over Nazi-Duitsland] en [over Hitler]]].

Marie read books about Nazi.Germany and about Hitler

(111) a. [De man [die hier net was]] is een bekend schrijver.

the man who here just was is a well-known writer

'The man who was here just now is a well-known writer.'

b. [De man [die Russisch sprak]] is een beroemd schrijver.

the man who Russian spoke is a famous writer

'The man who spoke Russian is a famous writer.'

c. [De man [[die hier net was] en [die Russisch sprak]]] is een beroemd schrijver. the man who here just was and who Russian spoke is a famous writer 'The man who was here just now and who spoke Russian is a famous writer.'

It is, however, not a trivial matter to decide whether or not two constituents are of the "same kind". This subsection discusses three aspects that may be relevant for determining this.

\section{A. The coordinands have the same syntactic function}

It has been suggested that the coordinands must be of the same syntactic category. This would account for the contrast between the (110c) and (112c): while coordination of two PP-modifiers is possible, coordination of a postnominal PP and a relative clause is not, despite the fact that they both clearly function as a modifier of the noun phrase.

(112) a. Marie las [boeken [over Hitler]].

[PP-modifier]

Marie read books about Hitler

b. Marie las [boeken [die Els had gekocht]].

[relative clause]

Marie read books which Els had bought

c. *Marie las [boeken [[over Hitler] en [die Els had gekocht]]]. Marie read books about Hitler and which Els had bought

The examples in (113) show, however, that categorial identity is not sufficient for coordination, as it is not possible to coordinate two postnominal modifiers of the same category if their meaning contributions differ: while the PP-modifier over Hitler specifies the subject matter of the books, the van-PP refers to their author or possessor, and coordination is highly questionable. 
(113) a. Marie las [boeken [over Hitler]].

[subject matter]

Marie read books about Hitler

b. Marie las [boeken [van Els]].

Marie read books by/of Els

c. *Marie las [boeken [[over Hitler] en [van Els]]].

Marie read books about Hitler and by/of Els

The difference in meaning contribution of the two PP-modifiers in (113) is also reflected in the fact that they can co-occur. Example (114a) first shows that the PPmodifiers in (110), which entertain an identical meaning relation to the modified noun, cannot co-occur as independent phrases inside a single noun phrase. Example (114b), on the other hand, shows that PP-modifiers such as the over- and van-PP in (113), which have different meaning contributions, can co-occur as independent phrases within a single noun phrase; this suggests that they have different syntactic functions and that it is this fact that blocks coordination. If so, we can provide a similar account for the unacceptability of (112c), in which a PP-modifier and a relative clause are coordinated, because (114c) shows that they can also co-occur as independent phrases within a single noun phrase.

(114) a. *Marie las [[boeken [over Hitler]] [over Nazi-Duitsland]].

Marie read books about Hitler about Nazi.Germany

b. Marie las [[boeken [over Hitler]] [van Els]].

Marie read books about Hitler of/by Els

c. Marie las [[boeken [over Hitler]] [die Els had gekocht]].

Marie read books about Hitler which Els had bought

The examples in (115) show that categorial identity is not only insufficient but in fact not necessary for coordination to be possible: coordination of an adjectival and an adpositional ${ }^{\circ}$ complementive is possible; and the same holds for an adjectival and a prepositional adverbial phrase.
(115) a. Jan is [AP moe].
[adjectival complementive]
Jan is tired
$\mathrm{a}^{\prime}$. Jan is [pp in de war].
[prepositional complementive]
Jan is confused
$\mathrm{a}^{\prime \prime}$. Jan is [[moe] en [in de war]].
Jan is tired and confused
b. Jan at [AP gretig].
Jan ate greedily
$b^{\prime}$. Jan at [pp met smaak].
Jan ate with relish
[adjectival manner adverbial]
$b^{\prime \prime}$. Jan at [[gretig] maar [met smaak]].
Jan ate greedily but with relish

It has been suggested that the acceptability of $\left(115 \mathrm{a}^{\prime \prime} \& \mathrm{~b}^{\prime \prime}\right)$ can be reconciled with the categorial identity requirement by assuming that we are dealing with coordination of predicative phrases (that is, PredPs) in (115a") and adverbial phrases (that is, AdvPs) in $\left(115 b^{\prime \prime}\right)$. This may be undesirable because it seems to be based on mixing the notion of syntactic category and that of syntactic/semantic 
function. Moreover, it is not needed given that the easier alternative in (116) presents itself (provided that we assume that the notion of adverbial function is used to cover a set of different syntactic functions, as is claimed in V8 on independent grounds); see also Dik (1968:25), Haeseryn et al. (1997:1450), Hendriks (2001b) and many others.

Co-occurrence restriction on coordinands (to be revised): Coordination is possible only if the coordinands can have the same syntactic function as the coordinate structure as a whole.

Generalization (116) predicts linking of adjectival and nominal predicates to be possible as well. This is indeed borne out, although there seem to be additional restrictions that are not fully understood. The examples in (117), for instance, have been taken to show that such linking is only possible when the nominal predicate is in a sense "gradable"; cf. Goodall (1987:45).

(117) a. Jan is [[aardig] en [een (enorme) steun voor zijn moeder]].

Jan is kind and an immense support for his mother

'Jan is kind and a great help to his mother.'

b. Jan is [[aardig] en [een ${ }^{\$}(*$ enorme $)$ taalkundige $]$.

Jan is kind and an immense linguist

Compare: 'Jan is kind and very much a linguist.'

The examples in (118), however, suggest that the evaluative nature of the nominal predicates may also play a role: the use of adversative coordinator maar is possible with the nominal predicate een leugenaar 'a liar' because its negative connotation contrasts with the positive property denoted by the adjective aardig 'kind', but impossible with the nominal predicate een steun 'a support' because this predicate does not have a negative connotation.

(118) a. Jan is [[aardig] en/\$maar [een (enorme) steun]].

Jan is kind and/but an immense support

b. Jan is [[aardig] maar/ $/$ en [een (enorme) leugenaar]].

Jan is kind but/and an immense liar

'Jan is kind but (very much) a liar.'

The examples in (119) show that [+human] nouns can easily be coordinated more generally with adjectives denoting some property typically (dis)associated with them: if the property is expected for the individuals denoted by the noun, the coordinator en followed by the adverbial $d u s$ 'therefore' is used, but if the adjective denotes an unexpected property, the adversative coordinator maar 'but' is used.

(119) a. Jan is [[rechter] en *(dus) [streng]].

Jan is a.judge and therefore stern

b. Jan is [[een taalkundige] maar [slordig in zijn taalgebruik]].

Jan is a linguist but sloppy in his language use

Because we have little more to say about the factors affecting the acceptability of linking of adjectival and nominal predicates, we leave this issue for future research; 
for the moment, it suffices to observe that the acceptable examples in (117)-(119) show that such linking is allowed by syntax.

An apt illustration of the co-occurrence restriction on coordinands in (116) is given in (120); although the verb wegen 'to weigh' can select a referential noun phrase such as de appels 'the apples' in (120a) or a non-referential noun phrase such as 70 kilo ' 70 kilos' in (120b), the coordinate structure in (120c) is impossible. This is arguably due to the fact that the two noun phrases have different syntactic functions. The referential noun phrase clearly has the function of direct object given that it allows passivization: De appels worden gewogen 'the apples are weighed'. The non-referential noun phrase does not function as direct object as it does not allow passivization: *Er wordt/worden 70 kilo gewogen. Example (120c) is therefore correctly excluded by restriction (116).
(120) a. Jan weegt de appels
Jan weighs the apples
b. Jan weegt 70 kilo
Jan weighs 70 kilos
c. *Jan weegt [[de appels] en [70 kilo]].
Jan weighs the apples and 70 kilos

On the assumption that the notion of adverbial function is an umbrella term, the formulation in (116) also correctly predicts that, e.g., place and time adverbials cannot be coordinated. This accounts for the acceptability contrast in the (a)examples in (121), but leaves as a mystery why examples such as (121b) are acceptable; cf. Schachter (1977:91). We will assume that the latter case is a fixed collocation because this example refers to a single (prospective) eventuality at a certain time and place, while clauses with coordinated time or place adverbials normally refer to distinct eventualities: cf. e.g., Ik ontmoet Jan morgen en volgende week maandag 'I will meet Jan tomorrow and Monday next week'. The claim that we are dealing with a collocation can perhaps also be supported by the fact that the order of the two coordinands is more or less fixed in that at least some speakers prefer the order in (121b) to the order in $\left(121 b^{\prime}\right)$.

(121) a. Ik ontmoet Jan [volgende week] [in Amsterdam].

I meet Jan next week in Amsterdam

'I will meet Jan in Amsterdam next week.'

$\mathrm{a}^{\prime}$. *Ik ontmoet Jan [[volgende week] en [in Amsterdam]].

I meet Jan next week and in Amsterdam

b. [Waar en wanneer] ontmoet je Jan?

where and when meet you Jan

'Where and when will you meet Jan?'

$\mathrm{b}^{\prime} .{ }^{\%}[$ Wanneer en waar] ontmoet je Jan?

when and where meet you Jan

\section{B. The coordinands have the same syntactic distribution}

The co-occurrence restriction on coordinands in (116), which states that coordinands must be able to have the same syntactic function as the coordinate structure as a whole, differs from the categorial identity requirement in that it 
correctly allows for examples such as Jan is [[AP moe] en [PP in de war]] 'Jan is tired and confused' in (115). In other respects, however, it seems to cover more or less the same ground due to the fact that many syntactic functions are prototypically expressed by phrases of a specific syntactic category. Yet, the formulation in (116) still seems to be inadequate, as it wrongly predicts that nominal and clausal phrases can be coordinated in the function of subject or object; the primed examples in (122) are therefore wrongly predicted to be fully acceptable.

(122) a. [Dat boek]/[Dat Jan komt] is leuk.

[subject]

that book/ that Jan comes is nice

$\mathrm{a}^{\prime}$. ??[[Dat boek] en [dat Jan komt]] is leuk. that book and that Jan comes is nice

b. [Dat boek]/[Dat Jan komt] vind ik leuk. that book/that Jan comes consider I nice

$\mathrm{b}^{\prime}$. ??[[Dat boek] en [dat Jan komt]] vind ik leuk. that book and that Jan comes consider I nice

That coordinate structures consisting of a noun phrase and a clause do not often occur as a subject or object is not surprising: the coordinands arguably occupy different positions in the prototypical case when used in the same function. The primeless examples in (123) show that ${ }^{\circ}$ argument clauses are normally preceded by the ${ }^{\circ}$ anticipatory pronoun het 'it' and appear in postverbal position, that is, in a position where a nominal subject cannot appear. The primed examples show that argument clauses are not readily possible in the preverbal positions normally occupied by the nominal arguments.

(123) a. dat het leuk is [dat Jan komt].

[subject] that it nice is that Jan comes

$\mathrm{a}^{\prime}$. dat dat boek ? ? $^{\text {? }}$ dat Jan komt] leuk is. that that book/that Jan comes nice is

b. dat ik het leuk vind [dat Jan komt]. that $\mathrm{I}$ it nice consider that Jan comes

[object]

$\mathrm{b}^{\prime}$. dat ik dat boek $/^{\text {? }}$ [dat Jan komt] leuk vind. that I that book/that Jan comes nice consider

Given that nominal and clausal arguments occupy different positions in the clause we may account for the markedness of primed examples in (122) by adding to the generalization in (116) that the coordinands should be able to occur in the same syntactic positions as the coordinate structure as a whole.

Co-occurrence restrictions on coordinands (to be revised): Coordination is possible only if the coordinands can have the same syntactic function and occur in the same syntactic positions as the coordinate structure as a whole.

The formulation in (124) predicts that the coordinands of a coordinate structure that functions as an argument can all be nominal or all be clausal, as in as (125a-b), but cannot easily be mixed: example $\left(122 \mathrm{a}^{\prime}\right)$, repeated below as $(125 \mathrm{c})$ is predicted to be at best equally acceptable as $\left(123 \mathrm{a}^{\prime}\right)$ with a subject clause. 
(125) a. [[Dat boek] en [die plaat]] zijn leuk. that book and that record are nice

b. Het is leuk [[dat Jan komt] en [dat hij een lezing geeft]]. it is nice that Jan comes and that he a talk gives 'It is nice that Jan is coming and that he will give a talk.'

c. "?[Dat boek] en [dat Jan komt]] is leuk. that book and that Jan comes is nice

The same holds for object clauses; example $\left(122 b^{\prime}\right)$, repeated below as $(126 c)$, is predicted to be at best equally acceptable as $\left(123 b^{\prime}\right)$ with an object clause.

(126) a. Ik vind [[dat boek] en [die plaat]] leuk.

I consider that book and that record nice

b. Ik vind het leuk [[dat Jan komt] en [dat hij een lezing geeft]].

it consider it nice that Jan comes and that he a talk gives

'I consider it nice that Jan is coming and that he will give a talk.'

c. ??[[Dat boek] en [dat Jan komt]] vind ik leuk. that book and that Jan comes consider I nice

It should be noted that the co-occurrence restrictions on coordinands in (124) do not categorically exclude coordination of nominal and clausal constituents. For instance, Section V5.1.2.3 has shown that factive verbs such as betreuren 'to regret' do allow object clauses in preverbal position and they do indeed allow coordination of a nominal and clausal object.

(127) a. dat Jan [zijn vroege vertrek] erg betreurt.

that Jan his early departure much regrets

b. dat Jan [dat hij niet kan spreken] erg betreurt.

that Jan that he not can speak much regrets

c. dat Jan [[zijn vroege vertrek] en [dat hij niet kan spreken]] erg betreurt.

that Jan his early departure and that he not can speak much regrets 'that Jan deeply regrets his early departure and that he cannot give a talk.'

Another "mixed" case allowed by the formulation (124) is given in (128): the first two examples show that nominal and clausal adverbial phrases of time can both occur in preverbal position and the third example shows that they can also be coordinated.

(128) a. dat Jan 's morgens onder de douche gaat. that Jan in.the.morning under the shower goes

b. dat Jan [nadat hij gesport heeft] onder de douche gaat. that Jan after he exercised has under the shower goes

c. dat Jan [['s morgens] en [nadat hij gesport heeft]] onder de douche gaat. that Jan in.the.morning and after he exercised has under the shower goes 'that Jan takes a shower in the morning and after he has exercised.'

The literature mentions a number of apparent counterexamples to the cooccurrence restrictions on coordinands in (124), which we will discuss next; see Zhang (2010: Section 3.3.1) for an overview and references. Consider the English 
examples in (129), which are taken to show that "mixed" coordinate structures of the form [NP and clause] can be the ${ }^{\circ}$ complement of a preposition despite the fact that it is not possible for a preposition to take a clausal complement. Example (129d) shows that mixed coordinate structures in which the clause comes first are also unacceptable.

(129) a. You can depend on my assistance.

b. *You can depend on that I will be on time.

c. You can depend on my assistance and that I will be on time.

d. *You can depend on that I will be on time and my assistance.

It is relevant to note here that all examples of mixed coordinate structures provided by Zhang are sentence-final; this makes an analysis possible according to which we are dealing with an extraposed PP-complement. In order to see why this is relevant, we have to consider the Dutch counterparts of these examples. First, consider the Dutch (130a), which shows that complement-PPs containing a nominal complement can precede or follow the verb(s) in clause-final position. The (b)-examples show that PPs with a clausal complement are marked in both positions, and that the complement-PP is normally realized instead by a clause in postverbal position preceded by the ${ }^{\circ}$ anticipatory pronominal PP erop 'on it' in preverbal position.

(130) a. Je kan <op mijn hulp $>$ rekenen $<$ op mijn hulp $>$.

you can on my assistance count

b. ${ }^{* ?} \mathrm{Je}$ kan <op dat ik op tijd ben> rekenen <op dat ik op tijd ben>. you can on that I on time am count

$b^{\prime}$. Je kan erop rekenen [dat ik op tijd ben]. you can on.it count that I on time am 'You can depend on it that I will be on time.'

However, we should not account for the markedness of (130b) by prohibiting that complement-PPs may contain a clausal complement, as this is at least marginally possible in topicalization constructions such as (131a). The acceptability contrast between (130b) above and (131a) below seems related to the fact illustrated in (131b) that topicalization is excluded when the anticipatory pronominal PP erop 'on it' is present; cf. Haslinger (2007).

(131) a. ?[Op dat ik op tijd kom] kan je rekenen.

on that I on time come can you count

b. *[Dat ik op tijd kom] kan je erop rekenen.

that I on time come can you on.it count

Now consider the Dutch counterparts of the English examples in (129c\&d), which are given in (132). The acceptability of (132a) is expected, as it is in accordance with the co-occurrence restrictions on coordinands in (124) as well as the earlier observation that clauses may occur as complements of PP-complements when the anticipatory pronominal PP erop 'on it' cannot be used for some reason or other. The unacceptability of (132b) is not expected on syntactic grounds but it may be degraded for the quite superficial reason that the P-NP sequences are more frequent than P-clause sequences and are therefore easier to parse. Now, if English PP- 
complements exhibit the same behavior as their Dutch counterparts, the acceptability pattern found in (129) is accounted for.

(132) a. Je kan rekenen [op [[mijn hulp] en [dat ik op tijd ben]]].
you can count on my help and that I on time am
'You can count on my help and that I'll be on time.'
b. '? 'Je kan rekenen [op [[dat ik op tijd ben] en [mijn hulp]]].
you can count on that I on time am and my help

Note that examples such as (133) are also fairly acceptable in Dutch. If examples of this sort are to be considered grammatical, we may be dealing with a case of "split" coordination; Subsection IIB will analyze what looks like the extraposed part of such splits as a reduced clause.

$$
\begin{aligned}
& \text { 'Je kan op mijn hulp rekenen en dat ik op tijd ben. } \\
& \text { you can on my help count and that I on time am } \\
& \text { 'You can count on my help and that I'll be on time.' }
\end{aligned}
$$

A similar "split" coordination analysis may also account for the other mixed examples provided by Zhang. We illustrate this for example (134a), in which an object DP and an adverbial PP seem to have entered into a single coordinate structure, which would be rendered as (134b) in Dutch; we provide the clause in its embedded form in order to show that we are dealing with "split" coordination.

(134) a. He read only The Times and only on Sundays.

b. dat hij alleen The Times leest en hij alleen op zondag leest. that he only The Times reads and that he only on Sunday reads 'that he only reads The Times and only on Sundays.'

We provisionally conclude from this brief discussion that the English data in Zhang have simply received an incorrect analysis and that the generalization in (124) can be maintained in full force. This conclusion is desirable given that it is fully in line with the hypothesis found in the semantic literature that the coordinands in a coordinate structure must be of the same semantic type (cf. Section 1.1, sub IVF), as syntactic functions can be rephrased in terms of semantic types in the prototypical case. There are, however, some problems of a theory-internal nature for the semantic approach that do not arise with (124). For instance, proper nouns and definite descriptions are normally taken to be semantically different: while proper nouns are normally considered to be entities (type $e$ ), definite descriptions are taken to denote sets of properties (type $<<e, t>, t>$ ). If coordinands should be of the same semantic type, we need a type-changing operation in order to allow for coordinate structures such as (135c); cf. Winter (2001a). Note that we do not put this remark forward as an argument against the semantic approach, as this type-changing operation may be needed for independent reasons. In fact, that syntactic and semantic approaches converge on this issue may be what is expected. 
(135) a. Jan heeft gewandeld.

[type e]

Jan has walked

b. De honden hebben gewandeld. the dogs have walked

c. [[Jan] en [de honden]] hebben gewandeld. Jan and the dogs have walked

Note that we do not put this remark forward as an argument against the semantic approach, as the type-changing operation mentioned aboe may be needed for independent reasons. We in fact believe that it is quite promising that syntactic and semantic approaches converge on this issue.

It is important to note that generalization (124) does not claim that a coordinate structure can always be replaced by its individual coordinands, as there may be various interfering factors unrelated to coordination that may affect the acceptability of the resulting structure. One of these factors is subject-verb agreement: while the coordinate structure in (135c) above can be replaced by its second coordinand, which would result in (135b), it is not possible to replace it by its first coordinand just like that, as this would result in an agreement mismatch: *Jan hebben gewandeld. Another factor may involve the semantic selection restrictions imposed by the predicate on its arguments: a verb such as zich verspreiden 'to spread' in (136) selects a plural subject and consequently it is impossible to leave out the second coordinand even if we adjust the form of the finite verb.

(136) a. Jan en zijn vrienden verspreiden zich.

Jan and his friends spread REFL

'Jan and his friends are spreading out.'

b. Zijn vrienden verspreiden zich. his friends spread REFL 'His friends are spreading.'

c. ${ }^{\$}$ Jan verspreidt zich. Jan spreads REFL

The examples in (137) show that there are also inverse cases, that is, cases in which a coordinate structure cannot be used in a position in which its coordinands are possible as independent phrases. This is related to the fact that example (137a) involves the fixed collocation een foto nemen 'to take a picture', while een koekje nemen 'to take a cookie' is (137b) is fully compositional. The dollar sign indicates that under the interpretation intended here, example (137c) would normally be interpreted as a linguistic pun, and considered marked otherwise.

(137) a. Marie nam een foto.

Marie took a picture

b. Marie nam een koekje.

Marie took a cookie

c. ${ }^{\$}$ Marie nam [[een foto] en [een koekje]].

Marie took a picture and a cookie

Another idiomatic case is given in (138) with the expression de geest geven 'to die'; the nominal expression de geest cannot be coordinated with a nominal expression 
functioning as a referential theme argument of geven 'to give'; of course, the verbal expression as a whole can be coordinated with the compositional verbal projection het geld geven, as is illustrated in (138b).

(138) a. *De koning gaf [het geld en de geest]. the king gave the money and the spirit

b. De koning [gaf het geld] en [gaf de geest]. the king gave the money and gave the spirit 'The king gave the money and died.'

A third case, adapted from Dik (1997:200ff.), is illustrated in the examples in (139): while the simple clauses in $(139 \mathrm{a} \& b)$ are both fully acceptable, the coordinate structure in $(139 \mathrm{c})$ is severely degraded.

(139) a. Jan zag [Marie vallen].

Jan saw Marie fall

'Jan saw Marie fall.'

b. Jan zag [dat Marie opstond].

Jan saw that Marie up-got

'Jan saw that Marie got to her feet.'

c. *Jan zag [[Marie vallen] en [dat zij opstond]].

Jan saw Marie fall and that she up-got

Dik claims that the two verbal complements are of a different semantic type and attributes the unacceptability to the selection restrictions imposed by the perception verb zien 'to see'. Alternative accounts may appeal to the fact that the infinitival construction in (139a) has certain special syntactic properties lacking in the construction in (139b): the subject of the infinitival clause, for instance, is dependent on the perception verb zien for case assignment and the verbal ${ }^{\circ}$ head of the infinitival clause and the perception verb form a verb cluster; $\mathrm{cf}$. the discussion of perception verbs in Section V5.2.3.3. It is not so easy to choose between the available options: an appeal to selection restrictions would predict that examples such as (140) are unacceptable while, e.g., the verb-cluster approach would predict that such examples are possible. However, examples like those in (140) seem to have an intermediate status; they are marked but certainly less degraded than example (139c).

(140) a. ??Jan heeft me beloofd [[dat hij komt] en [om te blijven eten]]. Jan has me promised that he comes and COMP to stay eat Compare: 'Jan promised me that he will come and to stay for dinner.'

b. 'Jan heeft me beloofd [[om te komen] en [dat hij blijft eten]]. Jan has me promised COMP to come and that he stays eat Compare: 'Jan promised me to come and that he will stay for dinner.'

Whatever the correct analysis of the degraded status of (139c) may be, also this case illustrates that the co-occurrence restrictions on coordinands in (124) do not imply that a coordinate structure can always be used in a position in which its coordinands are possible as independent phrases, since there may be interfering factors unrelated to coordination that may affect the acceptability of the resulting structure. 


\section{Predicative coordinands: the individual/stage-level distinction}

A final case that should be mentioned is illustrated in (141). These examples show that the selection restrictions imposed by the predicative coordinands on their subjects must be similar; while the individual-level predicate zijn zoogdieren triggers a generic reading on the bare plural subject, the stage-level predicate op dit moment buiten blaffen triggers an indefinite reading. The examples in (142) show that we find essentially the same for the singular noun phrase een hond 'a dog'.

(141) a. Honden zijn zoogdieren.

[generic subject] dogs are mammals

b. Er blaffen op dit moment honden buiten. there bark at this moment dogs outside

[indefinite subject] 'Dogs are barking outside at this moment.'

c. *Honden [[zijn zoogdieren] en [blaffen op dit moment buiten]]. dogs are mammals and bark at this moment outside

(142) a. Een hond is een zoogdier.

[generic subject] a dog is a mammal

b. Er blaft op dit moment een hond buiten. there barks at this moment a dog outside 'A dog is barking outside at this moment.'

c. *Een hond [[is een zoogdier] en [blaft op dit moment buiten]]. a $\operatorname{dog}$ is a mammal and barks at this moment outside

As far as Dutch is concerned, one might question whether it is really necessary to assume that coordinated predicates must impose similar selection restrictions on their subject, given that generic and indefinite subjects in the (a)- and (b)-examples clearly occupy different positions: the co-occurrence restriction on coordinands in (116) thus suffices to exclude the (c)-examples. Furthermore, the examples in (143) show that predicates that select a cumulative and a distributive subject, respectively, can be coordinated.

(143) a. De jongens ruimden samen de troep op.

the boys cleared together the mess up

'The boys cleared up the mess together.'

b. De jongens kregen elk 10 Euro. the boys got elk 10 Euro

'The boys got 10 Euro each.'

c. De jongen [[ruimden samen de troep op] en [kregen elk 10 Euro]]. the boys cleared together the mess up and got each 10 Euro 'The boys tidied up the mess together and received 10 Euros each.'

Since the English renderings of (141c) and (142c) are also unacceptable (cf. Zhang 2010:188), despite the fact that the generic and indefinite subjects seem to occupy the same position, this may suggest that we are minimally dealing with a restriction on the semantic type of predicative coordinands: "mixed" cases of individual and stage-level predicates cannot be coordinated. 


\section{Other restrictions}

The previous subsections have shown that coordinate structures must meet the cooccurrence restrictions on coordinands in (144). We have found only a limited number of remarks on restrictions concerning the semantic nature of the coordinands in the literature we consulted; more inquiry seems needed in order to establish whether any finer distinctions go beyond the individual-stage and stagelevel distinction. We did not extensively discuss the hypothesis found in the semantic literature that the coordinands should be of the same semantic type (entity, predicate, etc.) because this hypothesis is more or less equivalent to the first part of restriction (144a); see Subsection B for a brief discussion of this.

\section{(144) Co-occurrence restrictions on coordinands:}

a. Coordinands in a coordinate structure are of the same syntactic type: they can have the same syntactic function and occur in the same syntactic positions as the coordinate structure as a whole.

b. Predicative coordinands are of the same type: individual-level or stage-level.

It should be mentioned that there are a number of co-occurrence restrictions that are not (immediately) related to those given in (144). Given the difference in syntactic function of the two PPs in (145a), it follows directly from (144a) that the coordinate structure in (145b) is impossible (on the intended interpretation), but it may not be immediately clear why $(145 \mathrm{c})$ is also unacceptable, as this is only indirectly related to syntactic function; here the PP cannot be interpreted as an ${ }^{\circ}$ argument and a place adverbial at the same time.

(145) a. Jan wacht op Peter/op het perron.

[complement/place adverbial]

Jan waits for Peter/on the platform

'Jan is waiting for Peter/on the platform.'

b. *Jan wacht [[op Peter] en [op het perron]].

Jan waits for Peter and on the platform

c. *Jan wacht [op [Peter en het perron]].

Jan waits OP Peter and the platform

The (c)-examples in (146) and (147) show that coordination is sometimes sensitive to the thematic role of the coordinands as well: while the coordinands can all be used as subjects they cannot be coordinated due to the fact that they have different semantic roles: agent versus instrument/means.

(146) a. Jan agent $_{\text {opende de deur (met de sleutel }}$ instrument $_{\text {) }}$.

Jan opened the door with the key

b. De sleutel instrument $_{\text {opende de deur. }}$ the key opened the door

c. *[Jan agent en de sleutel $\left.\mathrm{I}_{\text {instrument }}\right]$ openden de deur. Jan and the key opened the door 
(147) a. Jan agent $_{\text {vulde het gat (met het zand }}$ means).

Jan filled the hole with the sand

b. Het zand means $_{\text {vulde het gat. }}$ the sand filled the hole

c. * $\left[\mathrm{Jan}_{\mathrm{agent}}\right.$ en het $\left.\mathrm{zand}_{\text {means }}\right]$ vulden het gat. Jan and the sand filled the hole

Although this does not seem to follow from (144a) at first sight, it can be derived from it in a straightforward way. While Section V9.5 has argued that agents (that is, the external argument of $\mathrm{V}$ ) are arguably base-generated in the highest specifier of the lexical part of the verbal projection $(v \mathrm{P})$, it seems plausible that instruments/means are generated in some other position (e.g., corresponding to that of the met-PP); if this is indeed the case, the unacceptability follows from (144a) on the plausible (and normally tacitly adopted) assumption that coordinate structures are formed before they are inserted in some larger syntactic structure.

\section{Coordinate structure constraint and across-the-board movement}

This subsection discusses the restrictions on movement from coordinate structures, which have come to be known as the COORDINATE STRUCTURE CONSTRAINT. We will more specifically address the question as to whether or not these restrictions should be accounted for by appealing to independently established locality conditions on movement. Because the coordinate structure constraint can be violated if movement applies in a so-called ACROSS-THE-BOARD fashion, we will conclude that this is not possible, and that the valid part of the coordinate structure constraint should instead be accounted for in terms of the co-occurrence restrictions on coordinands in (124) from Subsection I.

\section{A. Coordinate structure constraint}

Coordinate structures exhibit ${ }^{\circ}$ island effects in the sense that it is normally not possible to extract a constituent from them. This generalization is known as the coordinate structure constraint.

(148) Coordinate structure constraint: Extraction from a coordinate structure is impossible: neither the coordinands themselves nor any phrase contained in them can be extracted from the coordinate structure by movement. Adapted from Ross (1967 (4.84)).

The two instances mentioned in (148) are illustrated in (149) by means of whmovement of (a subpart of) a direct object: while (149a) shows that it is possible to wh-move an object as a whole, the (b)-examples in (149) show that it is not possible to $w h$-move the first (or second) coordinand from a coordinate structure functioning as a direct object, and the (c)-examples show that it is not possible to $w h$-move an object if the verbal projection including it functions as a coordinand in a coordinated structure. 
(149) a. Welk boek $\mathrm{i}_{\mathrm{i}}$ heeft Jan $t_{\mathrm{i}}$ gelezen?

which book has Jan read

b. Jan heeft [jouw boek en haar artikel] gelezen.

Jan has your book and her article read

'Jan has read your book and her article.'

$\mathrm{b}^{\prime}$. *Welk boek $\mathrm{k}_{\mathrm{i}}$ heeft Jan $\left[t_{\mathrm{i}}\right.$ en haar artikel $]$ gelezen?

which book has Jan and her article read

$\mathrm{b}^{\prime \prime} .{ }^{*}$ Welk $\operatorname{artikel}_{\mathrm{i}}$ heeft Jan [jouw boek en $t_{\mathrm{i}}$ ] gelezen?

which article has Jan your book and read

c. Jan heeft [[jouw boek gelezen] en [haar artikel bestudeerd]].

Jan has your book read and her article studied

'Jan has read your book and studied her article.'

$\mathrm{c}^{\prime}$. *Welk boek $\mathrm{k}_{\mathrm{i}}$ heeft Jan [[ $t_{\mathrm{i}}$ gelezen] en [haar artikel bestudeerd]]?

which book has Jan read and her article studied

$\mathrm{c}^{\prime \prime} .{ }^{*}$ Welk artikel ${ }_{\mathrm{i}}$ heeft Jan [[jouw boek gelezen] en $\left[t_{\mathrm{i}}\right.$ bestudeerd]]? which article has Jan your book read and studied

Note in passing that the primed examples are also unacceptable when the wh-phrase remains in situ, as is clear from the fact that example (150a), in which the coordinate structure remains in its base position, and example (150b), in which the coordinate structure is $w h$-moved into clause-initial position, are both unacceptable. This shows that coordination of interrogative and non-interrogative phrases is always unacceptable unless we are dealing with echo-interpretation: cf. Jan heeft jouw boek en WAT gelezen? 'Jan has read your book and what?'.

(150) a. *Jan heeft [jouw boek en welk artikel] gelezen?

Jan has your book and her article read

b. *[Jouw boek en welk artikel] heeft Jan gelezen? your book and which article has Jan read

\section{B. An apparent counterexample: "split" coordinate structures}

A potential counterexample against the coordinate structure constraint in (148) is given in (151), which suggests that it is possible in some cases to split coordinate structures by placing the coordinator and the coordinand following it (henceforth: [en/of/maar XP]) after the verbs in clause-final position.

(151) a. dat ik Marie en Jan gisteren ontmoette.

that I Marie and Jan yesterday met

'that I met and Jan Marie yesterday'

$\mathrm{a}^{\prime}$. dat ik Marie gisteren ontmoette, en Jan. that I Marie yesterday met and Jan

b. dat de directeur met zijn vader of zijn moeder gesproken heeft. that the principal with his father or his mother spoken has 'that the principal has spoken with his father or mother.'

$\mathrm{b}^{\prime}$. dat de directeur met zijn vader gesproken heeft, of zijn moeder. that the principal with his father spoken has or his mother 
c. dat deze leraar erg streng maar geliefd is. that this teacher very strict but popular is 'that this teacher is very strict but popular.'

$\mathbf{c}^{\prime}$. dat deze leraar erg streng is, maar geliefd. that this teacher very strict is but popular

The coordinate structure constraint predicts that the split pattern cannot be derived by movement and the following two subsections will show that there are indeed independent reasons for assuming that a movement approach is not viable. We will therefore argue in favor of an ellipsis approach, that is, we will suggest that we are dealing here with clausal coordinands with ellipsis in the second coordinand: example $\left(151 \mathrm{a}^{\prime}\right)$, for instance, is assigned the structure [[dat ik gisteren Marie ontmoette] en [Jan ], in which strikethrough indicates non-pronunciation.

\section{Leftward movement of first coordinand}

One might want to relate the primed and primeless examples in (151) to each other by movement. The first logically possible option would be to assume that the coordinate structure is base-generated to the right of the clause-final verb(s), and that the split pattern in the primed examples is derived from the same structure underlying the primeless examples by leftward movement of the first coordinand into preverbal position; cf. Johannessen (1998: Section 6.2). A serious problem facing this approach would be that the [en/of/maar XP] remnants in (151) surface in a position that normally does not allow for a direct object or a complementive, as is illustrated in (152).

(152) a. *dat ik gisteren ontmoette Jan. that I yesterday met Jan

b. *dat deze leraar is geliefd. that this teacher is popular

\section{Extraposition of the [en/of/maar XP] string}

The second logically possible option would be to assume that the coordinate structure is base-generated to the left of the clause-final verb(s) and that the [en/of/maar XP] string is extraposed while ${ }^{\circ}$ stranding the first coordinand; cf. Munn (1993:15). This proposal faces the problem that the presumed movement can only be rightward: deriving the topicalization structures in (153) from the primeless examples in (151) gives rise to unacceptable and, in fact, uninterpretable results; see also Zhang (2010: section 2.3.2), and references cited there.

(153) a. *En Jan ontmoette ik Marie gisteren. and Jan met I Marie yesterday

b. *Of zijn moeder heeft de directeur met zijn vader gesproken. or his mother has the principal with his father spoken

c. *Maar geliefd is deze leraar erg streng. but popular is this teacher very strict 
The ${ }^{\circ}$ extraposition approach also runs into various other problems with coordinate structures functioning as subjects (which, in fact, would probably also carry over to the first option under standard assumptions on agreement). First, if (154b) is derived from the same underlying structure as (154a), it remains unclear why the two structures differ in subject-verb agreement; cf. Neijt (1979) and De Vries \& Herringa (2008).

(154) a. dat Marie en Jan morgen op visite komen/*komt. that Marie and Jan tomorrow on visit come/comes 'that Marie and Jan will visit us tomorrow.'

b. dat Marie morgen op visite komt/*komen, en Jan. that Marie tomorrow on visit comes/come and Jan

Second, if (155b) were derived from the same underlying structure as (155a), it is also unclear why the reciprocal elkaar 'each other' cannot be licensed in (155b), as the supposed underlying form of both examples does satisfy the condition that the reciprocal has a plural antecedent.

(155) a. dat Els en Marie met elkaar discussiëren. that Els and Marie with each.other discuss 'that Els and Marie are arguing with each other.'

b. dat Els (*met elkaar) discussieert, en Marie. that Els with each.other discusses and Marie

A third problem is raised by examples such as (156) with a collective verbal expression such as ruzie hebben 'to argue'; while (156b) unambiguously expresses that both the boys and the girls are arguing, example (156a) is ambiguous in that it can also express that the boys are arguing with the girls. This meaning difference again suggests that the two examples do not have the same underlying structure.

(156) a. dat de jongens en de meisjes ruzie hebben.

that the boys and the girls an.argument have

'that the boys and the girls are having an argument.'

b. dat de jongens ruzie hebben, en de meisjes.

that the buys an.argument have and the girls

'that the boys are having an argument, and the girls.'

A fourth potential problem for a movement analysis is that "split" coordination is incompatible with the adverbial modifiers samen 'together' and beiden 'both' which disambiguate example (157a) with respect to the distributive/cumulative dichotomy. This suggests again that the two examples do not have the same underlying structure.

(157) a. Els en Marie hebben samen/beiden de rots opgetild.

Els and Marie have together/both the rock prt.-lifted

'Els and Marie have both lifted the rock/lifted the rock together.'

b. *Els heeft samen/beiden de rots opgetild, en Marie.

Els has together/both the rock prt.-lifted and Marie 
In fact, the examples in (158) show that split coordination is incompatible with the cumulative reading: while example (158a) does allow the reading that Els and Marie are collaborators, (158b) does not.

(158) a. dat Els en Marie een goed team vormen.

that Els and Marie a good team constitute

'that Els and Marie make a good team.'

b. dat Els een goed team ${ }^{*}$ vormt/*vormen, en Marie. that Els a good team constitutes/constitute and Marie

\section{Ellipsis accounts}

The two previous subsections have shown that split coordination cannot be derived by means of movement and thus does not constitute a counterexample against the coordinate structure constraint in (148). The conclusion must be that split coordination is base-generated: we are dealing with a construction with a clause functioning as the first coordinand: [clause en/of/maar XP]. The split and unsplit variant thus have structures of the kind given in (159).

(159) a. dat ik gisteren [Marie en Jan] gesproken heb.

[unsplit]

that I yesterday Marie and Jan spoken have

'that I talked with Marie and Jan yesterday.'

b. [[dat ik gisteren Marie gesproken heb] en [Jan]].

that I yesterday Marie spoken have and Jan

'that I talked with Marie yesterday, and Jan.'

One argument in favor of the base-generation approach can be based on the acceptability contrast found in (160). First, it is unclear how the movement approaches discussed earlier can account for the acceptability contrast between these two examples: why would leftward movement be restricted to a single coordinand, and why would rightward movement of the [en XP] sequence be allowed from a dyadic but not from a polyadic coordinate structure? Second, the acceptability contrast in (160) follows straightforwardly under the base-generation account, given that the first clausal coordinand in (160b) simply violates the distributional restriction on asyndetic coordinate structures that they cannot occur as clausal constituents. That this is the case is clear from the fact that the clause is also unacceptable without the "postverbal" [en XP] sequence: cf. *dat ik gisteren Els, Marie gesproken heb.

(160) a. dat ik gisteren Els, Marie en Jan gesproken heb

that I yesterday Els, Marie and Jan spoken have

'that I talked with Els, Marie and Jan yesterday.'

b. *[[dat ik gisteren Els, Marie gesproken heb] en [Jan]].

that I yesterday Els, Marie spoken have and Jan

Third, the data from the previous subsection on the extraposition approach receive a natural account in the base-generation approach: the examples in (161) are simply unacceptable because the clauses constituting the first coordinand are unacceptable by themselves: the clause in (161a) exhibits the wrong subject-verb agreement, the 
clause in (161b) does not contain a proper antecedent for the reciprocal elkaar, and the clauses in $(161 \mathrm{c} \& \mathrm{~d})$ do not have a subject suitable for licensing the adverbial modifiers or for satisfying the selection restriction of the verb vormen (in its the intended meaning "to constitute"); see also Chaves (2012:fn.2) and De Vries (2017:fn.6).

(161) a. *[[dat Marie morgen op visite komen], en [Jan]].

[agreement] that Marie tomorrow on visit comes and Jan

b. *[[dat Els met elkaar discussieert], en [Marie]]. that Els with each.other discusses and Marie

c. *[[Els heeft samen/beiden de rots opgetild], en [Marie]]. [modifiers] Els has together/both the rock prt.-lifted and Marie

d. " [[dat Els een goed team vormt], en [Marie]]. that Els a good team constitutes and Marie

[selection]

If split coordinate structures really have the form [clause en/of/maar XP], the question should be raised what XP is. Since the co-occurrence restrictions on coordinands discussed in Subsection I require that the coordinands following en are clauses (or perhaps some smaller verbal projections), we would like to suggest that $\mathrm{XP}$ is an ellipsis remnant of these clausal coordinands. That is, we would be dealing with clausal coordination [[clause $W X P Z]$ en/of/maar [clause YP Z]], where the strings $\mathrm{W}$ and $\mathrm{Z}$ are elided in the second clause under identity with the same strings in the first clause. This in fact revives Cremer's (1993: section 2.5.1) conclusion that examples such as (162b) must be biclausal because they must be construed as referring to two separate events. Recall that an example such as (162a) is ambiguous in this respect: it refers to two separate events when the conjunction Jan en Peter is interpreted distributively but to a single event when it is interpreted comulatively.

(162) a. Marie heeft daarna Jan en Peter opgebeld.

Marie has aftter.that Jan and Peter prt.-called

'Marie phoned Jan and Peter after that.'

b. Marie heeft daarna Jan opgebeld, en Peter.

Marie has aftter.that Jan prt.-called and Peter

[two events]

'Marie phoned Jan and Peter after that.'

Evidence in favor of the ellipsis approach can also be provided by so-called specifying coordination constructions such as given in (163); cf. Kraak \& Klooster (1972:259). Examples like these are special in that the coordinator en 'and' does not have its prototypical meaning contribution: (163a) does not express that Jan has bought a dog and a poodle (two separate entities), but that he has bought a dog, which is a poodle (one entity); and (163b) does not express that Jan went downstairs and to the cellar (two separate events), but that he went downstairs, that is, to the cellar (one event). In short, the [en wel XP] phrases provide a specification of the denotation of some phrase mentioned earlier. 
(163) a. Jan heeft een hond gekocht, en wel een poedel.

Jan has a dog bought and PRT a poodle

'I have bought a dog, a poodle.'

b. Jan is naar beneden gegaan, en wel naar de kelder.

Jan is to downstairs gone and PRT to the cellar

'Jan has gone downstairs, to the cellar.'

Kraak \& Klooster suggest that the examples in (163) are of a similar kind as those in (164), in which [en wel XP] provides a further specification of the denotation of the VP in the preceding clause. The crucial point here is that the [en wel XP] phrases in (164) are clearly not base-generated as part of a coordinate structure embedded within the clause, as the clauses do not contain any constituent that could function as the first coordinand of such a presumed coordinate structure.

(164) a. De jongens zijn vertrokken, en (wel) vroeg.

the boys are left, and PRT early

'The boys have left, early.'

b. De jongens zijn aan het dansen, en wel met elkaar.

the boys are AAN HET dance and PRT with each.other

'The boys are dancing, with each other.'

For this reason, the co-occurrence restrictions on coordinands in (124) entail that the phrases following en are reduced clauses (or some smaller verbal projections) and that the structures of (163a) and (164a) should therefore be as indicated in (165); cf. De Vries (2006/2009). Note in passing that we have placed the ${ }^{\circ}$ particle wel in a position external to the second coordinand for convenience but that this requires more argumentation and might well be wrong.

(165) a. [[Ik heb een hond gekocht] en wel [1 een poedel ]

I have a dog bought and PRT I have a poodle bought

b. [[De jongens zijn vertrokken] en wel [dejons ajjn vroeg the boys are left, and PRT the boys are early left

The analysis in (165) also accounts for the fact that the [en wel XP] phrases cannot easily be placed in preverbal position. The (a)-examples in (166) show that this is relatively acceptable in examples like those in (163), but only if [en XP] is parenthetical, that is, preceded and followed by an intonation break. The (b)examples in (166) show that this is straightforwardly impossible for the examples in (164); these are only acceptable if the coordinator is dropped.

(166) a. ${ }^{(?)}$ Ik heb een hond -en wel een poedel- gekocht.

I have a dog and PRT a poodle bought

$\mathrm{a}^{\prime}$. (?) Jan is naar beneden -en wel naar de kelder- gegaan.

Jan is to downstairs and PRT to the cellar. gone

b. De jongens zijn (*en wel) vroeg vertrokken.

the boy are and PRT early left

$b^{\prime}$. De jongens zijn (*en wel) met elkaar aan het dansen.

the boys are and PRT with each.other AAN HET dance 
If we are indeed dealing with reduced clauses in split coordination constructions, the phonetic reduction may be of similar kind as found in the gapping constructions discussed in Section 2.2 and/or fragment clauses discussed in Section V5.1; see Johannessen (1998: section 6.3.2), Schwarz (1999), and Zhang (2010: section 2.3.2), and the references cited there. We will return to this issue in Section 2.2, and provisionally conclude for the moment that apparent cases of "split" coordination cannot be used to refute the coordinate structure constraint in (148).

\section{More potential counterexamples: asymmetrical coordination}

It has been stated that in certain forms of so-called asymmetrical coordination it is possible to violate the part of the coordinate structure constraint prohibiting extraction of a phrase from a single coordinand. A prototypical case for English is given in (167b), which seemingly allows wh-movement from the second (but not from the first) coordinand.

(167) a. John [[went to the store] and [bought some ice cream]].

b. What ${ }_{i}$ did John [[go to the store] and [buy $\left.\left.t_{i}\right]\right]$ ?

Example (168b) shows that similar examples are definitely impossible in Dutch. This strongly suggests that Ross (1967: section 4.2.3) and Schmerling (1975) are correct in arguing that the examples in (167) are cases of "fake" coordination, although this has remained a topic of debate until the present day; we refer the reader to Zhang (2010: section 5.3) for a concise review and references.

(168) a. Jan heeft [[het museum bezocht] en [een mooi schilderij gezien]]. Jan has the museum visited and a beautiful painting seen

b. ${ }^{*}$ Wat $_{\mathrm{i}}$ heeft Jan [[het museum bezocht] en [ $t_{\mathrm{i}}$ gezien]]. what has Jan the museum visited and seen

$\mathrm{b}^{\prime} .{ }^{*} \mathrm{Wat}_{\mathrm{i}}$ heeft Jan $\left[\left[t_{\mathrm{i}}\right.\right.$ bezocht] en [een mooi schilderij gezien $\left.]\right]$. what has Jan visited and beautiful painting seen

Section 1.4.1, sub IC, will show, however, that Dutch has various other types of asymmetrical coordination, which express a special semantic (causal, concessive, etc.) relation between the first and second coordinand. Van der Heijden (1999:65) has claimed that some of these cases also allow extraction of a phrase from a single coordinand. One example (adapted from her work) is (169b); the percentage sign in (169b) is used to indicate that some speakers (including ourselves) do not consider this example acceptable.

(169) a. Jan kan 50 eieren eten en toch niet ziek worden. Jan is.able 50 eggs eat and PRT not ill become 'Jan can eat 50 eggs without getting ill.'

b. ${ }^{\%}$ Hoeveel eieren $n_{\mathrm{i}}$ kan je $t_{\mathrm{i}}$ eten en toch niet ziek worden? how many eggs can one eat and still not sick get 'How many eggs can one eat without getting ill?'

It is not quite evident that examples such as (169b) should be considered counterexamples to the coordinate structure constraint because their internal structure is not clear. First, the presupposition that we are dealing with some sort of 
VP-coordination is problematic because it does not seem to be possible to construe the root (deontic) modal kunnen 'to be able' in the examples in (169) with the second coordinand, as is clear from the fact that the modal verb in (170a) preferably receives an epistemic reading. Second, De Vries (2005) notes that extraction is only possible from the first coordinand: the fact that examples such as (170b) cannot be derived from (169a) would be surprising if the coordinate structure constraint did not apply to asymmetrical coordinate structures.

(170) a. Jan/Je kan daardoor toch niet ziek worden. Jan/one can by that PRT not ill become 'Jan/One cannot get ill because of that.'

b. *Wat $t_{\mathrm{i}}$ kan Jan 50 eieren eten en toch niet $t_{\mathrm{i}}$ worden? what can Jan 50 eggs eat and still not become Literally: 'What can Jan eat 50 eggs and still not become?'

De Vries (2005) suggests a third type of potential counterexample, which is based on a construction known in the Dutch literature as BALANSSCHIKKING, which will be discussed more extensively in Section 1.4.1, sub IID. Consider example (171a) in which the first coordinand modifies the second conjunct in the way indicated by the English translation. De Vries adopts the controversial, but possibly correct, position that we are dealing with normal disjunction and claims that $w h$-extraction from the first coordinand is acceptable. For the sake of the argument we will take for granted that (171b) is grammatical although some informants (including ourselves) reject such examples, as is indicated by the percentage sign.

(171) a. Jan had het boek nog niet gekregen of hij gaf het weg. Jan had the book yet not received or he gave it away 'Jan gave away the book immediately after he received it.'

b. ${ }^{\%} \mathrm{Wat}_{\mathrm{i}}$ had Jan nog niet $t_{\mathrm{i}}$ ontvangen of hij gaf het weg? what had Jan yet not received or he gave it away Intended: 'What did Jan give away immediately after he received it?'

It should be noted, however, that example (171b) is not a counterexample to the coordinate structure constraint because we are dealing with coordination of two main clauses and wh-movement targets the first position of the first main clause. Or, to put it differently, we are dealing with a disjunction of an interrogative and a declarative main clause (which may be the reason why some informants reject this example; cf. Section 1.4.1, sub IIA). The structure of (171b) is thus as given in (172), which does not violate the coordinate structure constraint.

$$
\begin{aligned}
& \text { [[Wat } \mathrm{t}_{\mathrm{i}} \text { had Jan nog niet } t_{\mathrm{i}} \text { ontvangen] of [hij gaf het weg]]? } \\
& \text { what had Jan yet not received or he gave it away } \\
& \text { 'What did Jan give away immediately after he received it?' }
\end{aligned}
$$

This analysis also accounts for the fact noted by De Vries that similar "extraction" is impossible from the second coordinand: the only way to derive *Wat $t_{\mathrm{i}}$ was Jan nog niet thuis of hij gaf Marie $t_{\mathrm{i}}$ from (173a) is by moving the wh-object of the second clausal coordinand clause into the initial position of the first clausal coordinand, which is not allowed for independent reasons. 
(173) a. [Clause Jan was nog niet thuis] of [Clause hij gaf Marie het boek]. Jan was yet not home or he gave Marie the book 'Jan gave Marie the book immediately after he came home.'

b. *[Clause Wat ${ }_{i}$ was Jan nog niet thuis] of [Clause hij gaf Marie $t_{i}$ ]. what was Jan yet not home or he gave Marie

This subsection has discussed some potential violations of the coordinate structure constraint involving asymmetrical coordination. The first case can only be demonstrated for English and has been argued to involve "fake" coordination. The second case is found both in English and in Dutch (although not all Dutch speakers accept it) but it is unclear whether we are truly dealing with run-of-the-mill coordination. The third case (also rejected by some speakers) is found in so-called BALANSSCHIKKING constructions but was shown to be irrelevant, as it seems to be based on the wrong presupposition that the movement targets a position external to the first coordinand. We therefore conclude that $w h$-movement in asymmetrical coordination does not provide conclusive evidence against the coordinate structure constraint.

\section{Across-the-board movement}

A well-known exception to the coordinate structure constraint is so-called ACROSSTHE-BOARD MOVEMENT: extraction from a coordinate structure is possible if movement is applied in such as way that it affects the same type of constituent in all coordinands. A characteristic example is given in (174a), in which the wh-phrase welk boek 'which book' is related to the two interpretative gaps indicated by $t_{\mathrm{i}}$, which function as the direct object of the first and the second coordinand, respectively. The (b)-examples give the corresponding examples in which the movement is not applied in an across-the-board fashion for comparison. Detailed discussions of across-the-board movement can be found in, e.g., Ross (1967), Williams (1978), and De Vries (2017), and references cited there.

(174) a. Welk boek ${ }_{\mathrm{i}}$ heeft [[Jan $t_{\mathrm{i}}$ gelezen $]$ en [Els $t_{\mathrm{i}}$ bestudeerd]]? which book has Jan read and Els studied 'Which book has Jan read and Els studied?'

b. *Welk boek ${ }_{\mathrm{i}}$ heeft [[Jan $t_{\mathrm{i}}$ gelezen] en [Els het artikel bestudeerd]]? which book has Jan read and Els the article studied

$\mathrm{b}^{\prime} .{ }^{*}$ Welk boek $\mathrm{i}_{\mathrm{i}}$ heeft [[Jan het artikel gelezen] en [Els $t_{\mathrm{i}}$ bestudeerd]]? which book has Jan the article read and Els studied

It should be noted that across-the-board movement of the full coordinands themselves, as in (175b), is not possible. This should not be seen as an exception to across-the-board movement, however, because this may be due to the independently established fact that the coordinands in a coordinate structure cannot be identical in the prototypical case; examples such as (175a) are impossible if the two proper nouns refer to the same individual. The unacceptability of (175b) is thus related to the fact that the answer to this question will identify a unique girl functioning as the "filler" of the two interpretative gaps, so that providing the answer Marie will result in a representation similar to the one assigned to (175a). 


\section{(175) a. ${ }^{\$} \mathrm{Ik}$ heb gisteren [Marie en Marie] bezocht. \\ I have yesterday Marie and Marie visited 'I visited Marie and Marie yesterday.' \\ b. *Welk meisje $\mathrm{i}_{\mathrm{i}}$ heb jij gisteren $\left[t_{\mathrm{i}}\right.$ en $\left.t_{\mathrm{i}}\right]$ bezocht. which girl have you yesterday and visited}

This account of the unacceptability of (175b) receives more support from the fact that question (174a) presupposes that there is a unique book that was read by Jan and studied by Els. It should be noted, however, that De Vries (2017) claims that the presupposition of uniqueness need not always be present in the case of acrossthe-board movement. This holds especially for examples such as (176), in which the moved phrase contains an anaphor like zichzelf 'him/herself'. Speakers who accept such examples require a so-called sloppy reading of the reflexive zichzelf: zichzelf is construed as co-referential with, respectively, Jan and Marie. Since the acceptability judgments on examples such as (176) are not very clear and seem to vary from speaker to speaker, we will not dwell on this any further.

$$
\begin{aligned}
& { }^{\%}\left[\text { Welk schilderij van zichzelf }{ }_{\mathrm{j} \text { resp k }}\right]_{\mathrm{i}} \text { heeft } \\
& \text { which picture of REFL } \\
& {\left[\mathrm{Jan}_{\mathrm{j}} t_{\mathrm{i}} \text { gekocht] en [Marie }{ }_{\mathrm{k}} t_{\mathrm{j}}\right. \text { geschilderd]]? }} \\
& \mathrm{Jan} \text { bought and Marie painted }
\end{aligned}
$$

The following subsections will investigate across-the-board movement in greater detail but first it should be noted that this type of movement is not restricted to coordinate structures with two coordinands. The examples used for illustration will generally involve coordinate structures with two coordinands for reasons of simplicity, but the reader should keep in mind that across-the-board movement can also apply to coordinate structures with three (or more) coordinands; we illustrate this in example (177).

(177) a. Welk boek $k_{\mathrm{i}}$ heeft [[Jan $t_{\mathrm{i}}$ gelezen] en [Els $t_{\mathrm{i}}$ bestudeerd]]? which book has Jan read and Els studied

'Which book has Jan read and Els studied?'

b. Welk boek $\mathrm{i}_{\mathrm{i}}$ heeft [[Jan $t_{\mathrm{i}}$ gelezen], [Els $t_{\mathrm{i}}$ bestudeerd], [Peter $t_{\mathrm{i}}$ which book has Jan read Els studied Peter geannoteerd] en [Marie $t_{\mathrm{i}}$ samengevat]]? annotated and Marie summarized

'Which book has Jan read, Els studied, Peter annotated, and Marie summarized?'

We will further follow the general practice of restricting our attention mainly to conjunctions with en 'and': again, the reader should keep in mind that across-theboard movement is also possible in disjunctions with of 'or' and in adversative conjunctions with maar 'but'; this is illustrated in (178). 
(178) a. [Over ATB $]_{\mathrm{i}}$ kan [[ik een lezing $t_{\mathrm{i}}$ geven] of [Jan een artikel $t_{\mathrm{i}}$ schrijven]]. about ATB can I a talk give or Jan an article write 'I can give a talk on ATB, or Jan can write an article about it.'

$\mathrm{a}^{\prime}$. Daar ${ }_{\mathrm{i}}$ kan [[ik een lezing over $t_{\mathrm{i}}$ geven] of [Jan een artikel over $t_{\mathrm{i}}$ schrijven]]. there can I a talk about give or Jan an article about write 'I can give a talk about that or Jan can write an article about it.'

b. [Over ATB $]_{\mathrm{i}}$ wil ik [[een lezing $t_{\mathrm{i}}$ geven] maar [geen artikel $t_{\mathrm{i}}$ schrijven]]. about ATB want I a talk give but no article write

'I am willing to give a talk on ATB but not to write an article on it.'

$\mathrm{b}^{\prime} . \quad$ Daar ${ }_{\mathrm{i}}$ wil ik [[een lezing over $t_{\mathrm{i}}$ geven] maar [geen artikel over $t_{\mathrm{i}}$ schrijven]]. there want I a talk about give but no article about write 'I am willing to give a talk on that but not to write an article on it.'

\section{Across-the-board movement is indeed movement}

The fact that $w h$-questions such as (179b) differ from regular $w h$-questions such as (179a) in that a single $w h$-phrase is associated with more than one interpretative gap might suggest that we are not dealing with movement from a coordinate structure but with some other (interpretative) mechanism.

(179) a. Welk boek $\mathrm{i}_{\mathrm{i}}$ heeft Jan $t_{\mathrm{i}}$ gelezen?

which book has Jan read

b. Welk boek $\mathrm{i}_{\mathrm{i}}$ heeft [[Jan $t_{\mathrm{i}}$ gelezen] en [Els $t_{\mathrm{i}}$ bestudeerd]]? which book has Jan read and Els studied

For instance, one might assume that the interpretative gaps are not movement ${ }^{\circ}$ traces but phonetically empty deictic elements: after all, examples such as (180a) show that one phrase can easily function as the antecedent of more than one (occurrence of a) deictic element such as hij 'he'. However, this approach would not account for the fact that the relation between the $w h$-phrase and the interpretative gap must be established in an across-the-board fashion in questions such as (179b), because the (b)-examples in (180) show that this does not hold for the deictic relation between an overt pronoun and its antecedent.

$\operatorname{Jan}_{\mathrm{i}}$ vertelde me $\ldots$

Jan told me

a. [[dat hij $\mathrm{j}_{\mathrm{i}}$ ziek was] maar [dat hij (toch) zou komen]]. that he ill was but that he nevertheless would come

'Jan told me that he was ill but that he would come (nevertheless).'

b. [[dat Marie ziek was] maar [dat hij $\mathrm{j}_{\mathrm{i}}$ zou komen]]. that Marie ill was but that he would come

'Jan told me that Marie was ill but that he would come.'

$\mathrm{b}^{\prime}$. [[dat hij $\mathrm{j}_{\mathrm{i}}$ ziek was] maar [dat Marie zou komen]]. that he ill was but that Marie would come 'Jan told me that he was ill but that Marie would come.'

Furthermore, the alternative approach would not account either for the fact that the relation between the $w h$-phrase and the interpretive gaps within coordinate 
structures can be blocked by uncontroversial islands for movement. First consider the acceptable cases of long $w h$-movement in the examples in (181).

(181) a. Wat ${ }_{i}$ denk je $\left[t^{\prime}{ }_{i}\right.$ dat Jan $t_{\mathrm{i}}$ gekocht heeft $]$ ?

what think you that Jan bought has

'What do you think that Jan has bought?'

b. Wat ${ }_{\mathrm{i}}$ denk je $\left[t^{\prime}{ }_{\mathrm{i}}\right.$ dat Els $t_{\mathrm{i}}$ geleend heeft]?

what think you that Els borrowed has

'What do you think that Els has borrowed?'

c. Wat ${ }_{\mathrm{i}}$ denk je $\left[t^{\prime}{ }_{\mathrm{i}}\right.$ dat [[Jan $t_{\mathrm{i}}$ gekocht] en [Els $t_{\mathrm{i}}$ geleend] $]$ heeft $]$ ? what think you that Jan bought and Els borrowed has 'What do you think that Jan has bought and Els has borrowed?'

In all the examples in (181) long wh-movement may proceed via the initial position of the embedded clause, thereby satisfying the independently established fact that wh-movement is normally clause-bound and can escape from its own clause only via the clause-initial position (SpecCP) of the embedded clause; cf. Section V11.3.1.2. Now consider the unacceptable examples in (182) in which the matrix verb weten 'to know' selects a dependent wh-question: Jan weet [wie dat boek gekocht/geleend heeft] 'Jan knows who has bought/borrowed that book.' Since the initial position of the embedded clause is already occupied by the wh-subject wie 'who', it is no longer accessible to the wh-object wat 'what', which correctly predicts that long $w h$-movement is excluded in $(182 \& \mathrm{~b})$.

(182) a. *Wat i $_{\mathrm{i}}$ weet Jan [wie $t_{\mathrm{i}}$ gekocht heeft]?

what knows Jan who bought has

b. *Wat $t_{\mathrm{i}}$ weet Jan [wie $t_{\mathrm{i}}$ geleend heeft]?

what knows Jan who borrowed has

The crucial thing is that the same holds for cases in which the interpretative gaps are part of a coordinate structure: example (183b) is just as deviant as the two examples in (182). This would follow immediately if the wh-phrase is associated with these gaps by means of movement, but would not be expected if the interpretative gaps were empty deictic elements related to the $w h$-phrase by some other means.

(183) a. Jan weet [[wie het boek gekocht heeft] en [wie het geleend heeft]]. Jan knows who the book bought has and who it borrowed has 'Jan knows who has bought the book and who has borrowed it.'

b. *Wat $t_{\mathrm{i}}$ weet Jan [[wie $t_{\mathrm{i}}$ gekocht heeft] en [wie $t_{\mathrm{i}}$ geleend heeft]]? what knows Jan who bought has and who borrowed has

In (183) the two coordinands act as islands, but we see the same effect if one of the coordinands contains an island for movement; the unacceptability of (184b) can be attributed to the fact that the second ${ }^{\circ}$ trace is contained by a relative clause, and $w h$ movement from such clauses is always impossible.

(184) a. Hij bewondert [[dit boek] en [de schrijver [die het geschreven heeft]]]. he admires this book and the writer REL it written has 'He admires this book and the writer who wrote it.' 
b. *Welk boek ${ }_{\mathrm{i}}$ bewondert hij $\left[t_{\mathrm{i}}\right.$ en [de schrijver [die $t_{\mathrm{i}}$ geschreven heeft]]]? which book admires he and the writer REL written has Compare: 'Which book does he admire and the writer who has written?'

The facts in (183b) and (184b) showing that across-the-board movement is sensitive to islands clearly support the standard assumption that we are dealing with regular movement.

\section{All movement types can be applied across-the-board}

Subsection D has illustrated that across-the-board movement is easily possible in the case of $w h$-movement. But it is also possible with other types of ${ }^{\circ} \mathrm{A}^{\prime}$-movement. We illustrate this in (185) for topicalization and relativization; the strikethrough indicates non-pronunciation due to backward conjunction reduction; we return to this phenomenon in Section 2.1.

(185) a. Dit boek $\mathrm{i}_{\mathrm{i}}$ heeft [[Jan $t_{\mathrm{i}}$ gelezen] en [Els $t_{\mathrm{i}}$ bestudeerd]].

this book has Jan read and Els studied

'This book, Jan has read and Els has studied.'

b. Dit is het boek $\mathrm{i}_{\mathrm{i}}$ [dat $\mathrm{d}_{\mathrm{i}}$ [Jan $t_{\mathrm{i}}$ gelezen en [Els $t_{\mathrm{i}}$ bestudeerd heeft]]]? this is the book REL Jan read has and Els studied has

'This is the book which Jan has read and Els has studied.'

Across-the-board movement is also possible in the case of A-movement, as is illustrated in $\left(186 \mathrm{a}^{\prime}\right)$ for passivization and in (186b) for ${ }^{\circ}$ subject raising.

(186) a. Jan heeft [[de auto gekocht] en [hem direct doorverkocht]].

Jan has the car bought and him directly prt.-resold

'Jan has bought the car and resold it immediately.'

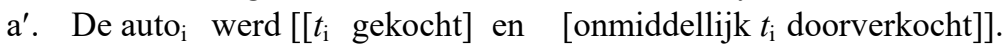

the car was bought and immediately prt.-resold

'The car was bought and resold immediately.'

b. $\operatorname{Jan}_{\mathrm{i}}$ bleek [[те $t_{\mathrm{i}}$ ziek te zijn] en [ $t_{\mathrm{i}}$ daardoor niet te kunnen komen]]. Jan turned.out ill to be and for.that.reason not to be.able come 'Jan turned out be ill and not to be able to come for that reason.'

The examples in $(187 \mathrm{a} \& \mathrm{~b})$ show that ${ }^{\circ}$ scrambling can also be applied across-theboard, regardless of whether it is of the A-type discussed in Section V13.2 or of the $\mathrm{A}^{\prime}$-type discussed in Section V13.4. Example (187c) is a case of ${ }^{\circ} \mathrm{R}$-extraction.

(187) a. Jan heeft de auto ${ }_{i}\left[\right.$ gisteren $\left[t_{\mathrm{i}}\right.$ gekocht]] en [direct [ $t_{\mathrm{i}}$ doorverkocht $\left.]\right]$. Jan has the car yesterday bought and directly prt.-sold 'Jan bought the car yesterday and resold it immediately.'

b. Jan heeft hem h $\left[\right.$ gisteren $\left[t_{\mathrm{i}}\right.$ gekocht $\left.]\right]$ en [direct $\left[t_{\mathrm{i}}\right.$ doorverkocht $\left.]\right]$. Jan has him yesterday bought and directly prt.-sold 'Jan bought it yesterday and resold it immediately.'

c. Ik wil er $\mathrm{r}_{\mathrm{i}}$ [[een lezing over $t_{\mathrm{i}}$ geven] en [een artikel over $t_{\mathrm{i}}$ schrijven]]. I wants there a talk about give and an article about write 'I want to give a talk about it and write an article about it.' 
Section V13.3.1 has established that so-called negation movement is obligatory in Dutch. Example (188) therefore shows that $\mathrm{A}^{\prime}$-movement that targets a position in the ${ }^{\circ}$ middle field of the clause can also be applied in an across-the-board fashion.

(188) a. Jan heeft niets $s_{\mathrm{i}}\left[\left[t_{\mathrm{i}}\right.\right.$ gezien $]$ of $\left[t_{\mathrm{i}}\right.$ gehoord $\left.]\right]$.

Jan has nothing seen or heard

'Jan hasn't seen or heard anything.'

b. Jan is nergens $\mathrm{i}_{\mathrm{i}}$ [[bang [voor $\left.t_{\mathrm{i}}\right]$ ] of [zenuwachtig [over $\left.\left.\left.t_{\mathrm{i}}\right]\right]\right]$. Jan is nowhere afraid for or nervous about 'Jan isn't afraid of or nervous about anything.'

Example (189a) suggests that ${ }^{\circ}$ verb-second can also be applied across-the-board. A potential problem is that a similar sequence of words could also arise by ellipsis, more specifically, the process of ${ }^{\circ}$ gapping discussed in Section 2.2; the structure resulting from gapping is given in (189b) with strikethrough indicating elision.

(189) a. Morgen koopt $t_{\mathrm{i}}$ [[Marie een boek $\left.t_{\mathrm{i}}\right]$ en [Jan een CD $\left.t_{\mathrm{i}}\right]$ ].

tomorrow buys Marie a book and Jan a CD

'Tomorrow, Marie will buy a book and Jan will buy a CD.'

b. [[Morgen koopt $\mathrm{i}_{\mathrm{i}}$ MARIE een BOEK] en [AN een CD]]. tomorrow buys Marie a book and tomorrow buys Jan a CD 'Tomorrow, Marie will buy a book and Jan a CD.'

It should be observed, however, that the two examples in (189) differ in prosody: while the nominal gapping remnants in the second coordinand of (189b) must be pronounced with contrastive accent, indicated by small caps, the corresponding nominal phrases in (189a) are normally pronounced in a more neutral way. It therefore seems safe to conclude that verb-second can be applied in an across-theboard fashion.

\section{Replacement test}

The previous subsections have shown that across-the-board movement out of coordinate structures is possible, which strongly suggests that we cannot account for the coordinate structure constraint by appealing to the independently motivated locality restrictions on movement. This raises the question as to why the primed examples in (149), repeated here as (190a\&b), are unacceptable. The reason for this can be found in the independently established co-occurrence restrictions on coordinands in (124), according to which the coordinands are generally able to replace the coordinate structure as a whole (unless this is blocked for independent reasons). In (190a) the first coordinand (the ${ }^{\circ}$ trace) is able to do this but the second coordinand is not, as illustrated by the primed examples. The same holds for (190b): the primed examples show that the first coordinand (containing the trace) is able to replace the coordinate structure as a whole but the second coordinand is not.

(190) a. *Welk boek ${ }_{\mathrm{i}}$ heeft Jan $\left[t_{\mathrm{i}}\right.$ en haar artikel] gelezen?

which book has Jan and her article read

$\mathrm{a}^{\prime}$. Welk boek $\mathrm{i}_{\mathrm{i}}$ heeft Jan $t_{\mathrm{i}}$ gelezen?

$\mathrm{a}^{\prime \prime} .{ }^{*}$ Welk boek $\mathrm{k}_{\mathrm{i}}$ heeft Jan haar artikel gelezen? 
b. ${ }^{*}$ Welk boek $\mathrm{i}_{\mathrm{i}}$ heeft Jan [[ $t_{\mathrm{i}}$ gelezen $]$ en [haar artikel bestudeerd] $]$ ? which book has Jan read and her article studied

$\mathrm{b}^{\prime}$. Welk boek $\mathrm{k}_{\mathrm{i}}$ heeft Jan $t_{\mathrm{i}}$ gelezen?

$\mathrm{b}^{\prime \prime}$. *Welk boek $\mathrm{i}_{\mathrm{i}}$ heeft Jan haar artikel bestudeerd?

In short, the primeless examples in (190) are unacceptable for the same reason as the doubly primed examples: there are two noun phrases competing for the syntactic function of direct object of the verb gelezen/bestudeerd; cf., e.g., Goodall (1987:65). This problem does not arise in the case of across-the-board-movement: the two coordinands in (174a), repeated here as (191a), can both be used to replace the coordinate structure as a whole: they both contain a movement trace.

(191) a. Welk boek heeft [[Jan $t_{\mathrm{i}}$ gelezen] en [Els $t_{\mathrm{i}}$ bestudeerd]]? which book has Jan read and Els studied

'Which book has Jan read and Els studied?'

b. Welk boek $\mathrm{i}_{\mathrm{i}}$ heeft Jan $t_{\mathrm{i}}$ gelezen?

c. Welk boek $\mathrm{i}_{\mathrm{i}}$ heeft Els $t_{\mathrm{i}}$ bestudeerd?

The discussion above supports the claim that coordinate structures need not be islands in the technical sense that they block movement. Section V11.3 has argued that such islands may sometimes trigger ${ }^{\circ}$ pied piping of non-interrogative material in wh-questions: the examples in (192) show that, because the interrogative pronoun wiens 'whose' cannot be extracted from the object, the object is wh-moved as a whole.

(192) a. *Wiens $s_{\mathrm{i}}$ heb je $\left[t_{\mathrm{i}}\right.$ boek $]$ gekocht?

whose have you book bought

b. Wiens boek $\mathrm{k}_{\mathrm{i}}$ heb je $t_{\mathrm{i}}$ gekocht? whose book have you bought

'Whose book have you bought?'

If the unacceptability of (193a) were the result of some locality restriction that prohibits movement of the first coordinand, we would expect that the construction can be saved by pied piping of the non-interrogative part of the coordinate structure: cf. Ross (1967: (4.140)). Example (193b) shows, however, that this expectation is not borne out. The fact that the wh-phrase welk boek can neither ${ }^{\circ}$ strand nor ${ }^{\circ}$ piedpipe the non-interrogative part of the coordinate structure shows that the ungrammaticality of the examples in (193) does not pertain to wh-movement as such. This, in turn, supports the analysis in terms of co-occurrence restrictions on coordinands suggested above.

(193) a. *Welk boek ${ }_{\mathrm{i}}$ heeft Jan $\left[t_{\mathrm{i}}\right.$ en haar artikel] gelezen? which book has Jan and her article read

b. *[Welk boek en haar artikel $]_{\mathrm{i}}$ heeft Jan $t_{\mathrm{i}}$ gelezen? which book and her article has Jan read

\section{The coordinands are of the same of type}

We have claimed on the basis of example (174) that across-the-board movement is possible if the movement affects the same type of constituent in all coordinands 
without specifying how sameneness, that is, "being of the same type" should be interpreted. The examples in the previous subsection all involve direct objects and this suggests that the sameness of syntactic function may be the relevant notion, but it may also be the case that some more restrictive or looser notion is relevant; see De Vries (1992: section 2.2.3) for an early discussion.

A more restrictive notion of sameness involves the notion of ${ }^{\circ}$ thematic role (agent, theme, goal, etc.). That this notion is not relevant for across-the-board movement is clear from the fact that examples such as (194a) are fully acceptable. If sameness of thematic role were required, this example should be unacceptable: the gap in the first conjunct is the theme argument of the ${ }^{\circ}$ unaccusative verb komen 'to come', while the gap in the second coordinand is the agent of the transitive verb halen 'to fetch'. The same is clear from the fact that the subjects of active and passive clauses can be wh-moved across-the-board, as illustrated by (194b): the gap in the first coordinand is the agent of the transitive verb lezen 'to read', while the gap in the second coordinand is the non-agentive argument of the verb helpen 'to help'.

(194) Across-the-board movement of arguments with mixed thematic roles

a. $\mathrm{Wie}_{\mathrm{i}}$ wil $\left[\left[t_{\mathrm{i}}\right.\right.$ komen $]$ en $\left[t_{\mathrm{i}}\right.$ het boek halen $\left.]\right]$ ?

who wants come and the book fetch

'Who is willing to come and fetch the book?'

b. Wie $\mathrm{W}_{\mathrm{i}}$ wil $\left[\left[t_{\mathrm{i}}\right.\right.$ dit boek lezen $]$ en $\left[t_{\mathrm{i}}\right.$ daarbij geholpen worden $\left.]\right]$ ? who wants this book read and with.that helped be

'Who wants to read this book and be assisted with that?'

The acceptability of the examples in (194) would follow on the hypothesis that the gaps must have the same syntactic function (here: subject). Testing this hypothesis is not easy, however, because judgments sometimes waver. For instance, if the gaps must have the same syntactic function, we would expect examples such as (195b) to be fully unacceptable because the wh-pronoun wie 'who' functions as direct object in the first coordinand but as an indirect object in the second. However, many speakers seem to accept them, although judgments may differ from speaker to speaker; cf. De Vries (2017). The indices in the examples below are used in order to clarify the intended interpretations.

(195) a. Hij heeft [[Marie ${ }_{i}$ ontmoet] en [haar ${ }_{i}$ het boek gegeven]].

$[\mathrm{DO}+\mathrm{IO}]$ he has Marie met and her the book given

'He has met Marie and given her the book.'

b. ${ }^{\%} \mathrm{Wie}$ heeft hij $\left[\left[t_{\mathrm{i}}\right.\right.$ ontmoet $]$ en $\left[t_{\mathrm{i}}\right.$ het boek gegeven $\left.]\right]$ ? who has he met and the book given

'Who has he met and given the book?'

Before we can consider the question as to whether mixed subject-object cases are possible, we must note that across-the-board movement of subject is possible from coordinated main clauses, as is illustrated in (196). 
(196) a. [[ $\mathrm{Jan}_{\mathrm{i}}$ is hier geweest] en [hij $\mathrm{j}_{\mathrm{i}}$ heeft het boek meegenomen]]. [SU+SU] Jan is here been and he has the book prt.-taken

'Jan has been here and has taken the book with him.'

b. $\mathrm{Wie}_{\mathrm{i}}\left[\left[t_{\mathrm{i}}\right.\right.$ is hier geweest $]$ en $\left[t_{\mathrm{i}}\right.$ heeft het boek meegenomen $\left.]\right]$ ? who is here been and has the book prt.-taken

'Who has been here and has taken the book with him?'

We should also mention that examples such as (196b) raise problems of a theoretical nature. First, it is not likely that the finite auxiliary verbs occupy the positions indicated in (196b): since verb-second is obligatory in Dutch, we expect the auxiliaries to raise across the subject trace into the complementizer position. This would result in the structure indicated in (197), in which non-maximal projections (namely $C^{\prime \prime}$ 's) are coordinated, which may be excluded on general grounds. cf. Section 2.1, sub VI, for some relevant discussion.

$$
\left[{ }_{C P} \operatorname{wh}_{\mathrm{i}}\left[\left[\mathrm{C}^{\prime} \mathrm{V}_{\text {fin }}\left[t_{i} \ldots . .\right]\right] \text { en }\left[\mathrm{C}^{\prime} \mathrm{V}_{\text {fin }}\left[t_{\mathrm{i}} \ldots . .\right]\right]\right]\right]
$$

Second, we should note that example (196a) alternates with example (198a), which suggests that $w h$-movement does not have to apply in an across-the-board fashion, as in (196b), but can also apply in a run-of-the-mill fashion, as in (198b). Note, however, that $(198 \mathrm{a} \& \mathrm{~b})$ are also problematic in light of verb-second in that they raise similar problems as discussed for example (196b).

(198) a. Jan [[is hier geweest] en [heeft het boek meegenomen]].

Jan is here been and has the book prt.-taken

'Jan has been here and has taken the book with him.'

b. $\mathrm{Wie}_{\mathrm{i}}\left[t_{\mathrm{i}}\right.$ [[is hier geweest] en [heeft het boek meegenomen]]]. who is here been and has the book prt.-taken

'Who has been here and taken the book with him?'

We will not elaborate on these issues here but simply note that the problems they raise may be solved by adopting Rizzi's (1997) proposal that the CP-projection should be split into a larger number of functional projections. For the moment, we will simply assume an analysis of the type in (197), and concentrate on the question as to whether mixed cases with subjects are possible. As with (195), judgments on the $w h$-questions in (199) seem to differ from speaker to speaker, and it is not clear what the varying judgments indicate about the grammaticality of these examples. De Vries, for instance, suggests that they are grammatical and that the deviance is due to extraneous factors, but because he does not provide conclusive arguments in favor of this conclusion, we will leave this issue open.

(199) a. [[ $\mathrm{Jan}_{\mathrm{i}}$ is hier geweest] en [zij heeft hem $\mathrm{i}_{\mathrm{i}}$ gesproken]]. Jan is here been and she has him spoken 'Jan has been here and she has talked with him.'

$\mathrm{a}^{\prime}$. ${ }^{\%} \mathrm{Wie}_{\mathrm{i}}\left[\right.$ [is $t_{\mathrm{i}}$ hier geweest] en [heeft zij $t_{\mathrm{i}}$ gesproken]]? who is here been and has she spoken Compare: 'Who has been here and has she talked with?' 
b. [[Jan $n_{\mathrm{i}}$ is hier geweest] en [zij heeft hem $\mathrm{i}_{\mathrm{i}}$ dat boek gegeven]]. [SU+IO] Jan is here been and she has him that book given 'Jan has been here and she has given him that book.'

$\mathrm{b}^{\prime} .{ }^{\circ} \mathrm{Wie}_{\mathrm{i}}\left[\left[\right.\right.$ is $t_{\mathrm{i}}$ hier geweest] en [heeft zij $t_{\mathrm{i}}$ dat boek gegeven]]? who is here been and has she that book given Compare: 'Who has been here and has she given that book?'

Observe that the grammaticality judgments are perfectly clear in (200), in which the indirect object is realized as a PP. Across-the-board movement is excluded for all speakers due to fact that the wh-movement of wie is generally excluded from PPs; we should note that this shows again that we are truly dealing with movement and not with some other mechanism relating the $w h$-phrase and the interpretative gaps.

(200) a. [[ $\mathrm{Jan}_{\mathrm{i}}$ is hier geweest] en [zij heeft dat boek [pp aan hem $\left.{ }_{\mathrm{i}}\right]$ gegeven]]. Jan is here been and she has that book to him given 'Jan has been here and she has given him that book.'

b. ${ }^{*} \mathrm{Wie}_{\mathrm{i}}\left[\left[t_{\mathrm{i}}\right.\right.$ is hier geweest] en [heeft zij dat boek [pp aan $\left.t_{\mathrm{i}}\right]$ gegeven $\left.]\right]$ ? who is here been and has she that book to given

The discussion so far has shown that at least some speakers allow across-theboard movement of $w h$-phrases with different syntactic functions. One factor clearly affecting the judgments is that the $w h$-phrases do not have alternating case forms in Dutch: wie 'who', for instance, can be used in all relevant syntactic functions. That morphological case may affect the acceptability judgments is clear from the fact that topicalization of pronouns in an across-the-board fashion is excluded for all speakers of standard Dutch if it involves a subject and an object.

(201) a. $\quad \mathrm{Hij}_{\mathrm{i}}\left[\left[t_{\mathrm{i}}\right.\right.$ is hier geweest $]$ en $\left[t_{\mathrm{i}}\right.$ heeft het boek meegenomen $\left.]\right] . \quad$ [SU+SU] he is here been and has the book prt.-taken

'He has been here and has taken the book with him.'

b. ${ }^{\%}$ HeM heeft hij [[ $t_{\mathrm{i}}$ ontmoet $]$ en $\left[t_{\mathrm{i}}\right.$ het boek gegeven $\left.]\right]$. him has he met and the book given

Compare: 'HIM, he has met and given the book.'

c. ${ }^{*} \mathrm{HIJ} / \mathrm{Hem}\left[\left[\right.\right.$ is $t_{\mathrm{i}}$ hier geweest] en [heb ik $t_{\mathrm{i}}$ gesproken]]. he/him is here been and have I spoken Compare: 'He/Him has been here and have I talked to.'

d. *HiJ/HEm [[is $t_{\mathrm{i}}$ hier geweest] en [heb ik $t_{\mathrm{i}}$ dat boek gegeven]]. [SU+IO] he/him is here been and has I that book given Compare: 'He/Him has been here and have I given that book.'

So far we have considered various versions of the sameness restriction on acrossthe-board movement in morpho-syntactic terms The version appealing to the thematic roles of the interpretive gaps must be rejected because it is clearly too strict. The version appealing to the syntactic functions of the gaps would be descriptively adequate if we declared example (195b) and the primed examples in (199) to be ungrammatical, but too strict if declared them to be grammatical. The version appealing to morphological (case) form also depends on the status of these examples, as it would be too permissive if we deemed them ungrammatical. 
Although we cannot make a well-grounded choice between the syntactic and the morphological version of the sameness restriction on across-the-board movement, this the choice is important, as it may have repercussions for the formulation of the co-occurrence restriction on coordinands in (202), repeated from Subsection I.

(202) Co-occurrence restrictions on coordinands: Coordination is possible only if the coordinands can have the same syntactic function and occur in the same syntactic positions as the coordinate structure as a whole.

It has been argued that the gaps resulting from across-the-board movement may affect the semantic type of the coordinands, and that the current version of (202) in terms of sameness of syntactic functions of the gaps can be replaced more insightfully by a version couched in terms of sameness of the semantic types of the coordinands; see, e.g., Gazdar (1981), Schachter (1977) and Zamparelli (2011: section 3.2). Since it is unlikely that the semantic type of the coordinands is sensitive to the morphological form of the antecedent of the gaps, the semantic perspective on the co-occurrence restrictions on coordinands seems to be incompatible with the morphological version of the sameness restriction on acrossthe-board movement. The syntactic perspective on these restrictions, on the other hand, would be consistent with the morphological version by claiming that the moved phrase must simply have a morphological shape (case-form) consistent with the two gaps. This implies that determining the precise versions of the sameness restriction is important for establishing whether a formulation of the co-occurrence restriction in purely semantic terms would be tenable; we leave this issue for future research.

\section{Embedding/recursivity}

This subsection will argue that coordinate structures are hierarchically structured. In order to show this we have to consider coordinate structures with three or more coordinands, as in (203), which we will henceforth refer to as POLYADIC coordinate structures, in contrast to DYADIC coordinate structures with just two coordinands.

(203) a. Jan is [vriendelijk en intelligent en ijverig].

Jan is friendly and intelligent and diligent

b. Ik koop [een boek, een CD of een DVD].

I buy a book a CD or a DVD

'I will buy a book, a CD or a DVD.'

Although it is often assumed that polyadic coordinate structures with en 'and' in (203a) and of 'or' in (203b) have the "flat" structures in the primeless examples in (204), we cannot a priori exclude the possibility that such structures are hierarchically structured, as in the primed examples.
(204) a. [XP en YP en ZP]
$\mathrm{a}^{\prime}$. $\quad[\mathrm{XP}$ en [YP en ZP]]
b. [XP of YP of ZP]
$a^{\prime \prime}$. [[XP en YP] en ZP]
$b^{\prime}$. [XP of [YP of ZP]]
$b^{\prime \prime}$. [[XP of YP] of ZP] 
If the structures in the primed examples are really possible, we should conclude that coordinate structures are recursive in the sense that coordinate structures can be embedded in (that is, be used as a coordinand of) a larger coordinate structure. We might even go one step further by arguing that the availability of the "flat" structures in $(204 \mathrm{a} \& b)$ is only apparent; the illusion of flatness reflects the special property of the coordinators en 'and' and of 'or' that they are just like the logical connectives $\wedge$ and $\vee$ in that they exhibit the properties of ASSOCIATIVITY and COMMUTATIVITY, which will be discussed in Subsection A. We will argue in favor of the null hypothesis that all coordinators link two coordinands, and, consequently, that polyadic coordinate structures must be hierarchically organized. Then we will discuss a number of properties of polyadic coordinate structures related to their internal structure concerning word order, intonation and ambiguities. Finally, we will discuss a potential problem for the null hypothesis that all coordinators are twoplace connectives.

\section{A. Associativity and commutativity of conjunction and disjunction}

The logical connectives $\wedge$ and $\vee$ used for translating the coordinators en 'and' and of 'or' exhibit the COMMUTATIVITY property. This property refers to the fact that the order of the coordinands has no effect on the truth value; if the sentence Jan komt en/of Marie komt 'Jan is coming and/or Marie is coming' is true, this also holds for the sentence Marie komt en/of Jan komt; this is expressed by the two commutativity laws in (205).

- Commutative laws of conjunction and disjunction

a. Conjunction: $\varphi \wedge \psi \equiv \psi \wedge \varphi$

b. Disjunction: $\varphi \vee \psi \equiv \psi \vee \varphi$

Another property of the logical connectives $\wedge$ and $\vee$ is that they exhibit the property of ASSOCIATIVITY in (206). The property refers to the fact that the bracketing of polyadic conjunctions/disjunctions, which of course is the result of the order in which conjunction/disjunction applies, does not affect the truth value.

- Associative laws of conjunction and disjunction

a. $\quad((\varphi \wedge \psi) \wedge \chi) \equiv(\varphi \wedge(\psi \wedge \chi))$

b. $\quad((\varphi \vee \psi) \vee \chi) \equiv(\varphi \vee(\psi \vee \chi))$

The proof for the associative laws in (206) is given in the following two truth tables: Table 7 shows that the two formulas $((\varphi \wedge \psi) \wedge \chi)$ and $(\varphi \wedge(\psi \wedge \chi))$ are logically equivalent because they are both true only if the proposition $\varphi, \psi$ and $\chi$ are all true; Table 8 shows that $((\varphi \vee \psi) \vee \chi)$ and $(\varphi \vee(\psi \vee \chi))$ are equivalent because they are both false only if the propositions $\varphi, \psi$ and $\chi$ are all false. 
Table 7: Prooffor the associativity of multiple conjunctions

\begin{tabular}{||c|c|c||c|c||c|c||}
\hline$\varphi$ & $\psi$ & $\chi$ & $(\varphi \wedge \psi)$ & $(\psi \wedge \chi)$ & $((\varphi \wedge \psi) \wedge \chi)$ & $(\varphi \wedge(\psi \wedge \chi))$ \\
\hline \hline 1 & 1 & 1 & 1 & 1 & 1 & 1 \\
\hline 1 & 1 & 0 & 1 & 0 & 0 & 0 \\
\hline 1 & 0 & 1 & 0 & 0 & 0 & 0 \\
\hline 1 & 0 & 0 & 0 & 0 & 0 & 0 \\
\hline 0 & 1 & 1 & 0 & 1 & 0 & 0 \\
\hline 0 & 1 & 0 & 0 & 0 & 0 & 0 \\
\hline 0 & 0 & 1 & 0 & 0 & 0 & 0 \\
\hline 0 & 0 & 0 & 0 & 0 & 0 & 0 \\
\hline
\end{tabular}

Table 8: Proof for the associativity of multiple disjunctions

\begin{tabular}{||c|c|c||c|c|c|c||}
\hline$\varphi$ & $\psi$ & $\chi$ & $(\varphi \vee \psi)$ & $(\psi \vee \chi)$ & $((\varphi \vee \psi) \vee \chi)$ & $(\varphi \vee(\psi \vee \chi))$ \\
\hline \hline 1 & 1 & 1 & 1 & 1 & 1 & 1 \\
\hline 1 & 1 & 0 & 1 & 1 & 1 & 1 \\
\hline 1 & 0 & 1 & 1 & 1 & 1 & 1 \\
\hline 1 & 0 & 0 & 1 & 0 & 1 & 1 \\
\hline 0 & 1 & 1 & 1 & 1 & 1 & 1 \\
\hline 0 & 1 & 0 & 1 & 1 & 1 & 1 \\
\hline 0 & 0 & 1 & 0 & 1 & 1 & 1 \\
\hline 0 & 0 & 0 & 0 & 0 & 0 & 0 \\
\hline
\end{tabular}

In tandem, the commutative and associative laws account for the fact that reordering of the conjuncts/disjuncts in polyadic conjunctions/disjunctions does not affect the truth conditions either. This is illustrated in (207) for triadic conjunctions: the two primeless examples are logically equivalent on the basis of the associative law in (206a) and the primed examples are equivalent with the primeless examples on the basis of the commutative law in (205a). This shows that all six possible permutations are logically equivalent.
(207) a. $\quad((\varphi \wedge \psi) \wedge \chi)$
b. $(\varphi \wedge(\psi \wedge \chi))$
$\mathrm{a}^{\prime} . \quad((\psi \wedge \varphi) \wedge \chi)$
$\mathrm{b}^{\prime} .(\varphi \wedge(\chi \wedge \psi))$
$\mathrm{a}^{\prime \prime} . \quad(\chi \wedge(\varphi \wedge \psi))$
$\mathrm{b}^{\prime \prime} .((\psi \wedge \chi) \wedge \varphi)$

Since the bracketing of multiple conjunctions has no effect on the truth conditions, it is mostly left out (cf. Gamut 1991: Section 2.6), which leaves the impression of a "flat" semantic structure. This impression is of course strengthened by the fact that polyadic conjunctions and disjunctions can be reordered in any imaginable way without affecting the truth value. It is important to stress, however, that leaving out the bracketing is just for notational convenience; conjunction and disjunction are both defined as two-place connectives, so that strictly speaking the hierarchical notations in the last two columns of Table 7 and Table 8 are the only correct (and most explicit) ones. This can be supported by the fact that "mixed" cases, with both a conjunction and a disjunction, do not exhibit the property of associativity. This is 
illustrated in the following truth table: the shaded cells show that the formulas in the header of the last two columns are not equivalent.

Table 9: Proof for the non-associativity of "mixed" cases

\begin{tabular}{||c|c|c|c|c||c|c||}
\hline$\varphi$ & $\psi$ & $\chi$ & $(\varphi \wedge \psi)$ & $(\psi \vee \chi)$ & $((\varphi \wedge \psi) \vee \chi)$ & $(\varphi \wedge(\psi \vee \chi))$ \\
\hline 1 & 1 & 1 & 1 & 1 & 1 & 1 \\
\hline 1 & 1 & 0 & 1 & 1 & 1 & 1 \\
\hline 1 & 0 & 1 & 0 & 1 & 1 & 1 \\
\hline 1 & 0 & 0 & 0 & 0 & 0 & 0 \\
\hline 0 & 1 & 1 & 0 & 1 & 1 & 0 \\
\hline 0 & 1 & 0 & 0 & 1 & 0 & 0 \\
\hline 0 & 0 & 1 & 0 & 1 & 1 & 0 \\
\hline 0 & 0 & 0 & 0 & 0 & 0 & 0 \\
\hline
\end{tabular}

The discussion above has shown that polyadic conjunctions and disjunctions are hierarchically structured by definition. Since it is clearly desirable to assume that syntactic and semantic derivations proceed in parallel, as this would greatly simplify matching syntactic and semantic structures, we conclude that the null hypothesis should be that "flat" coordinate structures of the type in (208a) do not exist. In short: syntactic coordinators are all two-place linkers, just like their corresponding logical connectives, which gives rise to hierarchical structures such as given in $(208 \mathrm{~b} \& \mathrm{c})$.

(208) a. * * XP en YP en ZP]

b. [XP en [YP en ZP]]

c. $[[\mathrm{XP}$ en $\mathrm{YP}]$ en $\mathrm{ZP}]$

Before leaving the matter of coordinators and coordinands, we want to point out that we will treat cases with clausal and non-clausal coordinands in terms of proposition calculus with respect to the commutative and commutative laws in (205) and (206). Strictly speaking, this is not correct, as the cases with non-clausal coordinands should be phrased in terms of predicate calculus, but it is relatively innocuous if we construe the two laws in terms of the entailments of coordinate structures. This is shown for the commutative laws by the examples in (209): the two (a)-examples both entail that the sentences Jan komt and Marie komt are both true, regardless the actual order of the coordinands; the two (b)-examples both entail that at least one of the sentences Jan komt and Marie komt is true, again regardless of the actual order of the coordinands.

(209) a. [[Jan komt] en [Marie komt]]. Jan comes and Marie comes

$\mathrm{a}^{\prime}$. [Jan en Marie] komen. Jan and Marie come b. [[Jan komt] of [Marie komt]]. Jan comes or Marie comes

$\mathrm{b}^{\prime}$. [Jan of Marie] komt. Jan or Marie comes

The examples in (210) show for the coordinator en 'and' that the associative law in (206a) also holds for non-clausal polyadic coordination if we construe it in terms of entailments; the same holds for the coordinator of 'or'. The symbol $\Vdash$ means "entails the truth of". 
(210) a. [[Jan en Marie] en Els] komen

Jan and Marie and Els come

$\mathrm{a}^{\prime}$. I $\vDash$ Jan en Marie komen $\wedge$ Els komt

$\mathrm{a}^{\prime \prime}$. I $\vDash$ Jan komt $\wedge$ Marie komt $\wedge$ Els komt

b. [Jan en [Marie en Els]] komen.

Jan and Marie and Els come

$\mathrm{b}^{\prime}$. I \& Jan komt $\wedge$ Marie en Els komen

$b^{\prime \prime} . \quad$ I Jan komt $\wedge$ Marie komt $\wedge$ Els komt

The discussion of (209) and (210) thus shows that phrasing the discussion of nonclausal coordination in terms of proposition calculus does not pose any serious problems, so that we can opt for this option for the sake of brevity and simplicity.

\section{B. Hierarchically ordered coordinate structures}

An important stepping stone for showing that polyadic coordinate structures are indeed hierarchically structured is the fact that not all coordinators share the property of en 'and' (and of 'or') that they can be used in what look like "flat" polyadic coordinate structures. Examples are coordinators like maar 'but', want 'because' and dus 'so', which can link at most two coordinands. This is illustrated for the adversative coordinator maar 'but' in the (b)-example in (211).

(211) a. Jan is [intelligent en ijverig].

Jan is intelligent and diligent

$a^{\prime}$. Jan is [vriendelijk en intelligent en ijverig].

Jan is friendly and intelligent and diligent

b. Jan is [streng maar vriendelijk].

Jan is strict but friendly

$\mathrm{b}^{\prime}$. *Jan is [streng maar vriendelijk maar lui].

Jan is strict but friendly but lazy

This difference between en and maar is not just an accidental property of the polysyndetic coordinate structures in (211) but also found in polyadic monosyndetic coordinate structures: the (a)-examples in (212) shows that the coordinator en may be found in monosyndetic constructions with two or three (or even more) coordinands, while the (b)-examples in (212) show that maar 'but' cannot easily enter polyadic monosyndetic coordinate structures.

(212) a. Jan is [intelligent en ijverig].

Jan is intelligent and diligent

$\mathrm{a}^{\prime}$. Jan is [vriendelijk, intelligent en ijverig].

Jan is friendly intelligent and diligent

b. Jan is [intelligent maar lui].

Jan is intelligent but lazy

$\mathrm{b}^{\prime}$. ?? Jan is [vriendelijk, intelligent maar lui].

Jan is friendly intelligent but lazy

To the extent that $\left(212 b^{\prime}\right)$ is interpretable, we obtain a reading in which the positively valued properties denoted by vriendelijk 'friendly' and intelligent 
'intelligent' are contrasted with the negatively valued property denoted by lui 'lazy'. In fact, this example becomes fully acceptable if we conjoin the first two adjectives by en 'and': Jan is vriendelijk en intelligent, maar lui 'Jan is friendly and intelligent but lazy'. The semantic intuition that the first two adjectives are contrasted with the last one strongly suggests that the "flat" structure in (213a) is incorrect and that we are dealing with the hierarchically organized structure in (213b). This conclusively shows that coordination can be recursive in the sense that a coordinate structure can be used as a coordinand of a larger coordinate structure; cf. Dik (1968/1997).

(213) a. *Jan is [vriendelijk en intelligent maar lui].

["flat" structure] Jan is friendly and intelligent but lazy

b. Jan is [[vriendelijk en intelligent], maar lui]. ["hierarchical” structure] Jan is friendly and intelligent but lazy

The fact that coordinate structures can be embedded in a larger coordinate structure also accounts for the observation in (214), which is attributed to Alma Næss in Johannessen (1998:149). Because the correlative coordinator of ... of ... is included in the second coordinand, we are led to think that we are dealing with two adjacent coordinators. If we were dealing with a "flat" structure, example (214a) would go against the otherwise exceptionless generalization that coordinands are linked by at most one overt coordinator. A similar example with the correlative coordinator zowel ... als .. 'both ... and ...' is given in (214b); the empty set sign $\varnothing$ stands for the phonetically empty counterpart of en 'and'.

(214) a. [Jan en [of Marie of Peter]] gaan samen op vakantie. Jan and either Marie or Peter go together on vacation 'Jan, and either Marie or Peter will go on vacation together.'

b. [Jan Ø [Peter en [zowel Els als Marie]]] zijn uitgenodigd. Jan Peter and both Els and Marie are prt.-invited

\section{Hierarchical coordinate structures: word order and meaning}

Subsection A has shown that the combined effect of the commutative laws in (205) and the associative laws in (206) is that polyadic conjunctions and disjunctions may give the impression of having a "flat" structure: the conjuncts/disjuncts may occur in any order without affecting the truth values. This also holds for polyadic coordinate structures with en 'and' and of 'or' in the prototypical case: the coordinands in the triadic coordinate structures in (215) may occur in any order without affecting the meaning of the sentence.

(215) a. Ik koop [een boek, een CD en een DVD].

I buy a book a CD and a DVD

'I will buy a book, a CD and a DVD.'

b. Ik koop [een boek, een CD of een DVD].

I buy a book a CD or a DVD

'I will buy a book, a CD or a DVD.'

The same holds for an example such as $\left(211 a^{\prime}\right)$, repeated as (216a): with all six logically possible orders of the adjectives, the sentence simply expresses that Jan 
has the three properties denoted by the adjectives. That polyadic coordinate structures can be hierarchically structured can now be illustrated by the fact that example (213b), repeated as (216b), has just one equivalent alternate order, due to the fact that it is not a pure conjunction but also expresses a contrast.

(216) a. Jan is vriendelijk en intelligent en ijverig.

Jan is friendly and intelligent and diligent

b. Jan is vriendelijk en intelligent maar lui. Jan is friendly and intelligent but lazy

The empirically established fact that maar 'but' links precisely two coordinands implies that (216b) has the structure in (217a); the commutative law in (205a) now correctly allows swapping of the first two adjectives, which correctly predicts that $\left(217 a^{\prime}\right)$ has the same meaning as (217a): they contrast the positively valued properties denoted by vriendelijk 'friendly' and intelligent with the negatively valued property denoted by lui 'lazy'. The two (equivalent) pairs in the (b)- and the (c)-examples express different contrasts, which is nicely reflected by the hierarchical organization indicated by brackets. It shows that the internal organization of polyadic coordinate structures has a semantic effect, as expected.

(217) a. Jan is [[vriendelijk en intelligent], maar lui]. [friendly/intelligent vs. lazy] Jan is friendly and intelligent but lazy

$\mathrm{a}^{\prime}$. Jan is [[intelligent en vriendelijk], maar lui]. Jan is intelligent and friendly but lazy

b. Jan is [[vriendelijk en lui], maar intelligent]. [friendly/lazy vs. intelligent] Jan is intelligent and lazy but intelligent

$\mathrm{b}^{\prime}$. Jan is [[lui en vriendelijk], maar intelligent]. Jan is lazy and friendly but intelligent

c. Jan is [[intelligent en lui], maar vriendelijk]. [intelligent/lazy vs. friendly] Jan is intelligent and lazy but friendly

$\mathrm{c}^{\prime}$. Jan is [[lui en intelligent], maar vriendelijk]. Jan is lazy and intelligent but friendly

\section{Hierarchical coordinate structures and prosody}

The hierarchical structure of polyadic coordinate structures does not only have semantic but also phonological effects. We will follow Wagner's (2010) generalization in (218) that prosodic boundaries (e.g., in the form of intonation breaks) reveal the hierarchical structure of polyadic coordinate structures; the reader is referred to Féry \& Kentner (2010) for a discussion of a wider range of prosodic effects.

Wagner's generalization: In a sequence $\mathrm{A}<\mathrm{B}<\mathrm{C}$, if the prosodic boundary separating $\mathrm{A}$ and $\mathrm{B}$ is weaker than the one separating $\mathrm{B}$ and $\mathrm{C}$, then $[[\mathrm{AB}] \mathrm{C}]$; if it is stronger, then $[\mathrm{A}[\mathrm{BC}]]$.

Consider the triadic structure in (219), for which we have earlier established the internal structure indicated by brackets. Hypothesis (218) is compatible with the fact that the embedded coordinate structure vriendelijk en intelligent is pronounced as a prosodic unit and can be followed by an intonation break; although this break 
may be difficult to perceive in running speech, we represent it by means of a comma. As always, the two coordinands of maar receive additional accent, indicated here by capitals, which is normally placed on the first coordinand of an embedded coordinate structure. Hypothesis (218) correctly predicts that polyadic coordinate structures with more than three coordinands may give rise to a wide range of prosodic patterns depending on their internal structures. Two examples are given in $(219 \mathrm{~b} \& \mathrm{c})$; we have ignored issues concerning the internal structure of the first coordinand of maar in (219c).

(219) a. Jan is [[VRIENdelijk en intelligENT], maar LUI]].

Jan is friendly and intelligent but lazy

b. Jan is [[VRIENdelijk en intelligENT], maar [LUI en ongeZEGlijk]]. Jan is friendly and intelligent but lazy and unruly

c. Jan is [[VRIENdelijk, creatIEF en intelligent], maar LUI]] Jan is friendly creative and intelligent but lazy

Wagner's generalization in (218) is quite helpful in resolving ambiguities that arise in "mixed" polyadic coordinate structures of the type Jan koopt een beeldscherm en een scanner of een printer 'Jan will buy a computer screen and a scanner or a printer'. This example can be pronounced with the two intonation patterns indicated in the primeless examples in (220). According to hypothesis (218) these intonation patterns evoke the bracketing indicated (or vice versa), and this correctly predicts that the primeless examples must be paraphrased as in the primed examples.

(220) a. Jan koopt [[een BEELDscherm en een SCANner], of een PRINter].

Jan buys a screen and a scanner or a printer

'Jan will buy a screen and a scanner, or a printer.'

$a^{\prime}$. Jan koopt een beeldscherm en een scanner of hij koopt een printer. Jan buys a screen and a scanner or he buys a printer 'Jan will buy a screen and a scanner, or he will buy a printer.'

b. Jan koopt [een BEELDscherm, en [een SCANner of een PRINter]]. Jan buys a screen and a scanner or a printer 'Jan will buy a screen, and a scanner or a printer.'

$\mathrm{b}^{\prime}$. Jan koopt een beeldscherm en hij koopt een scanner of een printer. Jan buys a screen and he buys a scanner or a printer 'Jan will buy a screen, and he will buy a scanner or a printer.'

\section{E. Ambiguities in triadic coordinate structures with en 'and'}

All polyadic coordinate structures with en considered so far are semantically wellbehaved in that they follow the associative and commutative laws discussed in Subsection A. This subsection will show that polyadic nominal coordinate structures do not always obey these laws. This is related to the fact discussed in Section 1.1, sub IVD, that such structures can have different readings: while nominal coordinate structures with a distributive reading are well-behaved with respect to the laws of associativity and commutativity, those with a cumulative reading are not. For convenience, we illustrate the difference between the two readings again in (221) for the ambiguous example Marie en Els tilden de tafel op 'Marie and Els lifted the table'. This example may have a distributive reading, 
which can be singled out by adding the modifier allebei 'both': then the truth of the proposition expressed by (221a) entails that the propositions expressed by the two sentences in $\left(221 a^{\prime}\right)$ are both true. This example may also have a cumulative reading, which can be singled out by adding the modifier samen 'together': then the truth of the proposition expressed by (221b) does not entail that the propositions expressed by the two sentences in $\left(221 b^{\prime}\right)$ are true.

(221) a. [Marie en Els] tilden allebei de tafel op.

[distributive AND $(\wedge)$ ]

Marie and Els lifted both the table up

'Marie and Els both lifted the table.'

$\mathrm{a}^{\prime}$. I I Marie/Els tilde de tafel op.

Marie/Els lifted the table up

b. [Marie en Els] tilden samen de tafel op.

Marie and Els lifted together the table up

[cumulative AND $(\oplus)$ ]

'Marie and Els lifted the table together.'

$b^{\prime}$. IF Marie/Els tilde de tafel op.

Marie/Els lifted the table up

This subsection will show that cumulative AND $(\oplus)$ is not subject to the law of associativity (although it does obey the law of commutativity). We will illustrate this by means of an example taken from Hoeksema (1983): Blücher en Wellington en Napoleon vochten tegen elkaar tijdens de Slag bij Waterloo 'Blücher and Wellington and Napoleon fought against each other near Waterloo'. This sentence is only factually true on the interpretation that Blücher and Wellington fought against Napoleon, that is, the phrase Blücher en Wellington must be construed as a collective that fights Napoleon, and should therefore be translated as $b \oplus \mathrm{w}$. The fact that the reciprocal elkaar 'each other' requires a plural subject shows that the subject as a whole also has a cumulative reading, which gives rise to the hierarchically organized semantic structure given in $\left(222 \mathrm{a}^{\prime}\right)$. This structure would also be in line with the intonation pattern of sentence (222a); cf. Wagner's generalization in (218). The crucial point for our present discussion is that using the order of proper nouns in (222a) is not sufficient for the sentence to be true: the internal organization of the coordinate structure must also be correct, as is clear from the fact that the intonation pattern in (222b) gives rise to a factually false contention.

(222) a. [[BLÜcher en WeLlington], en NaPOleon] vochten tegen elkaar. [true]

Blücher and Wellington and Napoleon fought against each.other

'Blücher and Wellington, and Napoleon fought against each other.'

$\mathrm{a}^{\prime}$. [[Blücher en Wellington], en Napoleon] [meaning: $\left.((\mathrm{b} \oplus \mathrm{w}) \oplus \mathrm{n})\right]$

b. [BLÜcher, en [WELlington en NaPOleon]] vochten tegen elkaar. [false]

Blücher and Wellington and Napoleon fought against each.other

'Blücher and Wellington, and Napoleon fought against each other.'

$b^{\prime}$. [Blücher en [Wellington en Napoleon]] [meaning: $\left.(b \oplus(w \oplus n))\right]$

The fact that the sentences in $(222 \mathrm{a} \& \mathrm{~b})$ are not logically equivalent shows that cumulative AND is not subject to the associative law. It is subject to the commutative law, however, as is clear from the fact that the coordinands of the 
embedded coordinate structure in (222a) as well as those of the higher coordinate structure can swap places, as is illustrated in (223).

(223) a. [[WELlington en BLÜcher], en NaPOleon] vochten tegen elkaar. [true] $\mathrm{a}^{\prime}$. [[Wellington en Blücher], en Napoleon] [meaning: $\left.((\mathrm{w} \oplus \mathrm{b}) \oplus \mathrm{n})\right]$ b. [NaPOleon, en [BLÜcher en WELlington]] vochten tegen elkaar. [true] $\mathrm{b}^{\prime}$. [Napoleon, en [Blücher en Wellington]] [meaning: $(\mathrm{n} \oplus(\mathrm{b} \oplus \mathrm{w})]$

Swapping places across a boundary, on the other hand, is impossible: this is illustrated by the fact that this would result in the factually false statements in (224) from the factually true statements in (222a) and (223). The fact that swapping places across a boundary has a semantic effect obviously follows from the fact that the semantic representations in (224) should be derived from their presumed counterparts in (222a) and (223) in two steps; first the bracketing is changed in accordance with the law of associativity, after which the coordinands swap places in accordance with the law of commutativity. Since the law of associativity does not apply to cumulative AND, the outputs in (224) differ from the inputs in truth conditions.

(224) a. [[BLÜcher en Napoleon], en WELlington] vochten tegen elkaar. [false] $\mathrm{a}^{\prime}$. [[Blücher en Napoleon], en Wellington] [meaning: $\left.((\mathrm{b} \oplus \mathrm{n}) \oplus \mathrm{w})\right]$

b. [[WELlington en NApoleon], en BLÜcher] vochten tegen elkaar. [false] $\mathrm{b}^{\prime}$. [[Wellington en Napoleon], en Blücher] [meaning: $\left.((\mathrm{w} \oplus \mathrm{n}) \oplus \mathrm{b})\right]$ c. [BLÜcher, en [Napoleon en WELlington]] vochten tegen elkaar. [false] $\mathrm{c}^{\prime}$. [[Blücher en Napoleon], en Wellington] [meaning: $\left.((\mathrm{b} \oplus \mathrm{n}) \oplus \mathrm{w})\right]$

It is important to note that Hoeksema's Waterloo examples discussed above are polysyndetic in the sense that both the embedded and the higher coordinate structure are syndetic. Leaving out the coordinator in the embedded coordinate structure is impossible: an example such as (225) can only be construed such that each of the referents fought against the other two (although in actual use the interpretation may sometimes be more "sloppy"). Such monosyndetic coordinate structures do seem to obey the associative and commutative laws: all logically possible orders of the coordinands give rise to the same interpretation, which is also signaled by the fact that such examples exhibit a flat intonation contour.

[Napoleon, Blücher en Wellington] vochten tegen elkaar.

Napoleon Blücher and Wellington fought against each.other

'Napoleon, Blücher and Wellington fought against each.other.'

The differences in meaning and intonation between monosyndetic and polysyndetic coordination suggest that they have somewhat different structures: Borsley (2005) and Zhang (2010: section 3.6), for instance, assume that polyadic monosyndetic constructions do not involve phonetically empty coordinators. De Vries (2005) suggests that the apparent ambiguity of en is due to a functional ${ }^{\circ}$ head Dist with the feature [ \pm distributive] on top of the coordinate structure, and assumes that monosyndetic structures involve a single Dist-head with two coordinators in its scope, while polysyndetic structures involve multiple Dist-heads (each with a single coordinator in their scope). We will not discuss these proposals in detail here. 
Monosyndetic and polysyndetic coordinate structures with distributive en 'and' are logically equivalent in that the two types seem to obey the associative and commutative laws: all permutations of the coordinands are fully acceptable, which is again indicated by a flat intonation contour. In light of considerations of economy, it need not come as a surprise that monosyndetic constructions are the ones that are normally used.

(226) a. [Peter en [Marie en Els]] tilden allemaal de tafel op.

Peter and Marie and Els lifted all the table up

'Peter, Marie and Els all lifted the table.'

b. [Peter en/Ø [Marie en Els]] tilden allemaal de tafel op.

Peter and Marie and Els lifted all the table up

'Peter, Marie and Els all lifted the table.'

\section{F. Ambiguities in larger polyadic coordinate structures with en 'and'}

In the previous subsection we have seen that the interpretation of triadic coordinate structures with en are sensitive to the nature of the coordinator itself (distributive versus cumulative) and the coordinate structure as a whole (monosyndetic versus polysyndetic). In light of this we may expect a wide range of ambiguities in polyadic structures; for practical reasons we will confine the discussion to cases with three or four coordinands. The null hypothesis that coordinators are two-place linkers implies that strings with three and four coordinands are assigned the hierarchical structures in (227), in which WP, XP, YP, and ZP represent the four coordinands, and \& stands for the coordinator en 'and' or its phonetically empty equivalent $\varnothing$. The structures in $(227 \mathrm{a} \& b)$ are the result of adding one coordinand at each step in the derivation; this derivation may of course give rise to several different orders depending on the question whether the embedded coordinate structure comes first or last in the higher coordinate structure, but we will ignore this for reasons of simplicity. The structure in $\left(227 b^{\prime}\right)$ arises by coordinating two coordinate structures formed independently of each other. We will show that it is the availability of the two structures in the (b)-examples which is the source of various more complex ambiguities.

- Dyadic coordination analyses for polyadic coordinate structures

a. $\quad[X P \&[Y P \& Z P]]$

b. [WP \& [XP \& [YP \& ZP]]]

[three coordinands]

$\mathrm{b}^{\prime} . \quad[[\mathrm{WP} \& \mathrm{XP}] \&[\mathrm{YP} \& \mathrm{ZP}]]$

[four coordinands]

[four coordinands]

The structures in $(227 \mathrm{a} \& \mathrm{~b})$ are the ones we normally get in monosyndetic coordinate structures. The semantic effect of adding a coordinand to distributive examples such as (221a) is that an entailment is added, as will be clear from the examples in (228) with the distributive modifier allemaal 'all'.

(228) a. [Peter Ø [Marie en Els]] tilden allemaal de tafel op.

Peter Marie and Els lifted all the table up

'Peter, Marie and Els all lifted the table.'

$a^{\prime} . \quad \vDash$ Peter/Marie/Els tilde de tafel op.

Peter/Marie/Els lifted the table up 
b. [Jan Ø [Peter Ø [Marie en Els]]] tilden allemaal de tafel op. Jan Peter Marie and Els lifted all the table up

'Jan, Peter, Marie and Els all lifted the table.'

$\mathrm{b}^{\prime}$. $\Vdash \vDash$ Jan/Peter/Marie/Els tilde de tafel op. Jan/Peter/Marie/Els lifted the table up

The semantic effect of adding a coordinand to cumulative examples such as (221b) is that an entity is added to the collective referred to by the complex coordinate structure: example (221b) expresses that the table was lifted by a group of two individuals, while (229a) and (229b) express that the relevant group consists of, respectively, three and four individuals.

(229) a. [Peter Ø [Marie en Els]] tilden samen de tafel op.

Peter Marie and Els lifted together the table up

'Peter, Marie and Els lifted the table together.'

b. [Jan Ø [Peter Ø [Marie en Els]]] tilden samen de tafel op. Jan Peter Marie and Els lifted together the table up 'Jan, Peter, Marie and Els lifted the table together.'

The interpretations of the monosyndetic coordinate structures discussed above remain intact when we substitute en 'and' for the occurrences of the phonetically empty coordinator $\varnothing$, although the resulting patterns would be considered to be more marked (emphatic) forms for expressing the same thought. More important for our present discussion is that the resulting strings may make different interpretations possible with collective predicates such as vechten met/tegen elkaar 'to fight with/against each other' in the (a)-examples such as given in (230), which trigger a cumulative interpretation of their subject.

(230) a. [Els en Marie] vechten met elkaar.

$[\mathrm{e} \oplus \mathrm{m}]$

Els and Marie fight with each.other

b. *Marie/Els vocht met elkaar.

Marie/Els fought with each.other

The two previous subsections have already shown that examples such as given in (231) also receive a cumulative interpretation, but that there are two possible readings depending on the intonation: if the coordinate structure is given a flat intonation contour, as in (231a), one entity is added to the collective referred to by the coordinate structure in (230a): the resulting reading is that we are dealing with a collective of three individuals who all fight with each other. If the coordinate structure contains a prosodic boundary, as in the (b)-examples, the subject refers to a collective consisting of one individual and one set of individuals: the resulting reading is that the individual is fighting with the collection of individuals. 
(231) a. [Peter en [Els en Marie]] vechten met elkaar Peter and Els and Marie fight with each.other

$[\mathrm{p} \oplus(\mathrm{e} \oplus \mathrm{m})]$

b. [PETER, en [ELS en MArie]] vechten met elkaar.

Peter and Els and Marie fight with each.other

'Peter is fighting with Els and Marie.'

$\mathrm{b}^{\prime}$. [[PETER en ELS], en MArie] vechten met elkaar.

Peter and Els and Marie fight with each.other 'Peter and Els are fighting with Marie.'

$[\mathrm{p} \oplus(\mathrm{e} \oplus \mathrm{m})]$

$[(p \oplus e) \oplus m)]$

It is important to note that the two overt coordinators in the (b)-examples in (231) must receive a cumulative reading, due to the fact that sentences like *Peter/Marie vecht tegen elkaar are unacceptable. This is crucially different in examples with four coordinands, such as given in (232), which can not only be assigned the fully cumulative meanings indicated between square brackets in $(232 \mathrm{a} \& \mathrm{~b})$ but also the partly distributive meaning in (232c).

(232) a. [Jan en [Peter en [Els en Marie]]] vechten met elkaar. $[\mathrm{j} \oplus(\mathrm{p} \oplus(\mathrm{e} \oplus \mathrm{m}))]$ Jan and Peter and Els and Marie fight with each.other

'Jan, Peter, Els and Marie are fighting each other.'

b. [[JAN en PETER] en [ELS en MArie]] vechten met elkaar. $[(j \oplus p) \oplus(e \oplus m)]$ Jan and Peter and Els and Marie fight with each.other

'Jan and Peter are fighting with Els and Marie.'

c. [[JAN en PETER] en [ELS en MArie]] vechten met elkaar. $[(j \oplus p) \wedge(e \oplus m)]$ Jan and Peter and Els and Marie fight with each.other

'Jan and Peter and Els and Marie are fighting.'

The interpretation of example (232a) goes along the same lines as that of (231a): yet another individual is added to the set of individuals so that we are now dealing with a collection of four individuals who all fight with each other, as depicted in situation III in Figure 28. Example (232b) is of a similar sort as the examples in $\left(231 b^{2} \& b^{\prime}\right)$ although we are now not linking an individual with a set of individuals but two sets of individuals; this gives rise to the situation IV in Figure 28. Example (232c) is of an entirely different sort as it does not refer to a single eventuality but to the two eventualities depicted by situations I and II in Figure 28.

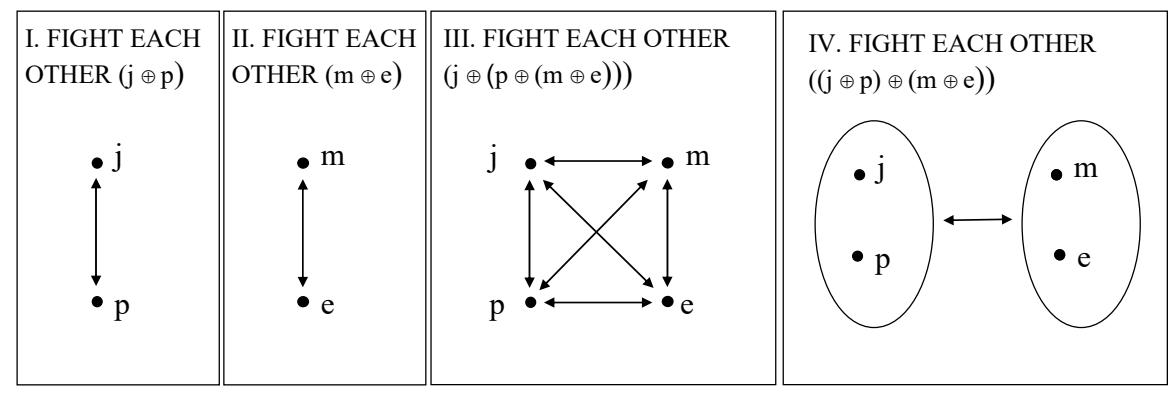

Figure 28: The interpretation of coordinate structures with four coordinands

The fact that the two interpretations given in $(232 \mathrm{~b} \& \mathrm{c})$ are both readily available shows that the meaning of the coordinator en does not have to be constant within a 
single polyadic coordinate structure. This favors the hypothesis that polyadic coordinate structures are hierarchically organized, as it would be very difficult to account for this if such structures were "flat", that is, if they were derived in one single step, while the computation is quite natural on the assumption that such polyadic coordinate structures consist of a hierarchically organized structure.

\section{G. A potential problem: polyadic coordinate structures with noch 'nor'}

This subsection is devoted to the fact that the null hypothesis apparently runs into problems with the coordinator noch 'nor'. Example (233a) strongly suggests that noch can be used in polysyndetic coordinate structures: this example entails that the propositions expressed by the three sentences in (233b) are all true. We will discuss the problem that arises in terms of these entailments, as this will enable us to keep the discussion maximally simple in terms of standard propositional calculus.

(233) a. Jan noch Marie noch Els komt morgen.

Jan nor Marie nor Els comes tomorrow

b. I Jan/Marie/Els komt morgen niet.

Jan/Marie/Els comes tomorrow not

'Jan/Marie/Els will not come tomorrow.'

Let us adopt the assumption made in Section 1.1, sub IVB, that noch is translated as logical NOR: $\neg(\varphi \vee \psi)$. If this coordinator were dyadic, we would expect that the syntactic structure of (233a) could be as given in the primed examples in (234), with the corresponding semantic translations in the primed examples. Table 10 shows that these are clearly not logically equivalent, so that we have to conclude that logical NOR $(\bar{v})$ differs from conjunction and disjunction in that it does not exhibit the property of associativity: $(\varphi \bar{v}(\psi \bar{v} \chi)) \leftrightarrow((\varphi \bar{v} \psi) \bar{v} \chi)$.

(234) a. [Jan noch [Marie noch Els]] komt morgen.

$\mathrm{a}^{\prime} . \quad \neg(\varphi \vee \neg(\psi \vee \chi))$

b. [[Jan noch Marie] noch Els] komt morgen.

$\left.\mathrm{b}^{\prime} . \quad \neg(\neg(\varphi \vee \psi) \vee \chi)\right)$

Table 10: Prooffor the non-associativity of noch 'nor'

\begin{tabular}{|c|c|c||c|c||c|c||}
\hline \hline & $\psi$ & $\chi$ & $\neg(\varphi \vee \psi)$ & $\neg(\psi \vee \chi)$ & $\neg(\varphi \vee \neg(\psi \vee \chi)$ & $\neg(\neg(\varphi \vee \psi) \vee \chi))$ \\
\hline \hline 1 & 1 & 1 & 0 & 0 & 0 & 0 \\
\hline 1 & 1 & 0 & 0 & 0 & 0 & 1 \\
\hline 1 & 0 & 1 & 0 & 0 & 0 & 0 \\
\hline 1 & 0 & 0 & 0 & 1 & 0 & 1 \\
\hline 0 & 1 & 1 & 0 & 0 & 1 & 0 \\
\hline 0 & 1 & 0 & 0 & 0 & 1 & 0 \\
\hline 0 & 0 & 1 & 1 & 0 & 1 & 0 \\
\hline 0 & 0 & 0 & 1 & 1 & 0 & 1 \\
\hline
\end{tabular}

The problem that is most relevant for our present discussion is that the last two columns in Table 10 show that the semantic translations in (234) are both incorrect, since they do not account for the entailments in (233b). It looks as if we need 
translations like those in (235a) or (235b): Table 11 shows that these are logically equivalent and do account for the entailments given in (233b) because they are true only if $\varphi, \psi$ and $\chi$ are all false.

(235) a. $\neg(\varphi \vee(\psi \vee \chi))$

b. $\neg((\varphi \vee \psi) \vee \chi))$

Table 11

\begin{tabular}{|c|c|c||c|c||c|c||}
\hline$\varphi$ & $\psi$ & $\chi$ & $(\varphi \vee \psi)$ & $(\psi \vee \chi)$ & $\neg(\varphi \vee(\psi \vee \chi)$ & $\neg((\varphi \vee \psi) \vee \chi))$ \\
\hline \hline 1 & 1 & 1 & 1 & 1 & 0 & 0 \\
\hline 1 & 1 & 0 & 1 & 1 & 0 & 0 \\
\hline 1 & 0 & 1 & 1 & 1 & 0 & 0 \\
\hline 1 & 0 & 0 & 1 & 0 & 0 & 0 \\
\hline 0 & 1 & 1 & 1 & 1 & 0 & 0 \\
\hline 0 & 1 & 0 & 1 & 1 & 0 & 0 \\
\hline 0 & 0 & 1 & 0 & 1 & 0 & 0 \\
\hline 0 & 0 & 0 & 0 & 0 & 1 & 1 \\
\hline
\end{tabular}

It is impossible, however, to derive the formulas in (235) in a compositional way on the assumption that noch is the natural language counterpart of the dyadic operator NOR. This suggests that we would need to follow Haeseryn et al. (1997:1482) in assuming that noch "links the members of the coordination (just like the ordinary linker en), while in addition it functions as a negation element with [either] all members in its scope [or ..]]" [our translation]. Haeseryn et al. thus seem to suggest that the coordinate structure in (233a) is "flat": this leads to the "flat" semantic translation in (236b), which is logically equivalent to $\left(236 b^{\prime}\right)$ because of the equivalence rule $\neg(\varphi \vee \psi) \equiv \neg \varphi \wedge \neg \psi$.

(236) a. [Jan noch Marie noch Els] komt morgen.

b. $\neg(\varphi \vee \psi \vee \chi)$

$\mathrm{b}^{\prime} . \quad \neg \varphi \wedge \neg \psi \wedge \neg \chi$

This does not fully solve the problem, however, because logical NOR is defined as a dyadic connective: $\varphi$ NOR $\psi$, which we represent by the logically equivalent formula $\neg \varphi \wedge \neg \psi$ in terms of the primitive semantic connectives. Consequently, it is still not possible to derive the formulas in $\left(236 \mathrm{~b} \& \mathrm{~b}^{\prime}\right)$ in a compositional manner. Two applications of NOR result in the formulas $\varphi$ NOR ( $\psi$ NOR $\chi)$ or ( $\varphi$ NOR $\psi)$ NOR $\chi$, which are logically equivalent to the two formulas in $(237 \mathrm{a} \& \mathrm{~b})$, which in turn are equivalent with the formulas in (235).

(237) a. $\neg \varphi \wedge \neg(\neg \psi \wedge \neg \chi)$

$$
\begin{aligned}
& \equiv \neg(\varphi \vee(\neg \psi \wedge \neg \chi)) \\
& \equiv \neg(\varphi \vee \neg(\psi \vee \chi))[=(234 \mathrm{a})]
\end{aligned}
$$

b. $\neg(\neg \varphi \wedge \neg \psi) \wedge \neg \chi$

$$
\begin{aligned}
& \equiv \neg((\neg \varphi \wedge \neg \psi) \vee \chi) \\
& \equiv \neg(\neg(\varphi \vee \psi) \vee \chi)[=(234 \mathrm{~b})]
\end{aligned}
$$


The discussion above has shown that accepting "flat" structures like those in (236) runs up against two well-established principles constituting the core of present-day formal semantics: (i) logical connectives are monadic or dyadic, and (ii) compositionality. For this reason, an alternative solution would be most welcome. One promising avenue is to pursue the idea that (233a) actually does not contain a coordinate structure with three coordinands, but the coordinate structure [Jan noch Marie] followed by a parenthetic noch phrase. Such an analysis can be supported by the apparent "split" coordination construction in (238a), as there is good reason for assuming that the final occurrence of noch in this example is not a coordinator but an adverbial phrase licensed by the sentence negation expressed by the coordinate structure in the preceding clause. That the second occurrence of noch in (238a) cannot be analyzed as a coordinator is clear from example (238b), in which it occupies the initial position of the second (reduced) sentence; this shows that we are dealing with a ${ }^{\circ}$ clausal constituent (probably an adverbial).

(238) a. Jan noch Marie komt morgen, noch Els.

Jan nor Marie comes tomorrow, nor Els

b. Ik heb noch Jan noch Marie gezien; noch (zag ik) Els.

I have nor Jan nor Marie seen nor saw I Els

'I have seen neither Jan nor Marie; nor (did I see) Els.'

Example (239a) further shows that adverbial noch can also be licensed by the negative adverb niet 'not'. It is important to note that the short version of (239a) cannot be derived by ${ }^{\circ}$ extraposition of the string noch Marie from a coordinate structure Jan noch Marie for the reasons indicated in Subsection IIB. That extraposition is not involved is also suggested by the fact that the use of niet in the would-be underlying structure in (239b) gives rise to an awkward result.

Ik heb Jan *(niet) gezien; noch (zag ik) Marie.
I have Jan not seen neither saw I Marie
'I haven't seen Jan; neither (did I see) Marie.'
Ik heb [Jan noch Marie] (*niet) gezien.
I have Jan nor Marie not seen

It seems worth noting that the licensing condition on adverbial noch also applies to the near-synonymous adverbial evenmin 'neither', as this adverbial must also be preceded by a negative clause: the two adverbials mainly differ in that noch must be the initial phrase in the (reduced) sentence, while evenmin is preferably more deeply embedded.

$$
\begin{aligned}
& \text { Ik heb Jan *(niet) gezien; Marie (zag ik) evenmin. } \\
& \text { I have Jan not seen Marie saw I neither } \\
& \text { 'I haven't seen Jan; neither (did I see) Marie.' }
\end{aligned}
$$

The adverbial use of noch can be traced back to the earliest stages of Dutch. According to the WNT (lemma noch), its distribution used to be much wider than in present-day Dutch in that it could also occur after an affirmative clause (see sub.1); WNT therefore translates this noch simply as "and not" and classifies it as a coordinator. However, that we are also dealing with a clausal constituent in the 
older stages as well is clear from the fact that WNT provides various examples in which this noch triggers subject-verb inversion (sub.1\&2).

The discussion of the examples in (238) and (239) suggests that the semantic problem posed by (233a) may be unrelated to coordination but instead will have to take into account the ambiguity of noch, which does not only function as a coordinator but also as an adverbial phrase in present-day Dutch. On the assumption that the string noch Els is a reduced parenthetical clause in (241a), we can derive the formula in (241b).

(241) a. [Jan noch Marie], noch Els, komt morgen.

$$
\text { Jan nor Marie nor Els comes tomorrow }
$$

b. $\neg(\varphi \vee \psi) \wedge \neg \chi$

Table 12 shows that this formula is logically equivalent to those given in (235), and correctly accounts for the entailment in (233b).

Table 12

\begin{tabular}{||c|c|c||c|c|c||}
\hline$\varphi$ & $\psi$ & $\chi$ & $\neg(\varphi \vee \psi)$ & $\neg \chi$ & $\neg(\varphi \vee \psi) \wedge \neg \chi$ \\
\hline \hline 1 & 1 & 1 & 0 & 0 & 0 \\
\hline 1 & 1 & 0 & 0 & 1 & 0 \\
\hline 1 & 0 & 1 & 0 & 0 & 0 \\
\hline 1 & 0 & 0 & 0 & 1 & 0 \\
\hline 0 & 1 & 1 & 0 & 0 & 0 \\
\hline 0 & 1 & 0 & 0 & 1 & 0 \\
\hline 0 & 0 & 1 & 1 & 0 & 0 \\
\hline 0 & 0 & 0 & 1 & 1 & 1 \\
\hline
\end{tabular}

The discussion above leads to the conclusion that the noch 'nor' cannot occur in polyadic coordinate structures of the type * $[X P$ noch YP noch ZP], regardless of their internal structure. It is not immediately obvious that this conclusion carries over to monadic structures of the type given in (242a) or structures with the correlative coordinator noch ... noch ... (noch ...) 'neither ... nor ... (nor ...)' in (242b), which have been claimed to have the same entailments as given for example (233a) in Haeseryn et al. (1997: section 25.3/8).

(242) a. Jan, Marie noch Els komt morgen.

[monadic] Jan Marie nor Els comes tomorrow

b. Noch Jan, noch Marie noch Els komt morgen. neither Jan nor Marie nor Els comes tomorrow

[correlative]

We start with the correlative construction in (242b). Its interpretation will follow immediately if (i) we assume that we are exclusively dealing with adverbial noch in such cases and (ii) take seriously the meaning description "(and) not" provided by WNT by assuming that each occurrence of noch correlates with one occurrence of the logical connective $\neg$ in its logical translation; for the sake of clarification, we assume that there is a phonetically empty conjunction in these examples. This would enable us to derive the formulas in $\left(243 b \& b^{\prime}\right)$ in a compositional way; these formulas are logically equivalent to those in (235), as desired. 
(243) a. [Noch Jan Ø [noch Marie Ø noch Els]] komt morgen.

$\mathrm{a}^{\prime} . \quad(\neg \varphi \wedge(\neg \psi \wedge \neg \chi)) \equiv \neg(\varphi \vee(\psi \vee \chi))$

b. [[Noch Jan Ø noch Marie] Ø noch Els] komt morgen.

$\left.\mathrm{b}^{\prime} . \quad((\neg \varphi \wedge \neg \psi) \wedge \neg \chi) \equiv \neg((\varphi \vee \psi) \vee \chi)\right)$

Monosyndetic forms such as (242a) do not seem to be eligible for the analyses given to the two alternative forms. First, we cannot give it a similar analysis as we gave of (241a), according to which the string noch Els is a (reduced) parenthetical clause, because omitting it results in an unacceptable clause: cf. ${ }^{*}$ Jan, Marie komt morgen. Second, we cannot give it a similar analysis as of (242b) according to which noch is adverbial: the fact that there is just a single occurrence of adverbial noch makes it impossible to account for the three occurrences of negation in a compositional way. This means that monosyndetic structures of the type $[X P, Y P$ noch $Z P]$ remain problematic. It is therefore urgent to discuss their status in more detail. First, we would like to start by noting that Haeseryn et al. (1997:1482) claim that the use of noch is more or less restricted to writing (at least when we put aside idiomatic cases such as kant noch wal raken 'to be nonsensical', boe noch ba zeggen 'to be speechless', kraak noch smaak hebben 'to be tasteless', etc, which are fairly frequent in speech); an example such as (244a), for instance, would come out in colloquial speech as the logically equivalent expression in (244b).

(244) a. Jan heeft [tijd noch geld] voor de opera.

Jan has time nor money for the opera

'Jan has time nor money for going to the opera.'

b. Jan heeft [geen tijd en geen geld] voor de opera.

Jan has no time and no money for the opera

'Jan has no time and no money for going to the opera.'

If noch is rare in (colloquial) speech as such, it is to be expected that coordinate structures with three coordinands such as the examples in (242) will be extremely rare, or perhaps even non-existent, which seems to be borne out by the fact that they are rarely found on the internet. Consequently, we have to ask ourselves whether all such cases should be included in our grammatical description of ${ }^{\circ}$ core syntax, that is, the part of syntax that arises spontaneously in the language learning child. This question gains momentum in light of the remark in Haeseryn et al. (1997:1504) that monosyndetic constructions such as Jan noch Marie are less common in speech than correlative structures such as noch Jan noch Marie, as well as the fact that at least some speakers find the monosyndetic example in (242a) less acceptable than the "correlative" one in (242b). We therefore suggest that the status of (242a) is insufficiently clear to be usable for confirming or refuting any semantic claim; it may simply be unacceptable in colloquial speech, that is, restricted to the ${ }^{\circ}$ periphery (consciously learned part) of the grammar. If so, we may conclude that the semantic problem posed by monadic coordinate structures with noch is not relevant for core grammar, and that the null hypothesis according to which "flat" polyadic coordinate structures do not exist can be maintained. 


\section{Are coordinate structures binary branching?}

Subsection III has argued that coordinators are two-place linkers, just like logical conjunction and disjunction in formal semantics. This implies that polyadic coordinate structures must be recursive, in the sense that coordinate structures can be embedded in larger coordinate structures: such structures are hierarchically ordered, as in [CoP XP Co [CoP YP Co ZP]], where Co stands for coordinator and XP, YP and ZP are the coordinands. This subsection will go one step further by arguing that dyadic coordinate structures are also hierarchically ordered; they do not have the "flat" but the binary branching "layered" structure in Figure 29; cf. Kayne (1994: section 6.1).
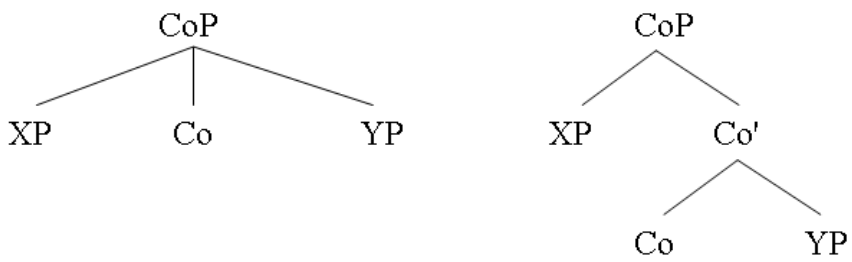

Figure 29: The internal structure of coordinate structures

The right-hand structure in Figure 29 would be preferable from the perspective of present-day generative grammar because it is widely assumed that structures are built bottom-up by combining no more than two elements at each derivational step (resulting in binary branching representations): since the left-hand structure combines three elements, the right-hand structure is to be preferred. It is, however, not easy to find conclusive empirical evidence in favor of the layered structure. Split coordination, for instance, has been argued to provide such evidence: the examples in (245) shows that the split is possible only if the coordinator is piedpiped by the supposed extraposed coordinand.

(245) a. Jan heeft over coördinatie en over ellipsis gesproken.

Jan has about coordination and about ellipsis spoken

'Jan has talked about coordination and about ellipsis.'

b. Jan heeft over coördinatie gesproken en over ellipsis.

$\mathrm{b}^{\prime}$. *Jan heeft over coördinatie en gesproken over ellipsis.

Subsection IIB has shown, however, that the split is not the result of extraposition and that the "extraposed" string [en over ellipsis] may in fact be a reduced clause. A somewhat more convincing example based on Grootveld (1992/1994) is provided in (246a), where the string en over ellipsis provides additional information as an afterthought. In this case it is immaterial whether ellipsis has occurred or not. Example (246b) shows that a similar use of strings such as [over coördinatie en] is not possible.

(246) a. Jan heeft over coördinatie gesproken. O ja, en over ellipsis! Jan has about coordination spoken oh yes, and about ellipsis 'Jan has talked about coordination. [....] And about ellipsis!'

b. Jan heeft over ellipsis gesproken. *O ja, over coördinatie en! Jan has about ellipsis spoken oh yes about coordination and 
Grootveld (1992/1994) further argues that the distribution of prosodic breaks supports the layered structure in Figure 29: these can precede but not follow the coordinator. This is illustrated by the answers in (247) to the question Wie komt/komen er? 'Who is/are coming?'; the comma's indicate intonation breaks. See also Zhang (2010:13), and references cited there.

$\begin{array}{rrr}\text { (247) a. Jan, en Peter, en Marie. } & \mathrm{a}^{\prime} \text {. *Jan en, Peter en, Marie. } \\ \text { Jan and Peter and Marie } \\ \begin{array}{l}\text { Jan } \text { ander and Marie } \\ \text { Jan, of Peter, of Marie. }\end{array} & \mathrm{b}^{\prime} \text {. *Jan of, Peter of, Marie. } \\ \text { Jan or Peter or Marie } & \text { Jan or Peter or Marie }\end{array}$

Wilder (1997:64) has argued that examples such as those in (248) also provide evidence for the layered structure in Figure 29. Example (248a) allows a bound variable reading of the pronoun zijn 'his', while example (248b) does not. Because the bound variable reading requires the pronoun to be ${ }^{\circ} \mathrm{c}$-commanded by its antecedent iedere hond 'every dog', the pattern in (248) is predicted by the layered structure; because the first coordinand c-commands $(\approx$ is in a structurally higher position than) the second one, the antecedent must be in the first position in order to license variable reading of zijn 'his'. The pattern in (248) is not consistent with the "flat" structure, in which the two coordinands mutually c-command each other, as this structure predicts that the antecedent should be able to license the variable reading regardless of its position.

(248) a. Iedere hond ${ }_{\mathrm{i}}$ en $\mathrm{zijn}_{\mathrm{i}}$ bezitter wordt gecontroleerd. every dog and his owner is checked 'Every dog and his owner is checked.'

b. ${ }^{*} \mathrm{Zijn}_{\mathrm{i}}$ bezitter en iedere hond $\mathrm{i}_{\mathrm{i}}$ wordt gecontroleerd. his owner and every dog is checked

Compare: 'Its $s_{\mathrm{i}}$ owner and every $\operatorname{dog}_{\mathrm{i}}$ is checked.'

Although the contrast between the two examples is sharp, examples such as (248a) are rarely used, as is clear from the fact that a Google search $(2 / 8 / 2017)$ on the string [iedere * en zijn] resulted in no more than three relevant hits. Furthermore, the reasoning leads to the expectation that anaphors such as the reciprocal pronoun elkaar 'each other' behave in the same way as the bound pronoun zijn in (248), but most of the Dutch speakers we consulted considered examples such as (249), which was used as the title of an internet page on the website of a finance company, as highly marked or even unacceptable.

?"samenwoners en elkaars pensioen
cohabitators and each.other's pension
'persons who live together and each other's retirement pension'

The unacceptability of examples such as (250a) might also be considered as evidence against the "layered" structure in Figure 29: because the first conjunct ccommands the second conjunct, the standard ${ }^{\circ}$ binding theory predicts that it should be acceptable. It might, however, also be the case that (250a) is infelicitous for the same reason why the two occurrences of Jan in (250b) cannot refer to one and the same person. 
(250) a. *Ik bezocht [Jan en zichzelf].

I visited Jan and himself

b. *Ik bezocht [ $\operatorname{Jan}_{\mathrm{i}}$ en $\mathrm{Jan}_{\mathrm{i}}$ ].

I visited Jan and Jan

It is not really surprising in the light of examples such as (249) and (250a), however, that not all linguists consider (248a) as a convincing argument in favor of the binary branching, "layered" structure in Figure 29; we refer the reader to Progovac (2003: section 1.2) for more arguments against c-command between the coordinands of a coordinate structure based on the standard arguments for establishing c-command relations relating to binding and licensing of negative polarity items, which also seem to refute the argument provided by Zhang (2010: section 2.2.1/2) in favor of the layered structure.

Important cross-linguistic evidence in favor of the layered (binary branching) structure is unbalanced coordination. This notion was introduced by Johannessen (1998) to refer to the fact that in some languages the highest coordinand in a binary branching CoP (which comes first in languages like Dutch and English) may entertain an agreement relation with some element external to CoP, but not the lower one(s). Standard Dutch is probably not one of these languages, but we do find this phenomenon in some Dutch varieties that exhibit complementizer agreement with the subject; we will briefly illustrate this on the basis of the dialect spoken in Tegelen, which is located in the Northern part of Limburg adjacent to the German border; cf. Van Koppen (2005). The complementizer in Tegelen Dutch finite subordinate clauses surfaces as det 'that' except when the subject is the second person singular pronoun doow 'you', in which case it surfaces as des; cf. (251a). The complementizer des can be analyzed as a merged form of the complementizer det and the person ending $-s$, which also shows up in finite verb form kums 'comes'. If doow 'you' is conjoined with some other phrase, the full coordinate structure becomes plural, as is clear from the fact illustrated in the (b)-examples that it triggers plural agreement on the finite verb and can act as the antecedent of the (reciprocal) plural pronouns $\hat{o s}$ 'us' and uch 'you'. We therefore expect the complementizer det to appear, but the (b)-examples show that this expectation is only borne out if doow is the second conjunct; if it is the first conjunct the complementizer must be inflected.

(251) a. Ik dink de-s doow morge kum-s.

I think that 2 p.sg you $_{2 \text {.sg }}$ tomorrow come $_{2 p . s g}$

'I think that you will come tomorrow.'

b. de-s [doow en ich] ôs treffe.

that $_{2 \text { p.sg }}\left[\text { you }_{2 \text { p.sg. and } I}\right]_{1 \text { p.pl }}$ each.other ${ }_{1 \text { p.pl }}$ meet $_{\text {pl. }}$.

'that you and I will meet.'

$\mathrm{b}^{\prime}$. $\operatorname{det} / *$ de-s [Marie en doow] uch treffe. that $/$ that $_{2 \text {.sg }}[\text { Marie an you } 2 \text { p.sg }]_{2 \text { p.pl. }}$ each.other 2 p.pl meet $_{\text {pl. }}$ 'that Marie and you will meet.'

By adopting the layered structure in Figure 29, a natural explanation for the observed pattern presents itself: the complementizer can only agree with the structurally highest coordinand, which blocks all agreement relations with the lower 
coordinands. For an extensive discussion of this type of first conjunct agreement including a critical review of a large number of alternative approaches, we refer the reader to Corbett (1983/2000) and, especially, Van Koppen (2005).

For completeness' sake, we want to note that Johannessen (1998:10-11) also discusses Dutch cases of (presumed) unbalanced coordination involving case marking, in which a case assigner can mark the highest coordinand but not the more deeply embedded one(s). Her example intends to illustrate this and is given here as (252) with the judgment provided by her, although at least some native speakers reject this example; see Van der Heijden (1999:47).

$$
\begin{aligned}
& \text { 'Ik heb [niet alleen de Kroaten in de Balkan voor ogen } \\
& \text { I have not only the Croats in the Balkans for eyes } \\
& \text { maar ook zijnom die elders wonen]. } \\
& \text { but also they who elsewhere live } \\
& \text { 'I have in mind not just the Croats who live in the Balkans, but also those } \\
& \text { living elsewhere.' }
\end{aligned}
$$

The occurrence of the nominative $z i j$ 'they' in the second coordinand is surprising as the coordinate structure as a whole functions as a direct object. Johannessen takes the fact that this example is taken from a quality newspaper as an indication that we are not dealing with an error, especially because the reporter of this case judged this example as less exceptional than Ik heb zij die elders wonen voor ogen. We agree with Zwart's (1995) review of Johannessen's thesis, however, in that these examples have more or less the same (marked) status and that the relative acceptability of (252) is rather related to the presence of the relative clause than to the fact that the pronoun occurs as part of the second coordinand, as is evident from the ungrammaticality of *Ik heb zij voor ogen. Consequently, we cannot use this example to argue in favor of layered coordinate structures (but Johannessen provides ample data from other languages). This conclusion is further supported by the fact ignored in the discussion above that the structure indicated in (252) cannot be correct, as the PP voor ogen cannot be part of the coordinate structure; we are in fact dealing with a "split" coordination construction.

The same conclusion holds for examples of the type in (253a), cited by Johannessen (1998:40\&145) from Van Zonneveld (1992). Zonneveld notices that the finite verb can occur in second position in the second coordinand, which results in an unbalanced coordination in the sense that a clause with embedded (V-final) order and a clause with non-embedded (V-second) order are coordinated. This fact cannot be used for arguing in favor of the layered structure in Figure 29, however. This option is a more or less idiosyncratic property of conditional clauses, as is clear from the fact that other (attested) cases such as (253b) mentioned by Zonneveld are impossible for many (perhaps all) speakers of standard Dutch; see also Haeseryn et al. (1997:1450-1). Note in passing that this kind of unbalanced coordination has a wider distribution in German; see Höhle (1990:225), Thiersch (1993b), and many others since. 
(253) a. [[Als je gepakt wordt] en [je <bent> al eens veroordeeld if you caught are and you are already before convicted $<$ bent $>$ ]], dan hang je. then hang you

'If you get caught and have already been convicted before, you are done for.'

b. Toen Esther al een jaar in Engeland zat en ze ${ }^{\%}$ sprak $>$ nog when Esther already a year in England was and she spoke still geen Engels $<$ sprak $>$, begon ik te twijfelen. no English started I to doubt

'When Esther has already lived in England for a year and still couldn't speak English, I started to doubt.'

Another reason why examples like (253) cannot be used for arguing in favor of layered coordinate structures is that the coordinate structures involved are adverbial; consequently, the coordinands need not be licensed by some element external to the coordinate structure. Furthermore, clauses such as the coordinated object clauses in (254) clearly do not allow the unbalanced pattern and thus do not provide evidence for binary branching.

$$
\begin{aligned}
& \text { Jan zei dat Els ziek is en Peter }<* \text { vervangt }>\text { haar }<\text { vervangt }>\text {. } \\
& \text { Jan said that Els ill is and Peter replaces her } \\
& \text { 'Jan said that Els was ill and Peter will replace her.' }
\end{aligned}
$$

\subsection{Coordinators}

This section provides more detailed information about the syntactic behavior, interpretation and use of individual coordinators. We will focus on the coordinators listed in (255), which are all common in colloquial speech. The more formal coordinators mentioned in Section 1.1, sub III, will be discussed only in as far as they shed light on issues that the coordinators in (255) cannot handle. Section 1.4.1 starts by discussing the simple coordinators; the correlative forms will follow in Section 1.4.2.

(255) a. Simple coordinators: en 'and', of 'or', noch 'neither', maar 'but', want 'because', dus 'so'

b. Correlative coordinators: en ... en ... 'as well as', zowel ... als ... 'both ... and ...', of ... of ... 'either ... or ...', noch ... noch ... 'neither ... nor ...'

We will focus on three recurring issues. The first one is whether the coordinator imposes categorial or semantic restrictions on its coordinands. While the coordinators en 'and' of 'or' seem fairly unrestricted in this respect, coordinators like maar 'but', want 'because' and dus 'so' seem to be restricted to propositional and predicative phrases. This difference is illustrated in (256) for maar 'but' by showing that it can be used for linking coordinating clauses (propositions) but not for linking coordinating referential noun phrases (entities). 
(256) a. [[Jan gaat naar school] en/maar [Marie blijft thuis]].

Jan goes to school and/but Marie stays home

b. [Jan en Marie] gaan naar school.

Jan and Marie go to school

$\mathrm{b}^{\prime}$. *[Jan maar Marie] gaan/gaat naar school.

Jan but Marie $\quad$ go $_{\mathrm{pl}} /$ goes $_{\mathrm{sg}}$ to school

The second issue concerns subject-verb agreement triggered by coordinate structures functioning as subjects. We will describe these by means of resolution rules of the type in (257); cf. Corbett (2000: ch.6).

(257) Nominal coordinate structures with:

a. singular coordinands coordinated by en 'and' are plural

b. singular coordinands coordinated by of 'and' are singular

These rules see to it that the conjunctive nominal coordinate structure in (258a) triggers plural agreement on the finite verb, while the disjunctive nominal coordinate structure in (258b) triggers singular agreement.

(258) a. Jan en Peter komen/*komt morgen.

Jan and Peter come $_{\mathrm{pl}} /$ comes $_{\mathrm{sg}}$ tomorrow

'Jan and Peter will come tomorrow.'

b. Jan of Peter komt/*komen morgen.

Jan or Peter comes $_{\mathrm{sg}} /$ come $_{\mathrm{pl}}$ tomorrow

'Jan or Peter will come tomorrow.'

However, in some cases no generally accepted resolution rules seem to be available. This is illustrated by the fact that example (259a) is highly marked no matter the form of the finite verb: both the third person form komt 'comes' selected by the proper noun Jan and the first person form kom 'come' selected by the referential pronoun $i k$ 'I' give rise to a degraded result.

(259) a. ${ }^{\%}[\mathrm{Jan}$ of ik] komt/kom dat boek ophalen.

Jan or I comes/come that book prt.-get

b. Jan komt/Ik kom dat boek ophalen.

Jan comes $_{3 \mathrm{p}} / \mathrm{I} \mathrm{come}_{1 \mathrm{p}}$ that book prt.-get

'Jan/I will pick up that book.'

The third issue involves the question as to whether the meaning contribution of the coordinator can be exhaustively described by using the descriptions normally found in the formal-logical literature in terms of conjunction and disjunction. One helpful distinction here is between symmetrical and asymmetrical coordination: because conjunction and disjunction exhibit the property of commutativity discussed in Section 1.3, sub IIIA, we expect coordinators with a purely truthconditional meaning to exhibit the same property, while coordinators with an additional meaning may lack this property. This gives rise to the distinction in (260). 
(260) a. Symmetrical coordination: truth-conditional meaning aspects only.

b. Asymmetrical coordination: additional temporal, causal, concessive, conditional or other meaning aspects.

The notion of (a)symmetry refers to the fact that the coordinands can(not) swap places without affecting the truth conditions of the sentence. This distinction, which is frequently discussed in relation to the coordinator en 'and' especially, is illustrated in (261). The coordinate structures in the (a)-examples are symmetrical in that changing the order of the coordinands does not affect the truth conditions. The (b)-examples, on the other hand, are asymmetrical as they express different relations between the two coordinands: example (261b) gives the death of the female person in question as the reason for burying her, while (261 b') gives the burial as the cause of her death; see Dik (1968:57) and Van Oirsouw (1987:13), among many others. Other special readings of the coordinators will be discussed as well.

(261) a. [[Jan is ziek] en [Marie is op vakantie]].

[symmetrical coordination] Jan is ill and Marie is on vacation

$\mathrm{a}^{\prime}$. [[Marie is op vakantie] and [Jan is ziek]]. Marie is on vacation and Jan is ill

b. [[Ze stierf] en [we begroeven haar]]. she died and we buried her

$b^{\prime}$. [[We begroeven haar] en [ze stierf]]. we buried her and she died

\subsubsection{Simple coordinators}

This section discusses the simple coordinators en 'and', of 'or', noch 'neither', maar 'but', want 'because', and dus 'so'. Although Section 1.1, sub IV, has shown that the meaning of these simple coordinators has a logical (truth-conditional) core, other meaning aspects may be present as well. The core function of coordinators is that they define a certain relationship between its coordinands, and Dik (1968: section 12.5) suggests that their meaning contribution should receive a description in these terms. He proposes the following scale of semantic specificity, which indeed seems to provide a proper place to all simple coordinators in (255a); note that Dik (1968:278) himself analyzes $d u s$ in (262d) as a clause adverbial.

(262) a. combinatory: en 'and' and noch 'nor'

b. alternative: of 'or'

c. adversative: maar 'but'

d. causal: want 'because' and dus 'so'

Dik suggests that the order of the relations given in (262) correlates with a decrease of the use of the coordinators and an increase of the restrictions on the coordinands. The data discussed in the following subsections support this: the restrictions imposed by the coordinators en and of on the coordinands are indeed less severe than those imposed by the remaining ones. We will also discuss for these coordinators issues concerning subject verb agreement and more special interpretations of the coordinate structures as a whole. 


\section{The simplex coordinator en 'and'}

The coordinator en 'and' is the most frequently used coordinator, as is clear from the fact that it is in the top 5 of the frequency lists in Uit den Boogaart (1975: list C) and De Jong (1979: list C1); it therefore need not surprise us that Subsection A will show that it is quite versatile in its use. Prototypical cases of subject-verb agreement can be captured relatively easily by means of a small set of resolution rules but Subsection B will show that there are also a number of cases that require special discussion. Subsections C and D conclude with a discussion of the meaning and interpretation of coordinate structures with en 'and', which will bear out that more can be said about this than has been done in terms of truth conditions in Section 1.1, sub IV. Coordinate structures with en expressing logical conjunction are symmetrical in the sense that the coordinands can be reordered without affecting the truth conditions of the construction as a whole, but Subsection $\mathrm{C}$ will show that en can also occur in asymmetrical coordinate structures, that is, structures in which reordering of the coordinands will affect the truth conditions. Subsection D discusses various cases with a more special interpretation. We will not discuss the distinction between distributive and cumulative readings found with nominal conjunctive coordinate structures (as well as plural noun phrases), as this was the main topic of Section 1.1, sub IVD.

\section{A. Restrictions on the coordinands}

The coordinator en 'and' is highly productive as a linker and is probably the least restrictive one when it comes to the nature of its coordinands. This subsection will show that it can be used to coordinate phrases of various syntactic categories and that the resulting structures can have a variety of syntactic functions (e.g., as argument, predicate, adverbial, and even more). Although there are various syntactic and semantic co-occurrence restrictions on the coordinands that amount to saying that they must be similar in a specific sense, we will see that there are various "mixed" cases when it comes to their grammatical specification for the features number, person and gender.

\section{Categorial/semantic restrictions on the coordinands}

The examples in (263) show that the coordinator en 'and' is highly productive as a linker; it can link clauses (CPs), noun phrases (DPs), APs and PPs.

(263) • Category of the coordinands

a. [[Jan is ziek] en [Marie gaat op vakantie]]. Jan is ill and Marie goes on vacation

b. [[De man] en [de vrouw]] zingen een lied. the man and the woman sing a song

c. Jan is [ziek en moe]. Jan is ill and tired

d. Jan wacht [[op een boek] en [op een CD]]. Jan waits for a book and for a CD

The illocutionary type of clauses does not seem to affect the acceptability of the resulting coordinate structures: declarative (Decl), interrogative $(\mathrm{Q})$, and imperative 
(Imp) clauses can all be coordinated. The case of declaratives was already illustrated in (263a), and the cases of interrogatives, imperatives and whexclamatives are illustrated in (264). Although not all linguists consider exclamatives as a special illocutionary clause type, it is worthwhile to note that exclamative clauses can also be coordinated.

(264) - Illocutionary types of clausal coordinands

a. [[Is Jan ziek] en [gaat Marie op vakantie]]?

$[$ yes/no-Q] is Jan ill and goes Marie on vacation 'Is Jan ill and is Marie going on vacation?'

$\mathrm{a}^{\prime}$. [[Wie is er ziek] en [wie gaat er op vakantie]]? [wh-Q] who is there ill and who goes there on vacation

'Who is ill and who is going on vacation?'

$\mathrm{a}^{\prime \prime}$. [[Wie is er ziek] en [gaat Marie op vakantie]]? who is there ill and goes Marie on vacation

[“mixed" Q]

'Who is ill and is Marie going on vacation?'

b. [[Neem een maand vrij] en [ga op vakantie]]! take a month off and go on vacation

'Take a month's leave and go on vacation!'

c. [[Wat draagt Jan een mooi horloge] en what wears Jan a beautiful watch and

[wat heeft Els een prachtige ring aan haar finger]]!

what has Els a splendid ring on her finger

'What a nice watch Jan is wearing and what a splendid ring Els has on her finger!'

The examples in (263a) and (264) involve main clauses, but (265) shows that dependent clauses can also be conjoined. Again, the clauses can be declarative, interrogative or exclamative, but imperatives are excluded for the independent reason that they cannot be embedded.

- Embedded clauses

a. Els zei [[dat Jan ziek is] en [dat Marie op vakantie gaat]]. Els said that Jan ill is and that Marie on vacation goes 'Els said that Jan is ill and that Marie is going on vacation.'

b. Els vroeg [[of Jan ziek is] en [of Marie op vakantie gaat]]. [yes/no-Q] Els asked if Jan ill is and if Marie on vacation goes 'Els asked whether Jan is ill and whether Marie is going on vacation.'

$\mathrm{b}^{\prime}$. Els vroeg [[wie er ziek is] en [wie er op vakantie gaat]]. [wh-Q] Els asked who there ill is and who there on vacation goes 'Els asked who is ill and who is going on vacation.'

$\mathrm{b}^{\prime \prime}$. Els vroeg [[of Jan ziek is] en [wie er op vakantie gaat]]. [“mixed" Q] Els asked if Jan ill is and who there on vacation goes 'Els asked whether Jan is ill and who is going on vacation.' 
c. Je zal niet geloven [[wat een mooi horloge Jan droeg] en [wh-excl] you will not believe what a beautiful watch Jan wore and [wat een prachtige ring Els aan haar vinger had]]. what a beautiful ring Els on her finger had

'You will not believe what a nice watch Jan was wearing and what a splendid ring Els had on her finger.'

Extended verbal projections smaller than clauses (CPs) can also be conjoined; we will refer to such smaller projections as VPs for convenience, but the reader should keep in mind that these projections may be larger than what is called VP elsewhere in this work. The (a)-examples in (266) show that differences in size of the conjoined projections may evoke differences in meaning. The clausal conjunction in (266a) can be construed as referring to two independent events: Jan may have gone to Amsterdam for sight-seeing while, in addition, he may have bought a computer in his home town. The conjunction in $\left(266 \mathrm{a}^{\prime}\right)$, on the other hand, preferably refers to a single composite event: Jan went to Amsterdam and bought a computer there (or, perhaps, in order to buy a computer there). If the subject is quantified, as in the (b)examples, the difference is even more conspicuous as the two examples do not only differ in the number of events but also in the number of individuals involved in performing them.

(266) - Verbal coordinands of different sizes

a. [[Jan ging naar Amsterdam] en [hij kocht een PC]]. Jan went to Amsterdam and he bought a PC

'Jan went to Amsterdam and he bought a computer.'

$\mathrm{a}^{\prime}$. Jan [[ging naar Amsterdam] en [kocht een PC]]. Jan went to Amsterdam and bought a PC 'Jan went to Amsterdam and bought a computer.'

b. [[Iemand ging naar Amsterdam] en [iemand kocht een PC]]. someone went to Amsterdam and someone bought a PC 'Someone went to Amsterdam and someone bought a computer.'

$\mathrm{b}^{\prime}$. Iemand [[ging naar Amsterdam] en [kocht een PC]]. someone went to Amsterdam and bought a computer 'Someone went to Amsterdam and bought a computer.'

Meaning differences of this sort can be used for arguing against approaches that derive the primed examples from the primeless ones by conjunction reduction because the difference follows in a more natural way if we assume that the coordinands in the conjunctive coordinate structure in the primed examples are smaller, predicative projections of the main verbs gaan 'to go' and kopen 'to buy'; we return to this issue in Section 2.1.

Nominal conjunctions of different sizes are also possible. The fact that the nouns in the primeless examples in (267) are both preceded by the article de 'the' shows that we are dealing with fully expanded nominal projections (DPs), while the fact that the nouns in the primed examples share a single article suggests that we are dealing with smaller nominal projections which we will provisionally refer to as NP; note that, again, these projections may be larger than the projections for which we have used the notion NP elsewhere in this work. 
(267) - Nominal coordinands of different sizes

a. [[De mannen] en [de vrouwen $]]$ zingen een lied.

the men and the women sing a song

$\mathrm{a}^{\prime}$. De [[mannen] en [vrouwen]] zingen een lied.

the men and women sing a song

b. De regisseur en de producent van deze film kregen/*kreeg een Oscar. [DPs] the director and the producer of this movie got $_{\mathrm{pl}} /$ got $_{\mathrm{sg}}$ an Oscar

$\mathrm{b}^{\prime}$. De regisseur en producent van deze film $\mathrm{kreeg} /{ }^{*} \mathrm{kregen}$ een Oscar. [NPs] the director and the producer of this movie got $_{\mathrm{sg}} /$ got $_{\mathrm{pl}}$ an Oscar

Again there are clear differences in meaning. Example (267a) may be ambiguous, due to the fact that the conjunction en can be taken to be either distributive or cumulative: cf. Section 1.1, sub IVD. In the distributive case, we are dealing with two separate events in which a group of women and a group of men are each singing a song each, while in the cumulative case we are dealing with a single event in which the men and women are singing a song together. Example (267a'), on the other hand, has only one reading: we are dealing with a single group of men and women singing a song together. The semantic difference in the (b)-examples is even clearer, as it is also reflected by subject-verb agreement: the coordinate structure in (267b) refers to two distinct individuals and triggers plural agreement on the verb, while the coordinate structure in $\left(267 b^{\prime}\right)$ refers to a single individual and triggers singular agreement on the verb; we refer the reader to Section N3.3.2.4 for a more extensive discussion of cases like these. It will be clear that meaning and agreement differences of this kind conflict with approaches that derive the primed examples from the primeless examples by conjunction reduction.

It is less easy to argue that adjectival coordinands may differ in the same way as the verbal and nominal ones. One argument might be built on the examples in (268). Examples (268a) is unambiguous and states that Jan has two independent properties: he is very young and he is also very inexperienced. The sentence Jan is erg jong en onervaren, on the other hand, is ambiguous in the way indicated by the bracketing in the two (b)-examples: the reading in (268b) asserts that Jan has the two independent properties of being very young and of being inexperienced, while $\left(268 b^{\prime}\right)$ asserts that he has the (single) complex property of being young and inexperienced; the modifier erg modifies this complex property, with the resulting entailments that Jan is very young and that he is very inexperienced. The structures in the two (b)-examples can be distinguished by means of intonation: (268b) allows emphatic accent on en, while $\left(268 b^{\prime}\right)$ does not.

(268) - Adjectival coordinands of different sizes

a. Jan is [[erg jong] en [erg onervaren]]. Jan is very young and very inexperienced

b. Jan is [[erg jong] en [onervaren]]. Jan is very young and inexperienced

$\mathrm{b}^{\prime}$. Jan is [erg [jong en onervaren]]. Jan is very young and inexperienced

[multiple-property reading]

[multiple-property reading]

[complex-property reading] 
Complex properties are normally composed of atomic properties that "fit" together in a natural way. This holds for the properties referred to by young and inexperienced but not for those referred to by old and inexperienced, which would lead to the expectation that the complex-property reading is more difficult to get in coordinate structures with the adjectives old and inexperienced. Judgments on the (b)-examples in (269) are not sharp but seem to go in this direction.

(269) a. Jan is [[erg oud] en [erg onervaren]].

Jan is very old and very inexperienced

b. Jan is [[erg oud] en [onervaren]]. Jan is very old and inexperienced

$\mathrm{b}^{\prime}$. 'Jan is [erg [oud en onervaren]]. Jan is very old and inexperienced [multiple-property reading]

[multiple-property reading]

[complex-property reading]

Note further that the complex-property reading is the only possible one in periphrastic comparative constructions such as (270). This can perhaps be attributed to the coordinate structure constraint: the postverbal dan-phrase can apparently be associated with to the full AP minder jong en onervaren in (270a) but not with the first AP-coordinand minder jong in (270b). We will not digress on this here but leave it to future research.

(270) a. dat Jan [minder [jong en onervaren]] is dan Peter. that Jan less young and inexperienced is than Peter 'that Jan is less young and inexperienced than Peter.'

b. *dat Jan [[minder jong] en [onervaren]] is dan Peter. that Jan less young and inexperienced is than Peter

The primeless examples in (271) suggest that adpositional coordinate structures also allow modifiers to take scope over both coordinands: the use of strikethrough indicates ellipsis as the result of backward conjunction reduction. However, it should be noted that alternative analyses for the primed examples present themselves, according to which we are dealing with two conjoined prepositions and just a single prepositional phrase.

(271) a. een film over Nederland [direct [[voor en [na WOII]] a movie about Netherland immediately before and after WOII 'A movie about the Netherlands immediately before and after WOII.'

$\mathrm{a}^{\prime}$. een film over Nederland [direct [[voor en na WOII $]^{\text {val }}$ a movie about Netherland immediately before and after WOII

b. Er reed een politieauto [vlak [[voor bus] en [achter de bus]]]. there drove a police.car right in.front.of and behind the bus 'There was a police car directly in front of and behind the bus.'

$b^{\prime}$. Er reed een politieauto [vlak [[voor en achter] de bus]]. there drove a police.car right in.front.of and behind the bus

We will opt for the conjunction reduction analysis in the primeless examples because we find the same phenomenon in examples such as (272), which cannot be analyzed by means of preposition conjunction. But even if this argument is not adequate for (271), we can still conclude on the basis of (272) that prepositional 
projections smaller than full-fledged PPs can be conjoined, as the modifier vlak is arguably an integrated part of PPs (as is clear from the fact that it must be piedpiped under topicalization).

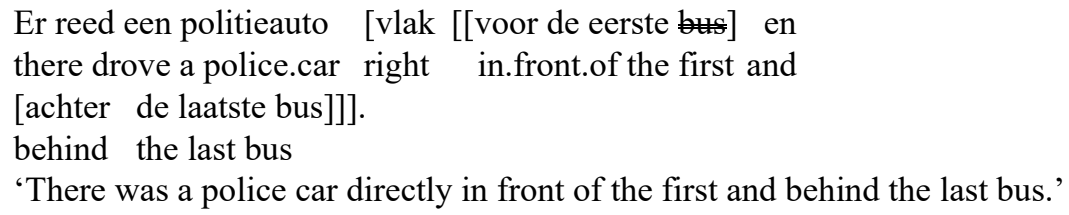

'There was a police car directly in front of the first and behind the last bus.'

Examples like (271) and (272) raise the question as to whether syntactic ${ }^{\circ}$ heads (V, $\mathrm{N}, \mathrm{A}$ and $\mathrm{P}$ ) can be conjoined at all. Because of the complexity of this issue and the fact that head conjunction analyses compete with conjunction reduction analyses, we will not discuss this issue here but postpone it to Section 2.1, where the discussion will find a more natural place.

\section{Syntactic functions of conjunctive coordinate structures}

Coordinate structures with en can be used in virtually all conceivable syntactic functions: the previous subsection has already shown that they can be used as full sentences, but they can also be used as arguments, complementives or supplementives, and various types of adverbial phrases. Some typical examples are given in (273).

- Syntactic function of coordinate structure

a. [[De man] en [de vrouw]] zingen een lied.

[subject] the man and the woman sing a song

$a^{\prime}$. Ik ontmoette [Jan en Marie]. I met Jan and Marie

$\mathrm{a}^{\prime \prime}$. Jan wacht [[op een boek] en [op een CD]]. Jan waits for a book and for a CD

b. Jan is [ziek en moe]. Jan is ill and tired

$\mathrm{b}^{\prime}$. Jan ging [ziek en moe] naar bed. [direct object] Jan went ill and tired to bed

c. Jan werkt [snel en nauwkeurig]. Jan works fast and accurately

$\mathrm{c}^{\prime}$. Jan werkt [morgen en overmorgen]. Jan works tomorrow and the.day.after.tomorrow

[prepositional object] [complementive] [supplementive]

[manner adverbial]

[time adverbial]

$\mathrm{c}^{\prime \prime}$. Jan werkt [in Amsterdam en in Utrecht]. Jan works in Amsterdam and in Utrecht

[place adverbial]

There are certain adverbial types that do not easily allow coordination, such as the modal adverbials in (274a), but it seems that the degraded status of the sentence is for purely semantic reasons: the modalities expressed by the two coordinands do not overlap and therefore we end up with a contradiction. If the modalities expressed do overlap, coordination is possible (with an intensifying reading as a side effect). 
(274) a. \$Jan komt [zeker en misschien].

Jan comes certainly and perhaps

b. Jan komt [vast en zeker].

Jan comes surely and certainly

'Jan will definitely come.'

Coordinate structures also occur below the level of clausal coordinands. The examples in (275) show that they can occur as nominal modifiers, as in the (a)examples, but also as smaller nominal projections, as in the (b)-examples where the modifiers have scope over both coordinands. Subsection 1 has already shown that similar examples can also be constructed with ease for adjectival and prepositional phrases, so we need not repeat this here.

(275) a. de [boeken [[in de bibliotheek] en [in de leeszaal]]] the books in the library and in the reading.room

$\mathrm{a}^{\prime}$. de [[[ongeopende] en [ongelezen]] boeken] the unopened and unread books

b. de [[boeken en tijdschriften] in de bibliotheek] the books and journals in the library

$\mathrm{b}^{\prime}$. de [ongelezen [boeken en tijdschriften]] the unread books and journals

We want to conclude by noting that coordinate structures can not only be used as complements of verbs but also of nouns, adjectives and prepositions. Example (276) provides three simple cases to illustrate this: the prepositional coordinate structures in (276a) and (276b) function as the complements of, respectively, the noun ouders and the adjective geïnteresseerd 'interested', and in (276c) the nominal coordinate structure functions as the ${ }^{\circ}$ complement of the preposition $o p$. Note in passing that the interpretation of (276a) may depend on the addressee's knowledge of Jan and Els: when they are brother and sister we are dealing with one set of parents, while we are dealing with two sets of parents when they are not.

(276) a. Ik ontmoet morgen de [ouders [[van Jan] en [van Els]]].

I meet tomorrow the parents of Jan and of Els

'I will meet the parents of Jan and (those) of Els tomorrow.'

b. Jan is [geïnteresseerd [[in taalkunde] en [in postzegels]]].

Jan is interested in linguistics and in stamps

c. Jan wacht [op [[een boek] en [een CD]]].

Jan waits for a book and a CD

\section{Coordinands of different types}

Subsection 1 has shown that conjunction of clauses is possible regardless of their illocutionary force. The examples in (277) make it clear, however, that it is not easy to conjoin clauses of different illocutionary types. The (a)-examples demonstrate that declaratives and interrogatives normally cannot be mixed: the interrogative part of these conjunctions is a polar yes/no-question but the same result would arise with the wh-question Wie is ziek? 'Who is ill?'. The (b)-examples illustrate that declaratives and imperatives normally cannot be mixed (although we will discuss 
some exceptional/special cases in Subsection C). The (c)-examples show that mixing declaratives and wh-exclamatives is not easily possible either; for convenience we italicized the exclamative pronoun wat as well as the adjective it modifies. Note that $\left(277 c^{\prime}\right)$ is fully acceptable when the two clauses are both pronounced with an exclamation contour. This is possible because declaratives preceded by en can be used as exclamatives; cf. Jan is ziek. Oh, en Marie gaat op vakantie! Vreselijk! 'Jan is ill. ... And Marie will go on holiday! Terrible!'.
a. *[J]an is ziek] en [gaat Marie op vakantie?]]
[Decl \& Q]
Jan is ill and goes Marie on vacation
$\mathrm{a}^{\prime}$. *[[Is Jan ziek?] en [Marie gaat op vakantie]].
is Jan ill and Marie goes on vacation
b. *[[Jan is ziek] en [ga op vakantie!]]
[Q \& Decl]
Jan is ill and go on vacation
$\mathrm{b}^{\prime} .{ }^{\#}[[\mathrm{Ga}$ op vakantie!] en [Jan is ziek $]]$. go on vacation and Jan is ill
c. *[J]an is ziek] en [wat gaat Marie vaak op vakantie!]] [Decl \& wh-excl] Jan is ill and what goes Marie often on holdiay
$\mathrm{c}^{\prime}$. \#[[Wat is Jan ziek!] en [Marie gaat op vakantie]]. what is Jan ill and Marie goes on holiday
[Decl \& Imp]
[Imp \& Decl]

- Mixing declaratives and clauses of other illocutionary types is impossible

Although coordination of a declarative and a clause of a different illocutionary type is normally not possible, there are exceptional cases. First, note that it is quite common, for instance, to find in narratives examples such as in (278a-b), in which a declarative is followed by a rhetoric question. The acceptability of such examples may be due to the fact that the question is immediately answered by the speaker, so that together they simply add a new proposition to the discourse. Semantically speaking, we are therefore dealing with the coordination of two declaratives. Example (278c) seems to be of a similar type but now the answer to the question is not given by the speaker himself but by the addressee. Examples of the type in (278) seem to play an important role in the organization/development of a narrative or a discourse.

(278) a. [[Jan stapte de kamer binnen] en [wie stond daar]]? Zijn beste vriend! Jan stepped the room inside and who stood there his best friend 'Jan stepped into the room and who was there? His best friend!'

b. [[De agent gaf Jan een boete] en [wat deed de oen]]? Hij begon te schelden! the copper gave Jan a fine and what did the moron he started to curse 'The copper gave Jan a fine and what did the moron do? He started cursing!'

c. Goed, [[je sprak hem aan] en [wat zei hij toen]]? okay you spoke him prt. and what said he then 'Okay, you addressed him and what did he say then?'

Second, it should be noted that examples such (279a) are fully acceptable. Under the plausible assumption that exclamative hoe is part of a reduced clause, we may be dealing with a potential counterexample to the claim that declaratives and exclamatives cannot be coordinated. The reason for this may be that the exclamative 
in (279a) performs a similar relation to the first clause as the manner adverb hard in the so-called specifying conjunction construction in (279a); see Section 1.4.1, sub ID, for more discussion of this construction. We assume that this modification relation between the two coordinands suffices to license the coordinate structure in (279a).

(279) a. [[Jan sloeg 'm op z'n gezicht]], en [hoe!]].

Jan hit him in the face and how

b. [[Jan sloeg 'm op z'n gezicht]], en [hard ook!]]. Jan hit him in the face and hard too

Given that in the prototypical case declaratives cannot be combined with clauses expressing a different, more marked illocutionary force, we may expect that the same holds for all other combinations. That this expectation is indeed borne out is illustrated in (280).

(280) - Mixing non-declarative clauses of different illocutionary types is impossible

a. *[[Is Jan ziek?] en [ga op vakantie!]] is Jan ill and go on vacation

$\mathrm{a}^{\prime} . *[\mathrm{Ga}$ op vakantie!] en [is Jan ziek?]] go on vacation and is Jan ill

b. *[[Is Jan ziek] en [wat gaat Marie vaak op vakantie!]] [Q \& wh-excl] is Jan ill and what goes Marie often on holdiay

$\mathrm{b}^{\prime}$. *[[Wat is Jan ziek!] en [gaat Marie op vakantie?]]. what is Jan ill and goes Marie on holiday

c. *[[Wat is Jan ziek!] en [ga op vakantie!]] [wh-excl \& Imp] what is Jan ill and go on vacation

$\mathrm{c}^{\prime}$. *[Ga op vakantie!] en [wat is Jan ziek!]]. [Imp \& wh-excl] go on vacation and what is Jan ill

The restrictions on mixing clauses of different types raises the question as to whether other types of mixed conjunctions are possible. The examples in (281) provide evidence that $e n$ 'and' can link phrases of different categories.

(281) a. Jan is [[een geschikte kandidaat] en [geïnteresseerd in deze baan]]. [DP\&AP] Jan is a suitable candidate and interested in this job

'Jan is a suitable candidate and interested in this job.'

b. Jan is [[geïnteresseerd in deze baan] en [goed op de hoogte]]. [AP\&PP] Jan is interested in this job and well in the know

'Jan is interested in this job and well-informed.'

c. Jan is [[een geschikte kandidaat] en [goed op de hoogte]]. Jan is a suitable candidate and well in the know 'Jan is a suitable candidate and well-informed.'

$[\mathrm{DP} \& \mathrm{PP}]$

Section 1.3 has already indicated that this kind of mixed conjunctions is possible only if the coordinands can have the same syntactic/semantic function (here: complementive) and occupy the same position as the coordinate structure as a whole: example (282c), for instance, is excluded because nominal and clausal 
objects occupy different positions relative to the verbs in clause-final position. We refer the reader to Section 1.3, sub I, for more examples.

(282) a. dat Jan mij een grap vertelde.

that Jan me a joke told

'that Jan told me a joke.'

b. dat Jan mij vertelde dat hij geslaagd was. that Jan me told that he passed was 'that Jan told me that he had passed the exam.'

c. dat Jan mij $<*$ vertelde $>$ [[een grap] en [dat hij geslaagd was]] $<$ ?"vertelde $>$. that Jan me told a joke and that he passed was

In nominal coordinate structures, the coordinands may differ in all nominal features: number, person and gender. Again the main restriction is that they may have the same syntactic function and appear in the same syntactic position as the coordinate structure as a whole. We will see in Subsection B, however, that mixed cases like these are sometimes difficult to integrate into the clause.

(283) a. Ik heb $\left.\left[[\mathrm{Jan}]_{\mathrm{sg}} \text { en [zijn kinderen }\right]_{\mathrm{pl}}\right]$ daar gezien.

I have Jan and his children there seen

'I have seen Jan and his children there.'

b. Ik heb $\left[\mathrm{Jan}_{3 \mathrm{p}}\right.$ en $\left.\mathrm{jou}_{2 \mathrm{p}}\right]$ daar gezien.

I have Jan and you there seen

'I have seen Jan and you there.'

c. Ik heb [[de man $]_{\text {non-neuter }}$ en [zijn hondje $\left.]_{\text {neuter }}\right]$ daar gezien.

I have the man and his dog $\operatorname{dim}_{\text {dim }}$ there seen

'I have seen the man and his little dog there.'

\section{Conclusion}

The limited set of examples in this subsection has made it clear that there are hardly any syntactic restrictions on coordinate structures with en. First, the coordinands are not liable to restrictions as to their categorial status. Second, coordinate structures can have various syntactic functions: they can be full-fledged clauses, clausal constituents of various sorts, but also parts of clausal constituents. There are various syntactic and semantic co-occurrence restrictions on the coordinands: they must be able to have the same function and occupy the same position as the coordinate structure as a whole, and clausal coordinands must (normally) be of the same illocutionary type. They do not have to be similar in all respects, however, as is clear from the fact that nominal coordinands may differ in number, person and gender features.

\section{B. Agreement with nominal coordinands with "mixed" feature specifications}

Subsection A3 has shown that nominal coordinands in conjunctive coordinate structures may differ in grammatical features like number, person and gender. This subsection will introduce a number of RESOLUTION RULEs that describe how the grammatical features of nominal coordinate structures as a whole depend on the features of their coordinands; cf. Corbett (1983; 2000:ch.6). These rules will be empirically motivated by observations related to pronominal ${ }^{\circ}$ binding (and deixis), 
and agreement. We will also show that in some cases there are no generally accepted resolution rules and that this may make it occasionally difficult or even impossible to integrate nominal conjunctions into larger syntactic structures.

\section{Person}

The examples in (284) show that the nominal coordinands can easily differ in person specification: a first person coordinand can co-occur with a second or third person coordinand, and a second person coordinand can co-occur with a third person coordinand. The order of coordinands is not syntactically significant although there are politeness and modesty conventions dictating that first person pronouns come last and (less stringent) that second person pronouns follow third person pronouns.

(284) a. $\quad\left[\mathrm{Jan}_{3 \mathrm{p}} / \mathrm{jij}_{2 \mathrm{p}}\right.$ en $\left.\mathrm{ik}_{1 \mathrm{p}}\right]$ zijn goede vrienden. Jan/you and I are good friends

b. $\quad\left[\mathrm{Jan}_{3 \mathrm{p}}\right.$ en $\left.\quad \mathrm{jij}_{2 \mathrm{p}}\right]$ zijn goede vrienden. Jan and you are good friends

c. $\left[\mathrm{Jan}_{3 \mathrm{p}}\right.$ en $\left.\mathrm{Marie}_{3 \mathrm{p}}\right]$ zijn goede vrienden. Jan and Marie are good friends

Coordinate structures such as found in (284) are only used when this is needed for clarity; if the context makes it sufficiently clear who are intended, the use of the examples in (285) is much preferred.

(285) a. Wij $\mathrm{W}_{1 \mathrm{p}}$ zijn goede vrienden.

we are good friends

b. Jullie 2 zijn goede vrienden. you are good friends

c. $\mathrm{Zij}_{3 \mathrm{p}}$ zijn goede vrienden. they are good friends

The fact that the examples in (284) and (285) can be equivalent in certain contexts shows that the full coordinate structure in (284a) and (284b) are, respectively, first and second person. This is confirmed by the binding facts in (286), which show that the coordinate structures in (284) and their corresponding pronoun in (285) both agree with the same reflexive pronoun. Similar facts arise in the case of pronominal deixis, but we will not demonstrate this here.

(286) a. [[ $\left.\operatorname{Jan}_{3 \mathrm{p}} / \mathrm{jij}_{2 \mathrm{p}}\right]$ en $\left.\mathrm{ik}_{1 \mathrm{p}}\right]$ wassen onszelf $\mathrm{f}_{1 \mathrm{p}}$. $\mathrm{Jan} / \mathrm{you}$ and I wash ourselves

b. $\left[\mathrm{Jan}_{3 \mathrm{p}}\right.$ en $\left.\mathrm{jij}_{2 \mathrm{p}}\right]$ wassen jezelf $\mathrm{j}_{2 \mathrm{p}}$. Jan and you wash yourselves

c. $\left[\begin{array}{lll}\mathrm{Jan}_{3 \mathrm{p}} & \text { en } & \mathrm{Marie}_{3 \mathrm{p}}\end{array}\right]$ wassen zichzelf $3 \mathrm{p}$. Jan and Marie wash themselves
$\mathrm{a}^{\prime}$. Wij $\mathrm{ip}_{\mathrm{p}}$ wassen onszelf $\mathrm{f}_{1 \mathrm{p}}$. we wash ourselves
$\mathrm{b}^{\prime}$. Jullie $2 \mathrm{p}$ wassen jezelf $\mathrm{fp}_{2 \mathrm{p}}$. you wash yourselves
$\mathrm{c}^{\prime} . \mathrm{Zij}_{3 \mathrm{p}}$ wassen zichzelf $\mathrm{z}_{3 \mathrm{p}}$. they wash themselves

The observations above can readily be captured by the "elsewhere" rules in (287). Elsewhere rules apply in a fixed order: if a rule $n$ applies, the search is terminated; if rule $n$ does not apply, the search continues with rule $n+1$. The following rules 
adapted from Corbett (1983:176) provide an adequate description of the Dutch data in this subsection; cf. Van Koppen (2005:28-29).

(287) - Resolution rules for person

a. If the conjuncts include a first person, first person agreement will be used for the conjunction as a whole.

b. If the conjuncts include a second person, second person agreement is used for the conjunction as a whole.

c. Third person agreement is used for the conjunction as a whole (default).

The (a)-examples match rule (287a), so that the search will be canceled and first person will be assigned to the coordinate structure as a whole. The (b)-examples do not match rule (287a) and the search will therefore continue with (287b); this rule matches these examples, and second person will be assigned to the coordinate structure as a whole. The (c)-examples do not match the two rules in $(287 \mathrm{a} \& \mathrm{~b})$; the coordinate structure will therefore be assigned third person in accordance with the default rule in $(287 \mathrm{c})$.

\section{Number}

Corbett (1983/2000) claims that the rule for number resolution is relatively simple: conjunctive nominal coordinate structures are non-singular. For languages such as Dutch which do not have dual forms, this entails that they are plural. This holds for coordinate structures with proper names or referential personal pronouns regardless of whether the coordinate structure is construed as distributive or cumulative; see the examples in (288), as well as in $(284) /(286)$ from the previous subsection.

- Proper nouns and referential pronouns

a. [Jan en Peter] hebben/*heeft (beiden/samen) de tafel opgetild. Jan and Peter have/has both/together the table prt.-lifted 'Jan and Peter have lifted the table.'

b. [Jij en ik] hebben (beiden/samen) de tafel opgetild. you and I have both/together the table prt.-lifted 'You and me have lifted the table.'

The examples in (289) show that conjoined definite and indefinite noun phrases also trigger plural agreement. We point out in passing that Haeseryn et al. (1997:1478) provide an example with indefinite noun phrases for which they claim that agreement can be either singular or plural (Er zijn/is een man en een vrouw aan de deur geweest 'there have/has been a man and a woman at the door'); some speakers do allow singular agreement of such examples with a kind of group reading of the noun ("a man with a woman"), while other speakers consider such examples quite artificial. The "group" reading seems harder to get when the verb is dynamic, as in (289). 
(289) - Definite and indefinite [+COUNT] noun phrases

a. $\left[[\text { De man }]_{\mathrm{sg}} \text { en }[\mathrm{de} \text { vrouw }]_{\mathrm{sg}}\right]_{\mathrm{pl}} \quad \operatorname{lopen}_{\mathrm{p}} /{ }^{*}{ }^{\mathrm{loopt}} \mathrm{sg}$ op straat. the man and the woman walk/walks in the.street

$\mathrm{a}^{\prime}$. Er lopen $\left._{\mathrm{pl}} /{ }^{*} \operatorname{loopt}_{\mathrm{sg}}\left[[\text { een man }]_{\mathrm{sg}} \text { en [een vrouw }\right]_{\mathrm{sg}}\right]_{\mathrm{pl}}$ op straat. there walk/walks a man and a woman in the.street

b. [[De man $]_{\mathrm{sg}}$ en $\left.\quad[\text { de vrouw }]_{\mathrm{sg}}\right]_{\mathrm{pl}}$ kletsen/*kletst $\mathrm{sg}_{\mathrm{sg}}$ op straat. the man and the woman chatter/chatters in the.street

$\mathrm{b}^{\prime}$. Er kletsen/*kletst $\left.t_{\mathrm{sg}}\left[[\text { een man }]_{\mathrm{sg}} \text { en [een vrouw }\right]_{\mathrm{sg}}\right]_{\mathrm{pl}}$ op straat. there chatter/chatters a man and a woman in the.street

Corbett's (1983/2000) formulation of the resolution rules makes it clear that he intends them to be used for coordinate structures with [+COUNT] coordinands. That this restriction is needed is also supported by the Dutch data in the remainder of this subsection; cf. Haeseryn et al. (1997:1476ff.), Cremers (2001), and Herringa \& De Vries (2008). A first illustration of this is that conjoined non-count noun phrases do not necessarily follow this rule: examples such as (290a) can trigger singular or plural agreement on the finite verb, and in ${ }^{\circ}$ expletive constructions such as (290b) singular agreement is even preferred.
a. [Zout en peper] staat $_{\mathrm{sg}} / \mathrm{staan}_{\mathrm{pl}}$ al op tafel. salt and pepper stands/stand already on table 'Salt and pepper is/are already on the table.'
b. Er staat $_{\mathrm{sg}}{ }^{\prime *}$ ? staan $_{\mathrm{pl}}$ al [zout en peper] op tafel. there stands/stand already salt and pepper on table 'Salt and pepper is/are already on the table.'

This choice for plural or singular agreement in (290a) may be related to semantics: zout en peper can be seen as referring to either "separate" or "complex" entities. This can be supported by the fact that the nouns may each take their own definite determiner, as in (291a), or share a determiner as in (291b); the coordinate structure in (291a) strongly prefers plural agreement on the finite verb, which suggests that we are dealing with two "separate" entities, while (291b) prefers singular agreement, which suggests that we are dealing with one "complex" entity.

(291) • Definite [-COUNT] NPs

a. [[Het zout] en [de peper]] $\operatorname{staan}_{\mathrm{pl}} / ?$ ? $\mathrm{staat}_{\mathrm{sg}}$ al op tafel. the salt and the pepper stand/stands already on table

b. [Het [zout en peper]] staat $_{\mathrm{sg}} \mathrm{g}^{\text {? }} \mathrm{staan}_{\mathrm{pl}}$ al op tafel. the salt and pepper stands/stand already on table

Note in passing that coordinate structures with non-count nouns denoting "complex" entities may differ in agreement behavior from logically equivalent expressions with plural count nouns, as is shown by the contrast between the two examples in (292); the formal plural marking on the noun talen in (292b) triggers obligatory plural marking on the verb. This can also be observed by the fact that plurale tantum non-count nouns such as hersenen 'brains' and ingewanden 
'intestines' also trigger plural subject-verb agreement: Er zitten/*zit hersenen in je hoofd 'there are brains in your head'.

(292) a. Er wordt $/$ worden hier Engels en Duits gesproken. there is/are here English and German spoken 'English and German are spoken here.'

b. Er worden/*wordt hier twee talen gesproken: Engels en Duits. there are/is here two languages spoken English and German 'Two languages are spoken here: English and German.'

Similar agreement facts can be observed with bare BARE-INF nominalizations (without a determiner) like roken 'smoking' and drinken 'drinking' in (293): the singular agreement in (293a) is related to the fact that the habit of smoking and drinking is presented as a characteristic of a certain lifestyle, while the plural agreement in (293b) is due to the fact that this examples expresses that the two habits often go together. The two primed examples show that we find a similar correlation as in (290) with respect to the number of determiners that can be used in the corresponding DET-INF nominalization in the primed examples and subject-verb agreement.

\section{- Nominalizations}

a. [Roken en drinken] is/?zijn ongezond. smoke and drink is/are unhealthy 'Smoking and drinking is unhealthy.'

$a^{\prime}$. [Dit [roken en drinken]] is/*zijn ongezond. this smoke and drink is/are unhealthy

b. [Roken en drinken] gaan/" gaat vaak samen. smoke and drink go/goes often together 'Smoking and drinking often go together.'

$\mathrm{b}^{\prime}$. [[Het roken] en [het drinken]] gaan/?"gaat vaak samen. the smoke and the drink go/goes often together

The contrast is not restricted to non-count nouns. Similar examples with count nouns are given in (294): the coordinate structure in (294a) reference is to two individuals while in the coordinate structure in (294b) refers to a single individual who happens to be the speaker's colleague as well as his best friend.

- Definite [+COUNT] NPs

a. [[Mijn collega] en [mijn beste vriend]] komen $_{\mathrm{pl}}$ op bezoek. [2 individuals] my colleague and my best friend come on visit

'My colleague and my best friend will visit me.'

b. [Mijn [collega en beste vriend]] komt sg op bezoek. my colleague and best friend comes on visit

'My colleague and best friend will visit me.'

Assume that it is justified to put examples such as (290a), (293) and (294) aside because the conjunctions zout en peper, roken en drinken and collega en beste vriend are more or less fixed collocations. Even then, we cannot adopt the more general rule that all nominal coordinate structures are plural, as this clearly does not 
hold for coordinands containing the distributive quantifiers elk(e) 'each' or ieder(e) 'every', which normally trigger singular agreement on the verb.

- NPs with the distributive quantifiers elk 'each' and ieder 'every'

a. Elk boek/Elke CD moet $_{\text {sg }}$ genummerd worden. each book/each CD must numbered be 'Each book/Each CD must be numbered.'

$\mathrm{a}^{\prime}$. [[Elk boek $]_{\mathrm{sg}}$ en $\left.[\text { elke CD }]_{\mathrm{sg}}\right]$ moet $_{\mathrm{sg}} /$ moeten $_{\mathrm{pl}}$ genummerd worden. each book and each CD must/must numbered be 'Each book and each CD must be numbered.'

b. Iedere student/docent krijgt sg korting. every student/teacher gets discount 'Every student/teacher gets a discount.'

$\mathrm{b}^{\prime}$. [[Iedere student] en [iedere docent]] krijgt $_{\mathrm{sg}} /$ krijgen $_{\mathrm{pl}}$ korting. every student and every teacher gets/get discount 'Every student and every teacher gets a discount.'

Similar examples are given in (296) for singular noun phrases with geen 'no', and the negative pronouns niemand 'nobody' and niets 'nothing'. These examples sound somewhat forced; the intended meanings would normally be expressed by means of the shorter (and logically equivalent) disjunctions in the primed examples.

(296) a. Er stond $\mathrm{sg}_{\mathrm{sg}} /$ stonden $_{\mathrm{pl}}$ [[geen boom] en [geen struik]] in de tuin. there stood/stood no tree and no shrub in the garden 'There was no tree and no shrub in the garden.'

$a^{\prime}$. Er stond [geen [boom of struik]] in de tuin. there stood no tree or shrub in the garden 'There wasn't any tree or shrub in the garden.'

b. [[Niemand uit mijn klas] en [niemand uit mijn vriendenkring]] was $/{ }^{*}$ waren er. nobody from my class and nobody from my inner.circle was/were there 'There was nobody from my class and nobody from my inner circle.'

$\mathrm{b}^{\prime}$. [Niemand uit mijn [klas of vriendenkring]] was/*waren er. nobody from my class or inner.circle was/were there 'There was nobody from my class or inner circle.'

Something similar holds for conjoined generic noun phrases: the coordinate structures in the primeless examples trigger singular agreement, although Haeseryn et al. (1997:1478-9) claim that plural agreement is also possible as a marked option. It should be noted that the primeless examples in (297) are highly formal, and that the same meanings would be expressed in more informal speech by the shorter forms in the primed examples.

(297) a. [[Een hond die blaft] en [een hond die jankt]] bijt $/{ }^{\%}$ bijten niet. a dog that barks and a dog that whines bites/bite not

'A dog that barks and a dog that whines do not bite.'

$a^{\prime}$. [Een hond die [blaft of jankt]] bijt niet. a dog that barks or whines bites not

'A dog that barks or whines does not bite.' 
b. [[Hij die moordt] en [hij die brandsticht]] wordt $/^{\#}$ worden gestraft. he who kills and he who fire.sets is/are punished 'He who kills and he who commits arson will be punished.'

$\mathrm{b}^{\prime}$. [Hij die [moordt of brandsticht]] wordt gestraft. he who kills or fire.sets is punished 'He who kills or commits arson will be punished.'

De Vries \& Herringa (2008; section 3) suggest that the "exceptional" agreement patterns in (295) to (297) should be accounted for by appealing to the obligatory distributive (non-collective) interpretation of these examples.

Haeseryn et al. (1997:1477-8) note that the neuter nominal coordinate structure dit en dat 'this and that' always triggers singular agreement, whereas this does not hold for its non-neuter counterpart deze en die 'this and that' (we will ignore here the fact that the pronouns deze and die can also be construed as plural, that is, as "these" and "those", although this will become relevant shortly).

(298) a. Dit $t_{\text {neuter,sg }}$ en dat neuter,sg $\mathrm{kan}_{\mathrm{sg}} / * \mathrm{kunnen}_{\mathrm{pl}}$ opgeruimd worden. this and that can/can put.away be

'This and that can be tidied away.'

b. Deze $\mathrm{nnn-neuter,sg}_{\text {en }}$ die $_{\text {non-neuter,sg }}$ kunnen $_{\mathrm{pl}} / \mathrm{kan}_{\mathrm{sg}}$ opgeruimd worden. this and that can/can put.away be

'This and that can be tidied away.'

Example (299) shows that the contrast only arises if the demonstratives are used as pronominal arguments, and not as modifiers of a noun; in the latter case plural agreement is obligatory.

(299) a. Dit boek en dat artikel kunnen 1 p ${ }^{*} \mathrm{kan}_{\mathrm{sg}}$ opgeruimd worden. this book and that article can/can putaway be 'This book and that article can be put away.'

b. Deze jurk en die rok kunnen 1 p ${ }^{*} \mathrm{kan}_{\mathrm{sg}}$ opgeruimd worden. this dress and that skirt can/can put.away be 'This dress and that skirt can be put away.'

Herringa \& De Vries (2008) suggests that the special behavior of the coordinate structure dit en dat is related to the fact that dit and dat differ from deze and die in that they do not have to be used to refer to entities, but can also be used to refer to collectives or masses. Suppose that Jan and Marie are dividing a collection of CDs between each other. The demonstratives dit and dat are then used to refer to a subset, while deze and die are used refer to a collection of individual items.

(300) a. Dit is voor jou en dat is voor mij.

this is for me and that is for you

b. Deze zijn voor mij en die zijn voor jou. these are for me and those are for you

Furthermore, the contrast between the (a)-examples in (301) shows that die can only be used to refer to a specific contextually determined quantity of some substance denoted by non-neuter noun; in all other cases dat must be used. In other words, the 
primeless examples show that only dat can be used to refer to a specific type of substance.

(301) a. $\mathrm{Olie}_{[- \text {-nuter] }}, \mathrm{dat}_{[+ \text {neuter] }} / * \mathrm{die}_{[- \text {-neuter] }}$ is kostbaar.

oil that that is valuable

'Oil, that is valuable.'

$\mathrm{a}^{\prime}$. De olie [-neuter],$\quad \operatorname{die}_{[- \text {-neuter }]} / *$ dat $_{[+ \text {neuter] }}$ is kostbaar. the oil that/that is valuable

b. Goud $_{[+ \text {neuter }]}$, dat ${ }_{[+ \text {neuter }]}$ is kostbaar. gold that is valuable 'Gold, that is valuable.'

$\mathrm{b}^{\prime}$. Het $\operatorname{goud}_{[+ \text {neuter }]}$, dat $\mathrm{t}_{[+ \text {neuter }]}$ is kostbaar. the gold that is valuable

The fact that the neuter pronouns dit and dat do not have to refer to contextually determined entities but can also refer to indeterminate collectives and masses may give us a handle to understanding why the coordinate structure in (298a), dit en dat kan/*kunnen opgeruimd worden, behaves like a coordinate structure with indefinite non-count nouns in that it can trigger singular agreement on the finite verb, but it remains mysterious why singular agreement is obligatory. For completeness' sake, note that the examples in (302), in which the conjoined demonstratives dit 'this' and dat 'that' are qualified by the modifiers hier 'here' and daar 'there', respectively, are less restrictive in that singular and plural agreement are both possible: the acceptability judgments may differ from speaker to speaker and also seem to depend on the nature of the predicate and probably various other factors. The reason for this may be that the modifiers emphasize the individual nature of the referents of the demonstratives.

(302) a. Dit hier en dat daar $\operatorname{kan}_{\mathrm{sg}}{ }^{\left({ }^{(?)}{ }^{2} \mathrm{kunnen}\right.} \mathrm{pl}$ opgeruimd worden. this here and that there can/can put.away be

'This over here and that over there can be put away.'

b. Dit hier en dat daar wisselen $/{ }^{3}$ wisselt voortdurend van plaats. this here and that there change/changes continuously of place 'This over here and that over there swap places continuously.'

A puzzle that seems similar to the previous one is that the nominal coordinate structure het een en het ander 'the one thing as well as the other thing' in (303a), (which speakers often tend to confuse with the indefinite noun phrase het een en ander 'some things') also triggers singular agreement, especially in view of the fact that the more or less synonymous example in (303b) does have plural agreement. We leave this issue for future research.

(303) a. Het een en het ander is/*zijn onjuist. the one and the other is/are incorrect

b. Beide zijn/*is onjuist.

both are/is incorrect 
The primeless examples in (304) show that coordinated subject clauses normally trigger singular agreement; note that this also holds if the ${ }^{\circ}$ anticipatory pronoun het 'it' is present.

$$
\text { - Finite subject clauses (default case) }
$$

a. [[Dat Jan ziek is] en [dat Els afwezig is]] is/*zijn vervelend. that Jan ill is and that Els absent is is/are annoying 'That Jan is ill and that Els is absent is annoying.'

$a^{\prime}$. Het is vervelend [[dat Jan ziek is] en [dat Els afwezig is]]. it is annoying that Jan ill is and that Els absent is

b. [[Wie er waren] en [wat zij deden]] is/*zijn onduidelijk. who there were and what they did is/are unclear 'Who were present and what they did is unclear.'

$\mathrm{b}^{\prime}$. Het is onduidelijk [[wie er waren] en [wat zij deden]]. it is unclear who there were and what they did

The examples in (305) demonstrate that in some cases clausal coordinate structures may trigger either singular or plural agreement. The fact that this correlates with the number imposed by the nominal predicates een vervelende zaak/vervelende zaken suggests that the choice of singular or plural agreement is again related to semantics, viz., the question as to whether the two clauses refer to a single state of affairs or to separate states of affairs. Observe from the primed examples that we find the same contrast when the anticipatory pronoun het 'it' is present.

(305) - Finite subject clauses in examples with nominal predicates

a. [[Dat Jan ziek is] en [dat Els afwezig is]] is/*zijn een vervelende zaak. that Jan ill is and that Els absent is is/are an unpleasant situation 'That Jan is ill and that Els is absent is an unpleasant situation.'

$a^{\prime}$. Het is een vervelende zaak [[dat Jan ziek is] en [dat Els afwezig is]]. it is an annoying situation that Jan ill is and that Els absent is 'That Jan is ill and that Els is absent is an unpleasant situation.'

b. [[Dat Jan ziek is] en [dat Els afwezig is]] zijn/*is vervelende zaken. that Jan ill is and that Els absent is are/is unpleasant situations 'That Jan is ill and that Els is absent are unpleasant situations.'

$\mathrm{b}^{\prime}$. Het zijn vervelende zaken [[dat Jan ziek is] en [dat Els afwezig is]]. it are unpleasant situations that Jan ill is and that Els absent is 'That Jan is ill and that Els is absent are unpleasant situations.'

It is harder to test whether the same holds for infinitival subject clauses because it seems more difficult for them to occur in subject position; the examples in (306) show that while te-infinitivals do occur in constructions with the ${ }^{\circ}$ anticipatory pronoun het 'it', they appear degraded in constructions without it. For this reason, we will not digress on this issue here but refer to Cremers (1993: section 2.2.2) for a number of apparent exceptional cases. 
(306) - Te-infinitival clauses

a. Het is/*zijn verboden [[alcohol te drinken] en [wiet te roken]]. it is/are forbidden alcohol to drink and weed to smoke 'It is forbidden to drink alcohol or smoke weed.'

b. *[[Alcohol te drinken] en [wiet te roken]] is/zijn verboden. alcohol to drink and weed to smoke is/are forbidden

Example (293) has already indicated that bare BARE-INF nominalizations used as subjects allow both singular and plural subject-verb agreement; cf. [[Alcohol drinken] en [wiet roken]] is/zijn verboden 'Drinking alcohol and smoking weed is/are forbidden'. This is irrevelvant in the present context, however, as these are noun phrases (and not clauses).

Subject-verb agreement in examples with AP subjects again depends on the interpretation: while talking about certain designs, example (307a) can be used for expressing that simple designs in blue are the most beautiful, while (307b) would be used for expressing that blue designs and simple designs are the most beautiful ones; see Haeseryn et al. (1997:1464) for similar examples.

- AP subjects

a. [Blauw en simpel] is het mooist.

blue and simple is the most.beautiful

b. [Blauw en simpel] zijn het mooist.

blue and simple are the most.beautiful

The same holds for PP subjects, albeit in a more indirect way. Section A6.6 has argued that the pronoun het 'it' in examples such as (308) is an anticipatory pronoun that differs from the ones found in examples such as provided in (305) in that it does not introduce subject clauses but subject PPs. Again we can see that the agreement on the finite verb depends on contextual information.

a. Het is/*zijn warm [[in de keuken] en [op zolder]]. it is/are warm in the kitchen and in attic 'It is warm in the kitchen and in the attic.'

b. Het ${ }^{(?)} \mathrm{zijn} / *$ is warme plekken [[in de keuken] en [op zolder]]. it are/is warm spots in the kitchen and in attic 'The kitchen and the attic are warm spots.'

The discussion in this subsection has shown that Corbett (1983/2000) correctly restricts the resolution rule stating that conjunctive coordinate structures are plural to nominal [+COUNT] coordinands; in other cases number agreement is semantically determined in the sense that it depends on the reference of the coordinate structure as a whole. Haeseryn et al. (1997) present a larger number of examples illustrating this, which we have skipped here because they strike us as formal, idiosyncratic or obsolete.

\section{Gender}

Resolution rules for gender can be expected in two cases: determiner selection and agreement of nouns with attributively used adjectives. We start with the selection of 
definite articles and demonstratives: het 'the' and dit/dat 'this/that' are used for singular neuter nouns, while de 'the' and deze/die are used in all other cases. The examples in (309) show that it is possible to use a single article or demonstrative for coordinate structures with more than one plural noun. The semantic difference between the examples in (309) is that while (309a) can be interpreted either distributively of cumulatively, (309b) has a cumulative reading only.

(309) - Determiners with plural [+COUNT] NPs of "mixed" gender

a. [De/Die jongens en de/die meisjes] dansen. the/those boys and the/those girls dance 'The/Those boys and girls are dancing.'

b. [De/Die [jongens en meisjes]] dansen. the/those boys and girls dance 'The/Those boys and girls are dancing.'

The acceptability of (309b) is expected in light of the fact that the determiner de/die is used for both neuter and non-neuter plurals. The fact that neuter and non-neuter singulars select different determiners raises the question as to what happens if such nouns are conjoined. The (b)-examples in (310) makes it clear that it is impossible for them to share a determiner; these examples illustrate this by means of definite articles de/het but the same results arise when we replace them by the demonstratives die/dat.

(310) - Determiners with singular [+COUNT $]$ NPs of "mixed" gender
a. [[De jongen $\left.n_{\text {non-neuter }}\right]$ en [het meisje neuter $\left.]\right]$ dansen. the boy and the girl dance
b. $*\left[\right.$ De/Het $\left[\right.$ jongen $_{\text {non-neuter }}$ en meisje $\left.\left._{\text {neuter }}\right]\right]$ dansen. the/the boy and girl dance
$\mathrm{b}^{\prime} . *\left[\mathrm{De} / \mathrm{Het}\left[\right.\right.$ meisje $_{\text {neuter }}$ en jongen non-neuter $]$ dansen. the/the girl and boy dance

It is tempting to attribute the unacceptability of the (b)-examples to problems with the gender specifications of the conjoined nouns. This is not tenable, however, since we find a similar contrast between plural and singular forms when the coordinands are of the same gender; the percentage sign in (311b) indicates that such cases do occur on the internet but are considered marked by our informants.

(311) - Determiners with plural and singular [+COUNT] NPs of the same gender

a. De mannen en vrouwen dansen. the men and women dance

'The men and women are dancing.'

b. ${ }^{\circ}$ De man en vrouw dansen. the man and woman dance

The examples in (310) and (311) show that count nouns are not suitable for investigating the resolution rules for gender, but this may be different for mass nouns. A Google search (2/24/2017) has shown that the strings in (312) all occur on the internet except for the one in (312d), which indeed strikes us as weird. The same pattern was found for strings in which the neuter noun afval 'garbage' was replaced 
by the neuter nouns vuil 'dirt' and stof 'dust'. The results of this search therefore suggest that there are no generally accepted resolution rules for cases like these: the coordinate structure may take the non-neuter article $d e$, as in (312a), or the article is selected by the first conjunct, as in $(312 b \& c)$; the third possibility that the article is selected by the second conjunct is not attested.

$$
\begin{aligned}
& \text { - Determiners with [-COUNT] NPs of "mixed" gender (pattern I). } \\
& \text { a. de afval } l_{\text {neuter }} \text { en troep } p_{\text {non-neuter }} \\
& \text { the garbage and mess } \\
& \text { b. de troep non-neuter en afval } \text { neuter }_{\text {na }} \\
& \text { the mess and garbage }
\end{aligned}
$$

We do not have sufficient data for showing that the same pattern arises with demonstratives, as we only found three cases of the string die troep en afval, which is neutral with respect to the two competing rules; stating that the coordinate structure takes a non-neuter determiner and stating that the determiner is selected by the first conjunct both result in the selection of the demonstrative die. We should also note that the pattern in (312) does not arise for all mixed cases; this is clear from the fact that all word groups in (313) occur frequently on the internet and that they can all be quite naturally inserted on the dots in: Zet ... even op tafel! 'Please, put ... on the table!'.
a. de zout $_{\text {neuter }}$ en peper $_{\text {non-neuter }}$ the salt and pepper
b. de peper $_{\text {non-neuter }}$ en zout $_{\text {neuter }}$ the pepper and salt
- Determiners with [-COUNT] NPs of "mixed" gender (pattern II).
c. het zout neuter en peper $_{\text {non-neuter }}$ the salt and pepper
d. het peper ${ }_{\text {non-neuter }}$ en zout $_{\text {neuter }}$ the pepper and salt

The contrast between (312d) and (313d) may be related to the fact that peper en zout is a more or less fixed collocation or perhaps even a morphologically complex nominal form. The latter view can be supported by the fact that this collocation frequently occurs as the initial part in nominal compounds like peper-enzoutstel(letje) and peper-en-zoutset 'pepper and salt set'. Note that zout-enpeperstel(letje) also occurs but less frequently. In complex nominal forms of the $\mathrm{N}_{1}$ $e n-\mathrm{N}_{2}$ type, the determiner is determined by $\mathrm{N}_{2}$, as is clear from examples such as (314), which is often given as a prototypical example of this type. Consequently, analyzing peper en zout as a morphological compound would account for the acceptability of (313d).

$$
\begin{aligned}
& \text { de/*het paard-en-wagen } \\
& \text { the/the horse-and carriage } \\
& \text { 'the horse cart' }
\end{aligned}
$$

[het paard; de wagen]

We therefore provisionally conclude that agreement pattern I in (312) is the genuine one; coordinate structures with [-COUNT] NPs of "mixed" gender either take the determiner $d e$ or the determiner selected by its first conjunct. It should be clear, though, that the data underpinning this conclusion are not conclusive and that more research is required. 
The discussion above has made it reasonably clear that establishing the resolution rules for gender is not an easy task as far as determiner selection is concerned. It is in fact even more difficult in the case of attributive adjectival inflection. The reason is that gender only affects the inflection of singular indefinite noun phrases: Table 13, taken from A5.1.1, shows that the inflectional $-e$ ending is omitted with singular indefinite neuter nouns such as boek 'book' but not with singular indefinite non-neuter nouns such as stoel 'chair'.

Table 13: The inflectional patterns of attributively used adjectives

\begin{tabular}{||c||l|l||l|l||}
\hline \multirow{2}{*}{\multicolumn{1}{||}{}} & \multicolumn{2}{c||}{ SINGULAR } & \multicolumn{2}{c||}{ PLURAL } \\
\cline { 2 - 5 } & \multicolumn{1}{|c|}{ DE-NOUNS } & \multicolumn{1}{c|}{ HET-NOUNS } & \multicolumn{1}{c|}{ DE-NOUNS } & HET-NOUNS \\
\hline \hline DEFINITE & $\begin{array}{l}\text { de oude stoel } \\
\text { the old chair }\end{array}$ & $\begin{array}{l}\text { het oude boek } \\
\text { the old book }\end{array}$ & $\begin{array}{l}\text { de oude stoelen } \\
\text { the old chairs }\end{array}$ & $\begin{array}{l}\text { de oude boeken } \\
\text { the old books }\end{array}$ \\
\hline INDEFINITE & $\begin{array}{l}\text { een oude stoel } \\
\text { an old chair }\end{array}$ & $\begin{array}{l}\text { een oud- } \varnothing \text { boek } \\
\text { an old book }\end{array}$ & $\begin{array}{l}\text { oude stoelen } \\
\text { old chairs }\end{array}$ & $\begin{array}{l}\text { oude boeken } \\
\text { old books }\end{array}$ \\
\hline
\end{tabular}

Furthermore, the examples in (315) show that the indefinite article een is like the definite articles het/de 'the' in that it cannot easily be used with conjoined singular noun phrases: many speakers prefer the second article to be present.

(315) a. Er waren [[een jongen] en [een meisje]] op het feest. there were a boy and a girl at the party 'A boy and a girl were at the party.'

b. ${ }^{? ?} \mathrm{Er}$ waren [een [jongen en meisje]] op het feest. there were a boy and girl at the party

Furthermore, the examples in (316) show that attributive modification is simply not allowed if the two nouns share the indefinite article. Note, however, that speakers who allow (315b) may find the examples in (316) acceptable if the adjective aardig 'kind' is construed with the first conjunct only, that is, they may find (316a) acceptable with the form aardige selected by jongen, and (316b) with the form aardig selected by meisje.

- Attributively used adjectives in [+COUNT] NPs

a. *Er waren een aardig(e) jongen $n_{\text {non-neuter }}$ en meisje $_{\text {neuter }}$ op het feest. there were a kind boy and girl at the party 'A kind boy and girl were at the party.'

b. *Er waren een aardig meisje $e_{\text {neuter }}$ en jongen ${ }_{\text {non-neuter }}$ op het feest. there were a kind girl and boy at the party Compare: 'A kind girl and boy were at the party.'

For speakers who reject (315b) the effect of gender can only be established by means of conjoined mass nouns, as in (317); again, providing reliable judgments on these examples is not easy. It seems clear that the inflected form cannot be used in (317b) and that the non-inflected form cannot be used in $\left(317 b^{\prime}\right)$, which leads to the conclusion already established earlier that agreement with the second noun is excluded. The non-inflected form can be used in (317b) but it does not seem 
possible to modify the second noun, so it is likely that we are dealing with the structure [[stinkend vuil] en [troep]], not with [stinkend [vuil en troep]]. The same holds for the non-inflected form in $\left(317 b^{\prime}\right)$ : it is likely that we are dealing with the structure [[stinkende troep] en [vuil]], not with [stinkende [troep en vuil]].
a. Er ligt [veel [vuil neuter $_{\text {en troep }}$ non-neuter] $]$ op de grond. there lies much dirt and mess on the floor
'There is a lot of dirt and mess on the floor.'
b. Er ligt [veel stinkend(*e) vuil en troep] op de vloer. there lies much smelly dirt and mess on the floor
$\mathrm{b}^{\prime}$. Er ligt [veel stinkend*(e) troep en vuil] op de vloer. there lies much smelly mess and dirt on the floor

If our semantic intuitions are correct, we should conclude that there are no resolution rules for attributive adjectives: these simply cannot be used for modifying conjoined nominal projections. Resolution rules for determiners, on the other hand, may be available: the non-neuter form $d e$ is used, or the form selected by the first conjunct. That the resolution rules for gender are less clear than those for person and number may not be accidental; it may simply bolster up Corbett's (1983) claim that the resolution rules for person and number are widespread across languages while those for gender are more idiosyncratic and language-specific.

\section{Special interpretations: asymmetrical conjunction}

Section 1.1, sub IV, discussed the meaning contribution of the coordinator en 'and' in terms of truth conditions, and has shown that, especially in the case of clausal coordination, it prototypically expresses logical conjunction: by uttering (318a) a speaker commits himself to the truth of the propositions expressed by the two coordinands. That the meaning contribution of en is purely truth-conditional is reflected in the fact that the order of the clauses can be reversed without affecting the truth conditions of the sentence, in agreement with the commutative law of conjunction discussed in Section 1.3, sub IIIA. Because of this property this type of coordination is sometimes also referred to as symmetrical coordination.

$$
\text { - Symmetrical coordination }
$$

a. [[Jan is ziek] en [Marie is op vakantie]]. Jan is ill and Marie is on vacation

b. [[Marie is op vakantie] en [Jan is ziek]]. Marie is on vacation and Jan is ill

There are, however, many cases of coordination with en 'and' which receive an interpretation that goes beyond pure logical conjunction; such coordinate structures are asymmetrical in the sense that reversal of the clauses does affect interpretation. By uttering (319a), the speaker does not only commit himself to the truth of the propositions expressed by the two coordinands but he also conveys that the eventuality expressed by the first clause temporally precedes the eventuality expressed by the second clause. Example (319b) shows that reversing the two conjuncts does not result in fully equivalent expressions in that it reverses the 
temporal precedence relation. The use of the dollar sign indicates that the temporal ordering expressed by (319b) clashes with expectations based on our knowledge of the world.

\section{- Asymmetrical coordination}

a. [[Jan stond op] en [hij kleedde zich aan]].

$[\mathrm{p} \wedge \mathrm{q} ; \mathrm{p}<\mathrm{q}]$ Jan stood up and he dressed REFL prt.

'Jan got out of bed and he dressed.'

b. ${ }^{\$}[[$ Jan kleedde zich aan] en [hij stond op]]. Jan dressed REFL prt. and he stood up

I will assume that temporal ordering, or perhaps some more general notion such as priority (cf. Schmerling 1975), is the default interpretation of asymmetrical coordination although we will see that our knowledge of the world can also trigger more specific (causal, concessive, etc.) readings. Since asymmetrical coordination is always clausal in nature, we can regularly express the intended interpretations by means of proposition letters (p, q, etc.) for the semantic content of the propositions expressed by the coordinated clauses and the standard logical connectives (including " $<$ " for precedence).

\section{Temporal (consecutive) ordering}

Two prototypical cases of asymmetrical coordination are given in (320). Although all examples are impeccable from a syntactic point of view, the primed examples seem a little odd in that they clash with our knowledge of the world. This is due to the fact that the linear order of the coordinands appears to be interpreted in such a way that it coincides with the temporal order of the eventualities expressed by them: cf. Dik (1968:56-7). Example (320a') is odd, because it refers to the unconventional state of affairs of Jan getting dressed in bed (before getting up), and (320b') is odd since it refers to the unconventional state of affairs of Jan undressing in the bath (after getting into it).

\section{- Asymmetrical coordination (temporal)}

a. [[Jan stond op] en [hij kleedde zich aan] Jan stood up and he dressed REFL prt.

'Jan got up and he dressed.'

$\mathrm{a}^{\prime} .{ }^{\$}[$ Jan kleedde zich aan] en [hij stond op]]. $\quad[\mathrm{q} \wedge \mathrm{p} ; \mathrm{q}>\mathrm{p}]$ Jan dressed REFL prt. and he stood up

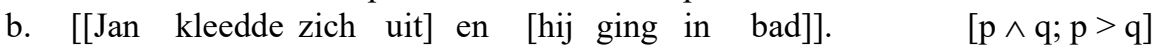
Jan dressed REFL prt. and he went into bath

'Jan undressed and he took a bath.'

$\mathrm{b}^{\prime} .{ }^{\$}[[\mathrm{Jan}$ ging in bad] en [hij kleedde zich uit]]. [q $\wedge \mathrm{p} ; \mathrm{q}>\mathrm{p}]$ Jan went into bath and he dressed REFL prt

Asymmetrical coordination normally occurs only if the coordinands entertain a certain semantic relation and form an integrated semantic whole in the sense that "we understand the two events as being connected as part of a larger event"; cf. Culicover \& Jackendoff (1997). This is only possible when the eventualities referred to by the coordinands are conceived as being inherently related, for which 
reason Zhang (2010) refers to such cases as "natural" coordination. All of this amounts to saying that the temporal interpretation is a pragmatic effect triggered by our knowledge of the world. The temporal ordering can of course also be made explicit by means of a deictic temporal adverbial phrase, as in (321), but such cases differ from temporal asymmetrical coordination in that the temporal order of the eventualities expressed by the coordinands does not have to coincide with the linear order of the coordinands: it does if daarna 'after that' is used, but not if daarvoor 'before that' is used.

[[Jan stond op] en ...

Jan stood up and

a. ... [hij kleedde zich daarna aan omdat het koud was]]. [p $>\mathrm{q}]$ he dressed REFL after.that prt. because it cold was 'Jan got up and he dressed after that because it was cold.'

b. ... [hij kleedde zich daarvoor aan omdat het koud was]]. $[\mathrm{p}<\mathrm{q}]$ he dressed REFL before.that prt. because it cold was

'Jan got up and he dressed before that because it was cold.'

The fact that the temporal adverbial phrase daarvoor 'before that' in (321b) can be used for canceling the default interpretation of (320a) provides additional support for the claim that the temporal (consecutive) ordering should be attributed to pragmatics. For completeness' sake, note that "natural" coordination sometimes seems to give rise to syntactic reanalysis (see 1.3, sub IIC for a potential case from English) but since this does not seem to have taken place in Dutch, we will not digress on this issue here.

\section{Reason/cause and concession}

The previous subsection has shown that asymmetrical coordination typically imposes temporal restrictions on the eventualities referred to by the coordinands, which are not inherently present in the truth-conditional meaning contribution of the coordinator. Schmerling (1975), Haeseryn et al. (1997: Section 25.1), Culicover \& Jackendoff (1997), Huddleston \& Pullum (2002:1299ff.) among others have shown that other, more complex, implicational relations can be expressed as well. The examples in (322), adapted from Dik (1968:57). are like the examples in (320) in that a temporal order of the eventualities expressed by the coordinands is implied but there is yet another additional meaning aspect: (322a) would normally be interpreted in such a way that the death of the female person in question is the reason for burying her, while (322b) gives the burial as the cause of her death.

- Asymmetrical coordination (reason/cause)

a. [[Ze stierf] en [we begroeven haar]]. she died and we buried her

b. [[We begroeven haar] en [ze stierf]]. we buried her and she died

The examples in (323) show that the implicational relations of reason and cause can be made explicit by adding the deictic adverbials daarom 'for that reason' and daardoor 'because of that' to the second clause. These adverbials are mutually 
exclusive in these examples for reasons related to our knowledge of the world (although some speakers can use daarom for indicating both reason and cause), which suggests that the interpretation of the examples in (322) is also pragmatic in nature.

(323) a. [[Ze stierf] en [daarom $/$ daardoor begroeven we haar $]$.

she died and for.that.reason/because.of.that buried we her

'She died and we buried her for that reason.'

b. [[We begroeven haar] en [daardoor/ ${ }^{\$}$ daarom stierf ze]].

we buried her and because.of.that/for.that.reason died she

'We buried her and she died because of that.'

Another case mentioned by Huddleston \& Pullum is illustrated in (324): (324a) is readily interpreted as concessive, while such an interpretation is not easy to get for (324b). Again the implied relation between the two clauses can be made explicit by means of a deictic adverbial: desondanks 'despite of that' fits in naturally in (324a) but not in (324b).

- Asymmetrical coordination (concession)

a. [[Jan eet te veel] en [hij blijft (desondanks) te mager]]. Jan eats too much and he remains despite.that too skinny

'Jan eats too much and (in spite of that) he remains too skinny.'

b. ${ }^{\$}[[\mathrm{Jan}$ blijft te mager] en [hij eet (desondanks) te veel]]. Jan remains too skinny and he eats despite.that too much

The restrictions on the adverbials in (323) and (324) show that the information of the available semantic relations between the eventualities expressed by the clausal coordinands is part of the ${ }^{\circ}$ common ground, that is, the information shared by the participants in the discourse. This suggests again that temporal ordering is the default interpretation of asymmetrical coordination, and that the more specific interpretations are superimposed on the basis of our knowledge of the world. That the interpretation of (324a) is based on our knowledge of the world can be further supported by comparing it to (325), in which the predicate te mager 'too skinny' is replaced by te dik 'too fat'.

$$
\text { [[Jan eet te veel] en [hij blijft (daardoor) te dik]]. }
$$

Jan eats too much and he remains because.of.that too fat

'Jan is eating too much and he remains too fat (because of that).'

The syntactic structure is identical but the interpretation has changed from a concessive into a causal one, as is clear from the fact that adding the adverbial desondanks to the second coordinand in (325) would clash with our expectation; the causal adverbial daardoor is the more natural addition.

\section{Condition}

This subsection discusses the even more special cases of asymmetrical coordination in (326) with a conditional interpretation; cf., e.g., Kraak \& Klooster (1972:276), Haeseryn et al. (1997:1529) and Van der Heijden (1999: section 4.1). At an observational level, these examples differ from those in the previous subsections in 
that the conditional interpretation cannot be made explicit by means of a deictic adverbial. It is also surprising that the first clausal coordinand can be imperative, given that Subsection A3 has shown that imperative and declarative clauses normally cannot be coordinated; the rationale for this restriction may be that a runof-the-mill conjunctive interpretation is blocked given that declaratives normally have a truth value in a specific situation, while imperatives do not, as they are used for persuading the addressee to bring about a truth transition (that is, as a request to the addressee to make some proposition true).

- Asymmetrical coordination (conditional)

a. [[Jan komt binnen] en [hij begint te praten]]. Jan comes inside and he starts to talk

'Jan enters and he starts talking' or 'When(ever) Jan enters, he starts talking.'

b. [[Kom hier] en [ik schiet]]!

come here and I shoot

'Come here and I'll shoot.'

It seems clear that we are not dealing with some idiosyncratic property of the coordinate structures at hand, because we find the same phenomenon in various languages. However, there does not seem to be an established view on how to account for the conditional interpretation of examples like those in (326). Huddleston \& Pullum (2002:1301) suggest that we are dealing with a pragmatic 'implicature, while Culicover \& Jackendoff (1997) suggest that the interpretation is due to a specific correspondence rule linking syntactic and semantic structure, which transforms a semantic conjunction into a material implication. Unfortunately, the two proposals have not been not worked out in sufficient detail for a proper evaluation, but we will argue here that the pragmatic approach is the most promising one and, as a consequence, that no correspondence rules are needed. Huddleston \& Pullum suggest that the semantic link between the conjunctive and conditional interpretation is that both $\mathrm{p} \wedge \mathrm{q}$ and $\mathrm{p} \rightarrow \mathrm{q}$ exclude cases in which $\mathrm{p}$ is true and $q$ is false. They thus suggest that the speaker and the addressee only "see" the shaded rows of Table 14 by considering cases in which $\mathrm{p}$ is false irrelevant for the evaluation of the examples in (326).

Table 14: Truth table for conjunction and material implication

\begin{tabular}{|c|c||c|c|}
\hline $\mathrm{p}$ & $\mathrm{q}$ & $\mathrm{p} \wedge \mathrm{q}$ & $\mathrm{p} \rightarrow \mathrm{q}$ \\
\hline \hline 1 & 1 & 1 & 1 \\
\hline 1 & 0 & 0 & 0 \\
\hline 0 & 1 & 0 & 1 \\
\hline 0 & 0 & 0 & 1 \\
\hline
\end{tabular}

Huddleston \& Pullum do not spell out the details of their pragmatic reasoning leading to this "more restricted window" on Table 14. Our proposal, which will be given in (329) below, takes as its point of departure the observation that the conditional reading normally does not arise in past tense constructions. 
(327) a. [[Jan komt binnen] en [hij begint te praten]]. [present: ambiguous] Jan comes inside and he starts to talk

'Jan enters and he starts talking' or 'When(ever) Jan enters he starts talking.'

b. [[Jan kwam binnen] en [hij begon te praten]]. [past: non-conditional] Jan came inside and he started to talk

'Jan entered and he started talking.'

The difference between present and past tense is that past tense is normally used for describing a state of affairs that has actually occurred before speech time, while the present tense can have various functions: it can be used for describing the state of affairs at speech time, but it can also be used as a non-realis (henceforth: irrealis) form for expressing wishes, expectations, etc. about future states-of-affairs or as generic statements when the (linguistic or non-linguistic) context provides clues favoring this.

(328) a. Jan wandelt op de hei.

[(preferably) realis; statement]

Jan walks on the moor

'Jan is walking on the moor.'

b. Jan wandelt morgen op de hei.

[irrealis]

Jan walks tomorrow on the moor

'Jan will be walking on the moor tomorrow.'

c. Jan wandelt normaal gesproken op de hei.

[generic]

Jan walks normally speaking on the moor

'Jan normally walks on the moor.'

The ambiguity of a present tense example such as (327a) is due to the fact that it allows both for a realis and for an irrealis/generic interpretation. The default interpretation seems to be the realis interpretation. For example, when (327a) is used as a stage direction in a play, the author will generally not be after the irrealis/generic reading; it is quite possible that the character Jan will remain/remains silent after coming on stage in other scenes of the play.

The conditional reading of (327a) is only compatible with an irrealis/generic interpretation. In such cases, the eventuality referred to by the first coordinand is most likely not actualized at speech time: $\mathrm{p}=0$.

Now recall Huddleston \& Pullum's intuition that the link between the conjunctive and the conditional interpretation is that $\mathrm{p} \wedge \mathrm{q}$ and $\mathrm{p} \rightarrow \mathrm{q}$ both exclude cases where $\mathrm{p}$ is true and $\mathrm{q}$ is false. The pragmatic reasoning in (329), based on Grice's (1975) ${ }^{\circ}$ cooperative principle, shows that the irrealis interpretation makes it possible to account for this intuition by appealing to the earlier observation that asymmetrical coordination has the characteristic property of temporal ordering. Note that $\mathrm{p}$ and $\mathrm{q}$ in (329) correspond with the propositions expressed by the first and second clause in (327a), respectively. 
(329) - Pragmatic reasoning leading to a conditional reading of (327a)

a. The utterance does not describe an existing state of affairs because $p=0$, which entails that $p \wedge q=0$. The utterance should therefore be interpreted as a non-existing state of affairs, i.e., as an irrealis; cf. ${ }^{\circ}$ maxim of relation.

b. Speaker $\mathrm{S}$ commits himself to $\mathrm{p} \wedge \mathrm{q}=1$ at some time $\mathrm{t}$; $\mathrm{cf}$. maxim of quality.

c. The truth of $p \wedge q$ is not checked for any time $t$ at which $p=0$ because $p<q$; the truth of $\mathrm{p} \wedge \mathrm{q}$ will only be checked for some/any time $\mathrm{t}$ at which $\mathrm{p}=1$.

d. Only the first two rows in Table 14 are relevant for evaluating the truth of (327a) and these are compatible with a conditional interpretation of this example.

Although imperatives cannot be assigned a truth value, it seems even easier to derive the conditional interpretation of Kom hier en ik schiet in (326b). The crucial thing is that because imperatives are used to urge the addressee to bring about a certain truth transition (that is, to make a proposition $\mathrm{p}$ true), we can once more account for the conditional reading by appealing to the temporal ordering of the asymmetrically coordinated clauses and Grice's (1975) cooperative principle. The pragmatic reasoning is given in (330), where $\mathrm{p}$ refers to the proposition that the addressee is urged to make true and q corresponds to the proposition expressed by the second clause in (326b). For more discussion of this construction type, I refer the reader to Proeme (1984) and Fortuin \& Boogaart (2009).

- Pragmatic reasoning leading to a conditional reading of (326b)

a. The utterance does not describe an existing state of affairs because $p=0$, which entails that $\mathrm{p} \wedge \mathrm{q}=0$.

b. The imperative invites the addressee $A$ to make $p$ true.

c. If $A$ does not make $p$ true, $S$ cannot make $p \wedge q$ true; if A does make $p$ true, $S$ can make $\mathrm{p} \wedge \mathrm{q}$ true by making $\mathrm{q}$ true. Therefore, $\mathrm{S}$ commits himself to making q true if A makes $\mathrm{p}$ true: cf. maxim of quality.

d. Only the first two rows in Table 14 are relevant for evaluating the truth of (326b) and these are compatible with a conditional interpretation of this example.

For completeness' sake, we want to point out that examples such as (331a) can be used either as an encouragement or as a warning, depending on the question as to whether or not proposition $\mathrm{q}$ is favorable for addressee A: (331a) will be seen as an encouragement if both addressee $\mathrm{A}$ and speaker $\mathrm{S}$ know that $\mathrm{A}$ would liked to be kissed by S, but as a warning if they both know that A does not want to be kissed by $\mathrm{S}$. The pragmatic lines of reasoning leading to these results are given in $\left(331 \mathrm{~b} \& \mathrm{~b}^{\prime}\right)$, which take the conclusion in (330c) as their point of departure. We will see in Subsection IIC2 that the corresponding construction Kom hier of ik kus je! 'Come here or I'll kiss you!' with the disjunctiv coordinator of 'or' can only be construed as a warning.

(331) a. [[Kom hier] en [ik kus je]]! come here and I kiss you

'Come here and I'll kiss you!' 
b. If A makes $\mathrm{p}$ true, $\mathrm{S}$ will make $\mathrm{q}$ true. Since $\mathrm{S}$ knows that A likes $\mathrm{q}$ to become true, (331a) is intended as an encouragement.

$\mathrm{b}^{\prime}$. If A makes $\mathrm{p}$ true, $\mathrm{S}$ will make $\mathrm{q}$ true. Since $\mathrm{S}$ knows that $\mathrm{A}$ does not like $\mathrm{q}$ to become true, (331a) is intended as a warning.

The discussion above has shown that the conditional interpretation of clausal coordinate structures with en 'and' can be achieved by appealing to the temporal ordering expressed by asymmetrical coordination in tandem with more or less standard pragmatic reasoning; see Fortuin \& Boogaart (2009: Figure 3) for the same conclusion. This makes it unnecessary (and therefore undesirable) to introduce special syntactic or semantic machinery such as the correspondence rule proposed in Culicover \& Jackendoff (1997) to account for such cases.

\section{Deixis}

Coordinate structures may also fail to obey the commutative law if the second coordinand contains a deictic element that refers to some element included in the first coordinand; cf. Kraak \& Klooster (1972:253-4). In fact, Subsection 2 has already shown that the second coordinand of certain asymmetrical coordinate structures can optionally contain a deictic adverbial phrase that explicates the implied semantic relation.

(332) a. [[Ze stierf] en [daarom begroeven we haar]].

she died and for.that.reason buried we her

'She died and that is why we buried her.'

b. [[We begroeven haar] en [daardoor stierf ze]].

we buried her and because.of.that died she

'We buried her and she died because of that.'

Other deictic elements have a similar effect, as illustrated in (333) for referential pronouns: the pronoun can only refer to the proper noun Jan if it is part of the second coordinand; if the pronoun is part of the first coordinand, it must refer to some other discourse entity. We use indices to indicate possible and impossible referential dependencies.

(333) a. $\left[[\mathrm{Jan}]_{\mathrm{i}}\right.$ en $\left.\left[\text { zijn }_{\mathrm{i} / \mathrm{j}} \text { broer }\right]_{\mathrm{k}}\right]$

Jan and his brother

$\mathrm{a}^{\prime} . \quad\left[\left[\mathrm{zijn}_{\mathrm{j} / *_{\mathrm{i}}} \text { broer }\right]_{\mathrm{k}}\right.$ en $\left.[\mathrm{Jan}]_{\mathrm{i}}\right]$

his brother and Jan

b. [[ $\mathrm{Jan}_{\mathrm{i}}$ is ziek] en $\left[\mathrm{hij}_{\mathrm{i} / \mathrm{j}}\right.$ blijft thuis $\left.]\right]$.

Jan is ill and he stays home

'Jan is ill; and he will stay at home.'

$\mathrm{b}^{\prime}$. $\quad\left[\left[\mathrm{Hij}_{\mathrm{j} / *_{\mathrm{i}}}\right.\right.$ blijft thuis $]$ en $\left[\mathrm{Jan}_{\mathrm{i}}\right.$ is ziek $\left.]\right]$.

he stays home and Jan is ill

Other deictic elements have the same effect: the (a)-examples in (334) illustrate this for the pronominal PP eronder 'under it', and the (b)-examples illustrate this for the proform dat which refers to the verbal predicate in the first conjunct. For more examples, we refer the reader to Haeseryn et al. (1997:1454-5). 
(334) a. [[De kat zat [op de tafel $\left.]_{i}\right]$ en [de hond zat eronder $\left.\left.\mathrm{i}_{i}\right]\right]$.

the cat sat on the table and the dog sat under.it

'The cat sat on the table and the dog sat under it.'

$\mathrm{a}^{\prime}$. *[[De hond zat eronder $\left.{ }_{\mathrm{i}}\right]$ en [de kat zat [op de tafel $\left.\left.]_{\mathrm{i}}\right]\right]$.

b. [[Jan wil dansen $\left.{ }_{i}\right]$ en [Marie wil dat ${ }_{i}$ ook $\left.]\right]$.

Jan wants dance and Marie wants that too

'Jan wants to dance and Marie wants to dance too.'

$\mathrm{b}^{\prime}$. *[[Marie wil dat $\mathrm{i}_{\mathrm{i}}$ ook] en [Jan wil dansen $\left.\mathrm{H}_{\mathrm{i}}\right]$ ]

The examples so far have involved referential dependencies of various types, but other kinds of dependencies may also be involved, as will be clear from the following examples adapted from Kraak \& Klooster (1972:254), which do not allow inversion of the coordinands.

(335) a. Jan bewondert Peter en omgekeerd.

Jan admires Peter and the.other.way.around

'Jan admires Peter, and vice versa.'

b. Jan keek naar links en Peter keek naar de andere kant.

Jan looked at left Peter looked at the other side

'Jan looked to the left and Peter looked in the other direction.'

\section{Fixed collocations and ordering conventions}

There are many fixed (lexicalized) collocations, such as the epistemic modal adverbial vast en zeker 'certainly' mentioned earlier, which do not allow reordering of their coordinands; more examples are given in (336). Note in passing that Belgium Dutch also allows the inverse order zeker en vast but not with an epistemic meaning (cf. taaladvies.net/taal/advies/vraag/1452).

(336) a. Time/place adverbials: af en toe 'occasionally', nu en dan 'sometimes', hier en daar 'in places', op stel and sprong 'immediately', voor dag en dauw 'very early'.

b. Amplifying degree adverbials: in en in (triest) 'very (sad)', door en door (bedorven) 'thoroughly (spoiled)'.

c. Referential nouns: paard-en-wagen 'horse cart', kop-en-schotel 'cup and saucer', hang-en-sluitwerk 'fastenings', gooi-en-smijtfilm 'slapstick movie'.

d. Indefinite nouns: (het) een en ander 'some (indeterminate) things'.

Conjunctions sometimes occur as parts of fixed verbal expressions. The examples in (337a-c) show that nominal conjunctions occur relatively frequently in such expression, and often have a universal impact (cf. Postma 1995).

(337) a. met man en macht (werken aan ..) 'to work with might and main'

b. met man en muis (vergaan) 'to go down with all hands'

c. man en paard (noemen) 'to give all the details'

d. Het gaat op en af.

it goes up and down

'Sometimes it goes better, sometimes worse.' 
Linearization of the coordinands normally follows certain conventions: positively valued notions precede negatively valued ones (goed en kwaad 'good and evil'), male denoting nouns precede female denoting nouns (vader en moeder 'father and mother') but not necessarily in vocatives (Dames en heren! 'Ladies and Gentlemen!' versus Jongens en meisjes! 'boys and girls!'), old precedes young (vader en zoon 'father and son'), and important precedes unimportant (Scotch en soda 'Scotch and soda').

It goes without saying that fixed orders are also found in proper names such as Taal en Tongval (Dutch journal on language variation); see Haeseryn et al. (1997:1456-7) for more examples. Conjunctions occurring in (abbreviations of) names of firms, shops and products are often spelled as "\&": Peek \& Cloppenburg $(\mathrm{P} \& \mathrm{C})$, Vroom \& Dreesman (V\&D), M\&Ms, etc. Conjunctions also play an important role in the formation of complex numerals such as vijfentwintig 'twentyfive'; we refer the reader to Subsection D5 below for discussion.

\section{Special uses}

This subsection discusses various other types of conjunctive coordinate structures with a more specialized semantic function.

\section{Partitioning conjunction}

Partitioning conjunction involves coordinate structures in which the coordinands denote properties that are predicated of certain parts of an entity (or set); see also Haeseryn et al. (1997:1474) and Winter (2001a: section 2.4). Two distinctive cases are given in (338): example (338a), for instance, does not express logical conjunction in the sense that it does not entail that zebras are black and that zebras are white, but rather that zebras are partly black and partly white.

(338) a. Zebra's zijn zwart en wit. zebras are black and white

b. De Nederlandse vlag is rood, wit en blauw. the Dutch flag is red, white and blue

The adjectival coordinate structures in (338) come close to compounds, as is also clear from the fact that they cannot be used attributively with the attributive $-e$ inflection on the separate adjectives (on the intended reading); attributive use is acceptable with inflection of the last adjective only, although the true compound form rood-wit-blauw is by far the most frequent in this position.

(339) a. " de rode, witte en blauwe vlag the red white and blue flag

b. de rood, wit en blauwe vlag the red white and blue flag

c. de rood-wit-blauwe vlag the red-white-blue flag

Similar examples with adjectives denoting properties other than color also occur but may have somewhat different implicatures: example (340a), for instance, does not express that Jan is partly happy and partly sad, but that he has mixed feelings. 
Haeseryn et al. also include the examples in (340b\&c) in this category, but it is debatable whether this can be justified. This is clearest in (340b), which simply expresses that Jan's "emotional state" varies over time, which can easily be expressed by appealing to a run-of-the-mill conjunctive meaning. Example (340c) with the conjunctive adverbials enerzijds 'on the one hand' and anderzijds 'on the other hand' is more complex as these express that the appropriateness of adjectival predicates depends on the point of view one adopts, but we fail to see why this could not be expressed by appealing to the logical conjunction reading of en. This is in fact quite common in question-answer pairs such as Ben je gelukkig? Ja en nee. 'Are you happy? Yes and no, on the one hand I am but on the other hand I am not.'

(340) a. Jan is gelukkig en droef.

Jan is happy and sad

b. Soms is Jan gelukkig en soms is hij droef. sometimes is Jan happy and sometimes is he sad 'Sometimes Jan is happy and sometimes he is sad.'
c. Enerzijds
is Jan gelukkig (en) anderzijds
is hij droef.
on.the.one.hand is Jan happy and on.the.other.hand is he sad
'On the one hand, Jan is happy, and on the other, he is sad.'

It seems that the partitioning conjunction reading is pragmatic in the sense that it depends on our knowledge or the world. Consider example (341a); it differs from the cases in (338) and (340a) in that it does not allow for an interpretation according to which the castle has been partly demolished and partly restored, but only for the asymmetrical conjunction interpretation that it was first completely demolished and subsequently reconstructed. Partitioning is possible but this requires explicit marking by, e.g., addition of the modifier gedeeltelijk 'partly' in (341b), but such cases can again be analyzed as involving logical conjunction.

(341) a. Het kasteel is gesloopt en hersteld.

the castle has.been demolished and restored

'The castle has been demolished and (subsequently) restored.'

b. Het kasteel is gedeeltelijk gesloopt en gedeeltelijk hersteld. the castle has.been partly demolished and partly restored 'The castle has been partly demolished and partly restored.'

Finally, we note that that conjoined predicates occasionally receive a union reading instead of the expected intersection reading, as in De jongens [zingen en dansen] 'The boys sing and dance'. This is potentially relevant for the present discussion, but was already discussed in Section 1.1, sub IVE.

\section{Emphatic conjunction}

Haeseryn et al. (1997:1474) provide the examples in (342) as a special form of emphatic conjunction. This form of conjunction is characterized by the fact that the coordinands occur in a fixed order and that the second coordinand contains a focus 'particle like zelfs 'even' or ook 'too'. We seem to be dealing with regular logical conjunction, though, as is clear from the fact that (342a) entails the propositions expressed by the two sentences given in the (b)-examples; cf. Kraak \& Klooster 
(1972:255ff.). Observe in this connection that the focus particle can be pied-piped under topicalization and can thus be assumed to be part of the PP: Zelfs aan mijn kinderen heb ik het verteld 'Even to my children I have told it'.

(342) a. Ik heb het aan mijn vrouw en zelfs aan mijn kinderen verteld.

I have it to my wife and even to my children told 'I have told it to my wife and even to my children.'

b. Ik heb het aan mijn vrouw verteld.

I have it to my wife told

$\mathrm{b}^{\prime}$. Ik heb het zelfs aan mijn kinderen verteld.

I have it even to my children told

Emphatic conjunctions may be ambiguous between true conjunction and structures with a parenthetic en-phrase, which may account for the fact that it is regularly claimed that emphatic nominal conjunctions may trigger either singular or plural inflection on the verb if they function as a subject. The parenthetic reading is forced if the phrase en-XP is preceded or followed by an intonation break, or if it is placed in sentence-final position, in which case the finite verb definitely must be singular. It is difficult to judge, however, to what extent plural agreement is really acceptable in colloquial speech: speakers' judgments are not sharp, which suggests that plural agreement may be restricted to the more formal registers.

(343) a. Mijn vader en ook/zelfs mijn moeder houdt $/ \%$ houden van honden.

my father and also/even my mother likes/like of dogs

'My father and also/even my mother like(s) dogs.'

b. Mijn vader -en ook/zelfs mijn moeder- houdt/*houden van honden.

my father and also/even my mother likes/like of dogs

'My father -and also/even my mother- like(s) dogs.'

c. Mijn vader houdt/*houden van honden, en ook/zelfs mijn moeder. my father likes/like of dogs and also/even my mother

'My father likes dogs, and so does (even) my mother.'

Example (344a) further shows that emphatic conjunctions can never be used as antecedents for the reciprocal elkaar 'each other'. This may perhaps be used as an argument against saying that emphatic conjunctions can be the result of run-of-themill coordination and in favor of a parenthetic analysis accros-the board. A similar conclusion can perhaps be drawn from the fact illustrated in (344b) that emphatic conjunctions cannot receive a cumulative reading.

(344) a. [Mijn vader en (*ook/zelfs) mijn moeder] houden van elkaar. my father and also/even my mother love of each.other

'My father and my mother love each other.'

b. [Mijn vader en (*ook/zelfs) mijn moeder] gaan samen op vakantie. my father and also/even my mother go together on holiday 'May father and my mother go on holiday together.'

Emphatic conjunction is frequent with nominal coordinands but the examples in (345) show that it can also occur with other phrases, such as PP-complements, complementives and verbal predicates (VPs). 
(345) a. dat Jan graag [[over zijn werk] en [ook over zijn hobby's]] praat. that Jan gladly about his job and also about his hobbies talks 'that Jan likes to talk about his job and also about his hobbies.'

b. dat Jan haar [vriendelijk en zelfs aardig] vindt. [complementive] that Jan her friendly and even kind considers 'that Jan considers her friendly and even kind.'

c. dat Jan morgen [[komt] en [zelfs blijft slapen]]. that Jan tomorrow comes and even stays sleep 'that Jan will come tomorrow and even stay the night.'

What is not possible, however, is clausal conjunction. This is illustrated in the primeless examples in (346) for main and embedded clauses; note that the number sign is used to indicate that the focus particle can be used, but only if it has scope over the matrix verb, that is, with the meaning "Els even says that ..." instead of the intended meaning "Jan will even stay the night'. It should be noted, however, that the primed examples show that the focus particle can be located within the clause, which suggests that it should be part of the second coordinand; the unacceptability of the primeless clauses on the intended readings can therefore be attributed to the fact that the clause-initial position is not available for the particle.

(346) a. *[Jan komt morgen] en [zelfs hij blijft slapen].

Jan comes tomorrow and even he stays sleep

$\mathrm{a}^{\prime}$. [[Jan komt morgen] en [hij blijft zelfs slapen]]. Jan comes tomorrow and he stays even sleep

'Jan will come tomorrow and he will even stay the night.'

b. "Els zegt [[dat Jan morgen komt] en [zelfs dat hij blijft slapen]]. Els says that Jan tomorrow comes and even that he stays sleep

$\mathrm{b}^{\prime}$. Els zegt [[dat Jan morgen komt] en [dat hij zelfs blijft slapen]]. Els says that Jan tomorrow comes and that he even stays sleep 'Els says that Jan will come tomorrow and that he will even stay the night.'

The coordinators alsmede and alsook 'and also' are specialized forms for emphatic conjunction; they are only found in formal language. We therefore refer the reader to Haeseryn et al. (1997: section 25.2) for a discussion of these forms.

\section{Comment (specification, qualification, correction, etc.)}

Phrases introduced by en can often be used as additional comments: these comments involving specification, corrections or other qualifications. A very common case is specification: the phrase introduced by en provides further specification of one of the constituents in the clause, and is mostly realized as a parenthetic phrase or placed in sentence-final position.

(347) a. Jan heeft een auto -en wel een electrische- gekocht. Jan has a car and in.fact an electric.one bought

b. Jan heeft een auto gekocht, en wel een electrische. Jan has a car bought and in.fact an electric.one 'Jan has bought a car-an electric one.' 
The phrase following en in a sense replaces one of the phrasal constituents in the preceding clause, as in (348a), but it may also add information that was lacking, as in (348b); cf. Kraak \& Klooster (1972: section 11.3.2).
(348) a. Jan is naar Amerika vertrokken en wel naar New York. Jan is to America left and in.fact to New York 'Jan has left for the USA, for New York.'
b. Jan is vertrokken en wel naar New York. Jan is left and in.fact to New York 'Jan has left, for New York.'

The phrase following en may be of the same category as its associate phrase in the clause preceding en but it may also be different; in (349) the noun phrase de hond is "replaced" by a clause expressing a proposition about its referent.

$$
\begin{aligned}
& \text { dat we over de hond spraken en dat hij ziek was. } \\
& \text { that we about the dog talked and that he ill was } \\
& \text { 'that we talked about the dog, and that it was ill.' }
\end{aligned}
$$

The specifying nature of the examples in (347) and (348) is made explicit by the use of the modifier wel, which cannot easily be omitted: see N3.1.3.

(350) a. Jan heeft een auto gekocht, en *(wel) een electrische. Jan has a car bought and in.fact an electric.one

b. Jan is (naar Amerika) vertrokken en *(wel) naar New York. Jan is to America left and in.fact to New York

Other relations with the preceding clause occur as well: in (351a) the en-phrase simply mentions a (presupposed but false) alternative to the relevant noun phrase in the preceding clause, and in (351b) it mentions other people having a different idea than the speaker; cf. Haeseryn et al. (1997:1530).

(351) a. Ik heb een boek gekocht, en geen CD.

I have a book bought and no CD

'I have bought a book, and not a CD.'

b. Marie is erg knap, en volgens sommigen zelfs briljant.

Marie is very clever and according to some even brilliant

'Marie is very clever, and even brilliant according to some.'

There is good reason for assuming that we are not dealing with run-of-the-mill coordination in the cases above; cf. De Vries (2009). This is especially clear for subjects, as these trigger singular agreement on the finite verb; this suggests that the en-XP phrase in (352a) is a parenthetical phrase, just as in the "split" case in (352b), which is also supported by the fact that it can easily be preceded and followed by an intonation break.

(352) a. Jan, en mogelijk ook Marie, is/*zijn ziek.

Jan and possibly also Marie is/are ill

b. Jan is ziek, en mogelijk ook Marie

Jan is ill, and possibly also Marie 


\section{Intensifying conjunction}

Coordinate structures with en 'and' have an intensifying function when the coordinands are identical. This holds especially for elements with a quantitative meaning aspect including time, distance and weight denoting nouns, and numerals.

(353) a. Er gingen jaren en jaren voorbij.

there went years and years past

'Many years went by.'

b. Nederland heeft kilometers en kilometers an strand.

Netherland has kilometers and kilometers of beach

'The Netherlands has many kilometers of beaches.'

c. Jan is kilo's en kilo's te zwaar.

Jan is kilos and kilos too heavy

'Jan is severely overweight.'

d. Er waren duizenden en duizenden mensen aanwezig.

there were thousands and thousands people present

'There were many thousands of people present.'

Conjunction of identical comparatives is used to indicate intensifying progression: (354a) indicates that the train is accelerating and (354b) that (the quality of) each new book by Arthur Japin exceeds the previous one. Note in passing that these constructions do not allow for the addition of a comparative als/dan-phrase.

(354) a. De trein reed sneller en sneller (*dan de auto).

the train drove faster and faster than the car

'The train drove faster and faster.'

b. De boeken van Japin worden beter en beter. the books by Japin become better and better 'Japin's books are getting better all the time.'

Conjunction of identical main verbs does not only have an intensifying but also an aspectual effect in the sense that it indicates that the eventuality stretches over time. The same effect can be observed with nearly equivalent verbs.

(355) a. Jan zeurde en zeurde/zanikte tot hij zijn zin kreeg.

Jan nagged and nagged/nagged until he his way got

'Jan nagged continuously until he had his way.'

b. Jan werkte en werkte tot hij erbij neerviel.

Jan worked and worked until he with.it down-fell

'Jan kept on working until he dropped in his tracks.'

Generally speaking, it seems that the conjunction of two or more identical elements (or strings of words) results in an unbounded reading, which can be interpreted in various ways; cf. Corver (2015b) for more discussion.

\section{Additive conjunction}

Haeseryn et al. (1997:1530) refers to cases such as (356a) as additive conjunction; in cases such as this the coordinator en can readily be replaced by the name of the mathematical symbol "+". For this reason, we may wonder whether we are dealing 
with natural language or scientific jargon. An argument in favor of the latter is that in sums with more than two members the coordinator must be repeated before each member except the first, that is, the unmarked monosyndetic construction is not well-formed. We are clearly not dealing with logical conjunction, as the entailments drie/vier is zeven 'three/four is seven' are invalid, but perhaps this can be solved by assuming that (356a) is in fact an abbreviated form of (356c).

(356) a. Drie en/plus vier is zeven.

three and/plus four is seven

b. drie en/plus vier en/plus vijf is twaalf

three and/plus four and/plus five is twelve

c. De som van drie en vier is zeven.

the sum of three and four is seven

The conjunction en can also be used with an additive function in the formation of complex numerals such as eenentwintig 'twenty one'. We will not discuss this here as there is good reason for assuming that it is not a case of syntactic coordination. This will become clear when we compare the two examples in (357), where deelbaar zijn door means that division results in a natural number: first, while the complex numeral in (357a) triggers singular agreement, the syntactic conjunction in (357b) triggers plural agreement; second, while the statement in (357a) is true $(21 / 3$ $=7)$ the statement in (357b) is false $(1 / 3=0.333$ and $20 / 3=6.666)$.

(357) a. Eenentwintig is deelbaar door drie.

[complex numeral] twenty-one is divisible by three

b. Een en twintig zijn deelbaar door drie. one and twenty are divisible by three

[syntactic conjunction]

We conclude from the agreement facts that complex numbers with en are complex morphological forms that are treated as units by syntax: for more discussion of the formation of complex numbers, we refer the reader to Section N6.1.

\section{Coordinate structures with missing conjuncts}

The conjunction en 'and' is normally used to link two coordinands. There are, however, also cases such as those in $(358 \mathrm{a} \& \mathrm{~b})$ in which one coordinand seems to be missing. Examples such as these require a special context: a speaker using (358a) will be aware that the addressee has had a meeting with Marie on some important issue and he wants to know the outcome of this meeting, while a speaker can use (358b) for requesting more information about a certain incident. Examples like these are important tools in the organization of a discourse and thus resemble example (358c), repeated from Subsection IA3, which is also exceptional in that it involves coordination of clauses with a different illocutionary force.

(358) a. En wat zei Marie?

and what said Marie

'And what did Marie say?'

b. Goed, je sprak hem aan en? good you spoke him prt. and

'All right, you addressed him and [what happened next]?' 
c. Goed, [[je sprak Marie aan] en [wat zei ze toen?]] good you spoke Marie prt. and what said she then 'All right, you addressed Marie and what did she say then?'

Given the fact illustrated in $(358 \mathrm{a} \& \mathrm{~b})$ that the initial and the second coordinand can be omitted, it need not come as a surprise that the speaker can sometimes be even more economical by leaving out both coordinands: En? The meaning of this utterance largely depends on the context: it can be used as a request for more information En (toen)? 'and (then)?' but it can also be used as a sign of indifference (Nou) en? 'So what?'. There is also a stronger form of the coordinator, enne, which is often used for introducing a new argument or discourse topic: Enne ..., ik wou je ook nog vragen of ... 'I also wanted to ask you whether ...'; see Overdiep (1937:562) and Corver (2014).

Overdiep (1937:562) already noted that sentences with en in initial position normally relate to the ${ }^{\circ}$ common ground (that is, the shared knowledge of discourse participants): the utterance En nu naar bed! after reading a bedtime story will only be effective if the child is used to going to sleep after such a story. Overdiep also noted that the coordinator en normally receives emphatic accent in such cases and that this adds an expressive component to the utterance: examples such as given in (359a-b), for instance, tend to express surprise, indignation, etc. Some construction types such as the en maar $V_{i n f}$ construction in $(359 \mathrm{c})$ even have a specialized expressive meaning; cf. Broekhuis \& Corver (2017).

(359) a. En ik maar denken dat ze ziek was! [after hearing that Els is on a vacation] and I PRT think that she ill was

'And I was thinking all the time that she was ill.'

b. En je zei dat Jan schrijver was! and you said that Jan writer was

'And you told me that he was a writer!'

c. En maar zeuren de hele dag!

and PRT nag the whole day

'Nag, nag, nag, ... the whole day long!'

All examples discussed in this subsection involve full coordinands that are omitted. For completeness' sake, we want to note that occasionally it is also possible to omit parts of coordinands. First, consider example (360), in which the sequence of the coordinator en and the of-clause is a fixed formula for ensuring that something is the case (here: that Jan knew it). Probably, the phrase following en is already a reduced (main) clause, but it can be even further reduced to Nou en of! 'absolutely'.

$$
\begin{aligned}
& \text { Nou, en of Jan dat wist! } \\
& \text { well and whether Jan that knew } \\
& \text { 'No doubt that Jan knew that.' }
\end{aligned}
$$

This subsection has shown that there are cases in which one or more conjuncts are omitted from a coordinate structure. It seems plausible that the missing conjuncts are syntactically present but not phonetically realized. We have seen that such cases play an important role in structuring the discourse and often have an expressive or emotional function. 


\section{The simplex coordinator of 'or'}

The coordinator of 'or' resembles the coordinator en 'and' in that it is highly frequent and quite versatile in its use. The overall organization of our discussion of of is similar to our discussion of en 'and' in subsection I. Subsection A starts by discussing the co-occurrence restrictions on the coordinands, Subsection B continues with a discussion of the problems arising with agreement when the feature specifications of the nominal coordinands differ. Subsection $\mathrm{C}$ discusses issues concerning the interpretation of disjunctive coordinate structures: after a brief discussion of the inclusive and the exclusive reading of of, we discuss a number of asymmetrical disjunctive coordinate structures, that is, structures in which reordering of the coordinands affects the truth conditions. Subsection D briefly discusses a special type of asymmetrical disjunction which has become known as BALANSSCHIKKING (balanced ordination) in the literature. Subsection E concludes with a number of more special uses of of.

\section{A. Restrictions on the coordinands}

The coordinator of 'or' is highly productive as a linker: it can be used to coordinate phrases of various syntactic categories and the resulting structures can have a variety of syntactic functions (e.g., as argument, predicate, adverbial, and even more). Although there are various syntactic and semantic co-occurrence restrictions on the coordinands that amount to stating that they must be similar in a specific sense, we will see that there are also various "mixed" cases.

\section{Categorial/semantic restrictions on the coordinands}

The examples in (361) show that, like the coordinator en 'and', the coordinator of 'or' is highly productive as a linker; it can coordinate clauses (CPs), noun phrases (DPs), APs and PPs.

$$
\begin{aligned}
& \text { - Category of the coordinands } \\
& \text { a. [[Marie is ziek] of [ze is op vakantie]]. } \\
& \text { Marie is ill or she is on vacation } \\
& \text { b. [[De man] of [de vrouw]] zingt een lied. } \\
& \text { the man or the woman sings a song } \\
& \text { c. Jan is [[ziek] of [oververmoeid]]. } \\
& \text { Jan is ill or overtired } \\
& \text { d. Jan wacht [[op een boek] of [op een CD]]. } \\
& \text { Jan waits for a book or for a CD }
\end{aligned}
$$

The illocutionary type of clauses may affect the acceptability of the resulting coordinate structures: declarative (Decl), yes/no questions (Q), and imperative (Imp) clauses can all be coordinated. This was already illustrated for declaratives by (361a), and the examples in (362a\&b) illustrate this for yes/no-questions and imperatives. 
(362) - Illocutionary types of clausal coordinands

a. [[Is Marie ziek] of [is ze op vakantie]]?

[yes/no-Q]

is Marie ill or is she on vacation

'Is Marie ill or is she having a vacation?'

b. [[Neem een maand vrij] of [ga op vakantie $]]$ !

[Imp]

take a month off or go on vacation

'Take a month's leave or go on vacation!'

The examples in (363) show, however, that it is difficult to coordinate $w h$-questions or wh-exclamatives. To our knowledge, the contrast between the interrogatives in (362a) and (363a) has not been discussed before, but intuitively it seems to be of a semantic or pragmatic nature. That $(362 a)$ is acceptable is not surprising given that it presents the addressee with two clear alternatives, namely the propositions "Marie is ill" and "Marie is on vacation". That (363a) is marked may be due to the fact that it does not present the addressee with such clear alternatives. The reason for the markedness of the disjunction of $w h$-exclamatives in (363b) may be that it leads to a pragmatic paradox: the use of the wh-exclamatives indicates that the speaker commits himself to the high-degree reading of the adjectives mooi 'beautiful' and ontroerend 'moving', which is contradicted by the fact that the disjunction indicates that the speaker is not willing to commit himself to the truth of both coordinands.
(363) a. ${ }^{\$}[[$ Wie is er ziek] of [wie gaat er op vakantie]]? [wh-Q] who is there ill or who goes there on vacation
'Who is ill or who is going on vacation?'
b. $\$$ [Wat een mooie tekening heeft Jan gemaakt] of what a beautiful drawing has Jan made [wat een ontroerend gedicht heeft Els geschreven]! what a moving poem has Els written

The examples in (361a) and (362) are main clauses, but (364) shows that dependent clauses can also be coordinated. The clauses can be declaratives or yes/noquestions, but imperatives are excluded for the independent reason that they cannot be embedded at all. A remarkable fact is that the complementizer of the second embedded yes/no-question in (364b) cannot be introduced by the interrogative complementizer of but must be introduced by the "declarative" complementizer dat 'that'. This may be the result of haplology, in tandem with the fact that many speakers allow the use the complementizer form of dat in embedded interrogative clauses: cf. of of dat.

(364) - Embedded clauses

a. Els denkt [[dat Marie ziek is] of [dat ze op vakantie is]]. [Decl] Els thinks that Marie ill is or that she on vacation is

'Els believes that Marie is ill or that she is having a vacation.'

b. Els vroeg [[of Marie ziek is] of [dat/*of ze op vakantie is]]. [yes/no-Q] Els asked if Marie ill is or that/if she on vacation is 'Els asked whether Marie is ill or whether she is having a vacation.' 
Example (365a) is marked for a similar reason as (363a) if the embedded clauses both refer to questions that Jan has asked, but is acceptable if the speaker wants to assert that Jan asked one of the questions but that he does not know which one. The acceptability of the second reading is perhaps even clearer in question (365b) adapted from Haeseryn et al. (1997:1491), which makes explicit that the speaker wants to know whether Jan has asked how much it costs or whether he has asked how much he has to pay. This shows that there is clearly no syntactic constraint on disjunctive coordination of wh-clauses, which supports our earlier suggestion that the markedness of (363a) is of a semantic or a pragmatic nature. Note that speakers who allow the complementizer of (dat) in embedded whinterrogative can also use it in (365): Jan vroeg [[wie of (dat) er ziek was] of [wie of (dat) er op vakantie was]]. This of course supports the haplology account of the impossibility of the complementizer of in (364b) given above.

(365) a. Jan vroeg [[wie er ziek is] of [wie er op vakantie gaat]]. [wh-Q] Jan asked who there ill is or who there on vacation goes 'Jan asked to know who is ill or who is going on holiday.'

b. Heeft Jan gevraagd [[hoeveel het kost] of [hoeveel hij moet betalen]]? has Jan asked how.much it costs or how.much he must pay

'Has Jan asked how much it costs or how much he has to pay?'

The examples in (366) finally show that extended verbal projections smaller than clauses (CPs) can also be linked by of; we provisionally refer to such smaller projections as VP for convenience, although the reader should keep in mind that these projections may be larger than what is called VP elsewhere in this work. The primeless examples are main clauses while the primed examples are the corresponding embedded clauses. Observe that the finite verb zal 'will' in (366b) has been extracted in an ${ }^{\circ}$ across-the-board fashion from the coordinated VPs in order to satisfy the verb-second requirement; we have marked the original VPinternal positions of the finite verb by means with the ${ }^{\circ}$ trace $t_{\mathrm{v}}$.

- Verbal coordinands of different sizes

a. [[Els wil een boek lezen] of [ze wil een gedicht schrijven]]. [CPs] Els wants a book read or she wants a poem write 'Els wants to read a book or she wants to write a poem.'

$a^{\prime}$. Ik denk [[dat Els een boek wil lezen] of [dat ze een gedicht wil schrijven]]. I think that Els a book wants read or that she a poem wants write 'I think that Els wants to read a book or that she want to write a poem.'

b. Els zal [[een boek $t_{\mathrm{v}}$ lezen] of [een gedicht $t_{\mathrm{v}}$ schrijven]]. Els will a book read or a poem write 'Els will read a book or write a poem.'

$\mathrm{b}^{\prime}$. Ik denk dat Els [[een boek zal lezen] of [een gedicht zal schrijven]]. I think that Els a book will read or a poem will write 'I think that Els will write a book or write a poem.' 


\section{Syntactic functions of disjunctive coordinate structures}

Coordinate structures with of 'or' can be used in virtually all conceivable syntactic functions: they can be used as full sentences, but also as arguments, (complementive or supplementive) predicates, and various types of adverbial phrases. Some typical examples are given in (367); most of these examples convey that the speaker is insufficiently informed or uncertain about the situation described. For this reason, some of the coordinate structures may sound somewhat forced in declarative clauses but they all become fully acceptable in yes/no-questions. For instance, while example (367d) is forced in that it requires a quite specific context to be usable, its interrogative counterpart Werkt Jan snel of traag? 'Does Jan work fast or slow?' would be a quite natural question.

(367) - Syntactic function

a. [[Marie is ziek] of [ze is op vakantie]]. Marie is ill or she is on vacation

b. [[De man] of [de vrouw]] zingt een lied. the man or the woman sings a song

$b^{\prime}$. Ik zal [[een boek] of [een CD]] kopen. I will a book or a CD buy

$\mathrm{b}^{\prime \prime}$. Jan zoekt [[naar een boek] of [naar een CD]]. [prepositional object] Jan looks for a book or for a CD

c. Jan is [ziek of overwerkt].

[complementive] Jan is ill or overworked

$c^{\prime}$. Jan ging [ziek of moe] naar bed.

[subject]

[direct object] Jan went ill or tired to bed

d. Jan werkt [snel of traag]. Jan works fast or slow

$d^{\prime}$. Jan werkt [morgen of overmorgen]. Jan works tomorrow or the.day.after.tomorrow

$d^{\prime \prime}$. Jan werkt [in Amsterdam of in Utrecht]. Jan works in Amsterdam or in Utrecht

[supplementive]

[manner adverbial]

[time adverbial]

[place adverbial]

As in the case of en 'and', there are certain adverbial types that do not easily allow disjunction for semantic or pragmatic reasons. The oddity of (368a) seems attributable to the fact that the disjunctive coordinate structure zeker of mogelijk is not more informative than the simple use of the modal mogelijk. And the oddity of (368b) may be ascribed to the fact that the disjunction of the polar adverbials wel and niet is not quite informative. That we are not dealing with a syntactic restriction is clear from the fact illustrated in the primed examples that the same coordinate structures are acceptable in interrogative clauses where the addressee is given a clear choice. A similar case is Je moet nu beslissen of je [wel of niet] meedoet 'You have to decide now whether or not you will participate', where wel of niet can also be replaced by the more idiomatic form al dan niet. 
(368) a. \$Jan komt [zeker of mogelijk].

Jan comes certainly or possibly

$\mathrm{a}^{\prime}$. Komt Jan [zeker of mogelijk]? comes Jan certainly or possibly

'Is it possible or certain that Jan will come?'

b. \$Jan komt [wel of niet] vandaag. Jan comes AFF or not today

$\mathrm{b}^{\prime}$. Komt Jan [wel of niet] vandaag? comes Jan AFF or not today 'Is or isn't Jan coming today?'

Disjunctive coordinate structures also occur below the level of clausal coordinands. The examples in (369) show that they can occur as nominal modifiers, as in the (a)-examples, but also as smaller nominal projections, as in the (b)examples where the modifiers have scope over both coordinands; see Section N3.3.2.5 for more information about modifiers and scope.

(369) a. Er zijn momenteel [tomaten [[uit Spanje] of [uit Italië]]] verkrijgbaar. there are at.present tomatoes from Spain or from Italy available 'Tomatoes from Spain or from Italy are available right now.'

$\mathrm{a}^{\prime}$. [Leerlingen [die te laat komen] of [die niet aanwezig zijn]] worden gestraft. pupils who too late come or who not present are are punished 'Pupils who are too late or who are not present will be punished.'

b. [De niet aanwezige [leerlingen of studenten]] worden gestraft. the not present pupils or students are punished 'The absent pupils or students will be punished.'

$\mathrm{b}^{\prime}$. [[Leerlingen of studenten] die niet aanwezig zijn] worden gestraft. pupils or students who not present are are punished 'Pupils or students who are not present will be punished.'

Disjunctive coordinate structures can not only be used as complements of verbs but also of nouns, adjectives and prepositions. Example (370) provides three simple cases illustrating this: the prepositional coordinate structures in (370a) and (370b) function as the complements of, respectively, the noun ouders and the adjective geïnteresseerd 'interested', and in (370c) the nominal coordinate structure functions as the ${ }^{\circ}$ complement of the preposition $o p$.

(370) a. Ik ontmoet morgen de [ouders [[van Jan] of [van Els]]].

I meet tomorrow the parents of Jan or of Els

'I will meet the parents of Jan or (those) of Els tomorrow.'

b. Jan is [geïnteresseerd [[in taalkunde] of [in postzegels]]]. Jan is interested in linguistics or in stamps

c. Jan wacht [op [[een boek] of [een CD]]].

Jan waits for a book or a CD 


\section{Coordinands of different types}

Subsection 1 has shown that disjunction of clauses is possible regardless of their illocutionary force (although disjunction of $w h$-questions is sometimes impossible for non-syntactic reasons). The examples in (371) make it clear, however, that linking clauses of different illocutionary types is not easy; changing the order of the clauses does not improve the result.

- Mixing clauses of different illocutionary types is impossible

a. *[[Marie is ziek] of [gaat Jan op vakantie?]].

[Decl \& Q] Marie is ill or goes Jan on vacation

b. *[[Marie is ziek] of [ga op vakantie!]].

[Decl \& Imp]

Marie is ill or go on vacation

c. *[[Is Marie ziek?] of [ga op vakantie!]].

is Marie ill or go on vacation

[Q \& Imp]

$O f$ 'or' can link phrases of different categories, as in (372), provided they have a similar syntactic function (here: complementive).

(372) a. Ik vraag me af of Jan [[slim] of [een sukkel]] is. [AP\&DP] I wonder REFL prt. whether Jan smart or a dope is 'I wonder whether Jan is smart or a dope.'

b. Ik vraag me af of Jan [[ziek] of [op vakantie]] is. I wonder REFL prt. whether Jan ill or on vacation is

[AP\&PP] 'I wonder whether Jans is ill or on vacation.'

c. Ik vraag me af of Jan [[een sukkel] of [in de war]] is. [DP\&PP] I wonder REFL prt. whether Jan a dope or in the WAR is

'I wonder whether Jan is a dope or confused.'

In nominal coordinate structures, the coordinands may differ in all nominal features: number, person and gender. Again the main restriction is that they must have the same syntactic function and be able to appear in the same syntactic position as the coordinate structure as a whole. We will see in Subsection B, however, that mixed cases like these are sometimes difficult to integrate into the clause.

(373) a. Heb je [[Jan $]_{\mathrm{sg}}$ of [zijn kinderen $\left.]_{\mathrm{pl}}\right]$ daar gezien?

have you Jan or his children there seen

'Have you seen Jan or his children there?'

b. Ik heb $\left[\mathrm{Jan}_{3 \mathrm{p}}\right.$ of $\left.\mathrm{jou}_{2 \mathrm{p}}\right]$ daar gezien.

I have Jan or you there seen

'I have seen Jan or you there.'

c. Heb je [[de man $]_{\text {non-neuter }}$ of [zijn zoontje $\left.]_{\text {neuter }}\right]$ daar gezien?

have you the man or his $\mathrm{son}_{\mathrm{dim}}$ there seen

'Have you seen the man or his little son there?'

\section{Conclusion}

The limited set of examples in this subsection has shown that there are hardly any syntactic restrictions on coordinate structures with of 'or'. First, the coordinands are not restricted with respect to their categorial status. Second, coordinate structures can have virtually all syntactic functions: they can be full-fledged clauses, ${ }^{\circ}$ clausal 
constituents (arguments, adverbials or complementives), but also parts of clausal constituents. There are various syntactico-semantic co-occurrence restrictions on the coordinands: they must be able to perform the same function and occupy the same position as the coordinate structure as a whole, and clausal coordinands must be of the same illocutionary type. They do not have to be similar in all respects, however, as is clear from the fact that nominal coordinands may differ in number, person and gender features.

\section{B. Agreement with nominal coordinands with "mixed" feature specifications}

Subject-verb agreement of coordinate structures with of 'or' depends on the feature specification of the coordinands. To illustrate: the examples in (374a\&b) show that if the coordinands all have either the feature $3 \mathrm{sg}$ or the feature $3 \mathrm{pl}$, the finite verb will be marked $3 \mathrm{sg}$ or $3 \mathrm{pl}$, too. However, if the coordinands are, respectively, $3 \mathrm{sg}$ and $3 \mathrm{pl}$, the resulting clause will be degraded regardless of the inflection of the finite verb: it cannot be $3 \mathrm{sg}$ or $3 \mathrm{pl}$, nor is there some default form that can be used to save the structure. Some speakers may marginally accept examples such as (374c): we ignore this for the moment but will return to it at the end of this subsection.

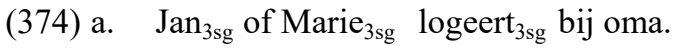

Jan or Marie stays with granny

'Jan or Marie will stay with granny.'

b. $\left[[\text { De jongens }]_{3 \mathrm{pl}}\right.$ of $\left.[\text { de meisjes }]_{3 \mathrm{pl}}\right] \operatorname{logeren}_{3 \mathrm{pl}}$ bij oma.

the boys or the girls stay with granny

'The boys or the girls will stay with granny.'

c. *[[Jan $]_{3 \mathrm{sg}}$ of [zijn zusjes $\left.]_{3 \mathrm{pl}}\right]$ logeert ${ }_{3 \mathrm{sg}} / \operatorname{logeren}_{\mathrm{pl}}$ bij oma.

Jan or his sisters stays/stay with granny

'Jan or his sisters will stay with granny.'

The degraded stauts of (374c) suggests that Dutch does not have clear (generally accepted) resolution rules for number conflicts in disjunctive coordinate structures with of 'or'. This also holds for person conflicts: the examples in (375) show for singular coordinands that disjunctions can act as antecedents for an anaphor only if the coordinands have the same person specification; the same holds for plural coordinands but this is not shown here. Note in passing that the acceptable instance in (375d) cannot be rendered into English given that this language differs from Dutch in that singular masculine and feminine (pro)nouns must agree in gender with the anaphor.

- Anaphor binding: person (singular)

a. *[Ik of jij] keek naar mezelf/jezelf/zichzelf.

I or you looked at REFL ${ }_{1 p . s g} / \operatorname{REFL}_{2 p . s g} / \operatorname{REFL}_{3 p . s g}$

b. *[Ik of hij] keek naar mezelf/zichzelf.

I or he looked at REFL $L_{\text {1p.sg }} /$ REFL $_{3 p . s g}$

c. *[Hij of jij] keek naar jezelf/zichzelf. he or you looked at $\mathrm{REFL}_{2 \mathrm{p} . \mathrm{sg}} / \mathrm{REFL}_{3 p . s g}$

d. [Hij of zij] keek naar zichzelf. he or she looked at REFL $L_{3 p . s g}$ 
One exception to the restriction that the coordinands must have the same person specification is given in (376): this is due to the fact that the polite second person form $u$ 'you' can function as the antecedent of the third person reflexive pronoun zichzelf. Substitution of the polite second person reflexive form uzelf for zichzelf yields an unacceptable result.

(376) a. [Hij of u] keek naar zichzelf.

he or you looked at REFL

b. [U of hij] keek naar zichzelf. you or he looked at REFL

Subject-verb agreement between a nominal disjunction and a finite verb is (fully) acceptable only if the coordinands trigger the same inflection on the finite verb. This means that subject-verb agreement does not cause any problems if the nominal coordinands are all plural since plural nouns uniformly trigger the inflectional -en suffix on the finite verb.

- Subject-verb agreement: plural

a. $\mathrm{Wij}_{1 \mathrm{pl}}$ of $\mathrm{jullie}_{2 \mathrm{pl}} / \mathrm{zij}_{3 \mathrm{pl}} \operatorname{logeren}_{\mathrm{pl}}$ bij oma.

we or you/they stay with granny

'We or you/they will stay with granny.'

b. Jullie 2 pl of $\mathrm{zij}_{3 \mathrm{pl}} \operatorname{logeren}_{\mathrm{pl}}$ bij oma. you or they stay with granny

'You or they will stay with granny.'

However, if one of the coordinands in (377) is replaced by a singular form, the examples become degraded, as singular subjects are not compatible with the -en suffix on the finite verb; use of the singular and the plural verb form both lead to an unacceptable result. Note in passing that (as expected) example (378b) is acceptable with singular agreement on the verb if the pronoun $z i j$ is interpreted as the $3 \mathrm{sg}$ female pronoun.

- Subject-verb agreement: mixed number
a. ${ }^{*} \mathrm{Ik}_{1 \mathrm{sg}}$ of jullie $_{2 \mathrm{p}} / \mathrm{zij}_{3 \mathrm{pl}}$ logeer $\mathrm{Isg}_{\mathrm{sg}} / \operatorname{logeren} \mathrm{pl}_{\mathrm{pl}}$ bij oma.
I or you/they stay/stay with granny
$\mathrm{a}^{\prime} .{ }^{*} \mathrm{Wij}_{1 \mathrm{pl}}$ of $\mathrm{jij}_{2 \mathrm{sg}} / \mathrm{hij}_{3 \mathrm{sg}} \operatorname{logeren}_{\mathrm{p} /} /$ logeert $_{2 \mathrm{sg}}$ bij oma.
we or you/he stay/stay with granny
$\begin{array}{lll}\text { b. }{ }^{*} \mathrm{Jij}_{2 \mathrm{sg}} \text { of } \mathrm{zij}_{\mathrm{pl}} & \operatorname{logeert}_{2 \mathrm{sg}} / \operatorname{logeren}_{\mathrm{pl}} & \text { bij oma. } \\ \text { you or they stay/stay } & \text { with granny }\end{array}$
$\mathrm{b}^{\prime} .{ }^{*}{ }^{\mathrm{J} u l l i e_{2 p l}}$ of hij $\mathrm{jsg}_{\text {sg }} \operatorname{logeren}_{\mathrm{pl}} /$ logeert $_{3 \mathrm{sg}}$ bij oma.
you or he stay/stays with granny
c. ${ }^{*} \mathrm{Jan}_{3 \mathrm{sg}}$ of zijn zusjes 3 pl $\operatorname{logeert}_{3 \mathrm{sg}} / \operatorname{logeren}_{\mathrm{pl}}$ bij oma.
Jan or his sisters stays/stay with granny

If both coordinands are singular but differ in person specification, the acceptability depends on the inflected verb form. The examples in (379) illustrate this for first and second person: if the coordinands trigger the same finite verb form, as in the case of modal verbs and past tense forms, the result is fully acceptable, but if they trigger a different form, as is the case in many present tense constructions, the result 
is degraded (with judgments varying from speaker to speaker); cf. (379a\&b). That we are dealing with a morphological and not a syntactic effect is clear from the fact that (379b) becomes fully acceptable in subject-verb inversion constructions, as in such cases the inflected first and second person verb forms are identical in the present tense (viz., the bare stem); cf. (379c).

$$
\begin{aligned}
& \text { - Mixed coordinands: } 1 \text { sg and } 2 \mathrm{sg} \\
& \text { a. Ik of jij kan }{ }_{\text {sg }} \text { bij oma logeren. } \\
& \text { I or you can with granny stay } \\
& \text { b. }{ }^{\%} \text { Ik of jij logeer }{ }_{1 \mathrm{sg}} / \text { logeert }_{2 \mathrm{sg}} \text { bij oma. } \\
& \text { I or you stay/stay with granny } \\
& \text { c. Logeer }{ }_{1 / 2 \mathrm{sg}} \text { ik of jij bij oma? } \\
& \text { stay I or you with granny } \\
& \text { 'Who will stay with granny, you or me?' }
\end{aligned}
$$

Observe that we may in fact even be dealing with a mere phonetic (and not a morphological) effect, as examples with the order in (379b) are fully acceptable if the verb stem ends in / $t /$ : Jij of ik zit voor 'You or me will be chairing'. This is even clearer when the verb stem ends in $/ \mathrm{d} /$, which is pronounced as $[\mathrm{t}]$ in word-final position: because the inflectional ending $-t$ is visible in writing, an example such as Jij of ik laad(t) de auto in 'You or me will load the car' will be frowned upon in writing regardless the spelling of the verb, but it will go unnoticed in speech. We will not digress on this issue here.

Mixed cases with second and third person singular are normally not problematic as they both trigger a $-t$ ending on the finite verb in the present tense, as is illustrated in $(380 \mathrm{a} \& \mathrm{~b})$ for a main and an embedded clause. However, problems may arise in main clauses with subject-verb inversion as second and third person subjects trigger different present tense inflection in such cases (without and with $-t$, respectively). Note that the distinction does not occur with modal verbs and such cases are acceptable, as expected: cf. Waarschijnlijk kan jij of Peter bij oma logeren 'Probably you or Peter can stay with granny'.

(380) - Subject-verb agreement: 1sg and 3sg

a. Peter of jij logeert ${ }_{2 / 3 s g}$ bij oma.

Peter or you stay(s) with granny

b. dat Peter of jij bij oma logeert 2/3sg. $_{\text {. }}$. that Peter or you with granny stays
c. ${ }^{\%}$ Logeert $_{3 \mathrm{sg}} /$ Logeer $_{2 \mathrm{sg}}$ Peter of jij bij oma? [O.K. with past tense logeerde] stays/stay Peter or you with granny
'Who will stay with granny, you or Peter?'

The same holds for the mixed cases in (381): if the present tense form of the verb is the same for first and third person, as in the case of the modal verbs, the result is fully acceptable, but if the verb form differs the result is highly marked (with judgments differing from speaker to speaker), both in constructions with and without subject-verb inversion. 
(381) - Mixed coordinands: $1 \mathrm{sg}$ and 3sg
a. [Jan of ik] $\mathrm{kan}_{\mathrm{sg}}$ bij oma logeren. Jan or I can with granny stay
b. ${ }^{\%}\left[\right.$ Jan of ik] logeer ${ }_{1 \text { sg }} /$ logeert $_{3 \text { sg }}$ bij oma.
[O.K. with past tense logeerde] Jan or I stay/stays with granny
c. ${ }^{\%}$ Logeer $_{1 \mathrm{sg}} /$ Logeert $_{3 \mathrm{sg}}$ [Jan of ik] bij oma? [O.K. with past tense logeerde] stay/stays Jan or I with granny
'Who will stay with granny, Jan or me?'

Apparently, speakers cannot resolve the morphological/phonetic problem that mixed cases pose for verb inflection in a generally accepted way. It therefore stands to reason that mixed coordinate structures seem to be avoided across-the-board (which is in fact also the advice normally given by language consultants). The tendency to avoid disjunctive coordinate structures with first or second person pronouns is in fact so strong that even acceptable examples can hardly be found on the internet; a Google search (3/29/17) on the two strings [ik of jij] and [jij of ik] resulted in fewer than 300 hits in total (including many cases involving coordinate structures in functions other than subject or not involving coordination at all). Searches on the other combinations of pronouns also resulted in a relatively low number of hits.

It should be noted that mixed cases of the sort discussed in this subsection have been claimed to be acceptable in Haeseryn et al. (1997:1490) if the finite verb agrees with the coordinand closest to it, but it is unclear to us to what extent this holds for other speakers. De Vries \& Herringa (2008), for instance, agree that there is a contrast but still do not consider agreement with the closest coordinand fully "gratifying", while some of our own informants flatly reject such cases. Judgments on subject-verb agreement are also problematic in other cases. Haeseryn et al. (1997:1490) claim that in the case of inclusive disjunction plural agreement is possible as a marked option, but again the judgments are not shared by all speakers, as is clear from the fact that De Vries \& Herringa (2008:4) as well as our informants judge such cases as degraded.

(382) a. [Peter of Dirk] $\mathrm{zal}_{\mathrm{sg}} /{ }^{\%}$ zullen $_{\mathrm{pl}} \mathrm{u}$ helpen.

Peter or Dirk will/will you help

'Peter or Dirk will help you.'

b. $\quad \mathrm{Is}_{\mathrm{sg}}{ }^{\circ}{ }^{\%} \mathrm{Zijn} \mathrm{n}_{\mathrm{pl}}$ Jan of Marie hier geweest?

Is/are Jan or Marie here been

'Has Jan or Marie been here?'

One general conclusion seems clear, however: disjunctive coordinate structures are only fully acceptable as subjects if all coordinands trigger the same inflection on the finite verb, and give rise to (severely) degraded results otherwise. The unacceptability of the degraded structures is not due to syntax but to a morphological or perhaps even a phonetic clash. Various more or less artificial resolution rules are being promoted on linguistic platforms but have not been very successful so far: these rules should evidently be considered to belong to the ${ }^{\circ}$ periphery of the grammar and are therefore unsuitable for arguing for or against 
any theoretical position by definition; see Newmeyer (1983: section 2.2.2) for relevant discussion.

\section{Special interpretations}

Section 1.1, sub IV, has discussed the meaning contribution of the coordinator of 'or' in terms of truth conditions: we adopted the standard semantic position that of expresses inclusive disjunction in the sense that a speaker uttering (383a) commits himself to the truth of at least one of the propositions expressed by the two coordinands. There are, however, many cases, in which an exclusive interpretation of of is preferred: a speaker uttering an example such as (383b) normally commits himself to the truth of at most one of the propositions expressed by the two coordinands. Subsection 1 will take up this issue and argue that this is not a matter of semantics but of pragmatics.

(383) a. [[Jan is ziek] of [Marie is op vakantie]]. Jan is ill or Marie is on vacation

b. [[Jan is ziek] of [hij is op vakantie]]. Jan is ill or he is on vacation

The remainder of this subsection will show that disjunctive coordinate structures are like conjunctive coordinate structures in that they can be symmetrical or asymmetrical. In symmetrical coordinate structures such as (384a), of has a purely truth-conditional interpretation, which is reflected in the fact that the order of the clauses can be reversed without affecting the truth conditions of the sentence, in agreement with the commutative law of disjunction discussed in Section 1.3, sub IIIA.

- Symmetrical coordination

a. [[Jan is ziek] of [Marie is op vakantie]]. Jan is ill or Marie is on vacation

b. [[Marie is op vakantie] of [Jan is ziek]]. Marie is on vacation or Jan is ill

The interpretation of asymmetrical coordinate structures with of, on the other hand, goes well beyond mere logical disjunction; example (385a), for instance, receives a conditional reading "If I don't go now, I will be too late". The special readings of asymmetrical structures are disrupted if the clausal coordinands are reversed, which we indicate in (385b) by means of the number sign "\#”. We will discuss a limited number of different subtypes of asymmetrical disjunctive coordination.

- Asymmetrical coordination

a. [[Ik ga] of [ik kom te laat]].

I go or I come too late

Literally: 'I will go (now) or I'll be too late.'

Conditional: 'If I don't go now, I will be too late.'

b. " [Ik kom te laat] of [ik ga].

I come too late or I go 
The Dutch literature on asymmetrical disjunction in Dutch is vast and often extends far beyond syntax/semantics proper. Since it is impossible to do full justice to the non-syntactic literature here, we will restrict ourselves to pointing out that the description of the special reading expressed by asymmetrical disjunctions does not seem to require the introduction of any special syntactic or semantic stipulations but can be captured by more or less standard pragmatic reasoning.

\section{Inclusive and exclusive disjunction}

It is sometimes claimed that the coordinator of 'or' is ambiguous between inclusive and exclusive disjunction; cf. Tarski (1995:21ff.). As a matter of fact, it seems that the inclusive interpretation of of is often dispreferred for declaratives. The question is whether this is a matter of semantics or something else. Gamut (1991: section 6.4) claims that the latter is the case; the examples in (386) illustrate this point. When the speaker knows that he is going to swim and play tennis, the most informative utterance would be the one in (386a) and the inclusive reading of (386b) will therefore be blocked by Grice's (1975) cooperation principle: the ${ }^{\circ}$ maxim of quantity requires the speaker to make his contribution as informative as is required in the context, and the addressee will therefore conclude from (386b) that the speaker does not know whether he is going to swim or whether going to play tennis; see also Levinson (2000:108).

(386) a. Ik ga morgen zwemmen en tennissen.

I go tomorrow swim and tennis

'I am going to swim and play tennis tomorrow.'

b. Ik ga morgen zwemmen of tennissen.

I go tomorrow swim or tennis

'I am going to swim or play tennis tomorrow'

Huddleston \& Pullum (2002) provide a conclusive semantic argument for the hypothesis that the exclusive reading of the coordinator of 'or' is not of a semantic but of a pragmatic nature. Consider the negated counterpart of example (386b) in (387).

$$
\begin{aligned}
& \text { Ik ga morgen niet zwemmen of tennissen. } \\
& \text { I go tomorrow not swim or tennis } \\
& \text { 'I am not going to swim or play tennis tomorrow.' }
\end{aligned}
$$

The truth table for XNOR (exclusive logical NOR) in the last column of Table 15 shows that if the exclusive-disjunction reading of (386b) were of a purely semantic nature, we would wrongly predict that (387) is true in two situations: the speaker may be going to be engaged either in both activities or in none. This is clearly incorrect: (387) is true only if the speaker is not going to be engaged in either activity, as indicated by the truth table for logical NOR. This shows that the coordinator of 'or' is semantically inclusive and that the exclusive reading is due to a pragmatic ${ }^{\circ}$ implicature; see Huddleston \& Pullum (2002:1294ff.) for more arguments. 
Table 15: Truth tables for inclusive/exclusive disjunction and logical NOR/XNOR

\begin{tabular}{||c|c||c|c|c|c||}
\hline \hline \multicolumn{2}{||c||}{ INPUT } & \multicolumn{4}{c||}{ OUTPUT } \\
\hline$\varphi$ & $\psi$ & $\begin{array}{c}\varphi \vee \psi \\
\text { inclusive } \\
\text { disjunction }\end{array}$ & $\begin{array}{c}\neg(\varphi \vee \psi) \\
\text { logical NOR }\end{array}$ & $\begin{array}{c}\varphi \underline{\mathrm{V}} \psi \\
\text { exclusive } \\
\text { disjunction }\end{array}$ & $\begin{array}{c}\neg(\varphi \underline{\vee} \psi) \\
\text { logical XNOR }\end{array}$ \\
\hline \hline 1 & 1 & 1 & 0 & 0 & 1 \\
\hline 1 & 0 & 1 & 0 & 1 & 0 \\
\hline 0 & 1 & 1 & 0 & 1 & 0 \\
\hline 0 & 0 & 0 & 1 & 0 & 1 \\
\hline
\end{tabular}

The inclusive reading is also prominent in yes/no-questions. Chiercha (2004:54) notes that if such questions could be interpreted exclusively, the truth table for exclusive disjunction in Table 15 would wrongly predict that the negative answer in (388b) should be fully acceptable. It can further be added that also the affirmative answer in $\left(388 b^{\prime}\right)$ is consistent with the truth table for inclusive disjunction only. We refer the reader to De Vries \& Herringa (2008:5) for more examples.

(388) a. Is Jan of Marie hier geweest?

is Jan or Marie here been

'Has Jan or Marie been here?'

b. "Nee, ze zijn beiden hier geweest.

no, they are both here been

$\mathrm{b}^{\prime}$. Ja, ze zijn beiden hier geweest.

yes, they are both here been

'Yes, they have both been here.'

For a brief review of the various stances on the question as to whether a semantic distinction should be made between inclusive and exclusive of 'or' or whether the exclusive reading should be seen as a pragmatic implicature, we refer the reader to Van Canegem-Ardijns \& Van Belle (2010).

Huddleston \& Pullum (2002: 1297) indicate that of 'or' is sometimes construed as equivalent to en 'and', as in (389a): the speaker clearly does not mean to express that it is possible that the book can be obtained via the publisher only. The conjunction reading of of must be due to pragmatic reasons given that the negative counterpart of $(389 a)$ in $(389 b)$ has the regular "neither ... nor ..." reading. Huddleston \& Pullum claim that the conjunctive reading of (389a) is most common in modal contexts (cf. verkrijgbaar $\approx$ can be obtained) and comparative als/dan phrases: Een jachtluipaard is sneller dan een tijger of een leeuw 'A cheetah is faster than a tiger or a lion'.

(389) a. Dit boek is verkrijgbaar via de uitgever of de boekwinkel.

this book is available via the publisher or the bookshop

'This book is available from the publisher or in a bookshop.'

b. Dit boek is niet verkrijgbaar via de uitgever of de boekwinkel. this book is not available via the publisher or the bookshop 'This book is available neither from the publisher nor in a bookshop.' 
They further claim that the conjunctive reading is especially prominent when the speaker presents a choice between alternatives that give rise to the same truthconditional result. If (389a) were part of an advertisement, the pragmatic reasoning would go as follows: the advertiser knows where the book can be obtained and it would be in the mutual interest of the advertiser and the reader not to mention the possibility of obtaining the book via the publisher/in a bookshop if that were not a true option; consequently, both options must be available.

Examples like the ones in (390) have been put forward to show that the choice between the inclusive or exclusive reading may be affected by intonation: cf. Kraak \& Klooster (1972: section 11.4.1) and Haeseryn et al. (1997:1487). We have already seen that yes/no-questions typically favor an inclusive reading: all that matters for (390a) is whether or not the addressee has contacted his mother. The use of contrastive accent in (390b), on the other hand, clearly favors an exclusive reading: the speaker presupposes that the addressee has contacted his mother but he does not know in which way. This is clear from the fact that (390b) cannot be felicitously answered by a simple $j a$ 'yes' or nee 'no', while it does suffice to indicate the mode of communication only.

(390) a. Heb je je moeder [gemaild of gebeld]?

have you your mother e-mailed or phoned

'Have you emailed or phoned your mother?'

a'. Ja (gemaild/gebeld/beide).

yes emailed/phoned/both

'Yes, I have emailed/phoned/emailed and phoned her.'

b. Heb je je moeder [gemaILd of geBELd]?

have you your mother e-mailed or phoned

'Have you emailed or phoned your mother?'

$\mathrm{b}^{\prime}$. (Ja), geMAILd/geBELd.

yes emailed/phoned

'(Yes) I have emailed/phoned her.'

If the proper way-in to the interpretative contrast between (390a) and (390b) is by appealing to the notions of inclusiveness and exclusiveness, the pragmatic nature of these notions is highlighted by the fact that the addressee can easily cancel the speaker's presupposition expressed by (390b) by the affirmative answer $J a$, beide 'Yes, I did both'. We may therefore conclude that the coordinator of 'or' is always inclusive and that its exclusive reading is due to pragmatics; cf. Hendriks (2001b).

For completeness' sake, note that according to Haeseryn et al. (1997:1492) the disjunctive coordinator ofwel 'or' is virtually always interpreted as exclusive disjunction (or as a means of introducing an alternative name for the entity mention by the first coordinand: cf. Section E). We need not digress on this here given that this form is more or less restricted to writing: according to Uit den Boogaart (1975:136) it occurs in the spoken language of speakers with an academic background only, and it does not occur at all in the frequency list of spoken language in De Jong (1979). The same holds to an even higher degree for the use of dan (wel) as a disjunctive coordinator. 


\section{Asymmetrical disjunction I: $p \vee q$}

Subsection IC3 has shown that coordinate structures with the conjunctive coordinator en 'and' can sometimes be interpreted as conditionals. The examples in (391) show the same for coordinate structures with the disjunctive coordinator of 'or'; cf. Haeseryn et al. (1997:1534) and Van der Heijden (1999: section 4.1) The coordinate structure in (391a) contains two declarative main clauses and can be used to motivate the speaker's decision to leave due to its conditional reading "If I don't go (now), I will be too late". The coordinate structure in (391b) contains an imperative and a declarative clause and is normally used as a warning with the conditional interpretation "If you don't go (now), you will be too late"; cf. Kraak \& Klooster (1972:276).

- Asymmetrical disjunction (conditional)

a. [[Ik ga] of [ik kom te laat]].

I go or I come too late

Literally: 'I will go (now) or I'll be late.'

Paraphrase: 'If I don't go (now), I'll be too late.'

b. [[Ga] of [je komt te laat]]!

go or you come too late

Literally: 'Go (now) or you'll be too late.'

Paraphrase: 'If you don't go (now), you'll be too late.'

The question as to why these utterances can receive a conditional interpretation seems less complicated than the same question with regard to their conjunctive counterparts, as Table 16 shows that the disjunction $\mathrm{p} \vee \mathrm{q}$ is logically equivalent to $\neg \mathrm{p} \rightarrow \mathrm{q}$, which corresponds neatly with the conditional paraphrases given above.

Table 16

\begin{tabular}{||c|c||c|c|c||}
\hline $\mathrm{p}$ & $\mathrm{q}$ & $\neg \mathrm{p}$ & $\mathrm{p} \vee \mathrm{q}$ & $\neg \mathrm{p} \rightarrow \mathrm{q}$ \\
\hline \hline 1 & 1 & 0 & 1 & 1 \\
\hline 1 & 0 & 0 & 1 & 1 \\
\hline 0 & 1 & 1 & 1 & 1 \\
\hline 0 & 0 & 1 & 0 & 0 \\
\hline
\end{tabular}

That $\mathrm{p} \vee \mathrm{q}$ and $\neg \mathrm{p} \rightarrow \mathrm{q}$ are logically equivalent does not imply, however, that coordinate structures with of 'or' are always interpreted as conditionals. This is clear from the fact that a conditional interpretation is not easily available for example (392a): the propositions expressed by the coordinands in (392) are simply presented as independent of each other; they can be reversed without affecting the meaning of the coordinate structure. We are dealing with symmetrical disjunction: both coordinands can be used as a plausible explanation for, e.g., the observation that the light is on in Jan's apartment (on the premise that Jan normally switches the light off when he goes out). 
(392) - Symmetrical disjunction
a. [[Jan is thuis] of [hij heeft per ongeluk het licht aangelaten]]. [p $\mathrm{p}$ ] Jan is home or he has by accident the light on-left
'Jan is at home or he has accidentally left the light on.'
b. [[Jan heeft het licht per ongeluk aangelaten] of [hij is thuis]]. Jan has the light by accident left.on or he is home 'Jan has accidentally left the light on or he is at home.'

The examples in (391), on the other hand, are clearly asymmetrical; reversing the order of the clausal coordinands in (391a), repeated here as (393a), results in the loss of the conditional interpretation. The resulting structure in (393b) is in fact quite marked due to a lack of coherence (which is indicated by the dollar sign). Reversing the imperative and declarative clauses in (391b) simply leads to a completely unacceptable result; cf. *[[Je komt te laat] of [ga]]! (literally.: "You will come too late or go!').

\section{- Asymmetrical disjunction}

a. [[Ik ga] of [ik kom te laat]].

I go or I come too late

[conditional]

'I go (now) or I'll be too late.'

b. $\$[$ IIk kom te laat] of [ik ga]].

I come too late or I go

[non-conditional]

As in the corresponding coordinate structures with en 'and', discussed in Subsection IC3, the conditional interpretation is normally not possible if the utterance is in the past tense. Example (394) may be syntactically well-formed but is just as incoherent as (393b), which suggests that the conditional interpretation of asymmetrical disjunctive coordinate structures is also restricted to, and possibly even triggered by, irrealis contexts.

$$
\begin{aligned}
& \text { \$[ I Ik ging] of [ik kwam te laat }]] \text {. } \\
& \text { I went or I came too late } \\
& \text { Literally: 'I went or I came too late.' }
\end{aligned}
$$

The conditional interpretation of (391/393a) is related to the temporal ordering typically found in asymmetrical coordination constructions: because the eventuality expressed by the first coordinand precedes the eventuality expressed by the second coordinand, manipulation of the truth value of $p$ restricts the truth value of $q$. This relation is more transparently expressed by means of the "conditional" formula $\neg p$ $\rightarrow \mathrm{q}$ than by the more "neutral" formula $\mathrm{p} \vee \mathrm{q}$; see Van Canegem-Ardijns \& Van Belle (2010) for a somewhat different proposal in the same spirit.

(395) - Pragmatic reasoning leading to a conditional reading of (391a)

a. The utterance does not describe an existing state of affairs: $p \vee q=0$. The utterance should therefore be interpreted as irrealis; cf. ${ }^{\circ}$ maxim of relation.

b. Speaker $\mathrm{S}$ commits himself to $\mathrm{p} \vee \mathrm{q}=1$ at some time $\mathrm{t}$; cf. maxim of quality.

c. If $\mathrm{S}$ makes $\mathrm{p}$ true, $\mathrm{q}$ may be false or true in order for $\mathrm{p} \vee \mathrm{q}$ to be true; if $\mathrm{S}$ makes $\mathrm{p}$ false, $\mathrm{q}$ must be true in order for $\mathrm{p} \vee \mathrm{q}$ to be true.

d. Because $\mathrm{q}$ is undesirable for $\mathrm{S}$, the conditional reading $\neg \mathrm{p} \rightarrow \mathrm{q}$ provides a motivation for $\mathrm{S}$ for making $\mathrm{p}$ true. 
Although imperatives cannot be assigned a truth value, it is even easier to derive the conditional interpretation of utterance (391b). Because the use of an imperative urges the addressee to make a certain proposition $p$ true, we can again account for the conditional reading by appealing to the temporal ordering of the asymmetrically coordinated clauses and Grice's (1975) ${ }^{\circ}$ cooperative principle, where $\mathrm{p}$ refers to the proposition that the addressee is urged to make true and $\mathrm{q}$ corresponds to the proposition expressed by the second clause.

(396) - Pragmatic reasoning leading to a conditional reading of (391b)

a. The utterance does not describe an existing state of affairs: $p \vee q=0$.

b. The imperative invites the addressee A to make $p$ true.

c. If $A$ makes $p$ true, $p \vee q=1$ regardless of the truth of $q$; if A makes $p$ false, $\mathrm{p} \vee \mathrm{q}=1$ only if $\mathrm{q}=1$.

d. Because $\mathrm{q}$ is undesirable for $\mathrm{A}$, the conditional reading $\neg \mathrm{p} \rightarrow \mathrm{q}$ provides a warning to A not to make $\mathrm{p}$ false.

That the examples in (391a) and (391b) can both be construed as providing a rationale for making $\mathrm{p}$ true is crucially based on the fact that $\mathrm{q}$ is undesirable for, respectively, the speaker and the addressee. This raises the question as to why examples such as given in (397) sound so weird (on the assumption that being on time is desirable for the speaker/addressee) or receive an ironic interpretation.

(397) a. ${ }^{\$}[[\mathrm{Ik}$ blijf $]$ of [ik kom op tijd]].

I stay or I come in time

Compare: 'I stay or I'll be in time.'

b. ${ }^{\$}[[$ Blijf $]$ of [je komt op tijd]].

stay or you come in time

Literally: 'Stay or you'll be in time.'

Pragmatic reasoning along the lines of (396) would lead to the wrong conclusion that the utterances provide a rationale for making $\mathrm{p}$ false, as this would leave open the possibility that $q$ would become true. The reason for the markedness of (397b) may be that the normal function of the imperative is to persuade the addressee to make a certain proposition $\mathrm{p}$ true. This is at odds with the conclusion, drawn from the pragmatic reasoning in (396), that it would be better for the addressee not to make $\mathrm{p}$ true. In other words, the utterance leads to a pragmatic paradox by providing the addressee with conflicting signals; cf. Van Canegem-Ardijns \& Van Belle (2010). This may also be the reason for the markedness of (397a): the speaker leads the addressee down the garden path by first providing him with a positive declarative that must be rejected later on the basis of pragmatic reasoning.

The conditional readings of the disjunctive coordinate structures discussed so far are based on the equivalence rule $\varphi \vee \psi \equiv \neg \varphi \rightarrow \psi$. There is a second conditional-like reading, illustrated in (398), which has been referred to as the exceptive reading. This reading is triggered when the second clause is (irrealis) past tense and contains the modal verb moeten 'must'; see Welschen (1999:16ff.) for extensive discussion. 


$$
\begin{aligned}
& \text { We gaan wandelen of het moest/zou moeten regenen. } \\
& \text { we go walk or it should/would must rain } \\
& \text { Literally: 'We go walk, or it should/would have to rain.' } \\
& \text { Paraphrase: 'We will go for a walk, unless it rains.' }
\end{aligned}
$$

Assuming that the meaning of unless can be described as "if not", we can translate the paraphrase of (398) as: $\neg \mathrm{q} \rightarrow \mathrm{p}$. Table 17 shows that this reading is expected given that $\neg \mathrm{q} \rightarrow \mathrm{p}$ is also logically equivalent to $\mathrm{p} \vee \mathrm{q}$.

Table 17

\begin{tabular}{||c|c||c|c|c||}
\hline $\mathrm{p}$ & $\mathrm{q}$ & $\neg \mathrm{q}$ & $\mathrm{p} \vee \mathrm{q}$ & $\neg \mathrm{q} \rightarrow \mathrm{p}$ \\
\hline \hline 1 & 1 & 0 & 1 & 1 \\
\hline 1 & 0 & 1 & 1 & 1 \\
\hline 0 & 1 & 0 & 1 & 1 \\
\hline 0 & 0 & 1 & 0 & 0 \\
\hline
\end{tabular}

The exceptive reading of (398), which seems part of formal language, is clearly related to the subjunctive-like impact of irrealis past tense forms like moest 'should', zou moeten 'would have to', etc. The pragmatic reasoning leading to this reading is briefly outlined in (399).

(399) - Pragmatic reasoning leading to the exceptive reading of (398):

a. Irrealis past tense entails: $\mathrm{q}=0$ or $\mathrm{q}=1$ at contextually determined time $t$.

b. S commits himself to making $\neg \mathrm{q} \rightarrow \mathrm{p}$ true at $t$.

c. If $\neg \mathrm{q}=1$ at $t,(398)$ is true regardless the truth of $\mathrm{p}$; cf. shaded rows in Table 17.

d. If $\neg \mathrm{q}=0$ at $t,(398)$ is true only if $\mathrm{p}=1$; cf. non-shaded rows in Table 17 .

e. If $\neg \mathrm{q}=0$ at $t, \mathrm{~S}$ commits himself to $\mathrm{p}=1$ at $t$.

This subsection has shown that the more special readings assigned to the disjunctive examples of the form $\mathrm{p} \vee \mathrm{q}$ can easily be accounted for by appealing to logical equivalence rules and standard pragmatic reasoning; we therefore do not need any unconventional syntactic or semantic means in order to account for these data.

\section{Asymmetrical disjunction II: $\neg p \vee q$}

The conditional reading of the type of disjunctive coordinate structures discussed in the previous subsection, illustrated again in (400), is based on the logical equivalence of the two statements $\mathrm{p} \vee \mathrm{q}$ and $\neg \mathrm{p} \rightarrow \mathrm{q}$; cf. Table 16 .

$$
\begin{aligned}
& \text { [[Ik ga] of [ik kom te laat]]. } \\
& \text { I go or I come too late } \\
& \text { Literally: 'I'll go or I'll be too late.' } \\
& \text { Paraphrase: 'If I do not go (now) I'll be too late.' }
\end{aligned}
$$

This subsection discusses a second kind of disjunctive coordinate structure with a conditional reading, in which the first coordinand is a negative declarative clause; the conditional reading of such examples is illustrated in (401). 
(401) [[Ik blijf niet langer] of [ik kom te laat]].

$[\neg \varphi \vee \psi \equiv \varphi \rightarrow \psi]$

I stay no longer or I come too late

Literally: 'I won't stay any longer or I'll be too late.'

Conditional paraphrase: 'If I stay any longer, I'll be too late.'

We can account for the conditional reading of (401) by applying the logical equivalence rule given in the square brackets, which is illustrated in Table 18.

Table 18

\begin{tabular}{|c|c|c||c|c|}
\hline $\mathrm{p}$ & $\mathrm{q}$ & $\neg \mathrm{p}$ & $\neg \mathrm{p} \vee \mathrm{q}$ & $\mathrm{p} \rightarrow \mathrm{q}$ \\
\hline \hline 1 & 1 & 0 & 1 & 1 \\
\hline 1 & 0 & 0 & 0 & 0 \\
\hline 0 & 1 & 1 & 1 & 1 \\
\hline 0 & 0 & 1 & 1 & 1 \\
\hline
\end{tabular}

The equivalence rule deriving the conditional reading in (400) actually suffices to derive the conditional reading of (401) as well: applying it to the formula $\neg \mathrm{p} \vee \mathrm{q}$ results in $\neg \neg \mathrm{p} \rightarrow \mathrm{q}$, which is in turn equivalent with $\mathrm{p} \rightarrow \mathrm{q}$ because the two negative operators cancel each other out. We would therefore expect that there is little to say about examples such as (401) because we can follow essentially the same pragmatic reasoning leading to the conditional interpretation of (400). However, there is a complication in that cases of the type in (401) can express a somewhat wider range of interpretations. Example (402a), for instance, does not only allow a conditional reading but also a temporal (consecutive) reading with a generic, habitual or iterative flavor.

(402) a. [Jan kan niets zeggen] of [Marie protesteert].

Jan can nothing say or Marie protests

Literally: 'Jan cannot say anything or Marie protests.'

b. Conditional paraphrase: 'If Jan says something, Marie protests.'

$\mathrm{b}^{\prime}$. Temporal paraphrase: 'Marie protests when(ever) Jan is saying something.'

Following Van den Toorn (1972), we can derive the temporal reading from the equivalence rule $\neg \varphi \vee \psi \equiv \neg(\varphi \wedge \neg \psi)$, according to which (402a) can be paraphrased as "it is not true that Jan says something and Mary does not protest". The temporal reading is even more prominent in the past tense counterpart of example (402a) in (403), which is in accordance with our earlier claim that the conditional reading requires an irrealis context.

[Jan kon niets zeggen] of [Marie protesteerde].

Jan could nothing say or Marie protested

Literally: 'Jan could not say anything or Marie protested.'

Temporal paraphrase: 'When(ever) Jan said anything, Marie protested.'

\section{Another case of asymmetrical disjunction with logical impact?}

Another potential case of asymmetrical disjunction (not mentioned in the literature as far as we know) is given in (404). Examples such as these start with a declarative clause followed by a yes/no-question. From an affirmative answer to the question, 
the participants would conclude that the statement made in the declarative clause would be false.

$$
\begin{aligned}
& \text { Marie is niet thuis. Of zijn de lichten aan? } \\
& \text { Marie is not at.home. or are the light on } \\
& \text { 'Marie is not at home. Or are the lights on?' }
\end{aligned}
$$

It seems however, that we are dealing here with a run-of-the-mill argumentation based on the following hidden premise: "if the light is on, Marie is at home". This accounts for the fact that an affirmative answer to the question would falsify the contention given in the declarative clause. Similar examples starting with an imperative and an interrogative clause are given in (405). The effect of these examples is again based on some hidden premise. Example (405a) is based on the hidden premise that being deaf would be a good excuse for not obeying a verbal order and example (405) on the hidden premise that being an abstainer would be a valid reason for declining a glass of wine.

(405) a. Ga nu naar boven! Of ben je doof?

go now upstairs or are you deaf

'Go upstairs! Or are you deaf?'

b. Wil je een glaasje wijn? Of drink je niet meer? want you a glass [of] wine or drink you not anymore

'Would you like a glass of wine? Or don't you drink anymore?

It should be noted, however, that it is not a priori clear that the clauses in (404) and (405) are linked by the coordinator of 'or'. It might well be the case that we are dealing with a disjunction with a missing coordinand, which would be in line with the fact that the two clauses are pronounced as separate sentences (and can also be presented as such in writing). We leave examples like these for future research.

\section{Fixed collocations and ordering conventions}

As in the case of conjunctions, there are many disjunctions that do not allow reordering of their coordinands. Some of these disjunctions have a specialized meaning such as vandaag of morgen 'one of these days' (literally: today or tomorrow) and hier en daar 'in some points/places' (literally: here and there) in (406).

(406) a. Vandaag of morgen vermoord ik hem nog eens. today or tomorrow kill I him PRT PRT

'One of these days I will kill him.'

b. Hier of daar moet het huis bijgeschilderd worden. [also: hier en daar] here or there must the house in-painted be

'The house should be touched up in some places.'

There are also coordinate structures like those in (407) with a fixed combination of coordinands. Changing the order of the coordinands leads to a degraded result. Note that the disjunctions in (407) all have an exclusive flavor. 
(407) a. Het is nu of nooit.

[*nooit of $n u]$

it is now or never

b. Het is alles of niets.

[*niets of alles $]$

it is all or nothing

c. Het is graag of niet.

[*niet of graag]

it is gladly or not

'You either accept/do/... it willingly or you don't accept/do/... it.'

d. Het is erop of eronder.

[*eronder of erop $]$

it in on.it or under.it

'It is either winning or loosing.'

Disjunctions are occassionally found in more or less fixed verbal expressions such as (408a). An interesting case is niet of nauwelijks 'not or hardly' in (408b), in which the disjunction seems logically equivalent with nauwelijks but is used with an intensifying effect.

(408) a. Hij kon geen boe of bah meer zeggen. [*geen bah of boe]

he could no boo or ba anymore say

'He couldn't say a single word anymore.'

b. We hebben hem niet of nauwelijks gezien. we have him not or hardly seen

'We have hardly seen him.'

[*nauwelijks of niet]

\section{Conclusion}

The main conclusion of this subsection is that the more special readings assigned to disjunctive examples of the form $p \vee q$ and $\neg p \vee q$ can be accounted for by means of logical equivalence rules and standard pragmatic reasoning; we do not need any special syntactic or semantic means in order to account for these data. Readers interested in more information about the classification of the special interpretations that can be assigned to asymmetrical disjunctions and the pragmatics involved in deriving these are referred to Proeme (1984), Boogaart (2004), Fortuin \& Boogaart (2009), Van Canegem-Ardijns \& Van Belle (2010), and the references cited there. We have ignored in our discussion so far an influential stream within the more traditional literature, which denies that asymmetrical disjunction involves "true" coordination. Subsection D will discuss the arguments that underlie this conclusion and show that these are all flawed.

\section{Balanced ordination (balansschikking)}

The previous subsection has argued that the more special readings assigned to disjunctive examples of the form $\neg p \vee q$ do not necessitate the introduction of any special syntactic or semantic mechanism. This goes against one approach to the subject in the literature on Dutch, which denies that asymmetrical disjunctions of this form involve "true" coordination. An important argument leading to this conclusion is that, although we are at least superficially dealing with coordination in examples such as (409a), the initial clauses receive a subordinate adverbial-like interpretation, as is clear from the paraphrases in the (b)-examples. 
(409) a. [Jan kan niets zeggen] of [Marie protesteert].

Jan can nothing say or Marie protests

Literally: 'Jan cannot say anything or Marie protests.'

b. Als Jan iets zegt, protesteert Marie.

if Jan something says protests Marie

'If Jan says something, Marie protests.'

$\mathrm{b}^{\prime}$. Zodra Jan iets zegt, protesteert Marie.

as.soon.as Jan something says protests Marie

'As soon as Jan says something, Marie protests.'

This (presumed) discrepancy between form and interpretation is problematic for the so-called form-meaning correspondence hypothesis, according to which differences in interpretation should be reflected directly in syntactic structure; see, e.g., the introduction by G.F. Bos and H. Roose in their edition of De Groot (1949) and Ellfers-van Ketel (1991:189ff). Bos (1964) solved this problem by claiming that constructions such as (409a) are instantiations of a set of syntactic constructions with properties of both coordination and subordination, which she dubbed BALANSSCHIKKING "balanced ordination". The principal aim of this subsection is to show that Bos' arguments for claiming that balanced ordination is a third type of syntactic relation besides coordination and subordination are all flawed and can therefore not be used for arguing in favor of it. But we will first set the stage for the discussion by briefly reviewing the more logically oriented literature on the set of supposed balanced ordination constructions.

\section{A bird's eye view on the logically oriented literature}

The logical approach to what has become known as balanced ordination since Bos (1964) was initiated by Terwey (1892), who distinguishes three subcategories. The first category consists of various construction types with a conditional interpretation. Examples of this type were discussed in Subsection $C$, in which we have shown that their interpretation can easily be accounted for by appealing to the logical equivalence rule $\neg \varphi \vee \psi \equiv \varphi \rightarrow \psi$; cf. Van den Toorn (1972), Van der Heijden (1999: section 4.2.2) among others. Some more examples are given in (410).

(410) a. [[Ik blijf niet langer] of [ik kom te laat]].

I stay no longer or I come too late

Literally: 'I will not stay any longer or I will be too late.'

Paraphrase: 'If I stay any longer, I'll be too late.'

b. [Er is geen mens] of [hij moet sterven].

there is no human.being or he must die

Literally: 'There is no human being or he must die.'

Paraphrase: 'All people must die.'

c. Er is geen probleem zo groot of het kan opgelost worden.' there is no problem that big or it can prt.-solved be

Literally: 'There is no problem that big or it can be solved.'

Paraphrase: 'However big, every problem can be solved.' 
The second category distinguished by Terwey contains constructions that receive a temporal (consecutive) interpretation. Such examples may have a generic flavor, as the examples in (402a)/(403a), or may simply express succession, as the examples in (411). Van den Toorn (1972) has claimed that such interpretations can be accounted for by appealing to the equivalence rule $\neg \varphi \vee \psi \equiv \neg(\varphi \wedge \neg \psi)$. Van Hauwermeiren (1973) has shown, however, that this holds true for examples such as (411a) but not for examples such as (411b).

(411) a. [Jan was nog niet thuis] of [de telefoon ging].

Jan was not yet at. home or the telephone rang

Literally: 'Jan was not yet home or the telephone rang.'

Paraphrase: 'The phone rang immediately after Jan came home.'

b. [Jan was nauwelijks thuis] of [de telefoon ging].

Jan was hardly (=not long) home or the telephone rang

Literally: 'Jan had hardly arrived home or the telephone rang.'

Paraphrase: 'The phone rang immediately after Jan came home.'

The easiest way of demonstrating Van Hauwermeiren's point is by considering the entailments in (412) of the clausal coordinands preceding the coordinator of 'or' in (411); the entailment in (412a) shows that the first coordinand of the coordinate structure in (411a) is a negative declarative clause $(\neg p)$, while the entailment in (412b) shows that the first coordinand in (411b) is a positive declarative clause (p). This means that the two examples in (411) have the propositional logical translations in the primed examples. These translations thus refute Van den Toorn's suggestion that all consecutive readings can be derived by the equivalence rule $\neg \varphi$ $\vee \psi \equiv \neg(\varphi \wedge \neg \psi)$; this is evidently not the case for (411b).

(412) a. Jan was nog niet thuis $\Vdash$ Jan was niet thuis

[negative declarative]

$a^{\prime} . \quad(411 a): \neg p \vee q$

b. Jan was nauwelijks thuis $\Vdash$ Jan was thuis

$b^{\prime}$. (411b): $p \vee q$

[positive declarative]

It is not easy to show either that the equivalence rule $\neg \varphi \vee \psi \equiv \neg(\varphi \wedge \neg \psi)$ plays a role in deriving the consecutive reading of example (411a), due to the fact that the meaning contribution of the adverbial nog 'yet' is not immediately clear. In order to see this, we should note that the two examples in (413) can be considered each other's polar counterparts.

(413) a. Jan is nog niet thuis.

Jan is yet not home

b. Jan is al thuis.

Jan is already home

Consequently, the application of the equivalence rule $\neg \varphi \vee \psi \equiv \neg(\varphi \wedge \neg \psi)$ to (411a) would give rise to the paraphrase it was not the case that Jan was already at home and the phone didn't ring. This correctly expresses that on the premise that Jan was already at home, we must conclude from (411a) that the phone rang.

The third category distinguished by Terwey contains constructions of the type in (414). Examples like these express several types of modifying functions: het 
scheelde niet veel of ... is a conventional means of expressing approximation, similar to that expressed by the adverbial bijna 'almost' in the paraphrase in $\left(414 \mathrm{a}^{\prime}\right)$; the meaning of het kan niet anders of ... comes very close to that of the epistemic verb moeten 'must' in $\left(414 b^{\prime}\right)$, and ik twijfel er niet aan of ... has more or less the same meaning as the modal adverb ongetwijfeld 'undoubtedly' in $\left(414 \mathrm{c}^{\prime}\right)$.

(414) a. Het scheelde niet veel of hij had de eerste prijs gewonnen. it differed not much or he had the first prize won

$a^{\prime}$. Hij had bijna de eerste prijs gewonnen.

[paraphrase] he had nearly the first prize won

'He had nearly won the first prize.'

b. Het kan niet anders of hij heeft de eerste prijs gewonnen. it can not be.different or he has the first prize won

$\mathrm{b}^{\prime}$. Hij moet de eerste prijs hebben gewonnen. [paraphrase] he must the first prize have won

'He must have won the first prize.'

c. Ik twijfel er niet aan of hij heeft de eerste prijs gewonnen. I doubt there not of or he has the first prize won

$c^{\prime}$. Hij heeft ongetwijfeld de eerste prijs gewonnen. he has undoubtedly the first prize won 'He will undoubtedly have won the first prize.'

The placement of the finite verbs in second position of the clauses following of strongly suggests that we are dealing with coordination. This is also suggested by the fact that the string of hij had gewonnen cannot be topicalized: cf. *Of hij had de eerste prijs gewonnen scheelde (het) niet veel. Note that we placed het 'it' in brackets because ${ }^{\circ}$ anticipatory pronouns normally cannot appear when the clause they introduce is topicalized, so that het would be expected not to be present in this "topicalization" construction. However, the acceptability of the examples in (415) suggests that this string can be pronominalized. It is therefore not very surprising that it has sometimes been suggested that we are dealing with embedded clauses after all.

(415) a. Dat scheelde niet veel.

that escaped not much

'That was close.'

b. Dat kan niet anders.

that can not be.different

'That must be so.'

c. Ik twijfel daar niet aan.

I doubt there not about

'I don't doubt that.'

It will be clear that the second and the third category are problematical for a rigid coordination approach. This was in fact already noticed by Terwey (1892), who accordingly provides a special account of these categories. He argues that the conditional examples from the first category developed in the $16^{\text {th }}$ and $17^{\text {th }}$ century from juxtaposition of two clauses, one negative and one (probably) positive, by 
adding the coordinator of 'or'. After this development had taken its course, the second and third category developed along the lines of the first one. This process will have been facilitated by the fact, discussed below example (412), that at least some instances of the second category are superficially similar to the conditional constructions from the first category. Hauwermeier's (1973) observation that the intended interpretation of the balanced ordination construction in (416b) is the same as expressed by the coordinate structure with standard conjunction in (416a) shows that the analogical change does not require more than replacement of en 'and' by of 'or'.
(416) a.
[Jan was nauwelijks
thuis] en [de telefoon ging].
Jan was hardly (=not long) home and the telephone rang
'Jan had hardly arrived home and the telephone rang.'
b. [Jan was nauwelijks thuis] of [de telefoon ging]. [= $(411 \mathrm{~b})]$ Jan was hardly (=not long) home or the telephone rang
Literally: 'Jan had hardly arrived home or the telephone rang.'
Paraphrase: 'The phone rang immediately after Jan came home.'

According to Terwey, the analogical change was also facilitated by the fact that in all three categories the initial clause always includes some form of negation. Terwey's analogy hypothesis justifies assigning examples of the second and third category an idiomatic status; this manifestly holds for examples of the third category, as these are generally of a formulaic nature.

\section{Balanced ordination (balansschikking) is not a syntactic relation}

The syntactic literature on balanced ordination constructions has mainly focused on the question as to whether we are really dealing with "true" coordination in such cases. The main reason for denying this is that balanced ordination does not exhibit properties typically found in disjunctive coordinate structures, such as those indicated in (417). This argument for concluding that we are not dealing with runof-the-mill coordination is still cited with approval in more recent works such as Haeseryn et al. (1997: section 26.6), Van der Heijden (1999), and Welschen (1999).

$$
\text { - Properties of of 'or' in symmetrical disjunctions (Bos 1964: chapter IV) }
$$

a. Polyadic disjunction is possible.

b. Correlative disjunction is possible.

c. Inversion of coordinands is possible.

d. Conjunction reduction is possible.

e. Omission of of is sometimes possible.

f. The illocutionary force of the clausal coordinands need not be declarative.

g. Omission of one coordinand does not affect the meaning of the other.

That we are not dealing with syntactic subordination either is immediately clear from the fact that the linked clauses both have the shape of main clauses with the finite verb (given in italics) in second position; these verbs cannot occur in clausefinal position, that is, in a position following the direct object. 
(418) - Placement of the finite verbs
a. Jan kan niets zeggen of Marie bespot hem.
Jan can nothing say or Marie mocks him
Literally: 'Jan cannot say anything or Marie mocks him.'
b. *Jan kan niets zeggen of Marie hem bespot.
[main + non-main]
c. *Jan niets kan zeggen of Marie bespot hem.
[non-main + main]
d. *Jan niets kan zeggen of Marie hem bespot.
$[$ main + main $]$

It should be pointed out, however, that what happens in embedded contexts is less clear. Welschen (1999:8) has claimed that the second coordinand is frozen in the sense that it must appear as a main clause in such contexts. This is illustrated in (419).

(419) a. ${ }^{\%} \mathrm{Ik}$ denk [dat Jan niets kan zeggen] of [Marie bespot hem].
I think that Jan nothing can say or Marie mocks him
b. ${ }^{*} \mathrm{Ik}$ denk [dat Jan niets kan zeggen] of [dat Marie hem bespot].
I think that Jan nothing can say or that Marie him mocks

Although the acceptability contrast between the two examples in (419) seems real, examples such as (419a) do not sound fully natural and do not seem to occur in colloquial speech. Furthermore, acceptability judgments seem to depend on various factors, such as the choice of matrix predicate: speakers seem to accept examples of this kind most readily if the predicate is a verb of saying or cognition (such as zeggen 'to say' and denken 'to think'). Examples like those in (420), on the other hand, are judged as marked and speakers do not seem to be able to grasp the intended conditional reading without explicit instruction (that is, without directing them to the form in (418a)).

(420) a. 'Het is vervelend [dat Jan niets kan zeggen] of [Marie bespot hem]. it is annoying that Jan nothing can say or Marie mocks him

b. ?[Het feit [dat Jan niets kan zeggen] of [Marie bespot hem]] is vervelend. the fact that Jan nothing can say or Marie mocks him is annoying

The artificiality of the examples such as (419a) makes it difficult to decide whether they should/can be used for evaluating the competing proposals. That care should be taken before jumping to a conclusion is especially clear in the light of the earlier conclusion that at least some supposed balanced ordination constructions are idiomatic in nature.

That we are not dealing with syntactic subordination is also clear from topicalization and pronominalization. If we were dealing with subordination, the string starting with the element of would be the most likely candidate, but this string does not behave like a ${ }^{\circ}$ clausal constituent; the examples in (421) show that it differs from true subordinate clauses such as the object clause of Marie komt in (421a) in that it can neither be topicalized nor pronominalized. Note that the dots in $\left(421 b^{\prime \prime}\right)$ are used to indicate that the string starting with of cannot be replaced by any proform other than $d a t$ 'that' either. 
- Topicalization and pronominalization of the second clause

a. Jan weet niet [of Marie komt].

Jan knows not whether Marie comes

'Jan doesn't know whether Marie will come.'

$\mathrm{a}^{\prime}$. Of Marie komt weet ik niet.

$\mathrm{a}^{\prime \prime}$. Ik weet dat niet.

b. [Jan kan niets zeggen] of [Marie protesteert]. Jan can nothing say or Marie protests

'Jan cannot say anything or Marie protests.'

$\mathrm{b}^{\prime}$. *Of Marie protesteert kan Jan niets zeggen.

$\mathrm{b}^{\prime \prime}$. *Jan kan niets dat/... zeggen.

The conflicting data led Bos (1964) to suggest that we are neither dealing with coordination nor subordination but with a third syntactic relation she dubs BALANSSCHIKKING "balanced ordination". As the postulation of this novel syntactic relation is crucially based on problems pertaining to the properties of disjunctive coordination listed in (417), we will review them in what follows and argue that they are less problematic for a coordination approach than is generally assumed: we are dealing with a collection of pre-theoretical problematic issues that largely disappear when we look at them more closely.

Property (417a) states that polyadic disjunction is possible and refers to the fact discussed in Section 1.3, sub III, that disjunctive coordination is recursive in the sense that coordinate structures with of 'or' may contain more than two coordinands; cf. [Jan leest een gedicht] (of) [Marie zingt een lied] of [Els speelt orgel] 'Jan reads a poem (or) Marie sings a song or Els plays the organ'. Bos claims that polyadic constructions do not allow a conditional reading. Example (422a) seems to support this claim (at least under a flat intonation contour) but its unacceptability need not be syntactic in nature; it might simply be due to the fact that it expresses an incoherent meaning. That this might indeed be the proper tack to take can be supported by the fact that example (422b), in which the string [Jan kan niets zeggen] of [Marie protesteert] is replaced by the conditional clause Als Jan iets zegt, protesteert Marie, is also incoherent. Note in passing that the two examples in (422) are fully acceptable if the second occurrence of of is preceded by an intonation break; such cases should be put aside because the clause de voorzitter grijpt in would then be interpreted as an afterthought.

(422) a. *[[Jan kan niets zeggen] of [Marie protesteert]] of [de voorzitter grijpt in]. Jan can nothing say or Marie protests or the chairman interferes

b. *[Als Jan iets zegt, protesteert Marie] of [de voorzitter grijpt in]. if Jan something says protests Marie or the chairman interferes

This account of the unacceptability of $(422 a)$ is based on the assumption that it has the structure $[[\mathrm{XP}$ or $\mathrm{YP}]$ or $\mathrm{ZP}]$. We could also assign it the alternative structure [XP or [YP of ZP]], which would lead to a coherent reading corresponding to that of the conditional construction in (423b). According to Wagner's generalization discussed in Section 1.3, sub IIID, such a structure should be recognizable by a nonflat intonation contour involving an intonation break before the first occurrence of $o f$. This break is indicated by a comma in example (423a), which indeed strikes us 
as relatively acceptable under the intended interpretation. This shows Bos' claim as straightforwardly refuted. Because the effect of intonation on the acceptability and interpretation of examples such as (422a) and (423a) has not been discussed in the literature so far, we will not digress on this issue here, especially as our main conclusion does not crucially depend on it.

(423) a. ${ }^{(?)}$ [Jan kan niets zeggen], of [[Marie protesteert] of [de voorzitter grijpt in]]. Jan can nothing say or Marie protests or the chairman interferes

b. Als Jan iets zegt, [[protesteert Marie] of [grijpt de voorzitter in]]. if Jan something says protests Marie or the chairman interferes 'If Jan says something, Marie protests or the chairman interferes.'

The main conclusion is that the unacceptability of (422a) is not a matter of syntax but of semantics. The logical equivalence rule $\neg \varphi \vee \psi \equiv \varphi \rightarrow \psi$ can be applied only once to $((\neg p \vee q) \vee r)$, which results in $((p \rightarrow q) \vee r)$. The two examples in (422) are therefore logically equivalent, and we may therefore conclude that $(422 \mathrm{a})$ is infelicitous for the same reason as (422b): they are both semantically incoherent.

Property (417b) states that correlative disjunction is possible and refers to the fact that disjunctive coordinate structures come in two guises: one with the simplex coordinator of 'or' and one with the correlative coordinator of ... of ... 'either ... or ...'. Example (424b) shows that correlative of ... of ... blocks the conditional reading, which we indicate by the number sign \#.

(424) a. Of [Jan leest een gedicht] of [Marie zingt een lied].

either Jan recites a poem or Marie sings a song

b. ${ }^{\#}$ Of [Jan kan niets zeggen] of [Marie protesteert].

either Jan can nothing say or Marie protests

The fact that the conditional reading is not available should not surprise us in the light of the fact that correlative of ... of ... expresses exclusive disjunction, and Table 19 shows that $\neg \mathrm{p} \underline{\mathrm{v}} \mathrm{q}$ is not equivalent to $\mathrm{p} \rightarrow \mathrm{q}$. The fact that (424b) has no conditional reading is thus clearly not related to syntax, but is a straightforwardly semantic matter.

Table 19

\begin{tabular}{||c|c|c||c|c||}
\hline \hline $\mathrm{p}$ & $\mathrm{q}$ & $\neg \mathrm{p}$ & $\neg \mathrm{p} \underline{\mathrm{v}} \mathrm{q}$ & $\mathrm{p} \rightarrow \mathrm{q}$ \\
\hline \hline 1 & 1 & 0 & 1 & 1 \\
\hline 1 & 0 & 0 & 0 & 0 \\
\hline 0 & 1 & 1 & 0 & 1 \\
\hline 0 & 0 & 1 & 1 & 1 \\
\hline
\end{tabular}

Note in passing that this does not necessarily imply that there are no asymmetrical exclusive-disjunctive structures. However, if such structures existed, they would be interpreted as a material equivalence $(\mathrm{p} \leftrightarrow \mathrm{q})$ given the equivalence rule $\neg \varphi \underline{\vee} \psi \equiv \varphi$ $\leftrightarrow \psi$. Wim Klooster (p.c.) observes that the examples in (425), discussed earlier in Kraak \& Klooster (1968:275) may be of this type: the coordinate structure is characterized by the fact that of is accented, which is a hallmark of exclusive 
disjunction, and the interpretation is something like "not $\mathrm{p}$ unless perhaps if q", which comes quite close to "p if and only if q".

(425) a. Dat beest daar is geen hond of het is een poedel.

that animal over.there is no dog or it is a poodle

Literally: 'That animal over there is not a dog or it is a poodle.'

Paraphrase: 'If that animal is a dog, it can only be a poodle.'

b. Er zit geen fout in het artikel oF het moest een typefout zijn.

there sits no error in the article or it should a typo be

Literally: 'There is no error in the article or it should be a typo.'

Paraphrase: 'If this article contains any error, it can only be a typo.'

Property (417c) states that inversion of coordinands is possible and refers to the fact that the coordinands in a disjunctive coordinate structure can often change places without affecting the logical meaning of the structure as a whole: the meaning expressed by example (426a) is logically equivalent to the meaning expressed by example (426a'). The (b)-examples, on the other hand, show that inversion of the coordinand in the conditional construction puts paid to the conditional reading, which is again indicated by the number sign \#. It is not unlikely, however, that this is related to the fact that the antecedent of the conditional temporally precedes the consequence. We may thus be dealing not with a syntactic but a pragmatic effect; cf. Section 1.4.1, sub IC1.

(426) a. [Jan leest een gedicht] of [Marie zingt een lied]. Jan recites a poem or Marie sings a song

$a^{\prime}$. [Marie zingt een lied] of [Jan leest een gedicht].

b. [Jan kan niets zeggen] of [Marie protesteert]. Jan can nothing say or Marie protests

$\mathrm{b}^{\prime} .{ }^{\#}$ [Marie protesteert] of [Jan kan niets zeggen].

Property (417d) states that conjunction reduction is possible and refers to the fact that disjunctive coordinate structures such as (427a) can apparently be reduced, as in $\left(427 a^{\prime}\right)$. The (b)-examples, on the other hand, show that reduction blocks the conditional reading, which is indicated again by the number sign \#.

(427) a. [Jan heeft een gedicht gelezen] of [hij heeft een lied gezongen].

Jan has a poem read or he has a song sung

$a^{\prime}$. [Jan heeft een gedicht gelezen] of [hij heen lied gezongen].

b. [Jan kan niets zeggen] of [hij kan vertrekken] Jan can nothing say or he can leave

$\mathrm{b}^{\prime}$. " [Jan kan niets zeggen] of [hij kan vertrekken].

Section 2.1 will argue that forward conjunction reduction of the type in the primed example does not exist and that we are dealing instead with non-clausal coordination, as indicated in (428); we are not dealing with two separate propositions but with a single proposition with a complex predicate. As the conditional reading can only arise when we are dealing with two separate propositions, we may conclude that the presumed problem with property $(417 \mathrm{~d})$ is based on an incorrect presupposition and can ultimately be attributed to semantics. 
(428) a. Jan heeft [[vp een gedicht gelezen] of [vP een lied gezongen]].

b. Jan kan [[vp niets zeggen] of [vp vertrekken]].

Bos only provides examples with forward conjunction reduction, but gapping and backward conjunction reduction are also impossible. The examples in (429) show that this is not an incidental property of asymmetrical disjunction: the (a)-examples show that sentence negation in the first coordinand always blocks gapping in coordinate structures with en 'and' and of 'or' (see also Neijt 1979:65-66), although it is possible with maar 'but' if the second coordinand features the affirmative marker wel as well; the (b)-examples show that the same holds for backward conjunction reduction. Consequently, we do not expect gapping or backward conjunction in asymmetrical coordinate structures with en/of either.

(429) a. *Jan won de auto niet en/of Marie de fiets. Jan won the car not and/or Marie won the bike

[Gapping] Compare: '*Jan didn't win the car and/or Marie the bike.'

$\mathrm{a}^{\prime}$. Jan won de auto niet maar Marie de fiets *(wel). Jan won the car not but Marie won the bike AFF. 'Jan didn't win the car but Marie did win the bike.'

b. *Jan heeft geen boeken en/of Els heeft drie CDs gekocht. [BCR] Jan has no books bought and/or Els has three CDs bought Intended: 'Jan hasn't bought any books and/or Els has bought three CDs.'

b'. Jan heeft geen boeken maar Els heeft wel drie CDS gekocht. Jan has no books bought but Els has AFF three CDs bought 'Jan hasn't bought any books but Els has bought three CDs'.

Since the primeless examples in (429) show that gapping and backward conjunction reduction always lead to degraded results when applied to clausal coordinate structures of the form $[[\ldots n e g . .$.$] en/of [\ldots($ pos $) ..]$.$] , we do not expect asymmetrical$ coordinate structures of this type either.

Property (417e) states that omission of of 'or' is sometimes possible. The problem is that this is not possible in conditional/temporal constructions such as (430).

$$
\begin{aligned}
& \text { [Jan kan niets zeggen] *(of) } \text { [Marie protesteert]. } \\
& \text { Jan can nothing say or Marie protests } \\
& \text { Literally: 'Jan cannot say anything or Marie protests.' }
\end{aligned}
$$

We believe that this argument is invalid in view of the fact that omission of the disjunctive coordinator is rare anyway and is subject to stringent conditions: see also Section 1.2, sub I. Bos (1964:242) provides two examples only. Her first example is the following: Hij wandelde wat in the tuin, ging op het terras zitten, amuseerde zich met steentjes keilen 'He strolled in the garden, sat on the terrace, entertained himself by skimming stones'. This example, which was probably constructed on the basis of a polysyndetic construction with of given earlier on the same page, seems marginal out of context; in fact, we can interpret it in a conjunctive fashion at best. Her second example is again highly marked out of context: Je doet het, je doet het niet (mij kan het niet schelen) (literally: "You do it, you leave it (I don't care)". The fact that this example must be interpreted as a 
disjunction is due to the fact that a conjunctive interpretation would lead to a contradiction, which only leaves us with an exclusive-disjunction reading; cf. Van den Toorn (1972:105). All in all, the fact that leaving out the coordinator in examples such as (430) is impossible does not seem to be problematic for assuming that we are dealing with a coordinate structure here.

Property (417f) states that the illocutionary force of the clausal coordinands need not be declarative. The problem concerns the alleged facts that the two clausal coordinands in supposed balanced ordinations must be declarative, which is illustrated by Bos (1964:242) by means of the infelicitous example in (431a) with two imperative clauses. This problem disappears, however, in view of the acceptability of example (431b) with an imperative as first coordinand.

(431) a. ${ }^{\$}$ Twijfel er niet aan of [kom terug]! doubt there not about or come back

b. [Kom niet hier] of [ik schiet]! come nothere or I shoot

'Don't come here or I'll shoot!'

The fact that the coordinands are prototypically declarative is of course not surprising given that conditionals involve a relation between two propositions, and declaratives are the prototypical means by which propositions are expressed.

Property $(417 \mathrm{~g})$ refers to the fact that omission of one coordinand in an example such as (432a) does not affect the meaning of the remaining one: example (432b) has the same meaning as the first coordinand of (432a) and (432c) has the same meaning as the second coordinand.

(432) a. [Jan leest een gedicht] of [Marie zingt een lied] Jan recites a poem or Marie sings a song

b. Jan leest een gedicht.

c. Marie zingt een lied.

Bos contends that this does not always hold for the type of conditional construction under discussion. One piece of her evidence is given in (433): example (433a) is a generic construction while (433b) is a negative existential construction, and her claim is that the meaning of the clause er is geen mens differs in the two examples.

(433) a. [Er is geen mens] of [hij moet sterven].

there is no human.being or he must die

'All people must die.'

b. $[\mathrm{Er}$ is geen mens].

there is no human.being

'There are no people (here).'

Because Bos does not make explicit what the alleged difference in meaning is, arguing against her claim is difficult, but I assume that what she proposes is that a speaker uttering (433a) presupposes that there are human beings while a speaker uttering (433b) explicitly denies this presupposition (see p.249). Presuppositions are not part of semantics proper, however, but part of the common ground (the shared knowledge about the discourse domain). Bos seems to confuse this with the 
meaning of a sentence, which is related to the commitment of a speaker. A speaker using the sentence er is geen mens in (433b) commits himself to the truth of the formula $\neg \exists \mathrm{x}$ MENS(x) within the discourse domain. A speaker using the sentence er is geen mens of hij moet sterven does not commit himself to the truth of $\neg \exists \mathrm{x}$ MENS(x), but to the situation depicted in the Venn diagram in Figure 30, where A stands for the property denoted by mens 'human' and B for the property denoted by sterfelijk 'mortal' (that is, must die); the set of people must be properly included in the set of entities denoted by sterfelijk. The fact that Figure 30 is also the settheoretical representation of material implication shows that the generic reading of (433a) can again be derived by means of the equivalence rule $\neg \varphi \vee \psi \equiv \varphi \rightarrow \psi$.

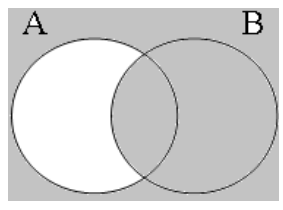

\section{Figure 30: Material implication $p \rightarrow q$}

The discussion above inevitably leads to the conclusion that there are no reasons for assuming that the clause $\mathrm{Er}$ is geen mens has a different meaning in the two examples in (433): it simply has the meaning expressed by $\neg \exists \mathrm{x}$ MENS(x). There are differences in use conditions for the two examples but these are not of a semantic nature but fully determined by pragmatic considerations (the common ground).

\section{Conclusion}

The previous subsection has shown that Bos' objections to attributing a run-of-themill coordinate structure to asymmetrical disjunctive coordinate structures are all flawed in one way of another. Therefore they cannot be used in favor of the postulation of balanced ordination as a third syntactic relation besides coordination and subordination. This is a welcome result as so far it has never become clear how balanced ordination can be implemented in syntactic terms. It should be emphasised once more that the interpretations of the set of alleged balanced ordination constructions can all be accounted for by standard syntactico-semantic and pragmatic means. There is a subset of cases that probably should be assigned an idiomatic status, but which can be divided on the basis of their interpretation into various subclasses; we will not address this issue here but refer the reader to Welschen (1999) and Malepaard (2007/2008) for extensive discussion.

\section{E. Other special uses}

This subsection discusses various special uses of disjunctions; we start with the use of the disjunction of 'or' in coordinate structures used for paraphrasing or expressing approximation. This is followed by a discussion of the use of the string of niet 'or not'.

\section{Paraphrasing and approximative of 'or'}

There are more constructions with the coordinator of 'or', for which it is not a priori clear that the disjunctive meaning of of 'or' is relevant. A first case, which seems to 
be characteristic of formal/written language, is given in (434), where of is linking two terms that are (near) synonyms-we are dealing with alternative formulations; cf. Kraak \& Klooster (1972: section 11.4.2). In many cases the of-YP string is preceded by an intonation break or written in parentheses, which raises the question as to whether the string XP-of-YP should be considered a run-of-the-mill coordinate structure. In cases like these, of is often followed by the parenthetic phrase anders gezegd 'said differently' or replaced by the even more formal form of(te)wel; see also Section N3.1.3, sub IIB.

(434) a. Het [subject of onderwerp] congrueert met de persoonsvorm.

the subject or subject agrees with the finite verb

'The subject agrees with the finite verb.'

b. [Het subject] of [het onderwerp] congrueert met de persoonsvorm. the subject or the subject agrees with the finite verb 'The subject agrees with the finite verb.'

A potentially related case, which can easily be observed in colloquial speech, is given in (435a), where the coordinate structure [NP of iets dergelijks] seems to have the specialized meaning "something resembling a screwdriver". The string of iets dergelijks can easily be replaced by of zo with a similar approximative meaning, but which differs from iets dergelijks in that it can not only be used with nominal phrases but also with predicates and adverbials; cf. (Corver 2005). This is illustrated in (435).

(435) a. Hij stak haar met [een schroevendraaier of iets dergelijks].

he stabbed her with a screwdriver or something of.the.sort

'He stabbed her with with a screwdriver or something like it.'

b. Hij stak haar met [een schroevendraaier of zo].

he stabbed her with a screwdriver or so

$\mathrm{b}^{\prime}$. Is Jan [boos of zo]?

Is Jan angry or so

'Is Jan angry, or something of the kind?'

$b^{\prime \prime}$. Ik kom morgen of zo wel langs.

I come tomorrow or so PRT by

'I will come by tomorrow, or thereabouts.'

That coordinate structures of this kind can have a specialized meaning is also clear from the existence of fixed collocations such as een of ander(e) $N$ 'some $\mathrm{N}$ ' in (436a) and de een of ander 'some person' in (436b).

(436) a. [Een of andere] gek heeft een bomaanslag gepleegd. one or another idiot has a bomb.attack committed 'Some idiot (or other) has carried out a bomb attack.'

b. De een of ander heeft een bomaanslag gepleegd. the one or another has a bomb.attack committed 'Some person has carried out a bomb attack.' 


\section{Of niet 'or not'}

Examples such as (437a) as well its reduced counterparts in (437b) occur relatively frequently in speech. This is remarkable given that they are truisms: $p \vee \neg p$ is necessarily true. Van der Wouden \& Zwarts (2017) conclude from this that the contribution of examples of this kind is not truth-conditional but pragmatic in nature.

(437) a. Je doet het of je doet het niet.

you do it or you do it not

'Either you do it or you don't.'

b. Je doet het of niet. you do it or not

The pragmatic load of the examples in (437) depends on context. The speaker may express, for instance, that he does not care whether or not $\mathrm{p}$ is true, that it is immaterial whether or not $\mathrm{p}$ is true, or that the addressee should make a choice between the two options. The speaker could also have made the same contention explicit by means of the examples in (438). The paraphrases in (438) do not exhaust the possible interpretation of the examples in (437); they can also be used in case the addressee has already made up his mind whether he will do it, but in that case they express that the addressee should accept the consequences.

(438) a. Het kan me niet schelen of je het doet of niet (doet).

it can me not care whether you it do or not do

'I don't care whether or not you do it.'

b. Het maakt niet uit of je het doet of niet (doet).

it makes not prt. whether you it do or not do

'It makes no difference whether or not you do it.'

c. Je moet beslissen of je het doet of niet (doet).

you must decide whether you it do or not do

'You must decide whether or not you do it.'

The examples in (439) show that under specific conditions the embedded clauses in (438) can also occur as independent non-main clauses. Here we seem to be dealing with two separate main clauses, one of which is reduced (indicated by [...]).

(439) a. [...] Of je het doet of niet (doet); ik bewonder je toch. whether you it do or not do I admire you PRT

'Whether or not you do it, I will admire you still.'

b. [...] Of je het doet of niet (doet); de wereld draait door. whether you it do or not does the world turns on

'Whether or not you do it, the world will keep turning.'

Constructions of the type in (439) can also be non-declarative. The yes/no-questions in (440) do not add much semantically to the simple question Doe je het (niet)? But they may reveal a certain uncertainty on the part of the speaker, which he would like to see eliminated, or they can be used as an encouragement for the speaker to make a decision. 
(440) a. Doe je het of doe je het niet?

do you it or do you it not

'Will you do it or won't you do it?'

b. Doe je het of niet?

do you it or not

A similar construction with of niet 'or not' can be found in V2-questions of the type in (441a), which are mainly used as requests for eliminating doubt on the part of the speaker (e.g., by reconfirming an earlier appointment). This means that of niet has more or less the same interpretation as of heb ik het mis 'or am I wrong' in (441b).

(441) a. Je komt morgen toch eten, of niet?

you come tomorrow PRT eat or not

'You will come for dinner tomorrow, won't you?'

b. Je komt morgen toch eten, of heb ik het mis?

you come tomorrow PRT eat or have I it wrong

'You will come for dinner tomorrow, or am I wrong?'

The imperatives in (442) can be seen as a (less friendly) encouragement for the speaker to (finally) make a decision. Or, in case the addressee has already made up his mind, to take up the task with dedication and energetically.

(442) a. Doe het of doe het niet!

do it or do it not

'Do it or don't do it.'

b. Doe het of niet.

do it or not

Note that adding the disjunction ja of nee to questions may have a similar function as of niet in urging the addressee to answer the question in full.

$$
\begin{aligned}
& \text { Doe je het? Ja of nee? } \\
& \text { do you it yes or no } \\
& \text { 'Will you do it? Yes or no?' }
\end{aligned}
$$

\section{The simplex coordinator noch 'nor'}

This subsection discusses coordinate structures with noch 'nor'. The use of noch is more or less restricted to writing: according to Uit den Boogaart (1975:136) it only occurs in the spoken language of speakers with an academic background, and it does not occur at all in the frequency list of spoken language in De Jong (1979). This suggests that in spoken language the forms in the primed examples will be preferred to the forms in the primeless examples.

(444) a. [Jan noch Marie] is hier geweest.

[formal]

Jan nor Marie is here been

'Jan nor Marie has been here.'

$\mathrm{a}^{\prime}$. [Jan en Marie] zijn hier niet geweest.

[colloquial]

Jan and Marie are here not been

'Jan and Marie have not been here.' 
b. Jan heeft [Marie noch Els] gezien.

[formal]

Jan has Marie nor Els seen

'Jan has seen Marie nor Els.'

$\mathrm{b}^{\prime}$. Jan heeft [Marie en Els] niet gezien.

Jan has Marie and Els not seen

'Jan hasn't seen Marie and Els.'

Haeseryn et al. (1997:1482) claim that coordinate structures with the correlative coordinator noch ... noch ... 'neither ... nor ...' are more frequent, that is, that examples like those in (445) are preferred to the primeless examples in (444). Although we may conclude from this that noch 'nor' is not part of ${ }^{\circ}$ core syntax, we will briefly discuss it in this subsection.

(445) a. Noch Jan noch Marie is hier geweest. neither Jan nor Marie is here been

'Neither Jan nor Marie has been here.'

b. Jan heeft [noch Marie noch Els ] gezien.

Jan has neither Marie nor Els seen

'Jan has seen neither Marie nor Els.'

\section{A. Restrictions on the coordinands}

The coordinator noch can be used to link constituents of various kinds. The examples in (444) above have already illustrated that the coordinate structure may be nominal with the syntactic function of subject or object. The examples in (446) show that coordinate structures can have various other syntactic functions and may link categories of various sorts (VP, NP, AP and PP). Note that, in accordance with the claim in Haeseryn et al. (1997:1482), all examples sound somewhat more natural with the correlative form noch ... noch ... 'neither ... nor ...'.

(446) a. Jan heeft [op vader noch op moeder] gewacht.

[PP-complement]

Jan has for father nor for mother waited

'Jan has waited neither for father nor for mother.'

b. Jan is [gelukkig noch tevreden].

[complementive]

Jan is happy nor content

'Jan was neither happy nor content.'

c. Jan kon Marie [[thuis] noch [op haar werk]] bereiken.

[adverbial]

Jan could Marie home nor at her work reach

'Jan could reach Marie neither at home nor at work.'

d. Jan had [gewassen noch gekookt].

Jan had washed nor cooked

'Jan had neither washed nor cooked.'

e. Jan leest [Engelse noch Amerikaanse] kranten. [attributive modifier]

Jan reads English nor American newspapers

'Jan reads neither English nor American newspapers.'

Because noch expresses negation inherently, it is not surprising that problems arise when it links negated coordinands. Consider the examples in (447), in which the 
primeless examples are expected to be logically equivalent with the corresponding primed ones.
(447) a. bloemen noch kransen flowers nor wreaths
b. *geen bloemen noch geen kransen no flowers nor no wreaths
c. " geen bloemen noch kransen no flowers nor wreaths
d. *bloemen noch geen kransen flowers nor no wreaths
$a^{\prime}$. geen bloemen en geen kransen no flowers and no wreaths
$b^{\prime}$. bloemen en kransen
flowers and wreaths
$c^{\prime}$. bloemen en geen kransen flowers and no wreaths
$\mathrm{d}^{\prime}$. \# geen bloemen en kransen no flowers and wreaths

We have already seen that (447a) is the formal counterpart of the colloquial form in $\left(447 \mathrm{a}^{\prime}\right)$ : it is a formulaic expression used in obituary notices for expressing the wish that participants at the funeral do not bring flowers or wreaths. The unacceptability of (447b) may be due to the fact that it is computationally more complex than (447b'): it first translates as $\neg(\neg$ flowers $\vee \neg$ wreaths), which must subsequently be reduced to the simpler formula flowers $\wedge$ wreaths. If computational considerations play a role in the unacceptability of (447b), we expect the same for the examples in $(447 \mathrm{c} \& d)$; this is clearly borne out for $(447 \mathrm{~d})$ despite the fact that $\left(447 \mathrm{~d}^{\prime}\right)$ will normally not be interpreted as [[geen bloemen] en [kransen]] because it is preferably assigned the simpler alternative structure [geen [bloemen en kransen]] involving coordination of NPs (not DPs); see the discussion of example (267) in Subsection IA1.

Example $(447 \mathrm{c})$ is acceptable but not with the same meaning as $\left(447 \mathrm{c}^{\prime}\right)$; it is only acceptable with the same meaning as $\left(447 \mathrm{a}^{\prime}\right)$. The reason is that noch is actually an ambiguous form that can not only be used as a coordinator but also as an adverb meaning "(and) not"; see Section 1.3, sub IIIG. This suggests that $(447 \mathrm{c})$ is only acceptable as a shorthand for (448b), which indeed results in the desired reading. That we are not dealing with run-of-the-mill coordination in $(447 \mathrm{c})$ is also supported by the observation in Haeseryn et al. (1997:1483) that this form is acceptable only if noch kransen is preceded by an intonation break.

(448) a. Marie is niet thuis; noch is zij op haar werk.

Marie is not home neither is she at her work

'Marie isn't at home; neither is she at work.'

b. We willen geen bloemen; noch willen we kransen.

we want no flowers neither want we wreaths

'We do not want any flowers, and we do not want any wreaths either.'

Although (446) has shown that noch can be used to coordinate phrases of various types, example (449a) shows that it cannot be used to coordinate main clauses. The desired reading $\neg(\varphi \vee \psi)$ can be expressed by (449b); noch is not a coordinator in this example but an adverbial constituent of the second clause. This is clear from the fact that it occupies the initial position of the main clause, that is, the position immediately preceding the finite verb in second position; for concreteness' sake, we have assumed that the two clauses are linked by an empty conjunctive coordinator Ø. Section 1.3, sub IIIG, has shown that adverbial noch is not translated as logical 
NOR but as "(and) not", which accounts for the fact that the first coordinand is also negated in order to obtain the desired meaning $\neg \varphi \wedge \neg \psi$ (which is logically equivalent to $\neg(\varphi \vee \psi))$. For completeness' sake, (449c) shows that adverbial noch requires the first clausal coordinand to be negated, which would be surprising if noch were simply a coordinator, but not if it were an adverbial as this property is also found with the adverbial evenmin 'neither': cf. (240) in Section 1.3, sub IIIG.

(449) a. *[[Vader is in de tuin] noch [hij is binnen]].

father is in the garden nor he is inside

b. [[Vader is niet in de tuin] Ø [noch is hij binnen]].

father is not in the garden nor is he inside

'Father is not in the garden and he isn't inside either.'

c. *[[Vader is in de tuin] $\varnothing$ [noch is hij binnen]].

father is in the garden nor is he inside

'Father is not in the garden and he isn't inside either.'

That noch functions as an adverb in clausal coordinate structures is also supported by the fact that it can license negative polarity items of the form ook maar XP, which always must have a negative licenser in their sentence.

$$
\begin{aligned}
& \text { [[Jan is niet in de tuin] Ø [noch is hij ook maar ergens te vinden]]. } \\
& \text { Jan is not in the garden nor is he OOK MAAR somewhere to find } \\
& \text { 'Jan is not in the garden; neither can he be found anywhere.' }
\end{aligned}
$$

Although Haeseryn et al. (1997:1444/85) correctly observe that noch occupies the first position of the second clause in examples such as (449b), they stick to analyzing noch as a coordinator. We, on the other hand, take this as conclusive evidence for claiming that the coordinator noch cannot be used to link main clauses.

Note, finally, that coordinate structures of the sort in (451a) sound quite marked, while examples such as (451b), in which we analyze the second coordinand as a clause reduced by gapping, are fully acceptable (in writing). We did not mark (451a) with an asterisk but with a dollar sign because it is not clear to us whether it should be considered ungrammatical or whether we are dealing with a "garden path" effect: at first, the addressee will interpret the string Jan wist dat Marie ziek is as a positive declarative clause, which must be corrected at the moment that noch is reached.

(451) a. \$Jan weet [[dat Marie ziek is] noch [dat Els afwezig is]]. Jan knows that Marie ill is nor that Els absent is

b. [[Jan weet niet [dat M. ziek is]] Ø [noch hij [dat E. afwezig is]]]. Jan knows not that $\mathrm{M}$. ill is nor knows he that E. absent is 'Jan doesn't know that M. is ill, and he doesn't know either that E. is absent.'

\section{B. Agreement with nominal coordinands with "mixed" feature specifications}

We can be brief with respect to subject-verb agreement between nominal coordinate structures with noch and the finite verb: since such coordinate structures with noch are the negated counterpart of coordinate structures with of 'or', we expect them to exhibit the same behavior with respect to subject-verb agreement. This is indeed 
borne out: the judgments on the examples with of given in Subsection IIB do not change when we substitute noch for of. Since the reader can construct the relevant examples himself, we only give a limited set of examples with mixed number and person features. The examples in (452) show that mixing singular and plural noun phrases normally gives rise to an unacceptable result (although some speakers may be more lenient with some of these cases, particularly (452c)).

$$
\begin{aligned}
& \text { - Subject-verb agreement: mixed number }
\end{aligned}
$$

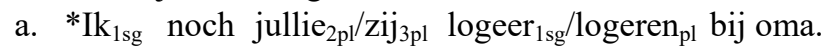

$$
\begin{aligned}
& \text { I nor you/they stay/stay with granny }
\end{aligned}
$$

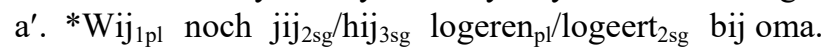

$$
\begin{aligned}
& \text { we nor you/he stay/stay with granny } \\
& \text { b. }{ }^{*} \mathrm{Jij}_{2 \mathrm{sg}} \text { noch } \mathrm{wij}_{3 \mathrm{pl}} \operatorname{logeert}_{2 \mathrm{sg}} / \text { logeren }_{\mathrm{pl}} \text { bij oma. } \\
& \text { you nor we stay/stay with granny } \\
& \mathrm{b}^{\prime} \text {. }{ }^{*} \text { Jullie }_{2 \mathrm{pl}} \text { noch hij } \mathrm{j}_{\text {sg }} \operatorname{logeren}_{\mathrm{pl}} / \text { logeert }_{3 \mathrm{sg}} \text { bij oma. } \\
& \text { you nor he stay/stays with granny } \\
& \text { c. }{ }^{*} J_{a n}{ }_{3 s g} \text { noch zijn zusjes } 3 \text { pl } \operatorname{logeert}_{3 \mathrm{sg}} / \operatorname{logeren}_{\mathrm{pl}} \text { bij oma. } \\
& \text { Jan nor his sisters stays/stay with granny }
\end{aligned}
$$

The examples in (453) show that mixing person features is possible, but only if the two coordinands trigger the same form of the finite verb. In the (a)- and (b)examples this depends on subject-verb inversion: if inversion does not apply, the $2 \mathrm{sg}$ pronoun $j i j$ 'you' triggers the $-t$ ending on the verb just like $3 \mathrm{sg}$ subjects, while it triggers no (overt) inflection on the verb ending, just like the 1 sg subject pronoun $i k$ ' $\mathrm{I}$ ', if no inversion applies. The (c)-examples are both marked because $1 \mathrm{sg}$ and $3 \mathrm{sg}$ subjects always trigger different forms of the finite verb. The past tense counterparts of these examples are all acceptable as all pronouns select the same form of the finite verb, vz. logeerde 'stayed'.

(453) a. ${ }^{\%} \mathrm{Ik}$ of jij logeer $_{1 \mathrm{sg}} /$ logeert $_{2 \mathrm{sg}}$ bij oma.

I or you stay/stay with granny

$\mathrm{a}^{\prime}$. Logeer L $_{1 / 2 \mathrm{sg}} \mathrm{ik}$ of jij bij oma?

stay I or you with granny

'Who will stay with granny, you or me?'

b. Peter of jij logeert $2 / 3 s g$ bij oma.

Peter or you stay(s) with granny

$\mathrm{b}^{\prime} .{ }^{\%}$ Logeert $_{3 \mathrm{sg}} /$ Logeer $_{2 \mathrm{sg}}$ Peter of jij bij oma? stays/stay Peter or you with granny

Intended reading: 'Who will stay with granny, Peter or you?'

c. ${ }^{\%}\left[\mathrm{Jan}\right.$ of ik] logeer ${ }_{1 \mathrm{sg}} /$ logeert $_{3 \mathrm{sg}}$ bij oma. Jan or I stay/stays with granny

$c^{\prime} .{ }^{\%}$ Logeer $_{1 \mathrm{sg}} /$ Logeert $_{3 s g}$ [Jan of ik] bij oma? stay/stays Jan or I with granny

'Who will stay with granny, Jan or me?' 


\section{Meaning/interpretation}

In dyadic coordinate structures, noch can be translated straightforwardly as logical NOR: $\neg(\varphi \vee \psi)$. We will not discuss cases with more than two coordinands because at least some of our informants experience the monosyndetic example in (454a) as marked compared to the apparent "correlative" one in (454b), and also because Section 1.3, sub IIIG, has given semantic reasons for rejecting the idea that the coordinator noch can be used in polyadic coordinate structures such as (454a).

(454) a. ${ }^{\%}$ Jan, Marie noch Els komt morgen.

[monadic] Jan Marie nor Els comes tomorrow

b. Noch Jan, noch Marie noch Els komt morgen. neither Jan nor Marie nor Els comes tomorrow

[“correlative"]

Section 1.3, sub IIIG, has in fact shown that noch in polyadic coordinate structures such as (454b) cannot be translated as logical NOR either, as this would give rise to the wrong interpretation, and concluded from this that noch functions as an adverbial with the meaning "(and) not"; the reader is referred to this subsection for a more detailed discussion.

\section{$I V$. The simplex coordinator maar 'but'}

This subsection discusses coordinate structures with maar 'but'. Subsection A will start by showing that the restrictions on the coordinands are not of a syntactic nature but are due to the fact that the coordinands must be adversative. Subsection B continues by looking at problems related to agreement between nominal coordinate structures and the finite verb. Subsection $\mathrm{C}$ concludes with a discussion of various more special interpretations of coordinate structures with maar; we will argue that these are not of a logico-semantic or syntactic but of a pragmatic nature.

\section{A. Restrictions on the coordinands}

The adversative coordinator maar 'but' occurs in dyadic constructions only and is prototypically used for linking declarative clauses. The examples in (455) show that the clauses must be in some sense contrastive but need not be syntactically parallel. The latter aspect is illustrated in example (455b): the two coordinands differ in that the first one expresses propositional modality (cf. V5.2.3.2, sub III) by means of the matrix verb denken 'to think/believe' while the second one expresses it by means of the modal adverb zeker 'certainly', which results in the conjunction of two propositions expressed by, respectively, an embedded clause and a main clause.

$$
\text { - Declarative clauses }
$$

a. [[Marie is in New York] maar [Jan is in Utrecht]].

Marie is in New York but Jan is in Utrecht

'Marie is in New York but Jan is in Utrecht.'

b. [[Ik denk dat Marie in New York is] maar [Jan is zeker in Utrecht]]. I think that Marie in New York is but Jan is certainly in Utrecht 'I think that Marie is in New York, but Jan is in Utrecht for sure.' 
It is easily possible for maar to link two imperative clauses, but this is more difficult in the case of questions: Haeseryn et al. (1997:1498) provide the yes/noquestion in (456b) but the shorter form in $\left(456 b^{\prime}\right)$ seems much more natural.

(456) a. [[Kom morgen langs] maar [laat je hond thuis]]!

[Imp] come tomorrow by but let your dog home

'Drop by tomorrow but leave your dog at home!'

b. [[Is dit niet juist] maar [is het toch gepubliceerd]]? [yes/no-Q] is this not correct but is it nevertheless published

$\mathrm{b}^{\prime}$. Is dit [[niet juist] maar [toch gepubliceerd]]? is this not correct but nevertheless published

The instances in (457) show that maar differs from en 'and' in that it cannot easily link $w h$-questions. This contrast may be due to the fact that there is no clear contrast between the two examples.

(457) a. [Wie zijn gezakt] en [wie zijn geslaagd]? who are failed and who are passed

'Who have failed the exams and who have passed them?'

b. ${ }^{\$}[$ Wie is gezakt] maar [wie is geslaagd]? who is failed but who is passed

Coordination of $w h$-exclamatives is possible but seems to be subject to (at least) two conditions: (i) the predicative parts of the clausal coordinands must express a suitable contrast and (ii) these predicative parts are predicated of the same (possibly singleton) set of entities. Example (458a) satisfies both conditions and is acceptable, while $(458 \mathrm{~b})$ violates the second one and is marked.

[[Wat waren de jongens blij toen ze vertrokken] maar
what were the boys happy when they left but
[wat waren ze teleurgesteld toen ze aankwamen]]!
what were they disappointed when they arrived

'How happy the boys were when they left, but how disappointed they were when they arrrived!'

b. ${ }^{\$}$ What waren er veel jongens gezakt] maar what were there many boys failed but [wat waren er veel meisjes geslaagd]]! what were there many girls passed

Maar differs from en in that it can link sentences with different illocutionary force, as in (459). Note that $w h$-questions are also easily possible in such cases. We have not been able to construct natural-sounding examples with a question and an imperative: It is not clear to us whether the unacceptability is due to a syntactic restriction or to some pragmatic constraint. 

(459) a. [[Ik heb weinig tijd] maar [kom morgen langs!]] [Decl + Imp]
I have little time but come tomorrow by
'I have little time but do drop by tomorrow!'
b. [[Het boek is interessant] maar [is het publicabel]]? [Decl +yes/no-Q] the book is interesting but is it publishable
'The book is interesting but is it fit for publication?'
$\mathrm{b}^{\prime}$. [[Het boek is interessant] maar [wie wil het publiceren]]? [Decl $\left.+w h-\mathrm{Q}\right]$ the book is interesting but who wants it publish
'The book is interesting but who is willing to publish it?'

As stated above, it is not so easy to construct good examples of a question and an imperative linked by maar out of the blue. The markedness of examples such as (460a) is probably not due to a syntactic restriction because it is possible to construct more or less natural-sounding examples with some more background: a student living on his own tells his mother that he always eats vegetables with potatoes, for instance, may easily get the advice in (460b).

(460) a. ${ }^{\$}$ Kom morgen maar waarom laat je je hond thuis? [Imp + wh-Q] drop.in tomorrow but why let you your dog home

Literally: 'Drop in tomorrow but why do you leave your dog at home?'

b. [[Eet vooral groente] maar [waarom gebruik je niet af en toe rijst]]? eat surely vegetable but why use you not sometimes rice

'Be sure to eat vegetables but why don't you use rice sometimes?'

Coordination with maar is also easily possible with set-denoting adjectives if they denote properties not a priori expected to be compatible. We see this in (461) for all syntactic functions in which these adjectives can be used.

(461) a. Marie is [streng maar rechtvaardig].

[complementive]

Marie is severe but just

b. Marie is een [strenge maar rechtvaardige] rechter. [attributive modifier]

Marie is an severe but just judge

c. Els ging [moe maar tevreden] naar huis.

[supplementive]

Els went tired but happy to home

d. Jan werkt [snel maar nauwkeurig].

Jan works fast but meticulously

[manner adverbial]

It is also possible to use nominal predicates in coordination with maar, provided that a suitable contrast is available. This contrast can be due to constituent negation, as in (462a), but may also be related to some property normally attributed to the denotation of the noun, as in (462b). Example (462c) is added to show that nominal and adjectival predicates can also be linked.

(462) a. Jan is [[een briljant natuurkundige] maar [geen Einstein]]. [nom. predicates] Jan is a brilljant physicist but no Einstein

b. Jan is [[timmerman] maar [een onhandige]]. [nom. predicates]

Jan is carpenter but a clumsy.one

'Jan is a carpenter but a clumsy one.' 
c. Jan is [[timmerman] maar [zeer onhandig]].

[nom. + adj. predicates]

Jan is carpenter but very clumsy

'Jan is a carpenter but very clumsy.'

While the examples above bear out that predicates can easily be linked by maar, it is difficult for maar to link arguments, as is illustrated in the primeless examples in (463) for subjects and (prepositional) objects. The primed examples show, however, that all examples become fully acceptable if the first (or second) coordinand is preceded by constituent negation, which suggests that the unacceptability of the primeless examples is not syntactic in nature but due to the absence of an appropriate contrast.

(463) a. *[Jan maar Marie] ging naar huis.

[subject] Jan but Marie went to home

$a^{\prime}$. [Niet Jan maar Marie] ging naar huis. not Jan but Marie went to home

b. *Ik heb [het boek maar de CD] gekocht.

I have the book but the CD bought

[object]

$\mathrm{b}^{\prime}$. Ik heb [niet het boek maar de CD] gekocht.

I have not the book but the CD bought

c. *Ik heb [[op vader] maar [op moeder]] gewacht. [prepositional object]

I have for father but for mother waited

$\mathrm{c}^{\prime}$. Ik heb [[niet op vader] maar [op moeder]] gewacht.

I have not for father but for mother waited

A similar thing can be observed for adverbial phrases of place or time, as in (464).

(464) a. dat Els [[*(niet) op kantoor] maar [thuis]] werkt.

[place adverbial] that Els not in office but home works

'that Els doesn't work at her office but at home.'

b. dat ik $\left[\left[\left({ }^{*}\right.\right.\right.$ niet $)$ op zondag] maar [op vrijdag $\left.]\right]$ kom. [time adverbial $]$ that I not on Sunday but on Friday come 'that I will come not on Sunday but on Friday.'

We are not dealing with a syntactic restriction here, as can also be supported by the fact that the examples in (465) are just as marked as the primeless examples in (463), despite the fact that we are dealing with coordinated clauses; cf. Van Oirsouw (1987:ch.2). The use of constituent negation again improves the results, although they sound clumsy compared to the corresponding shorter forms in the primed examples in (463)).

(465) a. [[*(Niet) Jan ging naar huis] maar [Marie ging naar huis]]. not Jan went to home but Marie went to home

b. [[Ik heb *(niet) het boek gekocht] maar [ik heb de CD gekocht]].

I have not the book bought but I have the CD bought

c. [Ik heb (niet) op vader gewacht] maar [ik heb op moeder gewacht]].

I have not for father waited but I have for father waited 
Embedded clauses can be linked by maar given that the propositions they express are contrastive: this is illustrated in (466) for a direct object, an adverbial and a relative clause. We provide the matrix clause in (466b) in its embedded form, in order to show that the adverbial coordinate structure may occur in its ${ }^{\circ}$ middle field; however, the example sounds more natural if the (heavy) coordinate structure is placed in postverbal position.
(466) a. Jan zei [[dat Marie naar NY gaat] maar [dat Jan thuis blijft]]. Jan said that Marie to NY goes but that Jan at.home stays 'Jan said that Marie will go to NY but that Jan will stay at home.'
b. dat Jan [[voordat Els had gezongen] maar [nadat ze had gedanst]] vertrok. that Jan before Els had sung but after she had danced left 'that Jan left before Els had sung but after she had danced.'
c. een studie [[die onovertroffen is] maar [die niemand kent]] a study that unsurpassed is but that nobody knows 'a study that is unsurpassed but that nobody knows about'

If the propositions expressed by the embedded clauses are not contrastive, the addition of constituent negation may again make coordination available. We illustrate this for ${ }^{\circ}$ complement and adverbial clauses only, because constituent negation cannot occur between a relative clause and its antecedent. Note that example (467b) sounds more natural if the (heavy) coordinate structure occurs in postverbal position.

(467) a. Jan zei *(niet) dat Marie ziek was maar dat zij afwezig was. Jan said not that Marie ill was but that she absent was 'Jan didn't say that Marie was ill but that she was absent.'

b. dat Jan *(niet) nadat Els had gezongen maar nadat ze had gedanst vertrok. that Jan not after Els had sung but after she had danced left 'that Jan didn't leave before Els had sung but after she had danced.'

Constituent negation is often immediately followed by the focus ${ }^{\circ}$ particle alleen and a second focus particle in the second coordinand, which gives rise to sequences of the form niet alleen XP maar ook/zelfs YP 'not only XP but also YP'. Some instances are provided in (468).

(468) a. dat [niet alleen Jan maar ook/zelfs Marie] aanwezig is. that not only Jan but also/even Marie present is 'that not only Jan but also/even Marie is present.'

b. dat Jan [niet alleen van Marie maar ook/zelfs van Els] hulp kreeg. that Jan not only from Marie but also/even from Els help got 'that Jan received help not only from Marie but also/even from Els.'

c. dat afvaldiëten [niet alleen nutteloos maar ook/zelfs schadelijk] zijn. that slimming.diets not only useless but also/even harmful are 'that slimming diets are not only useless but also/even harmful.'

d. dat Jan [niet alleen vandaag maar ook/zelfs morgen] aanwezig is. that Jan not only today but also/even tomorrow present is 'that Jan will not only be present today but also/even tomorrow.' 
The primeless examples in (469) show that leaving out the focus particle in the second coordinand makes the coordinate structure unacceptable. The singly-primed examples show that leaving out the sequence niet alleen, on the other hand, gives rise to a marked result with the focus particle zelfs 'even' in the second coordinand, but seems possible with the particle ook 'also'. Omitting the full sequence niet alleen ... ook/zelfs ... is impossible in these cases because the "bare" coordinands are not contrastive.

(469) a. *dat [niet alleen Jan maar Marie] anwezig is. that not only Jan but Marie present is

$\mathrm{a}^{\prime}$. dat [Jan maar ook/?zelfs Marie] aanwezig is. that Jan but also/even Marie present is

$\mathrm{a}^{\prime \prime}$. *dat [Jan maar Marie] aanwezig is. that Jan but Marie present is

b. *dat Jan [niet alleen van Marie maar van Els] hulp kreeg. that Jan not only from Marie but from Els help got

$\mathrm{b}^{\prime}$. dat Jan [van Marie maar ook $/{ }^{2}$ zelfs van Els] hulp kreeg. that Jan from Marie but also from Els help got

$\mathrm{b}^{\prime \prime}$. *dat Jan [van Marie maar van Els] hulp kreeg. that Jan from Marie but from Els help got

c. *dat afvaldiëten [niet alleen nutteloos maar schadelijk] zijn. that slimming.diets not only useless but harmful are

$\mathrm{c}^{\prime}$. dat afvaldiëten [nutteloos maar ${ }^{(?)}$ ook/'zelfs schadelijk] zijn. that slimming.diets useless but also/even harmful are

$\mathrm{c}^{\prime \prime}$. *dat afvaldiëten [nutteloos maar schadelijk] zijn. that slimming.diets useless but harmful are

d. *dat Jan [niet alleen vandaag maar morgen] aanwezig is. that Jan not only today but tomorrow present is

$\mathrm{d}^{\prime}$. dat Jan [vandaag maar ook $/{ }^{\prime}$ zelfs morgen] aanwezig is. that Jan today but also/even tomorrow present is

$\mathrm{d}^{\prime \prime}$. *dat Jan [vandaag maar morgen] aanwezig is. that Jan today but tomorrow present is

\section{B. Subject-verb agreement}

We see in (470) that nominal coordinate structures with maar 'but' functioning as subject trigger singular agreement on the verb if the coordinands are both singular. This is expected for cases such as (470a), which expresses that there is only one individual present: we are dealing with what is known in Dutch linguistics as SUBSTITUTING COORDINATION because the second coordinand is in a sense substituted for the first one. Singular agreement may be unexpected for (470b), as this example involves ADDITIVE COORDINATION in the sense that the predicate is not only applicable to the first but also to the second coordinand: what is expressed is that there are two individuals present. 
(470) a. dat [niet Jan maar Marie] aanwezig is. that not Jan but Marie present is 'that not Jan but Marie is present.'

b. dat [niet alleen Jan maar ook/zelfs Marie] aanwezig is/*zijn. that not only Jan but also/even Marie present is/are 'that not only Jan but also/even Marie is present.'

The fact that (470b) obligatorily triggers singular agreement is compatible, however, with the hypothesis discussed in Section 1.1, sub IVD, that coordinate structures with an inherent distributive reading must trigger singular agreement on the finite verb when their coordinands are both singular. That nominal coordinate structures of the form niet XP maar ook/zelfs YP are inherently distributive is clear from the fact that they do not allow a cumulative reading for (471): this example can only be used for expressing that Els and Marie lifted the rock individually.

$$
\begin{aligned}
& \text { dat [niet alleen Els maar ook/zelfs Marie] de rots opgetild heeft. } \\
& \text { that not only Els but also/even Marie the rock prt.-lifted has } \\
& \text { 'that not only Els but also/even Marie has lifted the rock.' }
\end{aligned}
$$

Haeseryn et al. (1997:1497) claim that the finite verb normally agrees with the second coordinand in "mixed" coordinate structures functioning as subject. The primeless examples show that this is indeed the normal pattern if the subject precedes the finite verb, but judgments are less clear if the subject follows the finite verb: to our ear, such examples are awkward although agreement with the first conjunct is somewhat better.

$$
\begin{aligned}
& \begin{array}{l}
\text { - Subject-verb agreement: mixed number } \\
\text { a. [Niet wij maar Jan] heeft }{ }_{3 \mathrm{sg}} / \text { *hebben }_{\mathrm{pl}} \text { gisteren geklaagd. }
\end{array} \\
& \text { not we but Jan has/have yesterday complained } \\
& \text { 'Not we but Jan complained yesterday.' } \\
& \mathrm{a}^{\prime} \text {. Gisteren 'hebben } \mathrm{p}_{\mathrm{p}} / \text { heeft }_{3 \mathrm{sg}} \text { [niet wij maar Jan] geklaagd. } \\
& \text { yesterday have/has not we but Jan complained } \\
& \text { b. [Niet Jan maar wij] hebben } / \text { p/ }{ }^{*} \text { heeft }_{3 \mathrm{sg}} \text { gisteren geklaagd. } \\
& \text { not Jan but we have/has yesterday complained } \\
& \text { 'Not Jan but we complained yesterday.' } \\
& \mathrm{b}^{\prime} \text {. Gisteren 'heeft } \mathrm{Ssg}_{\mathrm{sg}} / \text { 'hebben }_{\mathrm{pl}} \text { [niet Jan maar wij] geklaagd. } \\
& \text { yesterday has/have not Jan but we complained }
\end{aligned}
$$

Cases in which the coordinands are both plural do not cause any specific problems; they simply trigger plural agreement on the verb. This means that we must assume the following resolution rules for number, although we should keep in mind that cases in which the subject follows the finite verb are generally somewhat marked. 
(473) - Resolution rules for number in coordinate structures with maar
a. If the coordinands are both singular, singular agreement will be used for the conjunction as a whole.
b. If the coordinands are both plural, plural agreement will be used for the conjunction as a whole.
c. If the coordinands differ in number, agreement will be determined by the coordinand closest to the finite verb.

To our ear, cases with "mixed" person features follow the same pattern: when the two coordinands trigger different forms of the finite verb, the one closest to the verb will determine the form of the verb: we illustrate this for combinations of first and third person (singular) only, but the other combinations exhibit similar behavior.
- Subject-verb agreement: person
a. [Niet ik maar Jan] heeft $3 \mathrm{sg} / *$ heb $_{1 \mathrm{sg}}$ geklaagd. not I but Jan has/have complained 'Not I but Jan has complained.'
$\mathrm{a}^{\prime}$. Gisteren ${ }^{?} \mathrm{heb}_{1 \mathrm{sg}} /{ }^{*}$ heeft $_{3 \mathrm{sg}}$ [niet ik maar Jan] geklaagd. yesterday have/has not I but Jan complained
b. [Niet Jan maar ik] heb ${ }_{1 \mathrm{sg}} / *^{*}$ heeft $_{3 \mathrm{sg}}$ geklaagd. not Jan but I have/has complained 'Not Jan but I have complained.'
$\mathrm{b}^{\prime}$. Gisteren 'heeft ${ }_{3 \mathrm{sg}} /{ }^{*}$ heb ${ }_{1 \mathrm{sg}}$ [niet Jan maar ik] geklaagd. yesterday has/have not Jan but I complained

A similar tack can be followed in the area of anaphor binding: the coordinand closest to the anaphor determines its form. The primed examples in (475) are especially noteworthy, given that they sound relatively good despite the fact that subject-verb agreement and agreement with the anaphor is determined by different coordinands.

$$
\text { - Anaphor binding: person }
$$

a. [Niet ik maar Jan] heeft zich $_{3 \mathrm{sg}} / * \mathrm{me}_{1 \mathrm{sg}}$ beklaagd over stank. not I but Jan has REFL/REFL complained about stench 'Not I but Jan has complained about stench.'

$\mathrm{a}^{\prime}$. Gisteren heb [niet ik maar Jan] ${ }^{\left({ }^{(}\right)} \mathrm{zich}_{3 \mathrm{sg}} /{ }^{*} \mathrm{me}_{1 \mathrm{sg}}$ beklaagd over stank. yesterday have not I but Jan REFL/REFL complained about stench

b. [Niet Jan maar ik] heb $\mathrm{me}_{1 \mathrm{sg}} / *_{\text {zich }}$ ssg beklaagd over stank. not Jan but I have REFL/REFL complained about stench 'Not Jan but I have complained about stench.'

$\mathrm{b}^{\prime}$. Gisteren heeft [niet Jan maar ik] ${ }^{(?)} \mathrm{me}_{1 \mathrm{sg}} /{ }^{*} \mathrm{zich}_{3 \mathrm{sg}}$ beklaagd over stank. yesterday has not Jan but I REFL/REFL complained about stench

When the two coordinands differ in person feature but trigger the same verb form, the coordinate structure as a whole will also select this form: the primed examples in (474), for instance, are fully acceptable in the past tense because $1 \mathrm{sg}$ and $3 \mathrm{sg}$ both trigger the same past tense form had. Something similar is shown in the primed examples for anaphor binding: because the $2 \mathrm{p}$ politeness form $u$ 'you' can be the 
antecedent of both $z i c h(z e l f)$ or $u(z e l f)$, the primed examples are impeccable when zich is used.

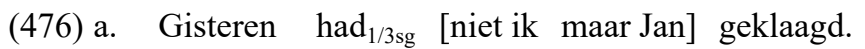
yesterday had not I but Jan complained

$a^{\prime}$. [Niet Jan maar u] heeft zich beklaagd over stank. not Jan but you has REFL complained about stench

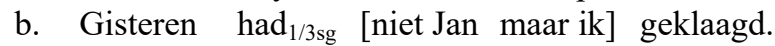
yesterday had not Jan but I complained

$\mathrm{b}^{\prime}$. Gisteren heeft [niet Jan maar u] zich beklaagd over stank. yesterday has not Jan but you REFL complained about stench

Split coordination is possible but it affects subject-verb agreement: the finite verb always agrees with the first "coordinand". We illustrate this in (477) and (478), which should be compared to (472) and (476), respectively. The contrast in agreement patterns is compatible with the suggestion made in Section 1.3, sub IIB, that non-split and split cases are not derived from the same underlying source; the apparently "extraposed" string [maar XP] in (477)/(478) should be analyzed as a reduced clause: cf. [maar XP AUX geklatigd].

(477) a. Niet wij hebben $n_{\mathrm{p}} /$ $^{\text {heeft }}$ 3sg geklaagd, maar Jan. not we have/has complained but Jan

$\mathrm{a}^{\prime}$. Gisteren hebben $\mathrm{p}_{\mathrm{p}} /$ heeft $_{3 \mathrm{sg}}$ niet wij geklaagd, maar Jan. yesterday have/has not we complained but Jan

b. Niet Jan heeft ${ }_{3 s g} /$ hebben $_{\text {pl }}$ geklaagd, maar wij. not Jan has/have complained but we

$\mathrm{b}^{\prime}$. Gisteren heeft ${ }_{3 \mathrm{sg}} /{ }^{*}$ hebben $\mathrm{pl}_{\mathrm{pl}}$ niet Jan geklaagd, maar wij. yesterday has/have not Jan complained but we

(478) a. Niet ik heb 1sg $/ *$ heeft 3 sg geklaagd, maar Jan. not I have/has complained but Jan

$\mathrm{a}^{\prime}$. Gisteren $\mathrm{heb}_{1 \mathrm{sg}} / *$ heeft 3 sg niet ik geklaagd maar Jan. yesterday have/has not I complained but Jan

b. Niet Jan heeft ${ }_{3 s g} /$ heb $_{1 \text { sg }}$ geklaagd, maar ik. not Jan has/have complained but I

$\mathrm{b}^{\prime}$. Gisteren heeft $_{3 \mathrm{sg}} / *$ heb $_{1 \mathrm{sg}}$ niet Jan geklaagd, maar ik. yesterday has/have not Jan complained but I

The examples in (472) to (478) all involve substituting coordination. More or less the same observations can be made for additive coordination, that is, the judgments on the examples do not change in any significant way when we replace the string niet XP (...) maar YP by the string niet alleen XP (...) maar ook YP (where the dots are used for indicating the split pattern).

\section{Meaning/interpretation}

The coordinator maar 'but' is normally taken to be adversative, indicating some contrast between the coordinands: a coordinate structure XP maar YP expresses that in some way YP is contrary to (an implication of) XP, or that YP would not be expected in connection with (an implication of) XP. It is also generally assumed 
that the logical meaning of maar 'but' is that of the logical conjunction $(\wedge)$. Dik (1968:277) concludes from this that differences in interpretation must be "due to properties of the [coordinands], to differences in context and situation and other interpretational factors". This seems an apt description of the various kinds of coordination with maar. First take a standard case like (479a): this example is indeed conjunctive in that its truth entails the truth of the two (b)-examples and it is also implied that the truth of $\left(479 b^{\prime}\right)$ is a lttle unexpected (e.g., because Marie and Jan are normally staying in the same town).

(479) a. [[Marie is in New York] maar [Jan is in Utrecht]].

Marie is in New York but Jan is in Utrecht

'Marie is in New York but Jan is in Utrecht.'

b. [Marie is in New York].

$\mathrm{b}^{\prime}$. [Jan is in Utrecht].

That the interpretation may be affected by properties of the coordinands and the ${ }^{\circ}$ common ground can be seen in example (480a): this example is conjunctive in that it entails the two (b)-examples, and it is adversative in nature because the entailment in $\left(480 b^{\prime}\right)$ is unexpected in light of the presupposition from the common ground that rich people are happy. The unexpectedness of the truth of the entailment in $\left(480 b^{\prime}\right)$ can be emphasized by using adverbs like desondanks 'in spite of that' or ${ }^{\circ}$ particles like toch 'nevertheless'. The relation between the two coordinands is sometimes described in terms of concession because the same thought can be expressed by means of a concessive clause: Hoewel hij rijk is, is hij ongelukkig 'Although he is rich, he is unhappy'. In example (480a), the concessive relation can be brought out by using modal adverbial phrases like weliswaar 'indeed' or zonder twijfel 'without doubt'.

(480) a. Jan is (weliswaar) rijk maar (toch) ongelukkig.

Jan is indeed rich but nevertheless unhappy

b. Jan is rijk.

$\mathrm{b}^{\prime}$. Jan is ongelukkig.

It seems that in example (479a) the two coordinands can be inverted without any interpretative effect, but this does not hold for (480a). Although (481a) has the same entailments, it differs from (480a) in that it does not evoke the background assumption that rich people are happy, as is clear from the fact that addition of the "unexpectedness" marker toch also gives rise to a marked result, or invokes some other background assumption, viz., that unhappy people are poor.

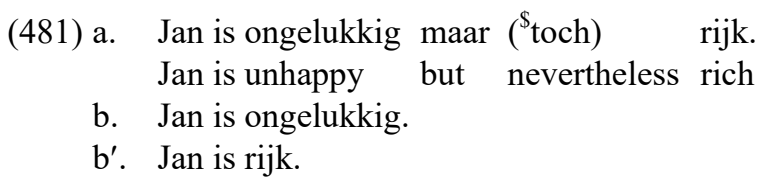

Other examples showing that changing the order of the coordinands can change the background assumption are given in (482). These cases are again logically equivalent, in the sense that they both entail the propositions expressed by Marie is aanwezig and Jan is ziek. The most natural reading of example (482a) seems to be 
based on the expectation that both Marie and Jan are present; the contrast between the two coordinands is that Marie meets this expectation but Jan does not because he is ill. Example (482b), on the other hand, is based on the expectation that Jan is present, e.g., in order to perform some task: this expectation is not borne out but the speaker suggests another candidate for the task at hand who is available. The fact that the two examples in (482) receive different interpretations is therefore not due to semantics but to pragmatics.

(482) a. [[Marie is aanwezig] maar [Jan is ziek]].

Marie is absent but Jan is ill

b. [[Jan is ziek] maar [Marie is aanwezig]]. Jan is ill but Marie is present

Cases of substituting coordination of the sort discussed in Subsection B are also conjunctive in nature, as is clear from the fact that examples such as (483a\&b) entail the propositions in the primed examples. Substituting coordination is used for canceling a presupposition in the common ground by replacing it by some other proposition.

(483) a. Niet Jan maar Marie is aanwezig. b. Jan is niet slank, maar dik. not Jan but Marie is present Jan is not slim but fat $\mathrm{a}^{\prime}$. Jan is niet aanwezig.

$\mathrm{a}^{\prime \prime}$. Marie is aanwezig. $\mathrm{b}^{\prime}$. Jan is niet slank. $\mathrm{b}^{\prime \prime}$. Jan is dik.

More or less the same holds for the form of additive coordination in (484). The background assumption triggered by the use of the focus particle alleen 'only' in (484a) is that Jan is the only person present from a specific contextually determined set of individuals. The use of constituent negation in niet alleen cancels this expectation and the second conjunct lists the unexpected properties. Example (484b) adds a second (positive) property to the one that is presented as part of the common ground.

(484) a. Niet alleen Jan maar ook Marie is aanwezig.

not only Jan but also Marie is present

$a^{\prime}$. Jan is (niet alleen) aanwezig.

$\mathrm{a}^{\prime \prime}$. Marie is (ook) anwezig.

b. Jan is niet alleen slank maar ook lang. Jan is not only slim but also tall

$\mathrm{b}^{\prime}$. Jan is (niet alleen) slank.

$\mathrm{b}^{\prime \prime}$. Jan is (ook) lang.

Since the list of background assumptions is unbounded, the contrasts that may exist between the two coordinands can be infinite as well. For example, the two coordinands in (485a) are contrastive in the sense that the first one indicates that Jan did not meet the expectation of being present but did meet the expectation of announcing his absence. The two coordinands in (485b) provide a general characterization of Jan's behavior as well as an exception to it, and (485c) that the speaker has ambivalent feelings about the film in question. 
(485) a. [[Jan was niet aanwezig] maar [hij had wel afgezegd]].

Jan was not present but he had AFF prt.-canceled

'Jan was not present but he had told us about it.'

b. Meestal is Jan aardig maar soms gedraagt hij zich naar.

generally is Jan kind but occasionally behaves he REFL nasty

'Jan is generally kind but occasionally he can be nasty.'

c. Enerzijds was de film spannend, maar anderzijds was hij te lang. on.the.one.hand was the film exciting but on.the.other was he too long

'On the one hand the film was exciting but on the other it was too long.'

Given Dik's claim that differences in interpretation are not due to the coordinator maar itself but to properties of the coordinands and/or contextual factors, it is not surprising that these interpretations are often supported by the use of specific linguistic markers contained within the coordinands. Examples of such markers are the unexpectedness marker toch 'nevertheless' in (480a), constituent negation niet 'not' in (483a\&b), the focus markers niet alleen ... (maar) ook in (484a\&b), the negative/positive polar elements niet and wel in (485a), the frequency adverbs meestal 'generally' and soms 'occasionally' in (485b), and the conjunctive adverbials enerzijds .... anderzijds ... 'on the one hand ... on the other hand ...' in (485c). The examples in (486) show that these markers sometimes appear external to the coordinate structures: Haeseryn et al. (1997:1498) suggest that this is only seemingly so and that we are in fact dealing with coordination of two main clauses with forward conjunction reduction. Because we will argue in Section 2.1 that forward conjunction does not exist, we cannot adopt this proposal.

(486) a. Jan heeft ${ }^{\$}$ (niet) gezegd [[dat Marie ziek was] maar [dat ze afwezig was]]. Jan has not said that Marie ill was but that she absent was 'Jan didn't say that Marie was ill but that she was absent was.'

$\mathrm{a}^{\prime}$. [[Jan heeft niet gezegd dat Marie ziek was] maar [at ze afwezig was]].

b. Jan heeft $\$$ (niet alleen) gezegd [[dat hij zou komen] maar Jan has not only said that he would come but [ook dat hij hier blijft slapen]]. also that he here stays sleep 'Jan has not only said that he would come but also that he would stay here.'

$\mathrm{b}^{\prime}$. [[Jan heeft ${ }^{\$}$ (niet alleen) gezegd dat hij zou komen] maar [hij ook dat hij hier blijft slapen]].

We will not attempt to provide a full inventory of the available differences in interpretation and the linguistic markers associated with them because this would lead us into insufficiently explored territory, but we hope that we have at least illustrated some of the pragmatic factors involved.

\section{Special uses}

The coordinator maar normally requires some contrast to be present; this contrast is normally propositional or predicational but it seems that it is occasionally related to other aspects of the coordinands such as the illocutionary force. Some typical instances are given in (487). The use of maar seems to be licensed by the fact that 
performing the illocutionary force of the second clausal coordinand contrasts with what is expressed by the first clause, as indicated by the English paraphrases in the translation.

(487) a. Ik mag het niet vertellen maar Jan wordt de nieuwe decaan.

I may it not tell but Jan becomes the new dean

'I am not allowed to tell you but I'll do it anyway: Jan will be the new dean.'

b. Ik weet zeker dat ze het niet goedkeurt, maar vraag het haar.

I know certain that she it not allows but ask it her

'It's no use asking her approval, but I advise you to do it anyway.'

c. Ik weet niet of je het weet maar Els is ziek.

I know not whether you it know but Els is ill

'I don't know whether you know, but I'll tell you anyway: Els is ill.'

Just as in the case of conjunction and disjunction, there are some more or less fixed coordinate structures with maar, which normally occur with a rigid word order.

(488) a. Jan is klein maar dapper.

Jan is small but brave

[*dapper maar klein $]$

b. Ons huis is klein maar fijn.

our kitchen is small but neat

[*fijn maar klein $]$

c. Het is jammer maar helaas.

it is a.pity but unfortunate

'There's nothing you can do about it.'

[*helaas maar jammer]

The coordinator maar prototypically links two coordinands but it is also possible to omit one of the coordinands. In the more or less conventionalized television announcement in (489a), maar clearly relates the clause following it to information available in the ${ }^{\circ}$ common ground. Sentences starting with maar often have some additional expressive function, as is illustrated in (489b\&c).

(489) a. Om 9 uur begint de film. Maar nu eerst het journaal. at 9 o'clock starts the movie but now first the newscast 'The movie will start at 9 o'clock. But we first have the newscast.'

b. Maar wie hebben we daar!? but who have we there 'But look who's there!?'

c. Maar begrijp je dat dan niet?

[disbelief]

but understand you that then not

'But can't you see that?'

Example (490a) shows that the second coordinand can also be left out, in which case the addressee is supposed to understand that there are also some shady sides to Jan which the speaker does not want to make explicit. The utterance Maar ...? can be used when the addressee seems to have some objection on his mind and the speaker wants him to bring that in the open. 
(490) a. Jan is erg aardig, maar .....

Jan is very nice but

'Jan is very nice but [there is something fishy concerning him].'

b. A: Ik vind het een mooie auto ... B: Maar?

I believe it a beautiful car but

A: hij is te duur voor me.

he is too expensive for me

'A: It is a beautiful car. B: But? A: It is too expensive for me.'

\section{$V$. The simplex coordinators want 'because' and dus 'so'}

This subsection takes the coordinators want 'because' and dus 'so' together because they exhibit a quite similar behavior. The logical meanings of these coordinators were already discussed in Section 1.1, sub IVB, where it was shown that the coordinate structures $\Phi$ want/dus $\Psi$ receive the logical translations in (491). The meaning of these coordinators thus differs from that of the coordinator en 'and' in that they do not simply conjoin the propositions expressed by the two coordinands. Instead they express that one of these propositions functions as the antecedent of a material implication that takes the other proposition as its consequent. The logical translations in (491) thus account for the intuition that the truth of one of the coordinands in a sense explains the truth of the other coordinand. The two coordinators only differ in the direction of the explanation: in the case of want, the second coordinand provides an explanation for the first one, while in the case of $d u s$, the first coordinand gives an explanation for the second one.

(491) a. $\Phi$ want $\Psi \cong \psi \wedge(\psi \rightarrow \varphi)$

b. $\Phi d u s \Psi \cong \varphi \wedge(\varphi \rightarrow \psi)$

Want 'because' and dus 'so' differ from the other simple coordinators in that they impose severe restrictions on their coordinands: these are normally main clauses. The examples in (492) show, for instance, that while coordination of main clauses gives rise to a perfectly acceptable result, coordination of smaller, non-clausal verbal projections and arguments is impossible. It seems plausible to relate these restrictions to the conditional part of the meaning of these coordinators.

(492) a. [[Jan ging naar huis] want [hij was ziek]].

[main clauses]

Jan went to home because he was ill

'Jan went home because he was ill.'

$\mathrm{a}^{\prime}$. *Jan [[ging naar huis] want [was ziek]].

Jan went to home because was ill

$\mathrm{a}^{\prime \prime}$ * *Jan want Marie] was ziek.

[verbal predicates]

Jan because Marie was ill

[arguments]

b. [[Jan was ziek] dus [hij kwam niet]].

[main clauses]

Jan was ill so he came not

'Jan was ill so he didn't come.'

$\mathrm{b}^{\prime}$. *Jan [[was ziek] dus [kwam niet]].

Jan was ill so came not

$\mathrm{b}^{\prime \prime}$. *[Jan dus Marie] was ziek.

Jan so Marie was ill

[verbal predicates]

[arguments] 
Haeseryn et al. (1997:1547) claim that there are a number of exceptional cases in which at least some speakers accept want as a linker of set-denoting adjectives; these examples are not problematic for the generalization that want links main clauses only, as they are clearly marked; they seem to be restricted to formal language and should therefore be excluded from ${ }^{\circ}$ core syntax. Bos (1962:55) has also claimed on basis of the meaning of such constructions (the second adjective counts as an explanation for the first) as well of their intonation contour that we are dealing here not with coordination but with appositional constructions: Hij rookt goede-want dure-sigaren and Hij werkt langzaam-want uiterst nauwkeurig. Potentially more problematic is the fact mentioned by Haeseryn et al. (1997:1552) that similar examples with $d u s$ are fully acceptable in colloquial speech. Some of their examples are given in (493).

(493) a. ${ }^{\%} \mathrm{Hij}$ rookt [[goede want dure] sigaren].

he smokes good because expensive cigars

$\mathrm{a}^{\prime}$. Hij rookt [[dure dus goede] sigaren].

he smokes expensive so good cigars

b. ${ }^{\%} \mathrm{Hij}$ werkt [langzaam want uiterst nauwkeurig].

he works slowly because extremely accurately

$\mathrm{b}^{\prime}$. Hij werkt [uiterst nauwkeurig dus langzaam].

he works extremely accurately so slowly

We may, however, assume with good reason that Haeseryn et al. incorrectly analyze $d u s$ in the primed examples of (493) as a coordinator; cf. Van der Heijden (1999:19/202). We may be dealing with asyndetic constructions in which $d u s$ functions as an adverbial. That $d u s$ can function as an adverbial is clear from the contrast between the two examples in (494).

$\begin{array}{ll}\text { [[Jan was ziek] (*en) dus [hij kwam niet]]. } & \text { [dus = coordinator] } \\ \text { Jan was ill and so he came not } & \\ \text { 'Jan was ill so he didn't come.' } & \text { [dus = adverbial }] \\ \text { [[Jan was ziek] (en) [dus kwam hij niet]]. } & \\ \text { Jan was ill and therefore came he not } & \\ \text { 'Jan was ill and therefore he didn't come.' } & \end{array}$

That $d u$ s functions as an adverbial in (494b) is clear from two things: (i) it can be preceded by the coordinator en 'and' and (ii) it triggers subject-verb inversion, which shows that it occupies the initial position of the second main clause and thus functions as a ${ }^{\circ}$ clausal constituent. That $d u s$ functions as a coordinator in (494a) is also clear from two things: (i) it cannot be preceded by en and (ii) it does not trigger subject-verb inversion, which shows that it is external to the second main clause and thus cannot be analyzed as a clausal constituent. The reason for assuming that $d u s$ in the primed examples in (493) is an adverbial is that it can also be preceded by the coordinator en, as is shown in the examples in (495). 


(495) a. Hij rookt [[dure en dus goede] sigaren].
he smokes expensive and therefore good cigars
b. Hij werkt [uiterst nauwkeurig en dus langzaam].
he works extremely accurately and therefore slowly

The fact that en is optional in (494b) shows that adverbial dus can occur in asyndetic coordinate structures and this makes it plausible to assume that the primed examples in (493) involve asyndetic coordination. If so, we can maintain the generalization that want 'because' and dus 'so' can only be used for linking main clauses in full force. This also voids the need to include a discussion of subject-verb agreement for the simple reason that want 'because' and dus 'so' do not occur in nominal coordinate structures.

The logical translations of want and dus in (491) may be somewhat strict when it comes to the actual use of these coordinators because many coordinate structures with these coordinators are not strictly conditional: generally speaking, we are dealing with one coordinand functioning as some sort of rationale for the other one. For instance, it does not seem to be the case that the examples in (496) warrant the conclusion that the common ground contains the general rule "If Jan is tired, he is going home early". The relation is much weaker: Jan's tiredness is given as a reason for his going home early. Particles like maar can be used to highlight this weakening.

(496) a. [Jan ging (maar) vroeg naar huis] want [hij was moe].

Jan went PRT early to home because he was tired

'Jan went home early because he was tired.'

b. [Jan was moe] dus [hij ging (maar) vroeg naar huis]].

Jan was tired so he went PRT early to home

'Jan was tired so he want home early.'

That want is often used to combine a non-declarative as the first coordinand with a declarative as the second coordinand is related to this fact. Of course, an imperative or a question cannot be used as the consequent of a material implication, but this is not what these examples express: the propositional content of the second clause is used as a rationale for performing the illocutionary act of requesting/asking the addressee to come. We refer to Bos (1964:229ff.) and Haeseryn et al. (1997:1544-5) for a more extensive discussion of examples of this sort.

$\begin{array}{lll}\text { (497) a. }[[\text { Kom }] \text { want }[\text { ik wil met je praten }]] ! & \text { [Imp + Decl }] \\ \text { come because I want with you talk } & \\ \text { 'Come because I want to talk with you.' } & {[\mathrm{Q}+\text { Decl }]} \\ \text { b. }[[\text { Kom je] want [ik wil met je praten }]] ? & \\ \text { come you because I want with you talk } & \end{array}$

The acceptability of the combinations in (497) leads us to expect that similar combinations are possible with $d u s$ 'so' in inverse order. Although this may be less common, the examples in (498) show that this expectation is fulfilled; the naturalness of these cases even improves considerably when the particle nou is used, which functions as a kind of urgency marker. 
$\begin{array}{llll}\text { (498) a. Ik wil met je praten dus kom (nou)! } & \text { [Decl + Imp] } \\ \text { I want with you talk so come PRT } & \\ \text { 'I want to talk to you so (please) come!' } & \text { [Decl + Q] } \\ \text { b. Ik wil met je praten dus kom je (nou)? } & \\ \text { I want with you talk so come you PRT } & \end{array}$

Finally, we want to note that $d u$ is often used separately, without a first conjunct. In such cases the rationale for the main clause following $d u s$ is left implicit: the addressee is assumed to be able to construct it himselg from the context or situation; cf. Haeseryn et al. (1997:1551).

(499) a. Dus [jij wil later arts worden]. so you want later doctor become

'So, you want to be a doctor later.'

b. Dus [we moeten maar eens vertrekken]. so we must PRT PRT leave 'So we'd better leave.'

Such examples are less common with want 'because', unless there is some preceding utterance that can be construed as the first conjunct: A: Zulke mensen moeten opgesloten worden 'Such people should be locked up'; B: Ja, want je kan dat soort gedrag toch niet goedkeuren 'Yes, because one cannot approve of that kind of behavior'.

\subsubsection{Correlative coordinators}

This section discusses sequences such as zowel ... als ... 'both ... and ...', of ... of ... 'either ... or...', and noch ... noch 'neither ... nor ...', which are traditionally analyzed as complex coordinators; although we will see that it may be incorrect, we will adopt this analysis as the starting point of our discussion and therefore refer to these sequences as CORRELATIVE COORDINATORs. The examples in (500) illustrate that these complex coordinators are characterized by their discontinuity, in that they consist of minimally two members: the first member of these sequences appears in front of the first coordinand, while the second one appears in front of all later coordinands. We will refer to the two members as, respectively the INITIAL part and NON-INITIAL part of the entire coordinate structure, which will be referred to as a correlative coordinate structure.

(500) a. Zowel Marie als Peter (is ziek).

both Marie and Peter is ill

b. Zowel Marie als Jan als Peter (is ziek). both Marie and Jan and Peter is ill

There are also sequences about which there is less agreement as to whether they should be considered as correlative coordinators. We adopt the list in (501) from Haeseryn et al. (1997) as our starting point (a longer list could be compiled on the basis of Paardekooper 1986, section 7.1), but we will see that there are reasons for eliminating various forms from this set. 
(501) Correlative coordinators (to be revised): en ... en ... 'as well as', \# evenmin ... als ... 'neither ... nor ..., \# hetzij ... hetzij/of'either ... or ...', noch ... noch ... 'neither ... nor ...', of ... of ... 'either ... or ...', ofwel ... ofwel ... 'or ... or ...', \#(net) zomin ... als ... 'neither ... nor ...', zowel ... als ... 'both ... and ...'

The forms marked with a number sign are given by Haeseryn et al. as formal, but Table 20 shows that most forms are highly infrequent and hardly occur in speech at all; the frequencies in this table are taken from Uit den Boogaart (1975) and include all cases in which the initial form is marked as "introductory part of a coordinate structure" (code 740). The most frequent form is zowel ... als ... 'both ... and ...', but even the frequency of this sequence is negligible compared to frequencies of simplex en 'and' (14592 in writing/3650 in speech), of 'or' (1686/452), and maar 'but' (3224/1437) in the same corpus. Table 20 therefore strongly suggests that correlative coordinators are characteristic of written texts and formal speech, and should therefore not be considered as a part of ${ }^{\circ}$ core grammar. We will nevertheless discuss these elements, as they have received a fair bit of attention in the linguistic literature, and postpone further discussion of the issue as to whether correlative coordinators are part of core syntax to Subsection III.

Table 20: Frequency of correlative coordinators; cf. Uit den Boogaart (1975)

\begin{tabular}{|c|c|c|}
\hline CORRELATIVE COORDINATOR & WRITING & SPEECH \\
\hline en ... en ... 'as well as' & 4 & 1 \\
\hline${ }^{\#}$ evenmin ... als ... 'neither ... nor ...' & 0 & 0 \\
\hline${ }^{\#}$ hetzij ... hetzij/of ... 'either ... or ...' & 10 & 1 \\
\hline noch ... noch ... 'neither ... nor ...' & 18 & 1 \\
\hline of ... of ... 'either ... or ...' & 34 & 2 \\
\hline \#ofwel ... ofwel ... 'or ... or ...' & 0 & 0 \\
\hline$\#($ net $)$ zomin ... als ... 'neither ... nor ...' & 0 & 0 \\
\hline zowel ... als ... 'both ... and ...' & 127 & 2 \\
\hline
\end{tabular}

Grammars and individual linguists tend to define the set of correlative coordinators in an enumerative manner, which is undesirable because it may lead to a quite bewildering description of (coordinate structures with) these elements. Subsection I will therefore investigate to what extent the sequences in (501) exhibit the defining property of simplex coordinators, i.e., that they are external to the coordinands: the forms that do not have this property will be excluded from this set. Subsection II will investigate a number of properties of the remaining forms. Subsection III concludes by discussing the syntactic representation of correlative coordinate structures. Our review will show that there is a steadily growing consensus in the theoretical literature that the initial part should not be considered as a subpart of a correlative coordinator but has a more special status; if this line of investigation is on the right track, it may lead to the conclusion that the notion of correlative coordinator is a misnomer resulting from an incorrect syntactic analysis. 


\section{General discussion}

There does not seem to be a generally accepted definition of correlative coordinator. Haeseryn et al. (1997), for instance, simply present the list in (501) as established, and take it without any discussion as their point of departure for the description of the properties of this type of coordinators. This methodology is undesirable; instead, we will take the view that correlative coordinators should at least meet the criterion met by all simplex coordinators, i.e., that they are external to the coordinands. This will lead to a reduction of the list in (501).

\section{A. Correlative coordinators versus correlative adverbials}

Correlative coordinators can easily be confused with correlative adverbial phrases like enerzijds ... anderzijds ... 'on the one hand ... on the other (hand) ...' and niet alleen ... ook ... 'not only ... also ...'. The crucial difference is that correlative coordinators are external to the coordinands while correlative adverbials are part of them. This can be readily illustrated by means of clausal coordinands: in (502a), the initial positions of the coordinated main clauses (in square brackets) are occupied by their subjects, which means that the two parts of the correlative coordinator en .... en ... are clause-external; in (502b), on the other hand, the correlative adverbial phrases occupy the initial positions, as is evident from the fact that they trigger subject-verb inversion. Observe that we are dealing with an asyndetic construction in $(502 \mathrm{~b})$, but that it is possible to replace the phonetically empty coordinator by the coordinator maar 'but'.

(502) a. En [de schatkist is leeg] en [de werkeloosheid neemt toe]. and the treasury is empty and the unemployment increases prt. 'And the treasury is empty and the unemployment increases.'

b. [Niet alleen is de schatkist leeg] Ø [ook neemt de werkeloosheid toe]. not only is the treasury empty also increases the unemployment prt. 'Not only is the treasury empty, the unemployment also increases.'

A problem in the application of the word order test in (502) is that not all correlative coordinators can link main clauses, as is illustrated in (503a) for zowel ... als ... 'both .... and ...'. Example (503b) shows, however, that the two parts of the correlative coordinator cannot occupy the initial positions of the coordinated clauses either, which provides slightly weaker evidence for claiming that they are not clausal constituents.

(503) a. *Zowel [de schatkist is leeg] als [de werkeloosheid neemt toe]. both the treasury is empty and the unemployment increases prt.

b. *[Zowel is de schatkist leeg] $\varnothing$ [als neemt de werkeloosheid toe]. both is the treasury empty] also increases the unemployment prt.

It has nevertheless been claimed that there is reason to assume adverbial status for the initial part of the correlative coordinator, zowel: Haeseryn et al. (1997:1515), for instance, claim that it can penetrate into the first coordinand. This claim is crucially based on their assumption that (504b) involves conjunction reduction (indicated by means of strikethrough). We have marked the structure in (504b) with an asterisk because the analysis suggested by Haeseryn et al. is highly problematic in light of 
the fact that the deleted part cannot be overtly realized; a more natural alternative analysis would be that we are simply dealing with coordination of PP-modifiers, as indicated in $\left(504 b^{\prime}\right)$.

(504) a. [Zowel de antwoorden van Marie als de antwoorden van Jan] zijn fout. both the answers of Marie and the answers of Jan are wrong 'Both Marie's answers and Jan's answers] are wrong.'

b. *[De antwoorden zowel van Marie als van Jan] zijn fout. the answers both of Marie and the answers of Jan are wrong

$b^{\prime}$. De antwoorden [zowel van Marie als van Jan] zijn fout. the answers both of Marie and of Jan are wrong

In addition, it should be pointed out that some speakers consider the order in the (b)-examples as marked compared to (504a). This order becomes even more degraded if the noun is singular: $(505 \mathrm{~b})$ is at best marginally acceptable if the string zowel van Marie als van Jan is parenthetical, that is, preceded and followed by an intonation break. The unacceptability of $(505 \mathrm{~b})$ on the non-parenthetical reading would be unexpected in a conjunction reduction analysis, which should therefore be rejected.

(505) a. [Zowel het antwoord van Marie als het antwoord van Jan] is fout. both the answer of Marie and the answer of Jan is wrong 'Both Marie's answer and Jan's answer] are wrong.'

b. *[Het antwoord zowel van Marie als van Jan] is fout. the answers both of Marie and of Jan is wrong

Note in passing that Neijt (1979:6-7) has shown that examples such as $\left(504 b^{\prime}\right)$ are impossible with other correlative coordinate structures: replacing zowel ... als ... by en ... en ... 'and ... and ...', of ... of ... 'either ... or ...', or noch ... noch ... 'neither ... nor ...' gives rise to severely degraded results (on the intendend, non-parenthetical reading). This would again be unexpected in a conjunction reduction analysis. Haeseryn et al. (1997:1517) also provide a conjunction reduction analysis for example (506a), with coordination of main clauses (CPs). An alternative analysis would involve coordination of verbal predicates (VPs), as indicated in (506b).

(506) a. [[ср Jan zal zowel de rozen snoeien] als [ср zan de tulpen planten]]. Jan will both the roses prune and Jan will the tulips plant 'Jan will both cut back the roses and plant the tulips.'

b. Jan zal [zowel [vp de rozen snoeien] als [vp de tulpen planten]]. Jan will both the roses prune and the tulips plant

The conjunction reduction approach suggested by Haeseryn et al. is again problematic because it cannot account for the unacceptability of example (507a), as the (presumed) clausal coordinands are both syntactically wellformed. The VPcoordination analysis, on the other hand, fares better here because example (507b) is unacceptable for two reasons: (i) the finite verb snoeit has been extracted from the first VP-coordinand by verb-second in violation of the coordinate structure constraint discussed in Section 1.3, sub II, and (ii) the finite verb plant in the second coordinand cannot undergo verb-second at all because the verb-second position is 
already taken by snoeit. That the unacceptability of (507a\&b) should be accounted for in terms of verb-second is supported by the fact that their embedded counterpart (without verb-second) in (507c) is fully acceptable; cf. Neijt (1979:7ff.).

(507) a. *[[CP Jan snoeit zowel de rozen] als [CP plant de tulpen]].
Jan prunes both the roses and Jan plants the tulips
b. *Jan snoeit [zowel [vp de rozen $t_{\mathrm{v}}$ ] als [vp de tulpen plant]].
Jan prunes both the roses and the tulips plants
c. dat Jan [zowel [vp de rozen snoeit] als [vp de tulpen plant]].
that Jan both the roses prunes and the tulips plants

The discussion above has shown that the two parts of correlative coordinators must be external to the coordinands. This casts doubt on the generally accepted claim that noch ... noch ... 'neither ... nor ...' is a correlative coordinator. The examples in (508) show that the two occurrences of noch are internal to the clausal coordinands: the (a)-examples show that noch obligatorily triggers subject-verb inversion and (508b) shows that noch can even occur in the ${ }^{\circ}$ middle field of the first clause.

(508) a. [[Noch zal hij de rozen snoeien], Ø [noch zal hij de tulpen planten]]. neither will he the roses prune nor will he the tulips plant

'Neither will he prune the roses, nor will he plant the tulips.'

$\mathrm{a}^{\prime}$. *Noch [hij zal de rozen snoeien], noch [hij zal de tulpen planten]. neither he will the roses prune nor he will the tulips plant

b. [[Hij zal noch de rozen snoeien], Ø [noch zal hij de tulpen planten]]. he will neither the roses prune nor will he the tulips plant 'Neither will he prune the roses, nor will he plant the tulips.'

The examples in (508) thus conclusively show that noch ... noch ... can be used as correlative adverbials, which need not surprise us given that Section 1.3, sub IIIG, has already shown that noch can be used as an adverbial with the meaning (en) niet 'and not'. Of course, it is not the case that these examples provide conclusive proof that the sequence noch ... noch ... cannot occur as a correlative coordinator in other contexts: the unacceptability of $\left(508 \mathrm{a}^{\prime}\right)$ may simply be due to some idiosyncratic restriction on the coordinands of correlative noch ... noch ... It will be clear, however, that the burden of proof rests on those who would like to maintain the traditional analysis. Those rejecting this analysis cannot rest rest their case either, however, as they should provide a better alternative for cases such as $I k$ heb noch Jan noch Marie gezien 'I have seen neither Jan nor Marie', in which noch ... noch ... seems to behave as a coordinator. We will return to this issue in Subsection III.

\section{B. Correlative coordinators versus correlative adverbial phrases}

Haeseryn et al. (1997:1517) claim that the intended meaning of the unacceptable example in (507a) can be expressed by means of example (509a). They rate this example as fully acceptable but our informants consider it unacceptable or at least quite marked, and the same holds for example (509b), which is claimed to occur alongside (506a). The examples in (509) are cited regularly in the literature as counterexamples to the generalization that coordinands in a coordinate structure must be of the same kind in the sense formulated in Section 1.3, sub I. 
(509) a. ${ }^{\%}$ Jan snoeit zowel de rozen als dat hij de tulpen plant.

Jan prunes both the roses and that he the tulips plants

b. ${ }^{\%}$ Jan zal zowel de rozen snoeien als dat hij de tulpen zal planten. Jan will both the roses prune and that he the tulips will plant 'Jan will both cut back the roses and plant the tulips.'

We believe that theoretical claims building on these marked, constructed examples should be approached warily: we would be happy to assume that they are not part of ${ }^{\circ}$ core syntax and should be considered a quirk of the formal register, that is, as a relic from the older adverbial use of zowel als as described in the Woordenboek der Nederlandsche Taal (item Zoowel, sub 1); see also Van Zonneveld (1992:340).

The examples in (510) show that similar structures seem acceptable with even min/(net) zo $\min$... als ... 'neither ... nor ...' (although some speakers object to (510b), which we have indicated with the percentage sign). There is, however, no $a$ priori reason for analyzing these sequences as coordinators; an adverbial analysis may also be viable given that they have the shape of an equative; cf. even/(net) zo aardig als ... '(just) as kind as'; we will return to this in Chapter 3. Note in passing that, for this reason, we will not stick to the orthographical rule that that even min and zo min are written as single words; elsewhere, when their status as ${ }^{\circ}$ head/phrase is not at issue, we do follow the orthographical rule.

(510) a. Jan zal even min de rozen snoeien als dat hij de tulpen zal planten. Jan will neither the roses prune ALS that he the tulips will plant 'Jan will neither cut back the roses nor plant the tulips.'

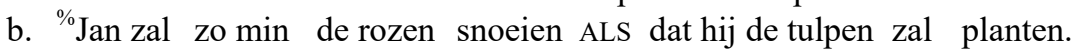
Jan will neither the roses prune and that he the tulips will plant 'Jan will neither cut back the roses nor plant the tulips.'

We also have good empirical reasons for excluding even $\mathrm{min} / \mathrm{zo}$ min ... als ... from the set of correlative coordinators and for analyzing them as -of-the-mill adverbially used equatives of the form even/zo $A$ als ... 'as A as'. First, note that zo min is typically modified by the degree modifier net 'just as', which is impossible for a coordinator but common for adjectives premodified by zo 'as'; cf. net zo aardig (als) 'just as nice (as)'.

(511) a. Jan zal (*net) zowel de rozen snoeien als de tulpen planten.

Jan will just.as both the roses prune ALS the tulips plant

b. Jan zal net zo min de rozen snoeien als de tulpen planten.

Jan will just.as neither the roses prune ALS the tulips plant

Second, if we were dealing with correlative coordinators, we would expect the alspart to be obligatory; the cases in (512) show that this is borne out by zowel ... als ... but not by even $\mathrm{min} / z o \mathrm{~min}$... als ...; just as in the case of even/net zo aardig 'just as kind' the als-part can be left out if its content can be reconstructed from the context.

(512) a. *Jan zal zowel de rozen snoeien.

Jan will both the roses prune

b. Jan zal even min/net zo min de rozen snoeien.

Jan will neither/neither the roses prune 
Third, we have seen in subsection A that the two parts of the correlative coordinator zowel ... als ... cannot occupy the initial position of clausal coordinands. Example (513b) shows, however, that this is possible for the initial part of the supposed coordinators even $\mathrm{min} / \mathrm{zo}_{\mathrm{min}}$... als ... The fact that even min and net zo min trigger subject-verb inversion shows that they are clausal constituents.

(513) a. *Zowel zal Jan de rozen snoeien (als de tulpen planten). both will Jan the roses prune ALS the tulips plant

b. Even min/Net zo min zal Jan de rozen snoeien. neither/neither will Jan the roses prune 'Jan will not cut back the roses either'

Fourth, example (514b) shows that even $\min / z o$ min ... als ... would be unique among coordinators in being unable to coordinate nominal phrases. The intended meaning can be expressed by $\left(514 b^{\prime}\right)$, but in such cases even min/zo min als-phrases clearly have an independent adverbial function. The (a)-examples show that zowel ... als... again exhibits exactly the opposite behavior.

(514) a. [Zowel Jan als Peter] zal de rozen snoeien. both Jan and Peter will the roses prune

$\mathrm{a}^{\prime}$. *Jan zal zowel als Peter de rozen snoeien. Jan will both and Peter the roses prune

b. *[Even $\mathrm{min} /$ net zo min Jan als Peter] zal de rozen snoeien. neither/neither Jan ALS Peter will the roses prune

$\mathrm{b}^{\prime}$. Jan zal even $\mathrm{min} / \mathrm{net}$ zo min als Peter de rozen snoeien. Jan will neither/neither ALS Peter the roses prune 'That Jan will no more prune the roses than Peter.'

The claim that the even $\mathrm{min} / z$ o min als-phrase has an independent syntactic function in $\left(514 b^{\prime}\right)$ seems uncontroversial, as Haeseryn et al. (1997:1517) provide the same analysis for similar examples. They also analyze net zo min ... als Peter in example $(515 \mathrm{~b})$ as adverbial. This analysis can be supported by the fact that net zomin in (515b) can be replaced by other degree adverbials, as shown by Jan is net zo goed/zeer een schurk als Peter 'Jan is just as well a croudel as Peter'; a similar replacement of zowel is never possible, probably because it is a single word.

(515) a. *Jan is zowel een schurk als Peter.

Jan is both a scoundrel as Peter

b. Jan is net zomin een schurk als Peter.

Jan is just as.less a scoundrel as Peter

'Jan is no more a scoundrel than Peter.'

The (b)-examples in (511) to (515) all provide evidence in favor of the claim that even $\min$ and zo min are clausal constituents; it seems therefore safe to conclude that even $\mathrm{min} / \mathrm{zo}$ min ... als ... are not correlative coordinators but should be analyzed as adverbially used equatives of the form even/zo $A$ als ... 'as A as'. The fact that the (a)-examples show that zowel ... als ... systematically exhibits a different behavior can be construed as evidence for analyzing it as a genuine 
correlative coordinator. Reader interested in more discussion of the internal structure of even $\min /$ zo $^{\mathrm{min}}$... als ... phrases are referred to Section 3.1, sub I.

\section{Conclusion}

This subsection has scrutinized the set of presumed correlative coordinators in (501) from the point of view that such coordinators are like simplex coordinators in that they are external to their coordinands. This has led to the conclusion that the two members of the sequence noch ... noch ... should be analyzed as adverbial phrases in the case of clausal coordination; nevertheless, we will not exclude this sequence from the list in (501) for the simple reason that noch ... noch ... may still function as a correlative coordinator in other contexts. We will exclude the sequences even $\min / z o \mathrm{~min} . .$. als ... from the list because there is compelling evidence that these are not correlative coordinators but adverbially used equatives of the form even/zo $\mathrm{A}$ als ... 'as A as'. The result of all this is the reduced list in (516).

$$
\begin{aligned}
& \text { Correlative coordinators: en ... en ... 'as well as', }{ }^{\sharp} \text { hetzij ... hetzij/of 'either ... } \\
& \text { or ...', noch ... noch ... 'neither ... nor ...', of ... of ... 'either ... or ...', ofwel ... } \\
& \text { ofwel ... 'or ... or ...', zowel ... als ... 'both ... and ...' }
\end{aligned}
$$

\section{The four most frequent forms}

This subsection discusses the four most frequent correlative coordinators: en ... en ... 'as well as', noch ... noch ... 'neither ... nor ...', of ... of ... 'either ... or ...', and zowel ... als ... 'both ... and ...'. The two remaining forms hetzij ... hetzij/of 'either ... or ...' and ofwel ... ofwel ... 'or ... or ...' will only be discussed to the extent that they exhibit behavior markedly distinct from of ... of ....

$A$. En ... en ... 'and ... and'

One of the characteristic properties of the correlative coordinator en ... en ... 'and ... and ...' is that its initial and non-initial parts are accented, for which reason they are often written with an accent: Ik heb én Jan én Marie gezien 'I have seen and Jan and Marie'. This subsection will show that coordinate structures with correlative en ... en ... differ from those with simplex en in that they (i) exhibit additional restrictions on the coordinands, (ii) cannot be interpreted cumulatively, and (iii) exhibit special agreement properties.

The examples in (517) show that the correlative en .. en ... behaves like simplex $e n$ in that it can link clauses (CPs), noun phrases (DPs), APs and PPs.

$$
\text { - Category of the coordinands }
$$

a. [En Jan is ziek en Marie gaat op vakantie]. and Jan is ill and Marie goes on vacation

b. [En de man en de vrouw] zingt een lied. and the man and the woman sings a song

c. Jan is [en ziek en moe]. Jan is and ill and tired

d. Jan werkt [en in Amsterdam en in Utrecht]. Jan works and in Amsterdam and in Utrecht 
The correlative and simplex forms differ, however, in that the former links declarative main clauses only: linking interrogative $(\mathrm{Q})$, imperative (Imp) or exclamative (Excl) clauses gives rise to a degraded result; see also Neijt (1979:16). Consider the corresponding examples with simplex en 'and' in Section 1.4.1, sub IA1, for comparison.
- Illocutionary types of clausal coordinands
a. *[En is Jan ziek en gaat Marie op vakantie]?
$[$ yes/no-Q] and is Jan ill and goes Marie on vacation
$\mathrm{a}^{\prime} .{ }^{*}[$ En wie is er ziek en wie gaat er op vakantie]? and who is there ill and who goes there on vacation
b. *[En neem een maand vrij en ga op vakantie]! and take a month off and go on vacation
c. *[En wat draagt Jan een mooi horloge en and what wears Jan a beautiful watch and wat heeft Els een prachtige ring aan haar finger]! what has Els a splendid ring on her finger

Dependent declarative and interrogative clauses, on the other hand, behave alike in that they both can be conjoined; imperatives are excluded for the independent reason that they cannot be embedded at all.

\section{- Embedded clauses}

a. Els zei [en dat Jan ziek is en dat Marie op vakantie gaat]. Els said and that Jan ill is and that Marie on vacation goes 'Els said both that Jan is ill and that Marie is going on vacation.'

b. Els vroeg [en of Jan ziek is en of Marie op vakantie gaat]. [yes/no-Q] Els asked and if Jan ill is and if Marie on vacation goes 'Els asked both whether Jan is ill and whether Marie is going on vacation.'

c. Els vroeg [en wie er ziek is en wie er op vakantie gaat]. [wh-Q] Els asked and who there ill is and who there on vacation goes 'Els asked both who is ill and who is going on vacation.'

Correlative en ... en ... also differs from simplex en in that it is more restricted when it comes to conjunction of extended verbal projections smaller than clauses: while example (520a) is fully acceptable, example (520b) is very much worse. The difference seems to be related to verb-second of the main verb, as comparable coordination is possible when the main verb does not have to undergo verb-second: this is illustrated in the primed examples for embedded clauses and for main clauses with complex verb constructions such as the perfect tense.

(520) - Coordination of extended verbal projections smaller than clauses

a. Jan [las het boek en schreef er een recensie over]. Jan read the book and wrote there a review about 'Jan read the book and wrote a review of it.'

b. *Jan [en las het boek en schreef er een recensie over]. Jan and read the book and wrote there a review about 
$\mathrm{b}^{\prime}$. dat Jan [en het boek las en er een recensie over schreef]. that Jan and the book read and there a review about wrote 'that Jan both read the book and wrote a review of it.'

$\mathrm{b}^{\prime \prime}$. Jan heeft [en het boek gelezen en er een recensie over geschreven]. Jan has and the book read and there a review about written 'Jan has both read the book and written a review of it.'

For completeness sake, the examples in (521) are added to show that the same observations can be made for constructions with monadic verbs.

(521) a. De jongens [(*en) zingen en dansen].

the boys and sing and dance

'The boys (both) sing and dance.'

b. dat de jongens [(en) zingen en dansen]. that the boys and sing and dance

'that the boys (both) sing and dance.'

c. De jongens hebben [(en) gezongen en gedanst]. the boys have and sung and danced

'The boys have (both) sung and danced.'

The simplex and the correlative coordinators also exhibit different behavior in embedded clauses with complex verb constructions: while in (522a) simplex en can be used to conjoin main verbs, correlative en ... en ... cannot. Example (522b) shows that they do exhibit similar behavior when they conjoin a larger verbal projection that includes the auxiliary.

(522) a. dat de jongens hebben [(*en) gezongen en gedanst].

that the boy have and sung and danced

'that the boys have both sung and danced.'

b. dat de jongens [(en) hebben gezongen en hebben gedanst]. that the boy and have sung and have danced

'that the boys have both sung and danced.'

The differences in behavior of simplex en and correlative en ... en... show that the simplex coordinator is able to conjoin a larger set of constituents than the correlative one; cf. Neijt (1979: section 1.1). This conclusion can also be drawn on the basis of non-verbal coordination. First, the correlative coordinator is more restricted when it comes to conjunction of nominal projections smaller than DP; example (523b) shows that while simplex en is able to do this, correlative en ... en ... is not.

(523) - Nominal coordinands of different sizes

a. $[($ En $)[D P$ de mannen] en [DP de vrouwen] $]$ dansen. and the men and the women dance

b. De [(*en) [NP oude mannen] en [NP jonge vrouwen]] dansen. the and old men and young women dance

c. De oude [(*en) [N mannen] en [N vrouwen]] dansen. the old and men and women dance 
Second, the examples in (524) suggest that the same holds for adjectival phrases. Example (524a) states that Jan has the two independent properties of being very young and being (very) inexperienced. The sentence Jan is erg jong en onervaren, on the other hand, can be interpreted in such a way that Jan has the (single) complex property of being young and inexperienced, which Section 1.4.1, sub IA1, accounted for by assigning it the structure in (524b). The primed examples show that the correlative coordinator is compatible with the multiple-property reading only, that is, cannot coordinate the smaller adjectival projections without the degree adverbial; see Corver (1990:53) for more examples.

- Adjectival coordinands of different sizes
a. Jan is [erg jong en (erg) onervaren]. Jan is very young and very inexperienced
$a^{\prime}$. Jan is [(en) erg jong en (erg) onervaren]. Jan is and very young and very inexperienced
b. Jan is [erg [jong en onervaren]]. Jan is very young and inexperienced
$\mathrm{b}^{\prime}$. *Jan is [erg [(en) jong en onervaren]]. Jan is very and young and inexperienced
[multiple-property reading]

Third, as shown in (525), it appears that whereas both the simplex and the correlative coordinator are able to coordinate full PPs, they differ in that the simplex but not the correlative coordinator can coordinate smaller projections of the preposition (cf. (525b)) or the nominal ${ }^{\circ}$ complement of the preposition (cf. the (c)examples).

(525) a. [(en) vlak boven het schilderij en vlak onder de spiegel] and just above the painting and just below the mirror

b. vlak [(*en) boven het schilderij en onder de spiegel] just and above the painting and below the mirror

c. vlak boven $[(*$ en) het schilderij en de spiegel] just above and the painting and the mirror

$\mathrm{c}^{\prime}$. precies tussen $[(* \mathrm{e})$ het schilderij en de spiegel] precisely between and the painting and the mirror

Finally, we see in (526) that coordination of attributive modifiers by means of correlative en ... en ... gives rise to a marked result, while coordination by simplex en is easy; see Corver (1990:51) for more examples.

(526) a. de [boeken [ [?"en) in de bibliotheek] en [in de leeszaal]]] the books and in the library and in the reading.room

b. de [(?"en) ongeopende en ongelezen] boeken] the and unopened and unread books

Neijt concludes from data of the kind above that correlatives can only be used to link ${ }^{\circ}$ major phrases, that is, the set of "fully expanded" projections of the lexical categories $\mathrm{N}, \mathrm{A}$ and $\mathrm{P}$ functioning as clausal constituents, as well as to specific smaller, non-clausal verbal projections ("VPs"). 
There do not seem to be any restrictions on the type of clausal constituent. As shown in (527), correlative coordinate structures with en ... en ... can be used as arguments, as complementive and (to a lesser extent) supplementive, and in various adverbial functions; there is no clear difference in this respect with the corresponding constructions with simplex en given in Section 1.4.1, sub I.

- Syntactic function of correlative coordinate structures with en ... en ...
a. [En de man en de vrouw] zingt een lied.

Coordinate structures with correlative en ... en ... differ semantically from those with simplex en in that they cannot be interpreted cumulatively: while example (528a) is ambiguous between a distributive and a cumulative reading, as is clear from the fact that the modifiers beiden 'both' and samen 'together' can both be used, example $\left(528 \mathrm{a}^{\prime}\right)$ has a distributive reading only. That coordinate structures with correlative en ... en ... cannot be interpreted cumulatively is also clear from the fact that such coordinate structures cannot act as antecedent for the reciprocal elkaar 'each other'.

(528) a. Jan en Marie hebben (beiden/samen) de tafel opgetild. [ambiguous] Jan and Marie have both/together the table prt.-lifted 'Jan and Marie have lifted the table.'

$a^{\prime}$. En Jan en Marie heeft de tafel opgetild. and Jan and Marie has the table prt.-lifted

[distributive only] 'Both Marie and Jan have lifted the table.'

b. [Jan en Marie $]_{i}$ bewonderen elkaari. Jan and Marie admire each.other

$\mathrm{b}^{\prime} . *[\text { En Jan en Marie }]_{\mathrm{i}}$ bewondert elkaar ${ }_{\mathrm{i}}$. and Jan and Marie admires each.other

The two (a)-examples in (528) also differ in subject-verb agreement: while the coordinate structure with simplex en triggers plural agreement on the finite verb, the one with correlative en ... en ... normally triggers singular agreement. Judgments are not always sharp but Haeseryn et al. (1997:1501) claim that singular agreement is 
always the preferred option, which would be in line with the hypothesis discussed in Section 1.1, sub IVD, that coordinate structures with an inherent distributive reading must trigger singular agreement on the finite verb when their coordinands are both singular; another clear example illustrating this is given in (529a). Example (529b) shows that, not surprisingly, correlative coordinate structures with en ... en ... trigger plural agreement when the two nominal coordinands are plural. Mixed cases are normally less good, although De Vries \& Herringa (2008: section 3) claim that there is a tendency for agreement with the coordinand closest to the verb; see also G. de Vries (1992: section 2.4). Since examples such as these are not used in colloquial speech and native speakers tend to reject them categorically, it is difficult to evaluate this claim; we therefore simply mark the degraded examples with a percentage sign.

(529) a. [En Jan en Marie] danst $3 \mathrm{sg} / *$ dansen $_{\mathrm{pl}}$. and Jan and Marie dances/dance

b. [En de jongens en de meisjes] dansen ${ }_{\mathrm{pl}} /$ danst $_{3 \mathrm{sg}}$. and the boys and the girls dance/dances

c. ${ }^{\%}$ [En Jan en de meisjes] danst ${ }_{3 \mathrm{sg}} /$ dansen $_{\mathrm{pl}}$. and Jan and the girls dances/dance

$\mathrm{c}^{\prime} .{ }^{\%}$ Danst $_{3 \mathrm{sg}} /$ Dansen $_{\mathrm{pl}}$ [en Jan en de meisjes]? dances/dance and Jan and the girls

Similar problems with subject-verb agreement arise with mixed person features: when the coordinands trigger the same morphological form on the finite verb, as in $(530 \mathrm{a} \& \mathrm{~b})$, the result is generally deemed acceptable but if they trigger different forms, as in the (c)-examples, the result is severely degraded.

(530) a. [En hij en ik] wil $1_{\mathrm{sg}}$ dansen.

and he and I want dance

'Both he and I want to dance.'

b. [En zij $\mathrm{pl}_{1}$ en wij] dansen $\mathrm{pl}_{\mathrm{pl}}$ goed. and they and we dance(s) well

c. *[En hij en ik] dans 1 /danst 3 graag. and he and I dance/dances gladly

$\mathrm{c}^{\prime}$. * ${ }^{*} \mathrm{Dans}_{1 \mathrm{p}} /$ Danst $_{3 \mathrm{p}}$ [en hij en ik] goed? dance/dances and he and I well

B. Zowel ... als... 'both ... and ...'

Subsection I has already shown that correlative zowel ... als ... 'both ... and ...' differs from correlative en ... en ... 'both ... and ...' in that it cannot link clausal coordinands. The other instances in (531) show, however, that the two coordinators do not differ when it comes to coordination of coordinands of other categories.

(531) - Category of the coordinands

a. *[Zowel Jan is ziek als Marie gaat op vakantie].

both Jan is ill and Marie goes on vacation

b. [Zowel de man als de vrouw] zingt een lied. both the man and the woman sings a song 
c. Jan is [zowel ziek als moe]. Jan is both ill and tired

d. Jan werkt [zowel in Amsterdam als in Utrecht]. Jan waits both in Amsterdam and in Utrecht

The examples in (531b-d) also show that correlative coordinate structures with zowel ... als ... may be used as argument, complementive or adverbial phrase; the same is shown by the fact that substituting correlative zowel... als... for en ... en ... in the examples in (527) in Subsection A does not affect the acceptability judgments in any crucial way; the reader will be able to construct the examples for himself.

Coordinate structures with correlative zowel ... als ... also behave like those with en ... en ... in that they are normally used as major phrases in Neijt's sense: they are always clausal constituents or larger verbal projections. The latter is illustrated by the examples in (532) and (533), which correspond to the examples in (521) and (522) from Subsection A with correlative en ... en ....

(532) a. *De jongens [zowel zingen als dansen]. the boys both sing and dance

b. dat de jongens [zowel zingen als dansen]. that the boys both sing and dance 'that the boys both sing and dance.'

c. De jongens hebben [zowel gezongen als gedanst]. the boys have both sung and danced 'The boys have both sung and danced.'

(533) a. *dat de jongens hebben [zowel gezongen als gedanst]. that the boys have both sung and danced

b. dat de jongens [zowel hebben gezongen als hebben gedanst]. that the boys both have sung and have danced 'that the boys have both sung and danced.'

That non-verbal coordinate structures are normally clausal constituents is clear from the fact that substitution of correlative zowel ... als ... for correlative en ... en ... in the examples in (523) to (526) from Subsection A does not affect the acceptability of these examples in any material way; we again leave it to the reader to construct the relevant examples. Judgments on examples with attributive modifiers are not always sharp, however, and it is not impossible to find on the internet examples such as those in (534).

- Prenominal attributive modifiers

a. Dit is [een zowel muzikaal als sociaal verschijnsel]. this is a both musical and social phenomenon

b. De overgang vraagt [een zowel lichamelijke als emotionele aanpassing]. the menopause requires a both physical and emotional adaptation

Such (potential) counterexamples to the claim that correlative coordinate structures are normally clausal constituents often sound formal or artificial; the more natural way of expressing the same thoughts would be as indicated in (535). These examples involve coordination of full noun phrases with backward ${ }^{\circ}$ conjunction 
reduction (indicated by strikethrough); we refer the reader to Section 2.1 for relevant discussion.

(535) a. Dit is [zowel een muzikaal als een sociaal verschijnsel]. this is both a musical and a social phenomenon

b. De overgang vraagt [zowel een lichamelijke als the menopause requires both a physical and een emotionele aanpassing]. an emotional adaptation

Another potential counterexample with postnominal modifiers adapted from Haeseryn et al. (1997:1573) is (536). However, this coordinate structure has a parenthetical ring about it, which is also corroborated by the fact that it can be used in postverbal position; we refer the reader to Subsection IA, example (504b), for a more extensive discussion of a similar counterexample.

(536) a. De boeken zowel van Jan als van Els zijn verkocht.

the books both of Jan and of Els are sold

'The books (both of Jan and of Els) are sold.'

b. De boeken zijn verkocht, zowel van Jan als van Els. the books are sold both of Jan and of Els

We will therefore put examples such as those in (534) and (536) aside. We note, however, that examples like those in (537) are completely natural, which is surprising if correlative coordinate structures are normally clausal constituents. At the present moment, we see no way of accounting for this.

(537) a. De boeken van [zowel Jan als Els] zijn verkocht.

the books of both Jan and Els are sold

b. Jan had bezwaren tegen [zowel de vorm als de inhoud van het artikel]. Jan had objections against both the form and the content of the article

Nominal coordinate structures with correlative zowel ... als ... are like those with en ... en ... in that they must be interpreted distributively: they cannot license adverbials such as samen 'together' and they cannot act as antecedent for the reciprocal elkaar 'each other'.

(538) a. [Zowel Jan als Marie] heeft (*samen) de tafel opgetild. both Jan and Marie has together the table prt.-lifted 'Both Marie and Jan have lifted the table.'

b. *[Zowel Jan als Marie $]_{i}$ bewondert elkaar ${ }_{i}$. both Jan and Marie admires each.other

The hypothesis discussed in Section 1.1, sub IVD, that coordinate structures with an inherent distributive reading must trigger singular agreement on the finite verb when their coordinands are both singular thus correctly predicts that (539a) exhibits singular agreement. Haeseryn et al. (1997:1516) claim that in some cases a plural finite verb is preferred but these examples have an artificial flavor and intuitions seem to differ among speakers; cf. De Vries \& Herringa (2008:12). De Vries \& Herringa also note that some cases of plural agreement seem to be of a semantic 
nature, which is especially clear when at least one of the nominal coordinands is a collection noun, as in the quite natural (b)-examples in (539), which are taken from taaladvies.net/taal/advies/vraag/949.

(539) a. [Zowel Jan als Marie] danst $3 \mathrm{sg} /{ }^{*}$ dansen $_{\mathrm{pl}}$ graag.

both Jan and Marie dances/dance gladly

'Both Jan and Marie like to dance.'

b. [Zowel de minister als zijn kabinet] is ${ }^{\%}$ zijn op de hoogte.

both the minister and his cabinet is/are informed

'Both the minister and his cabinet are informed.'

$\mathrm{b}^{\prime}$. [Zowel de politie als de brandweer] staat ${ }^{\%}$ staan klaar. both the police and the fire.brigade stands/stand ready

'Both the police and the fire brigade are ready.'

There is little new to add about subject-verb agreement, as we find the familiar pattern: cases in which the two coordinands trigger the same morphological form on the finite verb are fully acceptable, while cases in which the coordinands trigger different forms are degraded to various degrees: since judgments may differ from speaker to speaker and from case to case we simply mark the less felicitous cases with the percentage sign.

(540) a. [Zowel de jongens als de meisjes] dansen ${ }_{\mathrm{pl}} /{ }^{*}$ danst $_{3 \mathrm{sg}}$ graag. both the boys and the girls dance/dances gladly

b. [Zowel Jan als de meisjes] * danst $_{3 \mathrm{sg}} /{ }^{\%}{ }^{\text {dansen }}$ pl graag. both Jan and the girls dances/dance gladly

c. ${ }^{\%}\left[\right.$ Zowel hij als ik] danst 3 ssg $/$ dans $_{1 \text { sg }}$ graag. both he and I dances/dance gladly

C. Of ... of ... 'either ... or ..'

Correlative of ... of ... 'either ... or ...' behaves more or less like en ... en ... 'and ... and ...', as substituting the former for the latter in the examples in Subsection A does not affect acceptability in a crucial way. We will illustrate this here for some of the cases only. The examples in (541) first show that of ... of ... is able to coordinate coordinands of various categories as well as main clauses.

- Category of the coordinands

a. [Of Jan is ziek of Marie gaat op vakantie].

or Jan is ill or Marie goes on vacation

b. [Of de man of de vrouw] zingt een lied. or the man or the woman sings a song

c. Jan is [of ziek of moe]. Jan is or ill or tired

d. Jan werkt [of in Amsterdam of in Utrecht]. Jan waits or in Amsterdam or in Utrecht

In (541a), correlative of ... of ... precedes the initial position of the clausal coordinands and can thus safely be assumed to be external to them. This can be different in case of correlative of wel ... of wel ... 'either ... or ...'. The examples in 
(542) show that ofwel can not only be used external to the coordinands but may also occupy the initial position of the coordinated clauses. This suggests that the sequence ofwel ... of wel ... can be used both as a correlative coordinator and as a correlative adverbial. Haeseryn et al. (1997:1508), who analyze the two examples in (542) as correlative coordinate structures, claim that the order in (542a) is found especially in the Netherlands while (542b) is typically found in Belgium, but according to us both are equally acceptable in the standard variety. We represent (542b) as an asyndetic construction here but other analyses are conceivable such as of [wel ...] of [wel ...]; see Bredsneijder (1999:13) for discussion.

(542) a. Ofwel [ik kom naar jou toe] ofwel [ik ga naar oma].

or I come to you prt. or I go to granny

'Either I will come to you or I will go to granny.'

b. [Ofwel/*Of kom ik naar jou toe] $\varnothing$ [ofwel/*of ga ik naar oma]. or/or come I to you prt. or/or go I to granny

The examples in (541b-d) show that correlative coordinate structures with of ... of ... may be used as argument, complementive or adverbial phrase. Coordinate structures with correlative of ... of ... also behave like those with en ... en ... in that they must be used as major phrases in Neijt's sense: they are always clausal constituents or larger verbal projections. The latter is illustrated in (543) and (544), which correspond with the examples in (521) and (522) with correlative en ... en ... from Subsection A.

(543) a. De jongens $[(* 0)$ zingen of dansen]. the boys or sing or dance

'The boys sing or dance.'

b. dat de jongens [(of) zingen of dansen]. that the boys or sing or dance 'that the boys sing or dance.'

c. De jongens hebben [(of) gezongen of gedanst]. the boys have or sung or danced 'The boys have sung or danced.'

(544) a. dat de jongens hebben [(*of) gezongen of gedanst]. that the boys have or sung or danced 'that the boys have sung or danced.'

b. dat de jongens [(of) hebben gezongen of hebben gedanst]. that the boys or have sung or have danced 'that the boys have sung or danced.'

There is hardly anything new to say about subject-verb agreement, as we find the familiar pattern: cases in which the two coordinands trigger the same morphological form on the finite verb are fully acceptable, while cases in which the coordinands trigger different forms are worse in varying degrees. Since judgments may differ from speaker to speaker and from case to case we simply mark the degraded cases with the percentage sign. 


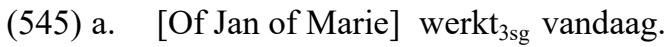

or Jan or Marie works today

'Or Jan or Marie is working today.'

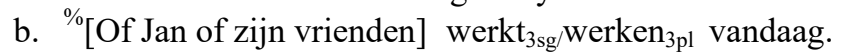
or Jan or his friends works/work today

c. ${ }^{\%}$ [Of hij of ik] werkt ${ }_{3 \mathrm{sg} /}$ werk $_{1 \mathrm{sg}}$ vandaag.

or he or I works/work today

The highly formal correlative hetzij ... hetzij/of ... differs from of ... of ... in that it cannot link main clauses: cf. *Hetzij ik kom naar jou hetzij ik ga naar oma. In fact, Haeseryn et al. (1997:1511) suggest that this correlative coordinator is mainly used for linking adverbial phrases: Ik kom hetzij vanmiddag, hetzij vanavond 'I will come either this afternoon or this evening'. Nevertheless, they subsequently discuss various kinds of cases suggesting that hetzij ... hetzij/of ... has more or less the same potential as of ... of ....

D. Noch ... noch ... 'neither ... nor ...'

Subsection IA has already shown that the correlative coordinator noch ... noch ... cannot coordinate clauses. It is able, however, to coordinate smaller constituents of various categories.

- Category of the coordinands

a. *[Noch Jan is ziek noch Marie gaat op vakantie]. neither Jan is ill nor Marie goes on vacation

b. [Noch de man noch de vrouw] zingt een lied. neither the man nor the woman sings a song

c. Jan is [noch ziek noch moe]. Jan is neither ill nor tired

d. Jan werkt [noch in Amsterdam noch in Utrecht]. Jan works neither in Amsterdam nor in Utrecht

These instances also show that correlative coordinate structures with noch ... noch ... may be used as argument (546b), complementive (546c) and as adverbial; again, replacing correlative en ... en ... in the examples in (527) from Subsection A by noch ... noch ... has no affect on acceptability. Correlative coordinate structures with noch ... noch ... also behave like those with en ... en ... in that they are ${ }^{\circ}$ major phrases: they are always clausal constituents or larger verbal projections. The latter is illustrated by the examples in $(547) /(548)$, which correspond with the examples in (521)/(522) with correlative en ... en ... from Subsection A.

(547) a. De jongens [(*noch) zingen noch dansen].

the boys neither sing nor dance

'The boys (neither) sing nor dance.'

b. dat de jongens [(noch) zingen noch dansen]. that the boys neither sing nor dance

'that the boys (neither) sing nor dance.'

c. De jongens hebben [(noch) gezongen noch gedanst]. the boys have neither sung nor danced 'The boys have (neither) sung nor danced.' 
(548) a. dat de jongens hebben [(*noch) gezongen noch gedanst]. that the boy have neither sung nor danced 'that the boys have neither sung nor danced.'

b. dat de jongens [(noch) hebben gezongen noch hebben gedanst]. that the boy neither have sung nor have danced 'that the boys have neither sung nor danced.'

With respect to subject-verb agreement, we find the by now familiar pattern: cases in which the two coordinands trigger the same morphological form on the finite verb are fully acceptable, while cases in which the coordinands trigger different forms are degraded to various degrees. Since judgments may differ from speaker to speaker and from case to case we mark the degraded cases with the percentage sign.

(549) a. [Noch Jan noch Marie] werkt ${ }_{3 s g}$ vandaag. neither Jan nor Marie works today

'Neither Jan nor Marie is working today.'

b. [Noch Jan noch zijn vrienden] ${ }^{*}$ werkt $_{3 \mathrm{sg}}{ }^{0}{ }^{\%}$ werken $_{3 p 1}$ vandaag. neither Jan nor his friends works/work today

c. ${ }^{\%}\left[\right.$ Noch hij noch ik] werkt ${ }_{3 s g}$ werk ${ }_{1 s g}$ vandaag. neither he nor I works/work today

\section{The syntactic representation of correlative coordinators}

Section 1.3, sub IV, has argued that coordinators are two-place linkers, in the sense that they connect no more and no less than two coordinands. We further suggested that coordinate structures are hierarchically structured, as in the representations in Figure 31; coordinate structures with more than two coordinands are built by embedding one coordinate structure (CoP) inside another.
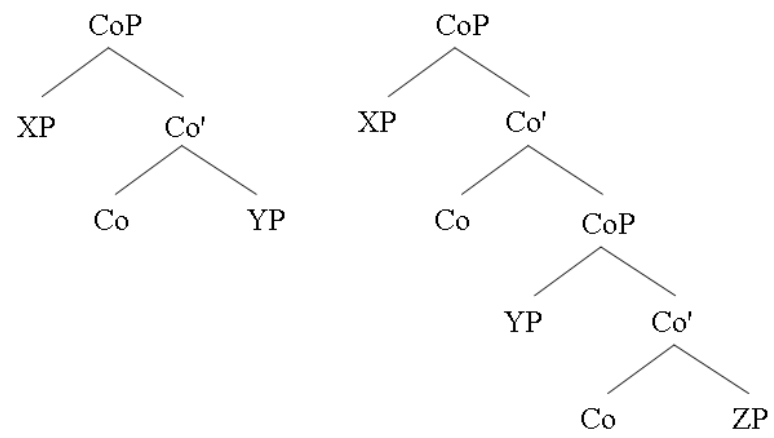

Figure 31: Coordinate structures with simplex coordinators

The claim that coordinators are two-place linkers raises various questions when we consider correlative coordinators such as zowel ... als ... 'both ... and ...' in (550). These examples show that the number of coordinands equals the number of subparts of the correlative coordinator, which suggests that at least the initial part of the correlative coordinator cannot be analyzed as a two-place linker. 
(550) a. Zowel Marie als Peter (is ziek).

both Marie and Peter is ill

b. Zowel Marie als Els als Peter (is ziek).

both Marie and Els and Peter is ill

c. Zowel Marie als Els als Jan als Peter (is ziek).

both Marie and Els and Jan and Peter is ill

The fact that we cannot analyze all members of correlative coordinators as twoplace linkers has given rise to a wide range of analyses of correlative coordinate structures such as (550). We will briefly review some of the proposals in the following subsections: these subsections are therefore more theoretical in nature but they also discuss several important empirical issues.

\section{A. Complex-head analysis}

A promising solution for the problem that the initial parts of a correlative coordinator cannot be analyzed as two-place linkers would be to assume that the two subparts $\mathrm{Co}_{1}$ (= the initial part) and $\mathrm{Co}_{2}$ constitute subparts of a single (complex) ${ }^{\circ}$ head; cf. Larson (1985). The base structure of correlative coordinate structures would then be as in the left-hand side of Figure 32, while the surface structure is derived by movement of the initial part to some position higher in the structure; the dotted line indicates an indeterminate number of nodes external to the coordinate structure CoP.
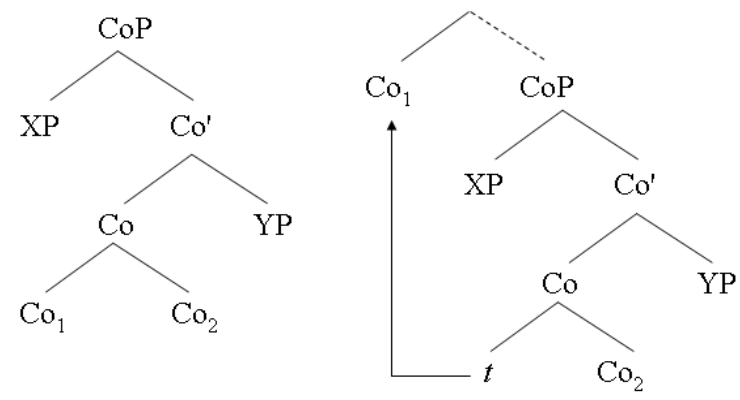

Figure 32: Complex-head hypothesis (Larson 1985)

Larson's main argument in favor of the analysis in Figure 32 is semantic in nature in that the presumed landing site of $\mathrm{Co}_{1}$ restricts the semantic scope of $\mathrm{Co}_{2}$, which was mainly argued on the basis of an observation concerning English either ... or ... We will not review the semantic arguments in what follows but instead concentrate on a number of syntactic arguments for and against this analysis.

\section{Arguments favoring the complex-head hypothesis}

Dutch seems to provide some evidence in favor of Larson's proposal in that the two parts of zowel ... als ... may occur side by side between the two coordinands, as in (551a): cf. Haeseryn et al. (1997:1514). This would follow from the complex-head hypothesis if we were to assume that movement of the initial part of zowel ... als ... is not obligatory: (551a) would then reflect the underlying order of correlative coordinate structures with this correlative coordinator. It should be noted, however, 
that (551a) is less common than the split pattern in (550a), and that the option of having the two parts adjacent is excluded for other correlative coordinators; see, e.g., Van der Heijden (1999:83). We illustrate the impossibility of adjacency with the highly formal correlative hetzij ... of ... in (551b), because one might want to argue that the unacceptability of examples such as (551c) is due to the fact that the two members of the correlative coordinator have the same form; movement of of may therefore be favored in order to avoid haplology.

(551) a. Marie zowel als Jan (is ziek).

Marie both as Jan is ill

b. *Marie hetzij of Jan (is ziek). Marie either or Jan is ill

c. *Marie of of Jan (is ziek). Marie or or Jan is ill

Because the acceptability of (551a) might simply be a quirk of the formal register, that is, a relic from the older adverbial use of zowel als as described in the Woordenboek der Nederlandsche Taal (item Zoowel, sub 1), it is not clear whether we can use it as an argument in favor of the complex-head hypothesis.

The evidence from English put forward by Larson in favor of this hypothesis unfortunately does not straightforwardly carry over to Dutch; we will illustrate this by comparing the crucial English data, which will not be taken from Larson's paper but from Schwarz (1999), to similar Dutch cases. Example (552a) provides the standard case in which the initial part of correlative either ... or ... precedes the first coordinand of the coordinate structure. This structure should be derived by moving either from its base position into a position immediately preceding the coordinate structure (e.g., by ${ }^{\circ}$ adjunction of either to CoP). This analysis can also be applied to the corresponding Dutch case in (552b).

(552) a. that John ate [either $\left[\right.$ [Cop rice [ [co' $\left[\mathrm{co} t_{\mathrm{i}}\right.$ or] beans]]].

b. dat Jan $\left[\mathrm{of}_{\mathrm{i}}\left[\mathrm{CoP}\right.\right.$ rijst $\left[\mathrm{Coo}^{\prime}\left[\mathrm{Co} t_{\mathrm{i}}\right.\right.$ of $]$ bonen $\left.\left.]\right]\right]$ at. that Jan either rice or beans ate

Larson has shown that either may also precede the main verb: that John either ate rice or beans. On the more traditional assumption that either occupies its base position and indicates the left edge of the coordinate structure, we could consider the two analytical options in (553). Representation (553a) should be rejected, however, because it violates the co-occurrence restriction on coordinands discussed in Section 1.3, sub I, that the coordinands must be syntactically similar. Representation (553b) with ellipsis in the second coordinand is suspect: Section 2.1 will show that there are reasons for not accepting forward conjunction reduction.

(553) a. that John either [[vp ate rice] or [DP beans]].

b. that John either [[vp ate rice] or [vp beans]].

The complex-head hypothesis avoids such problems elegantly if we assume that either can be moved into some position immediately preceding VP, as in (554a). The problem with extending this analysis to Dutch is that this movement leads to 
the same order as adjunction to CoP; we can only show that of has moved to a position external of VP if it had crossed some other constituent but we have not been able to construct convincing examples of this sort; for instance, example (554c) in which of has crossed an indirect object is not very good.

(554) a. that John [either $\left[\mathrm{vp}\right.$ ate [Cop rice [co' $\left[\mathrm{Co}_{0} t_{\mathrm{i}}\right.$ or] beans]]]].

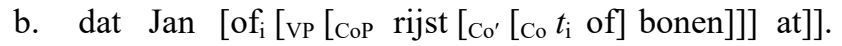
that Jan either rice or beans ate

c. *dat Jan [of ivp $_{\mathrm{i}}$ de hond [Cop rijst [Co' [co $t_{\mathrm{i}}$ of] bonen]]] te eten gaf]]. that Jan either the dog rice or beans to eat gave Intended reading: 'that Jan either fed the dog rice or beans.'

English either can also precede the subject of the clause: that either John ate rice or beans. Assuming that either occupies its base position and indicates the left edge of the coordinate structure, we again have the two analytical options in (555) but these should be rejected for the same reasons as those in (553): representation (555a) should be rejected because it violates the co-occurrence restriction on coordinands, and example (555b) is suspect because there are reasons for not accepting forward conjunction reduction.

(555) a. that either [[тр John ate rice] or [Dp beans]].

b. that either [[vp John ate rice] or [vp beans]].

The complex-head hypothesis can account for the acceptability of that either John ate rice or beans by assuming that either can be moved into some position immediately preceding $\mathrm{TP}$, as in (556a), but this analysis cannot be extended to Dutch because the resulting representation in (556b) is unacceptable: the first occurrence of of cannot precede the subject in Dutch.

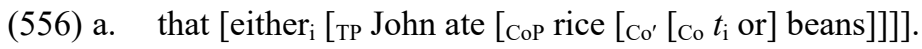

b. *dat [of $\mathrm{i}_{\mathrm{i}}\left[\mathrm{TP}\right.$ Jan [Cop rijst [Co' $\left[\mathrm{Co}_{\mathrm{i}}\right.$ of $]$ bonen $]$ at $\left.\left.]\right]\right]$. that either Jan rice or beans ate

Although the complex-head analysis provides an elegant solution for a number of interesting descriptive problems in English, the unacceptability of the examples in (554c) and (556b) shows that it overgenerates when it comes to Dutch.

\section{Arguments against the complex-head hypothesis}

Schwarz (1999) argues against the complex-head analysis of correlative coordinators on the basis of ${ }^{\circ}$ particle-verb constructions like those in (557); the diacritics are the ones given by Schwarz, who notes that all his informants judge the primed examples as degraded (ranging from marginal to unacceptable).

(557) a. She turned either the test or the homework in.

$\mathrm{a}^{\prime}$. ?"Either she turned the test or the homework in.

b. They locked either you or me up.

$\mathrm{b}^{\prime}$. ?'Either they locked you or me up.

Schwarz further notes that the instances in $(558 \mathrm{a} \& \mathrm{~b})$ below become marked when the coordinate structure is followed by some adverbial phrase, as in the 
corresponding primed examples. Schwarz (1999:349) concludes from this that the coordinate structure must be clause-final in order for either to occur detached from it; either normally immediately precedes the coordinate structure otherwise.

(558) a. Either he invited you or me.

$a^{\prime}$. 'Either he invited you or me (to a party).

b. Either this pleased Bill or Sue.

$\mathrm{b}^{\prime}$. 'Either this pleased Bill or Sue (a lot).

Interestingly, the same can be observed in Dutch: the examples in (559) show that (seemingly) displaced of is possible in main clauses with a finite main verb in second position but not with a non-finite main verb in final position.

(559) a. Of Jan at rijst of bonen.

either Jan ate rice or beans

'Either Jan ate rice or beans.'

b. *Of Jan heeft rijst of bonen gegeten.

either Jan has rice or beans eaten

'Either Jan has eaten rice or beans.'

Schwarz also observes that the English primed examples in (557) become fully grammatical when the (apparently) ${ }^{\circ}$ stranded or-XP phrase is placed after the particle, as in (560). He concludes from this that cases in which either is seemingly displaced are in fact (covert) split coordination constructions (with a reduced second coordinand; see below).

(560) a. [[Either she turned the test in] or [the homework]].

b. [[Either they locked me up] or [you]].

That we are dealing with some sort of "split" coordination is confirmed by the fact illustrated in (561) that the unacceptable Dutch example in (559b) also becomes fully acceptable if the of-XP phrase is placed after the participle gegeten 'eaten'.

$$
\begin{aligned}
& \text { Of Jan heeft rijst gegeten, of bonen. } \\
& \text { either Jan has rice eaten or beans } \\
& \text { 'Either Jan has eaten rice, or beans.' }
\end{aligned}
$$

Schwarz finally argues that split coordination constructions such as (560) involve clausal coordinands, with reduction of the second clause. This would be completely in line with the independently motivated conclusion from Section 1.3, sub IIB, that the split coordination construction in (562b) cannot be derived from the same underlying source as (562a) because this would leave the difference in subject-verb agreement unexplained; we concluded from this that the phrase following en is in all likelihood a reduced verbal projection.

(562) a. dat [Marie en Jan] morgen op visite komen/*komt. that Marie and Jan tomorrow on visit come/comes 'that Marie and Jan will visit us tomorrow.'

b. dat Marie morgen op visite komt/*komen, en Jan. that Marie tomorrow on visit comes/come and Jan 
Schwarz' alternative analysis makes the complex-head hypothesis as well as the concomitant movement of the initial part of the correlative coordinator in Figure 32 unnecessary. By denying that the initial part of the correlative $\mathrm{Co}_{1}$ can be moved, the apparent problem that the Dutch examples in (554c) and (556b) are unacceptable disappears as well. For these reasons we do not adopt the complexhead hypothesis.

\section{B. Double-head analyses}

A second line of investigation starts from the assumption that the constituting parts of correlative coordinators are all heads. On this assumption there seem to be two obvious possibilities of representing correlative coordinate structures: either the initial part of this structure takes the first coordinand as it complement, as in the left-hand representation in Figure 33, or it takes the full coordinate structure as its complement, as in the right-hand representation: see Kayne (1994:58) including footnote 2 .
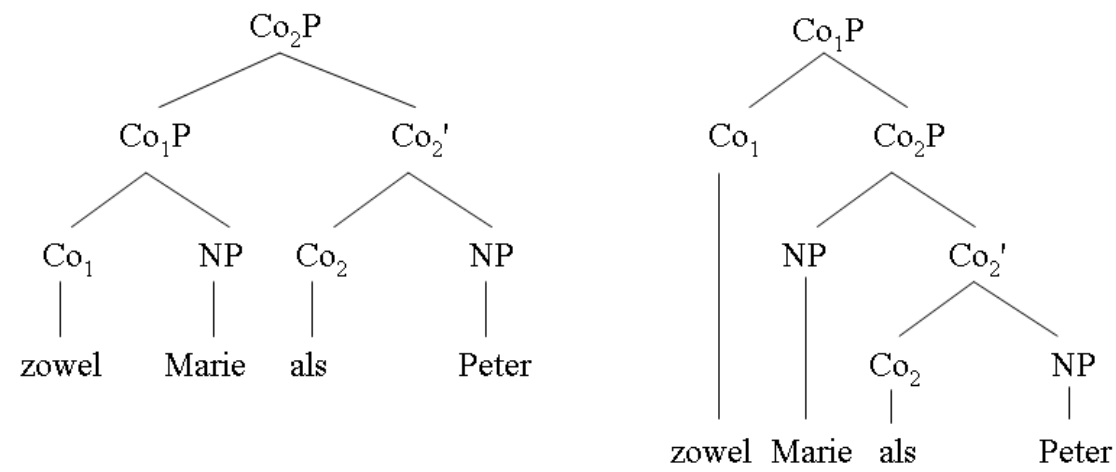

Figure 33: Double-head analysis of correlative coordinators

Both representations in Figure 33 are problematic in that the initial part of the correlative coordinator does not behave as a two-place linker: it takes a single complement only, viz., the noun phrase Marie in the left-hand structure and the coordinate structure $\mathrm{Co}_{2} \mathrm{P}$ in the right-hand structure. The left-hand representation also violates the co-occurrence restrictions on coordinands, according to which the coordinands must be syntactically similar, because als links the CoP zowel Marie and the noun phrase Peter. In the right-hand representation, zowel does not enter into a relation with the two coordinands at all. The two double-head analyses are therefore not very promising in their present form, but there are slightly more sophisticated versions of them that may be more promising.

\section{The AgrCoP-version of the double head analysis}

The two double-head hypotheses in Figure 33 entail that at least the initial part of the correlative coordinator cannot be analyzed as a two-place linker. If so, there is no well defined reason for assuming that the second member should be a two-place linker. This presupposition is indeed rejected by Van der Heijden (1999), who argues that the two parts of correlative coordinators are similar in that they just take a complement. This requires, however, the postulation of a separate head, which 
Van der Heijden calls AgrCo, that links the two CoPs. We illustrate this here for the correlative en ... en ... 'and ... and ...'.

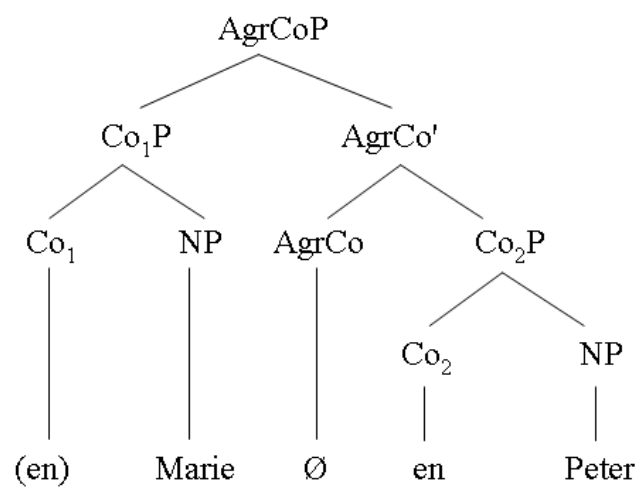

Figure 34: Double-head analysis: AgrP-analysis version

The parentheses around en, the initial part of the coordinate structure in Figure 34, are used to indicate that Van der Heijden claims that simplex and correlative coordinators have essentially the same structure: the only difference is whether the initial part is phonetically realized. The functional head AgrCo is assumed to perform several functions. First, it ensures agreement between $\mathrm{Co}_{1} \mathrm{P}$ and $\mathrm{Co}_{2} \mathrm{P}$, which is claimed to block unacceptable formations such en ... of ... in (563a). Second, it plays a role in the agreement relation with elements external to the coordinate structure by ensuring that the coordinate structure in (563b) triggers plural agreement on the finite verb despite the fact that the coordinands are singular. Third, the structure can be used to account for split coordination: $\mathrm{Co}_{1} \mathrm{P}$ and $\mathrm{Co}_{2} \mathrm{P}$ are maximal projections and can therefore be separated by movement, as illustrated by (563c).

(563) a. *[En Marie of Peter] danst/dansen. and Marie or Peter dances/dance

b. [Marie en Peter] dansen $/$ p $/$ danst $_{\mathrm{sg}}$. Marie and Peter dance/dances

c. Ik heb (en) Marie gezien en Peter. I have and Marie seen and Peter

Unfortunately, the proposal is not sufficiently worked out to fully evaluate it. Furthermore, the arguments based on $(563 \mathrm{~b} \& \mathrm{c})$ seem flawed. First, because simplex and correlative coordinators are claimed to make use of the same structure in Figure 34 , there is no a priori reason for expecting the difference in subject-verb agreement properties found between (563b) and (564a); although Van der Heijden acknowledges this difference, she does not provide an account of it. Second, on the assumption that the $\mathrm{Co}_{2} \mathrm{P}$ in Figure 34 can be moved to the right in order to derive (563c), we would wrongly expect the coordinate structure constraint violation in example (564b) also to be acceptable. Third, Section 1.3, sub IIB, has provided arguments to the effect that split coordination constructions such as (563c) cannot be derived from the same source as their non-split counterparts. 
(564) a. [En Marie en Peter] danst $\mathrm{sg}_{\mathrm{g}} /$ dansen $_{\mathrm{p} 1}$. and Marie and Peter dances/dance

b. *[En Peter $]_{\mathrm{i}}$ heb ik [(en) Marie $\left.t_{\mathrm{i}}\right]$ gezien. and Marie have I and Peter seen

The discussion above indicates that there are reasons not to adopt AgrCoP-version of the double head analysis in Figure 34 in its current stage of development.

\section{The CorP-version of the double head analysis}

The second version of the double-head analysis of correlative coordinators sustains the claim that coordinators are two-place linkers by dropping the assumption that the initial part is coordinator-like. Van Zonneveld (1992) proposes that the initial part is a special type of functional head, which he refers to as Cor, that takes a regular coordinate structure $(\mathrm{CoP})$ as its complement. On this assumption, the representation of correlative coordinate structures is as given in the right-hand representation in Figure 35.
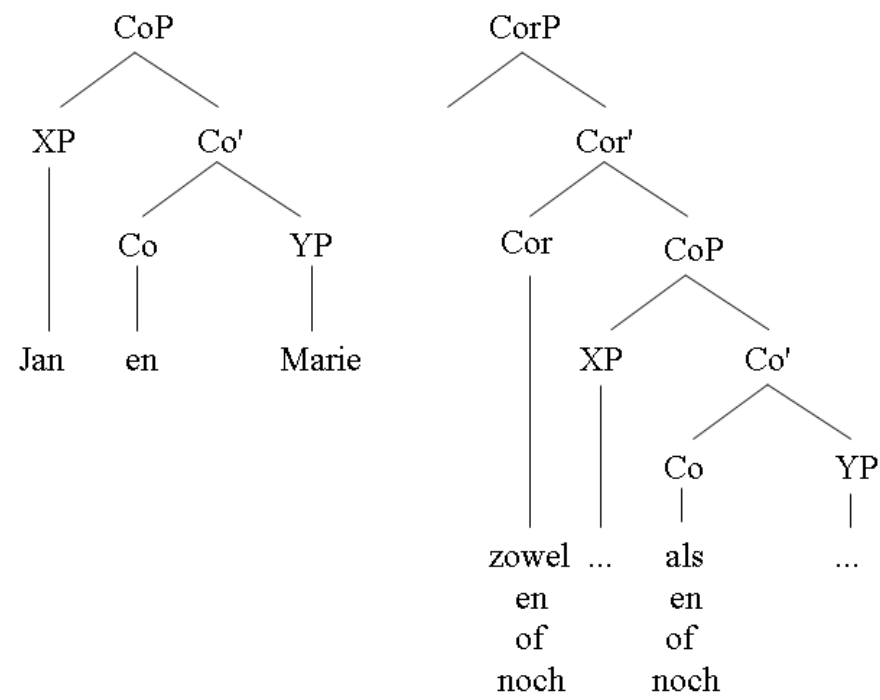

Figure 35: Double-head analysis: CorP-version

Zonneveld motivates the postulation of a CorP projection by referring to the fact discussed in Subsection II that coordinands of correlative coordinate structures are always ${ }^{\circ}$ major phrases. For instance, the examples in (565) show that while simplex en can link DPs, NPs and nominal heads, the correlative head en can only precede coordinated DPs. This can be made to follow by stipulating that the correlative head Cor can only select CoPs functioning as major phrases.

(565) a. [CorP (En) [CoP de mannen en de vrouwen]] dansen. and the men and the women dance

b. De [CorP $(*$ en) [CoP oude mannen en jonge vrouwen]] dansen. the and old men and young women dance

c. De [CorP oude (*en) [CoP mannen en vrouwen]] dansen. the old and men and women dance 
Another merit of the CorP-analysis is that it can easily explain why the initial part of zowel ... als ... 'both ... and ...' has a different form than the non-initial part by pointing to the fact that they have a different syntactic status: the initial part is not a coordinator but a Cor-head. This analysis may also account for the fact that in larger polyadic coordinate structures the non-initial parts of the coordinator must have the same form by saying that CorP is always the top projection of a correlative coordinate structure, and that the coordinators in its domain must be identical (in meaning and form).

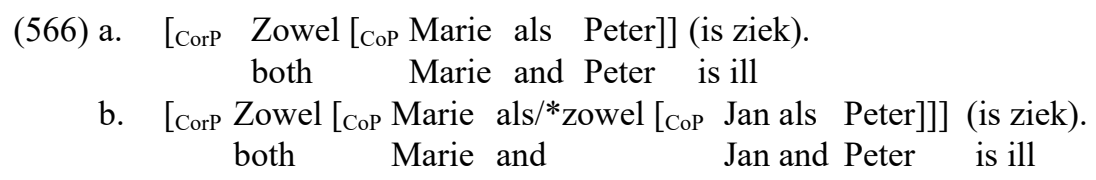

Subsection $\mathrm{C}$ will show that there are reasons to reject the CorP-hypothesis for the simple reason that the initial part is phrasal (and not a head). This does not imply that the suggestion that coordinate structures have a functional projection (such as CorP) on top of CoP should be abandoned too. De Vries (2005), for instance, provides a modified version which is compatible with the findings in Subsection C. However, since his motivation for assuming an additional functional layer on top of $\mathrm{CoP}$ is mainly based on recursive coordinate structures of the type discussed in Section 1.3, sub III, we will not discuss his version here.

\section{The initial part of a correlative coordinate structure is a focus particle}

The analyses discussed in Subsections A and B presuppose that the initial part of a correlative coordinate structure is (a subpart of) a head. There are also proposals that take the initial part to be phrasal. The rationale for assuming this is that the initial part exhibits similarities with focus ${ }^{\circ}$ particles such as restrictive alleen 'only'; cf. V13.3.2, sub IC. Hendriks (2001a), for example, has observed that the initial part resembles focus particles in that it must have an emphatically accented phrase in its domain. Because Section 1.1, sub V, has shown that coordinands normally cannot be unaccented (cf. Ik bezocht Peter en haar/*' $r$ 'I visited Peter and her'), this is not a conclusive argument for claiming that the initial parts of correlative coordinate structures are focus particles, but Subsection 1 will show that these elements do indeed exhibit striking similarities in syntactic behavior; see also Hendriks (2001b/2004) and Johannessen (2005).

(567) a. Peter heeft alleen JAN ontmoet.

Peter has only Jan met

b. Peter heeft zowel JAN als ELS ontmoet.

Peter has both Jan and Els met

$b^{\prime}$. Peter heeft of JAN of ELS ontmoet.

Peter has or Jan or Els met

$b^{\prime \prime}$. Peter heeft noch JAN noch ElS ontmoet.

Peter has nor Jan nor Els met 
Hendriks' conjecture that the initial parts of correlative coordinate structures are focus particles makes the same predictions as the CorP-analysis discussed in Subsection B: the initial and the non-initial part(s) of "correlative coordinators" can have a different form because the initial part is not a coordinator but a focus particle; that the non-initial parts must have the same form shows that the coordinators in the domain of the focus particle must be identical (both in meaning and in form). We will see in Subsections 1 and 2, however, that Hendriks' conjecture also accounts for various facts not expected under the CorP-analysis. Subsection 3 provides a more speculative discussion based on data suggesting that correlative structures are not (or at least need not be) a single phrase.

\section{The initial part of a correlative occupies a designated focus position I}

Section V13.3.2, sub I, has argued that Dutch has a designated position in the ${ }^{\circ}$ middle field of the clause for hosting focused phrases, just preceding the locus of sentence negation (if present). We illustrate this here again by means of the examples in (568) with a complementive AP headed by boos 'angry'. The (a)- and (b)-examples show that the PP-complement of boos must remain AP-internally if it is not accented, but can be moved into the designated ${ }^{\circ}$ focus position if it is contrastively focused (indicated by small caps).

(568) a. Jan is $<*$ op 'm $>$ niet [boos $<$ op 'm $>$ ] geweest.

Jan is with him not angry been

'Jan hasn't been angry with him.'

b. Jan is $<$ op HEM $>$ niet [boos $<$ op HEM $>$ ] geweest (maar op MARIE).

Jan is with him not angry been but with Marie

'Jan hasn't been angry with him but with Marie.'

The examples in (569) further show that this movement is obligatory if the focused PP is preceded by a focus particle such as alleen 'only', unless the designated focus position is filled by this focus particle itself, in which case the PP can remain in its AP-internal position. Although this is not an established fact, we will assume for concreteness' sake that the focus particle is base-generated within the PPcomplement of boos; see Section V13.3.2 for discussion.

(569) a. *Jan is [AP boos [*alleen op HEM] $]$ geweest.

Jan is angry only with him been

b. Jan is [alleen op HEM $]_{\mathrm{i}}\left[\right.$ boos $t_{\mathrm{i}}$ ] geweest.

Jan is only with him angry been

'Jan has only been angry with him.'

$\mathrm{b}^{\prime}$. Jan is alleen $\mathrm{i}_{\mathrm{i}}\left[\mathrm{boos}\left[t_{\mathrm{i}}\right.\right.$ op HEM $]$ geweest.

Jan is only angry with him been

'Jan has only been angry with him.'

Example (570a) shows that the focus particle alleen may also occur in sentenceinitial position if it pied-pipes the focused phrase. The (b)-examples show that the split pattern found in (569b) is normally not possible; the ${ }^{\circ}$ traces indicate the position occupied by alleen in the (b)-examples in (569). 
(570) a. [Alleen op HEM $]_{\mathrm{i}}$ is Jan $\left[\right.$ boos $\left.t_{\mathrm{i}}\right]$ geweest. only with him is Jan angry been

b. *Alleen ${ }_{\mathrm{j}}$ is Jan $\left[t_{\mathrm{j}} \text { op HEM }\right]_{\mathrm{i}}\left[\right.$ boos $\left.t_{\mathrm{i}}\right]$ geweest. only is Jan with him angry been

$\mathrm{b}^{\prime} .{ }^{*}{ }^{*}$ Alleen $_{\mathrm{i}}$ is Jan $t^{\prime}{ }_{\mathrm{i}} \quad$ [boos $\left[t_{\mathrm{i}}\right.$ op HEM $\left.]\right]$ geweest. only is Jan angry with him been

The examples in (571) support Hendriks' conjecture by showing that similar observations can be made for correlative coordinate structures. First, example (571a) shows that such structures give rise to a marked result when they occupy their base-position within AP, while the (b)-examples show that movement of either the full coordinate structure or its initial part gives rise to a fully acceptable result. The behavior of the correlative coordinate structure in (571) is thus fully parallel to that of the focus phrase in (569).

(571) a. *Jan is [AP boos [zowel op Els als op Marie]] geweest. Jan is angry both with Els and with Marie been

b. Jan is [zowel op Els als op Marie $]_{i}$ [boos $t_{i}$ ] geweest. Jan is both with Els and with Marie angry been 'Jan has been angry both with Els and with Marie.'

$\mathrm{b}^{\prime}$. Jan is zowel $\mathrm{i}_{\mathrm{i}}\left[\mathrm{boos}\left[t_{\mathrm{i}}\right.\right.$ op Els als op Marie $]$ geweest. Jan is both angry with Els and with Marie been 'Jan has been angry both with Els and with Marie.'

The examples in (572) indicate that the initial part of the correlative coordinate structure obligatorily pied-pipes the full coordinate structure if it is moved into sentence-initial position. The behavior of the correlative coordinate structure in (572) is again parallel to that of the focus phrase in (570).

(572) a. [Zowel op Els als op Marie] is Jan [boos $t_{\mathrm{i}}$ ] geweest. both with Els and with Marie is Jan angry been

b. ${ }^{*}$ Zowel $_{\mathrm{j}}$ is Jan $\left[t_{\mathrm{j}} \text { op Els als op Marie }\right]_{\mathrm{i}} \quad\left[\right.$ boos $\left.t_{\mathrm{i}}\right]$ geweest. both is Jan with Els and with Marie angry been

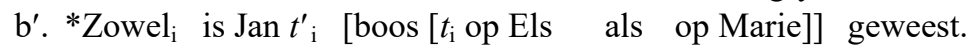
both is Jan angry with Els and with Marie been

Similar examples can be found with PP-complements of verbs: the (a)-examples in (573) show that such complements can optionally occur in clause-final (extraposed) position but not if they are adjacent to a focus particle. The (b)-examples show the same for correlative coordinate structures, although it should be noted that the marked order in $\left(573 b^{\prime}\right)$ improves when the postverbal phrase is parenthetical (that is, if zowel is preceded by an intonation break). See De Vries (1992:24-5) for more examples.

(573) a. Jan heeft <alleen op VADER> gewacht.

Jan has only for father waited

'Jan only waited for father.'

$a^{\prime}$. Jan heeft $<$ alleen $>$ gewacht $<*$ alleen $>$ op VADER.

Jan has only waited for father 
b. Jan heeft zowel op vader als op moeder gewacht. Jan has both for father and for mother waited 'Jan waited both for father and for mother.'

$\mathrm{b}^{\prime}$. Jan heeft $<$ zowel $>$ gewacht $<^{? ?}$ zowel $>$ op vader als op moeder. Jan has both waited for father and for mother 'Jan waited both for father and for mother.'

The split of the focus particle alleen and its associate phrase is normally optional, but obligatory if its associate is clausal. The examples in (574) show that the split is also obligatory with clausal correlative coordinate structures; cf. Hoeksema (1989).

\section{(574) a.}

b. Jan heeft $<$ zowel $>$ gezegd $<*$ zowel $>$ dat Marie komt als dat Els komt. Jan has both said that Marie comes and that Els comes 'Jan has both said that Marie is coming and that Els is coming.'

The data supporting Hendriks' conjecture are problematic for the more traditional approaches to correlative coordinate structures in that they either have to relax the co-occurrence restrictions on coordinands discussed in Section 1.3, sub I, or allow for forward conjunction reduction, which will be shown to be problematical in itself in Section 2.1. Example (575a), for instance, should be analyzed as a coordination of a complementive AP and a PP-modifier, as in (575a), or be derived by forward deletion of the adjective boos, as in (575a'). The (b)- and (c)-examples show that comparable problems arise in accounting for the examples in $(575 \mathrm{~b} \& \mathrm{c})$. The fact that Hendriks' conjecture avoids these problems can be seen as an argument in its favor.

(575) a. Jan is [zowel [AP boos op Jan] als [PP op Marie]] geweest. Jan is both angry with Jan and with Marie been

$\mathrm{a}^{\prime}$. Jan is [zowel [AP boos op Jan] als [AP op Marie]] geweest. Jan is both angry with Jan and angry with Marie been

b. Jan heeft [zowel [vp gewacht op vader] als [pp op moeder]]. Jan has both waited for father and for mother

$\mathrm{b}^{\prime}$. Jan heeft [zowel [vp gewacht op vader] als [pp op moeder]]. Jan has both waited for father and waited for mother

c. Jan heeft [zowel [vp gezegd dat Marie komt] als [CP dat Els komt]]. Jan has both said that Marie comes and that Els comes

$\mathrm{c}^{\prime}$. Jan heeft [zowel [vp gezegd dat Marie komt] als [vp dat Els komt]]. Jan has both said that Marie comes and said that Els comes

Let us now briefly return to the examples in $(571 \mathrm{~b} \& \mathrm{c})$, repeated as the (a)examples in (576). These examples would appear to cause trouble for Neijt's (1979) generalization that the coordinands in correlative coordinate structures are major phrases: because the op-PPs are arguably selected by the adjective boos 'angry' and not by the verb zijn 'to be', they do not count as major phrases and we therefore wrongly expect them to be unacceptable. Hendriks' conjecture, on the other hand, correctly predicts the acceptability of these examples, given that the focus constructions in the (b)-examples exhibit identical behavior. 
(576) a. Jan is zowel [boos [op Els als op Marie]] geweest.

Jan is both angry with Els and with Marie been

'Jan has been angry both with Els and with Marie.'

$\mathrm{a}^{\prime}$. Jan is [zowel op Els als op Marie $]_{\mathrm{i}}$ [boos $\left.t_{\mathrm{i}}\right]_{\text {geweest. }}$ ge

Jan is both with Els and with Marie angry been

b. Jan is alleen [boos op HEM] geweest.

Jan is only angry with him been

'Jan has only been angry at him.'

$\mathrm{b}^{\prime}$. Jan is [alleen op HEM $]_{\mathrm{i}}\left[\right.$ boos $t_{\mathrm{i}}$ ] geweest.

Jan is only with him angry been

The cases in (576) thus show that the proper generalization about correlative coordinate structures is not that the coordinands must be major phrases but that the coordinate structure as a whole must be able to undergo movement into the designated focus position. The question as to why the PP-complement can be moved into the designated focus position is of course still open but is not pertinent to the present discussion only. There are in fact more questions that await an answer, such as the fact illustrated in (577a) that correlative coordinate structures are occasionally used as attributive modifiers (see also Subsection IIB) despite the fact that such modifiers cannot be extracted from noun phrases; cf. *Dat dit [zo moeilijk] $]_{i}$ niet [een $t_{i}$ beslissing] is. Again, the same problem arises with focus phrases; example (577b) shows that the focusing elements niet alleen 'not only' and ook 'too' can also be used for modifying attributive modifiers. We will leave the task of making an inventory of such problems and providing a solution for them to future research.

(577) a. een [zowel moeilijke als belangrijke] beslissing a both difficult and important decision

b. een [niet alleen moeilijke] maar [ook belangrijke] beslissing a not only difficult but also important decision

\section{The initial part of a correlative occupies a designated focus position II}

The examples in the previous subsection have shown that the initial part of the correlative coordinator zowel ... als ... has the same syntactic distribution as the focus particle alleen 'only'. This does not only hold for this correlative coordinator but also for en ... en ... 'and ... and ...', of ... of ... 'either .... or ...', and noch ... noch ... 'neither ... not ...', which can all replace zowel ... als ... in the examples in (578).

(578) a. Jan is zowel [boos [op Jan als op Marie]] geweest.

Jan is both angry with Jan and with Marie been

'Jan has been angry both with Jan and with Marie.'

b. Jan heeft zowel gewacht op vader als op moeder.

Jan has both waited for father and for mother 'Jan waited both for father and for mother.'

c. Jan heeft zowel gezegd dat Marie komt als dat Els komt. Jan has both said that Marie comes and that Els comes 'Jan has both said that Marie is coming and that Els is coming.' 
Although the claim that initial en and of are focus particles may strike us as odd at first, this claim seems quite natural for noch: Section 1.3, sub IIIG, has shown that it can be used as an adverbial with the meaning "and not", of which the negative element niet 'not' behaves as a focus particle when used for marking constituent negation: Ik heb niet MARIE ontmoet maar PETER 'I have not met Marie but Peter.' That initial en may be a focus particle and must thus be located in the designated focus position in the middle field of the clause can perhaps be motivated by the contrast between the examples in (579) taken from De Vries (1992:20).

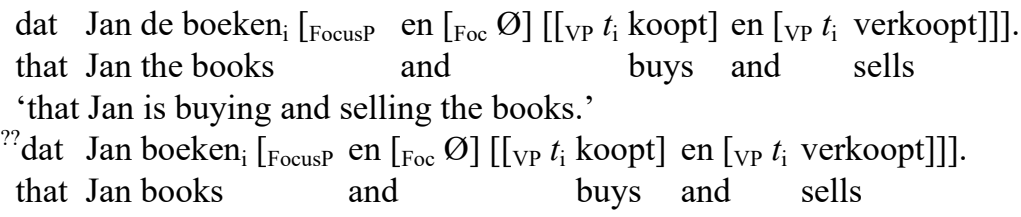

The acceptability of (579a) is expected if we assume that ${ }^{\circ} \mathrm{A}$-scrambling of the definite noun phrase de boeken 'the books' has applied across-the board: chapter V13 has shown that A-scrambling normally crosses the designated focus position. The markedness of (579b) also follows as (non-specific) indefinite noun phrases cannot be A-scrambled; example (579b) is only acceptable with a generic or habitual reading. The acceptability contrast between the two examples provides additional support for Neijt's conclusion discussed in Subsection II that correlatives can only be used for linking ${ }^{\circ}$ major phrases, because if we were dealing with coordination of verbal heads, (579b) would wrongly be predicted to be fully acceptable with the structure ?? dat Jan boeken [en [V koopt] en [V verkoopt]]]. Nevertheless, we need to discuss a potential problem for the A-scrambling analysis. Consider the examples in (580); cf. De Vries (1992:21).

(580) a. dat Jan [FocusP zowel [Foc Ø] [boeken koopt als verkoopt]].

that Jan both books buys and sells

'that Jan is both selling and buying books.'

b. dat Jan [Focusp en [Foc Ø] [boeken koopt en verkoopt]]. that Jan and books buys and sells

If we again adopt Neijt's conclusion that correlatives can only be used for linking major phrases, the phrases following initial zowellen cannot be VPs with coordinated verbal heads, that is, the structure in (581a) is deemed to be ungrammatical (the reader can construct the corresponding structure for (580a) by substituting en for both/als). The structure in (581b) is also unacceptable given that the transitive verb verkopen does not have a direct object. The only remaining way of deriving the examples in (580) is therefore by assuming that also in these examples the object is extracted from the coordinated VPs in an ${ }^{\circ}$ across-the-board fashion, as in $(581 \mathrm{c})$.

(581) a. *dat Jan [Focusp zowel [Foc Ø] [vp boeken [[v koopt] als [v verkoopt]]]]. that Jan both books buys and sells

b. *dat Jan [Focusp zowel [Foc Ø] [[vp boeken koopt] als [vp verkoopt]]]. that Jan both books buys and sells

c. dat Jan [Focusp zowel [boeken ${ }_{\mathrm{i}}\left[\mathrm{vp} t_{\mathrm{i}}\right.$ koopt] als [vp $t_{\mathrm{i}}$ verkoopt]]]. that Jan both books buys and sells 
The analysis in (581c) goes against the earlier assumptions (i) that A-scrambling must cross the designated focus position and (ii) that indefinite noun phrases do not A-scramble. It is, however, in full accordance with the independently motivated hypothesis in Broekhuis (2008) that A-scrambling comes in two kinds; the first type is the traditionally assumed form of A-scrambling discussed in V13.2 that extracts the object from the lexical domain of the clause (vP) and places it in a designated position in the functional domain of the clause under certain information-structural conditions; the second type applies obligatorily within the lexical projection of the verb and is claimed to be instrumental in the derivation of the Dutch surface OVorder from an underlying (universal) VO-order: $\left[{ }_{\nu \mathrm{P}} \ldots\right.$ Object $_{\mathrm{i}} \ldots$... [vP $\left.\left.\mathrm{V} t_{\mathrm{i}}\right]\right]$. Since "short" A-scrambling is mainly motivated by cross-linguistic considerations, we refer the reader to Broekhuis (2008:ch.2) for further discussion.

\section{Split correlative coordinate structures are biclausal}

The sentences in (582) show that correlative coordinate structures can easily be split; cf. De Vries (1992:26) and Haeseryn et al. (1997:ch.25).

(582) a. En Jan <en Marie> is hier geweest <en Marie>

and Jan and Marie is here been

'Both Jan and Marie have been here.'

b. Of Jan <of Marie> is hier geweest $<$ of Marie>

either Jan or Marie is here been

'Either Jan or Marie has been here.'

c. Noch Jan <noch Marie > is hier geweest $<$ noch Marie $>$.

neither Jan nor Marie is here been

'Neither Jan nor Marie has been here.'

Section 1.3, sub IIB, has argued that the non-split and split cases are not derived from the same underlying source and that the apparently "extraposed" string should be analyzed as a reduced clause. One of the reasons given in support for this claim relates to subject-verb agreement: while conjunctive coordinate structures of two singular noun phrases trigger plural agreement on the finite verb, the corresponding split constructions trigger singular agreement.

(583) a. Jan en Marie zijn/*is hier geweest.

Jan and Marie are/is here been

'Jan and Marie have been here.'

b. Jan is $/ *$ zijn hier geweest $<$ en Marie $>$.

Jan is/are here been and Marie

'Jan has been here, and Marie.'

This test cannot be applied to the examples in (582) because the unsplit correlative coordinate structures all trigger singular agreement as well. The test can be applied to coordinate structures with zowel ... als ... in so far as speakers accept plural agreement in examples such as (584a): while plural agreement is marginally accepted by some speakers, plural agreement is absolutely impossible in the "split" version in (584). 
(584) a. Zowel Jan <als Marie $>$ is $/{ }^{\%}$ zijn hier geweest.

both Jan and Marie is/are here been

'Both Jan and Marie have been here.'

b. Zowel Jan is/*zijn hier geweest als Marie.

both Jan is/are here been and Marie

If we can conclude from this that the biclausal analysis suggested for (583b) must be extended to cover the "split' examples in (582) and (584), we also have to accept the conclusion that the initial and non-initial part of "correlative coordinators" can be located in two different clauses. This would of course be unconceivable under the traditional analysis of correlative coordinators as (discontinuous) words, but becomes quite natural if the initial part is a focus particle. It may also shed new light on the acceptability of examples like those in (585). The traditional view would assign this example the structure in $(585 \mathrm{~b})$, violating the co-occurrence restrictions on coordinands discussed in Section 1.3, sub I, which we indicated by adding an asterisk to this structure. If the presumed initial part is a focus particle, however, we can simply assume that it occupies the designated focus position in the first clausal coordinand, and analyze the sentence as a case of clausal coordination, as in (585c).

(585) a. Jan zal of schuld bekennen of hij zal vluchten.

Jan will either guilt confess or he will flee

'Jan will either confess his guilt or he will flee.'

b. *Jan zal [of [vp schuld bekennen] of [CP hij zal vluchten]].

c. [[CP Jan zal [FocusP of [Foc $\varnothing]$ [vP schuld bekennen]]] of [CP hij zal vluchten]].

Example (586a) receives the same analysis as (585a). Note that Haeseryn et al. (1997:1502) suggest that examples of this sort are categorically rejected but it seems to us that this is an overstatement.

(586) a. Jan zal en schuld bekennen en hij zal vluchten.

Jan will and guilt confess and he will flee

'Jan will and confess his guilt and he will flee.'

b. *Jan zal [en [vp schuld bekennen] en [CP hij zal vluchten]].

c. [[CP Jan zal [FocusP en [Foc $Ø]$ [vP schuld bekennen]]] en [CP hij zal vluchten]].

Examples like (587) can be given essentially the same analysis, although we are concerned with asyndetic coordination of the clauses in this case: because noch triggers subject-verb inversion in the second coordinand it must occupy the initial position of the main clause; see Den Dikken (2006) for a similar discussion on English neither ... nor ... on the basis of subject-verb inversion in the translation of (587c).

(587) a. Jan zal noch schuld bekennen noch zal hij vluchten.

Jan will neither guilt confess nor will he flee

'Jan will neither confess his guilt nor will he flee.'

b. *Jan zal [noch [vP schuld bekennen] noch [CP zal hij vluchten]]. [traditional]

c. [[CP Jan zal noch schuld bekennen] Ø [CP noch zal hij vluchten]]. [focus part.] 
Similar constructions with the sequence zowel ... als ... 'both ... and ...' do not occur. This is expected because the sequence never occurs in clausal coordinate structures for some reason. Because there is no reason to expect problems with the first clausal coordinand, the reason for the unacceptability should be due to als: apparently it can neither function as a run-of-the-mill coordinator nor as a clausal constituent.

(588) a. *[Jan zal zowel schuld bekennen $]$ als [hij zal vluchten].
Jan will either guilt confess ALS he will flee
b. *[Jan zal zowel schuld bekennen $\varnothing$ [als zal hij vluchten].
Jan will either guilt confess and ALS will he flee

\section{Conclusion}

Since we have come to the conclusion that the initial parts of correlative coordinate structures are focus particles, we can also conclude that the postulation of a set of correlative coordinators is not justified. This may be problematic if one adopts Johannessen's (2005) view that the initial part of the supposed correlative coordinator "selects" the non-initial part, and that these two elements must therefore enter into some local relationship with each other. This would be a dubious claim, however, in the light of examples such as (589), where "initial" of is included in the initial clausal coordinand of a coordinate structure that in its turn functions as the initial coordinand of "non-initial" of; the relationship between the two occurrences of of cannot be seen as local in any of its usual syntactic definitions.

$$
\begin{aligned}
& \text { [[CP Je neemt of het boek mee] en [cP je leest het }] \text { of } \\
& \text { you take either the book prt. and you read it or } \\
& \text { [CP ik help je niet meer]]. } \\
& \text { I help you not anymore } \\
& \text { 'You will either take the book with you and you read it or I will not help you } \\
& \text { anymore.' }
\end{aligned}
$$

There is in fact no a priori reason for assuming that selection is involved. The correlative adverb enerzijds in the first clausal coordinand of the coordinate structure in (590a), for instance, requires the adverb anderzijds to be present in the second coordinand, and something similar holds for the focus elements niet alleen and ook in (590b); since the relation between these elements is not local in the usual syntactic sense either, we have to accept that this relation is not syntactic in nature.

(590) a. [[cP Enerzijds ben ik blij] maar [anderzijds ben ik droef]]. on.the.one.hand am I happy but on.the.other.hand am I sad

'On the one hand I am happy, but on the other I am sad.'

b. [[CP Ik ben niet alleen blij] maar [CP ik ben ook droef $]$.

I am not only happy but I am also sad

'I am not only happy, but I am also sad.'

Another thing that needs to be mentioned is that it is no longer a priori clear that the figures in Table 21, repeated from the introduction to this section on correlative coordinate structures, can still be used for arguing that correlative structures are not part of core syntax. We claimed in the introduction to this section that this is the case because even the frequency of zowel ... als ... 'both ... and ...' is negligible 
compared to the frequencies of simplex en 'and' (14592/3650), of 'or' (1686/452), and maar 'but' (3224/1437) in the same corpus. However, now that we have seen that the initial parts of these sequences are focus particles, things may have changed: on the assumption that Uit den Boogaart (1975) has listed the focus particle alleen as an adverbial (code 500), his corpus has up to 739 occurences in writing and 210 occurences in speech, which makes our earlier conclusion less persuasive (although not necessarily invalid): correlative constructions of the sort discussed in this section may be part of core syntax after all.

Table 21: Frequency of "correlative coordinators"; cf. Uit den Boogaart (1975)

\begin{tabular}{|l||c|c||}
\hline CORRELATIVE “COORDINATOR” & WRITING & SPEECH \\
\hline \hline en ... en ... 'as well as' & 4 & 1 \\
\hline noch ... noch .. 'neither ... nor ...' & 18 & 1 \\
\hline of ... of ... 'either ... or ...' . . & 34 & 2 \\
zowel .. als ... 'both ... and ... & 127 & 2 \\
\hline
\end{tabular}

The discussion in Subsection 3 further raises the question as to whether correlative constructions of the sort under discussion are indeed run-of-the mill coordinate structures. If one were to assume that the part between square brackets in example (591) is in fact a reduced parenthetical clause, we would immediately derive two basic facts: first, the fact that the correlative construction in this example must receive a distributional interpretation and, second, that it triggers singular agreement on the finite verb.

(591) En Jan [en Marie] heeft de tafel opgetild. and Jan and Marie has the table prt.-lifted 'Both Jan and Marie have lifted the table.'

We merely raise the point and will not develop this idea any further as this will lead us into unexplored territory, raising various new questions, such as why certain speakers allow nominal structures with zowel ... als ..., as in example (584a), to trigger plural agreement on the verb (which might just be a quirk of the formal register), and why this is even obligatory with its English counterpart both ... and ... (which might be related to the fact that both is not a focus particle but a true quantifier; cf. Munn 1993: section 4.6). 
This content downloaded from 131.211.104.173 on Wed, 19 Feb 2020 10:39:17 UTC All use subject to https://about.jstor.org/terms 


\title{
Chapter 2 \\ Ellipsis in coordinate structures
}

\author{
Introduction
}

2.1. Conjunction Reduction

I. Differences between backward and forward conjunction reduction 251

II. Arguments against forward conjunction reduction 253

III. Properties of backward conjunction reduction $\quad 256$

IV. Backward conjunction reduction is not a syntactic rule 259

V. Combinations of forward and backward conjunction reduction 261

VI. A residual problem: "shared" main-clause initial constituents 263

$\begin{array}{ll}\text { A. Can lexical heads be coordinated? } & 263 \\ \text { B. Can intermediate projections be coordinated? } & 266 \\ \text { C. Empty subject pronouns? } & 268\end{array}$

2.2. Gapping 271

I. A brief characterization of gapping $\quad 272$

A. Restrictions on the coordinator $\quad 272$

B. The remnants of gapping are contrastively focused 272

C. Gapping elides a finite verb; it targets clausal coordinands only 273

D. The elided material need not be a single constituent 275

E. Recoverability and maximization condition on elision $\quad 275$

F. Gapping may affect more than one target clause $\quad 277$

G. The remnants of gapping are prototypically major phrases $\quad 278$

H. The number of remnants of gapping $\quad 279$

II. The syntactic restrictions on gapping $\quad 281$

A. Restrictions on the antecedent and the target clause 282

1. Simple main clauses $\quad 282$

2. Main clauses with a verbal complex $\quad 284$

3. Embedded clauses $\quad 284$

4. Antecedent and target clauses are full coordinands 286

B. The clausemate restriction on gapping $\quad 288$

1. Clausal constituents that are clausemates 288

2. Other cases $\quad 292$

C. Potential counterexamples to the clausemate restriction 295

1. Target clauses with a sluiced complement clause 295

2. Genuine counterexamples: on gapping and A'-movement 298

D. Gapping is syntactic in nature $\quad 301$

1. Gapping and focus/topic movement 301

2. Verbal-head restriction on gapping 304

3. Interrogative, topicalized and negative phrases 305

4. Focus particles and negation 306

5. Elision of the negative marker niet 'not' is impossible 308

6. Concluding remarks 309

E. Some potentially problematic cases $\quad 309$

2.3. Combining conjunction reduction and gapping 310

$\begin{array}{lll}\text { 2.4. Conclusion } & 314\end{array}$ 


\section{Introduction}

This chapter discusses the two main types of (presumed) ellipsis that are prototypically found in coordinate structures: conjunction reduction and gapping. CONJUNCTION REDUCTION involves elision of material in one coordinand (the target coordinand) on the basis of phonetically identical material in another coordinand (the antecedent coordinand). The tradition following Ross (1967) distinguishes two different forms: forward conjunction reduction (FCR) refers to cases where the antecedent precedes the target, as in (1a), and backward conjunction reduction (BCR) refers to cases where the antecedent follows the target, as in (1b).

(1) a. [[Jan heeft Els bezocht] en [ haar het nieuws verteld]]. [FCR] Jan has Els visited and Jan has her the news told

'Jan has visited Els and told her the news.'

b. [[Jan heeft Els $]$ en [Marie heeft Peter bezocht]].

[BCR] Jan has Els visited and Marie has Peter visited

'Jan has visited Els and Marie has visited Peter.'

Neijt (1979) has argued, though, that backward conjunction reduction is the only genuine form of conjunction reduction; supposed cases of forward conjunction reduction such as (1a) should be reanalyzed as cases involving coordination of phrases smaller than clauses, as in (2). Decisive reasons for adopting this alternative analysis will be given in Section 2.1, where the two forms of conjunction reduction are discussed in more detail. However, until then we will continue to represent forward conjunction reduction as in (1a) rather than as in (2).

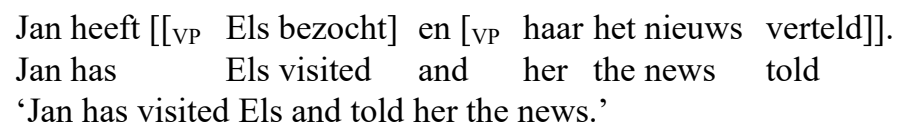

The two (presumed) types of conjunction reduction always involve elision of material in the periphery of the target coordinand; forward conjunction reduction elides material in the left periphery, while backward conjunction reduction elides material in the right periphery. This distinguishes conjunction reduction from GAPPING, which is illustrated in (3). The properties of this form of reduction, which minimally targets the finite verb and applies in a forward fashion only, will be discussed in Section 2.2.
a. [Jan bezoekt Els] en [Marie Peter]. Jan visits Els and Marie visits Peter 'Jan is visiting Els and Marie Peter.'
b. *[Jan ezokt Els] en [Marie bezoekt Peter]. Jan visits Els and Marie visits Peter

[gapping]

Although the examples in (4) show that conjunction reduction and gapping do not only occur in coordinate structures with conjunctive en 'and', but can also be used in coordinate structures with disjunctive of 'or' and adversative maar 'but', we will generally use the conjunction en in our examples. 
(4) a. [[Jan wil een boek lezen] of [Janil een film bekijken]].

[FCR]

Jan wants a book read or Jan wants a movie watch

'Jan wants to read a book or watch a movie.'

$\mathrm{a}^{\prime}$. [[Jan wil geen boek lezen] maar [Janil een film bekijken]].

Jan wants no book read but Jan wants a movie watch

'Jan doesn't want to read a book but to watch a movie.'

b. [[Jan heeft Els $]$ of [Marie heeft Peter bezocht]].

Jan has Els visited or Marie has Peter visited

$[\mathrm{BCR}]$

'Jan has visited Els or Marie has visited Peter.'

$\mathrm{b}^{\prime}$. [[Jan heeft Els

Jan has Els visited but Marie has nobody visited

'Jan has visited Els but Marie has visited nobody.'

c. [Jan bezoekt Els] of [Marie Peter].

Jan visits Els or Marie visits Peter

'Jan is visiting Els or Marie Peter.'

$\mathrm{c}^{\prime}$. [Jan bezoekt Els] maar [Marie niemand].

Jan visits Els but Marie visits nobody

'Jan is visiting Els but Marie nobody.'

Section 2.3 will show that backward conjunction reduction and gapping may cooccur in a single sentence; this is illustrated in (5), in which simple strikethrough is used for material elided by gapping and strikethrough in boldface for backward conjunction reduction.

[[Jan leest mijn ] en [Marie jouw boek]]. [BCR + gapping] Jan reads my book and Marie reads your book

'Jan is reading my and Marie your book.'

Many of the Dutch instances presented in Sections 2.1 to 2.3, as well as the conclusions drawn from them, are inspired by Neijt (1979), which we would like to acknowledge here in order to avoid continuous reference to the same source. For a discussion of ellipsis in contexts other than coordination, we refer the reader to V5.1.5 and A5.4.

\subsection{Conjunction Reduction}

Conjunction reduction involves reduction of a target coordinand by omission of material identical to material found in an antecedent coordinand. Ross (1967:ch.6) has claimed that conjunction reduction may proceed in a forward and in a backward fashion. When the target follows its antecedent, as in (6a), the elided material is located in the left periphery of the coordinand while the elided material is in its right periphery when the target precedes its antecedent, as illustrated in (6b); see also Kerstens (1980). Example (6c) shows that forward and backward conjunction reduction can apply simultaneously. 
(6) a. [[Jan heeft Els bezocht] en [ Jan heeft haar het nieuws verteld]]. [FCR] Jan has Els visited and Jan has her the news told 'Jan has visited Els and told her the news.'

b. [[Jan heeft Els ezent] en [Marie heeft Peter bezocht]]. Jan has Els visited and Marie has Peter visited 'Jan has visited Els and Marie has visited Peter.'

c. [[Jan heeft Marie vorige week en Jan has Marie last week visited and [Els gisteren bezocht]]. Jan has Els yesterday visited 'Jan visited Marie last week and he visited Els yesterday.'

Ross' proposal amounts to saying that forward and backward conjunction reduction are mirror images of one and the same reduction process, which predicts that they exhibit similar behavior. This receives support from the fact that they both apply optionally: not applying conjunction reduction in the examples in (6) gives rise to somewhat clumsy but fully acceptable results. Subsection I will show, however, that the two constructions also differ in various respects, which suggests that they can hardly be considered instantiations of the same reduction rule after all. Subsection II continues by showing that there are various reasons for reanalyzing forward conjunction reduction as coordination of non-clausal coordinands, that is, as coordination without any form of deletion. Subsection III continues with a more detailed discussion of backward conjunction reduction and Subsection IV argues on the basis of its properties that it is unlikely that backward conjunction reduction is a syntactic rule. Subsection V shows that backward conjunction reduction does not only apply in clausal but also in non-clausal coordinate structures; this accounts for the fact that backward and (supposed) forward conjunction reduction can occur simultaneously, even when we abolish the forward conjunction reduction rule. Subsection VI concludes by showing that rejecting the forward conjunction reduction rule still leaves residual problems. Before we begin the discussion, it should be noted that although the examples in this section will normally consist of no more than two coordinands for practical reasons, the "reduction" phenomena also occur in larger coordinate structures. If backward conjunction reduction simply involves coordination of non-clausal coordinands this is of course expected: cf. Jan heeft [[Els bezocht], [haar het nieuws verteld] en [haar geholpen het probleem op te lossen]] 'Jan has visited Els, told her the news and helped her solve the problem.' The examples in (7) show that backward conjunction reduction in larger coordinate structures is also possible provided that it applies to all coordinands.

(7) a. [[J. heeft E. [M. heeft P. Jan has Els visited Marie has Peter visited and Ans has Gerrit visited 'Jan has visited Els and Marie has visited Peter, and Ans has visited Gerrit.'

b. *[[J. heeft E. he [M. bleef thuis] en [A. heeft G. bezocht]]. Jan has Els visited Marie stayed home and Ans has Gerrit visited

c. ??[J. heeft E. Jan has Els visited Marie has Peter visited and Ans stayed at home 


\section{Differences between backward and forward conjunction reduction}

Intonation constitutes a first difference between backward and forward conjunction reduction. Backward conjunction reduction triggers a marked intonation pattern: (8b) shows that the direct object Els/haar preceding the elided material in (6b) above as well as its correlate in the antecedent clause must be contrastively stressed, and therefore cannot be replaced by a reduced pronoun. Example (8a), however, shows that such a marked intonation pattern is not needed in the case of forward conjunction reduction, as is clear from the fact that the indirect object in (6a) above can easily be replaced by a reduced pronoun. Backward, but not forward, conjunction reduction also requires a distinct intonation break preceding the coordinator en 'and', which is indicated by a comma in (8b); in later examples we will normally not indicate this break, for ease of representation.
a. Jan heeft Els/haar/'r bezocht en haar/'r het nieuws verteld. Jan has Els/her/her visited and her/her the news told 'Jan has visited Els/her and told her the news.'
b. Jan heeft ELS/HAAR/*'r, en Marie heeft PETER/HEM/*'m bezocht. [BCR] Jan has Els/her/her and Marie has Peter/him/him visited 'Jan has visited Els/her and Marie has visited Peter/him.'

A second difference is that (presumed) forward conjunction reduction generally involves full ${ }^{\circ}$ clausal constituents (arguments, adverbials and complementives) while backward conjunction reduction may also affect parts of clausal constituents. In the two (a)-examples in (9), for instance, the subject of the second coordinand can be affected as a whole, but it is impossible to omit just a part of it: the surface string Oude mannen zijn dom en vrouwen hebben geen gevoel voor humor can only be used to express that women in general have no sense of humor. Example (9b), on the other hand, shows that backward conjunction reduction is able to omit a part of a clausal constituent (here: the nominal ${ }^{\circ}$ head of the direct object oude mannen).

(9) a. [[Oude mannen zijn dom] en [ hebben geen humor]]. [FCR] old men are stupid and old men have no humor

'Old men are stupid and have no sense of humor.'

$\mathrm{a}^{\prime}$. *[[Oude mannen zijn dom] en [ vrouwen hebben geen humor]]. old men are stupid and old women have no humor

Intended reading: 'Old men are stupid and old women have no sense of humor.'

b. [[Jan helpt oude en [Marie helpt jonge mannen]]. [BCR] Jan helps old men and Marie helps young men

'Jan helps old men and Marie helps young men.'

Backward conjunction reduction is not only able to omit parts of phrases but even parts of words; the only conditions for allowing this are (i) that the omitted part has the same phonetic form as its antecedent and (ii) that the remnant can be used contrastively. The examples in (10) illustrating this are taken from Royen (1941). Although Royen objects to this kind of reduction for aesthetic reasons and considers it a Germanism, it is frequently used. We take the construction to be part of ${ }^{\circ}$ core syntax because we do not see any compelling reason for assuming that it should be 
considered part of the formal register. Note in passing that in writing the omitted part is normally represented by a hyphen, e.g., schrijf-en spreektaal.
a. schrijfal en spreektaal
write-language and speak-language
'writing and speech'
b. be en verwerken adapt and process
$\mathrm{b}^{\prime}$. zicht en tastbaar visible and tangible
c. impressionisme en expressionisme impressionism and expressionism

[compound]

[prefixed form]

[suffixed form]

[(synchronically) simplex form]

Similar forward conjunction reduction targeting parts of words is hard to find and constructed examples like those in (11) are unacceptable (under the intended reading).
(11) a. *huisdeur en huisbel house-door and house-bell Intended reading: 'front door and doorbell'
b. *bebouwen en bebossen build.on and afforest
$\mathrm{b}^{\prime}$. *kinderlijk en kinderachtig childlike and childish
c. *automaat en mobiel machine and automobile

[compound]

[prefixed form]

[suffixed form]

[(synchronically) simplex form]

A third difference is that while the target and its antecedent must have the same reference in the case of forward conjunction reduction of nominal arguments, this does not hold in the case of backward conjunction reduction; cf. Dik (1968:81ff.) and Van Oirsouw (1987:30ff.). The case of forward conjunction reduction in (12a') differs from its non-reduced counterpart in (12a) in that the existential quantifier iemand 'someone' must refer to the one and the same person: that is, the nonreduced form is generally interpreted such that there are two persons, one buying a box of cigars and one buying a bottle of gin, while the reduced form refers to a single person buying both a box of cigars and a bottle of gin. The case of backward conjunction reduction in (12b), on the other hand, does not differ from its nonreduced counterpart (not given here) in this way: both forms are preferably interpreted such that the book bought and the book sold refer to different entities.

(12) a. [Iemand kocht een doos sigaren] en [iemand kocht een fles gin]. someone bought a box [of] cigars and someone bought a bottle [of] gin 'Someone bought a box of cigars and someone bought a bottle of gin.'

$\mathrm{a}^{\prime}$. [Iemand kocht een doos sigaren] en [ een fles gin]. someone bought a box [of] cigars and someone bought a bottle [of] gin 'Someone bought a box of cigars and a bottle of gin.'

b. [Jan kocht en [Marie verkocht een boek]. Jan bought a book and Marie sold a book 'Jan bought and Marie sold a book.' 
Subsection II will show that the syntactic/morphological and semantic differences between forward and backward conjunction reduction follow naturally when we assume that the former differs from the latter in that it does not result from deletion but instead involves the coordination of phrases smaller than clauses.

\section{Arguments against forward conjunction reduction}

The differences between backward and forward conjunction reduction discussed in Subsection I suggest that the two phenomena cannot be considered as instantiations of a single reduction process. Neijt (1979:50ff.) claims that all acceptable structures supposedly derived by forward conjunction reduction can also be derived without reduction if we allow coordination of smaller, non-clausal phrases. An example such as Mannen zijn dom en gewelddadig, for instance, does not require forward conjunction reduction, as in (13a), but can also be derived without elision by coordinating the two APs, as in (13b). Neijt in fact claims that the representation in (13a) is ungrammatical, which we have indicated here by an asterisk. The remainder of this subsection will show that this enables us to derive the differences between forward and backward conjunction reduction discussed in Subsection I.
a. *[[Mannen zijn dom] en [menelddadig]]. men are stupid and men are violent
b. Mannen zijn [[AP dom] en [AP gewelddadig]]. men are stupid and violent
'Men are stupid and violent.'

Neijt (1979:53) supports her claim that forward conjunction reduction does not exist by pointing out that it also accounts for the fact that correlative coordinators cannot be used to coordinate the supposed reduced clause with its full antecedent clause in the case of forward conjunction reduction: example (14a) does not give rise to an acceptable surface form, while the surface form associated with (14b) is impeccable. For completeness sake, note that correlative coordinators can be used to coordinate the reduced clause with its full antecedent clause in the case of backward conjunction reduction: cf. Of Jan heeft Els of Els heeft Jan bezocht 'Either Jan has visited Els or Els has visited Jan'.

a. *[Of Jan heeft Els bezocht of han opgebeld]. or Jan has Els visited or Jan has her prt.-phoned

b. Jan heeft [of Els bezocht of haar opgebeld]. Jan has or Els visited or her prt.-phoned 'Jan has either visited Els or phoned her.'

If forward conjunction reduction is impossible, the contrast between the two (a)examples in (9) under the intended readings follows from the fact that they must be assigned the structures in (15). The attributive adjective oude 'old' must be joined with the head noun of the subject before the latter can be joined with the verbal predicate. The intended interpretation of the second clausal coordinand in (15b) "old women have no sense of humor" can thus only arise if the attributive modifier is overtly present: the number sign indicates that without it, the second clausal coordinand can only be interpreted generically as "women have no sense of humor". 
(15) a. [Clause [NP Oude mannen] [[vp zijn dom] en [vp hebben geen humor]]]. old men are stupid and have no humor

'Old men are stupid and have no sense of humor.'

b. [[Clause [NP Oude mannen] [vp zijn dom] en old men are stupid and

[Clause [NP ${ }^{\#}$ (oude) vrouwen] [vp hebben geen humor]]]. old women have no humor

Intended: 'Old men are stupid and old women have no sense of humor.'

Neijt's claim can also be used to account for the unacceptability of the examples in (11): if forward conjunction reduction is truly impossible, these forms should be derived directly in morphology. However, on the assumption that the embedded structures in (16) cannot be formed by morphology, they cannot function as input of the morphological rule deriving the surface form either. The asterisks again indicate that we are dealing with ungrammatical morphological structures.
a. *[huis-[deur-en-bel]] house-door-and-bell
b. *[be-[bouwen-en-bossen]] BE-build-and-forest
$\mathrm{b}^{\prime} . *[$ kinder-[lijk-en-achtig]] child-like-and-ish
c. *[auto-[maat-en-mobiel]] auto-MAAT-and-mobile

[compound based on *deur-en-bel]

[prefixed form]

[suffixed form]

[(synchronically) simplex form]

This account of the unacceptability of these forms seems perfectly sound for the two (b)-examples given the standard assumption that affixes must be linked to free morphemes. It is also plausible for (16c), given that, at least synchronically, the embedded structure consists of word parts that do not function as morphemes. However, it may require some more justification for the compound in (16a) in view of the acceptability of the frequently used compound zonsopgang-en-ondergang to which we will turn now. Example (17a) can be straightforwardly derived by backward conjunction reduction, as expected, but if forward conjunction reduction in (17b) is excluded, we must conclude that at least some coordinate structures with free morphemes can be the input for compounding, as in $\left(17 b^{\prime}\right)$. That this is indeed possible can be independently motivated because a morphological process is also needed for deriving diminutive and plural forms of compounds of the type kop-enschotel 'cup and saucer': [kop-en-schotel]-tje and [kop-en-schotel]-s.

(17) a. [zons[op]] en [zons[ondergang]]

sun-up.going and sun-down.going

'sunrise and sunset'

b. *[zons[opgang]] en [ondergang]]

sun-up.going and sun-down.going

'sunrise and sunset'

$\mathrm{b}^{\prime}$. [zons-[opgang en ondergang]]

sun up.going and down.going 
In order to account for the acceptability contrast between huisdeur-en-bel in (16) and zonsopgang-en-ondergang in (17), we also need to assume that the coordinate structures deur en bel and opgang en ondergang differ in that the latter but not the former can be analyzed as a morphologically complex form that can be the input for further compounding. That opgang en ondergang and the backwardly reduced form op- en ondergang can indeed be analyzed as morphologically complex forms is clear from the fact (i) that they normally occur in the order given here and (ii) that they can easily be preceded by a single determiner. A Google search (8-12-1017) on the two strings [de opgang en ondergang van] and [de op-en ondergang van] resulted in 51 and 149 hits, respectively. That deur en bel cannot be analyzed in this way is clear from the fact that our search on the string [de deur en bel] resulted in one relevant hit only.

Since forward conjunction reduction is not needed for providing a descriptively adequate description of the core data that have been put forward in favor of this rule, we may as well dispense with it in favor of the independently needed assumption that coordination of smaller phrases is possible. This assumption has been extensively motivated in Section 1.1, sub IV, on semantic grounds. Here we repeat just two simple cases: if the primed examples in (18) were derived from the primeless ones by forward conjunction reduction, we would wrongly expect these examples to be synonymous, but this is not the case.

(18) a. Sommige jongens hebben gezongen en sommige jongens hebben gedanst. some boys have sung and some boys have danced

$a^{\prime}$. Sommige jongens hebben gezongen en gedanst. some boys have sung and danced

b. Alle mannen zijn dom of alle mannen zijn gewelddadig. all men are stupid or all men are violent

$\mathrm{b}^{\prime}$. Alle mannen zijn dom of gewelddadig. all men are stupid or violent

The two (a)-examples differ in that $\left(18 \mathrm{a}^{\prime}\right)$ is true only if at least some boys were engaged both in the singing and the dancing, while this is not needed for (18a) to be true, as the weaker condition suffices that both activities were performed by at least some boys. If $\left(18 \mathrm{a}^{\prime}\right)$ is derived by means of coordination of two verbal projections, sommige jongens hebben [gezongen en gedanst], this interpretative contrast follows without further ado. The (b)-examples differ in that (18b) is true only if at least one of the propositions "all men are stupid" and "all men are violent' is true, while $\left(18 b^{\prime}\right)$ allows both propositions to be false as long as all men are included in the union of the two sets of entities denoted by dom 'stupid' and gewelddadig 'violent'. This interpretative contrast follows without further ado if $\left(18 b^{\prime}\right)$ is derived by means of coordination of two adjectival projections, alle mannen zijn [dom of gewelddadig].

The same line of reasoning also accounts for the contrast between the backward and (supposed) forward conjunction reduction examples in (12). If the "reduced" counterpart of (19a) is not derived by conjunction reduction but by coordination of two noun phrases, as in (19b), the fact that (19a) is interpreted as involving different persons while $\left(19 \mathrm{a}^{\prime}\right)$ is interpreted as involving a single person simply follows from 
the fact that the former structure involves two clauses, and hence two subjects, while in the latter structure there is only one clause, and hence only a single subject.

(19) a. [Iemand kocht een doos sigaren] en [iemand kocht een fles gin]. someone bought a box [of] cigars and someone bought a bottle [of] gin 'Someone bought a box of cigars and someone bought a bottle of gin.'

b. Iemand kocht [[NP een doos sigaren] en [NP een fles gin]]. someone bought a box [of] cigars and a bottle [of] gin

'Someone bought a box of cigars and a bottle of gin.'

The argument can be repeated for referential pronouns such as hij 'he' in (20); while (20a) would normally be interpreted as referring to two separate events involving different agents, (20) can only be interpreted as a single event involving a specific person buying both a box of cigars and a bottle of gin. This would again be unexpected if (20a) were a reduced version of (20b); we refer the reader to De Vries (1992:68ff.) for a more complex version of this argument based on the various uses of het 'it' (as ${ }^{\circ}$ argument, quasi-argument and ${ }^{\circ}$ anticipatory pronoun).

(20) a. [Hij kocht een doos sigaren] en [hij kocht een fles gin].

he bought a box [of] cigars and he bought a bottle [of] gin

'He bought a box of cigars and he bought a bottle of gin.'

b. Hij kocht [[NP een doos sigaren] en [NP een fles gin]].

he bought a box [of] cigars and a bottle [of] gin

'He bought a box of cigars and a bottle of gin.'

More arguments in favor of the assumption that coordination of smaller phrases is possible were given in Section 1.4.2 on correlative coordinators. We will only repeat one simple case. Since example (21a) illustrates that the correlative zowel ... als ... 'both ... and ...' cannot be used to coordinate main clauses, this a priori dooms to futility any attempt of deriving the (b)-examples by means of conjunction reduction; the acceptability of these examples follows immediately, however, if we assume that we are dealing with coordinated noun phrases and APs.
a. *Zowel Jan is ziek als Marie is op vakantie.
b. [Zowel Jan als Marie] is ziek. both Jan and Marie is ill
$\mathrm{b}^{\prime}$. Mannen zijn [zowel dom als gewelddadig]. men are both stupid and violent

Note that although this subsection has argued that the term forward conjunction reduction should be considered a misnomer, we will occasionally use this notion as a mere descriptive term in what follows.

\section{Properties of backward conjunction reduction}

This subsection discusses backward conjunction reduction in more detail and will argue that this form of reduction cannot be given a syntactic account. We have already seen that backward conjunction reduction affects the right periphery of the target coordinand. That omission of material located elsewhere is not allowed is 
illustrated by means of the acceptability contrast between the simple past tense examples in $(22 b \& c)$ and their perfect tense counterparts in the corresponding primed examples: $\left(22 b^{\prime}\right)$ is unacceptable and $\left(22 c^{\prime}\right)$ cannot be interpreted in the intended way (as indicated by the number sign) because backward conjunction reduction is blocked by the clause-final past participle in the first coordinand.

- BCR targets the right periphery of the target coordinand

a. [[Jan heeft Els ] en [Marie heeft Peter bezocht]]. Jan has Els visited and Marie has Peter visited 'Jan has visited Els and Marie has visited Peter.'

b. [[Jan kocht en [Marie leende het boek]]. Jan bought the book and Marie borrowed the book 'Jan bought and Marie borrowed the book.'

$\mathrm{b}^{\prime}$. *[J]an heeft gekocht] en [Marie heeft het boek geleend]]. Jan has the book bought and Marie has the book borrowed

c. [[Marie werkte Utrecht] en [Jan studeerde in Utrecht]]. Marie worked in Utrecht and Jan studied in Utrecht 'Marie worked and Jan studied in Utrecht.'

$c^{\prime}$. \#[[Marie heeft Utrecht gewerkt] en [Jan heeft in Utrecht gestudeerd]]. Marie has in Utrecht worked and Jan has in Utrecht studied

The primeless examples in (22) involve omission of a single main verb or a single clausal constituent but the elided sequence may also be larger. The examples in (23), for instance, show that it is also possible to elide more than one clausal constituent: (23a) shows this for two arguments, (23b) for two adverbial phrases, and $(23 \mathrm{c})$ for an argument and an adverbial phrase.
- BCR may target more than one clausal constituent
a. [[Els gaf en [Peter leende Marie een boek]]. Els gave Marie a book and Peter lent Marie a book 'Els gave and Peter lent Marie a book.'
b. [[Marie werkt ] en [Jan studeert al jaren in Utrecht]]. Marie works for years in Utrecht and Jan studies for years in Utrecht 'Marie has been working and Jan has been studying in Utrecht for years.'
c. [[Jan bezocht en [Els belde Marie gisteren]]. Jan visited Marie yesterday and Els phoned Marie yesterday 'Jan visited and Els phoned Marie yesterday.'

The embedded counterpart of (22a) in (24a) further shows that backward conjunction reduction may also affect $\mathrm{a}^{\circ}$ verb cluster, and the instances in (24b\&c) show that it is also possible to elide the clause-final verb (cluster) together with a clausal constituent, a direct object in (24b) and a temporal adverbial in (24c). Note in passing that the complementizer dat 'that' in the second coordinand of (24a) can also be omitted, in which case we may be dealing with coordination of smaller (non-clausal) verbal projections. 
(24) a. Ik denk [[dat Jan Els heeft en [dat Marie Peter bezocht heeft]]. I think that Jan Els visited has and that Marie Peter visited has 'I think that Jan has visited Els and that Marie has visited Peter.'

b. [[Els heeft Marie en [Peter heeft Jan een boek gegeven]]. Els has Marie a book given and Peter has Jan a book given 'Els has given a book to Marie and Peter has given a book to Jan.'

c. [[Jan zal Marie en [Els zal Peter vandaag bezoeken]]. Jan will Marie today visit and Els will Peter today visit 'Jan will visit Marie, and Els will visit Peter today.'

The facts in (23) and (24) are potentially problematic for providing a syntactic account of backward conjunction, as syntactic operations normally target single clausal constituents only. One might want to defend a syntactic approach by claiming that the omitted constituents in (23) and (24) form a constituent of some higher order, for instance, a verbal projection with the main verb extracted from it by verb-second in (23) or a verbal projection with one or more objects extracted from it by ${ }^{\circ} \mathrm{A}$-scrambling in (24). Such a proposal would run afoul, however, of examples like those in (25). The primeless examples first show that backward conjunction reduction may also target parts of clausal constituents: the elided part is the nominal part of a PP-complement of the verb in (25a) and the nominal part of a postnominal PP-modifier of the object in (25b). The embedded counterparts of these sentences in the primed examples further show that conjunction reduction may also affect the clause-final verb (cluster) plus a phrase embedded in a clausal constituent.

- BCR may target elements embedded in clausal constituents

a. [[Jan stemt [voor en [Els stemt [tegen de motie]]]. Jan votes for the motion and Els votes against the motion 'Jan will vote for and Els will vote against the motion.'

$\mathrm{a}^{\prime}$. [[dat Jan [voor en [dat Els [tegen de motie] stemt]]. that Jan for the motion votes and that Els against the motion votes 'that Jan will vote for and Els will vote against the motion.'

b. [[Els las [het boek [van Chemsky]]] en [Jan las [het boek [over Chomsky]]]]. Els read the book by Chomksy and Jan read the book about Chomsky 'Els read the book by Chomsky and Jan read the book about Chomsky.'

b'. [[dat Els [het boek [van ] ] en [dat Jan [het boek [over Ch.]] las]]. that Els the book by Ch. read and that Jan the book about Ch. read 'that Els read the book by Chomsky and Jan read the book about Chomsky.'

Since the omitted strings in the primed examples of (25) do not count as a constituent in any current theory, we cannot adopt the account suggested for (23) and (24) that we are dealing with deletion of some higher order verbal constituent. This argument against a syntactic account of backward conjunction reduction gains even greater strength from the fact that the elided string may be even more deeply embedded. Besides (25a), in which the elided string is the nominal complement of the preposition, we also have (26a), in which the elided string is the ${ }^{\circ}$ head of this nominal complement. And besides (25b), in which the elided string is the nominal complement of a postnominal modifier of the direct object, we have (26b), in which the elided string is a postnominal modifier of the nominal complement of a 
postnominal modifier. In short, it seems as if the depth of embedding of the elided element knows no principled bounds.

(26) a. [[Jan stemt [voor de eerste en [Els stemt [voor de tweede motie]]]. Jan votes for the first motion and Els votes against the second motion 'Jan will vote for the first and Els will vote for the second motion.'

b. [[Els las [een boek [van [een bewonderaar [ en Els read a book of an admirer of Chomsky

[Jan las [een boek [van [een tegenstander [van Chomsky]]]]]]. Jan read a book of an opponent of Chomsky

'Els read a book by an admirer and Jan read a book by an opponent of Chomsky.'

For completeness' sake, the examples in (27) show that the elided part can be preceded by various types of elements; it can be the finite verb, or (a subpart of) an argument, a complementive, or an adverbial phrase; there do not seem to be any independently motivated syntactic operations that could affect the strings preceding the elision site either.

(27) a. [Jan kookt deardappels] en [Marie bakt de aardappels].

[finite verb] Jan cooks the potatoes and Marie bakes the potatoes

'Jan is cooking and Marie is frying the potatoes.'

b. [Jan heeft een BOEK en [Els heeft een CD gekocht]. [argument] Jan has a book bought and Els has a CD bought

'Jan has bought a book and Els has bought a CD.'

$\mathrm{b}^{\prime}$. [Jan leest MIJN en [Els leest JOUW boek]. [part of argument] Jan reads my book and Els reads your book

'Jan is reading my book and Els is reading your book.'

c. [Jan is naar GOES en [Els is naar Oss gegaan]. [complementive] Jan is to Goes gone and Els is to Oss gone

'Jan has gone to Goes and Els has gone to Oss.'

$\mathrm{c}^{\prime}$. [Jan zit IN en [Els zit OP de auto]. [part of complementive] Jan sits in the car and Els sits on the car

'Jan sits inside and Els sits on top of the car.'

d. [Jan heeft GISTEREN en enst] en [ELS heeft VANDAAG gedanst]. [adverbial] Jan has yesterday danced and Els has today danced

'Jan danced yesterday and Els danced today.'

$\mathrm{d}^{\prime}$. [Jan vertrok VOOR lezing] en [Els vertrok NA de lezing]. [part of adverbial] Jan left before the talk and Els left after the talk

'Jan left before and Marie left after the talk.'

\section{$I V$. Backward conjunction reduction is not a syntactic rule}

The facts discussed in the previous subsection suggest that backward conjunction reduction is not a syntactic rule; cf. Neijt (1979: section 2.2) and Zwarts (1986:16). Since syntactic rules normally affect a single clausal constituent only, the fact illustrated in (23) that conjunction reduction may affect more than one clausal constituent raises a warning flag. The fact illustrated in (25) that conjunction reduction can affect parts of clausal constituents is also telling, as such parts normally cannot be affected by syntactic rules applying at the clausal level. The 
same is shown by the examples in (28) in which the elided strings are located within syntactic ${ }^{\circ}$ islands: an embedded $w h$-question in (28a), a relative clause in (28b), and a coordinate structure in (28c), although it should be noted some speakers object to the last case.

(28) a. [[Jan weet [waarom MARIE en

Jan knows why Marie the book read has and

[Peter weet [waarom ELs het boek gelezen heeft]]].

Peter knows why Els the book read has

'Jan knows why Marie has read the book and Peter know why Els has read it.'

b. [[Jan interviewde [de man [die CHOMSKY ] en

Jan interviewed the man who Chomsky admired and

[Els interviewde [de vrouw [die HAwKINS bewonderde]]]].

Els interviewed the woman who Hawkins admired

'Jan interviewed the man who admired Chomsky and Els interviewed the woman who admired Hawkins.'

c. $\%[$ Jan traint ['s morgens EN maar

Jan exercises in.the.morning and in.the.afternoon but

[Marie traint alleen ['s morgens OF 's middags]]].

Marie exercises only in.the.morning or in.the.afternoon

'Jan exercises in the morning and the afternoon and/but Marie exercises in the morning or the afternoon only.'

The claim that backward conjunction reduction is not a syntactic rule is in agreement with the fact that there can be no established syntactic relations between elements within a coordinate structure when they are located in different coordinands. We are therefore led to conclude that we are dealing with a postsyntactic phonological rule that deletes a right-peripheral string in the target coordinand under identity with a phonetically identical string in the antecedent clause. Note in passing that the conclusion that backward conjunction reduction is a post-syntactic rule is inevitable in theories that follow Kayne (1994) and, especially, Chomsky (1995: section 4.8) in assuming that information about linear order is not available in syntax, as this makes it impossible to formulate the condition that the elided string is right-peripheral in its clause in syntactic terms.

The conclusion that backward conjunction reduction is a phonological rule deleting a right-peripheral string in the target coordinand under identity with a phonetically identical string in the antecedent clause is still not fully descriptively adequate. Recall from Subsection I that the element preceding the elided material, as well as its correlate in the antecedent coordinand, must be contrastively stressed. This means that elements that cannot be stressed may not precede the gap. This is illustrated for reduced pronouns in (29a), for ${ }^{\circ} \mathrm{R}$-pronouns in (29b), and the indefinite article een ' $a$ ' in (29c). Contrastive accent is indicated by small caps. This shows that backward conjunction reduction should also be made sensitive to the prosodic properties of the element preceding the elided string.

(29) a. [JAN zal MARIE/HAAR/*'r helpen] en [ELS zal PETER/HEM helpen]. Jan will Marie/her/her help and Els will Peter/him help 'Jan will help Marie/her and Els will help Peter/him.' 
b. [JAN sprak HIER/*er en [ELS sprak DAAR over]. Jan spoke here/there about and Els spoke there about 'Jan spoke about this and Els spoke about that.'

c. [JAN las DIT/*een en [ELS las een ANDER boek]. Jan read this/a book and Els read another book

'Jan read this book and Els read a different book.'

Another complication is that the marked intonation pattern of backward conjunction reduction is mirrored by the fact that it always implies some semantic contrast: in (29a) for instance, two (ordered) pairs $<$ Jan, Marie $>$ and $<$ Els, Peter $>$ are contrasted. Note that the fact that the contrast in this example involves ordered pairs is accidental: in contexts such as (30) it may also involve singletons.

$$
\begin{aligned}
& \text { [Jan zal niet alleen MARIE helpen maar [hij zal ook PETER helpen]. } \\
& \text { Jan will not only Marie help but he will also Peter help } \\
& \text { 'Jan will not only help Marie but he will also help Peter.' }
\end{aligned}
$$

The main conclusion therefore seems to be that backward conjunction reduction does not only require that the elided string is recoverable from the antecedent coordinand but also that the rightmost part of the remnant and its correlate in the antecedent coordinand can be contrasted both phonetically and semantically. This suggests that backward conjunction reduction cannot be described in purely phonological terms.

\section{$V$. Combinations of forward and backward conjunction reduction}

The previous subsections mainly discussed coordinate structures with clausal coordinands. The cases in (31) show, however, that backward conjunction reduction may also apply to coordinands of other categorial types: we have instances of conjunction reduction within nominal, adjectival and adpositional coordinate structures. We refer the reader to the examples in (10) in Subsection I for examples showing that backward conjunction reduction not only applies within phrases but even within words.

$$
\text { - BCR may apply in coordinate structures of all categorial types }
$$

a. [[De brug OVER rivier] en [de tunnel ONDER de rivier]] zijn beide klaar. the bridge across the river and the tunnel under the river are both finished 'The bridge across and the tunnel underneath the river are both finished.'

b. Jan is [[moe VAN en [boos OVER Peters gezeur]] geworden. Jan is tired of Peter's nagging and angry about Peter's nagging become 'Jan has become tired of and angry at Peter's nagging.'

c. Jans kat wil altijd [[op ZIJN Jan's cat wants always on his lap or on Marie's lap sit 'Jan's cat always wants to sit on his or on Marie's lap.'

The fact that backward conjunction reduction is possible in non-clausal coordinands is important in the light of our earlier conclusion that forward conjunction reduction should be reanalyzed in terms of coordination of phrases smaller than clauses: it makes it possible to account for the fact that backward and forward conjunction reduction can co-occur by assuming that backward conjunction reduction can apply 
in smaller (non-clausal) verbal projections. We illustrate this here for example (6c) from the introduction: the original analysis of this example, repeated as (32a), can now be replaced by the analysis in (32b) with backward conjunction reduction in a coordinated structure with two smaller, non-clausal verbal projections (which we labeled as VP, for convenience).
a. [[Clause Jan heeft Marie vorige week en Jan has Marie last week visited and [CLAUSE Els gisteren bezocht]]. Jan has Els yesterday visited
b. Jan heeft [[vp Marie vorige week en [vp Els gisteren bezocht]]. Jan has Marie last week visited and Els yesterday visited 'Jan visited Marie last week and Els yesterday.'

Combinations of forward and backward conjunction reduction can also be found in nominal coordinate structures, as is illustrated in (33a). Note that the string oude mannen en vrouwen uit Duitsland is ambiguous in various ways and can also be analyzed as in, e.g., (33b). The intonation patterns associated with the two cases seem to differ: as always, backward conjunction reduction requires the element preceding the elided string in the target coordinand as well as its correlate in the antecedent coordinand to be contrastively accented, while examples such as (33b) allow a more neutral intonation pattern. Since we are not aware of any systematic investigation of this issue, we will leave this to future research.
(33) a. [oude [[MANNEN Duitsland] en [VROUWEN uit Duitsland]]] old men from Germany and women from Germany
b. [[oude mannen] en [vrouwen uit Duitsland]] old men and women from Germany

Similar ambiguities can be found in coordinated APs, as shown in (34). Again, the two cases given have different intonation patterns: the backward conjunction reduction case in (34a) has the by now familiar contrastive intonation pattern, while (34b) can easily be pronounced in a more neutral way.

(34) a. [Erg [[TELEURGESTELD en [BOOS over de weigering]]] very disappointed about the refusal and angry about the refusal ging Jan naar huis.

went Jan to home

b. [[Erg teleurgesteld] en [boos over de weigering $]$ ging Jan naar huis. very disappointed and angry about the refusal went Jan to home 'Jan went home very disappointed and angry at the refusal.'

Similar cases as in (32) to (34) are more difficult to construct for PPs but it seems that the interpretation of the two sentences in (35) is what we would expect: the contrastive intonation pattern in (35a) triggers a reading according to which each exercise is preceded and followed by the ringing of a bell; under a more neutral intonation pattern, (35b) seems compatible with a reading according to which the bell rings at the beginning of some contextually determined event (e.g., a training session) as well as after each exercise. 
(35) a. [Vlak [[voor het BEGIN ellening] en [na het EINDE

just before the start of each exercise and after the end van elke oefening]] gaat een bel. of each exercise goes a bell

'A bell sounds just before the beginning and after the end of each exercise.'

b. [[Vlak voor het begin] en [na het einde van elke oefening]] gaat een bel. just before the start and after the end of each exercise goes a bell

'A bell sounds just before the beginning, and after the end of each exercise.'

We conclude with a discussion of the more special case involving ${ }^{\circ} \mathrm{R}$-extraction in (36a). The most likely interpretation of this examples is that the degree modifier erg 'very' has both adjectives in its scope, which suggests the structure given in (36b). If this structure is correct, we must conclude that backward conjunction reduction applies after R-extraction since only then will the elided preposition be in the right periphery of the first coordinand. This finding is especially interesting for theoretical reasons because, under the standard assumption that syntactic rules apply cyclically, it supports our earlier conclusion that backward conjunction reduction is a phonological rule applying after the syntactic derivation has been completed. For completeness' sake, note that the alternative structure in $\left(36 b^{\prime}\right)$ is probably ungrammatical (which is indicated by an asterisk) given that R-extraction would then violate the coordinate structure constraint in Section 1.3, sub II.

(36) a. We zijn hier erg teleurgesteld en boos over.

we are here very disappointed and angry about

'We are very disappointed and angry about this.'

b. We zijn hier $r_{\mathrm{i}}$ [erg [[teleurgesteld $\left.t_{\mathrm{i}}\right]$ and [boos over $\left.\left.\left.t_{\mathrm{i}}\right]\right]\right]$.

$\mathrm{b}^{\prime}$. *We zijn hier [erg [[teleurgesteld] en [boos over $\left.\left.\left.t_{\mathrm{i}}\right]\right]\right]$.

\section{A residual problem: "shared" main-clause initial constituents}

The conclusion from Subsection II that forward conjunction reduction does not exist and should now be reanalyzed in terms of coordination of non-clausal phrases gives rise to several empirical (as well as theory-internal) problems that still need to be solved and in fact play an important role in Wilder's (1997) plea for the reintroduction of forward conjunction reduction. The most important empirical problem involves the status of the coordinands: is coordination restricted to maximal projections or is it also possible to coordinate (lexical) ${ }^{\circ}$ heads or intermediate projections?

\section{A. Can lexical heads be coordinated?}

That maximal projections can be coordinated has been amply illustrated in the preceding discussions. The examples in (37) show this once more for several of the maximal projections within the clause (that is, the extended projection of the verb): VP in (37a), TP in (37b) and CP in (37c). For examples showing that this also holds for the maximal projections within the extended projections of nouns, adjectives and adpositions, we refer the reader to Section 1.4.1, sub IA and IIA. 
(37) a. Ik denk [CP dat [TP Jan [[vp zijn werk afmaakt] en [vp naar huis gaat]]]]. I think that Jan his work finishes and to home goes 'I think that Jan will finish his work and go home.'

b. Ik denk [ср dat [[тр Jan zijn werk afmaakt] en [тр Els naar huis gaat]]]. I think that Jan his work finishes and Els to home goes 'I think that Jan will finish his work and that Els will go home.'

c. Ik vraag me af [[cP wie het werk afmaakt] en [CP wie naar huis gaat]]. I wonder REFL prt. who the work finishes and who to home goes 'I wonder who will finish the work and who will go home.'

It is less clear whether lexical ${ }^{\circ}$ heads can be coordinated. This option has been denied by Kayne (1994) by pointing out that weak (phonetically reduced, clitic-like) pronouns cannot be coordinated: he claims that strong pronouns such as those in the primeless examples are full noun phrases while weak pronouns are simply nominal heads; see also Chomsky (1995) and Cardinaletti \& Starke (1999) for relevant discussion. This is illustrated for Dutch by the examples in (38), in which the weak pronouns are italicized.

$$
\begin{aligned}
& \text { a. Ik heb [hem en haar] gezien. } \\
& \text { I have him and her seen } \\
& \text { 'I have seen him and her.' } \\
& \mathrm{a}^{\prime} . \text { *Ik heb [' } m \text { en haar] gezien. } \\
& \mathrm{a}^{\prime \prime} . \text { *Ik heb [hem en ' } r \text { ] gezien. } \\
& \mathrm{a}^{\prime \prime \prime} . \text { *Ik heb [' } m \text { en ' } r \text { ] gezien. }
\end{aligned}
$$

b. Hij heeft [jou en mij] geholpen. he has you and me helped 'He has helped you and me.' $\mathrm{b}^{\prime}$. *Hij heeft [je en mij] geholpen. $\mathrm{b}^{\prime \prime}$. *Hij heeft [jou en $m e$ ] geholpen. $\mathrm{b}^{\prime \prime \prime}$.*Hij heeft [je en $\left.m e\right]$ geholpen.

There are however, various constructions that seem to contradict the claim that coordination of lexical heads is excluded. Cases like (39a), for instance, suggest that coordination of prepositions is possible but such examples might just as well be analyzed as in (39b), that is, as coordination of PPs with backward conjunction reduction. The alternative analysis can be independently motivated by the fact that the simple coordinator en 'and' can be replaced by the correlative coordinator zowel ... als ... 'both ... and ...' because Section 1.4.2, sub II, has shown that correlatives can only link ${ }^{\circ}$ major phrases: cf. De katten slapen zowel op als onder het bed 'the cats sleep both on and under the bed'. This shows that there is no conclusive evidence for claiming that structure (39a) with coordinated prepositional heads is grammatical, for which reason we mark this structure with a number sign.
a. ${ }^{\#}$ De katten slapen [pp [[p op] en [p onder]] het bed]. the cats sleep on and under the bed 'The cats sleep (or: are sleeping) on and under the bed.'
b. De katten slapen [[pp op en [pp onder het bed]]. the cats sleep on the bed and under the bed

The same holds for the supposed cases of noun/adjective coordination in (40a\&b), since Subsection $\mathrm{V}$ has shown that these surface forms can also be derived by means of backward conjunction reduction, as illustrated again in the primed examples. The number signs again indicate that there is no conclusive evidence for claiming that the structures in the primeless examples are possible. 
(40) a. ${ }^{\#}\left[\right.$ oude $\left[{ }_{\mathrm{N}}\right.$ mannen $]$ en [N vrouwen $\left.]\right]$ uit Duitsland $]$

old men and women from Germany

$\mathrm{a}^{\prime}$. [oude [mannen Duitsland] en [vrouwen uit Duitsland]]

old men from Germany and women from Germany

b. ${ }^{\#}\left[\left[{ }_{A}\right.\right.$ teleurgesteld $]$ en [A boos $\left.]\right]$ over zijn weigering $]$ disappointed and angry at this refusal

$\mathrm{b}^{\prime}$. [[AP teleurgesteld en [AP boos over zijn weigering]] disappointed about this refusal and angry at this refusal

The supposed case of verb coordination in (41a) differs from the earlier examples in that it cannot be reanalyzed as VP coordination by appealing to backward conjunction reduction. Nevertheless, this example does not provide evidence in favor of head coordination either, because we can derive the surface form by object ${ }^{\circ}$ scrambling in an ${ }^{\circ}$ across-the-board fashion, as in (41b). Evidence favoring the VP coordination analysis is that the second coordinand can felicitously contain additional material, such as the adverbial onmiddellijk 'immediately' in the primed example. So, there is again no conclusive evidence for assuming that structure (41a) is grammatical, as indicated by the number sign.

(41) a. "Jan heeft het boek [[v gekocht] en [v gelezen]].

Jan has the book bought and read

'Jan has bought and read the book].'

b. Jan heeft het boek $\left[\left[\mathrm{vp} t_{\mathrm{i}}\right.\right.$ gekocht] en [vp $t_{\mathrm{i}}$ gelezen]].

Jan has the book bought and read

'Jan has bought and read the book.'

$\mathrm{b}^{\prime}$. Jan heeft het boek $\left[\left[\mathrm{vp} t_{\mathrm{i}}\right.\right.$ gekocht] en [vp $t_{\mathrm{i}}$ onmiddellijk gelezen]]. Jan has the book bought and immediately read 'Jan has bought the book and read it immediately.'

The embedded counterpart of the main clause discussed above is also acceptable: cf. dat Jan het boek heeft gekocht en gelezen. It is not clear whether this provides evidence for head conjunction, given that the analysis of verb-cluster formation is a topic of current debate. Linguists who adopt the traditional head movement analysis of verb clustering proposed by Evers (1975) will assign the embedded clause the structure in (42a) and conclude that verb clustering provides conclusive evidence in favor of head conjunction. Linguists who reject this claim, on the other hand, may assign the embedded clause the structure in $(42 \mathrm{~b})$ and conclude that verb clustering does not provide evidence in favor of head conjunction.

- Competing analyses for verb clustering

a. dat Jan het boek [v heeft [[v gekocht] en [v gelezen]]]. that Jan the book has bought and read

b. dat Jan het boek $k_{\mathrm{i}}$ heeft [[vp $t_{\mathrm{i}}$ gekocht] en [vp $t_{\mathrm{i}}$ gelezen]]. that Jan the book has bought and read 'Jan has bought and read the book.'

Instead of verb clusters being used for evaluating claims about head coordination, it seems that the conclusion as to whether head coordination is possible can be used for evaluating claims about verb clustering: if coordination of lexical heads turns 
out to be impossible, this would show that verb clusters cannot be analyzed as in (42a). We conclude that there is no clear evidence for assuming that clause-final verbs can be coordinated.

\section{B. Can intermediate projections be coordinated?}

The examples discussed in the previous subsection all involve cases of supposed head coordination which can easily be reanalyzed as non-head conjunction by appealing to backward conjunction reduction or across-the-board movement. There are, however, also cases that cannot be reanalyzed in this way and have been argued to involve coordination of verbal heads. These typically involve main clauses with finite main verbs, as in (43a\&b); see Neijt (1979), Klein (1986), Hendriks (2001b), Hendriks \& Zwart (2001), Corver (2005), among others. The structures in the primed examples purport to show that the primeless examples can easily be derived if we assumed forward conjunction reduction to be possible. We nevertheless marked these structures by a number sign to indicate that they may be ungrammatical for the reasons given earlier in Subsection II.

(43) a. Jan zong en danste.

Jan sang and danced

'Jan was singing and dancing.'

$\mathrm{a}^{\prime}$. "[[clause Jan zong] en [Clause danste]].

b. Jan danste en zong een liedje.

Jan danced and sang a song

'Jan was dancing and singing a song.'

$\mathrm{b}^{\prime}$. " [[Clause Jan danste] en [Clause zong een liedje]].

When we do away with forward conjunction reduction in favor of non-clausal coordination, it becomes more difficult to derive the primeless examples. We may of course assume that we are dealing with coordination with verbal heads, which would be fine in the case of (43a) but would run into the problem that the noun phrase een liedje in (43b) is not an object of the verb zong 'sang' but of the supposed coordinate structure danste en zong 'danced and sang'. A more likely analysis might therefore be VP coordination: however, we would then have to derive (43a\&b) as in (44) by moving the verbal heads of the first coordinands into the verb-second position while leaving the verb in the second coordinand in its VPinternal position. This derivation would violate at least two restrictions: (i) the coordinate structure constraint discussed in Section 1.3, sub II, and (ii) the requirement that finite verbs move into second position in main clauses; cf. Klein (1986).
a. *Jan zong [[vp $\left.t_{\text {zong }}\right]$ en [vp danste]].
b. *Jan danste [[vp $\left.t_{\text {danste }}\right]$ en [vp zong een liedje]].

It should further be noted that we cannot solve the problem for the coordinate structure constraint by saying that the finite verb of the second coordinand has also moved into second position and that (as a result of some rule yet to be formulated) a conjunction of verbal heads is formed in this position. This suggestion would wrongly predict that ( $45 \mathrm{a}$ ) is unacceptable as it can only be assighed the structure in (45b), and it would instead predict the linear order *Jan zong en danste een liedje, which is gibberish and certainly does not have the intended meaning. 
(45) a. Jan zong een liedje en danste.

Jan sang a song and danced

b. *Jan zong [[vp $t_{\text {zong }}$ een liedje] en [vp danste]].

If we want to maintain that forward conjunction reduction is excluded, there are at least four alternative ways in which we might try to account for the examples in (43a\&b) and (45a), but these are all problematic. The first option would be to adopt the plausible assumption that verb-second is not triggered by some requirement of the finite verb but by some requirement imposed by the verb-second position itself, so that moving exactly one finite verb into this position would be sufficient to satisfy the verb-second requirement. This does not really solve the problem, however, as it still results in a violation of the coordinate structure constraint; ; see the structures in (44) and (45b). A second option would be to assume that these examples involve coordination of an intermediate (non-maximal) projection of the projection containing the regular subject position (TP according to V9 and V11). This is illustrated in (46), where $\mathrm{T}^{\prime}$ stands for an intermediate projection between the head $\mathrm{T}$ and the maximal projection TP.

(46) a. [TP Jan $\left[\left[\mathrm{T}^{\prime}\right.\right.$ zong [vp $\left.\left.t_{\text {zong }}\right]\right]$ en [ $\mathrm{T}^{\prime}$ danste $\left.\left.\left.\left[\mathrm{vP} \mathrm{t}_{\text {danste }}\right]\right]\right]\right]$.

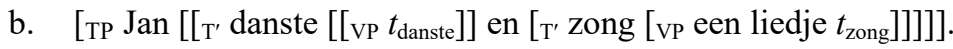

c. [тр Jan $\left[\left[\mathrm{T}^{\prime}\right.\right.$ zong $\left[\left[\mathrm{vp}\right.\right.$ een liedje $\left.\left.t_{\text {zong }}\right]\right]$ en $\left[\mathrm{T}^{\prime}\right.$ danste $\left.\left.\left.\left.\left[\mathrm{vp} \mathrm{t}_{\text {danste }}\right]\right]\right]\right]\right]$.

This approach could also derive the topicalization (and interrogative) constructions of the type in (47) by assuming that conjunction of the intermediate $\mathrm{C}^{\prime}$-projection is possible; cf. De Vries (1992: section 1.4). This option runs into the theory-internal problem, however, that syntactic operations normally do not target intermediate projections, but only heads and maximal projections.
a. Gisteren zong Jan een liedje en danste hij. yesterday sang Jan a song and danced he 'Yesterday, Jan sang a song and he danced.'

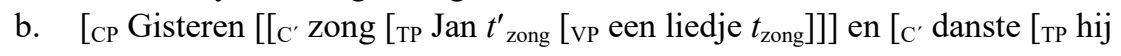 $\left.\left.\left.\left.t^{\prime}{ }_{\text {danste }}\left[\mathrm{vP} t_{\text {danste }}\right]\right]\right]\right]\right]$.

A third option would be to assume that we are dealing with coordination of TPs, but that the subject is moved across-the-board into the specifier of CP. This would be in agreement with the coordinate structure constraint but it complicates the description of verb-second by allowing the C-position to remain empty when adjacent to the finite verb in the head of TP.

(48) a. [CР $\operatorname{Jan}_{\mathrm{i}}[\mathrm{C} \varnothing]\left[\left[\mathrm{TP} t_{\mathrm{i}}\right.\right.$ zong [Vp $\left.\left.t_{\text {zong }}\right]\right]$ en [TP $t_{\mathrm{i}}$ danste [vp $\left.\left.\left.\left.t_{\text {danste }}\right]\right]\right]\right]$.

b. [CР $\operatorname{Jan}_{\mathrm{i}}[\mathrm{C} \oslash]\left[\left[{ }_{\mathrm{TP}} t_{\mathrm{i}}\right.\right.$ danste [vp $\left.\left.t_{\text {danste }}\right]\right]$ en [тр $t_{\mathrm{i}}$ zong [vp een liedje $\left.\left.\left.\left.t_{\text {zong }}\right]\right]\right]\right]$.

c. [CP $\operatorname{Jan}_{\mathrm{i}}[\mathrm{C} \oslash]\left[\left[\mathrm{TP} t_{\mathrm{i}}\right.\right.$ zong [vp een liedje $\left.\left.t_{\mathrm{zong}}\right]\right]$ en [ [тP $t_{\mathrm{i}}$ danste [vP $\left.\left.\left.\left.t_{\text {danste }}\right]\right]\right]\right]$.

Furthermore, this proposal cannot be easily extended to cover cases such as (47a), since it is generally assumed that topicalized phrases are already in the specifier of the highest functional projection of the clause. A fourth option would be to assume that the topicalized constituent is in a clause-external position; cf. Chomsky (1977:90ff) and Koster (1978). Evidence in favor of this approach is that 
topicalization may only target the initial position of main clauses; this approach would still run into problems with wh-questions such as (49b) given that $w h$-phrases may also target the initial position of coordinated clauses.
a. [Gisteren ${ }_{i}\left[\left[\mathrm{CP}_{\mathrm{OP}} \mathrm{OP}_{\mathrm{i}}\right.\right.$ zong Jan een liedje $]$ en $\left[\mathrm{CP}_{\mathrm{i}} \mathrm{t}_{\mathrm{i}} \mathrm{OP}_{\mathrm{i}}\right.$ danste hij]]]. yesterday sang Jan a song and danced he 'Yesterday, Jan sang a song and he danced.'
b. Wanneer zong Jan een liedje en danste hij? when sang Jan a song and danced he 'When did Jan sing a song and did he dance?'

The discussion above has made it clear that that coordinated main clauses with a "shared" initial position (e.g., a subject, or topic/wh-phrase) are problematic for the assumption that forward conjunction reduction does not exist. We have further shown that there are various potential solutions for this problem, which, however, all raise new questions that we will not try to solve here. For completeness' sake, we want to mention one final option that we did not discuss above because it leads to a wide range of theory-internal questions that cannot be properly addressed here, namely Rizzi's (1997) "split CP" hypothesis according to which there may in principle be various specifier positions (for subject, topicalized and focused phrases) preceding the finite verb. The discussion above will have made it abundantly clear that the proper analysis of examples with "shared" main-clause initial elements is still quite nebulous and requires further investigation.

\section{Empty subject pronouns?}

The previous subsection discussed the question as to whether coordination is restricted to maximal projections or whether it is also possible to coordinate (lexical) heads or intermediate projections on the basis of constructions with a "shared" main-clause initial constituent. We saw that the examples in (50) were the most difficult to solve in a satisfactory way.

$\begin{array}{ll}\text { (50) a. } & \text { Jan zong en danste. } \\ & \text { Jan sang and danced } \\ & \text { 'Jan was singing and dancing.' } \\ \text { b. } & \text { Jan danste en zong een liedje. } \\ & \text { Jan danced and sang a song } \\ & \text { 'Jan was dancing and singing a song.' } \\ \text { c. } & \text { Jan zong een liedje en danste. } \\ & \text { Jan sang a song and danced } \\ & \text { 'Jan was singing and dancing.' }\end{array}$

This subsection discusses another potentially problematic fact found in (presumed) coordinated main clauses with a "shared" initial position, which may shed new light on these examples. The examples in (49) in the previous subsection have already shown that the initial phrase need not be a subject but can also be a topicalized or interrogative phrase. It should be noted that (49) is well-behaved with respect to the ${ }^{\circ}$ verb-second constraint in that the second clause has the obligatory subject-verb inversion. The problem we want to discuss now is illustrated by (51a): many 
speakers report that they also allow omission of the subject in the second (italicized) coordinand of such constructions, which is unexpected for all approaches discussed earlier including forward conjunction reduction. It should be pointed out, however, that it is not obvious that (51a) should be assigned the structure in (51b); in fact, Haeseryn et al. (1997:1588-9) claim it to be impossible (indicated here by means of an asterisk) and provide two arguments favoring the alternative structure in $\left(51 b^{\prime}\right)$.

(51) a. Boos kwam hij binnen en begon te gillen.

angry came he in and started to yell

'He came in angry and started yelling.'

b. *[[Boos kwam hij binnen] en [begon te gillen]]. angry came he in and angry started he to yell

$\mathrm{b}^{\prime}$. [[Boos kwam hij binnen] en [hij begon te gillen]]. angry came he in and angry started to yell

The first argument is based on examples such as (52a): if the structure is as indicated in (52b), the (omitted) second person pronoun follows the finite verb, which is therefore wrongly predicted to appear without the $-t$ ending; cf. $N u$ ruim/*ruimt je de rommel op. If the structure is as indicated in $\left(52 \mathrm{~b}^{\prime}\right)$, the (omitted) second person pronoun precedes the finite verb, and this correctly predicts the $-t$ ending: cf. Je ruimt/*ruim de rommel op.

(52) a. $\mathrm{Nu}$ ga je naar je kamer en ruimt/*ruim de rommel op. now go you to your room and clean/clean the mess up

'Now you go to your room and clean up the mess.'

b. *[[Nu ga je naar je kamer] en [nu ruimt je de rommel op]].

$\mathrm{b}^{\prime}$. [[Nu ga je naar je kamer] en [je ruimt de rommel op]].

The second argument is based on examples such as (53a). The structure in (53b) cannot be correct, as it would give rise to a contradiction: ${ }^{\text {Sangzaam liep hij toen }}$ snel weg (literally: "Slowly he then walked away quickly"). The only option is therefore the structure in $\left(53 b^{\prime}\right)$.
a. Langzaam kwam hij overeind en liep toen snel weg. slowly got he up and walked then quickly away 'He got up slowly and then walked away quickly.'
b. *[[Langzaam kwam hij overeind] en [tam liep hij toen snel weg]].
$\mathrm{b}^{\prime}$. [[Langzaam kwam hij overeind] en [hili liep toen snel weg]].

If the structures in (52b) and (53b) are indeed imposible, this raises the question as to whether we are really dealing with conjunction reduction of the sort discussed here. If the structure were indeed as indicated in $\left(52 b^{\prime}\right)$ and $\left(53 b^{\prime}\right)$, one might want to develop a subject-drop analysis. This may not be too far-fetched because there is a wider range of construction that allow the sentence-initial position to be empty; the examples in (54), taken from Section V11.2.2 on topic drop, more specifically show that the subject of a main clause sometimes does not have to be phonetically realized when it is reconstructable from the context. The fact that there still is subject-verb agreement in these examples show that the empty subject is syntactically present. 
(54)
a. Waar is Jan? (Die) is sppsg $_{\text {s. }}$ al naar huis. where is Jan that is already to home 'Where is Jan? He has gone home already.'

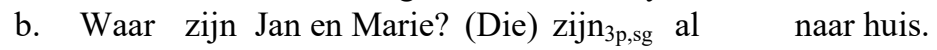 where is Jan and Marie those are already to home 'Where are Jan and Marie? They have gone home already.'

That the subject is syntactically present is also shown by examples like (55a\&b); since reflexive pronouns must have a syntactically realized antecedent in their clause, we have to assume that the subject is present even after topic drop; the form of the reflexive pronoun is determined by the person feature of the omitted topic.
a. Wat is er met je gebeurd? $\left(\mathrm{Ik}_{\mathrm{i}}\right)$ heb mezelf $\mathrm{f}_{\mathrm{i}}$ gesneden. what is there with you happened I have myself cut 'What has happened to you? I've cut myself.'
b. Wat is er met Peter gebeurd? (Die $\left.{ }_{i}\right)$ heeft zichzelf $f_{i}$ gesneden. what is there with Peter happened that has himself cut 'What has happened with Peter? He has cut himself.'

The examples in (54) show that there are reasons to assume that in certain contexts the subject can be realized as a phonetically empty pronoun. The topic drop analysis seems especially appropriate for (51) to (53) because we are dealing with asymmetrical (consecutive) coordinate structures, which are part of a narrative so that we may expect topic drop to arise. That topic drop does not apply in symmetrical coordinate structures, which are normally not narrative in nature, is illustrated by Soms eet Jan vlees en drinkt bier, which is dubbed ungrammatical by Van Oirsouw (1987:119): the structure in (56b) is ungrammatical for the same reason as the (b)-examples in (51) to (53), and $\left(56 b^{\prime}\right)$ is impossible because topic drop occurs in narratives only.

(56) a. [[Soms eet Jan vlees] en [soms drinkt Jan/hij bier]]. sometimes eats Jan meat and sometimes drinks Jan/he beer 'Sometimes Jan eats meat and sometimes Jan/he drinks beer.'
b. *[[Soms eet Jan vlees] en [soms drinkt Jan bier]]. sometimes eats Jan meat and sometimes drinks Jan beer
$\mathrm{b}^{\prime} .{ }^{\$}[[$ Soms eet Jan vlees] en [J drinkt bier]]. sometimes eats Jan meat and sometimes drinks beer

Consider, finally, the yes/no-question in (57a), adapted from Van Oirsouw $(1987: 108 / 145)$, which again shows that omission of the subject is not possible in subject verb inversion constructions. This is expected, as the subject cannot undergo topic drop in questions. Example (57b) shows the same for wh-questions.
a. *[[Is Jan ziek] en [moet slapen]]? is Jan ill and must Jan sleep
Intended: 'Is Jan ill and does he have to sleep?'
b. *[[Wanneer eet Jan vlees] en [drinkt bier]]? when eats Jan meat and when drinks Jan beer Intended: 'When does Jan eat meat and when does he drink beer?' 
We conclude from the discussion above that there seems to be sufficient evidence in support of the claim in Haeseryn et al. (1997) that (51a) is not relevant for our present discussion, as it should be analyzed as in $\left(51 b^{\prime}\right)$. For completeness' sake, we refer the reader to the discussion in Büring \& Hartmann (1998) and Hartmann (2000: section 2.3.3) on similar constructions in German; their analysis resembles our proposal given above in that they also postulate a phonetically empty subject pronoun but they maintain that structures such as $(51 \mathrm{~b})$, with the empty pronoun following the finite verb, are possible in German.

We conclude this subsection by noting that the now established fact that the subject of the second conjunct can sometimes be a phonetically empty pronoun may perhaps also solve the problem for the examples in (50) if we assume that we are dealing with coordination of main clauses, as in (58), with an empty subject pronoun (pro) in the second coordinand. We leave it the future research to investigate whether this is a viable option.
a. [[Jan ${ }_{\mathrm{i}}$ zong $\left.]\right]$ en $\left[\mathrm{pro}_{\mathrm{i}}\right.$ danste $\left.]\right]$. Jan sang and danced
b. [[ $\mathrm{Jan}_{\mathrm{i}}$ danste $]$ en $\left[\mathrm{pro}_{\mathrm{i}}\right.$ zong een liedje]]. Jan danced and sang a song
c. [[Jan ${ }_{\mathrm{i}}$ zong een liedje] en [ $\mathrm{pro}_{\mathrm{i}}$ danste $\left.]\right]$. Jan sang a song and danced

\subsection{Gapping}

This section discusses GAPPING, a forward reduction process prototypically applying in clausal coordinate structures with the coordinator en 'and', of 'or' or maar 'but' (although Chapter 3 will show that there is a wider set of constructions allowing gapping). Some illustrations are given in example (59); strikethrough and small caps indicate elision and contrastive accent, respectively.

(59) a. [[JAN las het BOEK] en [MARIE het ARTIKEL]].

Jan read the book and Marie read the article

'Jan read the book and Marie the article.'

b. [[JAN heeft het BOEK gelezen] en [ELS het ARTIKEL Jan has the book read and Marie has the article read

'Jan has read the book and Els the article.'

c. [[JAN gaf MARIE een boek] en [ELS PETER Jan gave Marie a book and Els gave Peter a book 'Jan gave Marie a book and Els Peter.'

Subsection I starts the discussion by giving a brief characterization of gapping, which will also clarify how gapping differs from the types of conjunction reduction discussed in Section 2.1. Subsection II continues by discussing in more detail the restrictions on the remnants left by gapping. It also discusses the nature of gapping: we will argue that there are various reasons for assuming that gapping is a syntactic rule. This conclusion means that gapping is of a very different nature than backward conjunction reduction, which was argued in Section 2.1 to be a post-syntactic rule. 


\section{A brief characterization of gapping}

This subsection provides a characterization of gapping by briefly reviewing a number of general properties of the elided string(s) and the remnants.

\section{A. Restrictions on the coordinator}

The introduction already mentioned that gapping is possible in coordinate structures with en 'and', of 'or' and maar 'but'; examples illustrating this are given in (60a\&b). Example (60c) shows, however, that gapping cannot apply in asymmetrical coordinate structures with want 'because' or dus 'so'.

(60) a. [[Jan gaat naar Marie] en/maar [Els naar Peter]].

Jan goes to Marie and/but Els goes to Peter

b. [[Jan gaat naar Marie] of [Marie naar Jan]]. Jan goes to Marie or Marie goes to Peter

c. *[JJan gaat naar Marie] want/dus [Els naar Peter]]. Jan goes to Marie and/but Els goes to Peter

The examples in $(61 \mathrm{a} \& \mathrm{~b})$ show that the correlative coordinators en ... en ... 'both ... and ...' and of ... of ... 'either ... or ...' can also be used in gapping constructions although some speakers seem to consider cases with en ... en ... somewhat marked, as indicated by the percentage sign in (61a). Example $\left(61 a^{\prime}\right)$ shows that the correlative zowel .. als .. 'both ... and ...' cannot be used, which is expected given that this correlative cannot be used for coordinating clauses.
a. ${ }^{\%}$ En Jan gaat naar Marie en Els naar Peter. and Jan goes to Marie and Els goes to Peter
$a^{\prime}$. *Zowel Jan gaat naar Marie als Els naar Peter. and Jan goes to Marie and Els goes to Peter
b. Of Jan gaat naar Marie of Marie naar Jan. or Jan goes to Marie or Marie goes to Jan

\section{$B$. The remnants of gapping are contrastively focused}

The remnants of gapping and their antecedents are characterized by the fact that they are (normally) assigned contrastive accent; cf. Hartmann (2000:ch.4). This requirement immediately accounts for the fact that elements that cannot be accented, such as the reduced pronouns in (62b), cannot occur as remnants in gapping constructions; cf. De Vries (1992:130).
a. [[JAN las een BOEK] en [MARIE een ARTIKEL]]. Jan read a book and Marie read an article 'Jan read a book and Marie an article.'
b. [[JAN bezocht ELS/HAAR/*'r] en [MARIE PETER/HEM/*'m]]. Jan visited Els/her/her and Marie visited Peter $/ \mathrm{him} / \mathrm{him}$ 'Jan visited Els/her and Marie Peter/him.'

Because of their contrastive ${ }^{\circ}$ focus reading, gapping constructions such as (62a) are very suitable for giving pair-list answers to questions like Wie las wat? 'Who read what?' or Wat hebben Jan en Marie gelezen? 'What did Jan and Marie read?'. Note 
in passing that wh-phrases can also be used as remnants in gapping constructions because they are inherently focused: example (63b) is perhaps slightly marked because the same question could be asked by the simpler form Wat lazen Jan en Els? 'What did Jan and Els read?', but it seems certainly acceptable. For completeness' sake, the primed (a)-example shows that gapping is also possible in multiple wh-questions.
a. [[WIE las het BOEK] en [WIE has het ARTIKEL]]?
who read the book and who read the article
$\mathrm{a}^{\prime}$. [[WIE las WELK BOEK] en [WIE las WELK ARTIKEL]]? who read which book and who read which article
b. [[WAT las JAN] en [WAT ELS]]? what read Jan and what read Els
'What did Jan read and what Els?'

The fact that the remnants of gapping and their antecedents are assigned contrastive accent may solve certain potential ambiguities; cf. Hartmann (2000) and Boone (2014). A gapping construction such Marie gaf Jan een boek en Els een CD 'Jan gave Marie a book and Els a CD' can have the two interpretations indicated by the two structures in (64a\&b): Els can function as the subject or as the indirect object of the target clause. The intonation of the antecedent clause, however, resolves this ambiguity; when contrastive accent is assigned to the subject Marie of the antecedent clause, Els also functions as the subject of the target clause, but when it is assigned to the indirect object Jan, Els also functions as an indirect object. The primed examples are added to show that the use of weak pronouns may also help to disambiguate such structures because they cannot be (contrastively) stressed.

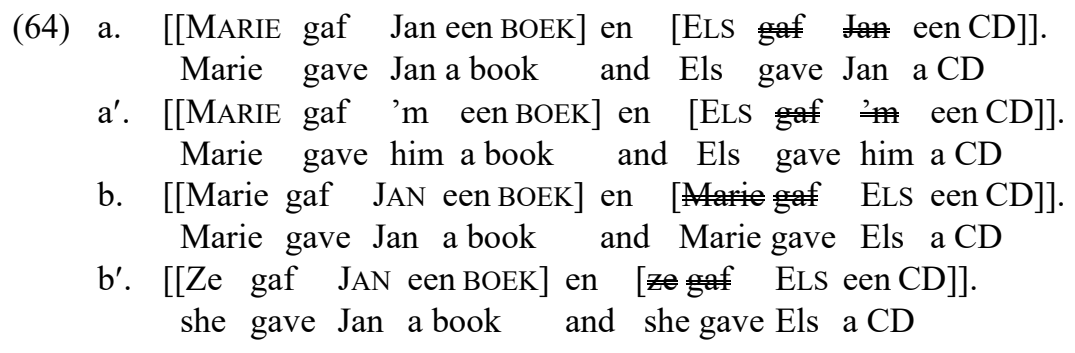

Note in passing that Haeseryn et al. (1997:1592) observe that the reading indicated in (64b) is normally more prominent than the one indicated in (64a). This may be related to (i) the fact that subjects are more likely to be interpreted as discourse-old information than objects and (ii) the fact that the use of contrastive accent in the first conjunct is of secondary importance and can even be completely absent in some cases (cf. Subsection H below).

\section{Gapping elides a finite verb; it targets clausal coordinands only}

Gapping is a reduction process prototypically found in clausal coordinate structures. The contrast between the examples in $(65 \mathrm{a} \& \mathrm{~b})$ shows that gapping minimally elides the finite verb: even when the finite verb is assigned contrastive accent, it cannot be overtly realized (note that the string Jan las een boek en Marie schreef is, of course, 
acceptable when the verb schrijven 'to write' is interpreted as a pseudo-intransitive verb). The contrast between the examples in $(65 \mathrm{a} \& \mathrm{c})$ further shows that gapping applies in a forward fashion only. Example (65a) also shows that gapping differs from the two types of conjunction reduction discussed in Section 2.1 in that the elided element(s) need not be in the periphery of the target coordinand.
a. [[JAN las EEN BOEK] en [MARIE las EEN ARTIKeL]]. Jan read a book and Marie read an article 'Jan read a book and Marie an article.'
b. *[[JAN LAS een boek] en [MARIE SCHREEF Jan read a book and Marie wrote a book Intended reading: 'Jan read a book and Marie wrote a book.'
c. *[[JAN las een BOEK] en [MARIE las een ARTIKEL]]. Jan read a book and Marie read an article

The position of the finite verb does not seem to play a role as is clear from the fact that gapping is not restricted to main clauses. First, example (66a) shows that gapping is also possible in the embedded counterpart of (65a); we return in Subsection IIA3 to the fact that the complementizer dat 'that' of the gapped clause must also be elided. The two (b)-examples in (66) show that the finite verb can also occur in sentence-initial position.

(66) a. Ik denk [[dat JAN EEN BOEK las] en [dat MARIE EEN ARTIKEL las]].

I think that Jan a book read and that Marie an article read 'I think that Jan read a book and Marie an article.'

b. [[Las JAN EEN BOEK] en [tas MARIE EEN ARTIKEL]]? [yes/no-questions] read Jan a book and read Marie an article

'Did Jan read a book and Marie an article?'

$\mathrm{b}^{\prime}$. [[Geef JAN EEN BOEK] en [geef MARIE EEN ARTIKEL]]! [imperatives] give Jan a book and read Marie an article

'Give Jan a book and Marie an article?'

Gapping can only apply to clauses, that is, it cannot apply to coordinate structures with nominal, adjectival or adpositional coordinands. This is illustrated in (67) for the INF- and ING-nominalizations of example (65a); the em-dash stands for the gapped string voortdurend lezen.

(67) a. JANS voortdurend lezen van BOEKEN (*en MARIES - van ARTIKELEN) Jan's continuous read of books and Marie's of articles 'Jan's continuous reading of books (is worrisome).'

b. JANS voortdurende gelees van BOEKEN (*en MARIES - van ARTIKELEN) Jan's continuous reading of books and Marie's of articles 'Jan's continuous reading of books (is worrisome).'

These observations have given rise to the finite-verb restriction in (68).

Finite-verb restriction on gapping:

Gapping elides the finite verb of its target clause. 
The finite-verb restriction predicts that gapping cannot be applied to infinitival clauses. Subsection IIA will show that there is no reason to assume that this prediction is correct, but for our present overview we can provisionally adopt this restriction, as we will be dealing with finite clauses only.

\section{The elided material need not be a single constituent}

Besides finite verbs, various kinds of other material may be elided. The elided string need not be a single constituent: in (69), for instance, it consists of the finite verb, an indirect object, and two adverbial phrases. The only requirement seems to be that the remnants of gapping have the same syntactic function as their correlates in the antecedent clause.

$$
\begin{aligned}
& \text { [[JAN geeft haar morgen waarschijnlijk een BOEK] en } \\
& \text { Jan gives her tomorrow probably a book and } \\
& \text { [ELS } \\
& \text { Els gives her tomorrow probably a CD } \\
& \text { 'Jan will probably give her a book tomorrow and Els a CD.' }
\end{aligned}
$$

The examples in (70) further show that the elided material does not have to form a single contiguous string but can also be dispersed over the target clause. Example (70a) shows this for the non-finite verb gelezen 'read', (70b) for a direct object, and (70c) for a prepositional indirect object.

(70) a. [[JAN heeft een BOEK gelezen] en [ELS een GEDICHT $]$. Jan has a book read and Els has a poem read 'Jan has read a book and Els a poem.'

b. [[JAN gaf MARIE een boek] en [ELS PETER Jan gave Marie a book and Els gave Peter a book 'Jan gave Marie a book and Els Peter.'

c. [[JAN gaf EENBOEK aan Marie] en [ELS een CD ] Jan gave a book to Marie and Els gave a CD to Marie 'Jan gave a book to Marie and Els a CD.'

\section{E. Recoverability and maximization condition on elision}

Example (71a) shows again that the elided material in the target clause can consist of more than one (clausal) constituent. However, the elided material has to be locally recoverable: since the adverbial phrase voor haar verjaardag in (71b) has no correlate in the antecedent clause, gapping is excluded (as is clear from the fact that this phrase cannot be present in the interpretation of the target clause).

- Recoverability condition on gapping

[[JAN geeft haar morgen waarschijnlijk een BOEK] en

Jan gives her tomorrow probably a book and

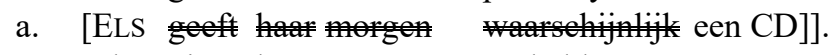

Els gives her tomorrow probably a CD

'Jan will probably give her a book tomorrow and Els a CD.'

b. *[ELS har hergen har verjardag]].

Els gives her tomorrow probably a CD for her birthday 
The examples in (72) further show that it is not possible to leave remnants in the target clause that are identical to some constituent in the antecedent clause, that is, there is a maximization condition on gapping that requires all non-contrastive material to be elided (but see Subsection IID5 for one notable exception). Since the acceptability of example (72h) shows that gapping as such is not obligatory, this shows that gapping is an all-or-nothing operation in the sense that it affects the noncontrastive part of the target clause as a whole, and not the non-contrastive constituents individually.

$$
\begin{aligned}
& \text { - Maximization condition on gapping } \\
& \text { [[JAN geeft Marie morgen waarschijnlijk een BOEK] en ... } \\
& \text { Jan gives Marie tomorrow probably a book and } \\
& \text { a. [ELS arie moren } \\
& \text { Els gives Marie tomorrow probably a CD } \\
& \text { 'Jan will probably give Marie a book tomorrow and Els a CD.' }
\end{aligned}
$$

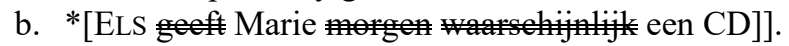

$$
\begin{aligned}
& \text { c. *[ELS morgen een CD]]. } \\
& \text { d. *[ELS warschijnlijk een CD]]. } \\
& \text { e. *[ELS Marie morgen aarschijnlijk een CD]]. } \\
& \text { f. *[ELS Marie waarschijnlijk een CD]]. } \\
& \text { g. *[ELS morgen waarschijnlijk een CD]]. } \\
& \text { h. [ELS geeft Marie morgen waarschijnlijk een CD]]. }
\end{aligned}
$$

Not only is there a maximization condition on elision but also on interpretation, in the sense that all non-contrastive material from the antecedent clause must be present in the interpretation of the target clause. This suggests that the target clause in (69) must have the form in (73a), and cannot have the forms in (73b-h). Note in passing that all examples are acceptable when the elided constituents are overtly realized.

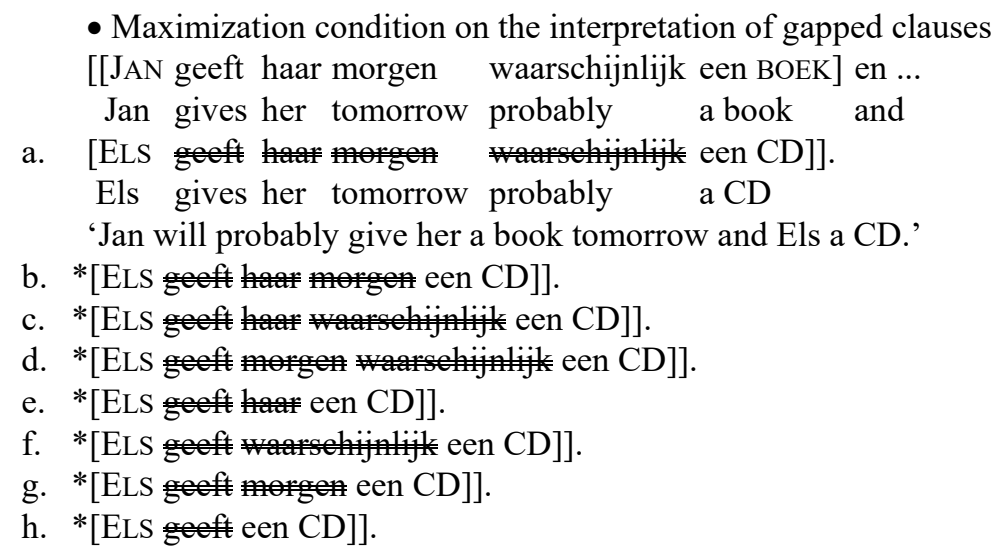

The recoverability and maximization conditions on gapping correctly entail that the remnants of gapping must have the same syntactico-semantic functions as their correlates in the antecedent clause; see all examples discussed so far. 


\section{F. Gapping may affect more than one target clause}

Gapping is not restricted to a single coordinand. The examples in $(74 \mathrm{a} \& \mathrm{~b})$ show that it can apply under identity with elements in the initial coordinand to an (in principle) infinite number of coordinands, as long as no coordinand is skipped by gapping. Example (74c) shows that gapping does not have to apply to all coordinands. Example (74d) further shows that examples in which gapping applies under identity with elements in a non-initial coordinand are degraded: the antecedents of the remnants of gapping must be in the initial coordinand.

(74) a. [[M. eet APPELS], [J. eet PEREN], [P. eet KERSEN], en [E. eet meloen]]. Marie eats apples Jan eats pears Peter eats cherries and Els eats melon 'Marie is eating apples, Jan pears, Peter cherries and Els melon.'

b. *[[M. eet APPELS], [J. PEREN], [P. drinkt sap], en [E. meloen]]. Marie eats apples Jan eats pears Peter drinks juice and Els eats melon

c. [[M. eet APPELS], [J. PEREN], [P. KERSEN], en [E. drinkt sap]]. Marie eats apples Jan eats pears Peter eats cherries and Els drinks juice 'Marie is eating apples, Jan pears, Peter cherries and Els is drinking juice.'

d. "?[M. drinkt sap], [J. eet PEREN], [P. KERSEN], en [E. meloen]]. Marie drinks juice Jan eats pears Peter eats cherries and Els eats melon 'Marie is drinking juice, Jan is eating pears, Peter cherries and Els melon.'

The internal organization of the complex coordinate structure does not affect this: the gapping process simply proceeds from left to right, from coordinand to coordinand, without paying heed to the hierarchical relations between the individual coordinands. This is illustrated by the examples in (75): example (75a) shows that in a complex coordinate structure such as [[WP and XP] or [YP and ZP]], WP may trigger gapping in XP, YP and ZP. Example (75b) shows that it is impossible for the complex coordinand [WP and XP] to trigger gapping of the finite verbs in the complex coordinand [YP and ZP]. It is likewise impossible to construct acceptable examples in which WP triggers gapping of the finite verb in YP, or in which XP triggers gapping of the finite verb in ZP (not illustrated).

$$
\begin{aligned}
& \text { a. [[[wp MARIE eet APPELS] en [xp JAN PEREN]] of } \\
& \text { Marie eats apples and Jan eats pears or } \\
& \text { [[yP MARIE eet PEREN] en [ZP JAN APPELS]]]. } \\
& \text { Marie eats pears and Jan eats apples } \\
& \text { 'Marie is eating apples and Jan pears, or Marie pears and Jan apples.' } \\
& \text { b. *[[[wP MARIE eet APPELS] en [XP JAN drinkt BIER }]] \text { of } \\
& \text { Marie eats apples and Jan drinks beer or } \\
& \text { [[yp MARIE PEREN] en [zp JAN wIJN]]]. } \\
& \text { Marie eats pears and Jan drinks wine }
\end{aligned}
$$

Note that example (75a) alternates with (76a), in which the finite verb of YP but not $\mathrm{ZP}$ is overtly realized, but not with (76b), in which the finite verb of ZP but not YP is overtly realized. The acceptability of (76a) is expected if we assume that the two complex coordinands of the disjunction of 'or' function as separate domains, in which the initial coordinands trigger gapping independently of each other in the non-initial coordinands: while WP triggers gapping in XP, YP triggers gapping in 
ZP. The unacceptability of (76b) seems more difficult to explain in light of the acceptability of (74c) above; we might be dealing with some (superficial) parallelism requirement on the two complex coordinands, but we will not push this idea here for want of conclusive arguments.

$$
\begin{aligned}
& \text { a. [[[wp MARIE eet APPELS] en [XP JAN PEREN]] of } \\
& \text { Marie eats apples and Jan eats pears or } \\
& \text { [[yp MARIE eet PEREN] en [zP Jan APPELS]]]. } \\
& \text { Marie eats pears and Jan eats apples } \\
& \text { b. *[[[wp MARIE eet APPELS] en [XP JAN PEREN }]] \text { of } \\
& \text { Marie eats apples and Jan eats pears or } \\
& \text { [[yp MARIE PEREN] en [zP JAN eet APPELS]]]. } \\
& \text { Marie eats pears and Jan eats apples }
\end{aligned}
$$

\section{$G$. The remnants of gapping are prototypically major phrases}

In the classic case, gapping remnants are ${ }^{\circ}$ major phrases in the sense of Neijt (1979): they can be clausal constituents (arguments, adverbials or complementives) or specific smaller, non-clausal verbal projections, which we will loosely refer to as "VP" for convenience. Examples of VP-remants are een film bekijken inf $^{\prime} /$ bekeken $_{\text {part }}$ 'watch(ed) a movie' in (77).

(77) a. [[JAN heeft [vp een BOEK gelezen]] en [ELS tvp een FILM bekeken]]]. Jan has a book read and Els has a movie watched 'Jan has read a book and Els has watched a movie.'

b. [[JAN wil [vp een BOEK lezen]] en [ELS [vp een FILM bekijken]]]. Jan wants a book read and Els wants a movie watch 'Jan wants to read a book and Els wants to watch a movie.'

That the remnants of gapping are typically clausal constituents of the target clause, and thus cannot be more deeply embedded, is illustrated by the acceptability contrast between the primeless and primed examples in (78). The (a)-examples show that while the remnant can be the object clause of the elided finite verb weet 'knows', it cannot be a constituent embedded in this clause; the (b)-examples similarly show that while the remnant can be the nominal object of the elided verb kocht, it cannot be a phrase embedded in this noun phrase.

(78) a. [[JAN weet [dat Els komt]] en [PETER [dat MARIE komt]]]. Jan knows that Els comes and Peter knows that Marie comes 'Jan knows that Els is coming and Peter that Marie is coming.'

$\mathrm{a}^{\prime}$. *[[JAN weet [dat Els komt]] en [PETER [ MARIE Jan knows that Els comes and Peter knows that Marie comes

b. [[JAN kocht [het huis op het PLEIN]] en [ELS [het huis bij het PARK]]]. Jan bought the house on the square and Els bought the house near the park 'Jan bought the house on the square and Els the house near the park.'

$\mathrm{b}^{\prime}$. *[[JAN kocht [het huis op het PLEIN]] en [ELS [ [ bij het PARK]]]. Jan bought the house on the square and Els bought the house near the park 
Note in passing that examples with a postnominal van- or over-PP are less suitable for showing this because they are not easy to distinguish from adverbial PPs headed by van or over with a restrictive function; see N2.2.1, sub VC, for more discussion.

There are a number of exceptions to the generalization that the remnants must be clausal constituents of the clause with the elided finite verb. This is illustrated in (79): the PP op Peter in (79a) functions as the ${ }^{\circ}$ complement of the adjective boos, but it can nevertheless appear as a remnant of gapping; similarly, the measure phrase vier meter 'four meters' in (79b) functions as a modifier of the adjective diep 'deep' but again it can appear as a remnant of gapping.
a. [[JAN is [erg boos op MARIE]] en [ELS is [eos PETER]]]. Jan is very angry with Marie and Els is very angry with Peter 'Jan is very angry with Marie and Els is very angry with Peter.'
b. [[DEZE kuil is [DRIE meter diep]] en [DIE kuil is [VIER meter diep]]]. this pit is three meter deep and that pit is four meter deep 'This pit is three meters deep and that one is four meters deep.'

The restriction to major phrases as well as the counterexamples to this restriction will be discussed in more detail in Subsection II where it will be argued that the exceptional cases in (79) are not accidental and that the acceptability contrast between, e.g., $\left(78 b^{\prime}\right)$ and $(79 a)$ is related to the contrast in acceptability of ${ }^{\circ}$ focus movement in the primed examples of (80); cf. Subsection IID. The number sign in $\left(80 \mathrm{a}^{\prime}\right)$ is used to indicate that this example is acceptable when the PP op het plein functions as a locational adverbial phrase indicating the location where the purchasing event took place.
(80) a. Els kocht [het huis op het plein]].
Els bought the house on the square
$\mathrm{a}^{\prime}$. " Els kocht [op het PLEIN] $]_{\mathrm{i}}$ [het huis $t_{\mathrm{i}}$ ].
Els bought on the square the house
b. Els is [erg boos [op Peter]].
Els is very angry with Peter
$\mathrm{b}^{\prime}$. Els is [op PETER] $]_{\mathrm{i}}$ [erg boos $t_{\mathrm{i}}$ ].
Els is with Peter very angry

\section{H. The number of remnants of gapping}

The examples in the previous subsections all involve cases with precisely two remnants of gapping. Neijt (1979) claims, however, that it is also possible to have cases with one remnant, or three or more remnants. However, gapping constructions with more than three remnants sound artificial and quickly degrade as the number of remnants increases. This may be related to the fact that they contain so many contrastive accents (cf. Johnson 2017:1745), but at first sight there is no clear reason for assuming that they are ungrammatical (although this may in fact follow from the analysis of gapping that will be suggested in Subsection IID). 


[[Jan heeft gisteren een boek naar Els gestuurd] en ...
Jan has yesterday a book to Els sent and

Examples such as (81a) were discussed in Section 1.3, sub IIB, under the heading of split coordination. There, we left open the question as to whether we are dealing with some kind of fragment clause or with gapping. The gapping analysis is supported by the fact that the remnant in the target clause is normally contrastively accented but it may be problematic in view of the fact that its correlate in the antecedent clause is normally not contrastive. So, if split coordination was analyzed as a case of gapping, the focus requirement should be restricted to the remnants of gapping. Support for this conclusion can be found in the fact that gapping also seems to occur in dialogues like (82), where speaker B provides additional information to A's assertion; cf. Neijt (1979:37ff.). The crucial fact is that A's utterance would normally have a non-contrastive intonation pattern because A does not anticipate B's reply.
Marie heeft gisteren een boek naar Els gestuurd.
Marie has yesterday a book to Els sent
'Marie sent a book to Els yesterday.'
a. Ja, en [Marie heefteren een RING yes and Marie has yesterday a ring to Els sent
'Yes, and a ring.'

b. Ja, en [Marie VANDAAG een RING yes and Marie has today a ring to Els sent

'Yes, and a ring today.'

c. Ja, en [Marie VANDAAG een RING naar JAN yes and Marie has today a ring to Jan sent 'Yes, and a ring to Jan today.'

d. Ja, en [PETER VANDAAG een RING naar JAN yes and Peter has today a ring to Jan sent 'Yes, and Peter a ring to Jan today.'

The fact that the examples in (81) and (82) are fully parallel suggests that they should be given a similar account: we will therefore assume that contrastive accent on the antecedents of the remnants of gapping in (81) is indeed of a secondary nature, due to conscious planning by the speaker. Because speaker A clearly does 
not anticipate the reaction by speaker B in the dialogues in (82), contrastive accent on the antecedents will not be realized. To conclude, the fact that fragment clauses of the kind in (83) look very much like gapping naturally raises the question as to whether such clauses are also a kind of gapping constructions. We believe this to be the case, and refer the reader to Chapter 3 for arguments showing that the traditional claim that gapping is exclusively found in coordinate structures is incorrect.
a. Wie las wat? who read what
b. [[JAN een BOEK], [ELS een ARTIKEL], en [PETER een GEDICHT]]. Jan read a book Els read an article and Peter read a poem 'Jan read a book, Els an article, and Peter a poem.'

\section{The syntactic restrictions on gapping}

This subsection discusses the syntactic restrictions on gapping in more detail. Subsection A starts by discussing more extensively the traditional claim introduced in subsection IC, repeated here as (84a), that finite verbs must be elided by gapping and thus differ from non-finite verbs, which can be remnants. We will see that this restriction must be modified as in (84b) in order to account for the fact that gapping can also target infinitival clauses.

\section{a. Finite-verb restriction on gapping:}

Gapping elides the finite verb of its target clause.

b. Verbal-head restriction on gapping; Gapping elides all functional and lexical heads with verbal features $\left(\mathrm{C}, \mathrm{T}\right.$ and $\left.\mathrm{V}_{\text {finite }}\right)$ of its target clause.

Subsection B continues by showing that the remnants of gapping are typically ${ }^{\circ}$ clausal constituents of the target clause, which leads to the CLAUSEMATE RESTRICTION in (85a). Subsection C, however, will discuss a number of apparent as well as true exceptions to this restriction, and Subsection D will argue that the true exceptions can be accounted for by rephrasing the clausemate restriction in terms of ${ }^{\circ} \mathrm{A}^{\prime}$-movement, as in (85b). We will take the notion of $\mathrm{A}^{\prime}$-movement in its widest possible sense: it does not only refer to $w h$-movement into clause-initial position but also to ${ }^{\circ} \mathrm{A}^{\prime}$-scrambling of contrastive topics/foci and negative phrases; we refer the reader to Section V13.3 for a discussion of these forms of $\mathrm{A}^{\prime}$-movement.

\section{a. Clausemate restriction on gapping:}

Remnants of gapping are ${ }^{\circ}$ major phrases of the target clause.

b. Correlation restriction on gapping and $\mathbf{A}^{\prime}$-movement:

Remnants of gapping can undergo $\mathrm{A}^{\prime}$-movement in non-reduced clauses.

Subsection D also discusses a number of facts suggesting that the correlation restriction in (85b) follows from the fact that gapping remnants are actually moved into designated $\mathrm{A}^{\prime}$-positions and that gapping elides everything but these positions. This subsection will also show that the resulting $\mathrm{A}^{\prime}$-movement hypothesis in (86) makes the verbal-head restriction on gapping in (84b) superfluous. Subsection E concludes by pointing out some residual potentially problematic issues. 


\section{$A^{\prime}$-movement hypothesis:}

Remnants of gapping have undergone $\mathrm{A}^{\prime}$-movement.

Before we start our discussion of gapping, a red flag should be raised: Dutch gapping may not be the same phenomenon as what has been called gapping in, e.g., English, which may account for the fact that various differences have been reported between the two languages. The $\mathrm{A}^{\prime}$-movement hypothesis in (86) entails in fact that the two phenomena are different, as English may not have all types of $\mathrm{A}^{\prime}$ movement found in Dutch, more specifically, it may not have the various types of $\mathrm{A}^{\prime}$-scrambling discussed in Section V13.3. Non-Dutch speakers may therefore encounter Dutch gapping constructions that are marked or even unacceptable in their own language.

\section{A. Restrictions on the antecedent and the target clause}

Subsection IC has discussed the standard assumption that gapping obligatorily elides the finite verb of the target clause. This subsection will show that this generalization correctly predicts that main and embedded finite clauses can both be the target of gapping. It also predicts that target clauses cannot be infinitival because such clauses by definition do not have a finite verb, but this prediction will be shown to be wrong. This subsection also introduces an additional restriction, viz., that the antecedent clause and the target clause must both be immediate constituents of the coordinate structure, that is, they cannot be embedded within the coordinands.

\section{Simple main clauses}

The examples in $(87 \mathrm{a} \& b)$ were given in Subsection I as an illustration of the fact that gapping must target a finite verb: gapping the object while leaving the finite verb intact is impossible. We have added the backward conjunction reduction construction in (87c) here in order to show that there is nothing wrong with contrastively stressing the finite verb, so that the unacceptability of (87b) on the intended reading should indeed be attributed to gapping as such.

$$
\begin{aligned}
& \text { a. [[JAN las een BOEK] en [MARIE as een ARTIKEL]]. } \\
& \text { Jan read a book and Marie read an article } \\
& \text { 'Jan read a book and Marie an article.' } \\
& \text { b. *[[JAN LAS een boek] en [MARIE SCHREEF } \\
& \text { Jan read a book and Marie wrote a book } \\
& \text { Intended reading: 'Jan read a book and Marie wrote a book.' } \\
& \text { c. [[Jan LAS en [Marie SCHREEF een boek]]. } \\
& \text { Jan read a book and Marie wrote a book } \\
& \text { Intended reading: 'Jan read a book and Marie wrote a book.' }
\end{aligned}
$$

[gapping]

Observe that the linear string Jan las een boek en schreef een artikel 'Jan read a book and wrote an article' is fully acceptable but cannot be considered a case of gapping if omission of the finite verb in the target clause is indeed the hallmark of gapping: the only available structure is the one in (88a). The conclusion that the alternative structure $(88 \mathrm{~b})$ is not available is supported by the fact that the string Jan 
las een boek en schreef een artikel would be pronounced with a non-contrastive intonation contour.

(88) a. Jan [[las een boek] en [schreef een artikel]].

Jan read a book and wrote an article

b. *[[Jan LAS een BOEK] en [Jan SCHREEF een ARTIKEL $]$.

Jan read a book and Jan wrote an article

The examples in (89) essentially show the same as $(87 \mathrm{a} \& \mathrm{~b})$, but in addition they involve the behavior of the finite verb and of the direct object. The acceptability of the two examples in $(89 \mathrm{a} \& b)$ shows that gapping of the object in the target coordinands is optional in the sense that it depends on its correlate in the antecedent clause: elision of the object is impossible when the two objects are contrastive, but possible when they are not contrastive. The acceptability contrast between the two examples in $(89 \mathrm{a} \& \mathrm{c})$, on the other hand, shows that gapping of the finite verb is not optional in the same sense; gapping constructions with an overt finite verb in the target clause are always unacceptable, regardless of whether or not the finite verb is contrasted with its correlate in the antecedent clause.

(89) a. [[JAN legt het boek op de STOEL] en [PETER op de TAFEL]]. Jan puts the book on the chair and Peter puts the book on the table

b. [[JAN legt het BOEK op de StOel] en [PETER de CD op de TAFEL]]. Jan puts the book on the chair and Peter puts the CD on the table

c. *[[JAN LEGT het boek op de STOEL] en [PETER ZET to in de KAST]]. Jan puts the book on the chair and Peter puts the book on the shelves

The examples in (90) further show that gapping of finite verbs has the conspicuous property that the gapped verb and its antecedent can have different forms; the two finite verbs may differ in subject-agreement (person and number) marking but not in tense (present/past) marking.
a.
[[JAN speelt
een SONATE] e
[WIJ spelen een CONCERTO]].
[number] Jan plays a sonata and we play a concerto
'Jan will play a sonata and we will play a concerto.'
b. [[JAN speelt VIOOL] en [IK BLOKFLUIT]].
Jan plays violin and I play recorder
'Jan plays the violin and I play the recorder.'
c. "? [JJAN zong GISTEREN] en [MARIE inge MORGEN]].
Jan sang yesterday and Marie sings tomorrow
'Jan sang yesterday and Marie will sing tomorrow.'
[person]
[tense]

This is an important finding because it shows that gapping differs in yet another way from backward conjunction reduction, which does require the deleted string to be identical with its antecedent. This make a unification of the two reduction rules as instantiations of one and the same phonological rule highly unlikely; we will see that this is only one piece of evidence showing that gapping is not a post-syntactic (phonological) rule but a syntactic one. 


\section{Main clauses with a verbal complex}

Example (91a) shows for the perfect tense counterpart of example (87a) that it is also possible to gap complete ${ }^{\circ}$ verbal complexes. The cases in $(91 \mathrm{~b} \& \mathrm{c})$ illustrate that the same holds for verbal complexes consisting of finite main verbs like wil 'wants' or probeert 'tries' and the verbal head of their transparent/semi-transparent infinitival ${ }^{\circ}$ complement clause; cf. Cremers (1983:196ff.) and De Vries (1992:ch.3). For an introduction to the notion of (semi-)transparency, we refer the reader to Section V4.4.

(91) a. [[JAN heeft een BOEK gelezen] en [ELS heeft een GEDICHT gelezen]]. Jan has a book read and Els has a poem read 'Jan has read a book and Els a poem.'

b. [[JAN wil een BOEK lezen] en [ELS een GEDICHT lezen]]. Jan wants a book read and Els wants a poem read 'Jan wants to read a book and Els a poem.'

c. [[JAN probeert een BOEK te lezen] en [ELS een GEDICHT lezen]]. Jan tries a book to read and Els tries a poem to read 'Jan tries to read a book and Els a poem.'

We nevertheless cannot claim that gapping requires elision of the complete verbal complex in view of the examples in (92), which show that non-finite verbs can also be remnants of gapping; the original claim that gapping must target the finite verb is thus the descriptively adequate one.
a. [[JAN heeft GEWERKT] en [PETER GESLAPEN]]. Jan has worked and Peter has slept
b. [[JAN wil WERKEN] en [PETER SLAPEN]]. Jan wants work and Peter wants sleep
'Jan wants to work and Peter wants to sleep.'
c. [[JAN probeert te WERKEN] en [PETER te SLAPEN]]. Jan tries to work and Peter tries to sleep

\section{Embedded clauses}

In the typical case, remnants of gapping are clausal constituents of the target clause, as expressed by the clausemate restriction in (85a). In (93) we see that the clause containing the remnants need not be a main clause but can also be an embedded clause. Observe that the contrast between the two (b)-examples shows that gapping does not only obligatorily elide the finite verb of the non-main target clause but also its complementizer dat 'that': we will return to this shortly.

(93) a. [[ELS is ZIEK] en [MARIE is AFWEZIG]].

Els is ill and Marie is absent

'Els is ill and Marie absent.'

b. Jan vertelde [[dat ELS ZIEK is] en [dat MARIE AFWEZIG is]]. Jan told that Els ill is and that Marie absent is 'Jan said that Els is ill and Marie absent.'

$\mathrm{b}^{\prime}$. *Jan vertelde [[dat ElS ZIEK is] en [dat MARIE AFWEZIG is]]. Jan told that Els ill is and that Marie absent is 
The finite-verb restriction in (84a) states that gapping targets at least a finite verb and thus predicts that gapping cannot apply in infinitival clauses. This prediction is false, however, as the acceptability judgments on the examples in $(94 \mathrm{a} \& \mathrm{~b})$ do not seem to differ significantly. The contrast between the two (b)-examples shows that, as in finite clauses, gapping must elide the complementizer; overt realization of om, as in $\left(94 b^{\prime}\right)$, makes the result of gapping unacceptable.

Jan heeft beloofd ...

Jan has promised

a. [[dat hij NU de DEUR verft] en [dataj MORGEN de VLOER taft]. that he now the door paints and that he tomorrow the floor paints 'Jan has promised that he will paint the door now and the floor tomorrow.'

b. [[om NU de DEUR te verven] en [em MORGEN de VLOER $]]$. COMP now the door to paint and COMP tomorrow the floor to paint

'Jan has promised to paint the door now and the floor tomorrow.'

$\mathrm{b}^{\prime}$. *[ [om NU de DEUR te verven] en [om MORGEN de VLOER $\left.]\right]$. COMP now the door to paint and COMP tomorrow the floor to paint

The fact that the finite and infinitival complementizers dat and om must also be elided in gapping constructions shows that the finite-verb restriction, repeated here as (95a), should be formulated in a more general way by including at least some functional ${ }^{\circ}$ heads associated with the finite verb, that is, the position $\mathrm{C}$, which does not only host the complementizer but also serves as the landing site of the finite verb in main clauses, and probably also the position $\mathrm{T}$, which introduces the present/past tense feature of the finite verb. A first attempt at obtaining a more descriptively adequate formulation is given in (95b); see also De Vries (1992:ch.3) for a proposal similar in spirit.

(95) a. Finite-verb restriction on gapping:

Gapping elides the finite verb of its target clause.

b. Verbal-head restriction on gapping; Gapping elides all functional and lexical heads with verbal features $\left(\mathrm{C}, \mathrm{T}\right.$ and $\left.\mathrm{V}_{\text {finite }}\right)$ of its target clause.

In order to say anything enlightening about the rationale of the verbal-head restriction in (95b), we first need to have a better understanding of the restrictions on the remnants of gapping; for this reason, we will first discuss in more detail the clausemate restriction on gapping in Subsections B and C, and return to the present issue in Subsection D, where it will be shown that the verbal-head restriction can be formulated in an even more general way.

For completeness' sake, we want to conclude this subsection with a brief look at gapping in infinitival clauses. Although an example such as (94b) clearly cannot be analyzed as a forward conjunction reduction construction because the elided teinfinitive te verven 'to paint' is not in the left periphery of the embedded clause, deciding between a gapping and a forward conjunction reduction analysis may depend on quite subtle differences when the te-infinitive is overtly present, as in (96). While example (96a), in which the adverbials and the te-infinitives are contrastively stressed, must be analyzed as a case of gapping because the direct object de deur 'the door' is not in the left periphery of the clause, example (96b) can 
also be analyzed as a case of forward conjunction reduction (that is, VPcoordination) with ${ }^{\circ}$ across-the-board scrambling of the object, although a gapping analysis might also be in order when we add contrastive accents. The close resemblance between the two examples in (96) shows that distinguishing the two cases is not always a trivial task.

Jan heeft beloofd ...

Jan has promised

a. [[Om NU de deur te SCHUREN] en [e MORGEN te VERVN]]. COMP now the door to sand and COMP tomorrow the door to paint

b. [om de deur $\mathrm{r}_{\mathrm{i}} \quad\left[\left[\mathrm{nu} t_{\mathrm{i}}\right.\right.$ te schuren] en [morgen $t_{\mathrm{i}}$ te verven]]]. COMP the door now to sand and tomorrow to paint

'Jan has promised to sand the door now and to paint it tomorrow.'

\section{Antecedent and target clauses are full coordinands}

The previous subsections have shown that both main and embedded clauses can be targets of gapping. It seems, however, that this is only possible when the antecedent and the target clause are immediate constituents of the coordinate structure: see, e.g., the equal conjunct requirement in Boone (2014: section 1.2). In example (97a) the two clauses cannot be embedded under different matrix verbs, while in (97b) it is also impossible for a main clause to act as the antecedent clause of an embedded target clause. Observe that the sentence Ik weet dat JAN het ARTIKEL leest en MARIE het $B O E K$ is fully acceptable but probably involves coordination of the two object clauses: cf. Ik weet [[dat JAN het ARTIKEL leest] en [dat MARIE het BOEK teest]], which is in accordance with the claim that the antecedent clause and the target clause are both immediate constituents of the coordinate structure.

a. *[[Ik denk [dat JAN het ARTIKEL leest]] en

I think that Jan the article reads and

[ik weet [dat MARIE het BOEK lest]]].

I know that Marie the book reads

Intended: 'I think that Jan is reading the article and I know that Marie is reading the book.'

b. *[[JAN leest het ARTIKEL] en [ik weet [dat MARIE het BOEK est]]]. Jan reads the article and I know that Marie the book reads Intended: 'Jan is reading the article and I know that Marie is reading the book.'

The main verb in the second coordinand of the examples in (97) is the factive verb weten 'to know'. We have used this verb on purpose because the result is often much better with the non-factive verb denken 'to think', as is shown by (98).

(98) a. [[Ik weet [dat JAN het ARTIKEL leest]] en

I know that Jan the article reads and

[ik denk [dat MARIE het BOEK lest]]].

I think that Marie the book reads

'I know that J. is reading the article and I think that M. is reading the book.' 
b. [[JAN leest het ARTIKEL] en [ik denk [dat MARIE het BOEK leest]]]. Jan reads the article and I think that Marie the book reads 'Jan is reading the article and I think Marie is reading the book.'

There is good reason for assuming that the contrast between the examples in (97) and those in (98) is due to the fact that the string $i k$ denk 'I think' in these examples is parenthetical in nature: cf. Boone (2014: Section 2.6.1) and the references cited there. The sentences in (99), for instance, make it clear that this string can be used in this way in non-clausal coordinate structures.

(99) a. [[Jan] en -ik denk- [Marie]] komen morgen op bezoek.

Jan and I think Marie come tomorrow on visit

'Jan and, I think, Marie will visit us tomorrow.'

b. Hij is hier [[morgen] en -ik denk- [overmorgen]].

he is here tomorrow and I think the.day.after.tommorow

'He will be here tomorrow and, I think, the day after tomorrow.'

If the string $i k$ denk is indeed parenthetical in (98), we would simply be dealing with coordination of two object clauses in example (98a) and with coordination of two main clauses in example (98b).

(100) a. Ik weet [[dat JAN het ARTIKEL leest] en -ik denk-

I know that Jan the article reads and I think

[dat MARIE het BOEK leest]].

that Marie the book reads

'I know that J. is reading the article and I think that M. is reading the book.'

b. [[JAN leest het ARTIKEL] en -ik denk- [MARIE leest het BOEK]].

Jan reads the article and I think Marie reads the book

'Jan is reading the article and I think Marie is reading the book.'

We therefore provisionally conclude that these cases do not constitute genuine counterexamples to the generalization that the antecedent and the target clause of gapping must be immediate constituents of the coordinate structure. That the generalization is correct and the examples in (98) are exceptional does not seem to be controversial because most other matrix verbs give rise to the same pattern as found in (97); this is illustrated for the verb ontkennen 'to deny' in (101).

(101) a. *Marie beweerde [[dat ELS de RING gestolen had] en

Marie claimed that Els the ring stolen had and

Peter ontkende [dat JAN het GELD

Peter denied that Jan the money stolen had

Intended: 'Marie claimed that Els had stolen the ring and Peter denied that Jan had stolen the money.'

b. *[[ELS had de RING gestolen] en

Els had the ring stolen and

[Peter ontkende [dat JAN het GELD estolen had]].

Peter denied that Jan the money stolen had

Intended: 'E. had stolen the ring and P. denied that J. had stolen the money.' 
For the sake of completeness, we also show in (102) that we find the same pattern with complement clauses of nouns. The acceptability contrast between (102a) and (102b) shows that gapping is possible if such complement clauses are immediate constituents of a coordinate structure but not if they are embedded in a nominal coordinate structure. It goes without saying that a main clause cannot trigger gapping on such complement clauses either; cf. example (102c).

(102) a. De politie onderzocht [[de bewering [dat ELS de RING gestolen had]] the police investigated the contention that Els the ring stolen had en [an het GELD ] and that Jan the money stolen had

'The police investigated the claim that E. had stolen the ring and J. the money.'

b. *De politie onderzocht [[de bewering [dat ELS de RING gestolen had]] the police investigated the contention that Els the ring stolen had en [de ontkenning [dat JAN het GELD and the denial that Jan the money stolen had Intended: 'The police investigated the contention that Els had stolen the ring and the denial that Jan had stolen the money.'

c. *[[ELS had de RING gestolen] maar [de politie onderzocht nog steeds Els had the ring stolen but the police investigated yet still [de bewering [dat JAN het GELD the contention that Jan the money stolen had Intended: 'Els had stolen the ring but the police was still investigating the contention that Jan had stolen the money.'

\section{B. The clausemate restriction on gapping}

This subsection adopts as its point of departure the traditional view that remnants of gapping are prototypically ${ }^{\circ}$ clausal constituents (arguments, adverbials or complementives) of the target clause, as expressed by the clausemate restriction in (85a), repeated here as (103). This subsection only presents data supporting this restriction; potential counterexamples will be discussed in Subsection C.

\section{Clausemate restriction on gapping:}

Remnants of gapping are ${ }^{\circ}$ major phrases of the target clause.

\section{Clausal constituents that are clausemates}

Remnants of gapping can be nominal ${ }^{\circ}$ arguments, as illustrated in (104a) for a subject and a direct object and in (104b) for a subject and an indirect object. The (c)-examples show that sentences such as Jan gaf Marie een boek en Els een CD 'Jan gave Marie a book and Els a CD' are ambiguous in writing but not in speech, as the intonation of the antecedent clause provides information about the intended reading: the proper noun Els is interpreted with the same syntactic function as the contrastively accented proper noun in the antecedent clause. The syntactic function is of course also reflected by case assignment when the remnant is pronominal. 
(104) - Nominal arguments

a. [[JAN las een BOEK] en [MARIE een ARTIKEL]].

Jan read a book and Marie read an article

'Jan read a book and Marie an article.'

b. [[JAN gaf MARIE een boek] en [ELS Paf PETER

Jan gave Marie a book and Els gave Peter a book

'Jan gave Marie a book and Els Peter.'

c. [[JAN gaf Marie een BOEK] en [ELS/ZIJ een CD]].

Jan gave Marie a book and Els/she gave Marie a CD

'Jan gave Marie a book and Els/she a CD.'

$\mathrm{c}^{\prime}$. [[Jan gaf MARIE een BOEK] en [ar ELS/HAAR een CD]].

Jan gave Marie a book and Jan gave Els/her a CD

'Jan gave Marie a book and Els/her a CD.'

Argument clauses can also be remnants, which is illustrated for a subject clause in (105a), for a direct object clause in (105b) and for an object clause introduced by the ${ }^{\circ}$ anticipatory pronominal PP erop in $(105 \mathrm{c})$. More can be said about subject clauses introduced by the ${ }^{\circ}$ anticipatory pronoun het 'it', but we postpone this to the end of this subsection.
- Argument clauses
a. [[[dat Jan komt LOGEREN] is LEUK] maar that Jan comes stay.over is nice but [[dat hij twee weken BLIJFT] is overdreven]]. that he two weeks stays is exaggerated

'That Jan will stay is nice but that he will stay for two weeks exaggerated.'

b. [[JAN zegt [dat Els ZIEK is]] maar [PETER [dat ze op VERLOF is]]]. Jan says that Els ill is but Peter says that she on leave is 'Jan says that Els is ill but Peter that she is on leave.'

c. [[JAN rekent erop [dat ELS komt]] en [Peter [dat Marie komt]]]. Jan counts on.it that Els comes and Peter counts on.it that Marie comes 'Jan counts on it that Els will come and Peter that Marie will come.'

Prepositional objects can also be used as remnants of gapping, as shown in (106). Example (106a) illustrates this for an intransitive construction and the (b)-examples for transitive constructions; in the latter cases, the interpretation of the nominal remnant is again determined by the syntactic function of the contrastively stressed noun phrase in the antecedent clause.

(106) • PP-complements

a. [[JAN wacht op MOEDER] en [ELS op VADER]]. Jan waits for mother and Els waits for father 'Jan is waiting for mother and Els for father.'

b. [[MARIE heeft haar huis tegen INBRAAK verzekerd] en Marie has her home against burglary insured and [ELS ham huis tegen BRAND

Els has her home against fire insured

'Marie has insured her home against burglary and Els against fire.' 
$\mathrm{b}^{\prime}$. [[Marie heeft haar AUTO tegen INBRAAK verzekerd] en Marie has her car against burglary insured and [ haar HUIS tegen BRAND d]].

Marie has her home against fire insured

'Marie has insured her car against burglary and her home against fire.'

The examples in (107) further show that ${ }^{\circ}$ complementives may also occur as remnants of gapping, and that the categorial status of the complementive (adjectival, nominal or adpositional) does not affect the acceptability of the output.

(107) • Complementives

a. [[De ROMAN is SAAI] maar [de FILM is SPANNEND]].

the novel is boring but the movie is thrilling

'The novel is boring but the movie thrilling.'

b. [[ELS is SYNTACTICUS] en [JAN is FONOLOOG]].

Els is syntactician and Jan is phonologist

'Els is a syntactician and Jan a phonologist.'

c. [[JAN gaat naar UTRECHT] en [ELS naar HAARLEM]].

Jan goes to Utrecht and Els goes to Haarlem]]

'Jan is going to Utrecht and Els to Haarlem.'

The examples in (108), finally, show that remnants of gapping can also be adverbial phrases provided that they can be used contrastively. The examples in (108a-c) involve, respectively, a temporal, a locational and a modal adverbial remnant. Example (108d) shows that it is also possible for all remnants to be adverbial.

(108) - Adverbial phrases

a. [[JAN leest het artikel VANDAAG] en [PETER MORGEN]]. Jan reads the article today and Peter reads the article tomorrow 'Jan reads the article today and Peter tomorrow.'

b. [[Jan leest het ARTIKEL in de TREIN] maar [at BOEK THUIS]]. Jan reads the article in the train but Jan reads the book home 'Jan will read the article in the train but the book at home.'

c. [[Jan is MISSCHIEN BOOS] maar [S ZEKER TELEURGESTELD]]. Jan is perhaps angry but Jan is certainly disappointed 'Jan will perhaps be angry but he will certainly be disappointed.'

d. [[Jan komt VANDAAG MISSCHIEN] maar [ MORGEN ZEKER]]. Jan comes today perhaps but Jan comes tomorrow certainly 'Jan will perhaps come today but certainly tomorrow.'

The examples in (109), repeated from Subsection IG, show that the remnants of gapping are not just clausal constituents but ${ }^{\circ}$ major phrases in the sense of Neijt (1979), that is, they can also be specific smaller verbal projections such as the

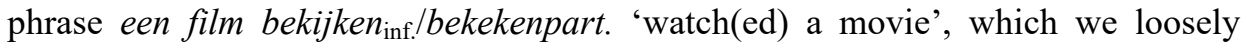
refer to as "VP" for convenience.

(109) a. [[JAN heeft [vp een BOEK gelezen]] en [ELS heeft [vp een FILM bekeken]]]. Jan has a book read and Els has a movie watched 'Jan has read a book and Marie has watched a movie.' 


\section{b. [[JAN wil [vp een BOEK lezen]] en [ELS wil [vp een FILM bekijken]]]. Jan wants a book read and Els wants a movie watch 'Jan wants to read a book and Els wants to watch a movie.'}

The examples above have not only shown that there are no restrictions with respect to the syntactic function of the remnants of gapping but also that there are no clear restrictions with respect to their categorial status: they can be verbal, nominal, adjectival, adpositional, and clausal.

We conclude this subsection with a brief digression on subject and object clauses. Although the examples in (105) have already shown that argument clauses are able to appear as remnants of gapping, it is not immediately clear whether such clauses may also appear as remnants if they are introduced by the anticipatory pronoun het 'it'. Example (110a) is acceptable but since the subject clauses are actually arguments of the complementive adjectives, and hence generated within the $\mathrm{VP}$, this example can also be analyzed as a case of forward conjunction reduction, that is, as VP-coordination with ${ }^{\circ}$ across-the-board movement of the finite verb is: cf. Het is [VP leuk $\mathrm{t}_{\text {is }}$ [dat Jan komt logeren]] maar [VP overdreven $\mathrm{t}_{\text {is }}$ [dat hij twee weken blijft]]. Something similar holds for example (110b), in which the object clauses are again arguments of the adjectives: this example can therefore be analyzed as VP-coordination with across-the-board ${ }^{\circ}$ scrambling of the anticipatory pronoun het: cf. Els vindt het [VP $\mathrm{t}_{\text {het }}$ leuk [dat Jan komt logeren]] maar [VP $\mathrm{t}_{\text {het }}$ overdreven [dat hij twee weken blijft]].

$$
\text { - Gapping analysis (to be rejected) }
$$

a. [[Het is leuk [dat Jan komt logeren]] maar it is fun that Jan comes stay.over but [het is overdreven [dat hij twee weken blijft]]]. it is exaggerated that he two weeks stays 'It's fun that Jan will stay but it's exaggerated that he will stay for two weeks.'

b. [[Els vindt [het leuk [dat Jan komt logeren]]] maar Els considers it fun that Jan comes stay.over but [Els [hes overdreven [dat hij twee weken blijft]]]]. Els considers it exaggerated that he two weeks stays 'Els considers it fun that Jan will stay but exaggerated that he will stay for two weeks.'

That the forward conjunction reduction analysis is superior is suggested by the fact that the gapping analysis wrongly predicts that example (111) is acceptable, while the forward conjunction reduction analysis predicts that the overt string is ungrammatical as it involves coordination of VPs (and not full clauses), so that there is simply no subject available in the second coordinand: cf. Els vindt [[VP ...] maar $[V P \ldots]]$. We therefore provisionally conclude that the structures in (110) are ungrammatical.

*[[ELS vindt [het LEUK [dat Jan komt logeren]]] maar
Els considers it fun that Jan comes stay.over but
[MARIE
Marie considers it exaggerated that he two weeks stays




\section{Other cases}

Subsection 1 has shown that, in the typical case, gapping remnants are clausal constituents of the target clause. This subsection will show that, in accordance with the clausemate restriction in (103), gapping remnants can normally not be embedded in such clausal constituents. The examples in (112) illustrate this for a remnant embedded in an object clause: while (112a) shows that the subject and the object clause of the matrix clause can be remnants of gapping, (112b) shows that the subject and the complementive embedded in the object clause cannot.

(112) a. [[JAN zegt [dat het boek SAAI is]] en [ELS [dat het SPANNEND is]]]. Jan says that the book boring is and Els says that it thrilling is 'Jan says that the book is boring and Els says that it is thrilling.'

b. *[[JAN zegt [dat het boek SAAI is]] en [ELS [d het SPANNEND is]]]. Jan says that the book boring is and Els says that the book thrilling is

That the two gaps must be clausemates also accounts for the fact that the sentence Jan zegt dat Els een boek wil and Peter een $C D$ cannot be assigned the structure in (113a) but must be interpreted on the basis of the structure in (113b).

(113) a. *[[JAN zegt [dat Els een BOEK wil]] en [PETER [ een CD Jan says that Els a book wants and Peter says that Els a CD wants

b. Jan zegt [[dat ELS graag een BOEK wil] en [dat PETER een CD il]]. Jan says that Els gladly a book wants and that Peter gladly a CD wants 'Jan says that Els would like to have a book and Peter a CD.'

The contrast between (114a) and (114b) shows once more that the remnant of gapping can be a full nominal subject but not its postnominal modifier. Similar cases with a nominal object are provided (115).

(114) [Het huis [op het PLEIN]] staat DRIE MAANDEN te koop] en ... the house on the square stands three months for sale and

a. [het huis [bij het PARK]] MEER DAN EEN JAAR R ]]. the house near the park stands more than a year for sale

'The house on the square has been for sale for three months and the house near the park for over a year.'

b. *[he huis [bij het PARK]] MEER DAN EEN JAAR the house near the park stands more than a year for sale

(115) [[JAN heeft [het huis [op het PLEIN]] gekocht] en ...

Jan has the house on the square bought and

a. [ELS [het huis [bij het PARK]]

Els has the house near the park bought

'Jan has bought the house on the square and Els the house near the park.'

b. *[ELS het hetis [bij het PARK]]

Els has the house near the park bought

It should be noted, however, that some speakers do allow for examples such as (115b) when the postnominal modifier occurs (or can occur) in extraposed position. This is illustrated in (116) for the object een fiets met zeven versnellingen 'a bike 
with seven gears'; as far as we know, the effect of ${ }^{\circ}$ extraposition on gapping has not been discussed in the literature but it deserves further investigation.

[[ELS heeft een fiets gekocht met DRIE versnellingen]] en ...

Els has a bike bought with three gears and

a. [JAN een fiets met ZEVEN versnellingen]].

Jan has a bike bought with seven gears

'Els has bought a bike with three gears, and Jan a bike with seven gears.'

b. ${ }^{\%}[$ JAN met ZEVEN versnellingen]].

Jan has a bike bought with seven gears

That the relative acceptability of (116b) may be due to the postnominal modifier being in extraposed position can be supported by the fact that the gapping remnant cannot be smaller than PP, despite the fact that the contrastive accent is assigned to a subpart of the modifier, namely the cardinal number; cf. *.. en $J_{A N}$ ZEVEN versnellingen and *.. en JAN ZEVEN This is related to the fact illustrated in (117) that complements of PPs normally cannot be remnants of gapping either. This is shown in the (a)-examples for a prepositional object and in the (b)-examples for an instrumental adverbial phrase; while the full PPs are licit remnants of gapping, their nominal complements are not.

(117) a. [[JAN kijkt vaak [naar FILMS]] en [ELS [naar TALKSHOWS]]]. Jan looks often at movies and Els looks often at talk.shows

'Jan often watches movies and Els talkshows.'

$\mathrm{a}^{\prime}$. *[JJAN kijkt vaak [naar FILMS]] en [ELS TALKSHOWS]]]. Jan looks often at movies and Els looks often at talk.shows

b. [[JAN schrijft met een POTLOOD] en [PETER met een PEN]]. Jan writes with a pencil and Peter writes with a pen

'Jan writes with a pencil and Peter with a pen.'

$\mathrm{b}^{\prime}$. *[[JAN schrijft [met een POTLOOD]] en [PETER Jan writes with a pencil and Peter writes with a pen

This does not hold for complements of postpositional phrases, however, which is related to the fact that a ${ }^{\circ}$ complement of postpositions can easily be moved into some more leftward position: cf. dat Els de beuk waarschijnlijk graag in klimt 'that Els probably likes to climb into the beech'.

(118) a. *[[Jan klom [in de eik]] en [Els klem [in de beuk]]]. Jan climbed into the oak and Els climbed into the beech

b. [[Jan klom [de eik in]] en [Els [de beuk ]]]. Jan climbed the oak into and Els climbed the beech into 'Jan climbed the oak tree and Els the beech tree.'

The generative literature on gapping has paid considerable attention to the question as to whether or not gapping is sensitive to ${ }^{\circ}$ islands for movement, in the sense that gapping remnants cannot occur in such islands. Neijt (1979), for instance, refers to examples such as (119a) to show that they cannot and concludes from this that gapping should be considered a syntactic rule. Although we will argue in Subsection D that Neijt's conclusion is correct after all, it should be pointed out that 
the island-sensitivity of gapping cannot be used as an argument in favor of this conclusion. Example (119a) with one remnant in an interrogative clause and another remnant in its matrix clause can be assumed to be degraded for the same reason as example (119b), which cannot be accounted for by an appeal to the supposed island-sensitivity of gapping.

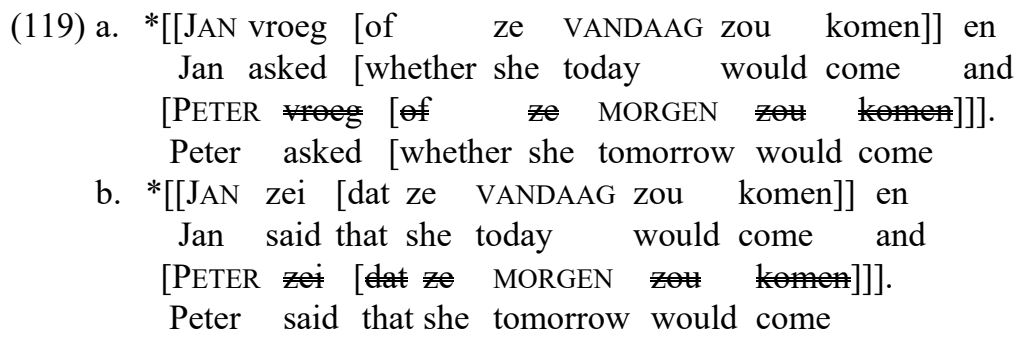

The clausemate restriction in (103) in fact rules out all cases in which a remnant is contained in an island embedded in the target clause of gapping; see also Boone (2014:40). The unacceptability of (120b), in which one remnant is contained in a complex NP island, for instance, can again be accounted for in the same way as the unacceptability of (115b), without making an appeal to the (presumed) islandsensitivity of gapping. It is crucial to note here that the relative clause as a whole cannot occur as remnant (that is, without its antecedent het boek) either, despite the fact that it can be extraposed; cf. the discussion of in (116).

$$
\begin{aligned}
& \text { [[JAN kocht [DP het boek [Rel-clause dat MARIE aanbevolen had]]] en ... } \\
& \text { Jan bought the book that Marie recommended had and } \\
& \text { a. [Els [DP het boek [Rel-clause dat PETER aanbevolen had]]]]. } \\
& \text { Els bought the book that Peter recommended had } \\
& \text { b. *[Els [DP } \\
& \text { Els bought the book that Peter 'recommended had }
\end{aligned}
$$

For completeness' sake, we provide a presumed violation of the coordinate structure constraint in (121). On the plausible assumption that the two coordinands of the coordinate structure functioning as a direct object are not clausal coordinands of the target clause, the acceptability contrast between the primeless and primed examples (on the intended reading that Els ate vegetables and potatoes) follows from the clausemate restriction; an appeal to island-sensitivity is again not needed.

(121) a. [[JAN at [RIJST en groente]] en [ELS [AARDAPPELS en groente]]]. Jan ate rice and vegetables and Els ate potatoes and vegetables

$\mathrm{a}^{\prime}$. *[JJAN at [RIJST en groente]] en [ELS at [AARDAPPELS ente]]. Jan ate rice and vegetables and Els ate potatoes and vegetables

b. [[JAN at [groente en RIJST]] en [ELS at [groente en AARDAPPELS]]]. Jan ate vegetables and rice and Els ate vegetables and potatoes

$\mathrm{b}^{\prime} .{ }^{*}[[\mathrm{~J}$ AN at [groente en RIJST]] en [ELS AARDAPPELS]]]. Jan ate vegetables and rice and Els ate vegetables and potatoes

The discussion above has shown that the island-sensitivity of gapping cannot be used for arguing that gapping is a rule of syntax. This does not imply, however, that 
syntactic islands are irrelevant for gapping constructions altogether, but this is an issue that we postpone to Subsection D1, where we will investigate the markedness of examples such as (119b) greater detail.

\section{Potential counterexamples to the clausemate restriction}

Subsection B has shown that the clausemate restriction on gapping, repeated here as (122), is able to account for a large set of data.

\section{Clausemate restriction on gapping:}

Remnants of gapping are ${ }^{\circ}$ major phrases of the target clause.

There appear to be a number of potential counterexamples to this restriction, however. Subsection 1 starts by arguing that examples such as (123), which apparently involve a target clause with a subject remnant of the matrix clause and an object remnant of an embedded clause, are only apparent violations of the clausemate restriction: we will argue that the second remnant is not the embedded object but the full object clause, which happens to be phonetically reduced by ${ }^{\circ}$ sluicing; cf. Section V5.1.5.

$$
\begin{aligned}
& \text { [[JAN weet [welke JONGENS komen]] en [ELS [welke MEISJES }]] \text {. } \\
& \text { Jan knows which boys come and Els knows which girls come } \\
& \text { 'Jan knows which boys are coming and Els which girls.' }
\end{aligned}
$$

Subsection 2 continues by discussing a number of true counterexamples to the clausemate restriction involving remnants that are arguably part of an adjectival or adpositional phrase: cf. [[JAN is [boos op MARIE]] en [ELS op PETER]]] 'Jan is angry with Marie and Els with Peter'. As such cases clearly refute the clausemate restriction in (122), we will replace it by the descriptively more adequate restriction on gapping in (124); cf. Neijt (1979).

\section{Correlation restriction on gapping and $\mathrm{A}^{\prime}$-movement:}

Remnants of gapping can undergo $\mathrm{A}^{\prime}$-movement in non-reduced clauses.

\section{Target clauses with a sluiced complement clause}

This subsection discusses an apparent counterexample to the clausemate restriction. Example (125a) first shows again that a ${ }^{\circ}$ clausal constituent of an object clause can normally not be a remnant of gapping when gapping targets the matrix clause. Example (125b) shows, however, that the result is impeccable when the remnant is a $w h$-phrase.

(125) a. *[[JAN weet [dat PETER komt] $]$ en [Els [dat MARIE Jan knows that Peter comes and Els knows that Marie comes

b. [[JAN weet [welke JONGENS komen]] en [ELS [welke MEISJES Jan knows which boys come and Els knows which girls come 'Jan knows which boys are coming and Els which girls.'

There is enough reason, however, for assuming that (125b) can be derived without violating the clausemate restriction on gapping. Example (126a) first shows that the object clause of the second coordinand can also appear in the form of the fragment 
clause welke meisjes as a result of so-called sluicing (cf. V5.1.5); we indicate the deleted part arising from sluicing by boldface in order to distinguish it from the deleted part arising from gapping. Subsequent application of gapping to the clausal coordinand Els weet welke meisjes by eliding the finite verb weet 'knows' is in full accordance with the clausemate restriction and results in (126b), which is essentially identical to (125b) apart from the use of boldface for sluicing.

(126) a. [[Jan weet [welke jongens komen]] en

Jan knows which boys come and

[Els weet [welke meisjes

[step 1: sluicing]

Els knows which girls come

'Jan knows which boys are coming and Els knows which girls.'

b. [[JAN weet [welke JONGENS komen]] en

Jan knows which boys come and

[Els [welke MEISJES komen]]]. [step 2; gapping]

Els knows which girls come

'Jan knows which boys are coming and Els knows which girls.'

The sluicing approach suggested above receives further support from the examples in (127). Example (127a) first shows that this example allows sluicing, and (127b) shows that the output of sluicing can subsequently be the input for gapping. The crucial fact is that (127b) cannot be derived by gapping directly (that is, without sluicing) because the two wh-phrases welke jongens and wanneer do not have the same syntactic function. It is also questionable whether the phrase die jongens is recoverable given that its counterpart in the target coordinand has the form of a whphrase; cf. Subsection IE. Example (127b) can, however, easily be derived from the sluicing construction in (127a) by gapping of the finite verb, because the embedded interrogative clause [welke jongens komen] in the antecedent clause has the same syntactic function as the fragment clause [wanneer target clause of gapping, namely that of direct object.

(127) a. [[Jan weet [welke jongens komen]] en

Jan knows which boys come and

[Els weet [wanneer $\mathbf{z e}$ /die jongens komen]]].

[step 1: sluicing]

Els knows when they/those boys come

'Jan knows which boys are coming and Els knows when.'

b. [[JAN weet [WELKE jongens komen]] en

Jan knows which boys come and

[ELS [WANNEER [step 2; gapping]

Els knows when they/those boys come

'Jan knows which boys are coming and Els knows when.'

Although the discussion above shows that the sluicing approach has much to recommend itself, there are also a number of potential problems. Neijt (1979:145ff.) rejects this approach on three grounds, two of which will be discussed here. First, she claims that in certain cases the supposed input string for gapping is unacceptable, which she illustrates by means of the examples in (128). 
(128) a. \$[ Jan mag beslissen [welke jongens er mee gaan]] en

Jan may decide which girls there with go and

[Peter mag beslissen [welke meisjes ef mee gaan]]].

Peter may decide which girls there with go

'J. may decide which boys may come along and P. may decide which girls.'

b. [[JAN mag beslissen [welke JONGENS er mee gaan]] en

Jan may decide which girls there with go and

[PETER maglisen [welke MEISJES er mee gam]]].

Peter may decide which girls there with go

'Jan may decide which boys may go along and Peter which girls.'

Neijt states that "most informants reject [(128a) above], since for them sluicing applies in contrastive contexts [....] only", that is, in contexts with the coordinator maar 'but' (in which case both examples are certainly perfectly acceptable). This does not show, however, that the construction in (128a) is ungrammatical but only that it violates a use condition (for which reason we have marked it with the dollar sign). Because we have seen that gapping constructions are contrastive by definition, it might be the case that the acceptability contrast between the two examples is due to the fact that the use condition is violated in (128a) but satisfied in (128b). The argument is therefore inconclusive - even apart from the fact that some speakers (including ourselves) do consider (128a) fully acceptable, though stylistically somewhat clumsy compared to its more economically phrased alternate in (128b).

Another reason given for rejecting the sluicing approach is that sluicing normally deletes the whole string following the $w h$-phrase in clause-initial position, as shown by the acceptability contrast between the two examples in (129).

[[Jan weet [dat de jongens vertrekken]] maar
Jan knows that the boys leave but
[Peter weet [wanneer $]]$.
Peter knows when the boys leave
'Jan knows that the boys will leave, but Peter knows when.'
*[Jan weet [dat de jongens vertrekken]] maar
Jan knows that the boys leave but
[Peter weet [wanneer de meisjes
Peter knows when the girls leave

Neijt claims that unacceptable examples such as (129b) cannot be the input for the gapping rule that derives example (130). There are various reasons for not accepting Neijt's conclusion; (i) Neijt herself notices that the gapping pattern found in (130) is "highly limited" in that the two gapping remnants in the embedded clause must be adjacent to each other (p.148), which is normally not needed; (ii) even if this special adjacency condition is met, the gapping pattern in (130) seems to be quite marked, which is indicated here by using the percentage sign; (iii) Neijt's implicit claim that gapping is exclusively responsible for the omitted material in (130) cannot be maintained in light of the fact that wh-phrase wanneer 'when' is not contrastive because it has no counterpart in the antecedent clause. 


${ }^{\%}[[\mathrm{JAN}$ weet [dat de jongens vertrekken] maar
Jan knows that the boys leave but
$[$ PETER
Peter knows when the girls leave

Finally, it should be noted that the premise underlying the second argument against the sluicing approach, viz., that the remnant of sluicing must be a single constituent, cannot be maintained in the light of the acceptability of embedded multiple whquestions as in (131), as the remnant of sluicing consists of two clausal constituents in this case, the subject wie 'who' and the object wat 'what'.

$$
\begin{aligned}
& \text { [[Ik weet [dat iedereen iets gelezen heeft]] maar } \\
& \text { I know that everyone something read has but } \\
& \text { [ik weet niet [wie wat } \\
& \text { I know not who what read has } \\
& \text { 'I know that everyone has read something, but I do not know who what.' }
\end{aligned}
$$

We conclude from the discussion above that Neijt has not conclusively shown that the sluicing approach to examples like (125b) and (127b) should be rejected; see also Den Besten (1981). Because of the positive evidence in favor of this approach, we provisionally conclude that these examples are only apparent counterexamples to the clausemate restriction.

\section{Genuine counterexamples: on gapping and A'-movement}

Genuine counterexamples to the clausemate restriction in (103) can be found in (132): example (132a) is a case in which one of the remnants functions as the PPcomplement of an adjective. This is prohibited by the clausemate restriction, but in agreement with another observation in Neijt (1979:ch3), viz., that constituents appearing as remnants of gapping are able to undergo ${ }^{\circ} \mathrm{A}^{\prime}$-movement in nonreduced clauses. This is illustrated in the (b)-examples by showing that the PPcomplement of boos 'angry' is able to undergo ${ }^{\circ}$ focus movement, topicalization, and $w h$-movement.

(132) a. [[JAN is [erg boos [op MARIE]]] en [Els [op PETER]]]]. Jan is very angry with Marie and Els is very angry with Peter 'Jan is very angry with Marie and Els with Peter.'

b. Els is [op PETER $]_{i}$ [erg boos $t_{i}$ ].

[focus movement] Els is with Peter very angry

$\mathrm{b}^{\prime}$. [Op Peter $]_{\mathrm{i}}$ is Els [erg boos $\left.t_{\mathrm{i}}\right]$. [topicalization] with Peter is Els very angry

$\mathrm{b}^{\prime \prime}$. [Op wie $]_{\mathrm{i}}$ is Els [erg boos $t_{\mathrm{i}}$ ]? with who is Els very angry 'Who is Els very angry with?'

[wh-movement]

We will formulate this observation as in (133b). We will show that the degree of descriptive adequacy of this correlation restriction on gapping is higher than that of the clausemate restriction in (133a). There are also a number of potential problems, but the discussion of these will be postponed to Subsection D. 
(133) a. Clausemate restriction on gapping:

Remnants of gapping are clausal constituents of the target clause.

b. Correlation restriction on gapping and $\mathbf{A}^{\prime}$-movement:

Remnants of gapping can undergo $\mathrm{A}^{\prime}$-movement in non-reduced clauses.

That restriction (133b) is superior to the clausemate restriction in (133a) is not only clear from the examples in (132) but also from those in (134). Example (134a) first shows that degree modifiers of adjectives cannot occur as remnants of gapping, which is in agreement with both restrictions: the degree modifier erg is not a clausal constituent and it cannot be $\mathrm{A}^{\prime}$-moved either. Example (134b), on the other hand, shows that nominal measure phrases functioning as modifiers of an adjective, can occur as gapping remnants. This is not in agreement with the clausemate restriction because such measure phrases are not clausal constituents, but it is in agreement with the correlation restriction on gapping and $\mathrm{A}^{\prime}$-movement, as is clear from the fact illustrated in $\left(134 \mathrm{~b}^{\prime}\right)$ that such phrases can easily be wh-moved; cf. Zwarts (1978:327), Neijt (1979) and Corver (1990).

(134) a. *[[DeZE kuil is [VRIJ diep]] en [DIE kuil is [ERG diep]]].

this pit is fairly deep and that pit is very deep

$\mathrm{a}^{\prime} .{ }^{*}[\mathrm{Hoe}]_{\mathrm{i}}$ is deze kuil $\left[t_{\mathrm{i}}\right.$ diep $]$ ?

how is this pit deep

Intended: 'How deep is this pit?'

b. [[DEZE kuil is [DRIE meter diep]] en [DIE kuil is [VIER meter diep]]].

this pit is three meter deep and that pit is four meter deep

'This pit is three meters deep and that pit four meters.'

$\mathrm{b}^{\prime}$. [Hoeveel meter $]_{\mathrm{i}}$ is deze kuil $\left[t_{\mathrm{i}}\right.$ diep $]$ ?

how.many meter is this pit deep

Subsection B2 has already shown that the clausemate restriction correctly predicts that clausal constituents of embedded clauses cannot occur as remnants of gapping targeting the matrix clause. The relevant examples are repeated in (135).

(135) a. *[[JAN weet [dat Els komt]] en [PETER [dat MARIE Jan knows that Els comes and Peter knows that Marie comes

b. *[[JAN zei [dat Els VANDAAG zou komen $]]$ en

Jan said that Els today would come and

[PETER [Aat MORGEN

Peter said that Els tomorrow would come

The clausemate restriction also predicts that clausal constituents embedded in infinitival clauses cannot occur as remnants of gapping. This seems to be borne out for $o m+t e$-infinitival clauses such as (136a) but not for $t e$-infinitival clauses such as (136b). Note that, although speakers vary somewhat in their judgments, the contrast seems real; see the discussion of comparable examples in Neijt (1979:183), Den Besten (1981:154), and Haeseryn (1997:1594). 


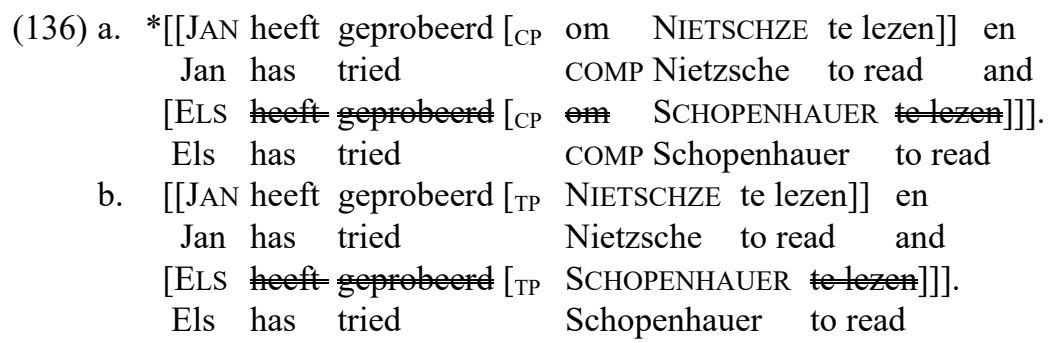

The contrast is in keeping with our conclusion from Section V5.2 that om + teinfinitival and $t e$-infinitival clauses have a different categorial status: the former are CPs, which are opaque domains for movement, while the latter are TPs, which are semi-transparent domains for movement. The correlation restriction on gapping and $\mathrm{A}^{\prime}$-movement thus correctly predicts that the acceptability contrast between the two examples in (136) correlates with the acceptability contrast between the "remnant extraposition" constructions in (137), which are discussed extensively in Section V5.2.2.3.

(137) a. *Jan heeft [dat boek $]_{\mathrm{i}}$ geprobeerd [cP om $t_{\mathrm{i}}$ te lezen]. Jan has that book tried COMP to read

b. Jan heeft [dat boek $]_{\mathrm{i}}$ geprobeerd [тр $t_{\mathrm{i}}$ te lezen]. Jan has that book tried to read 'Jan has tried to read that book'.

Section V4.4 has argued that modal verbs in examples such as Jan wil een boek kopen are main verbs that take a bare infinitival clause (VP) as their complement: the underlying hierarchical structure of this example is thus something like [Jan wil [VP een boek kopen]]. If so, a strictly orthodox reading of the clausemate restriction in (133a) would make the incorrect prediction that gapping examples such as (138a) are unacceptable because the object een $C D$ does not originate as a clausal constituent of the main clause but of the embedded bare infinitival clause, and is therefore not a clausemate of the subject Marie. The correlation restriction on gapping and $\mathrm{A}^{\prime}$-movement, on the other hand, correctly predicts that (138a) is possible because (138b) shows that the object can be wh-moved; see Section V5.2 for a more extensive discussion of the transparency of bare infinitival clauses.

(138) a. [[JAN wil [vp EEN BOEK kopen]] en [MARIE [vp een CD Jan wants a book buy and Marie wants a CD buy 'Jan wants to buy a book and Marie a CD.'

b. Wat ${ }_{\mathrm{i}}$ wil Jan $\left[\mathrm{vp} t_{\mathrm{i}}\right.$ kopen]? what wants Jan buy

'What does Jan want to buy?'

We conclude from the discussion so far that the correlation restriction on gapping and $\mathrm{A}^{\prime}$-movement in (133b) is superior to the clausemate restriction in (133a). Neijt argues that because the locality restrictions on movement are part of syntax, the correlation between gapping and $\mathrm{A}^{\prime}$-movement established in this subsection leads to the irrefutable conclusion that gapping is a rule of syntax. Subsection D will address the difficult question as to what the nature of this syntactic rule is. 


\section{Gapping is syntactic in nature}

Neijt (1979) noted a correlation between $w h$-movement and gapping and concluded from it that gapping (contrary to backward conjunction reduction) must be a rule of syntax. She did not take the next logical step, however, of assuming that whmovement is actually involved in the derivation of gapping, for reasons that will be reviewed in Subsection 1. This subsection will also show that these reasons do not apply when we formulate Neijt's correlation not in terms of wh-movement but in terms of the more general notion of ${ }^{\circ} \mathrm{A}^{\prime}$-movement, which does not only refer to wh-movement but also to the various forms of ${ }^{\circ} \mathrm{A}^{\prime}$-scrambling discussed in Section V13.3, that is, topic, focus, and negation movement.

\section{(139) a. Correlation restriction on gapping and $\mathbf{A}^{\prime}$-movement:}

Remnants of gapping can undergo $\mathrm{A}^{\prime}$-movement in non-reduced clauses.

b. A'-movement hypothesis:

Remnants of gapping have undergone $\mathrm{A}^{\prime}$-movement.

Subsections 2 to 5 present additional empirical evidence for replacing the restriction (139a) by the hypothesis in (139b). For (reviews of) earlier $\mathrm{A}^{\prime}$-movement analyses, we refer the reader to Johnson (2017: section 4) for English, Aelbrechts (2007) and Boone (2014) for Dutch, and Ai (2014) for Mandarin.

\section{Gapping and focus/topic movement}

The discussion of the examples in (135) to (138) in Subsection C 2 has sidestepped one important problem for the correlation restriction on gapping and $\mathrm{A}^{\prime}$-movement, namely the fact that clausal constituents can be $w h$-moved from finite embedded clauses. For what follows, it is important to repeat here that such wh-extraction does not apply in one fell swoop but proceeds via an intermediate position in the leftperiphery of the embedded clause (SpecCP), which can function as an escape hatch in so-called "bridge" contexts; cf. V11.3.1.2. This is indicated by the intermediate otrace $t^{\prime}$ in the examples in (140).

(140) a. Wat ${ }_{\mathrm{i}}$ denk je [CP $t_{\mathrm{i}}^{\prime}$ dat [TP Jan $t_{\mathrm{i}}$ wil kopen] $]$ ?

what think you that Jan wants buy

'What do you think that Jan will buy?'

b. Wanneer ${ }_{i}$ denk je [CР $t_{i}^{\prime}$ dat [TP Jan zal $t_{\mathrm{i}}$ komen]]?

when think you that Jan will come

'When do you think that Jan will come?'

That $w h$-extraction crucially relies on the availability of the escape hatch is normally illustrated by the fact that it cannot apply from embedded $w h$-questions such as (141): because the escape hatch is already filled by the wh-pronoun wie 'who', the unacceptability of the primed examples under the intended interpretation shows that extracting the object/adverbial phrase from the embedded clause in one fell swoop is not allowed. Note that complementizers in embedded $w$ h-questions are normally phonetically empty, which is indicated here by the use of " $\varnothing$ ". 
(141) a. Jan vraagt [ср wie $_{\mathrm{i}} \varnothing\left[{ }_{\mathrm{TP}} t_{\mathrm{i}}\right.$ dat boek wil kopen]]. Jan asks who that book wants buy 'Jan asks who wants to buy that book.'

$\mathrm{a}^{\prime}$. *Wat ${ }_{\mathrm{j}}$ vraagt Jan [ср wie $_{\mathrm{i}} \varnothing\left[\mathrm{TP}_{\mathrm{i}} t_{\mathrm{j}} t_{\mathrm{j}}\right.$ wil kopen]]? what asks Jan who wants buy

b. Jan vraagt [CP wie $_{\mathrm{i}} \varnothing\left[\mathrm{TP}_{\mathrm{i}} t_{\mathrm{i}}\right.$ morgen wil komen]]. Jan asks who tomorrow wants come

'Jan asks who wants to come tomorrow.'

$\mathrm{b}^{\prime}$. *Wanneer ${ }_{\mathrm{j}}$ vraagt Jan [ср wie $_{\mathrm{i}} \varnothing\left[{ }_{\mathrm{TP}} t_{\mathrm{i}} t_{\mathrm{j}}\right.$ wil komen]]? when asks Jan who wants come

Because wh-extraction in (140) is possible, the correlation restriction on gapping and $\mathrm{A}^{\prime}$-movement as stated in (139a) predicts that gapping should also be possible, but this seems to be incorrect, as examples such as given in (142) are normally ranked as degraded; cf. Neijt (1979:143). We use a percentage sign here (and not an asterisk) for reasons that will become clear shortly.

(142) a. ${ }^{\%}[$ ELs denkt [cP dat je een BOEK zal kopen] $]$ en

Els thinks that you a book will buy and

[MARIE denkt [CP dat je een CD zal kepen]]].

Marie thinks that you a $\mathrm{CD}$ will buy

b. ${ }^{\%}[$ [Els denkt [cP dat je VANDAAG zal komen]] en

Els thinks that you today will come and

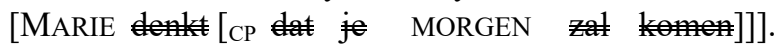

Marie thinks that you tomorrow will come

Neijt (1979:141-5) explains the acceptability contrast between the wh-examples in (140) and the corresponding gapping examples in (142) by appealing to the fact that the escape hatch in the left periphery of the embedded clause is only relevant for movement, but this raises the question as to why gapping exhibits so many other properties of $w h$-movement. The reason for this is that the relevant properties of gapping are not typical for $w h$-movement constructions only but for the wider class of $\mathrm{A}^{\prime}$-movement constructions including the $\mathrm{A}^{\prime}$-scrambling constructions derived by topic, ${ }^{\circ}$ focus and negation movement (cf. Section V13.3.2), which had not yet been identified when Neijt wrote her study. We therefore replace Neijt's original correlation restriction on gapping and $w h$-movement in (143a) by restriction (143b).

(143) a. Correlation restriction on gapping and $\boldsymbol{w h}$-movement (Neijt 1979):

Remnants of gapping can undergo $w h$-movement in non-reduced clauses.

b. Correlation restriction on gapping and $\mathbf{A}^{\prime}$-movement (revised version):

Remnants of gapping can undergo $\mathrm{A}^{\prime}$-movement ( $w h$-movement or $\mathrm{A}^{\prime}$-scrambling) in non-reduced clauses.

Assume for the moment that gapping remnants undergo focus/topic-movement in the prototypical case, which can be independently supported by the fact that they are contrastively accented in general. This assumption may explain the acceptability contrast between the wh-examples in (140) and the corresponding gapping examples in (142) in a very elegant manner, as the examples in (144) show that 
extracting a contrastive focus/topic phrase from its clause normally gives rise to a marked result: focus/topic movement apparently cannot easily be extracted via the escape hatch in the left periphery of the embedded clause.

(144) a. ${ }^{\%}$ Ik had [in de TUIN $]_{\mathrm{i}}$ gedacht [dat het feest $t_{\mathrm{i}}$ zou zijn].

I had in the garden thought that the party would be

'I had thought that the party would be in the GARDEN.'

b. ${ }^{\%}$ Ik had [een $\left.B O E K\right]_{\mathrm{i}}$ gedacht [dat Jan $t_{\mathrm{i}}$ zou kopen].

I had a book thought that Jan would buy

'I had thought that Jan would buy a BOоK.'

Section V13.3.2, sub IB3, has shown, however, that the results in bridge contexts (e.g., with a 'bridge verb such as denken 'to think') are better than in non-bridge contexts (e.g., with factive verbs such as betreuren 'to regret'). The contrast between the examples in (144) and (145) suggests that focus/topic movement out of an embedded clause is at least marginally possible for most speakers in bridge contexts.

(145) a. *Ik had [in de $T U I N]_{\mathrm{i}}$ betreurd [dat het feest $t_{\mathrm{i}}$ zou zijn].

I had in the garden regretted that the party would be

b. *Ik had [een $B O E K]_{\mathrm{i}}$ betreurd [dat Jan $t_{\mathrm{i}}$ zou kopen].

I had a book regretted that Jan would buy

If gapping remnants can undergo focus/topic movement in the prototypical case, we predict a similar contrast in the case of gapping. This can be tested by comparing the gapping examples in (142) to those in (146), which show that a similar contrast can indeed be found: the examples in (142) are less marked and easier to interpret in the intended sense than those in (146).

(146) a. *[[ELS betreurt [cP dat je een BOEK hebt gekocht] $]$ en

Els regrets that you a book have bought and

[MARIE beut [CP ja een CD helat]].

Marie regrets that you a CD have bought

b. *[[Els betreurt [CP dat je VANDAAG komt] $]$ en

Els regrets that you today come and

[MARIE

Marie regrets that you tomorrow come

If the judgments given above are correct, it would support the claim that there is not only a correlation between focus/topic movement and gapping but also that these movements are actually involved in the derivation of gapping. This leads to the hypothesis in (147).

\section{$\mathbf{A}^{\prime}$-movement hypothesis:}

Remnants of gapping have undergone $\mathrm{A}^{\prime}$-movement.

Hypothesis (147) entails that gapping elides all material that is not located in a designated $\mathrm{A}^{\prime}$-position, such as the specifier positions of the topic/focus projections. It thus revives earlier proposals stating that gapping constructions involve the listing of contrastively accented constituents; cf. Dik (1968), Van der Heijden \& Klein 
(1995) and Bart et al. (1998). The main difference from at least some of these earlier proposals is that we do not claim that we are dealing with a mere list, but that we can maintain that the gapping remnants are syntactically integrated in a regular clausal structure. That this is not a trivial matter will be made clear in Chapter 3 .

The set of designated $\mathrm{A}^{\prime}$-positions include at least the following: the clauseinitial position for interrogative and topicalized phrases (see Chapter V11) and the specifier positions of the topic, focus and negation projections in the ${ }^{\circ}$ middle field of the clause (see Section V13.3). Because the set of relevant A'-positions is finite, the $\mathrm{A}^{\prime}$-movement hypothesis may also account for the observation in Subsection $\mathrm{IH}$ that gapping constructions such as (148) with three remnants are fully acceptable but that the result of gapping quickly degrades when the number of remnants increases: contrastive focus/topic phrases, for instance, can only be moved into the specifier of CP (that is, the clause-initial position) and the specifiers of TopicP and FocusP located in the middle field of the clause.

(148) a. [[MARIE gaf het BOeK aan JAN]] en [Peter aaf de CD aan Els]]. Marie gave the book to Jan and Peter gave the CD to Els 'Marie gave the book to Jan and Peter the CD to Els.'

b. [[ELS legde het BOEK op TAFEL] en [JAN de KRANT op de BANK]]. Els put the book on table and Jan put the paper on the couch 'Els put the book on the table and Jan the newspaper on the couch.'

This means that we can readily accommodate the examples in (148), but that it remains to be seen whether this also holds true for cases with more than three remnants. We believe this to be a virtue of the $\mathrm{A}^{\prime}$-movement hypothesis.

\section{Verbal-head restriction on gapping}

A nice consequence of the $\mathrm{A}^{\prime}$-movement hypothesis is that it immediately explains one of the core properties of gapping, embodied in the finite verb restriction on gapping in (149), namely that the finite verb must be elided: $\mathrm{A}^{\prime}$-movement is restricted to phrases and thus cannot target the finite verb of the clause, which is not a phrase but a ${ }^{\circ}$ ead.

\section{Finite-verb restriction on gapping:}

Gapping elides the finite verb of its target clause.

The corollary, that the obligatory elision of the finite verb follows from the $\mathrm{A}^{\prime}$ movement hypothesis in (147), is significant as it entails that gapping may in principle also apply in the absence of a finite verb, as long as there are designated $\mathrm{A}^{\prime}$-positions available. It accounts for the fact discussed in Subsection A3 that gapping can also also occur in infinitival clauses, that is, clauses without a finite verb. This is illustrated here by means of example (150), adapted from Haeseryn et al. (1997:1597), in which the infinitival clauses function as adverbial phrases indicating goals. 
(150) Jan ging weg [[om bij de BAKKER BROOD te halen] en Jan went away COMP at the bakery bread to fetch and [ bij de APOTHEKER ASPIRINES ] COMP at the apothecary aspirins to fetch

'Jan left to buy bread at the bakery and aspirins at the pharmacy.'

The $\mathrm{A}^{\prime}$-movement hypothesis also provides an explanation for the fact observed in Subsection A3 that gapping targeting embedded clauses must elide the complementizer; the relevant examples are repeated in (151). This follows in the same way as the obligatory elision of the finite verb: $\mathrm{A}^{\prime}$-movement is restricted to phrases and thus cannot target the complementizer of the clause, because complementizers are not phrases but heads.

(151) a. Jan vertelde [[dat ELS ZIEK is] en [a*dat MARIE AFWEZIG is]]. Jan told that Els ill is and that/that Marie absent is

'Jan said that Els is ill and Marie absent.'

b. Jan heeft beloofd [[om NU de DEUR te verven] en Jan has promised COMP now the door to paint and [em/*om MORGEN de VLOER $/$. COMP/COMP tomorrow the floor to paint 'Jan has promised to paint the door now and the floor tomorrow.'

We may therefore conclude that the $\mathrm{A}^{\prime}$-movement hypothesis is supported by the fact that it simplifies the linguistic description by making superfluous the ad hoc restriction stating that gapping elides all functional and lexical heads with verbal features $\left(\mathrm{C}, \mathrm{T}\right.$ and $\left.\mathrm{V}_{\text {finite }}\right)$ of the target clause.

\section{Interrogative, topicalized and negative phrases}

The $\mathrm{A}^{\prime}$-movement hypothesis developed in the previous subsection predicts that elements occupying a designated $\mathrm{A}^{\prime}$-position can occur as gapping remnants. This correctly predicts that $w h$-phrases, which prototypically occupy the clause-initial position, can occur as gapping remnants. That this prediction is correct is shown by the examples in (152), which are repeated from Subsection IB.

(152) a. [[WIE las het BOEK] en [WIE het ARTIKEL]]?

who read the book and who read the article

b. [[WAT las JAN] en [WAT ELS]]?

what read Jan and what read Els

'What did Jan read and what Els?'

The $\mathrm{A}^{\prime}$-movement hypothesis also correctly predicts that topicalized phrases can survive gapping; cf. (153). The order of the gapping remnants and their correlates can be reversed in this construction; see also Van Oirsouw (1987:262), Cremers (1993:102-3), and references cited there. Similar non-parallel examples are not easy to construct for interrogatives for two reasons: (i) coordinated wh-clauses such as $(152 \mathrm{a} \& \mathrm{~b})$ always have a parallel word order because $w h$-movement of interrogative phrases is obligatory; (ii) examples such as ${ }^{* ?}$ Marie heeft JAN VANDAAG ontmoet en WANNEER Els? (lit.: Marie met Jan today and when Els?') are marked for the 
independent reason that declarative and interrogative clauses cannot easily be coordinated.

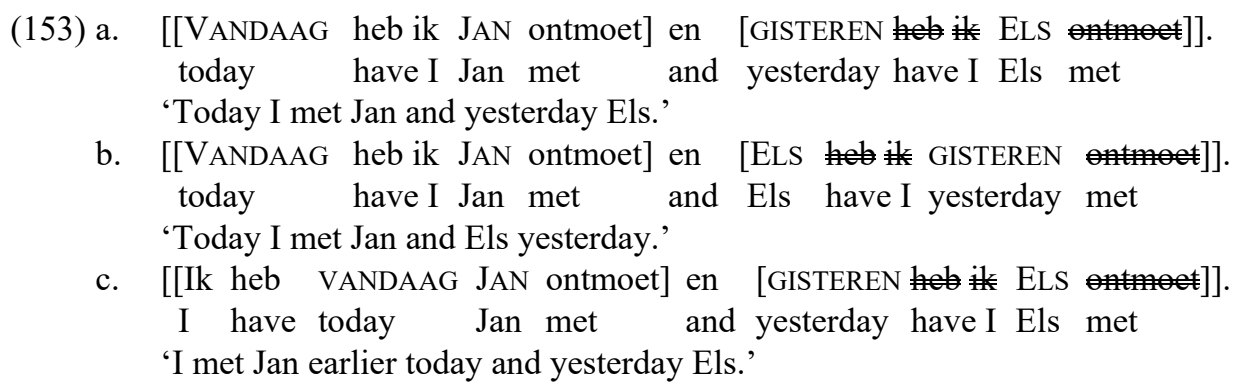

We also correctly predict, as shown in (154), that negative phrases expressing clausal negation may occur as remnants, since they occupy the specifier of NegP. There is more to be said about negation, but this will be done in the following subsections.

(154) a. [[Jan kreeg alles wat hij wou ] en/maar [Marie niets]]. Jan got everything which he wanted and/but Marie got nothing 'Jan got everything he wanted and Marie got nothing.'

b. [[Jan gaat vaak op vakantie] en/maar [Marie nooit epalantie]]. Jan goes often on holiday and/but Marie goes never on holiday 'Jan goes on holiday often, and/but Marie never.'

\section{Focus particles and negation}

Although the remnants of gapping normally have a correlate in the antecedent clause, there are two notable exceptions to this general rule. As shown in (155), focus 'particles such as ook 'also' and the adverb niet 'not' functioning as constituent negation can occur in the target clause without having a(n overt) correlate in the antecedent clause; cf. Van der Heijden \& Klein (1995:33).

(155) a. [[JAN houdt van MARIE] en [MARIE ook van JAN]]. Jan loves of Marie but Marie loves also of Jan 'Jan loves Marie and Marie loves Jan too.'

b. [[JAN houdt van MARIE] maar [MARIE niet van JAN]]. Jan loves of Marie but Marie loves not of Jan 'Jan loves Marie but Marie doesn't love Jan.'

That focus particles like alleen 'only', ook 'also' and zelfs 'even' are possible gapping remants is related to the fact that they are obligatorily located in the designated focus position. They can occupy this position together with their contrastively accented associate (here; op hem) but they may also occupy this position alone with their associate ${ }^{\circ}$ stranded in its base position, as shown in (156). Crucially, what is impossible is having the particles in the base position of their associate; see Section V13.3.2, sub IC2, for a more detailed discussion. 
(156) a. dat Jan <alleen op HEM> boos $<*$ alleen op HEM> is.

that Jan only with him angry is

'that Jan is only angry with him.'

$\mathrm{a}^{\prime}$. dat Jan alleen boos op HEM is.

that Jan only angry with him is

b. dat Jan <ook op HEM> boos $<*$ ook op HEM> is.

that Jan also with him angry is

'that Jan is also angry with him.'

$\mathrm{b}^{\prime}$. dat Jan ook boos op HEM is.

that Jan also angry with him is

c. dat Jan <zelfs op HEM> boos $<*$ zelfs op HEM> is.

that Jan even with him angry is

'that Jan is even angry with him.'

$\mathrm{c}^{\prime}$. dat Jan zelfs boos op HEM is.

that Jan even angry with him is

Because focus particles obligatorily occupy the designated focus position, that is, the specifier of a FocusP, a TopicP or a CP, the acceptability of gapping examples such as (155a) with the particle ook shows that target coordinands of gapping may include these projections, which is in agreement with the $\mathrm{A}^{\prime}$-movement hypothesis from Subsection 1. The fact illustrated in (155b) that the negative adverb niet 'not' may also be present is in accordance with the conclusion from Section V13.3.2, sub I, that this adverb also functions as a focus particle when it is used to express constituent negation.

We conclude this subsection by noting that the distribution of focus particles supports Neijt's claim discussed in Subsection IH that so-called split coordination is derived by means of a gapping-like operation (also known as stripping), as the examples in (157) show that focus particles may occur in such examples; see also Kraak \& Klooster (1972: section 11.2).

(157) a. [[JAN heeft met Marie gepraat] en [ELS ook Jan has with Marie talked and Els has also with Marie talked 'Jan has talked with Marie, and Els has too.'

$a^{\prime}$. [[JAN heeft met Marie gepraat] maar [ELS niet Jan has with Marie talked but Els has not with Marie talked 'Jan has talked with Marie, but Els hasn't.'

b. [[Jan heeft met MARIE gepraat] en [Jan ook MET PETER ] Jan has with Marie talked and Jan has also with Peter talked 'Jan has talked with Marie, and with Peter too.'

$b^{\prime}$. [[Jan heeft met MARIE gepraat] maar [ niet MET PETER Jan has with Marie talked but Jan has not with Peter talked 'Jan has talked with Marie, but not with Peter.'

This suggests that the distribution of focus particles can be used as a heuristic tool for finding a wider set of ellipsis constructions that can be subsumed under the $\mathrm{A}^{\prime}$ movement hypothesis in (147). One potentially relevant case would be the specifying coordination construction with the affirmative marker wel illustrated in (158), which is denied an elision analysis in Van der Heijden \& Klein (1995:33). 
Such an elision analysis would, however, be rather straightforward under the plausible assumption that wel is a focus particle which can be located in clauseinitial position: cf. [[Ik zie je niet meer], maar [wel zal ik je schrijven]] 'I won't see you anymore but I will write to you'.

$$
\begin{aligned}
& \text { [Jan gaf Els iets] en [wel af Jan een BOEK]. } \\
& \text { Jan gave Els something and AFF. gave Jan Els a book } \\
& \text { 'Jan gave Els something, namely, a book.' }
\end{aligned}
$$

\section{Elision of the negative marker niet 'not' is impossible}

The example sentences in the previous subsection have shown that it is possible to have a focus particle such as ook 'also' or a polarity particle (niet/wel) in the target clause without there having to be a correlate of it in the antecedent clause. The reason for this is that they are like the remnants of gapping in that they occupy a designated $\mathrm{A}^{\prime}$-position, and hence survive elision. If these particles must occupy designated $\mathrm{A}^{\prime}$-positions, we also predict that they in fact cannot delete; they will not delete even if they have an identical correlate in the antecedent clause. This is indeed what we find, as illustrated by the negative clauses in (159), adapted from Van der Heijden \& Klein (1995:33): see also Neijt (1979:66), De Vries (1992: section 3.9), and references cited there. The traditional view that gapping deletes material in the target clause under identity with material in the antecedent clause wrongly predicts that (159b) is acceptable with the intended reading; the alternative proposal that material occupying the designated $\mathrm{A}^{\prime}$-positions must survive deletion, however, correctly predicts that the negative particle niet must be overtly realized, as indicated in $(159 \mathrm{c})$.

(159) a. [[Jan heeft Els niet gezien] en [Peter heeft Marie niet gezien]]. Jan has Els not seen and Peter has Marie not seen

'Jan hasn't seen Els and Peter hasn't seen Marie.'

b. *[[JAN heeft ELS niet gezien] en [PETER MARIE Jan has Els not seen and Peter has Marie not seen

c. [[JAN heeft ELS niet gezien] en [PETER MARIE niet $]$. Jan has Els not seen and Peter has Marie not seen

A quirk that should perhaps be mentioned is that the affirmative particle wel differs from the negative particle niet in that at least some speakers allow omission of the affirmative marker in gapping constructions such as (160) with the adversative coordinator maar (but not with the simple conjunction en 'and'); cf. Van der Heijden \& Klein (1995:37).

$$
\begin{aligned}
& \text { [[JAN heeft ELS niet gezien] maar [PETER hef MARIE }{ }^{\%} \text { (wel) } \\
& \text { Jan has Els not seen but Peter has Marie AFF seen } \\
& \text { 'Jan has not seen Els but Peter has seen Marie.' }
\end{aligned}
$$

The acceptability of examples of this kind does not seem to be related to gapping as such, however, but to the fact that the affirmative marker has a zero form, which is the default in non-contrastive contexts but can also be used (at least marginally) in contrastive contexts; in this respect, the gapping construction in (160) behaves just like its non-reduced counterpart in (161). 


$$
\begin{aligned}
& \text { [[Jan heeft Els niet gezien] maar [Peter heeft Marie }{ }^{\circ}(\text { wel) gezien]]. } \\
& \text { Jan has Els not seen but Peter has Marie AFF seen } \\
& \text { 'Jan hasn't seen Els but Peter has seen Marie.' }
\end{aligned}
$$

It appears that the examples with and without the overt affirmative marker wel exhibit a subtle difference in meaning: the examples without wel seem to replace the false proposition Jan heeft Els gezien by the alternative true proposition Peter heeft Marie gezien, while the examples with wel seem to evaluate the truth values of two independent propositions. Note that negation must be used in contrastive constructions such as (162), which is expected because the negative form does not have a zero counterpart; this example also lacks the proposition-substitution reading.

$$
\begin{aligned}
& \text { [[JAN heeft ELS wel gezien] maar [PETER heft MARIE *(niet) ezien]]. } \\
& \text { Jan has Els AFF seen but Peter has Marie not seen } \\
& \text { 'Jan HAS seen Els, but Peter did not see Marie.' }
\end{aligned}
$$

\section{Concluding remarks}

The $\mathrm{A}^{\prime}$-movement hypothesis of gapping in (147) appears to be promising because it explains naturally that gapping always targets clauses and must minimally elide the finite verb and the complementizer of the target clause (if present). It also accounts for the well-known properties of the remnants of gapping that they must be able to undergo $\mathrm{A}^{\prime}$-movement in non-reduced clauses and that they must be contrastively accented. A further argument in favor of the $\mathrm{A}^{\prime}$-movement hypothesis is that it sheds new light on the fact that focus particles such as ook 'also' may occur as gapping remnants without there having to be a correlate in the antecedent clause as well as on the fact that the polarity marker niet 'not' cannot be elided, not even if niet is present in the antecedent clause. Obviously, the proposal should be fleshed out in more detail in order to show that it is feasible but we will leave this to future research.

\section{E. Some potentially problematic cases}

We conclude our discussion of gapping by looking at some cases that are equally problematic for all restrictions on gapping proposed so far. One example is given in (163a), in which the second remnant of gapping is a cardinal number interpreted as the premodifier of the noun boeken 'books'. Neijt (1979:112) claims that this is only an apparent counterexample because the noun boeken can also be omitted in non-gapping constructions such as (163b).

(163) a. [[JAN kocht TWEE boeken] en [Peter hIER Jan bought two books and Peter bought four books 'Jan bought two books and Peter four.'

b. [[Jan kocht twee boeken] en [Peter kocht *(er) vier]]. Jan bought two books and Peter bought there four 'Jan bought two books and Peter bought four books.'

A problem for Neijt's suggestion as far as Dutch is concerned is that it does not take into account the obligatory presence of so-called quantitative er in (163b) (in the standard variety Dutch at least). The gapping construction Jan kocht twee boeken en 
Peter vier therefore cannot be derived in a straightforward manner: representation (164a) seems ungrammatical because (163b) has shown that quantitative er must be present in the target clause, and representation (164b) is problematic because the elided form er does not seem to be recoverable in the sense that it does not have a syntactic correlate in the antecedent clause; cf. Subsection IE. Since we have no new insights to offer, we will leave this problem for future research.

(164) a. *[[JAN kocht TWEe boeken] en [PETER hiER]]. Jan bought two books and Peter bought four 'Jan bought two books and Peter bought four books.'

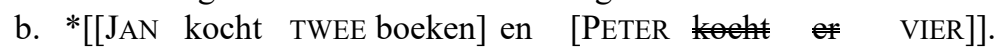
Jan bought two books and Peter bought there four 'Jan bought two books and Peter bought four books.'

Another potential problem arises with pronominal PPs in ${ }^{\circ} \mathrm{R}$-extraction contexts. The acceptability contrast between the two examples in (165) shows that while a full pronominal PP (R-word $+\mathrm{P}$ ) can be a remnant of gapping, its pronominal part cannot be a remnant in isolation.

(165) a. [[MARIE praat graag HIERover] en [JAN DAARover]].

Marie talks gladly here-about and Jan talks gladly there-about

'Marie likes to talk about this and Jan likes to talk about that.'

b. *[[MARIE praat HIER graag over] en [JAN DAAR

Marie talks here gladly about and Jan talks there gladly about

The unacceptability of (165b) is surprising as it seems to satisfy all regular restrictions on gapping. It is worthwhile noting, however, that a similar problem arises in the case of ${ }^{\circ}$ sluicing: cf. Section V5.1.5, sub IE. If sluicing elides all material to the right of the $w h$-phrase in the initial position of the embedded $w h$ clause, we would expect both examples to be acceptable.

$$
\begin{aligned}
& \text { Jan praat graag over iets maar ... } \\
& \text { Jan talks gladly about something but } \\
& \text { 'Jan likes to talk about something but ...' }
\end{aligned}
$$
a. $\quad .$. ik weet niet waarover himat.
I know not where-about he gladly talks
'... I don't know about what.'

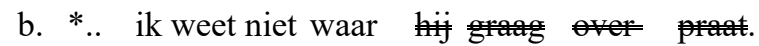
I know not where he gladly about talks

The similarity between gapping and sluicing strongly suggests that syntactically seen the two operations have a common core but we will not digress on the behavior of pronominal PPs because we do not have anything new to say about this issue either.

\subsection{Combining conjunction reduction and gapping}

Sections 2.1 and 2.2 have discussed two types of reduction processes that typically apply to coordinate structures: conjunction reduction and gapping. Some examples of these processes are repeated in (167). For convenience, we will use boldface for material (presumably) deleted by conjunction reduction. 
(167) - Conjunction reduction and gapping
a. [[Jan heeft Els bezocht] en [Jan heeft haar het nieuws verteld]]. [FCR] Jan has Els visited and Jan has her the news told
'Jan has visited Els and told her the news.'
b. [[Jan heeft Els bezoeht] en [Marie heeft Peter bezocht]].
Jan has Els visited and Marie has Peter visited
'Jan has visited Els and Marie has visited Peter.'
c. [[Jan bezoekt Els] en [Marie Peter]].
$[\mathrm{BCR}]$
Jan visits Els and Marie visits Peter
'Jan is visiting Els and Marie Peter.'

The structures in (167a\&b) are based on the assumption that conjunction reduction comes in two types, the first type applying forwards and the second one backwards. In Section 2.1, we followed Neijt (1979), however, in arguing that backward conjunction reduction is the only genuine form of conjunction reduction; presumed cases of forward conjunction reduction such as (167a) should be reanalyzed as cases involving coordination of phrases smaller than clauses, as in (168).

(168) - Reanalysis of forward conjunction reduction

Jan heeft [lvp Els bezocht] en [vp haar het nieuws verteld]].
Jan has $\quad$ Els visited and her the news told
'Jan has visited Els and told her the news.'

Section 2.1, sub V, has shown that (supposed) forward and backward conjunction reduction can easily co-occur; cf. (169a). This is also expected under the proposed reanalysis of forward conjunction reduction. We have seen in Section 2.1, sub V, that backward conjunction reduction is not limited to clausal coordinands but can apply in a wider range of coordinate structures: the analysis in (169a) can therefore be replaced by the one in (169b).

(169) a. [[CLAUSE Jan heeft Marie vorige week en
Jan has Marie last week visited and
[CLAUSE Jan heeft Els gisteren bezocht]].
Jan has Els yesterday visited
'Jan visited Marie last week and Els yesterday.'
b. Jan heeft [[vp Marie vorige week ezent] en [vp Els gisteren bezocht]]. Jan has Marie last week visited and Els yesterday visited
'Jan visited Marie last week and Els yesterday.'

Combinations of forward conjunction reduction and gapping are less likely to occur. Up to this point, we have assumed without discussion that examples such as Jan heeft haar een boek gegeven en hem een $C D$ 'Jan has given him a book and her a CD' are derived by gapping, as in (170a); cf. Section 2.2, sub IB. If forward conjunction reduction could be seen as a reduction rule, we could in principle also derive this sentence by a combination of (i) gapping of heeft and the participle phrase gegeven (after ${ }^{\circ}$ scrambling of the direct object $a C D$ ) and (ii) forward conjunction reduction of the subject Jan, as indicated in (170b). 


[JJan heeft HAAR EEN BOEK gegeven] en ...
Jan has her a book given and
a. [D HEM een CD
Jan has him a CD given $].$
b. [Jan hef HEM een CD
Jan has him a CD given

[gapping]

[presumed FCR+ gapping]

The hypothesis that forward conjunction reduction involves coordination of phrases smaller than clauses, on the other hand, excludes the derivation in (170b). The alternative structure in (171) is also ungrammatical, as gapping applies in clausal coordinate structures only: cf. Section 2.2. We therefore conclude that forward conjunction reduction and gapping do not co-occur, and that the structure in (170a) is the only available one. This is also desirable because the target sentence is not ambiguous in meaning either.

$$
\begin{gathered}
\text { *Jan heeft [[HAAR EEN BOEK gegeven] en [HEM een CD } \\
\text { Jan has her a book given and him a CD given }
\end{gathered}
$$

This leaves us with just one more case: the co-occurrence of backward conjunction reduction and gapping. Simple examples of gapping and backward conjunction reduction are given in (172a) and (172b), respectively, while example (172c) shows that the two reduction processes may also co-occur.

(172) a. [[Jan leest mijn boek] en [Marie jouw boek]].

[gapping] Jan reads my book and Marie reads your book

'Jan is reading my book and Marie your book.'

b. [[Jan leest mijn beek] en [Marie leest jouw boek]]. Jan reads my book and Marie reads your book

'Jan is reading my and Marie is reading your book.'

c. [[Jan leest mijn eek] en [Marie jouw boek]]. [gapping + BCR] Jan reads my book and Marie reads your book

'Jan is reading my and Marie your book.'

Although gapping and backward conjunction reduction can co-occur in examples such as (172c), various factors may conspire in blocking their co-occurrence in other cases. First, consider the cases of gapping in (173); the acceptability contrast between these two examples follows from the maximization requirement on gapping (cf. Section 2.2, sub IE), which prohibits gapping remnants identical to constituents in the antecedent clause (which can of course be derived from the $\mathrm{A}^{\prime}$ movement hypothesis proposed in Section 2.2, sub IID, according to which gapping remnants are prototypically contrastive topics/foci).

$$
\text { - Gapping }
$$

a. [[Jan heeft mijn boek gelezen] en [Marie jouw boek gelezen]]. Jan has my book read and Marie has your book read 'Jan has read my book and Marie your book.'

b. *[J]an heeft mijn boek gelezen] en [Marie heef jouw boek gelezen]]. Jan has my book read and Marie has your book read 
The maximization requirement does not hold in the case of backward conjunction reduction, as is clear from the fact that both examples in (174) are acceptable.

- Backward conjunction reduction

a. [[Jan heeft mijn boek gelezen] en [Marie heeft jouw boek gelezen]].

Jan has my book read and Marie has your book read

'Jan has read my book and Marie your book.'

b. [[Jan heeft mijn

Jan has my book read and Marie has your book read

It seems that gapping, as in (173a), may bleed backward conjunction reduction; because gapping elides the participle gelezen, the right periphery of the first coordinand is no longer phonologically identical to the right periphery of the second coordinand and this blocks backward conjunction reduction. This correctly predicts that the examples in (175) are unacceptable.

- Gapping followed by backward conjunction reduction

a. *[J]an heeft mijn boek jouw boek en [Marie ]

Jan has my book read and Marie has your book read

b. *[[Jan heeft mijn geek gelezen] en [Marie heeft jouw boek

Jan has my book read and Marie has your book read

At the same time it is not a priori predicted that backward conjunction reduction will block gapping. If we were to apply gapping to the examples in (174), we would derive the examples in (176). Although these examples are more intelligible than those in (175), which is obviously related to the fact that in (175) the main verb gelezen is omitted in both coordinands and hence not recoverable from the context, they are clearly degraded compared to those in (174). We assign the examples in (176) two question marks in order to do justice to their relative acceptability. Boldface is used again to indicate conjunction reduction.

- Backward conjunction reduction followed by gapping

a. "?[Jan heeft mijn boek gelezen] en [Marie jouw boek gelezen]]. Jan has my book read and Marie has your book read

b. ??[Jan heeft mijn Jan has my book read and Marie has your book read

The unexpectedly degraded status of examples like those in (176), which was brought to our attention by Anneke Neijt (p.c.), can be used to support our earlier conclusion that gapping and backward conjunction reduction are different in that the former is a regular syntactic rule (cf. Section 2.2, sub IIA) but the latter is a postsyntactic rule (cf. Section 2.1, sub IV). This implies that gapping must precede backward conjunction reduction, so that the examples in (176) cannot be derived for the simple reason that the conjunction reduction structures in (174) cannot be the input for gapping. It should be noted, however, that judgments seem to vary among speakers; Van Oirsouw (1987:120), for instance, rates the (a)-examples in (177) without any reservation as acceptable, and Haeseryn et al. (1997:1595) do the same with the slightly more complex (b)-examples. 
(177) a. [[Jan heeft kaas gekeht] en [Peter heeftes gekocht]].

Jan has cheese bought and [Peter has meat bought

$a^{\prime}$. [[Jan heeft een boek en

Jan has a book to Marie given and

[Peter heeft een CD aan Marie gegeven]].

Peter has a CD to Marie given

'Jan has given a book to Marie and Peter a CD.'

b. [[Wij kozen Jan en [jullie we elected Jan as chairman and you elected Els as chairman

'We elected Jan chairman and you elected Els.'

$\mathrm{b}^{\prime}$. [[Marie beslist [welke boeken ] en

Marie decides which books we sell and

[Jan estist [welke platen we verkopen]]].

Jan decides which records we sell

'Marie decides which books and Jan which records we sell.'

Although we believe the examples in (177) to be like those in (176) in that they are marked compared to the corresponding forms without gapping of the finite verb, the fact that Van Oirsouw and Haeseryn et al. rate them as acceptable shows that establishing their precise status is not an easy task. This means that the acceptability judgments on examples like (176) and (177) are simply not clear enough at this stage for them to be used in evaluating the claim that backward conjunction reduction is a post-syntactic rule that cannot precede gapping. We hope that future research will be able to shed more light on this issue

\subsection{Conclusion}

The discussion of conjunction reduction and gapping took as its point of departure the generally accepted view that these reduction processes occur in coordinate structures only. Van der Heijden \& Klein (1995) have argued that these processes may also occur in some subordinate contexts; this is illustrated for gapping in (178).

(178) a. [Jan gaf niemand iets] behalve [ats een boek Jan gave nobody anything except that Jan Els a book gave 'Jan gave nobody anything except that he gave Els a book.'

b. [Behalve data Els een boek gaf Jan Marie een CD. besides that Jan Els a book gave gave Jan Marie a CD 'Besides giving Els a book, Jan gave Marie a CD.'

The claim that we are dealing with gapping in examples like those in (178) may be controversial given that it exhibits certain properties that are not found in coordinate structures: this is immediately clear from the examples in (178) as (presumed) gapping apparently applies both in a forward and in a backward fashion. The claim that we are dealing with subordination in (178) is also controversial, as is clear from the fact that behalve has been analyzed as a coordinator in Paardekooper (1966), as a preposition in Landman \& Moerdijk (1980): it is now even common to analyze it as a hybrid category as, e.g., in Van der Heijden (1999). Chapter 3 will therefore continue the discussion of conjunction reduction and gapping by reviewing the arguments given for the various positions taken in the literature. 


\section{Chapter 3 \\ Borderline cases of coordination?}

$\begin{array}{ll}\text { Introduction } & 316\end{array}$

3.1. $\quad$ Four supposed borderline cases $\quad 316$

$\begin{array}{lr}\text { I. Comparative als 'as'/dan 'than' } & 317\end{array}$

II. Behalve 'except/besides' 321

A. The status of the behalve-phrase 322

B. Case marking of pronouns following behalve 324

C. Phrases following behalve are not categorically restricted 326

D. Nominal phrases following behalve cannot be weak pronouns 328

E. Two residual issues $\quad 329$

III. In plaats van 'instead of' $\quad 330$

IV. Laat staan 'let alone'

3.2. A note on the semantic side of gapping 332

3.3. Conclusion and a potential problem 334 


\section{Introduction}

This chapter discusses a small set of words/phrases that have been claimed to exhibit coordinator-like properties. These elements seem to have at least in common that they can be followed by a nominative noun phrase or a finite clause; this is illustrated in (1) for the element dan 'than' found in, e.g., adjectival comparative constructions. This property provides negative arguments for assuming that dan 'than' can function as a conjunction-like element; (i) the dan-phrase in (1a) cannot be a prepositional phrase with a nominal ${ }^{\circ}$ complement, as prepositions normally assign objective (and not nominative) case; (ii) the element dan in (1b) cannot be analyzed as a subordinator as it can be followed by an embedded clause introduced by the subordinator dat 'that'; cf. Den Besten (1978).
a. Jan komt vaker dan Marie/zij. Jan comes more.often than Marie/she
b. Jan komt vaker dan [dat Marie/zij komt]. Jan comes more.often than that Marie/she comes 'Jan is coming more often than Marie is coming.'

Besides these two negative arguments for assuming that dan 'than' is a conjunctionlike element, there is also a positive argument: example (2b) suggests that dan must be a coordinator because it can be followed by a gapping construction, which has been argued to occur in coordinate structures only. We have added (2a) in order to show that it is also possible to derive example (1a) by gapping.
a. Jan komt vaker
Jan comes more.
dan [ Marie/zij
Jan comes more.often than that Marie/she comes
'Jan is coming more often than Marie is coming.'
b. Jan bezoekt zijn moeder vaker dan [at Marie haar vader Jan visits his mother more.often than that Marie her father visits 'Jan visits his mother more often than Marie visits her father.'

The precise conclusion drawn from the data in (1) and (2) differs from study to study: Corver (1990:89ff/1993) and Hendriks (1995:ch.2) state that dan can function as a coordinator; Haeseryn et al. (1997: section 27.5.4) states that dan dat is a complex linker (with optional dat) with coordinator-like properties, and Van der Heijden (1999:ch.1) claims that dan is a "mixed" category in between coordinator and subordinator. We will not review the differences between these proposals but follow Van der Heijden \& Klein (1995) in arguing that there are reasons for rejecting the idea that we are dealing with coordination-like structures altogether.

\subsection{Four supposed borderline cases}

This section discusses a number of forms, for which it has been claimed that they exhibit coordinator-like behavior since they may introduce a gapped clause. The forms that will be discussed are als 'as' and dan 'than' in comparative constructions, behalve 'except/besides', in plaats van 'instead of', and laat staan 'let alone'. We will argue that they are run-of-the-mill subordinators, which goes against the traditional claim that gapping (as well as backward conjunction 
reduction) only occurs in coordinate structures. This then raises a number of novel questions on gapping, which are discussed in Section 3.2.

\section{Comparative als 'as'/dan 'than'}

This subsection discusses the status of the lexical items als 'as' and dan 'than' in comparative constructions like those given in (3). The introduction to this chapter has already shown that als/dan-phrases cannot be analyzed as regular PPs with a nominal complement, as this would wrongly predict that the noun phrases must be assigned objective case (although it should be noted that the object form of the pronouns can be encountered in colloquial speech).
a. Jan is even intelligent als Marie/zij $j_{\text {nom. }}$. Jan is as intelligent as Marie/she
b. Jan is slimmer dan Marie/zij $\mathrm{z}_{\text {nom }}$. Jan is brighter than Marie/she

The examples in (4) show that the case form of the pronouns is not determined by als/dan but instead depends on the noun phrase to which it is compared; the noun phrase in the als/dan-phrase receives nominative case when it is compared to the subject of the main clause, as in (3) and the (a)-examples in (4), whereas it receives accusative case if it is compared to the direct object, as in the (b)-examples in (4).

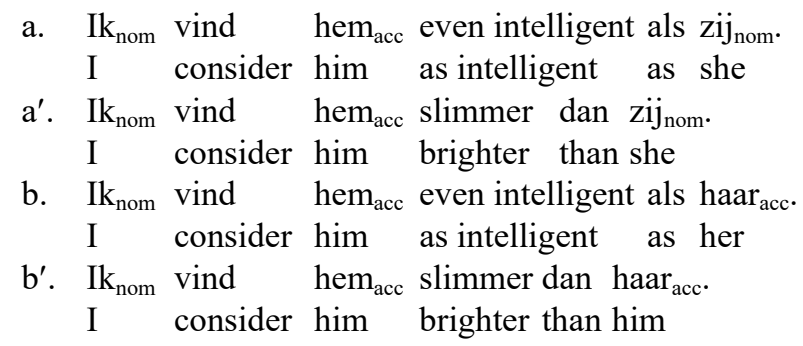

Because nominative case is normally restricted to subjects of finite clauses, the examples in (3) suggest that the complements of als and dan are clausal in nature. That the complement can be clausal in nature is also clear from the examples in (5), which feature a finite verb and the (optional) complementizer dat 'that' in the complement of als/dan. It is assumed that examples like these contain an empty adjectival predicate $[e]$ that receives an interpretation from its adjectival correlate in the matrix clause; we will not discuss the nature of the relation between the empty element $[e]$ and its correlate here, but refer the reader to A4.1.3 for extensive discussion. We have added the empty category $[e]$ for completeness' sake; since it does not play a role in our discussion here, the reader is free to ignore it in the examples to come.

$\begin{array}{ll}\text { a. Hij } & \text { is even intelligent als }\left[(\mathrm{dat}) \mathrm{zij}_{\text {nom }}[\mathrm{e}] \text { is]. }\right. \\ \text { he is as intelligent as that she is } \\ \mathrm{a}^{\prime} . \text { Hijnom is slimmer dan [(dat) } \mathrm{zij}_{\text {nom }}[\mathrm{e}] \text { is]. } \\ \text { he is brighter than that she is }\end{array}$


b. Ik vind hem acc even intelligent als [(dat) ik haar ${ }_{a c c}[\mathrm{e}]$ vind].

I consider him as intelligent as that $\mathrm{I}$ her consider

$\mathrm{b}^{\prime}$. Ik vind hem $\mathrm{acc}_{\mathrm{acc}}$ slimmer dan [(dat) ik haar $\mathrm{acc}_{\mathrm{acc}}[\mathrm{e}]$ vind].

I consider him brighter than that I her consider

The examples in (4) can now be derived by eliding everything in the clausal complement of als/dan apart from the compared noun phrases, as in (6). Note in passing that we have ignored the fact that the non-reduced forms in (5) sound clumsy compared to the more economical reduced version.

(6) a. Hijnom is even intelligent als [ $\mathrm{zij}_{\text {nom }}[\mathrm{e}]$ is].

he is as intelligent as that she is

$\mathrm{a}^{\prime}$. Hij $\mathrm{j}_{\text {nom }}$ is slimmer dan [dat $\left.\mathrm{zij}_{\text {nom }}[\mathrm{e}] \mathrm{is}\right]$.

he is brighter than that she is

b. Ik vind hem ${ }_{a c c}$ even intelligent als [dat haar ${ }_{a c c}[\mathrm{e}$ ] ind].

I consider him as intelligent as that I her consider

$\mathrm{b}^{\prime}$. Ik vind hem acc slimmer dan [ata haar ${ }_{\text {acc }}[\mathrm{e}]$ ].

I consider him brighter than that I her consider

The analysis given above raises the question as to what kind of elision operation we are dealing with. Since the deletion operation in (6) affects the finite verb, we hypothesize that we are dealing with some kind of gapping, which predicts that the als/dan-phrase may contain more than one remnant; the examples in (7) show that this prediction is correct.

(7) a. Jan ziet hem even vaak als [dat Peter haar [e] ziet].

Jan sees him as often as that Peter her sees

'Jan meets him as often as Peter meets her.'

b. Jan ziet hem vaker dan [dat Peter haar [e]

Jan sees him more.often than that Peter her sees

'Jan meets him more often than Peter meets her.'

The gapping analysis further predicts that the remnants must be contrastively accented. This truly seems to be the case; more support can be gained from the fact that weak (unaccented) pronouns cannot occur in the reduced constructions in (8), which should be compared to those in (6) and (7).
a. ${ }^{*} \mathrm{Hij}$ is even intelligent als [dat ze $\mathbf{z e}_{\text {weak }}[\mathrm{e}] \mathrm{is}$ ].
he is as intelligent as that she is
$\mathrm{a}^{\prime}$. *Hij is slimmer dan [dat $\mathbf{z e}_{\text {weak }}[\mathrm{e}]$ is].
he is brighter than that she is
b. *Ik vind hem even intelligent als [dat ${ }^{\prime} \mathbf{r}_{\text {weak }}[\mathrm{e}]$ ind].
I consider him as intelligent as that I her consider
$\mathrm{b}^{\prime}$. *Ik vind hem slimmer dan [dat ${ }^{\prime} \mathbf{r}_{\text {weak }}[\mathrm{e}$ ]
I consider him brighter than that I her consider
c. *Jan ziet 'm even vaak als [dat Peter ' $\mathbf{r}_{\text {weak }}$ [e]
Jan sees him as often as that Peter her sees
$c^{\prime}$. *Jan ziet 'm vaker dan [at Peter ' $\mathbf{r}_{\text {weak }}[\mathrm{e}]$.
Jan sees him more.often than that Peter her sees 
We also expect that the presumed remnants of gapping cannot be embedded within a ${ }^{\circ}$ clausal constituent (argument, adverbial or complementive), which also seems to be borne out. The acceptability contrast between the examples in (9) shows that while the remnant can be a full prepositional object, it cannot be its nominal part. Recal that, for our present purpose, the empty position $[e]$ in the reduced clause can be ignored; see the remark above example (5).

(9) a. Alcohol is voor vrouwen schadelijker dan [dat [e] voor mannen is] alcohol is for women more.harmful than that alcohol for men is 'Alcohol is more harmful for women than for men.'

b. *Alcohol is voor vrouwen schadelijker dan [dat al [e] mannen is]. alcohol is for women more.harmful than that alcohol for men is

The discussion above strongly suggests that the reduction operation affecting the complement of als/dan can indeed be identified as gapping. Hendriks (1995:ch.2) takes the fact that gapping is possible in comparative constructions as sufficient evidence that als 'as' and dan 'than' are coordinators; see also Haeseryn (1997:1601). If true, we would also expect backward conjunction to be possible in comparative constructions, and Hendriks shows that this expectation is fulfilled; see also Van der Heijden \& Klein (1995). For ease of representation, we use boldface for the elision resulting from backward conjunction reduction.
a. Ik lees vaker
het boek Marie
I read more.often the book by Marie dan [ dat ik [e] het artikel van Marie les]. than that I the article by Marie read 'I read more often the book than the article by Marie.'
b. Ik zit liever voor Jan dan [dat ik [e] achter Jan zit].
I sit more.gladly in.front.of Jan than that I behind Jan sit
'I prefer to sit in front of Jan rather than behind him.'

Note in passing that backward conjunction reduction is only possible if it follows gapping since otherwise the finite verb lees in the clause following dan in (10a) would block its application. This rule order follows automatically from our claim in Section 2.3 that gapping and backward conjunction differ in that the former is a rule of syntax while the latter is a post-syntactic rule.

A serious problem in assuming that we are dealing with coordination is that the clausal complement of als/dan must appear in its embedded form while the matrix clause is a main clause. We illustrate this again in (11); that the clauses following dan are non-main clauses is evident from the clause-final placement of the finite verb as well as the (optional) presence of the complementizer dat 'that'; cf. Van der Heijden \& Klein (1995).

(11) a. Ik lees vaker Maries boek dan [(dat) ik [e] haar artikel lees].

I read more other Marie's book than that I her article read 'I read more often the book than the article by Marie.'

b. Ik zit liever voor Jan dan [(dat) ik [e] achter hem zit].

I sit more.gladly in.front.of Jan than that I behind him sit

'I prefer to sit in front of Jan rather than behind him.' 
For this reason, some researchers consider the elements als and dan as borderline cases: although they behave like coordinators in some respects, they also have properties that are not found with regular coordinators like en 'and' and of 'or'; cf. Van der Heijden (1999). An obvious obstacle to the conclusion that als and dan constitute a kind of mixed category (with properties of coordinators and subordinators) is that they clearly do not coordinate the strings preceding and following them; the als/dan-phrases are clearly constituent parts of the adjectival phrases headed by vaker 'more often' and liever 'rather' (lit. "more gladly"), which is evident from the fact illustrated in (12) that they can jointly occupy the initial position of the sentence; cf. Haeseryn et al. (1997:1602). The use of parentheses indicates that this holds both for the non-reduced and for the reduced form; this also shows that topicalization does not affect the acceptability of the reduction.
a. [Vaker dan (dat ik) [e] haar artikel (lees)] lees ik haar boek. more.often than that I her article read read I her book
b. [Liever dan (dat ik) [e] achter hem (zit)] zit ik voor hem. more.gladly than that I behind him sit sit I in.front.of him

The claim that dan and als are borderline cases in between coordinator and subordinator mainly rests on the assumption that gapping (and backward conjunction reduction) are hallmarks of coordination. One might, however, also conclude on the basis of the evidence of examples like (11) and (12) that this supposition is incorrect and that gapping is relevant in a wider range of constructions. And there is in fact no a priori reason to reject this possibility if we see gapping as a process that can be applied in any construction with contrastive topics/foci, as long as the elided material is recoverable from the linguistic context.

Van der Heijden (1999) has shown that there are more constructions with als and dan with similar properties as found in the comparative constructions discussed above, but since they can be analyzed in a similar way, there is no real need to go into these cases. We would like to conclude this subsection, however, with a brief digression on our earlier discussion of the more or less fixed sequences evenmin/zomin ... als ..., which are given in Haeseryn et al. (1997:544/1518-22) as cases of correlative coordinators: Ik heb [evenmin Jan als Marie] gezien 'I have seen neither Jan nor Marie'. Section 1.4.2, sub IB, has provided arguments for assuming that these sequences are not coordinators but comparative adjectival phrases. This can also be supported by the fact illustrated in (13) that the als-phrases exhibit a behavior with respect to reduction which is similar to the als/dan-phrases discussed earlier in this subsection: (13a) shows that pronouns following als can be nominative; the contrast between (13a) and (13b) shows that the case marking of the pronoun depends on its correlate in the main clause; and (13c) shows that we can derive gapping-like structures.

(13) a. Marie heeft Jan evenmin gezien als [da ik [e] Marie has Jan neither seen ALS that I Jan seen have 'Marie hasn't seen Jan, and neither have I.'

b. Marie heeft Jan evenmin gezien als [dat Marie mij [e] Marie has Jan neither seen ALS that Marie me seen has 'Marie has seen neither Jan nor me.' 
c. Marie heeft Jan evenmin gezien als [dat Els Peter [e] gezien heeft]. Marie has Jan neither seen ALS that Els Peter seen has 'Marie hasn't seen Jan, and neither has Els seen Peter.'

The examples in (13) can only be accounted for when we assume that als takes a clausal complement, but it is nevertheless impossible to analyze them as involving coordination. First, the complements of als are embedded clauses as is clear from their non-reduced counterparts in (14).

(14) a. Marie heeft Jan evenmin gezien als [dat ik hem [e] gezien heb]. Marie has Jan neither seen ALS that I him seen have

b. Marie heeft Jan evenmin gezien als [dat zij mij [e] gezien heeft]. Marie has Jan neither seen ALS that she me seen has

c. Marie heeft Jan evenmin gezien als [dat Els Peter [e] gezien heeft]. Marie has Jan neither seen ALS that Els Peter seen has

Second, the fact illustrated in (15) that the phrase evenmin als ... can be topicalized shows that it functions syntactically as a clausal constituent of the matrix clause. The parentheses again indicate that this holds both for the reduced and for the nonreduced form.

(15) a. [Evenmin als [(dat) ik (Jan) [e] (gezien heb)]] heeft Marie Jan gezien. neither ALS that I Jan seen have has Marie Jan seen

b. [Evenmin als [(dat Marie) mij [e] (gezien heeft)]] heeft Marie Jan gezien. neither ALS that Marie me seen has has Marie Jan seen

c. [Evenmin als [(dat) Els Peter [e] (gezien heeft)]] heeft Marie Jan gezien. neither ALS that Els Peter seen has has Marie Jan seen

The examples in (13) to (15) thus conclusively show that evenmin/zomin ... als ... cannot be analyzed as a correlative coordinator, which supports the conclusion from Section 1.4.2, sub IB, that we are dealing with a more or less ordinary comparative adjectival construction.

\section{Behalve 'except/besides'}

This subsection discusses the status of the lexical element behalve 'except/besides' in examples such as given in (16). These examples show that behalve has two different readings, which Haeseryn et al. (1997:1604) refer to as restrictive and additive. Restrictive behalve typically modifies a (positive or negative) universal quantifier in the main clause, while additive behalve is typically associated with a phrase modified by the focus particle ook 'also'; cf. Paardekooper (1966). Note in passing that restrictive behalve exhibits more or less the same behavior as uitgezonderd 'except', which will not be discussed here.

(16) a. Iedereen/niemand is aanwezig, behalve Els.

[restrictive] everyone/nobody is present except Els

b. Behalve Els is ook Peter aanwezig. besides Els is also Peter present

[additive]

'Besides Els, Peter is also present.' 
In what follows, we will refer to the italicized string as the behalve-phrase and the universal and ${ }^{\circ}$ focused phrases as its associate. These notions should be taken as convenient descriptive terms, without the intention of saying that behalve-phrases and their associates function as separate clausal constituents. The reason for this is that the status of behalve is subject to debate. Although Komen (1994: section 6.1) has shown that this discussion already dates back to the eighteenth century, we take Paardekooper (1966/1986: section 3.5.1) to be the starting point of the debate in modern Dutch linguistics. Paardekooper argues that behalve functions as a coordinator in the sense that the behalve-phrases and their associates start out as parts of a coordinate structure: [[iedereen/niemand] behalve [Els]] and [[ook Peter] behalve [Els]]. This claim is disputed by Landman \& Moerdijk (1980), who argue in favor of a preposition status for behalve; behalve-phrases function as separate clausal constituents with an adverbial function. Since then the status of behalve has been a recurrent theme in the literature: see Klein (1985), Kooij (1992), Komen (1994:ch.6), Van der Heijden \& Klein (1995), Haeseryn et al. (1997), Van der Heijden (1999:ch.1) and others. This subsection will review the core data that have played a role in the debate on the categorial status of behalve, but we will start with the various analytic stances that have been defended in the literature.

\section{A. The status of the behalve-phrase}

Paardekooper (1966) provided a number of arguments for assuming that the element behalve behaves like a coordinator. An important argument in suggesting that the behalve-phrase and its associate form a coordinate structure is that they can occur together in sentence-initial position, which can normally be taken to show that they form a clausal constituent. This is illustrated in (17a) for the sentence with a restrictive interpretation. A problem with this argument is that it does not carry over to sentences with an additive interpretation; the (b)-examples in (17b) are unacceptable regardless the order of the behalve-phrase and its associate.

(17) a. Iedereen behalve Els is aanwezig. everyone except Els is present

b. *Ook Peter behalve Els is aanwezig. also Peter besides Els is present

$\mathrm{b}^{\prime}$. *Behalve Els ook Peter is aanwezig. besides Els also Peter is present

[restrictive] [additive]

One might of course conclude from the contrast between (17a) and the two (b)examples that restrictive and additive behalve are different; the former functions as a coordinator while the latter functions as a preposition. Landman \& Moerdijk (1980) have shown, however, that assuming coordinator status for restrictive behalve is also problematic: the behalve-phrase can occur in clause-initial position regardless of its interpretation, as shown in (18). Note in passing that we will ignore the fact reported in Komen (1994) that (18a) also allows the additive reading "besides Els, everyone else is also present'. 
(18) a. Behalve Els is iedereen aanwezig.

[restrictive] except Els is everyone present

b. Behalve Els is ook Peter aanwezig. besides Els/she is also Peter present 'Besides Els, Peter is also present.'

[additive]

The examples in (18) can be taken as evidence that behalve-phrases act as clausal constituents regardless of their interpretation. That (18) involves extraction of the behalve-phrase from a coordinate structure is also highly unlikely, as such extractions are never possible from coordinate structures with en 'and' or of 'or'. The two examples in (19) have the same syntactic structure and (19a) should therefore be excluded for the same reason as (19b), viz. the coordinate structure constraint discussed in Section 1.3, sub IIB.

a. *[Behalve Els $]_{\mathrm{i}}$ is [iedereen $\left.t_{\mathrm{i}}\right]$ aanwezig. except Els is everyone present

b. *[En/Of de meisjes $]_{\mathrm{i}}$ zijn [de jongens $t_{\mathrm{i}}$ ] aanwezig. and/or the girls are the boys present

Landman \& Moerdijk take the examples in (18) as evidence for their claim that the behalve-phrases are PPs with a restrictive/additive adverbial function. Klein (1985) challenges their conclusion by pointing out that behalve can be followed by a gapped clause. This is illustrated by the restrictive examples in (20), where (20b) is derived from the (clumsy but acceptable) example in (20a) by gapping.

[Jan heeft niemand iets gegeven] ...

Jan has nobody anything given

a. ... behalve [dat hij (=Jan) Els een boek gegeven heeft]. except that Jan Els a book given has

'Jan has given nobody anything except that he has given Els a book.'

b. ... behalve [ats Els een boek

... except that Jan Els a book given has

'Jan has given nobody anything except Els a book.'

Klein claims that behalve should therefore be considered a conjunction after all, given the traditional claim that gapping is possible in coordinate structures only. This conclusion is relaxed in Van der Heijden \& Klein (1995), where it says that we cannot be dealing with a regular coordinate structure, as the presumed coordinated clauses are not sufficiently similar: the first coordinand has the form of a main clause while the second clause has the form of an embedded clause, which suggests that we are dealing with some form of subordination after all. This conclusion receives support from behalve-phrases with a gapped clause occurring in the initial position of the main clause, as illustrated in (21) for both restrictive and additive cases. 
Behalve [dat Jan Els een boek heeft...

besides that Jan Els a book given has

a. ... heeft Jan niemand iets gegeven. has Jan nobody anything given

[restrictive]

'Jan has given nobody anything except Els a book.'

b. ... heeft Jan Marie (bovendien) een CD gegeven. [additive] has Jan Marie moreover a CD given

'Besides having given Els a book, Jan gave Marie a CD (as well).'

This supports Landman \& Moerdijk's argument against the conjunction analysis, as this kind of topicalization is excluded in average coordinate structures such as given in (22); moving the italicized string in (22a) into the initial position of the initial main clause gives rise to an unacceptable result.

(22) a. [[Jan kijkt naar de televisie] en [Marie leest een boek]].

Jan looks at the television and Marie reads a book

'Jan is watching television and Marie is reading a book.'

b. *En Marie leest een boek kijkt Jan naar de televisie.

and Marie reads a book looks Jan at the television

The brief excursion above has made it clear that there are in fact four main approaches to sentences with restrictive/additive behalve-phrases based on two parameters: behalve is a conjunction or a preposition; the phrase following behalve can be any XP (e.g., a noun phrase or a clause) or it is a clause which may or may not be gapped. The four possibilities are given in Table 1 .

Table 1: Theoretical approaches to restrictive/additive behalve-phrases

\begin{tabular}{|c|c|c|}
\hline & CATEGORICALLY UNRESTRICTED & (GAPPED) CLAUSES \\
\hline COORDINATION & $\begin{array}{l}\text { Paardekooper (1966): } \\
\text { [XP behalve YP] }\end{array}$ & $\begin{array}{l}\text { Klein (1985): } \\
\text { [Clause behalve Clause] }\end{array}$ \\
\hline SUBORDINATION & $\begin{array}{l}\text { Landman \& Moerdijk (1980): } \\
\text { XP ...[рP behalve YP] }\end{array}$ & $\begin{array}{l}\text { Van der Heijden \& Klein (1995): } \\
\text { Clause }_{\text {matrix }} . . \text { [behalve Clause } \\
\text { embedded }\end{array}$ \\
\hline
\end{tabular}

The discussion above has yielded some arguments for preferring one of the subordination approaches to the coordination approach, although we still have to provide an account of example (17a). The following subsections will review some more data that have played a role in the debate, and we will see that these support a subordination approach along the line of Van der Heijden \& Klein (1995).

\section{B. Case marking of pronouns following behalve}

That the behalve-phrases in (16) cannot be analyzed as adpositional phrases with a nominal complement is clear from the fact illustrated in (23) that behalve can be followed by a nominative pronoun when the behalve-phrase modifies the subject. 
(23) a. Iedereen/niemand was aanwezig, behalve $z i j$.

[restrictive] everyone/nobody was present except she

b. Behalve zij was ook Peter aanwezig.

[additive] besides she was also Peter present

'Besides Els/her, Peter was also present.'

That behalve cannot be a preposition assigning nominative case to the pronoun is clear from the fact that regular adpositions would take a noun phrase with objective (and not with nominative) case. This is illustrated in (24) for the near-synonymous examples with the restrictive phrasal adposition met uitzondering van and the additive preposition naast (which is somewhat formal in this use).

(24) a. Iedereen/niemand was aanwezig, met uitzondering van Els/haar. [restrictive] everyone/nobody was present with the.exception of Els/her

b. Naast Els/haar was (ook) Peter anwezig. [additive] next.to Els/her was also Peter present 'Besides Els/her, Peter was also present.'

That the noun phrase Els/zij is not assigned nominative case by behalve directly also appears from the fact illustrated in (25) that behalve is followed by a pronoun with objective case when the behalve-phrase modifies the object.

a. Ik heb iedereen gezien behalve Els/haar.

[restrictive]

I have everyone seen except Els/her

'I have seen everyone except Els/her.'

b. Behalve Els/haar heb ik (ook) Peter gezien.

[additive]

besides Els/her have I also Peter seen

'Besides Els/her, I have also seen Peter.'

Paardekooper concludes from the fact that the case marking of the pronouns depends on the associate of the behalve-phrase that the behalve-phrase and its associate start out as a coordinate structure that is assigned nominative or accusative case as a whole (just as would happen with coordinate structure of the form NP en/of NP). That the case marking of the pronouns depends on the associate of the behalve-phrase can, however, also easily be accounted for under a gapping approach, as the remnants of gapping must have the same syntactic function. That this is a feasible analysis can unproblematically be illustrated for the additive cases in (16b) and (25b), which can be assigned the structures in the primed example in (26), because their non-reduced counterparts in the primeless examples are also acceptable.

(26) a. Behalve [dat Els/zij aanwezig was], was (ook) Peter aanwezig. besides that Els/she present was was also Peter present

$a^{\prime}$. Behalve [dat Els/zij was (ook) Peter aanwezig. besides that Els/she present was was also Peter present

b. Behalve [dat ik Els/haar gezien heb] heb ik (ook) Peter gezien. besides that I Els/her seen have have I also Peter seen

$b^{\prime}$. Behalve [at Els/haar heb ik (ook) Peter gezien. besides that I Els/her seen have have I also Peter seen 
Illustrating that we are dealing with a reduced clause is more difficult in the case of the restrictive examples in (16a) and (25a), due to the fact that the non-reduced form (which is awkward anyway) seems to involve negation. Since it is not clear to us how to accommodate this in a reduction analysis, we leave this problem to future research and refer the reader to Van der Heijden \& Klein (1995) for relevant discussion. Note in passing that if the main clause contains a negative universal quantifier, as in the primed examples, the reduced clause has an implied affirmative marker: see Paardekooper (1966) for more discussion.

(27) a. Iedereen was aanwezig, behalve [dat Els/zij niet everyone was present except that Els/she not present was

$\mathrm{a}^{\prime}$. Niemand was aanwezig, behalve [dat Els/zij el nobody was present except that Els/she AFF. present was

b. Ik heb iedereen gezien behalve [at Els/haar I have everyone seen except that I Els/her not seen have

$\mathrm{b}^{\prime}$. Ik heb niemand gezien behalve [ [at ik Els/haar al I have nobody seen except that I Els/her AFF. seen have

Recall from Subsection A that the gapping analysis is independently supported by the fact that behalve can be followed by more than one remnant. We illustrate this again by means of the examples in (28) for a subject and an object remnant; the percentage sign is used to indicate that some speakers consider (28a) marked.

(28) a. ${ }^{\%}$ Iedereen heeft alle boeken gelezen

everyone has all books read

behalve [at Jan/hij Arthur Japins Kolja

except that Jan/he Arthur Japin's Kolja not read has

'Everyone has read all books except that Jan/he hasn't read Kolja by Japin.'

b. Behalve [dan Jan een boek

besides that Jan a book gets gets Els also yet a CD

'Besides Jan being given a book, Els is given a CD as well.'

\section{Phrases following behalve are not categorically restricted}

The examples in Subsection A and B have shown that the phrase following behalve can be nominal if the associate of the behalve-phrase is a nominal argument. However, there do not seem to be any categorial restrictions on this phrase. The examples in (29) show that its form depends on the associate: for instance, the phrase following behalve can be a PP in the examples of (29), where the associate is a prepositional object in the (a)-examples and a locational ${ }^{\circ}$ complementive in the (b)-examples.

(29) a. Ik heb op iedereen gewacht behalve op Jan.

I have for everyone waited except for Jan

'I have waited for everyone except Jan.'

$\mathrm{a}^{\prime}$. Behalve op Jan heb ik ook op Marie gewacht. besides for Jan have I also for Marie waited 'In addition to Jan, I have also waited for Marie.' 
b. Jan is overal geweest behalve in Amsterdam.

Jan is everywhere been except in Amsterdam

'Jan has been everywhere except in Amsterdam.'

$\mathrm{b}^{\prime}$. Behalve in Amsterdam is Jan ook in Utrecht geweest. besides in Amsterdam is Jan also in Utrecht been

'In addition to Amsterdam, Jan has also been in Utrecht.'

If the associate is a complementive, the phrase following can also be an adjectival phrase, as shown in (30). Note, however, that allesbehalve in (30a) seems to behave as a lexical unit, as is clear from the fact that the split pattern is highly marked: cf. *Jan is alles geweest behalve aardig.
a. Jan is alles behalve aardig geweest.
Jan is all except kind been
'Jan has been anything but kind.'
b. Behalve aardig is Jan ook behulpzaam.
besides kind is Jan also helpful
'Besides kind, Jan is also helpful.'

Paardekooper claims that because there is no clear categorial restriction on the phrase following behalve, this supports the coordinator approach as prepositions are normally not followed by PPs or APs, while APs and PPs can be coordinated; see Landman \& Moerdijk (1980) and Klein (1985) for more discussion of this issue. The examples in (29) can, however, also be derived by gapping; this is illustrated in (31), the non-reduced counterparts of which are laborious but also possible.

(31) a. Ik heb op iedereen gewacht behalve [at op Jan ] I have for everyone waited except that I for Jan waited have 'I have waited for everyone except for Jan.'

a'. [Behalve heb ik ook op Marie gewacht. besides that I for Jan waited have have I also for Marie waited 'In addition to Jan, I have also waited for Marie.'

b. Jan is overal geweest behalve [s] in Amsterdam Jan is everywhere been except that Jan in Amsterdam been is 'Jan has been everywhere except in Amsterdam.'

$\mathrm{b}^{\prime}$. Behalve [dat Ian in Amsterdam is Jan ook in Utrecht geweest. besides that Jan in Amsterdam been is is Jan also in Utrecht been 'In addition to Amsterdam, Jan has also been in Utrecht.'

A nice bonus of the gapping approach is that we now predict that the phrase following behalve must be a clausal constituent. The examples in (32) show that this prediction holds true by showing for the prepositional remnants in (31) that the prepositions must be overtly realized despite the fact that they are recoverable from the main clause. 
(32) a. Ik heb op iedereen gewacht behalve ??(op) Jan.

I have for everyone waited except for Jan

$a^{\prime}$. Behalve *(op) Jan heb ik ook op Marie gewacht. besides for Jan have I also for Marie waited

b. Jan is overal geweest behalve ?'(in) Amsterdam. Jan is everywhere been except in Amsterdam

$\mathrm{b}^{\prime}$. Behalve *(in) Amsterdam is Jan ook in Utrecht geweest. besides in Amsterdam is Jan also in Utrecht been

The sentences in (33) illustrate the same thing by showing that while the remnant can be a full direct object, it cannot be merely its postnominal modifier.

(33) a. Ik heb alle huizen al bezocht behalve *(het huis) op de hoek.

I have all houses already visited except the house at the corner

'I have already looked at all the houses except the house on the corner.'

b. Behalve *(het huis) op de hoek, heb ik ook het huis bij het park bezocht. besides the house at the corner have I also the house near the park visited 'Besides the house at the corner, I have also visited the house near the park.'

\section{Nominal phrases following behalve cannot be weak pronouns}

We see in (34) that nominal phrases following behalve cannot be weak pronouns; the primeless examples illustrate this for nominative and the (b)-examples for objective pronouns.

(34) a. *Iedereen was aanwezig, behalve ze $\mathbf{e}_{\text {weak }}$. everyone was present except she

[restrictive]

$\mathrm{a}^{\prime}$. *Ik heb iedereen gezien behalve ' $\mathbf{r}_{\text {weak }}$. I have everyone seen except her

b. *Behalve ze $\mathbf{z e}_{\text {weak }}$ was (ook) Peter aanwezig.

[additive] besides she was also Peter present

$\mathrm{b}^{\prime} .{ }^{*}$ Behalve ' $\mathbf{r}_{\text {weak }}$ heb ik (ook) Peter gezien. besides her have I also Peter seen

Paardekooper notes that this restriction is to be expected under a coordination approach, given that weak pronouns are not possible in coordinate structures either: this is illustrated for the conjunction en 'and' in (35).
a. [Jan en zij] waren aanwezig. Jan and she were present
b. Ik heb [Jan en haar] gezien. I have Jan and her seen
$\mathrm{a}^{\prime} . *$ Jan en ze] waren aanwezig. Jan and she were present
$\mathrm{b}^{\prime}$. *Ik heb [Jan en 'r] gezien.
I have Jan and her seen

The subordination approach, on the other hand, runs into trouble in accounting for the facts in (34), given that (stress-bearing) prepositions can normally take weak pronouns as their complement: cf. Marie keek naar hem/'m 'Marie looked at him'. This problem is solved, however, if behalve does not take a noun phrase but a gapped clause as its complement, given that remnants of gapping must be contrastively accented and thus cannot be weak pronouns; cf. Section 2.2, sub IB. 


\section{E. Two residual issues}

Subsection A has shown that the fact that behalve-phrases can occur in the initial position of main clauses poses a serious and probably insurmountable problem for the coordination approach. Since the subsequent subsections have shown that most data advanced in favor of the coordination approach can also be accounted for by the subordination approach when we assume that behalve takes a (gapped) clausal complement, we can now safely reject the coordination approaches. However, we still have to account for examples like those in (36), which were given in Paardekooper (1966) in support of the coordination approach; the fact that the behalve-phrase and its associate can co-occur in sentence-initial position suggests that we are dealing with a ${ }^{\circ}$ clausal constituent; cf. the ${ }^{\circ}$ constituency test.
a. Iedereen behalve Els/zij was aanwezig. everyone except Els/she was present
b. Iedereen behalve Els/haar heb ik gezien. everyone except Els/her have I seen

Although this argument in favor of the coordination approach is not very strong to begin with because it only applies to restrictive behalve-phrases, we still need an account for the acceptability of the examples in (36). Since we have concluded that preverbal strings cannot be clausal constituents, a plausible solution would be to assume that the behalve-phrases are parenthetical clauses, which can be supported by the fact that they can easily be preceded and followed by an intonation break.
a. Iedereen - behalve Els/zij (natuurlijk) - was aanwezig. everyone except Els/she of course was present
b. Iedereen - behalve Els/haar (natuurlijk) - heb ik gezien. everyone except Els/her of course have I seen

Another issue we have ignored so far but which needs some attention is the question as to why additive behalve-phrases differ from their restrictive counterparts in that they cannot occur in clause-final position. The examples in (38) illustrate once again that restrictive behalve-phrases can occur in clause-final position or be topicalized into sentence-initial position.
- Restrictive behalve-phrases
a. Iedereen was aanwezig behalve Els/zij. everyone was present except Els/she
$a^{\prime}$. Behalve Els/zij was iedereen aanwezig. except Els/she was everyone present
b. Ik heb iedereen gezien behalve Els/haar. I have everyone seen except Els/her
$\mathrm{b}^{\prime}$. Behalve Els/haar heb ik iedereen gezien. except Els/her have I everyone seen

The example in (39), on the other hand, show that additive behalve-phrases must be topicalized. We have marked the primeless examples in (39) with a dollar sign because there is no reason to assume that they are syntactically deviant. We have the impression that their unacceptability may be of a pragmatic nature, related to the 
fact that the behalve-phrase provides information from the ${ }^{\circ}$ common ground (i.e., Els was expected to be present) while the added new information that Peter was present too is expressed by the main clause.
- Additive behalve-phrases
a. ${ }^{\$}$ Peter was (ook) aanwezig behalve Els/zij.
Peter was also present besides Els/she
$a^{\prime}$. Behalve Els/zij was (ook) Peter aanwezig. besides Els/she was also Peter present
b. ${ }^{\$} \mathrm{Ik}$ heb (ook) Peter gezien behalve Els/haar.
I have also Peter seen besides Els her
$b^{\prime}$. Behalve Els/haar heb ik (ook) Peter gezien. besides Els/her have I also Peter seen

In this context it may be useful to point out that the contrast between the (b)examples in (38) and those in (39) is also reflected by those between the (a)- and (b)-examples in (40), in which the behalve-phrases occur in the ${ }^{\circ}$ middle field of the clause: restrictive behalve-phrases may either precede or follow their correlate while the additive ones must precede them.
(40) a. Ik heb iedereen behalve Els/haar gezien.
I have everyone except Els/her seen
$a^{\prime}$ Ik heb behalve Els/haar waarschijnlijk iedereen gezien.
I have except Els/her probably everyone seen
'I have (probably) seen everyone except Els/her.'
b. *Ik heb (ook) Peter behalve Els/haar gezien.
I have also Peter besides Els/her seen
$\mathrm{b}^{\prime}$. Ik heb behalve Els/haar gelukkig (ook) Peter gezien.
I have besides Els/her fortunately also Peter seen
'Besides Els/her, I fortunately have also seen Peter.'

Regardless of whether the pragmatic account of the restriction on the placement of additive behalve-phrases is on the right track, the fact illustrated in (40) that behalve-phrases may precede their associates (and be separated from them by, e.g., adverbs like waarschijnlijk 'probably' or gelukkig 'fortunately') again shows that they are clausal constituents, and not subparts of a coordinate structure. This provides a final piece of evidence in favor of the subordination approach.

\section{In plaats van 'instead of'}

Judgments on the use of the case forms of the pronouns in examples like those in (41) are not very sharp: they differ from case to case and most probably also from person to person. Our intuition is that the use the objective form is preferred when the examples are pronounced in a neutral way while the nominative form requires contrastive accent.

(41) a. Zij gaf een lezing in plaats van hem/ $/$ hij.

she gave a talk instead of him/he

$\mathrm{a}^{\prime}$. ZIJ gaf een lezing in plaats van $\mathrm{HIJ} /{ }^{\prime} \mathrm{HEM}$.

she gave a talk instead of him/he 

b. Zij werd ontslagen in plaats van hem $/{ }^{2}$ hij.
she was fired instead of him/he
$\mathrm{b}^{\prime}$. ZIJ werd ontslagen in plaats van $\mathrm{HIJ} /{ }^{2} \mathrm{HEM}$.
she was fired instead of him/he

If this intuition is on the right track, we can conclude that in plaats van 'instead of' is a regular (phrasal) preposition that may select either a nominal phrase, which is then assigned objective case, or a reduced clause, in which case nominative can be assigned to the noun phrase within the reduced clause. That reduction may very well be involved in the derivation of the primed examples in (41) can be supported by the fact illustrated by the primeless examples in (42) that in plaats van can take a finite clause; the examples with the nominative pronoun hij can now be derived by gapping, as in the primed examples.
a. Zij gaf een lezing in plaats van [dat hij een lezing gaf]. she gave a talk instead of that he a talk gave
$\mathrm{a}^{\prime}$. ZIJ gaf een lezing in plaats van [ HIJ Haf she gave a talk instead of that he a talk gave
b. Zij werd ontslagen in plaats van [dat hij ontslagen werd]. she was fired instead of that he fired was
$\mathrm{b}^{\prime}$. ZIJ werd ontslagen in plaats van [dat HIJ entslagen she was fired instead of that he fired was

The gapping analysis in the primed examples of (42) is also supported by the fact that nominative case is obligatory in examples with two remnants such as those in (43); cf. Klein (1985).

(43) a. ZIJ kuste HEM in plaats van [dat HIJ HAAR she kissed him instead of that he her kissed 'She kissed him instead of he her.'

b. ZIJ gaat naar HEM in plaats van [at HIJ naar HAAR she goes to him instead of that he to her goes 'She goes to him instead of he to her.'

Taking the possibility of gapping as an argument in favor of assuming coordinatorlike status for in plaats van would be unwise, however, as in all examples this element can be shown to head a clausal constituent. This is clear from, e.g., the topicalization constructions in (44); the parentheses are intended to show that the non-reduced and the reduced variant can both be placed in sentence-initial position.

(44) a. [In plaats van [(dat) HIJ (een lezing gaf)]] gaf ZIJ een lezing. instead of that he a talk gave gave she a talk

b. [In plaats van [(dat) HIJ (ontslagen werd)]] werd ZIJ ontslagen. instead of that he fired was was she fired

c. [In plaats van [(dat) HIJ HAAR (kuste)]] kuste ZIJ HEM. instead of that he her kissed kissed she him 'She kissed him instead of he her.' 


\section{$I V$. Laat staan 'let alone'}

The line of reasoning in the three preceding subsections can be repeated for the (lexicalized) phrasal element laat staan 'let alone' (lit. "let stand"), which only appears in negative clauses: cf. Haeseryn et al. (1997:566). The primeless examples in (45) make it clear that laat staan can be followed by a finite clause, which means that cases in which it is followed by a noun phrase can in principle be derived by means of gapping. That gapping is involved is clear from the fact that (nominative or objective) case marking of the pronouns in the primed examples depends on their correlate in the main clause.

(45) a. Jan kent hem niet, laat staan [dat Marie/zij hem kent]. Jan knows him not let stand that Marie/she him knows 'Jan doesn't know him let alone that Marie/she would know him.'

$a^{\prime}$. JAN kent hem niet, laat staan [dat MARIE/ZIJ hem kent]. Jan knows him not let stand that Marie/she him knows

b. Jan kent Peter/hem niet, laat staan [dat hij Els/haar kent]. Jan knows Peter/him not let stand that he Els/her knows 'Jan doesn't know Peter/him let alone that he would know Els/her.'

$\mathrm{b}^{\prime}$. Jan kent PETER/HEM niet, laat staan [a ELS/HAAR ]. Jan knows Peter/him not let stand that he Els/her knows

The remnants in the primed examples cannot be replaced by a weak pronoun but, contrary to the cases discussed in the previous subsections, this cannot be used as an argument for assuming that we are dealing with a gapping-like construction because the same holds for the pronouns in the non-reduced primeless examples. This may be due to the fact that the laat staan-construction is inherently contrastive; the use of the parentheses again is meant to show that the non-reduced and the reduced variant exhibit identical behavior.
a. *Jan kent hem niet laat staan [(dat) ze $\mathrm{ze}_{\text {weak }}$ (hem kent)]. Jan knows him not let stand that she him knows
b. *Jan kent Peter/hem niet laat staan [(dat hij) ${ }^{*}{ }^{\prime}{ }_{\text {weak }}$ (kent)]. Jan knows Peter/him not let stand that he her knows

Note further that the laat staan-phrases in (45) cannot be topicalized. It is not clear what this shows because this is a more common feature of phrases that can only occur in negative contexts: cf. the negative polarity item ook maar iets in Niemand heeft ook maar iets gezien 'Nobody has seen anything' and *Ook maar iets heeft niemand gezien.

\subsection{A note on the semantic side of gapping}

Section 3.1 has shown that elements like comparative dan/als 'than/as', behalve 'except/besides', in plaats van 'instead of' and laat staan 'let alone' are not coordinator-like elements but subordinators which (may) introduce a gapped clause. This goes against the traditional claim that gapping (and backward conjunction reduction) only occur in coordinate structures, and so it raises a number of new questions. One of these is what licenses gapping in subordinate clauses. The same 
question should in fact have been raised in the context of gapping in coordinate structures, because not all coordinators license gapping: gapping is not possible in coordinate structures with the coordinators want 'because' and less usual with the coordinator dus 'so'. cf. Section 2.2, sub IA.
a. *[[Jan kocht het boek] want [Marie de film]].
Jan bought the book because Marie bought the movie
Intended: 'Jan bought the book, because Marie bought the movie.'
b. "?[[Marie kocht de film] dus [Jan het boek]].
Marie bought the movie so Jan bought the book
Intended: 'Marie bought the movie, so Jan bought the book.'

So, if gapping can also apply in subordinate clauses introduced by the elements listed above it does not need to surprise us greatly that there are other cases of subordination in which gapping is excluded. Some examples are given in (48).
a. *[Jan kocht het boek [toen Marie de film
Jan bought the book when Marie the movie bought
Intended: 'Jan bought the book, when Marie bought the movie.'
b. * Jan kocht het boek [omdat Marie de film
Jan bought the book because Marie the movie bought
Intended: 'Jan bought the book, because Marie bought the movie.'
c. *[Jan kocht het boek [hoewel Marie de film
Jan bought the book although Marie the movie bought
Intended: 'Jan bought the book, although Marie bought the movie.'

One straightforward way of excluding gapping in examples like those in (48) would be pointing at the $\mathrm{A}^{\prime}$-movement hypothesis proposed in Section 2.2, sub IID, according to which the remnants of gapping must occupy a designated $\mathrm{A}^{\prime}$-position. Gapping in (48) would then be unacceptable because complementizers do not occupy such a position but cannot be elided either because they express information not recoverable from the linguistic context; toen 'then', omdat 'because', and hoewel 'although' cannot be deleted because they express temporal, causal and concessive information. Elements like dan/als 'than/as', behalve 'except/besides', in plaats van 'instead of' and laat staan 'let alone', on the other hand, are not part of the gapped clause and are thus not expected to interfere with gapping. Unfortunately, this approach leaves us in the lurch regarding the unacceptability of the examples in (47a): the coordinators want 'because' and $d u s$ 'so' are also external to the gapped clause and so are not expected to interfere with gapping either.

Another proposal aimed at making the correct distinction between gapping and non-gapping contexts is provided by Van der Heijden \& Klein (1995), who focus on the logical and arithmetical properties of gapping constructions. The general idea is that the contrastively accented parts of the antecedent and the target clause stand in a simple logical or arithmetical relationship specified by the linker (coordinator or subordinator). That something like this holds for the conjunctions in (49) is uncontroversial; see Section 1.1, sub IV, for more discussion. Note that we did not 
include the conjunction maar 'but' in (49), which is like en in that it can express conjunction and intersection but adds an adversative meaning aspect.

(49) a. En 'and': sum $(\mathrm{a}+\mathrm{b})$; conjunction $(\mathrm{a} \wedge \mathrm{b})$; intersection $(\mathrm{A} \cap \mathrm{B})$

b. $O f$ 'or': disjunction $(\mathrm{a} \vee \mathrm{b})$; union $(\mathrm{A} \cup \mathrm{B})$

c. noch 'nor': exclusion $(\neg[\mathrm{a} \vee \mathrm{b}]) ;(\neg[\mathrm{A} \cup \mathrm{B}])$

That want 'because' and dus 'so' cannot be used in gapping contexts can now be attributed to the fact that they do not specify a simple logical/arithmetical relation between subparts of the coordinands but a complex relation between the clausal coordinands as a whole, as is clear from the meanings attributed to them in Section 1.4.1, sub V, repeated here in (50).
a. $\Phi$ want $\Psi \cong \psi \wedge(\psi \rightarrow \varphi)$
B. $\Phi d u s \Psi \cong \varphi \wedge(\varphi \rightarrow \psi)$

Example (51) shows that the subordinators als and dan found in comparatives again specify a simple relation between subparts of the clauses, which can be expressed by means of logical symbols like "=", ">" and "<", which can be applied to quantities and degrees.

(51) a. even $\mathrm{A}(\mathrm{N})$ als 'as ... as': equal degree/number (=)

b. A-er (N) dan '-er ... than': different degree/number (either $>$ or $<$ )

Van der Heijden \& Klein (1995) further claim that the subordinating elements in (52) can also be seen as simple logical/arithmetical operators, although some of these do not have clear counterparts in standard logic/arithmetic. The general properties of these linkers is that they perform some operation (reduction, expansion or substitution) on some, possibly singleton, set given in the antecedent clause.

(52) a. restrictive behalve 'except'; set reduction (A/B), that is, set A minus B

b. additive behalve 'besides'; set expansion/union

c. In plaats van 'instead of': set substitution

The question is whether the semantic operations/relations should be used in the formulation of a restriction imposed on gapping or whether they should simply be seen as an inventory of semantic relations that can hold between the contrastively accented remnants of gapping and their correlates in the antecedent clause. Since the answer to this question largely depends on the model of grammar adopted, we will not digress on this issue here.

\subsection{Conclusion and a potential problem}

This chapter has shown that the claim that lexical items like als/dan 'as/than', behalve 'except/besides', in plaats van 'instead of' and laat staan 'let alone' are (or can be) coordinator-like categories mainly rests on the presupposition that gapping is possible in coordinate structures only; if we reject this presupposition we can simply analyze these elements as subordinators (e.g., prepositions) that may take a reduced clausal ${ }^{\circ}$ complement. This will also solve the problem that the gapping operation in the constructions under discussion differs from gapping in coordinate 
structures in that it (seemingly) does not only apply in a forward fashion but also in a backward fashion by pointing at the fact that the gapped clause is embedded in a clausal constituent that can be topicalized. So, the difference between gapping in the constructions discussed in this chapter and gapping in coordinate structures follows from the fact that topicalization of a string such as en-XP in (53) violates the coordinate structure constraint discussed in Section 1.3, sub IIB.
a. Jan heeft [Marie en Els] gezien.
Jan has Marie and Els seen
'Jan has seen Marie and Els.'
b. *[En Els $]_{\mathrm{i}}$ heeft Jan [Marie $\left.t_{\mathrm{i}}\right]$ gezien. and Els has Jan Marie seen

If gapping is possible in subordinate clauses, we expect that it can be applied to all contrastive ${ }^{\circ}$ focus/topic structures, provided that the elided material can be recovered from the immediate linguistic environment. This is a desirable move as it removes an ad hoc restriction on gapping and also supports our earlier conclusion in Section 2.2, sub IIIH, that gapping may be involved in the derivation of fragment clauses. Another potential case is given in (54b) adapted from Van der Heijden \& Klein (1995) and Haeseryn et al. (1997: 1605-6).
a. [Als Jan Marie mag kussen] $]_{\text {Main clause }}$ dan $_{\mathrm{i}}$ mag Marie Jan ook kussen]. if Jan Marie may kiss than may Marie Jan also kiss
'If Jan is allowed to kiss Marie, Marie is allowed to kiss Jan too.'
b. [Als Jan Marie mag kussen]i [main clause dan i $_{\text {ag }}$ Marie Jan ook if Jan Marie may kiss than may Marie Jan also kiss

Conditional constructions of the type in (54a) were analyzed in Section V8.3.3 as regular main clauses (here: dan mag Marie Jan ook kussen) preceded by an extrasentential conditional clause (here: als Jan Marie mag kussen), which is resumed in the main clause by means of the proform dan 'than'. What is especially important here is that dan is located in the initial position of the main clause and must therefore be construed as a clausal constituent, which implies that assuming semicoordinator status for dan is impossible. Example (54b) shows that the conditional clause can nevertheless trigger some form of gapping in the main clause, which again cannot easily be understood if gapping is restricted to coordinate structures. Dropping this restriction, on the other hand, opens up new avenues for investigating examples of the sort in (54b).

We want to conclude by mentioning a final potential problem for assuming that gapping is involved in the derivation of the constructions discussed in this chapter. Consider the examples in (55), adapted from Van der Heijden (1999:20), who rates them all as acceptable.
a. Ik weet dat hij vaker
wandelt [dan zwemt].
I know that he more.often walks than swims
'I know that he swims more often than he walks.'
b. Ik weet dat hij [behalve zwemt] ook graag wandelt.
I know that he besides swims also gladly walks
'I know that besides swimming he also likes walking.'


c. Ik weet dat hij graag wandelt [in plaats van zwemt].

I know that he gladly walks instead of swims

'I know that he likes walking instead of swimming.'

d. Ik weet dat hij niet graag wandelt [laat staan zwemt].

I know that he not gladly walks let stand swims

'I know he doesn't like to walk let alone that he likes to swim.'

The reduced clauses included in the bracketed phrases cannot have been derived by gapping, as they all contain a finite verb and finite verbs cannot occur as remnants of gapping. That examples like those in (55) are special is clear from the fact that the bracketed phrases are possible in embedded clauses only; the main clauses in (56) are all degraded compared to the corresponding examples in (55). The examples in (56) become fully acceptable if we replace the finite verb by the full finite clause dat hij zwemt 'that he swims'.
a. *Hij wandelt vaker [dan zwemt]. he walks more.often than swims
b. *[Behalve zwemt] wandelt hij ook graag. besides swims walks he also gladly
c. *Hij wandelt graag [in plaats van zwemt]. he walks gladly instead of swims
d. *Hij wandelt niet graag [laat staan zwemt]. he walks not gladly let stand swims

That the reduced clause cannot be a main clause can easily be demonstrated by means of example (57a): the fact that the verbal ${ }^{\circ}$ particle must precede the finite verb shows that the verb belt occupies the final position of the reduced clause. Example (57b) shows again that the antecedent clause of the reduced clause following dan cannot be a main clause.

(57) a. Ik denk [dat Marie mij vaker schrijft [dan <op $>$ belt $<*$ op $>$ ]].

I think that Marie me more.often writes than prt. phones

'I think that Marie writes to me more often than that she phones me.'

b. *Marie schrijft me vaker [dan $<$ op $>$ belt $<$ op $>$ ].

Marie writes me more.often than prt. phones

The unacceptability of (56) is, of course, expected under a gapping account but the acceptability of the examples in (55) remains a mystery, and the acceptability contrast between the two sets of examples is surprising in any event. For the moment, we will provisionally assume that the examples in (55) are not gapping constructions but represent a construction in its own right, the investigation of which we have to leave to future research. 


\section{Bibliographical notes}

The semantic and syntactic literature on coordination and ellipsis is vast. A concise review of the various syntactic approaches to coordination in the pre-generative area can be found in Bakker (1968) and Dik (1968), and of earlier generative approaches in Van Oirsouw (1987). Zamparelli (2011) provides a review of various semantic approaches to coordination and especially the distinction between the distributive and collective reading of coordinated phrases (and plural definite noun phrases). More recent reviews of the formal syntactic approaches to the internal structure of coordination can be found in, e.g., Grootveld (1992/1994), Johannessen (1998:ch.3), Bredschneijder (1999), Progovac (2003), Zhang (2010), and De Vries (2017). An exhaustive review of the theoretical approaches to the various forms of ellipsis within coordinate structures until the early 1980's is provided in Van Oirsouw (1987); information about more recent developments can be found in, e.g., Johannessen (1998:ch.3), Johnson (2006/2017), Progovac (2003), and De Vries (2017). We have not discussed the relation between conjunction reduction and gapping, on the one hand, and VP-ellipsis and pseudo-gapping, on the other, as the latter two phenomena do not occur in Dutch; cf. Van Oirsouw (1987:158ff.) and Corver \& Van Koppen (to appear). We refer the reader to Wilder (1997), Johnson (2006/2017), and Aelbrechts (2009) for discussion of English VP-ellipsis.

There seems to be little consensus on even the most fundamental questions concerning coordination. The position adopted in our discussion that coordination may target non-clausal constituents (VPs, NPs, APs, PPs, etc), which was forcefully defended by Dik (1968), has been rejected by various researchers over the last few decades: Van Oirsouw (1987), Goodall (1987:ch.2), Cremers (1993:ch.2), and to a certain extent Wilder (1997) have all argued in favor of the more traditional view that such structures are derived from coordination of clauses and some form of forward conjunction reduction; we refer the reader to Zhang (2010: section 3.5) for more references. Coordination has also received many formal syntactic analyses. The conventional analyses developed from entirely "flat" (Chomsky 1957:36) structures to "layered" (binary branching) structures in, e.g., Thiersch (1993a), Munn (1993), Kayne 1994:ch.6), Johannessen (1998), and Zhang (2010). More innovative analyses include various forms of parallel and three-dimensional structures: see, e.g., Goodall (1987), Grootveld (1992/1994), and G. de Vries (1992). The wide range of available syntactic analyses may reflect the progress made in formal linguistics but may also be partly due to the fact that coordination is special in that it goes beyond "regular" sentence syntax.

The discussion of ellipsis in Chapter 2 follows Neijt (1979) to a large extent, who claims (i) that backward conjunction reduction and gapping are sufficient for describing the core data, (ii) that backward conjunction reduction is a phonological operation, and (iii) that gapping is a syntactic rule subject to specific constraints on A'-movement; see also Neijt (1981a/1981b). These claims are again controversial; we have already listed a number of studies supporting forward conjunction reduction. De Vries (2005) and Citko (2017) review a number of alternative 
analyses for backward conjunction reduction; Van Oirsouw discusses a large variety of non-movement analyses for gapping (including one of his own). We have seen in Section 2.2, sub IID, that claim (iii) did not lead Neijt to the conclusion that A'movement is actually involved in the derivation of gapping constructions because of various differences between gapping and wh-movement, but various attempts to derive gapping by means of actual movement are reviewed and developed in Johnson (2006/2017: section 4.2), Aelbrecht (2007) and Boone (2014). The specific version of the movement analysis adopted in this work is based on recent developments in the domain of $\mathrm{A}^{\prime}$-scrambling reviewed in Section V13.3.2. We refer the reader to Pieters (2011) for an extensive review of the description of ellipsis in coordinate structures found in various Dutch grammars since 1900. A more general review of ellipsis phenomena can be found in Van Craenenbroeck \& Merchant (2013); for more general reviews of ellipsis in Dutch (dialects) we refer the reader to Van Craenenbroeck (2010), Zwart (2011: section 6.4), and Corver \& Van Koppen (to appear). 


\section{Glossary}

\section{A- and $A^{\prime}$-movement:}

See ${ }^{\circ}$ Movement.

\section{A- and $\mathbf{A}^{\prime}$-scrambling:}

See ${ }^{\circ}$ Scrambling.

\section{Across-the-board:}

Examples (ib\&b') show that subextraction from a coordinate structure is normally excluded; cf. ${ }^{\circ}$ Coordinate structure constraint. This does not hold, however, if the movement applies in a so-called across-the-board fashion, that is, affects all conjuncts: (ic) is acceptable due to the fact that the wh-phrase wat 'what' is in a sense moved from (related to an interpretative gap in) both conjuncts.

(i) a. Jan heeft [[een boek van Peter gestolen] en [een CD/boek aan Marie gegeven]]. Jan has a book from Peter stolen and a CD/book to Marie given

b. *Wat ${ }_{i}$ heeft Jan [[ $t_{i}$ van Peter gestolen] en [een boek aan Marie gegeven]]? what has Jan from Peter stolen and a book to Marie given

$\mathrm{b}^{\prime}$. *Wat ${ }_{\mathrm{i}}$ heeft Jan [[een boek van Peter gestolen] en [ $t_{\mathrm{i}}$ aan Marie gegeven]]? what has Jan a book from Peter stolen and to Marie given

c. Wat $t_{\mathrm{i}}$ heeft Jan [[ $t_{\mathrm{i}}$ van Peter gestolen] en $\left[t_{\mathrm{i}}\right.$ aan Marie gegeven $\left.]\right]$ ? what has Jan from Peter stolen and to Marie given

\section{Adjunct:}

A constituent in the domain of a lexical head $\mathrm{H}$ that is not selected by $\mathrm{H}$. An adjunct is distinct from an argument, which is selected by $\mathrm{H}$. Adjuncts and arguments differ in that the former are generally optional, whereas arguments are generally obligatorily present (or at least semantically implied). In (i), the PP in de keuken 'in the kitchen' is optional and can be considered an adjunct, whereas the NP de aardappelen 'the potatoes' is virtually obligatory, and can be considered an argument of the verb schillen 'to peel'. See also ${ }^{\circ}$ Adjunction.

(i) a. Jan schilt de aardappelen (in de keuken).

b. Jan schilt ${ }^{*}$ (de aardappelen) in de keuken.

Jan peels the potatoes in the kitchen

\section{Adjunction:}

A syntactic operation that creates a new position. It is often assumed, for instance, that certain ${ }^{\circ}$ adjuncts can be attached (adjoined) to a maximal projection [XP ... X ... leading to the structure $[\mathrm{XP}$ adjunct $[\mathrm{XP} \ldots .$.$] . The adjunction operation is not only$ found in generative grammar but also in, e.g., categorial grammar, where it is also assumed that the introduction of an adjunct creates an XP if applied to an XP. The adjunction operation is not uncontroversial: Cinque (1999), for example, assumes that adjuncts are placed in the specifier position of specific functional projections. 


\section{Anticipatory pronoun/pronominal PP:}

Clauses may have argument status with respect to a verb. Generally speaking, however, they occur in extraposed position, while the regular argument position is filled by the anticipatory pronoun het 'it' or the anticipatory pronominal PP er+P; this is illustrated in (i). See ${ }^{\circ} \mathrm{R}$-extraction for a discussion of the fact that the anticipatory pronominal PP erover is normally split.
a. Jan betwijfelt (het) of Marie komt.
Jan doubts it whether Marie comes
'Jan doubts whether Marie will come.'
b. Jan is (er) boos (over) dat Marie niet komt. Jan is there angry about that Marie not comes 'Jan is angry that Marie won't come.'

\section{Argument:}

An argument is a constituent in the domain of a lexical head $\mathrm{H}$ selected by $\mathrm{H}$. An argument is distinct from an ${ }^{\circ}$ adjunct, which is not selected by $\mathrm{H}$. Arguments and adjuncts differ in that the former are normally obligatorily present (or at least semantically implied), whereas adjuncts are optional. In (i), the noun phrase de aardappelen 'the potatoes' is virtually obligatory and can be considered an argument of the verb schillen 'to peel', whereas the PP in de keuken 'in the kitchen' is optional and can be considered an adjunct.

(i) a. Jan schilt *? (de aardappelen) in de keuken.

b. Jan schilt de aardappelen (in de keuken). Jan peels the potatoes in the kitchen

\section{Binding:}

A noun phrase (typically a pronoun) is said to be bound if it is coreferential with a ${ }^{\circ} \mathrm{C}$-commanding antecedent. Noun phrases differ with respect to the syntactic domain in which they must or can be bound. This is clear from the fact illustrated by the examples in (ia\&b) that reflexive and referential personal pronouns like zichzelf and hem are in complementary distribution. Referential expressions such as de jongen in (ic) normally remain free (= not bound) within their sentence.

(i) a. Ik denk dat $\operatorname{Jan}_{\mathrm{i}}$ zichzelf $_{\mathrm{i}} / *$ hem $_{\mathrm{i}}$ bewondert.

I think that Jan himself/him admires

'I think that Jan admires himself.'

b. $\mathrm{Jan}_{\mathrm{i}}$ denkt dat ik hem ${ }_{\mathrm{i}}{ }^{*}$ zichzelf $_{\mathrm{i}}$ bewonder.

Jan thinks that I him/himself admire

'Jan thinks that I admire him.'

c. ${ }^{*} J_{a n}$ denkt dat ik de jongen ${ }_{i}$ bewonder.

Jan thinks that I the boy admire

Data like (i) have given rise to the formulation of the three conditions in (ii), which have become known as binding conditions A, B and C. For the examples in (i), we may provisionally assume that the notion of local domain refers to the minimal clause containing the relevant noun phrase, but there are data that complicate matters; cf. Section N5.2.1.5, sub III, for a more detailed discussion. 
(ii) $\quad$ Binding conditions

a. Anaphors like zichzelf 'himself' must be bound in their local domain.

b. Pronouns like hem 'him' must be free (= not bound) in their local domain.

c. Referential expressions like Jan or de jongen 'the boy' must be free.

\section{Bridge verb:}

Wh-movement may sometimes extract interrogative argument/adjunct phrases from embedded complement clauses. Whether such extraction is possible or not often depends on the verb selecting the clause. Verbs that allow such extraction are called bridge verbs. The examples in (ia\&b) show that bridge verbs are normally nonfactive: factive verbs such as weten 'to know' normally do not license extraction.
a. Wat denk $^{*}$ weet je [dat Peter $t_{\mathrm{i}}$ gekocht heeft]?
what think/know you that Peter bought has
'What do you think that Peter has bought?'
b. Hoe $\mathrm{H}_{\mathrm{i}}$ denk je [dat ik die auto $t_{\mathrm{i}}$ kan repareren]?
how think you that I that car can repair
'How do you think that I can repair that car?'

\section{C-command:}

$\mathrm{C}$-command refers to a structural relation between the constituents in a phrase, which is generally defined in structural terms of a tree diagram: $\alpha$ c-commands $\beta$ if (i) $\alpha \neq \beta$, (ii) $\alpha$ does not dominate $\beta$, and (iii) the node that immediately dominates $\alpha$ also dominates $\beta$. If we restrict ourselves to ${ }^{\circ}$ clausal constituents, the c-command relation can often be expressed by means the functional hierarchy in (ii), where the notion $\mathrm{A}>\mathrm{B}$ expresses that $\mathrm{A}$ c-commands $\mathrm{B}$ and everything that is embedded in $\mathrm{B}$.

C-command hierarchy: subject $>$ indirect object-NP $>$ direct object $>$ indirect object-PP $>$ PP-object $>$ adjunct

It must be noted, however, that the hierarchy in (ii) differs from the structurally defined notion of c-command in that it does not take into account that movement may change the c-command relations within a clause.

\section{Clausal constituent:}

Translation of the Dutch term zinsdeel. Another English term used for this notion is part of speech. The notion denotes the constituents in the clause with an independent syntactic function (that is, arguments, complementives and adjuncts) including the ${ }^{\circ}$ verbal complex.

\section{Common Ground:}

Notion used in theories on language use that refers to the information, assumptions, beliefs, etc. shared by the participants in a specific discourse.

\section{Complement:}

The ${ }^{\circ}$ arguments of a lexical head $\mathrm{H}$, with the exception of the subjects of intransitive (but not ${ }^{\circ}$ unaccusative) verbs. In generative grammar, complements are generally called INTERNAL ARGUMENTs, whereas the subject is called the EXTERNAL ARGUMENT. Internal arguments of verbs are generally obligatorily present (or at least semantically implied), whereas external arguments can occasionally be 
suppressed, for instance in passive constructions. The term complement is sometimes also used for ${ }^{\circ}$ complementives and verbal projections selected by nonmain verbs.

\section{Complementive:}

The predicative complement of verbs in copular, resultative or vinden-constructions. In (i) some examples are given with adjectival predicates. A complementive may also be a nominal or a (spatial) adpositional phrase, e.g., Jan is leraar 'Jan is a teacher' and Jan heeft het boek in de kast gelegd 'Jan has put the book in the cupboard'. In prosodically neutral sentences complementives are left-adjacent to the clause-final verb. This is especially clear with PP-complementives, as these differ from other PPs in that they cannot undergo ${ }^{\circ}$ Extraposition: ${ }^{*} J a n$ heeft het boek gelegd in de kast.
a. Jan is erg aardig.
Jan is very kind
b. Jan slaat de hond dood.
Jan hits the dog dead
c. Ik vind Jan ergaardig.
I consider Jan very nice

\section{Conjunction reduction:}

In a coordinated structure, deletion of a phrase within one conjunct under identity with a phrase within another conjunct. If the deleted phrase belongs to the first conjunct, the deletion operation is referred to as BACKWARD conjunction reduction; if the deleted phrase belongs to the second conjunct, the operation is referred to as FORWARD conjunction reduction.
(i) a. [Jan kocht een blauwe _ ] en [Peter kocht een groene auto]. Jan bought a blue and Peter bought a green car
b. [Jan kocht een boek] en [_ leende een plaat]. Jan bought a book and borrowed a record

The existence of forward conjunction reduction is controversial; examples such as (ib) can readily be derived by assuming that some lower verbal projections are coordinated: Jan [[kocht een boek] en [leende een plaat]]; cf. Sectio 2.1.

\section{Constituency test:}

Test involving movement of a string of words into the sentence-initial position, that is, the position immediately preceding the finite verb in main clauses. Any string of words that can occupy this position in Dutch is considered a constituent. Satisfying this test is sufficient for assuming constituency, but not necessary given that constituents can be embedded within larger constituents that may function as ${ }^{\circ}$ islands for extraction. The test provides reasonably reliable results when it comes to the determination of the ${ }^{\circ}$ clausal constituents. Other tests that are often used are coordination and clefting. 


\section{Cooperative principle:}

A pragmatic principle introduced in Grice (1975) which contributors to an ordinary conversation can be expected to follow: "Make your conversational contribution such as is required, at the stage at which it occurs, by the accepted purpose or direction of the talk exchange in which you are engaged" (Grice 1989:26). See also ${ }^{\circ}$ Maxim.

\section{Coordinate Structure Constraint:}

This constraint prohibits movement of a conjunct out of a coordinated structure: for example, $w h$-movement of the second conjunct in (ia) is impossible, as shown in (ia'). The constraint also prohibits subextraction from one of the conjuncts: for example, subextraction from the second conjunct in (ib) is excluded, as shown in $\left(\mathrm{ib}^{\prime}\right)$. An exception to the ban on subextraction is when the movement applies in a so-called ${ }^{\circ}$ across-the-board fashion, that is, simultaneously affects all conjuncts.
a. Jan heeft [[een artikel] en [een boek ]] gelezen. Jan has an article and a book read
$\mathrm{a}^{\prime}$. *Wat ${ }_{\mathrm{i}}$ heeft Jan [[een artikel] en $\left.\left[t_{\mathrm{i}}\right]\right]$ gelezen? what has Jan an article and read
b. Jan heeft [[een boek van Peter gestolen] en [een CD aan Marie gegeven]]. Jan has a book from Peter stolen and a CD to Marie given
$\mathrm{b}^{\prime}$. *Wat heeft Jan [[een boek van Peter gestolen] en [ $t_{\mathrm{i}}$ aan Marie gegeven]]? what has Jan a book from Peter stolen and to Marie given

\section{Core grammar:}

Core grammar refers to those aspects of the internalized language system that arise spontaneously in the language learning child by exposure to utterances in the standard language. This notion is opposed to the periphery of grammar, which refers to those properties of the standard language that are explicitly taught at some later age.

\section{Expletive:}

The element $e r$ in existential or presentational constructions like (ia\&b).
a. dat er een probleem met de verwarming is. that there a problem with the heating is 'that there is a problem with the heating.'
b. dat er een man op straat loopt. that there a man in the.street walks 'that there is someone walking in the street.'

\section{Extraposition:}

A movement operation assumed to place a clause to the right of the verbs in clausefinal position. Under the traditional OV-analysis of Dutch, complement clauses are base-generated to the left of the main verb, as in (ib), and obligatorily moved to the right of the verb. Extraposition of PPs is sometimes called PP-over-V. Extraposition of noun phrases and APs is not possible in Dutch. 
(i) a. dat Jan [dat hij ziek is] denkt $\Rightarrow$ that Jan that he ill is thinks

b. dat Jan $t_{\mathrm{i}}$ denkt [dat hij ziek is $]_{\mathrm{i}}$

Since Kayne (1994) there has been an ongoing debate concerning the question as to whether (ib) is derived from (ia) by means of extraposition or whether the complement is base-generated to the right of V; cf. Baltin (2006) and Broekhuis (2008:ch.2) for a review of a number of the currently available proposals. This work uses the notion of extraposition as a purely descriptive term in order to refer to the placement of the clause to the right of the verb.

\section{Focus:}

The notion of focus is used in several different ways that should be kept strictly apart. In this volume, the notion of focus mainly refers to contrastive focus.

I. If we are concerned with the information structure of the clause, focus refers to the "new" information in the clause. As such it is opposed to presupposition, which refers to the "old" information in the clause.

II. Focus is also used for certain elements in the clause that are phonetically emphasized by means of accent. Often, a distinction is made between emphatic, contrastive and restrictive focus.

\section{Gapping:}

An operation applying to coordinated clauses, which involves deletion of elements in the second conjunct under identity with elements in the first conjunct. In finite clauses, gapping (in contrast to ${ }^{\circ}$ conjunction reduction) minimally affects the finite verb, as in (ia). If the clause contains an auxiliary, either the auxiliary alone, as in (ib), or the auxiliary and the main verb can be deleted, as in (ic). In addition to the verb(s), Gapping can also delete other constituents of the second conjunct, as in (id). The remnants of gapping are contrastively stressed. See Section 2.2 for details.
a. Jan schrijft een roman en Peter $[\mathrm{v} \varnothing]$ een toneelstuk. Jan reads a novel and Peter a play
b. Jan heeft een roman geschreven en Peter [AUX $\varnothing]$ een toneelstuk opgevoerd. Jan has a novel written and Peter a play performed
c. Jan heeft een roman geschreven en Peter [AUX $\varnothing]$ een toneelstuk [v $\varnothing]$. Jan has a novel written and Peter a play
d. Jan heeft Marie naar huis gebracht en Piet [aux $\varnothing]$ Karel [pP $\varnothing][v \varnothing]$. Jan has Marie to home brought and Piet Karel

\section{Head:}

An element that projects, which is to say that is the core of a projection. There are two notions of head: (i) lexical heads like $\mathrm{V}, \mathrm{N}, \mathrm{A}$ and $\mathrm{P}$ which are predicative in nature in the sense that they take ${ }^{\circ}$ arguments, and (ii) functional ${ }^{\circ}$ heads like $\mathrm{T}$ (ense) and $\mathrm{D}(\mathrm{et})$ which are not predicative and add more peripheral functional information. See Section V9.1 for a more extensive introduction of these notions. 


\section{Implicature:}

Information that is not part of the meaning expressed by the form of a sentence but can be deduced from it on the basis of specific pragmatic rules such as the ${ }^{\circ}$ maxims derived from the ${ }^{\circ}$ cooperative principle: "Make your conversational contribution such as is required, at the stage at which it occurs, by the accepted purpose or direction of the talk exchange in which you are engaged"; cf. (Grice 1989:26).

\section{Island for extraction:}

An island for extraction is a constituent out of which extraction cannot take place. A distinction can be made between strong and weak islands. Strong islands are constituents out of which extraction is blocked categorically, whereas weak islands are constituents out of which only specific elements (especially adjunct phrases) cannot be extracted.

\section{Major phrase:}

Notion referring to the set of "fully expanded" projections of the lexical categories $\mathrm{N}$, A and $\mathrm{P}$ functioning as ${ }^{\circ}$ clausal constituents, as well as to specific smaller verbal projections (which we conveniently refer to as VP in this volume). A characteristic property of major phrases is that they can be moved into clause-initial position by means of, e.g., topicalization. The examples in (i) illustrate this for a direct object and a VP consisting of a main verb and a direct object. See Hankamer (1971) and Neijt (1979) for more discussion

$$
\begin{aligned}
& \text { a. Ik wil [vp dat/een boek lezen] } \\
& \text { I want that/a book read } \\
& \text { 'I want to read that/a boek.' } \\
& \text { b. Dat boek wil ik [vp } t_{\mathrm{i}} \text { lezen]. } \\
& \text { that book want I read } \\
& \text { c. [vp Een boek lezen] wil ik } t_{\mathrm{i}} \\
& \text { a book read want I }
\end{aligned}
$$

\section{Maxim}

Notion from pragmatics related to Grice's $(1975 / 1989){ }^{\circ}$ cooperative principle according to which contributors to ordinary conversation are expected to optimize their conversational contribution to the talk exchange they are engaged in. Speakers are expected to follow the following rules (maxims):
a. Maxim of Quantity: make you contribution as informative as is required; do not make you contribution more informative than required.
b. Maxim of Quality: do not say what you believe to be false; do not say that for which you lack adequate evidence.
c. Maxim of Relation: be relevant.
d. Maxim of Manner: avoid obscurity of expression; avoid ambiguity; be brief; be orderly.

\section{Middle field:}

The middle field of the clause is defined as that part of the clause bounded to the right by the verbs in clause-final position (if present), and to the left by the complementizer in an embedded clause or the finite verb in second position of a 
main clause. The middle field of the examples in (i) is given in italics; see Section V9 for details.

(i) a. Gisteren heeft Jan met plezier dat boek gelezen. yesterday has Jan with pleasure that book read

b. Ik denk [dat Jan metplezier dat boek gelezen heeft]. I think that Jan with pleasure that book read has

It is important to realize that the middle field of a clause is not a constituent, but simply refers to a set of positions within the clause. This set of positions includes the canonical positions of the nominal arguments of the verb within VP (but not the verb itself), as well as a variety of positions external to VP such as the positions of the adverbial phrases and positions that can act as a landing site for, e.g., ${ }^{\circ}$ scrambling.

\section{Movement:}

The notion of movement is used to express that a given constituent is found in some other position than one might expect on the basis of its properties, e.g., syntactic function. For example, despite the fact that direct objects are normally placed before the verbs in clause-final position, they typically occur in clause-initial position if they are $w h$-phrases such as welk boek 'which book' in (ib). The 'trace $t_{\mathrm{i}}$ in (ib) indicates that the preposed $w h$-phrase functions as the direct object of the clause.

(i) a. Jan heeft gisteren De zondvloed van Jeroen Brouwers gelezen.

Jan has yesterday De zondvloed by Jeroen Brouwers read

'Jan read De zondvloed by Jeroen Brouwers yesterday.'

b. Welk boek $\mathrm{k}_{\mathrm{i}}$ heeft Jan gisteren $t_{\mathrm{i}}$ gelezen?

which book has Jan yesterday read

'Which book did Jan read yesterday?'

There are two main types of movement: A-movement and $\mathrm{A}^{\prime}$-movement. The first type involves movement of a phrase from an ${ }^{\circ}$ argument position into another argument position, as in passive and ${ }^{\circ}$ unaccusative constructions. The second type involves movement of a phrase into a non-argument position; the prototypical case is the clause-initial position targeted by $w h$-movement. For more discussion, see ${ }^{\circ}$ Argument position.

\section{Particle:}

The notion particle is difficult to define as it is often used to refer to elements with a specific syntactic function but which do not fit in any obvious way in the commonly distinguished parts of speech. We distinguish between modal particles, which are normally related to the speaker's attitude toward the propositional content of the utterance, focus particles, which are used for emphasizing a specific element in the clause and verbal particles, which form a meaning unit with the verb.

a. Je kwam morgen toch?

[modal particle]

you came tomorrow PRT

'Am I correct in assuming that you will come tomorrow?' 
b. Zelfs Peter heb ik gezien?

[focus particle] even Peter have I seen

'I have even seen Peter.'

c. Ik heb de kamer opgeruimd.

I have the room prt-cleared

[verbal particle]

'I have tidied up the room.'

Modal particles are like adverbial phrases in that they clearly have an ${ }^{\circ}$ adjunct status. Focus particles are more difficult to characterize in that they can function as a modifier, as in (ib), but can sometimes also occur independently. Verbal particles are often analyzed as ${ }^{\circ}$ complementives; cf. Section V2.2.1.

\section{Periphery of grammar:}

See ${ }^{\circ}$ Core syntax.

\section{Pied piping:}

In interrogative clauses the clause-initial position must be occupied by a wh-word, as in (ia). Occasionally, however, wh-movement may or must involve a phrase larger than a wh-word. In (ib), for example, the preposition must be moved along with the wh-element wie 'who'. This phenomenon is called pied piping: the $w h$ element wie pied pipes the preposition op. Pied Piping is also found in other movement types.
a. Wie heb je gezien?
who have you seen
'Who did you see?'
b. Op wie heb je gewacht?
for whom have you waited
'Who were you waiting for?'

The term pied piping stands in opposition to term stranding, which refers to cases in which the $w h$-word is extracted from a larger ${ }^{\circ}$ clausal constituent (as in the English translation of (ib), in which wh-movement strands the preposition for). Pied piping and stranding are often in complementary distribution, but this is not a hard and fast rule; the examples in (ii) show, for instance, that interrogative wat voor-phrases allow both options.

(ii) a. [Wat voor een boeken $]_{\mathrm{i}}$ heeft Peter $t_{\mathrm{i}}$ gekocht?

[pied piping] what for a books has Peter bought

'What kind of books has Peter bought?'

b. Wat ${ }_{\mathrm{i}}$ heeft Peter $\left[t_{\mathrm{i}}\right.$ voor een boeken] gekocht? what has Peter for a books bought

[stranding]

'What kind of books has Peter bought?'

\section{Projection:}

Each lexical head $\mathrm{L}$ is assumed to form a so-called lexical projection (= a larger structure) LP by combining with its ${ }^{\circ}$ arguments and (optional) modifiers. Generally, it is assumed that a lexical projection is hierarchically structured: first, L combines with its internal arguments (or ${ }^{\circ}$ complements) and after that it combines with its subject and modifiers. Evidence for this comes, e.g., from ${ }^{\circ}$ binding: a subject can 
bind an object but not vice versa. In current generative grammar it is commonly assumed that functional heads (like complementizers, numerals or determiners) project a so-called functional projection FP by combining with some lexical projection LP or some other functional projection.

\section{Quantitative er:}

Indefinite (but not definite) noun phrases containing a cardinal numeral or a weak quantifier may co-occur with so-called quantitative er; cf. (ia\&b). A noun phrase associated with quantitative $e r$ is characterized as containing an interpretative gap $[e]$. The descriptive content of this gap must be recoverable from the discourse or the extra-linguistic context. Example (ic) shows that the empty noun must be [+COUNT]; when it is [-COUNT], quantitative er cannot be used. Quantitative er is discussed in more detail in Section N6.3.

(i) a. Jan heeft twee (mooie) boeken en Piet heeft er [drie $[e]]$ [indefinite] Jan has two beautiful books and Piet has ER three

$\mathrm{a}^{\prime}$. *Jan heeft de twee boeken en Piet heeft er [de drie $\left.[e]\right]$ [definite] Jan has the two books and Piet has ER the three

b. Jan heeft weinig boeken maar Marie heeft er [veel $[e]]$. Jan has few books but Marie has ER many

c. *Jan heeft veel wijn maar Piet heeft er [weinig [e]]. Jan has much wine but Piet has ER little

\section{R-extraction:}

In Dutch, preposition stranding by means of movement of an NP-complement of the adposition is impossible; It can only be effected by means of extraction of an ${ }^{\circ} \mathrm{R}$-pronoun (er/waar) from pronominal PPs like er onder 'under it' or waar onder 'under what'. Stranding of the preposition may be the result of, e.g., scrambling of the R-pronoun, as in (ia), or wh-movement or relativization, as in (ib\& $\left.\mathrm{b}^{\prime}\right)$. A comprehensive discussion of R-extraction is given in Section P5.3.

(i) a. Jan heeft er gisteren naar gevraagd.

Jan has there yesterday for asked

'Jan asked for it yesterday.'

b. Waar heeft Jan naar gevraagd?

where has Jan for asked

'What did Jan ask for?'

$\mathrm{b}^{\prime}$. het boek waar Jan naar gevraagd heeft

the book where Jan for asked has

'the book that Jan has asked for'

\section{R-pronoun:}

In Dutch, prepositions cannot be followed by third person neuter pronouns like het 'it'. So, whereas (ia) is fully acceptable, (ib) is excluded: the neuter pronoun is obligatorily replaced by a so-called R-pronoun er/daar/ergens/..., as in (ib'). Occasionally, the replacement by an R-pronoun is optional, e.g., in the case of the quantificational pronouns iets 'something' or niets 'nothing' in (ic). See Section P5.2 for extensive discussion. 
(i) a. naar hem/haar 'to him/her'
b. *naar het
$\mathrm{b}^{\prime}$. er naar 'to it'
c. naar (n)iets
$c^{\prime}$. (n)ergens naar
'to something/nothing'
'to something/nothing'

\section{Scrambling:}

The word order of Dutch in the ${ }^{\circ}$ middle field of the clause is relatively free. Generally speaking, this is accounted for by assuming that Dutch has a set of "short" leftward movements that target clause-internal positions. In this way constituents may be moved across adverbial phrases, thus giving rise to word order variation. This is illustrated in (i).

(i) a. Jan zal waarschijnlijk morgen dat boek kopen.

Jan will probably tomorrow that book buy

'Jan will probably buy that book tomorrow.'

b. Jan zal waarschijnlijk dat boek morgen kopen.

c. Jan zal dat boek waarschijnlijk morgen kopen.

Scrambling is not a unitary phenomenon but actually functions as a cover term for several types of movement. In the prototypical case, scrambling is related to the information structure of the clause. In an example such as (ia), in which the noun phrase het boek is not scrambled, the noun phrase typically belongs to the ${ }^{\circ}$ focus ("new" information) of the clause. In (ic), where it is scrambled, it belongs to the presupposition ("old" information) of the clause; it is rather the adverb morgen that constitutes the focus of the clause. Scrambling can, however, also apply for other reasons. In (iia'), for example, the scrambled AP zo aardig is assigned emphatic focus, and in ( $\mathrm{iib}^{\prime}$ ), scrambling of the PP voor niemand is forced due to the presence of negation on the nominal complement of the preposition.

(ii) a. dat Jan nog nooit zo aardig geweest is.

that Jan yet never that kind been is

'that Jan has never been that kind before.'

$a^{\prime}$. dat Jan ZO aardig nog nooit geweest is.

b. ${ }^{*}$ dat Jan aardig voor niemand is.

that Jan kind for nobody is

'that Jan isn't kind for anybody.'

$\mathrm{b}^{\prime}$. dat Jan voor niemand aardig is.

There are many controversies concerning the nature of scrambling, including the question as to whether movement is involved, and, if so, whether this movement has properties normally associated with A-movement (like the movement that places the subject into the regular subject position), or with $\mathrm{A}^{\prime}$-movement (like wh-movement or topicalization), or with both; see N8.1 and V13 for detailed discussion.

\section{Sluicing}

Sluicing is an operation deriving fragment $w h$-questions such as (ib) by deletion of the non-wh part of the interrogative clause. The content of the deleted part of the interrogative clause can normally be reconstructed from the context; see Section V5.1.5 for discussion. 
(i)

a. Jan heeft gisteren iemand bezocht.

[speaker A]

Jan has yesterday someone visited

'Jan visited someone yesterday.'

b. Kan je me ook zeggen wie an heaker B] can you me also tell who Jan yesterday visited has

'Can you also tell me who (Jan visited yesterday)?'

\section{Stranding:}

See ${ }^{\circ}$ Pied piping.

\section{Subject raising:}

The phenomenon that the argument interpreted as the logical subject of an infinitival clause is grammatically realized as the nominative subject of a higher matrix clause. This phenomenon can be aptly illustrated by means of the near equivalent examples in (i), where the subject of the infinitival clause in (ia) appears as the subject of the entire construction in (ib). The standard generative analysis of examples like these is that the subject of the embedded clause is promoted to subject of the matrix clause in order to be assigned case. See Section V5.2.2.2 for discussion.

(i) a. Het schijnt dat Jan een nieuwe auto koopt.

it seems that Jan a new car buys

'It seems that Jan is buying a new car.'

b. $\operatorname{Jan}_{\mathrm{i}}$ schijnt $\left[t_{\mathrm{i}}\right.$ een nieuwe auto te kopen $]$.

Jan seems a new car to buy

'that Jan seems to be buying a new car.'

\section{Thematic role:}

A thematic role is a formal means of expressing the semantic relation between a head and its ${ }^{\circ}$ arguments. It is often assumed that arguments can be assigned different thematic roles, e.g., AGENT, THEME (or PATIENT), GOAL and SOURCE.

\section{Topicalization:}

Topicalization is a movement operation that places some constituent into the clauseinitial position of a main clause, that is, into the position in front of the finite verb. In (i), the italicized phrases are topicalized, although it has been suggested that the subject NP in (ia) has not been topicalized but occupies the regular subject position; cf. V6.1.2 and Zwart (1993/1997) for relevant discussion.

(i) a. Marie heeft dat boek gisteren op de markt gekocht.

Marie has that book yesterday at the market bought

'Marie bought that book at the market yesterday.'

b. Dat boek heeft Marie gisteren op de markt gekocht.

c. Gisteren heeft Marie dat boek op de markt gekocht.

d. Op de markt heeft Marie gisteren dat boek gekocht.

From a pragmatic point of view, a topicalized phrase can have several functions. It may be the topic of discourse: in (ia), for example, the discussion is about Marie, in (ib) about the book, etc. The topicalized phrase may also be used contrastively, for 
instance to contradict some (implicitly or explicitly made) supposition in the discourse, as in (ii). In these cases, the topicalized phrase receives contrastive accent.

(ii) a. MARIE heeft het boek gekocht (niet JAN).

Marie has the book bought not Jan

b. BOEKEN heeft ze gekocht (geen PLATEN).

books has she bought not records

\section{Trace $(t)$ :}

A formal means of representing ${ }^{\circ}$ movement. There are (at least) two main types of chains. A(rgument)-chains contain traces created by A-movement, also known as NP-movement, which moves/copies a noun phrase from one argument position into another where it can, e.g., be assigned case (as in passive, unaccusative and subject raising constructions). $\mathrm{A}^{\prime}$-chains are created by $\mathrm{A}^{\prime}$-movements like wh-movement, which places a constituent in a non-argument position where it can be assigned a specific semantic or discourse function.
a. $\quad[\text { Het boek }]_{\mathrm{i}}$ wordt door Peter $t_{\mathrm{i}}$ gekocht. the book is by Peter bought
'The book is bought by Peter.'

b. [Welk boek $]_{\mathrm{i}}$ heeft Jan $t_{\mathrm{i}}$ gekocht? which book has Jan bought

'Which book has Jan bought?'

[A-movement]

$\left[\mathrm{A}^{\prime}\right.$-movement $]$

\section{Unaccusative verb:}

Unaccusative verbs never take an accusative object. The subject of these verbs entertain a similar semantic relation with the unaccusative verb as the direct object with a transitive verb. This is quite clear in the pair in (i); the nominative noun phrase het glas 'the glass' in the unaccusative construction (ib) has the same relation to the verb as the accusative noun phrase het glas in the transitive construction in (ia). The fact that (ib) has a transitive alternant is an incidental property of the verb breken 'to break'. Some verbs, such as arriveren 'to arrive', only occur in an unaccusative frame.

$$
\begin{aligned}
& \text { a. Jan breekt het glas. } \\
& \text { Jan breaks the glass } \\
& \text { b. Het glas breekt. } \\
& \text { the glass breaks }
\end{aligned}
$$

It is often assumed that regular intransitive verbs and unaccusative verbs have three distinguishing properties: (a) intransitives take the perfect auxiliary hebben 'to have', whereas unaccusatives take the auxiliary zijn 'to be'; (b) the past/passive participle of unaccusatives can be used attributively to modify a head noun that corresponds to the subject of the verbal construction, whereas this is not possible with intransitive verbs; (c) the impersonal passive is possible with intransitive verbs only. These properties are illustrated in (ii) by means of the intransitive verb lachen 'to laugh' and the unaccusative arriveren 'to arrive', cf. Hoekstra (1984). See Section V2.1.2 for a comprehensive discussion. 
(ii)
- Intransitive
a. Jan heeft $/ *$ is gelachen. Jan has/is laughed
$\mathrm{a}^{\prime}$. *de gelachen jongen the laughed boy
$\mathrm{a}^{\prime \prime}$. Er werd gelachen. there was laughed

- Unaccusative

b. Jan is $/ *$ heeft gearriveerd. Jan is/has arrived

$b^{\prime}$. de gearriveerde jongen the arrived boy

$\mathrm{b}^{\prime \prime}$. *Er werd gearriveerd. there was arrived

\section{Verb-final:}

See ${ }^{\circ}$ Verb-second.

\section{Verb-second:}

The phenomenon in Dutch that the finite verb normally occupies the so-called second position of the main clause, that is, is preceded by precisely one constituent (see also ${ }^{\circ}$ constituency test). In embedded clauses the finite verb is placed in clausefinal position, just like the non-finite verbs, which is generally considered as its "base"-position; for this reason, verb-second is often used for referring to the movement operation placing the finite verb in second position.

As technical notions, verb-second and verb-final are used in strict opposition. This leads to the slightly awkward conclusion that certain verbs that are in final position of a clause do not count as verb-final but as verb-second. For example, main clauses like (ia) consisting of no more than an intransitive verb and its subject do not count as verb-final clauses in the technical sense given that the verb must appear in second position when more material is added; this is shown in (ib).

$$
\begin{aligned}
& \text { a. Jan wandelt. } \\
& \text { Jan walks } \\
& \text { 'Jan is walking.' } \\
& \text { b. Jan <*graag > wandelt < graag }>\text {. } \\
& \text { Jan gladly walks } \\
& \text { 'Jan likes to walk.' }
\end{aligned}
$$

\section{Verb clustering}

The phenomenon that verbs that are part of a ${ }^{\circ}$ verbal complex tend to cluster in clause-final position. In main clauses the cluster consists of non-finite verbs only, whereas in embedded clauses the cluster also involves the finite verb. Note that as a result of verb clustering the embedded clause may be split: in (i), for instance, the main verb lezen is separated from its argument een boek 'a book'.

a. Jan heeft een boek zitten lezen.

[main clause]

Jan has a book sit read 'Jan has been reading a book.'

b. dat Jan een boek heeft zitten lezen. that Jan a book has sit read 'that Jan has been reading a book.' 


\section{Verbal complex}

The term verbal complex is used as a translation of the Dutch term werkwoordelijk gezegde from traditional grammar. A verbal complex typically consists of a main verb, which may be supplemented by one or more non-main verbs. In the examples in (i), we find verbal complexes consisting of, respectively, one, two and three verbs. The complexes are given in italics. A characteristic property is that the nonfinite verbs tend to cluster in clause-final position, as in (ic). In embedded clauses the clause-final cluster also includes the finite verb; this is shown in the primed examples of (i). The examples in (i) also show that as a result of clustering the main verb can become separated from its arguments (here: the object het boek 'the book') by the non main verbs.
a. Jan leest een boek. Jan reads a book 'Jan is reading a book.'
b. Jan heeft een boek gelezen. Jan has a book read 'Jan has read a book.'
c. Jan heeft een boek zitten lezen. Jan has a book sit read 'Jan has been reading a book.'
$a^{\prime}$. dat Jan een boek leest. that Jan a book reads 'that Jan is reading a book.'
$\mathrm{b}^{\prime}$. dat Jan een boek heeft gelezen that Jan a book has read 'that Jan has read a book.'
$\mathrm{c}^{\prime}$. dat Jan een boek heeft zitten lezen. that Jan a book has sit read 'that Jan has been reading a book.'

\section{Wh-movement:}

Movement of some constituent into clause-initial position. The name is derived from the fact that in English the moved constituent often contains a wh-phrase such as who, as in the embedded wh-question in I wonder [who will be there] and the relative clause in the man [who was there]. However, the term wh-movement refers not only to movements in interrogative and relative constructions but also to movements in exclamative and topicalization constructions. Example (i) gives a sample of cases in Dutch that are derived by means of wh-movement; see Section V9.3.3 for more discussion.

(i) a. Wat heb je vandaag $t_{\mathrm{i}}$ gedaan?

[wh-question]

what have you today done

'What did you do today?'

b. de man [ $\left[\mathrm{die}_{\mathrm{i}} \mathrm{ik}\right.$ gisteren $t_{\mathrm{i}}$ gesproken heb]

[relative clause]

the man that I yesterday spoken have

'the man who I spoke to yesterday'

c. [Wat een leuk boek] heb je hem $t_{\mathrm{i}}$ gegeven!

[exclamative] what a nice book have you him given

'What a nice book you've given him!'

d. [Dat boek $]_{\mathrm{i}}$ heb ik gisteren $t_{\mathrm{i}}$ gelezen.

that book have I yesterday read

'That book, I read yesterday.'

[topicalization] 
This content downloaded from 131.211.104.173 on Wed, 19 Feb 2020 10:39:33 UTC All use subject to https://about.jstor.org/terms 


\section{Subject index}

\section{A}

Across-the-board movement

See Movement

Adjective

Attributively used $-\mathrm{s}$ See Coordination of attributively used adjectives

Coordination of See Coordination

Inflection 137

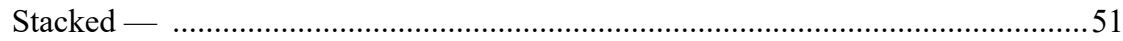

Adverbial

Correlative 212

Enerzijds ... anderzijds ... 'on the one hand ... on the other hand ...' 244

Even/(net) zo $\min$... als ... 'no more than ...' 215,320

Niet alleen .... (maar) ook ... 'not only ... but also ...' 212

Noch ... noch ... 'and not ... and not ...' 214

Ofwel ... of ... 'either ... or ...' 226

Agreement

Complementizer -

Subject-complementizer -

Subject-verb $.31,32,75,119,149,151,222,225,226,228,234,242$

Resolution rules $114,162,209$

Apposition 49, 208

Associativity of conjunction and disjunction See Law

\section{B}

Balanced ordination (Dutch: Balansschikking) See Asymmetrical disjunction

Becker's conjecture 9,15

Binding 161

Bound variable reading of pronouns .43, 110

Reciprocal elkaar 'each other' $31,75,99,149$

C

Calculus

Predicate $22,28,94$

Propositional 288,317

Case 316,324

\section{Category}

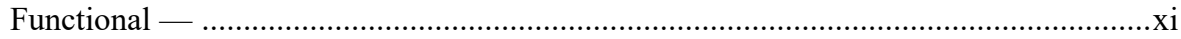

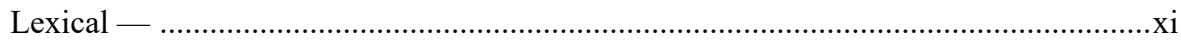




\section{Clause}

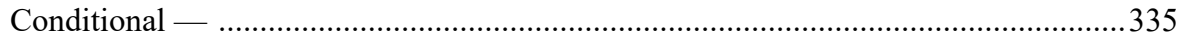

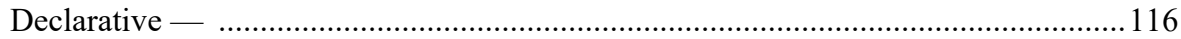

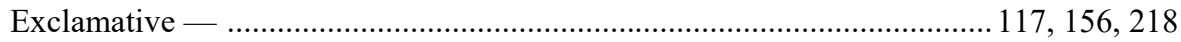

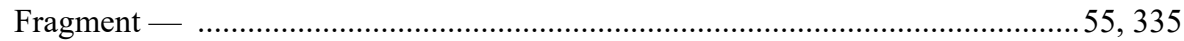

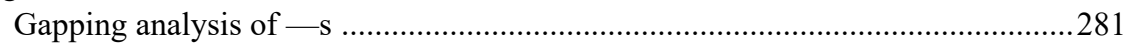

Illocutionary force …............................................................... 117, 155, 218

Imperative - ........................................................ 117, 142, 155, 169, 218

Infinitival -

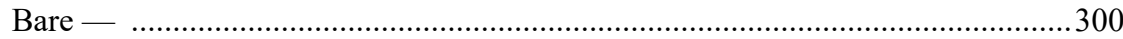

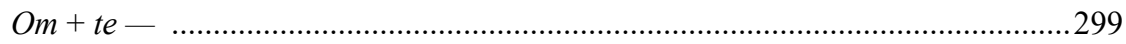

Interrogative - .............................................................. 117, 155, 156, 218

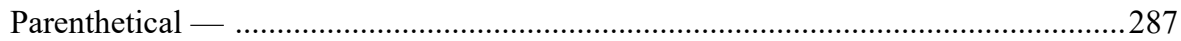

Commutativity of conjunction and disjunction ..................................................... See Law

Competence .................................................................................................... vii

Complementizer

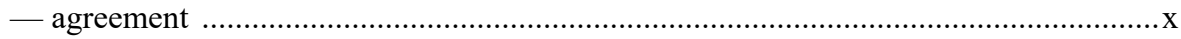

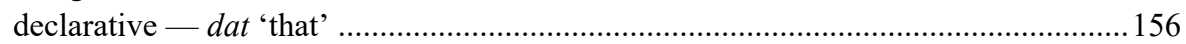

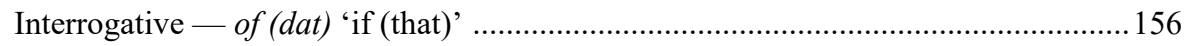

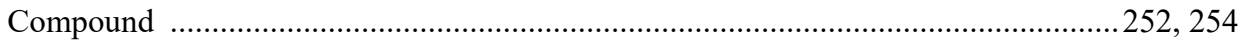

Conjunct ....................................................................................................... See Coordinand

Conjunction ........9, 116, 203, See also Coordination, Coordinate structure and Coordinator

— reduction ................................................................................ §2.1 (p.249)

— in polyadic coordinate structures .........................................................250

Backward - .....................................1, 120, 184, 224, 310, 319, §2.1 (p.249)

— in coordinate structures with clausal coordinands ...............................257

— in coordinate structures with non-clausal coordinands ........................261

— is a post-syntactic operation ......................................257, 260, 313, 319

Differences between backward and forward - .................................... 251, 253

Forward - ...............................16, 119, 183, 213, 230, 239, 310, §2.1 (p.249)

— does not involve ellipsis ..................................................................25

Periphery condition on - ................................................................. 249, 260

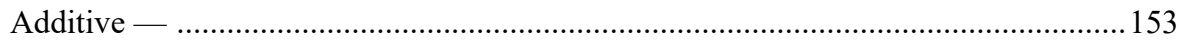

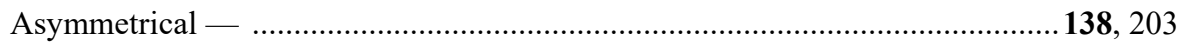

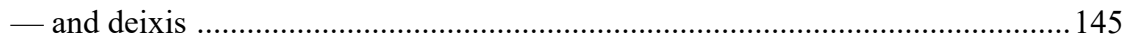

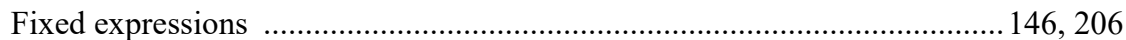

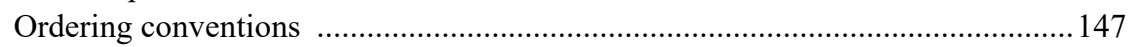

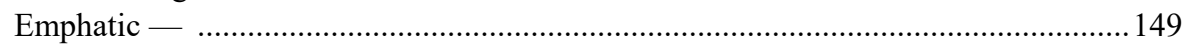

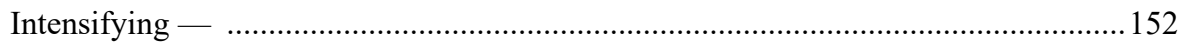

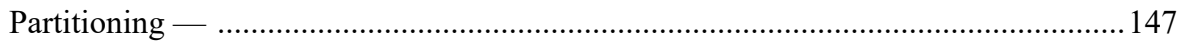

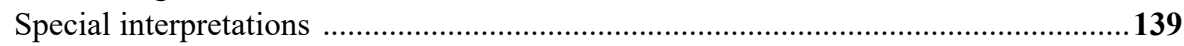

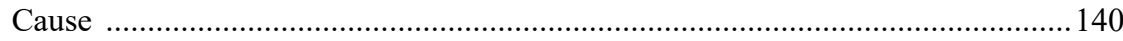

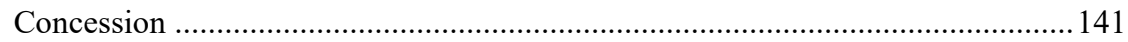

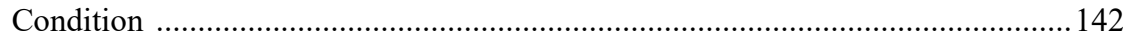

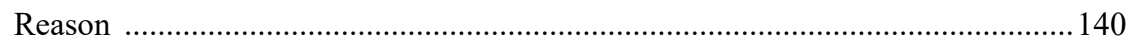

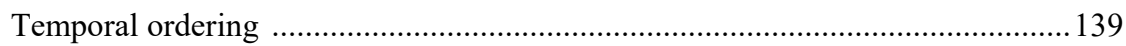

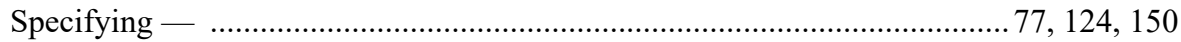


Construction

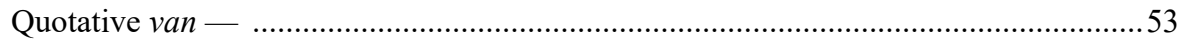

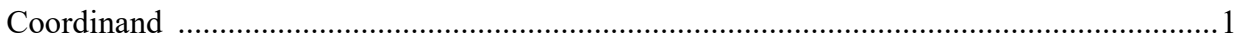

Co-occurrence restrictions on $-\mathrm{s} \ldots \ldots \ldots \ldots \ldots \ldots . . . .230,233,239,243, \S 1.3$ (p.59), See also

Coordination of ...

Adverbial phrases

$63,65,67,197$

Argument + non-argument

63,71

Arguments

$67,69,197$

Modifiers of NP

Non-verbal predicates

$61,62,70$

$\mathrm{NP}+$ clause

64,66

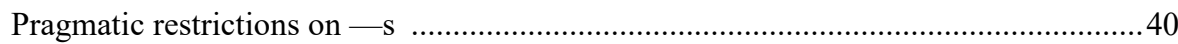

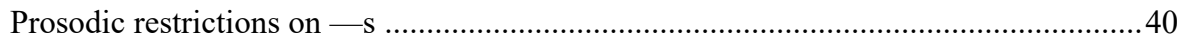

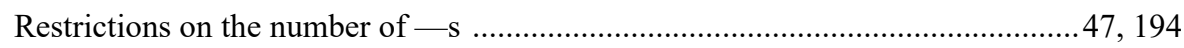

Coordinate structure .............................................................................................. Passim

— constraint …....................................... 59, 72, 120, 214, 234, 260, 294, 323, 335

— with a missing coordinand

$153,174,206,210$

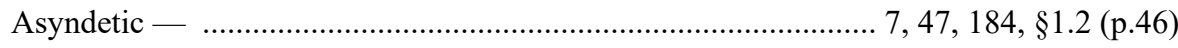

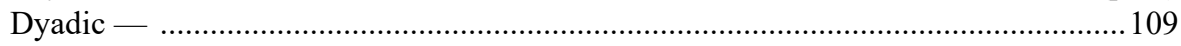

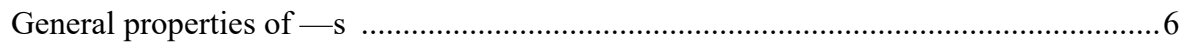

Internal organization of $-\mathrm{S}$........................... 228, See Recursive Coordinate structures

Monosyndetic - ........................................................ 7, 47, 56, 100, §1.2 (p.46)

Polyadic - ................................................................................... 91,181

Polysyndetic - .......................................................... 7, 56, 100, §1.2 (p.46)

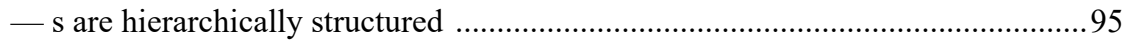

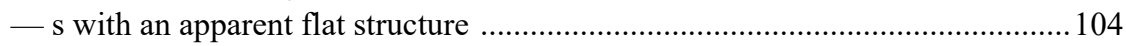

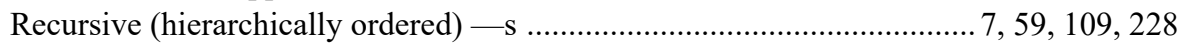

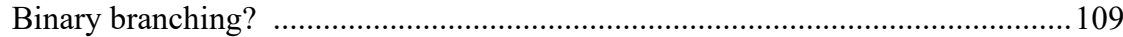

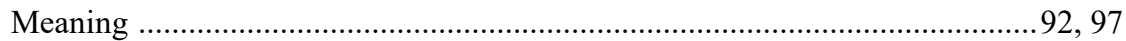

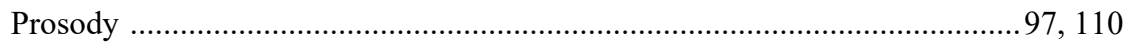

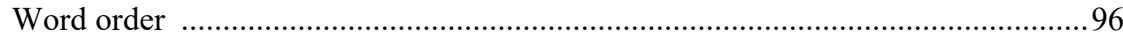

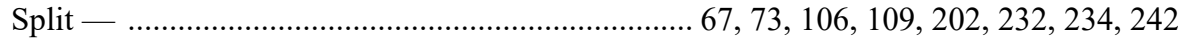

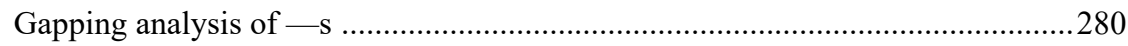

Syntactic use of $-\mathrm{s}$.......................................................... See Simple Coordinator

Coordination

Passim

—of (extended) adjectival projections ........................................ 119, 220, 223, 226

— of (extended) adpositional projections ...................................... 120, 220, 223, 226

— of (extended) nominal projections ................................... 118, 219, 223, 226, 235

— of (extended) verbal projections ......................... 118, 157, 207, 218, 223, 226, 227

- of APs ......................................116, 134, 155, 190, 196, 208, 217, 222, 225, 227

— of attributively used adjectives ........................................... 51, 147, 220, 223, 226

— of clauses ...54, 116, 117, 133, 155, 190, 192, 194, 207, 217, 222, 225, 227, 239, 271 — and illocutionary force .............117, 123, 142, 155, 160, 169, 185, 195, 209, 218

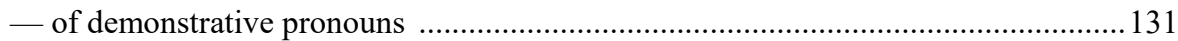

— of intermediate projections .............................................................. 89, 263, 266

— of lexical heads .......................................................................... 120, 263 
Coordination (continued)

— of noun phrases

$28,116,155,190,196,207,217,222,225,227,235$

Mixed person/number/gender features

125,160

Resolution rules

— for conjunction

Gender

Number

Person

126,201

— for disjunction

— of PPs $116,134,155,190,217,222,225,227$

- of predicates $28,33,119,124,160,195,208$

Additive 199, 204, 206

Asymmetrical 79, 138, 165

- versus symmetrical coordination

$114,139,270$

Borderline cases of Chapter 3 (p.315)

Behalve 'except/besides'

Comparative als 'as'/dan 'than' 316,317

In plaats van 'instead of' 330

Laat staan 'let alone' 332

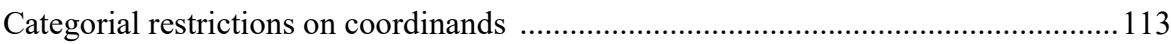

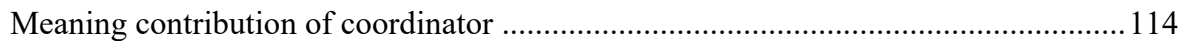

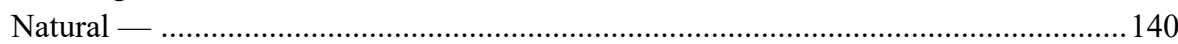

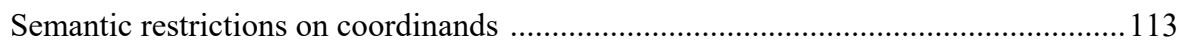

Split See Split Coordinate structure

Substituting 199, 204, 206

Unbalanced 111

Case marking 111

Verb-second 112

Coordinator $1, \S 1.4(\mathrm{p} .113)$

— $\mathrm{s}$ are not lexical heads

- $\mathrm{s}$ are two-place linkers $92,109,228,233$

Correlative $8,57,182,253, \S 1.4 .2$ (p.210)

- $\mathrm{s}$ versus correlative adverbial phrases

- $\mathrm{s}$ versus correlative adverbials

Apparent cases See Correlative adverbial

En ... en ... 'both ... and ...' 32, 210, 217, 272

Categorial restrictions on coordinands 217

Syntactic uses of coordinate structures with 210, 228, 236, 240, 243, 244, See also Focus particle

- is a focus particle

Noch ... noch ... 'neither ... nor ...'

$15,104,210,227$

Apparent/adverbial case of 214

Meaning

Non-initial part of $210,236,243,244$ 
Coordination, Correlative - (continued)

Of ... of ... 'either ... or ...'

$14,210, \mathbf{2 2 5}, 272$

Categorial restrictions on coordinands

Meaning

Syntactic uses of coordinate structures with -

226,227

Other cases

210

Hetzij ... hetzij ... 'either ... or ...' .......................................................222

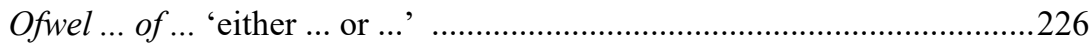

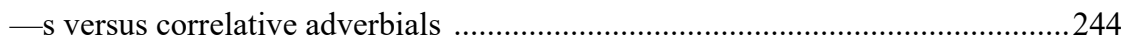

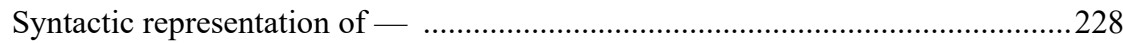

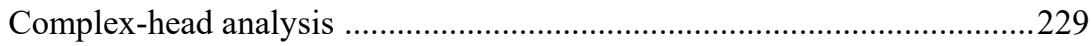

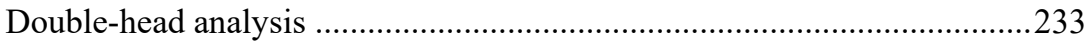

Zowel ... als ... 'both ... and ...' .......................................... 32, 210, 211, 222, 272

Categorial restrictions on coordinands ...............................................222

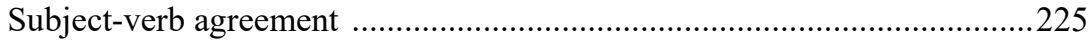

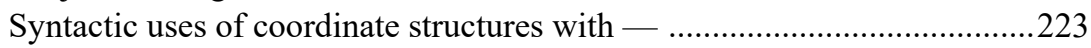

Differences from

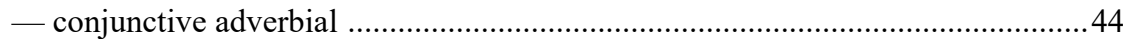

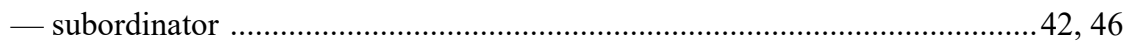

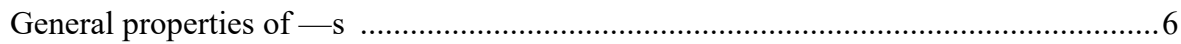

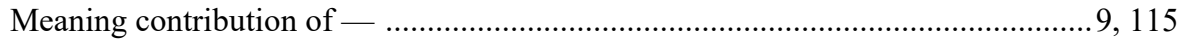

Simple — ..................................................................... 8, §1.4.1 (p.115)

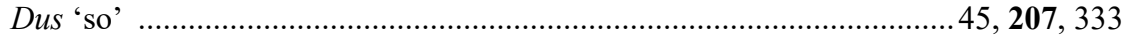

Apparent/adverbial case of - .................................................45, 208

Categorial restrictions on coordinands .................................................207

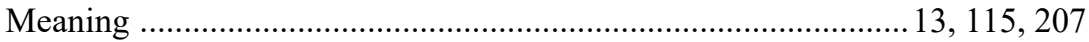

Syntactic uses of coordinate structures with - .......................................207

$E n$ 'and' .................................................................. 12, 91, 116, 248, 272

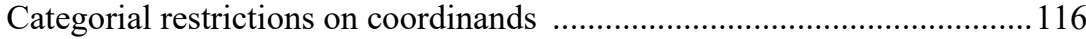

Meaning …..................................................................... 17, 115

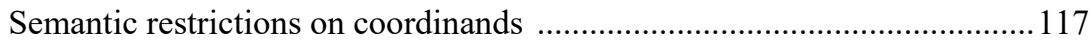

Syntactic uses of coordinate structures with - ....................................... 121

Maar 'but' .................................................................. 47, 95, 194, 248, 272

— and constituent negation:Niet .. maar .. 'not .. but ..' ................... 197, 199

— and focus: Niet alleen .. maar ook/zelfs .. 'not only .. but also/even ..' 198, 199

Meaning

115,203

Syntactic uses of coordinate structures with — ....................................... 196

Noch 'nor' ................................................................................. 15, 104, 189

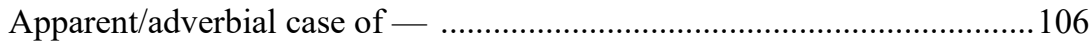

Categorial restrictions on coordinands .................................................... 190

Meaning …..................................................................... 115, 194

Syntactic uses of coordinate structures with - .................................... 190 
Coordination, Simple- (continued)

$O f$ 'or'

$14,91, \mathbf{1 5 5}, 248,272$

Categorial restrictions on coordinands

Meaning

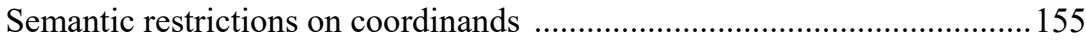

Syntactic uses of coordinate structures with - ........................................ 158

Want 'because'

Categorial restrictions on coordinands

Meaning

$12,115,207$

Syntactic uses of coordinate structures with - ......................................207

Syntactic function of -

\section{D}

Dative

Possessive . $\mathrm{x}$ Disjunction 9, 155, See also Coordination, Coordinate structure and Coordinator

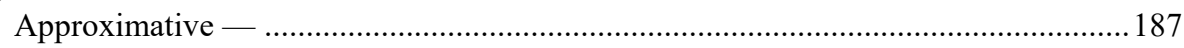

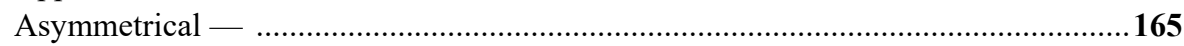

$\neg \mathrm{p} \vee \mathrm{q}$ 172,175

Fixed expressions 174

$\mathrm{p} \vee \mathrm{q}$ 169

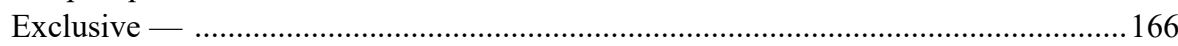

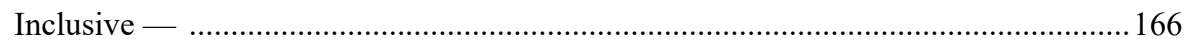

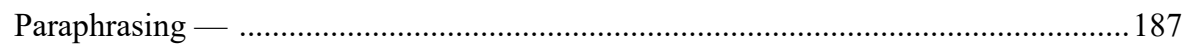

Special interpretations

Condition $169,172,176$

Exception 171

Modification 178

Succession 173,177

Distributive reading of noun phrases

Dus 'so'

See Noun phrases

Dutch

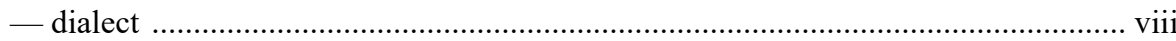

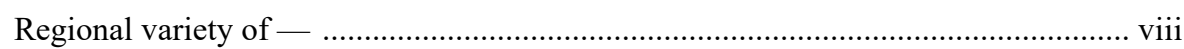

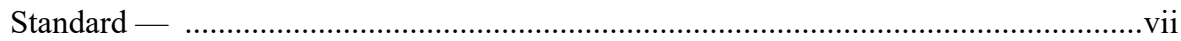

$\mathbf{E}$

Ellipsis Chapter 2 (p.247)

— in fragment clauses $55,74,76$

Noun- .52

En ... en ... 'both ... and ...'

$E n$ 'and' See Correlative coordinator

Extraposition See Simple coordinator

Remnant 300 


\section{F}

Focus

- movement See Movement

- particle See Particle

Contrastive 199, 272, 273, 276

Designated - position 237

\section{G}

Gapping $1,86,184,192,310,316, \S 2.2$ (p.271)

— and contrastive accent $273,276,280$

— and islands for movement 294

— and R-extraction 310

— and sluicing 296

— is not restricted to coordinate structures 316,335

- of finite verbs See also Finite verb restriction on gapping

- is not sensitive to person/number marking of the antecedent verb 283

— of finite verbs does not require an identical verb as antecedent 282

— of verbal complexes 284

- quantitative er 309

- remnants

— are major constituents 288

— are major phrases of the target clause .....278, See also Clausemate restriction on gapping

- have contrastive accent 272,328

- have the same syntactic function as their antecedents $275,296,325$

Number of 279,304

Syntactic function of 275,276

Types of 288

— versus forward conjunction reduction 291

$\mathrm{A}^{\prime}$-movement hypothesis of $301,303,304,333$

Clausemate restriction on $281,288,295$

Counterexamples

Apparent -

Genuine -

Clausal constituents embedded in a (semi-)transparent infinitival clause ..299

Clausal constituents embedded in a finite clause in bridge contexts ..........303

Nominal measure phrases modifying AP/PP-predicates ..........................2299

PP-complements of adjectival predicates 298

Correlation restriction on - and $\mathrm{A}^{\prime}$-movement $281,295,298,301,302$

Correlation restriction on - and Wh-movement 302

Finite verb restriction on $274,281,282,304,335$ 
Gapping (continued)

Restrictions on the clausal coordinands

$277,282,284$

Antecedent and target clause are immediate constituents of coordinate structures

286

Embedded finite clauses

284

Embedded non-finite clauses

$285,286,304$

Restrictions on the coordinator

$272,333,334$

Restrictions on the elided material 275

Maximization 276

Recoverablity 275

Verbal-head restriction on $281,285,305,335$ Generic reading of noun phrases See Noun phrases

\section{H}

Haplology $156,157,230$

Head

Functional 46

Lexical .46

\section{I}

Idiomatic verbal expression 68 Interwoven dependencies Inversion

Subject-verb $212,214,216,243$

Island for movement

Complex-NP 260, 294

Coordinate structure constraint See Coordinate structure Wh$84,260,301$

$\mathbf{L}$

Law

Associative - of conjunction and disjunction 92,99

Commutative - of conjunction and disjunction $12,92,114,183$

Left-dislocation 48

Logical

- connectives

Conjunction $(\wedge)$ 10

Disjunction

Exclusive -

Inclusive - $(\mathrm{v})$ 10,11

Logical NAND 12

Logical XNOR .12

Material equivalence $(\leftrightarrow)$

Material implication $(\rightarrow)$ 10

Negation $(\neg)$ 10 


\section{M}

Maar 'but' See Simple coordinator

Modifier

Cumulative - samen 'together'

$29,56,70,75,99$

Distributive - allebei/beiden 'both'

$29,75,99$

Movement

Across-the-board $59,72,81$

$\mathrm{A}^{\prime}$-movement 85

A-movement 85,265

Head-movement .86

Focus $237,239,303$

Negation -

86,306

Wh72, 79, 298, 299, 302, 305

Long 301

\section{$\mathbf{N}$}

Negation 105,191

— and ellipsis 184

Clausal 308

Constituent 196, 197, 199, 204, 241, 306

Of niet 'or not' 188

Negative polarity item 192,332

Noch

Adverbial use of - 'and not', 106, 191, 194

Correlative coordinator noch ... noch ... 'neither ... nor ...' .. See Correlative coordinator

Simple coordinator — 'nor' See Simple coordinator Nominalizations

BARE-INF- 129

DET-INF- 129

Noun phrases

Cumulative reading of conjoined and plural $28,56,70,75,99,149,221,224$

Distributive reading of conjoined and plural $28,56,70,75,200,221,224$

Semantic types of -

[+COUNT] $127,135,137$

[-COUNT] $128,136,138$

Existentially quantified expression $24,118,252,255,256$

Generic expression $.57,130$

Negative existentially quantified expression 25,130

Plural definite description

Pronoun

Referential -

Proper noun

Singular definite description

Universally quantified expression

.22, 255

— with the distributive quantifier elk 'each'/ieder 'all' 
$\mathbf{O}$

Of $\ldots$ of $\ldots$ ' 'either ... or ...'

See Correlative coordinator

$O f^{\prime}$ 'or' See Simple coordinator

Onomatopoeia .52

$\mathbf{P}$

Particle

Discourse -

Maar .209

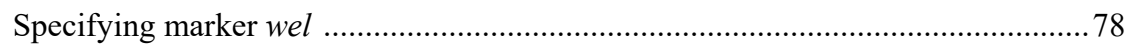

Unexpectedness marker toch 'nevertheless' ........................................................203

Urgency marker Nou 209

Focus $59,149,198,236,306$ Polarity -

Affirmative wel $77,150,158,184,308,309$

Niet 'not' 158,307

Verbal ..See Particle verb

Passivization .85

Performance vii

Pied piping $87,237,238$

Predicate

Individual/stage-level .70 Pronoun

Bound variable reading of $-\mathrm{s}$ See Binding Prosody ..... 47, 50, 55, 56, 58, 78, 97, 110, 119, 149, 151, 168, 181, 187, 191, 208, 213, 251, $260,273,280,283,288,329$

\section{Q}

Quantifier

Distributive - elk 'each'/ieder 'all' $.70,130$

Quantitative er 309

Question

Multiple wh- $.273,298$

$\mathbf{R}$

Raising

Subject .85

Recursivity 7, 91, 109, See also Recursive Coordinate structures

Reduplication .54

Respectievelijk 'respectively' .38

R-extraction $85,263,310$ 


\section{$\mathbf{S}$}

Scrambling

$\mathrm{A}^{\prime}-$ 281

Set theory

Complement 16

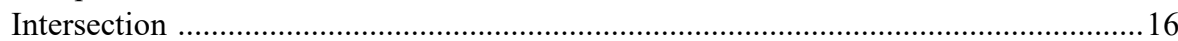

Union 16

Sluicing 295,310

Syntax ..vi

$\mathbf{T}$

Topic drop $48,54,269$

Topicalization $42,66,90,149,178,180,267,298,306,320,329$

V

Verb

— clustering ix, $69,257,258,259,265$

— $\mathrm{s}$ selecting a subject denoting a collection .68

Bridge 301,303

Factive .65

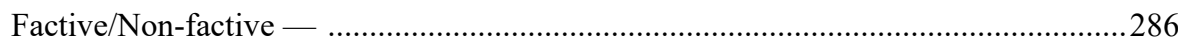

Particle 231

Verb-second ix, 44, 86, 112, 157, 214, 218, 266

\section{W}

Wagner's generalization See Recursive coordinate structure: Prosody Want 'because' See Simple coordinator

\section{$\mathbf{Z}$}

Zowel ... als ... 'both ... and ...' See Correlative coordinator 
This content downloaded from 131.211.104.173 on Wed, 19 Feb 2020 10:39:37 UTC All use subject to https://about.jstor.org/terms 


\section{List of references}

Aelbrecht, Lobke. 2007. A movement account of Dutch gapping. Paper presented at Linguistics in the Netherlands, Utrecht. Handout.

Aelbrecht, Lobke. 2009. The syntactic licensing of ellipsis. Amsterdam/Philadelphia: John Benjamins.

Ai, Ruixi Ressy. 2014. Topic-comment structure, focus movement, and gapping formation. Linguistic Inquiry 45: 125-145.

Bakker, Dirk Miente. 1968. Samentrekking in Nederlandse syntactische groepen, University of Leiden: PhD thesis.

Baltin, Mark. 2006. Extraposition. In The Blackwell companion to syntax, Volume II, eds. Martin Everaert and Henk van Riemsdijk, 237-271. Malden, MA/Oxford: Blackwell Publishing.

Becker, Karl Ferdinand. 1832. Schulgrammatik der deutschen Sprache. Frankfurt am Main.

Boogaart, Ronny. 2004. 'Meet het en je weet het': van gebod naar voorwaarde. In Taal in verandering, eds. Saskia Daalder, Theo Janssen and Jan Noordegraaf, 23-36. Münster: Nodus Publikationen.

Boone, Enrico. 2014. The syntax and licensing of gapping and fragments, University of Leiden: $\mathrm{PhD}$ thesis.

Borsley, Robert D. 2005. Against ConjP. Lingua 115: 461-482.

Bos, Gijsbertha F. 1962. The coordinative construction in modern Dutch. Lingua: 4558.

Bos, Gijsbertha F. 1964. Het probleem van de samengestelde zin, University of Utrecht: $\mathrm{PhD}$ thesis.

Bredschneijder, Martijn. 1999. Reeksvorming: initiële coördinatie in het Nederlands. Tabu 29: 1-20.

Broekhuis, Hans. 2008. Derivations and evaluations: object shift in the Germanic languages. Berlin/New York: Mouton de Gruyter.

Broekhuis, Hans. 2016. Syntax of Dutch: the data set. Nederlandse Taalkunde 21: 297325.

Broekhuis, Hans, and Norbert Corver. 2017. The expressive en maar-construction. In Crossroads semantics: computation, experiment and grammar, eds. Hilke Reckman, Lisa Cheng, Maarten Hijzelendoorn and Rint Sybesma, 305-325. Amsterdam/Philadelphia: John Benjamins.

Büring, Daniel, and Katharina Hartmann. 1998. Asymmetrische Koordination. Linguistische Berichte 174: 172-201.

Cardinaletti, Anna, and Michal Starke. 1999. The typology of structural deficiency: a case-study of the three classes of pronouns. In Clitics in the languages of Europe, ed. Henk Van Riemsdijk, 145-233. Berlin/New York: Mouton de Gruyter.

Chaves, Rui P. 2012. On the grammar of extraction and coordination. Natural Language \& Linguistic Theory 30: 465-512. 
Chierchia, Gennaro. 2004. Scalar implicatures, polarity phenomena, and the syntax/pragmatics interface. In Structures and beyond: the cartography of syntactic structures, volume 3, ed. Adriana Belletti. Oxford/New York: Oxford University Press.

Chomsky, Noam. 1957. Syntactic structures. The Hague: Mouton.

Chomsky, Noam. 1977. On wh-movement. In Formal syntax, eds. Peter W. Culicover, Thomas Wasow and Adrian Akmajian, 71-132. New York: Academic Press.

Chomsky, Noam. 1995. Bare phrase structure. In Government and binding theory and the minimalist program, ed. Gert Webelhuth, 383-439. Oxford/Cambridge, MA: Blackwell.

Chomsky, Noam. 1995. The minimalist program. Cambridge, MA: MIT Press.

Cinque, Guglielmo. 1999. Adverbs and functional heads: a cross-linguistic perspective. New York/Oxford: Oxford University Press.

Citko, Barbara. 2017. Right node raising. In The Wiley Blackwell companion to syntax [2nd, revised edition], eds. Martin Everaert and Henk van Riemsdijk, 38393871. Hoboken, New Jersey: Wiley Blackwell.

Corbett, Greville G. 1983. Resolution rules: agreement in person, number, and gender. In Order, concord and constituency, eds. Gerald Gazdar, Ewald Klein and Geoffrey K. Putnam, 175-206. Dordrecht: Foris publications.

Corbett, Greville G. 2000. Number. Cambridge/New York: Cambridge University Press.

Corver, Norbert. 1990. The syntax of left branch extractions, University of Tilburg: PhD thesis.

Corver, Norbert. 1993. A note on subcomparatives. Linguistic Inquiry 24: 773-781.

Corver, Norbert. 2005. Approximative of zo as a diagnostic tool. In Organizing grammar. Linguistic studies in honor of Henk van Riemsdijk, eds. Hans Broekhuis, Norbert Corver, Riny Huybregts, Ursula Kleinhenz and Jan Koster. Berlin/New York: Mouton de Gruyter.

Corver, Norbert. 2014. Recursing in Dutch. Natural Language \& Linguistic Theory 32: 423-457.

Corver, Norbert. 2015a. Interjections as structured root expressions. In Representing structure in phonology and syntax, eds. Marc van Oostendorp and Henk van Riemsdijk, 41-83. Berlin/Boston: De Gruyter Mouton.

Corver, Norbert. 2015b. (Un)boundedness across syntactic categories. Theoretical Linguistics: 151-165.

Corver, Norbert, and Marjo Van Koppen. to appear. Ellipsis in Dutch. In The Oxford handbook of ellipsis, eds. Jeroen Van Craenenbroeck and Tanja Temmerman. Oxford: Oxford University Press.

Cremers, Crit. 1983. On two types of infinitival complementation. In Linguistic categories: auxiliaries and related puzzles, Vol. 1, eds. Frank Heny and Barry Richards, 169-221. Dordrecht: Reidel.

Cremers, Crit. 1993. On parsing coordination categorially, University of Leiden: $\mathrm{PhD}$ thesis.

Cremers, Crit. 2001. Why pluralities don't mean a thing. In Quitte ou double sens. Articles sur l'ambiguïté offerts à Ronald Landheer, eds. Paul Boogaards, Johan Rooryck and Paul J. Smith, 33-43. Amsterdam/New York: Rodopi B.V.

Culicover, Peter W., and Ray Jackendoff. 1997. Semantic subordination despite syntactic coordination. Linguistic Inquiry 28: 195-217. 
De Groot, Albert W. 1949. Structurele syntaxis (2nd impression, 1965). Den Haag: Servire.

De Jong, Eveline D. 1979. Spreektaal. Woordfrequenties in gesproken Nederlands. Utrecht: Bohn, Scheltema \& Holkema.

De Vries, Gertrud. 1992. On coordination and ellipsis, University of Tilburg: PhD thesis.

De Vries, Mark. 2005. Coordination and syntactic hierarchy. Studia Linguistica 59: 83105.

De Vries, Mark. 2005. Ellipsis in nevenschikking: voorwaarts deleren en achterwaarts delen. Tabu 34: 14-46.

De Vries, Mark. 2006. The syntax of appositive relativization: on specifying coordination, false free relatives, and promotion. Linguistic Inquiry 37: 229270 .

De Vries, Mark. 2009. Specifying coordination: an investigation into the syntax of dislocation, extraposition and parenthesis. In Language and linguistics: emerging trends, ed. Cynthia R. Dreyer, 37-98. New York: Nova.

De Vries, Mark. 2017. Across-the-board phenomena. In The Wiley Blackwell companion to syntax [2nd, revised edition], eds. Martin Everaert and Henk van Riemsdijk, 20-50. Hoboken, New Jersey: Wiley Blackwell.

De Vries, Mark, and Herman Herringa. 2008. Congruentie met nevengeschikte subjecten: de invloed van distributiviteit. Tabu 37: 3-18.

Den Besten, Hans. 1978. On the presence and absence of wh-elements in Dutch comparatives. Linguistic Inquiry 9: 641-671. Reprinted in Den Besten (1989), Studies in West Germanic syntax. Amsterdam: Rodopi.

Den Besten, Hans. 1981. Review of Anneke Neijt. Gapping. A contribution to sentence grammar. GLOT 4: 133-161.

Den Dikken, Marcel. 2006. Either-float and the syntax of co-or-dination. Natural Language \& Linguistic Theory 24: 689-749.

Dik, Simon C. 1968. Coordination: its implications for the theory of general linguistics. Amsterdam: North-Holland Publishing Company.

Dik, Simon C. 1997. The theory of functional grammar. Part 2: complex and derived constructions, $2^{\text {nd }}$, revised edition.

Elffers-van Ketel, Els. 1991. The historiography of grammatical concepts: $19^{\text {th }}$ and $20^{\text {th }}$ century changes in the subject-predicate conception and the problem of their historical reconstruction, University of Amsterdam: $\mathrm{PhD}$ thesis.

Evers, Arnold. 1975. The transformational cycle in Dutch and German, University of Utrecht: PhD thesis.

Féry, Caroline, and Gerrit Kentner. 2010. The prosody of embedded coordinations in German and Hindi. In Proceedings of speech prosody, 5th International Conference, Chicago.

Fortuin, Egbert, and Ronny Boogaart. 2009. Imperative as conditional: from constructional to compositional semantics. Cognitive Linguistics 20: 641-673.

Gamut, L.F.T. 1991. Logic, language, and meaning, volume I: introduction to logic. Chicago/London: The University of Chicago Press.

Gazdar, Gerald. 1981. Unbounded dependencies and coordinate structure. Linguistic Inquiry 12: 155-184. 
Goodall, Grant. 1987. Parallel structures in syntax. Cambridge/New York: Cambridge University Press.

Grice, Herbert Paul. 1975. Logic and conversation. In Speech acts: Syntax and Semantics 3, eds. Peter Cole and Jerry L. Morgan, 41-58. New York: Academic Press.

Grice, Herbert Paul. 1989. Studies in the ways of words. Cambridge, MA: Harvard University Press.

Grootveld, Marjan. 1992. On the representation of coordination. In Linguistics in the Netherlands 1992, eds. Reineke Bok-Bennema and Roeland Van Hout, 61-73. Amsterdam/Philadelphia: John Benjamins.

Grootveld, Marjan. 1994. Parsing coordination generatively, University of Leiden/HIL: $\mathrm{PhD}$ thesis.

Haeseryn, Walter, Kirsten Romijn, Guido Geerts, Jaap de Rooij, and Maarten C. van den Toorn. 1997. Algemene Nederlandse spraakkunst, 2nd, revised edition. Groningen: Nijhoff.

Hankamer, Jorge. 1971. Constraints on deletion in syntax, Yale University: PhD thesis.

Hartmann, Katharina. 2000. Right node raising and gapping: interface conditions on prosodic deletion. Amsterdam/Philadephia: John Benjamins.

Haslinger, Irene. 2007. The syntactic location of events. Aspects of verbal complementation in Dutch, University of Tilburg: PhD thesis.

Hendriks, Petra. 1995. Comparatives and categorial grammar, University of Groningen: $\mathrm{PhD}$ thesis.

Hendriks, Petra. 2001a. Initial coordination and the law of coordination of likes. In Linguistics in the Netherlands 2001, eds. Ton Van der Wouden and Hans Broekhuis, 127-138. Amsterdam/Philadelphia: John Benjamins.

Hendriks, Petra. 2001b. Either as a focus particle. In University of Groningen Artifical Intelligence prepublications. Groningen.

Hendriks, Petra. 2004. Either, both and neither in coordinate structures. In The composition of meaning: from lexeme to discourse, eds. Alice ter Meulen and Werner Abraham, 115-138. Amsterdam/Philadelphia: John Benjamins.

Hendriks, Petra, and Jan-Wouter Zwart. 2001. Initiële coördinatie en de identificatie van woordgroepen. Tabu 31: 105-118.

Herringa, Herman, and Mark De Vries. 2008. Enkelvoudige congruentie bij nevenschikking met en: puzzels met betrekking to massa's en demonstratieven. Tabu 37: 19-38.

Hoeksema, Jack. 1983. Plurality and conjunction. In Studies in modeltheoretic semantics, ed. Alice Ter Meulen, 63-83. Dordrecht: Foris.

Hoeksema, Jack. 1989. Only in Dutch: a comparison of three adverbs. Penn Review of Linguistics 13: 106-121.

Hoekstra, Teun. 1984. Transitivity. Grammatical relations in government-binding theory. Dordrecht/Cinnaminson: Foris Publications.

Höhle, Tilman N. 1990. Assumptions about asymmetric coordination in German. In Grammar in progress. GLOW essays for Henk van Riemsdijk, eds. Joan Mascaró and Marina Nespor, 221-235. Dordrecht: Foris Publications.

Huddleston, Rodney, and Geoffrey Pullum (eds). 2002. The Cambridge grammar of the English language. Cambridge: Cambridge University Press. 
Johannessen, Janne Bondi. 1998. Coordination. Oxford/New York: Oxford University Press.

Johannessen, Janne Bondi. 2005. The syntax of correlative adverbs. Lingua 115: 419443.

Johnson, Kyle. 2006. Gapping. In The Blackwell companion to syntax, Volume II, eds. Martin Everaert and Henk van Riemsdijk, 407-435. Malden, MA/Oxford: Blackwell Publishing.

Johnson, Kyle. 2017. Gapping. In The Wiley Blackwell companion to syntax [2nd, revised edition], eds. Martin Everaert and Henk van Riemsdijk, 1745-1783. Hoboken, New Jersey: Wiley Blackwell.

Kayne, Richard S. 1994. The antisymmetry of syntax. Cambridge, MA: MIT Press.

Kerstens, Johan. 1980. Over samentrekking. De Nieuwe Taalgids 73: 375-394.

Klein, Maarten. 1985. Behalve; voorzetsel of voegwoord? De Nieuwe Taalgids 78: 363368.

Klein, Maarten. 1986. Coordinatieverschillen tussen het Nederlands en het Engels. Spektator 15: 396-405.

Komen, J.A.M. 1994. Over de ontwikkeling van absolute constructies, University of Amsterdam: PhD thesis.

Kooij, Jan. 1992. Naast en behalve: over reeksvormers en taalfouten. In De binnenbouw van het Nederlands. Een bundel artikelen voor Piet Paardekooper, eds. Hans Bennis and Jan W. de Vries, 209-215. Dordrecht: ICG Publications.

Koster, Jan. 1978. Why subject sentences don't exist. In Recent transformational studies in European languages, ed. S. Jay Keyser, 53-64.

Kraak, Albert, and Wim Klooster. 1972. Syntaxis, $2^{\text {nd }}$ edition. Culemborg: Stam/Robijns.

Lagerwerf, Luuk. 1998. Causal connectives have presuppositions. Effects on coherence and discourse structure, Tilburg University: $\mathrm{PhD}$ thesis.

Landman, Fred, and Ieke Moerdijk. 1980. Behalve als voorzetsel. Spektator 9: 335-347.

Larson, Richard K. 1985. On the syntax of disjunction scope. Natural Language \& Linguistic Theory 3: 218-264.

Levinson, Stephen C. 2000. Presumptive meanings: the theory of generalized conversational implicature. Cambridge (Mass.)/London: MIT Press.

Malepaard, Joop. 2007. Inverse disjuncties. Voortgang. Jaarboek voor de Neerlandistiek XXV: 311-360.

Malepaard, Joop. 2008. Anticipatie en versnelde successie als referentie van inverse disjuncties met nog niet en nog niet eens. Voortgang. Jaarboek voor de Neerlandistiek XXVI: 253-297.

Munn, Alan B. 1993. Topics in the syntax and semantics of coordinate structures, University of Maryland: PhD thesis.

Neijt, Anneke. 1979. Gapping. A contribution to sentence grammar, University of Utrecht: PhD thesis.

Neijt, Anneke. 1981a. Gaps and remnants: sentence grammar aspects of Gapping. Linguistic Analysis 8: 69-93.

Neijt, Anneke. 1981b. Gapping bestaat. Spektator 11: 80-84.

Newmeyer, Frederick J. 1983. Grammatical theory. Its limits and possibilities. Chicago/London: University of Chicago Press. 
Overdiep, Gerrit S. 1937. Stilistische grammatica van het moderne Nederlandsch. Zwolle: Tjeenk Willink.

Paardekooper, P.C. 1966. Behalve als zn-patroondeel. De Nieuwe Taalgids 59: 171-179.

Paardekooper, P.C. 1986. Beknopte ABN-syntaksis, 7th, revised edition. Eindhoven: P.C. Paardekooper.

Pieters, Lody. 2011. Lees maar, er staat (niet?) wat er staat. Over de beschrijving van samentrekking en andere onvolledige taaluitingen in Nederlandse grammatica's na 1900, Radboud University: PhD thesis.

Postma, Gertjan. 1995. Zero semantics. A study of the syntactic conception of quantificational meaning, University of Leiden: $\mathrm{PhD}$ thesis.

Proeme, Henk. 1984. Over de Nederlandse imperativus. Forum der Letteren 25: 241258.

Progovac, Ljiljana. 2003. Structure for coordination. In The second Glot International state-of-the-article book, eds. Lisa Cheng and Rint Sybesma, 241-287. Berlin/New York: Mouton de Gruyter.

Rizzi, Luigi. 1997. The fine structure of the left periphery. In Elements of grammar. Handbook of generative grammar, ed. Liliane Haegeman, 281-337. Dordrecht/Boston/Londen: Kluwer Academic Publishers.

Ross, John. 1967. Constraints on variables in syntax. Bloomington: Indiana University Linguistics Club [Reprinted as Infinite syntax!, Ablex, Norwood New Jersey, 1986].

Royen, P. Gerlach. 1941. Piet- en andere luttigheden. Taal en Leven V: 41-51; 95-107. Cited from P.Gerlach Royen O.F.M (1953): Taalrapsodie. Taalkundige en didaktische varia van her en der. Bussem: Paul Brand.

Schachter, Paul. 1977. Constraints on coordination. Language 53: 86-103.

Schmerling, Susan F. 1975. Asymmetric conjunction and rules of conversation. In Syntax and semantics, volume 3: speech acts, eds. Peter Cole and Jerry L. Morgan, 211-231. New York: Academic Press, Inc.

Schwarz, Bernard. 1999. On the syntax of either ... or ... Natural Language \& Linguistic Theory 17: 339-370.

Tarski, Alfred. 1995. Introduction to logic and to the methodology of deductive sciences. New York: Dover Publications [Reprint of the second, revised edition published in 1946 by Oxford University Press].

Terwey, Tijs. 1892. Over de zoogenaamde bijzinnen met $o f$, die met een ontkennenden hoofdzin in verband staan. Taal en Letteren 2: 76-91.

Thiersch, Craig. 1993a. On the formal properties of constituent coordination. Glow Newsletter 30: 70-71.

Thiersch, Craig. 1993b. Some remarks on asymmetrical coordination. In Linguistics in the Netherlands 1993, eds. Frank Drijkoningen and Kees Hengeveld, 141-152. Amsterdam/Philadelphia: John Benjamins.

Uit den Boogaart, Pieter C. 1975. Woordfrequenties in geschreven en gesproken Nederlands. Utrecht: Oosthoek, Scheltema \& Holkema.

Van Bart, Peter, Johan Kerstens, and Arie Sturm. 1998. Grammatica van het Nederlands: een inleiding. Amsterdam: Amsterdam University Press.

Van Canegem-Ardijns, Ingrid, and William Van Belle. 2010. Wanneer of geen en is. Asymmetrische exclusieve disjuncties in het Nederlands. Nederlandse Taalkunde 15: 54-78. 
Van Craenenbroeck, Jeroen. 2010. The syntax of ellipsis. Evidence from Dutch dialects. Oxford/New York: Oxford University Press.

Van Craenenbroeck, Jeroen, and Jason Merchant. 2013. Elllipsis phenomena. In The Cambridge handbook of generative syntax, ed. Marcel Den Dikken, 701-745: Cambridge University Press.

Van den Toorn, Maarten C. 1972. Balansschikking en disjunctie. De Nieuwe Taalgids 65: 104-123.

Van der Heijden, Emmeke. 1999. Tussen nevenschikking en onderschikking. Een onderzoek naar verschillende vormen van verbinding in het Nederlands, University of Nijmegen: PhD thesis.

Van der Heijden, Emmeke, and Maarten Klein. 1995. Rekenkundige voegwoorden: de 'logica' van samentrekkingen. De Nieuwe Taalgids 88: 22-38.

Van der Wouden, Ton, and Frans Zwarts. 2017. Whether you like it or not, this paper is about or not. In Crossroads semantics: computation, experiment and grammar, eds. Hilke Reckman, Lisa Cheng, Maarten Hijzelendoorn and Rint Sybesma, 249-261. Amsterdam/Philadelphia: John Benjamins.

Van Hauwermeiren, Paul. 1973. Enkele opmerkingen bij M.C. van den Toorn: Balansschikking en disjunctie. De Nieuwe Taalgids 66: 148-150.

Van Koppen, Marjo. 2005. One probe - two goals: aspects of agreement in Dutch dialects, University of Leiden: $\mathrm{PhD}$ thesis.

Van Koppen, Marjo. 2017. Complementizer agreement. In The Wiley Blackwell companion to syntax [2nd, revised edition], eds. Martin Everaert and Henk van Riemsdijk, 923-963. Hoboken, New Jersey: Blackwell.

Van Oirsouw, Robert S. 1987. The syntax of coordination. London/New York/Sidney: Croom Helm.

Van Zonneveld, Ron. 1992. Ongelijke nevenschikking en SGF. Tabu 22: 153-170.

Van Zonneveld, Ron. 1992. X-bar syntax and coordination. In Language and Cognition 2, eds. Dicky Gilbers and Sietze Looyinga. Groningen: University of Groningen.

Verhagen, Arie. 2000. Achter het Nederlands. Over interacties tussen taal en achtergrondcognitie. Inaugural address: University of Leiden.

Verhagen, Arie. 2005. Constructions of intersubjectivity: discourse, syntax, and cognition. Oxford/New York: Oxford University Press.

Wagner, Michael. 2010. Prosody and recursion in coordinate structures and beyond. Natural Language \& Linguistic Theory 28: 183-237.

Welschen, Ad. 1999. Duale syntaxis en polaire contractie. Negatief gebonden ofconstructies in het Nederlands, Free University Amsterdam: PhD thesis.

Wilder, Chris. 1997. Some properties of ellipsis in coordination. In Studies on universal grammar and typological variation, eds. Artemis Alexiadou and T. Alan Hall, 50-107. Amsterdam/Philadelphia: John Benjamins.

Williams, Edwin. 1978. Across-the-board rule application. Linguistic Inquiry 9: 31-43.

Winter, Yoad. 2001a. Flexible principles in Boolean semantics. The interpretation of coordination, plurality, and scope in natural language. Cambridge, MA: MIT Press.

Winter, Yoad. 2001b. Plural predication and the strongest meaning hypothesis. Journal of Semantics 18: 333-365. 
Zamparelli, Roberto. 2011. Coordination. In Semantics. An international handbook of natural language meaning [Volume 2], eds. Klaus von Heusinger, Claudia Maienborn and Paul Portner, 1713-1741. Berlin/Boston: De Gruyter Mouton.

Zhang, Niina Ning. 2010. Coordination in syntax. Cambridge (UK)/New York: Cambridge University Press.

Zwart, Jan-Wouter. 1993. Dutch syntax. A minimalist approach, University of Groningen: PhD thesis.

Zwart, Jan-Wouter. 1995. Review of Coordination: a minimalist approach by Janne Bondi Johannessen. GLOT International 1.

Zwart, Jan-Wouter. 1997. Morphosyntax of verb movement. A minimalist approach to the syntax of Dutch. Dordrecht: Kluwer Academic Publishers.

Zwart, Jan-Wouter. 2011. The syntax of Dutch. Cambridge: Cambridge University Press.

Zwarts, Frans. 1978. Extractie uit prepositionele woordgroepen in het Nederlands. In Proeven van Neerlandistiek, aangeboden aan prof. dr. Albert Sassen, eds. A. van Berkel, W. Blok, G. Brummel and Theo Van der Hoek, 303-399. Groningen: Nederlands Instituut Groningen.

Zwarts, Frans. 1981. Negatief polaire uitdrukkingen I. GLOT 4: 35-132.

Zwarts, Frans. 1986. Categoriale grammatica en algabraïsche semantiek. Een onderzoek naar negatie en polariteit in het Nederlands, University of Groningen: $\mathrm{PhD}$ thesis. 
Syntax of Dutch includes the following volumes:

Nouns and Noun Phrases (volume 1):

Hans Broekhuis \& Evelien Keizer

[appeared in 2012]

Nouns and Noun Phrases (volume 2):

Hans Broekhuis \& Marcel den Dikken

[appeared in 2012]

Adjectives and Adjective Phrase

[appeared in 2013]

Hans Broekhuis

Adpositions and Adpositional Phrases

[appeared in 2013]

Hans Broekhuis

Verbs and Verb Phrases (volume 1)

[appeared in 2015]

Hans Broekhuis, Norbert Corver \& Riet Vos

[appeared in 2015]

Verbs and Verb Phrases (volume 2)

Hans Broekhuis \& Norbert Corver

Verbs and Verb Phrases (volume 3)

Hans Broekhuis \& Norbert Corver

[appeared in 2016]

Coordination and Ellipsis

Hans Broekhuis \& Norbert Corver

[this volume]

Syntax of Hungarian is in progress, and the following volumes have been published:

Nouns and Noun Phrases (volume 1 \& 2)

[appeared in 2018]

Edited by Gábor Alberti \& Tibor Laczkó 


\section{Comprehensive Grammar Resources}

With the rapid development of linguistic theory, the art of grammar writing has changed. Modern research on grammatical structures has tended to uncover many constructions, many in-depth properties, many insights that are generally not found in the type of grammar books used in schools and in fields related to linguistics. The new factual and analytical body of knowledge that is being built up for many languages is, unfortunately, often tucked away in articles and books that concentrate on theoretical issues and are, therefore, not available in a systematized way.

The Comprehensive Grammar Resources (CGR) series intends to make up for this gap by publishing extensive grammars that are solidly based on recent theoretical and empirical advances. They intend to present the facts as exhaustively as possible and in a way that will "speak" to modern linguists but will also (and hopefully increasingly so) become a new type of grammatical resource for the semi- and nonspecialist.

Such grammar works are of necessity quite voluminous. And compiling them is a laborious business. Furthermore, no grammar can ever be complete. Instead, new subdomains may become the subject of scientific scrutiny, leading to additional volumes. We therefore intend to build up these grammars incrementally, volume by volume.

In view of the encyclopaedic nature of grammars, also the size of these works, adequate search facilities must be provided in the form of good indices and extensive cross-referencing. Furthermore, frequent updating of such resources is imperative. The best way of achieving these goals is by making the grammar resources available in electronic format on a specially established platform. Following current trends, they will therefore appear in dual mode: as open access objects freely perusable by anyone interested, and as hard copy volumes to cater to those who cherish holding a real book in their hands. The scientific quality of these grammar resources will be jointly guaranteed by the series editors Henk van Riemsdijk, István Kenesei and Hans Broekhuis and Amsterdam University Press.

Series editors:

Henk van Riemsdijk

István Kenesei

Hans Broekhuis 